Architectural Theatricality:
A Theoretical Discourse in Hospital Interiors \& Design of Patient Eating Environments 



\section{Architectural Theatricality: A Theoretical Discourse in Hospital Interiors \& Design of Patient Eating Environments}

Revised Version

PhD Thesis Defended in public at Aalborg University November 7, 2013

Tenna Doktor Olsen Tvedebrink

Department of Civil Engineering, The Faculty of Engineering and Science, Aalborg University, Aalborg, Denmark

River Publishers

Aalborg 
ISBN 978-87-93102-50-7 (e-book)

Published, sold and distributed by:

River Publishers

Niels Jernes Vej 10

9220 Aalborg Ø

Denmark

Tel.: +45369953197

www.riverpublishers.com

Copyright for this work belongs to the author, River Publishers have the sole right to distribute this work commercially.

All rights reserved (c) 2013 Tenna Doktor Olsen Tvedebrink.

No part of this work may be reproduced, stored in a retrieval system, or transmitted in any form or by any means, electronic, mechanical, photocopying, microfilming, recording or otherwise, without prior written permission from the Publisher. 


\title{
PROLOGUE
}

\author{
THE GASTRONOMIC ANALOGY
}

In December 1862 when talking to a group of military engineers, the Scottish-born architect James Fergusson (1808-1886) made a rather remarkable point on the principles of architectural quality, claiming that:

\author{
"The process by which a hut to shelter an image \\ is refined into a temple, or a meeting house into a cathedral, \\ is the same as that which refines a boiled neck of Mutton \\ into Côtellettes á l'Imperiale or a grilled fowl \\ into Poulet á la Marengo. \\ So essentially is the case that if you wish \\ to acquire knowledge of the true principle of design in \\ architecture, you will do better to study the words of \\ Soyer and Mrs. Glasse than any or all of the writers on \\ architecture, from Vitruvius to Pugin."
}

(Collins 1965:167)

The statement put forth by Fergusson can be found in the book: Changing Ideals in Modern Architecture, published in 1965 by the English-Canadian architect and theoretician Peter Collins. Herein he presented the Gastronomic Analogy together with three functional analogies - the Biological, the Mechanical and the Linguistic - as part of his controversial argument that 'modernity' in architecture, contrary to the claims of architectural historians such as Sigfried Giedion (Space, Time and Architecture, 1941), Nikolaus Pevsner (Pioneers of Modern Design, 1936), James Maude Richards (An Introduction to Modern Architecture, 1940) and Henry Russell Hitchcock (Modern Architecture: Romanticism and Reintegration, 1929), had emerged as early as 1750 together with the radical changes in ideals governing the thinking and writing in the architectural discipline, as well as in the sciences and arts.

According to Collins, what is so remarkable about the Gastronomic Analogy is that throughout the years the discipline of architecture has been compared not only to biology, mechanics and linguistics, but also science, music, geometry, language, and arts like dance, painting, and sculpture. Still, despite the curious fact that none of these comparisons come as close to the cultural significance attached to the word 'taste' as gastronomy, the Gastronomic Analogy had up until 1965 never be used by anyone else than Fergusson to describe and explain the qualities of architecture (Collins 1965:167). 


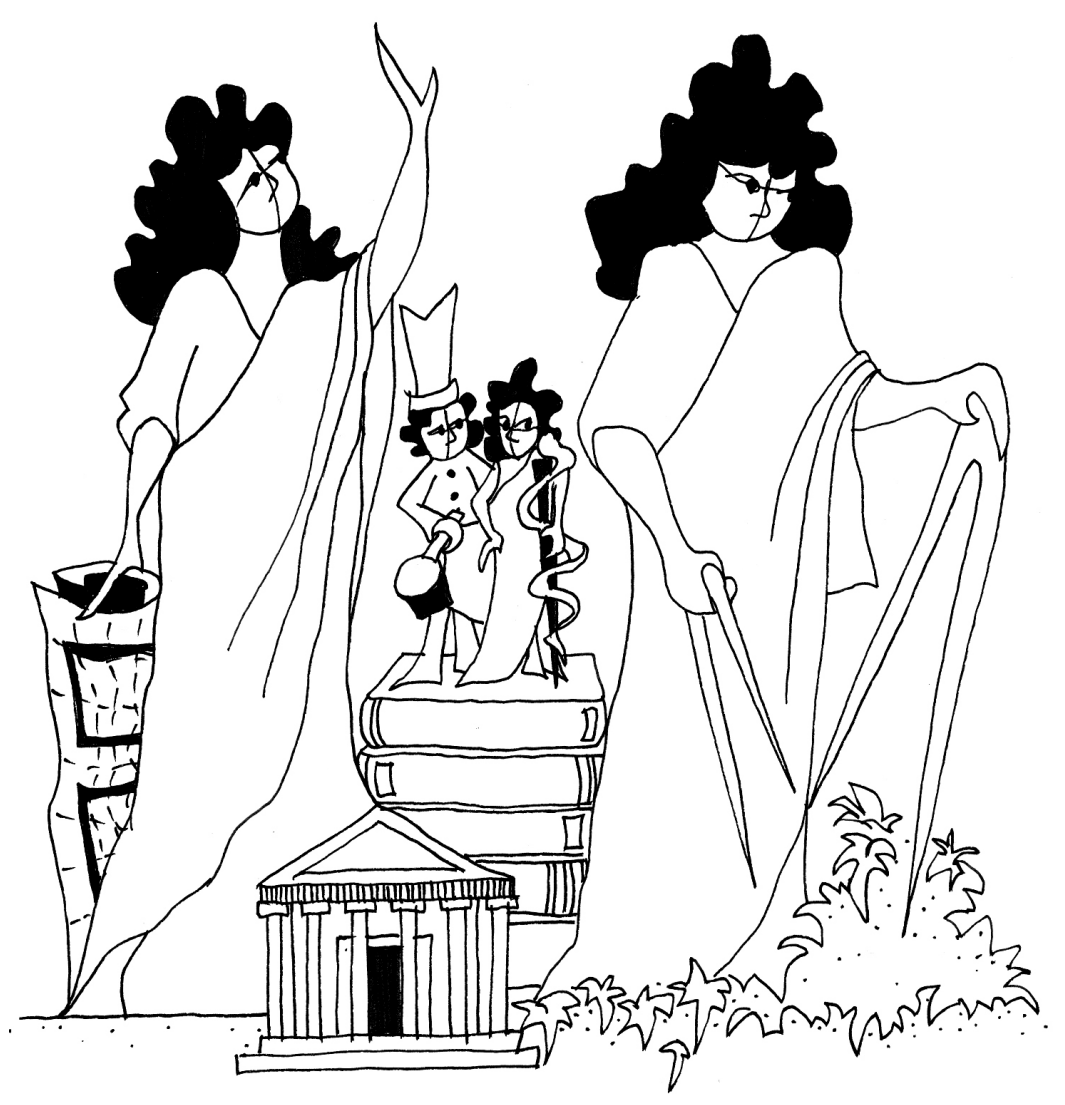

Fig. 1.1

"My wonders and curiosity about Architecture" Research focusing on the synthesis of health, food and architecture. 
1

\section{PREFACE}

ON FOOD \& ARCHITECTURE

I first came across the reference to the Gastronomic Analogy during the third semester of my education as a Civil Engineer with specialization in Architecture and Design. It was when my supervisor Anna Marie Fisker defended her PhD thesis: Mad og Arkitektur (Food and Architecture, 2003). As a young novice in the discipline of architecture I had no wider comprehension of architecture as anything beyond the physically built environment. At that specific time, I had just been introduced to the book: Rumanalyser (Space analysis, 1999), written by Danish art historian Lise Bek and architect Henrik Oxvig. Here they presented an art historical outline of the development of architecture as 'space' and on that background developed a five-point analytical model describing the formal, pragmatic-functional, social-scenographic, iconographic-signifying and visual-perceptive qualities of such an architectural 'space' (Bek \& Oxvig 1999:27-28). Simultaneously we had also just been introduced to another prime topic in our education called 'Tectonics'. It was the book: Studies in Tectonic Culture: the Poetics of Construction in Nineteenth and Twentieth Century Architecture (1995), written by American architectural theoretician Kenneth Frampton. In his book he merged the aesthetics and poetry of architecture with the structural knowledge of civil engineering on materials and construction, as well as sensitivity towards the specific building site (Frampton 2001). I was thus struggling with understanding the argument that architecture was more than what meets the eye. That architecture was not only a physical object made up from material construction, geometrical structure and different artistic styles, but also a poetic spatial configuration. Being presented with the idea that architecture possibly also had something to do with food, was a radical and quite shocking experience to me.

It was an intriguing idea, though, that planted great wonder in my mind about what had motivated Fergusson to pose his rather radical statement on architecture, but also curiosity towards what it was that defined this relationship between food and architecture?

Today my bookshelves are bursting with literature written by architects, historians and art critics depicting what architecture looks like; outlining how architectural styles have developed throughout history. There are books that explain architecture on the background of phenomenology, structuralism, behaviorism, existentialism, psychology, neurology or even gastronomy as proposed by Fergusson and Collins. There are many perspectives; narrow or wide reflections. For each book and writer, architecture is regarded from a new perspective presenting a slightly different intention creating a new theoretical discourse. If I then let my eyes move from the bookshelves to my desk there are likewise vast amounts of objects; drawings, sketches, photos of buildings and places I have visited around the world. As well as a series of architectural models left as exemplifications of the practical discourse I have been involved in, during my architectural education. There are objects that 
demonstrate architecture as multi-sensuous space, communicative media, healing landscape, political act, social facilitator, aesthetic object, mobile structure, or even theatrical event. Together my books with their architectural intentions and my desk with the architectural objects provide a wide basis for understanding the quality of architecture. However, as can be seen from these wide perspectives of architectural theory and practice, the qualities of architecture are neither static nor permanent, but are normative and polemical characteristics presumably part of an ever evolving history and culture. Together they represent a holistic view on architecture in scales varying from landscape and city, over building, interior and furniture, to tableware and food; that architecture, somehow, relates to everything man-made.

Nevertheless, throughout my education I could not help feeling that the knowledge provided to me during these lectures on space and structure were not fully able to neither describe nor explain the curiosity I had experienced with the significance of the Gastronomic Analogy. Despite a wide selection of theoretical models, like the ones presented with Bek \& Oxvig (1999) and Frampton (2001) describing how to analyze architecture, I felt that none of the literature really got to the core of answering my wonders and curiosity about what constitutes that possible relationship between food and architecture.

In my search for answers, I turned to another discipline. I took a one-year leave from architecture and instead studied sensory science, culinary design and consumer preferences, food sociology and food history at Copenhagen University, Department of Food Science and Department of Human Nutrition. Here I was introduced to scientific methods for investigating food and meal experiences by means of quantitative and qualitative tactics, as well as theories of perception and cognition. It was thinking developed within disciplines of neuroscience, food science, sociology, ethnography and anthropology. Furthermore I got the opportunity to work closely together with the Danish Culinary Team during a short period of time. At first hand those perspectives seemed radically different from the lectures I had been given on the history of architecture, design methods, tectonics, structural and material mechanics, as well as indoor environmental science such like heating, ventilation, acoustics and lighting. During that period it occurred to me that perhaps these two disciplines were not so different after all. That instead the discipline of gastronomy and architecture had a great deal to learn from each other? And perhaps that was what Fergusson had meant?

With the help of my supervisor Anna Marie, this intuitive idea culminated in a Master's thesis in 2008, representing my first attempt to do a research and design inquiry investigating not only the combination of theory and practice, but also the combination of the two disciplines; food and architecture (see Olsen 2008). The Master's thesis focused on how the architectural scenery surrounding the promotion of the newest chinaware from the Norwegian company Figgjo could also be used to provide extravagant meal experiences at international trade fairs. Here, as part of my initiate literature reviews, in a short essay written by Italian-American architectural theoretician Marco Frascari, published in the book: Eating Architecture (Horwitz \& Singley 2004), I came across the reference to the Gastronomic Analogy once more.

In his essay: Semiotica ab Edendo, Taste in Architecture (1986), Frascari criticizes modern architecture for overstressing the visual components, stripping away all the tactile pleasures and means of signification inherited in the history of architecture with the etymological understanding of the concept 'taste'. One of Frascari's points is that modern architecture seems to focus exclusively on the visual appearance of structural and functionalist elements as they appear to the mind, neglecting to approach the poetic, dramatic and sensual bodily encounters that are produced by the touch of hand or sense of smell, thus prioritizing the higher senses of sight and hearing above the lower senses of touch, smell and taste (Frascari 2004:192). In connection hereof, Frascari (2004:199) also emphasized that both the disciplines of architecture and gastronomy employ similar procedures of production that deal with a creative process which methodologically cannot be reduced to quantifiable recipes, formulas or strict evidence-based rules. But instead, because of their problem-solving basis "predicting" our future needs and desires for food and shelter suggest a creative process of interpretation where imagination and dreaming are essential "tools" for generating new ideas and creating objects of pleasure and well-being (Frascari 2004:199-200). Therefore both the architect and the chef naturally engage in speculations about what might be, instead of just observing that which is. 
In my Master's thesis, I did not have the knowledge or the courage to engage in a more profound understanding of the Gastronomic Analogy and the writings of Frascari. Instead I used the two references as a step stone in a tentative attempt to try and link my knowledge on culinary theory, sensory and consumer science with the phenomenological and structuralist viewpoints that were taught to me during my education with among others the writings of Bek \& Oxvig (1999) and Frampton (2001). This also led me to a study of the history of dining interiors, particularly the ancient Roman dining room also called 'Triclinium' and the contemporary 'food theatre': Madeleines Madteater. In these two specific cases I found a linking of the body and mind in the extravagant theatrical meal events and their multi-sensuous and almost choreographed interior architectural scenery. Based on my reading of writings by Bek \& Oxvig (1999) and the text: Making sense of food in performance: the table and the stage written by American professor in performance studies Barbara KirshenblattGimblett (2007), the question rose if the architectural scenery composing an eating environment could be compared to a theatre? In combination of these seemingly distinct theoretical positions of sensory science, phenomenology and semiotics, I found new and broader perspectives answering some of my wonders about the relationship between food and architecture. These perspectives suggested that architecture could be seen as theatrical scenery representing and signifying inherited cultural and spiritual values, possibly staging our social behavior and strongly relating to our being in the world. But the theatrical analogy also suggested that architecture invite for an embodied experience engaging both body and mind simultaneously, through the careful design of the total scenery. That architectural quality was perhaps therefore as much about the practical engagement in a holistic understanding of society, human life and behavior - a cultural space fostering social relations, staging human interaction and everyday rituals, places of belonging affecting our emotions, feelings and general well-being. Even though I did not use the terms back then, it was a Master's thesis very much concerned with what I with this dissertation have chosen to call 'Architectural Theatricality'. The term denotes, to me an architectural scenery evolving from the "inside-out" motivated by a greater awareness on the link of inner emotions and bodily experiences.

Since then research and practice within both food and architecture have grown rapidly. Today several architects, designers and researchers are writing and talking about food and architecture together. One example is British architect Carolyn Steel, who with the book: Hungry City (2009), emphasizes the concept of 'Sitopia' when approaching urban developments from the perspective of food production and consumption. Another is American environmental psychologist Karen A. Franck, who has published the two books: Food+Architecture (2002) and Food+the City (2005). Also, at the 11th International Architectural Biennale held in Venice in 2008, several of the exhibition designs were occupied with the relationship of food and architecture (see e.g. Massimiliano \& Doriana Fuksas; Gustafson Porter LTD \& Gustafson Guthrie Nichol LTD; Philippe Rahm Architects) (Marsilio 2008:67,84,85,135). Complementing this, the International Food Design Society (IFDS) recently defined the spaces conceived for food as 'Interior Design for Food'. Further arguing that the term 'Interior Design for Food' considers all the characteristics of the eating environment such as interiors, materials, colors, lighting, temperature, music, behavior, and employees' clothing (ifooddesign 2011). One of the points made by the Food Design Society is that even if food itself is not involved as a specific material, the methodology used in 'Interior Design for Food' involves knowledge regarding food, food preparation, and food consumption to be able to design spaces providing an aesthetic eating experience (ifooddesign 2011)[Tvedebrink et al. 2013b]

The point made by many of these interdisciplinary initiatives is that aspects of food are everywhere, and that architecture and design therefore relate to food and eating in many ways and on many different scales. The design of "food spaces" exists on the smallest architectural scale of developing a new food product, arranging the food on a plate, setting the table with plates, bowls and glasses, into the spatial arrangement of table and chairs, to the enclosing of walls, floor and ceiling, the kitchens, gardens as well as urban or rural landscape. However, as with the specific approach of my Master's thesis, most of these contemporary examples of food and architecture represent extravagance, consumerism on its highest in my point of view - they illustrate stateof-the-art design aimed at a very limited group of people. It is what we could perhaps call "design for the few". 
In 2009, during my time as a research assistant at the Center for Food Science, Design and Experience at Aalborg University, I was introduced to the project MORE. This project was initiated by a small group of doctors, nurses and nutritional staff from Aalborg Hospital in northern Denmark, who wanted to improve the treatment outcome, recovery process and general health of patients by focusing more on the importance of nutrition and eating during hospitalization (MORE 2009)[Olsen 2010:103]. During 2009 and 2010, I was allowed to follow the project and get insight in a cross-sectional study that they performed in three different hospital departments. Simultaneously with this, two research initiatives were established at Aalborg University called: $A A U$ Food Research and Healing Architecture.

The AAU Food Research was based on strategic attention towards upgrading Danish food research, education, innovation and technology with perspectives across faculties of Natural Science, Social Science and the Humanities (AAU Food Research 2010). The center engaged in research related food contexts, food services, public health and meals in public domains and gathered perspectives of among others the disciplines of architecture, experience design, ICT, communication, policy, health and engineering. The Healing Architecture initiative was a collaboration established between researchers and practitioners from disciplines in building regulation, healthcare, landscape, and architecture. It was launched with the employment of American environmental psychologist Roger Ulrich as a professor at Aalborg University (HA AAU 2013) and the founding of the PhD network group ResInHea, and aimed at improving research methods and knowledge relating to healthcare architecture.

With the coincidence of these three events; MORE, AAU Food Research and Healing Architecture, the opportunity to take my interest in the combination of food and architecture a step further was made. In the interdisciplinary domain of health, food and architecture I got the opportunity to engage in a more profound understanding of the Gastronomic Analogy and Theatrical Analogy, as well as perform research not just focusing on the extravaganza of culinary events reserved for "the few", but possibly use my personal interest to engage in the societal importance of providing food for "the many". Thereby positioning my research interests in a much broader and more challenging context where the relationship between food and architecture, based on a human-centered perspective, is used to improve the health and well-being of persons in need. In that way, this thesis is partly autobiographical. In many ways, it presents my own attempt to find a deeper understanding of the role of architecture during the last years, but it is also my first elaborate attempt towards exploring the integration of the research domains of health, food and architecture. This also means that I, in line with the explorative attempts of Fergusson and Collins, in a rather eclectic manner, have combined my architectural background with diverse and distinct research disciplines such as Healing Architecture and Food Science. In that way this thesis should be judged more as an effort of a synthesis of the three domains health, food and architecture from the perspective of an architect. And the content of this thesis is thus aimed at an interdisciplinary audience desiring or requesting an integration of the mindsets of health, food and architecture into a coherent whole. 


\title{
ACKNOWLEDGEMENTS
}

\author{
MY PERSONAL THANKS
}

My personal thanks go first of all to Anna Marie Fisker and Poul Henning Kirkegaard for being my supervisors, teachers and mentors throughout the last 11 years, but also for introducing me to the wonders of architecture. Without your guidance, patience, and extensive knowledge I would never have finished this thesis.

Secondly my thanks go to my two former colleagues and dear friends throughout my entire architectural education: Mads Dines Petersen and Marie Frier Hvejsel at the Department of Architecture, Design \& Media Technology for spectacular disciplinary and non-disciplinary inspiration. But also to my new colleagues at the Department of Civil Engineering: Hafdis Sunna Hermansdottir, Stina Holm Jensen, Rene Langdal Jørgensen, Jeppe Emil Mogensen and Mai Brink Rasmussen, who all of them every day encouraged me with cheerful talks about architecture and food. As well as not least my new "boss" Peter Frigaard for providing the opportunity to explore and unfold the curious relationship of health, food and architecture when nobody else would.

A very special thanks and warm thoughts go to Marco Frascari for inviting me to stay at Azrieli School of Architecture and participate in the newly established architectural $\mathrm{PhD}$ program at Carleton University, and for introducing me to a more profound historical and philosophical understanding of architecture. Furthermore thanks to Frascari's colleagues: Steven Fai, Roger Connah and Adriana Ross, but also to Diphna Horra, Michael Tawa, Alberto Pérez-Gómez, Federica Goffi, Diana Cheng, James Hayes, Karen Conty, Azin Dilmaghani and Maryam Mirsepassi for valuable discussions and making my stay in Canada unforgettable. Also thanks to Marco's wife Paula for letting me visit Marco in the hospital during a very difficult time. I will never forget that.

Further tanks go to the boys from the Danish Culinary Team of 2006 - in particular the chefs Thorsten Schmidt, Rasmus Kofoed and Søren Ledet as well as their team leader Per Mandrup for letting me experience gastronomy at its finest. But also to Karl Otto Schmidt head of the Danish department of the Order of Cordon Bleu du Saint Esprit, for always encouraging me with his talks of aesthetics and gastronomy.

Thanks to collaborators in the AAU Food Research at Aalborg University: Bent Egberg Mikkelsen and Sofie Husby for support and guidance in the initiate phase of the PhD project, and for inviting me to participate in the networks and conferences on food in schools and workplaces.

Also thanks to Louise Muxoll Grønhaug from the department of Orthopaedic Surgical Patients at Vejle Hospital for presenting the project on refurbishment of their patient eating environment. In particular also a great thanks to the staff and stakeholders involved in the project MORE at Aalborg Hospital: Henrik Højgaard Rasmussen, Jytta Svejstrup Mølgaard Højsleth, Tina Beermann, Marie Nerup Mortensen, Mette Holst, Lone Frandsen, Bitten Gøtzsche, Anette Damgård, Lotte Skadhauge and all your colleagues for allowing me to follow your work and get into the details of the project MORE. Your enthusiasm has been a great inspiration to me.

Last, but no least thanks to my wonderful little family, especially my loving husband Torben and dear son Marius for being very patient with me, enduring with me and most importantly for cooking all my favourite meals during the last period of writing. Thank you, I would never have managed without you. 


\title{
SUMMARY
}

\author{
ENGLISH
}

This $\mathrm{PhD}$ thesis is motived by a personal interest in the theoretical, practical and creative qualities of architecture. But also a wonder and curiosity about the cultural and social relations architecture represents through its occupation with both the sciences and the arts. Inspired by present initiatives in Aalborg Hospital to overcome patient undernutrition by refurbishing eating environments, this thesis engages in an investigation of the interior architectural qualities of patient eating environments. The relevance for this holistic perspective, synthesizing health, food and architecture, is the current building of a series of Danish 'super hospitals' and an increased focus among architectural practices on research-based knowledge produced with the architectural sub-disciplines Healing Architecture and Evidence-Based Design. The problem is that this research does not focus on patient eating environments and a knowledge gap therefore exists in present hospital designs. Consequently, the purpose of this thesis has been to investigate if any research-based knowledge exist supporting the hypothesis that the interior architectural qualities of eating environments influence patient food intake, health and well-being, as well as outline a set of basic design principles 'predicting' the future interior architectural qualities of patient eating environments.

Methodologically the thesis is based on an explorative study employing an abductive approach and hermeneutic-interpretative strategy utilizing tactics such as a literature review, timeline and historical outline to create a "knowledge map", which in an eclectic manner merges the positive, normative and polemical knowledge rooted in research, objects and writings. The results of these investigations show that sparse researchbased knowledge exist directly taking into account how the interior architectural qualities of eating environments influence patients' food intake, health and wellbeing. Whereas vast amounts of research-based knowledge exist indirectly indicating the importance of the interior architectural qualities of the eating environment on meal experiences and food intake, as well as a series of references exist linking the interior architectural qualities of healthcare environments with the health and wellbeing of patients. On the basis of these findings, the thesis presents the concept of Architectural Theatricality as well as a set of design principles putting an emphasis on architecture as unified scenery guided by the four motives hearth, enclosure, dressing and context. This theoretical framework draws on the Gastronomic Analogy put forth by James Fergusson in 1862 and an interpretation of the writings of the $19^{\text {th }}$ century architect Gottfried Semper, who links the fundamental architectural qualities to the characteristics of a theatre and the complex 'doubleness' of a mask. A sub-conclusion was that part of the quality lies in the constant revealing and concealing of the interior architecture as two-dimensional image and three-dimensional space together forming an assemblage of material objects, which through the inherited cultural, social and spiritual values are able to seduce us, spark our imagination and move us beyond time and place.

However, the conclusion is that more research needs to done to understand this complex relationship. Today there is a tendency to reductionism in the value of human experience and to remove the arts from the sciences. The significance of this thesis is therefore the holistic perspective and contribution with a theoretical discourse acknowledging not only the importance of multi-sensuous experiences which are revealed with the material appearance of objects, but also the imaginary world of dreams and memories which are concealed with the communicative significance of intentions when designing the future super hospitals. 


\section{SUMMARY}

DANISH

Denne Ph.d. afhandling er motiveret af en personlig interesse i arkitekturens teoretiske, praktiske og kreative kvaliteter, men også en underen over de kulturelle og sociale aspekter arkitekturen repræsenterer med sin inddragelse af både naturvidenskaberne og kunstarterne. Inspireret af de nuværende initiativer for at reducere underernæring blandt patienter ved at re-designe spisemiljøerne på Aalborg Hospital undersøger denne afhandling de arkitektoniske kvaliteter af patient spisemiljøer. Dette holistiske perspektiv, og en synergi mellem helbred, mad og arkitektur, er relevant dels på grund af den foregående planlægning af en række danske 'super hospitaler', men også på grund af en stigende interesse fra arkitektur praksis for forskningsbaseret viden produceret med de to arkitekturrelaterede forskningsdiscipliner Helbredende Arkitektur og Evidens-baseret Design. Problemstillingen og hovedfokus for denne afhandling er imidlertid at denne type arkitekturforskning på nuværende tidspunkt ikke fokuserer på patient spisemiljøer. Der er derfor potentielt en mangel på forskningsbaseret viden der kan støtte op om udviklingen af fremtidens hospitaler. Formålet med denne afhandling har derfor været at undersøge, om der findes forskningsbaseret viden der kan støtte op om hypotesen med at de arkitektoniske kvaliteter af spisemiljøer påvirker patienternes fødevareindtag, helbred og velvære, men også at opstille en række generelle design principper der kan sige noget om formgivningen af fremtidens patient spisemiljøer.

Metodisk er afhandlingen baseret på et eksplorativt studie, en abduktiv tilgang og en hermeneutisk-fortolkende strategi der udnytter taktikker såsom litteraturstudie, tidslinje og historisk oversigt til at skabe et "videnskort", der i eklektisk stil kobler positiv, normativ og polemisk viden lejret i forskning, objekter og intentioner. Resultatet af disse undersøgelser viser at der findes meget lidt forskningsbaseret viden der direkte påviser at spisemiljøets arkitektoniske kvaliteter påvirker patienternes fødevareindtag, helbred og velvære. Derimod findes der en større mængde viden der indirekte antyder, at de spisemiljøets arkitektoniske kvaliteter har stor betydning for oplevelsen af et måltid og indtaget af mad, samt ikke mindst en større mængde litteratur der kobler hospitalsmiljøets arkitektoniske kvaliteter med patienternes helbred og velvære. På baggrund af disse resultater, præsenterer denne afhandling konceptet Arkitektonisk Teatrikalitet, der fokuserer på arkitektur som et samlet 'scenery' udtrykt igennem de fire fundamentale design principper: 'hearth', 'enclosure,' 'dressing' og kontekst. Denne teoretiske ramme er baseret dels på fortolkningen af den gastronomiske analogi fremsagt at James Fergusson i 1862, men også af arkitekten Gottfried Sempers teorier fra det 19 århundrede der kobler arkitekturens kvaliteter med de fundamentale kvaliteter i et teater og en maskes dobbelthed. En del-konklusion for denne afhandling var derfor at den arkitektoniske kvalitet ligger i den konstante tildækning og afsløring af interiøret som både todimensionelt billede og tredimensionelt rum, der tilsammen udgør et "montage" af fysiske objekter der med deres kulturelle, sociale og åndelige værdier er i stand til at forføre os, igangsætte vores fantasi og flytte os i tid og sted.

Konklusionen er imidlertid, at der er brug for mere forskning for at forstå kompleksiteten af dette forhold. I dag er der en tendens til at reducere og underkende de "bløde" og mere poetiske værdier af menneskelige oplevelser og dermed til at adskille kunstarterne fra naturvidenskaben. Betydningen og bidraget af denne afhandling er derfor især den teoretiske diskurs og anderkendelsen af vigtigheden af multisensoriske oplevelser der røbes/afsløres med den materielle og visuelle fremtoning af objekterne, men også med den imaginære verden af drømme og erindringer som er maskeret med den kommunikative betydning der er lejret $\mathrm{i}$ hensigterne for designet af fremtidens super hospitaler. 


\title{
CHAPTER OUTLINE
}

\author{
MONOGRAPH
}

The Prologue introduced, on the background the writings of architectural theoretician Peter Collins the Gastronomic Analogy put forth by Scottish architect James Fergusson in 1862, the radical thinking that the ideals and basic design principles in architecture can be compared to those of gastronomy and food.

Chapter 1, Preface presented how my personal wonders and curiosity about the relationship of food and architecture, through my education and Master's thesis, fostered an interest in the analogy of theatre and a holistic perspective on the purpose and meaning of architecture, which together sparked the overall research topic, but also became the outset for my research on the interior architectural qualities of patient eating environments and an investigation of the synthesis of health, food and architecture.

Acknowledgements provided my personal thanks to involved parties in the $\mathrm{PhD}$ project.

Chapter 2, Introduction with an outset in Collins' writings on the radical changes in ideals governing architectural thinking in the $19^{\text {th }}$ century elaborates on the relationship and importance of health and architecture, including key issues such as the emergence of sub-disciplines like Interior Design, Healing Architecture and Evidence-Based Design.

Chapter 3, Problem Definition positions the relevance of my research to the two examples of MORE and VEJLE where the problem of patient undernutrition has fostered a specific interest in how the interior architectural qualities of eating environments influence patient food intake, health and well-being, but also in what research-based knowledge exist elaborating on the synthesis of health, food and architecture. In continuation hereof the chapter presents the hypothesis, aim and goal of my research and relates it to the contemporary challenge of designing the future Danish super hospitals. As well as outlines my two research questions.

Chapter 4, Research Approach discusses relative to the previous chapters how to approach research relating to such distinct domains as health, food and architecture, as well as outlines the overall research strategy used to engage in the research problem, and herein research tactics employed to collect, describe, analyze, explain, predict and communicate any 'evidence' supporting the research hypothesis and answering the two research questions.

Chapter 5, Positive Theory engages in research question (1) presenting a literature review investigating what research-based knowledge exists describing the interior architectural qualities of patient eating environments in existing 'positive theory' across the domains of health, food and architecture.

Chapter 6, Normative Theory outlines a Timeline and Historical Review analyzing the historical development of eating environments and hospital design, as well as "map" the state-of-the-art normative and polemical knowledge relating to the domains of health, food and architecture. 
Chapter 7, Polemical Theory presents in continuation of chapter 5, a more profound investigation of a the 'polemical theory' outlined in chapter 5, thereby explaining, on the background of Collins' writings and a more elaborate investigation of the Gastronomic Analogy, how architectural theoreticians during the $19^{\text {th }}$ century tried to describe, analyze and predict the fundamental interior architectural qualities in different ways.

Chapter 8, Design Principles unfolds the 'polemical theory' developed by the $19^{\text {th }}$ century German architect Gottfried Semper with his books: The Four Elements in Architecture and Style, in the attempt to outline a set of basic design principles predicting the interior architectural qualities of patient eating environments.

Chapter 9, Patient Eating Environments apply my development of a set of basic design principles to the specific example of project MORE and the Department of Infectious Diseases, thereby evaluating if the theoretical framework can be used to point out if any elements in the contemporary patient eating environment need to be improved in the design of future super hospitals.

Chapter 10, Reflections \& Perspectives summarizes the sub-conclusions of the previous chapters and the results of my investigations, thereby concluding the outcome of my research. Finally, the chapter in addition to this concluding perspective gives a reflection on the relevance, usability and significance of the research and the outlined research strategy and tactics.

The epilogue rounds off the monograph with a personal consideration on the potentials of a holistic perspective on architecture and the importance of a synthesis of health, food and architecture in future hospital design. 


\title{
READING GUIDE
}

\author{
MANDATORY PAGE \& CO-AUTHOR STATEMENTS
}

In continuation of the outline of the content of the different chapters presented in the thesis, I would like to emphasize that I have chosen to submit this thesis as a monograph instead of the traditional collection of papers. Still, parts of the arguments presented in this thesis/monograph has previously been published or presented in papers or presentations submitted a series of International Journals, International Conferences or for instance the following PhD-courses held at Aalborg University: Constructed views of Reality held by Professor Lars Brodersen in Marts 2010; Writing \& Reviewing Scientific Papers held by Professor Jacob Stoustrup in September 2010, The Research Process held by Professor Andrew Jamison in November 2012, Staging lives held by Professor Ole B. Jensen in November 2012 and the PhD-network ADPL supervised by Professor Ole B. Jensen in 2009/2010.

It should therefore be mentioned, in accordance with the guidelines of the Doctoral School of Engineering and Science at Aalborg University that: "This thesis has been submitted for assessment in partial fulfillment of the PhD degree. The thesis is based on the submitted or published scientific papers which are listed below. Parts of the papers are used directly or indirectly in the thesis." I have chosen to mark these parts in the thesis/monograph with square brackets in the following manner: [author, year:page]. "As part of the assessment, co-author statements have been made available to the assessment committee and are also available at the Faculty. The thesis is not in its present form acceptable for open publication but only in limited and closed circulation as copyright may not be ensured."

\section{Thesis title}

Architectural Theatricality: a theoretical discourse in hospital interiors and design of patient eating environments

\section{PhD student}

Tenna Doktor Olsen Tvedebrink

\section{Supervisors}

Anna Marie Fisker, Associate Professor, Department of Civil Engineering Aalborg University

Poul Henning Kirkegaard, Professor, Department of Civil Engineering Aalborg University

\section{List of published papers}

(1) Tvedebrink, T.D.O., Fisker, A.M. \& Kirkegaard, P.H.: "Architectural Theatricality: A food design perspective in hospitality studies", (published), Hospitality \& Society, 3, 3, 2013.

(2) Tvedebrink, T.D.O., Fisker, A.M. \& Kirkegaard, P.H.: "Sygdommens Spiserum: Har arkitekturen en overset eller glemt betydning her?", (published), Tidskrift for Forskning i Sygdom og Samfund, 18, 2013. 
(3) Tvedebrink, T.D.O., Fisker, A.M. \& Kirkegaard, P.H.: "Architectural Mealscapes - a paradigm for Interior Design for Food", (published), Conference proceedings from the International Conference on Designing Food and Designing for Food, IFDS, London, 2012.

(4) Tvedebrink, T.D.O.: "The Research Process: unfolding the methodological layers of my PhD project", (unpublished) paper for the PhD course, Aalborg University, 2012.

(5) Olsen, T.D. \& Fisker, A.M.: "Madens Rum: Handler patienternes spiseoplevelser ikke også om arkitekturen omkring måltidet?", (published), Tidskrift for Forskning i Sygdom og Samfund, 14, 2011.

(6) Fisker, A.M. \& Tvedebrink, T.D.O.: "The Cornucopia of the Senses: a banquet without peer", (published), Department of Architecture, Design \& Media Technology, Aalborg University, 2011.

(7) Olsen, T.D.: "Hospital Foodscape Design: considering if dining environment influence patient healing?", (published), In: Jensen, O.B., Design Research Epistemologies 1: Research in Architectural Design, Department of Architecture Design \& Media Technology, Aalborg University, 2010.

(8) Olsen, T.D., Fisker, A.M. \& Kirkegaard, P.H.: "Healing Architecture: how hospital food environments can help improve patient recovery - an integrative literary review", (unpublished), paper submitted for the conference Green Mega Foods held without proceedings, 2010.

(9) Olsen, T.D.: "Hospital Foodscape Design: can the architecture of dining facilities help improve patient recovery?", (unpublished), paper for $\mathrm{PhD}$ course, Aalborg University, 2010.

Besides the above mentioned papers, which are partly directly included in the thesis, a series of additional papers has been published throughout the PhD project, which I have chosen not to include directly in the thesis. But which still are important for my research. Together these two lists of publications illustrate my attempt to position the synthesizing of health, food and architecture in a broader context such as eating environments in schools, workplaces and urban domains:

(1) Nyberg, M. \& Olsen, T.D.: "Meals as work: integrating social and architectural aspects", (published), International Journal of Workplace Health Management, 3, 3, 2010.

(2) Mikkelsen, B.E., Andersen, B., Andersen, K.K., Andersen, T., Benn, J., Brinck, N.M., Carlsson, M.S., Hansen, M.W., Hansen, S.R., Holm, N.R., Husby, S., Kristensen, N.H., Laursen, R.P., Mikkelsen, M.V., Mortensen, L.H., Nordin, L.L., Olsen, T.D., Pedersen, D., Sabinsky, M., Tetens, I., Toft, U., Werther, M.N., \& Zinck, O.: "Projekt EVIUS: sammenfattende rapport", (published), Aalborg University, 2010.

(3) Mikkelsen, B.E. \& Olsen, T.D.: "Organic foods in Danish municipal school food systems: a multi stakeholder analysis of available evidence on constraints and perspectives", (published), Proceedings from the $3^{\text {rd }}$ International iPOPY Conference, ICROFS, 2010.

(4) Fisker, A.M. \& Olsen, T.D.: "Food, Architecture and Experience Design", (published), Nordic Journal of Architectural Research, 20, 1, 2008. 


\title{
CONTENT
}

\author{
PHD THESIS
}

PROLOGUE

INSPIRATION

"OUTLINING" inspiration

1. Preface

1.1 On Food and Architecture

Acknowledgements

Summary UK

Summary DK

Chapter Outline

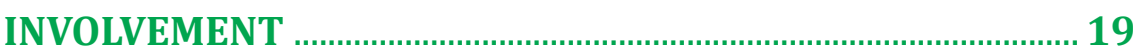

“INTRODUCING" involvement 19

$\begin{array}{lr}\text { 2. Introduction } & 19\end{array}$

2.1 On Health and Architecture 19

2.2 The wonders of Neuroscience $\quad 23$

$\begin{array}{ll}2.3 \text { The problem of patient undernutrition } & 27\end{array}$

"DEFINING" involvement $\quad 29$

3. Problem Definition $\quad 29$

$\begin{array}{ll}3.1 \text { On Health, Food and Architecture } & 29\end{array}$

$\begin{array}{ll}3.2 \text { Research Idea and Hypothesis } & 29 \\ 3.35 & 36\end{array}$

$\begin{array}{ll}\text { 3.3 Patient Eating Environments } & 36\end{array}$

$\begin{array}{ll}3.4 \text { Research Questions } & 36\end{array}$

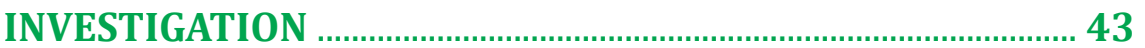

"CHOOSING" investigation

4. Research Approach $\quad 43$

4.1 Unfolding the research methodology 43

4.2 Research-based knowledge $\quad 45$

4.3 The system of inquiry $\quad 52$

4.4 The strategies and tactics 53

4.5 Research Approach $\quad 56$

4.6 Sub-conclusion on research approach $\quad 65$ 
INTERPRETATION

5.1 History of research

5.2 Results of Annotated Bibliography

5.3 Integrative Literature Review

5.4 Sub-conclusion on positive theory

"ANALYSING" interpretation 85

6. Normative Theory $\quad 85$

6.1 History of Objects $\quad 85$

$\begin{array}{lr}6.2 \text { Timeline } & 89\end{array}$

6.3 Historical Review $\quad 89$

$\begin{array}{lr}\text { 6.4 Sub-conclusion on normative theory } & 142\end{array}$

"EXPLAINING" interpretation $\quad 145$

7. Polemical Theory $\quad 145$

$\begin{array}{ll}7.1 \text { History of Intentions } & 145\end{array}$

$\begin{array}{lr}\text { 7.2 The Gastronomic Analogy reconsidered } & 159\end{array}$

$\begin{array}{ll}\text { 7.3 Sub-conclusion on polemical theory } & 163\end{array}$

"PREDICTING" interpretation 167

8. Design Principles 167

8.1 Unfolding Semper's polemical theory 167

$\begin{array}{ll}\text { 8.2 The underlying motives in architecture } & 168\end{array}$

$\begin{array}{ll}\text { 8.2 The dressing of the enclosure } & 169\end{array}$

$\begin{array}{ll}\text { 8.3 The notion of Theatricality } & 173\end{array}$

8.5 The concept of Architectural Theatricality 182

"EVALUATING" involvement 185

9. Patient Eating Environments $\quad \mathbf{1 8 5}$

$\begin{array}{lr}\text { 9.1 Returning to project MORE } & 185\end{array}$

$\begin{array}{lr}\text { 9.2 The future super hospitals } & 192\end{array}$

$\begin{array}{ll}9.3 \text { Sub-conclusion on patient eating environments } & 196\end{array}$

IMPLEMENTATION ................................................................... 199

“CONCLUDING" implementation 199

10. Reflections \& Perspectives $\quad 199$

$\begin{array}{ll}10.1 \text { The relevance of my research } & 199\end{array}$

10.2 Limitations to the research 203

$\begin{array}{ll}10.3 \text { Future considerations } & 205\end{array}$

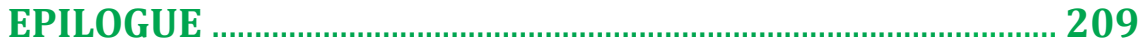

$\begin{array}{lr}\text { The magic of architecture } & 209\end{array}$

$\begin{array}{lr}\text { Bibliography } & 213\end{array}$

$\begin{array}{lr}\text { Illustrations } & 237\end{array}$ 


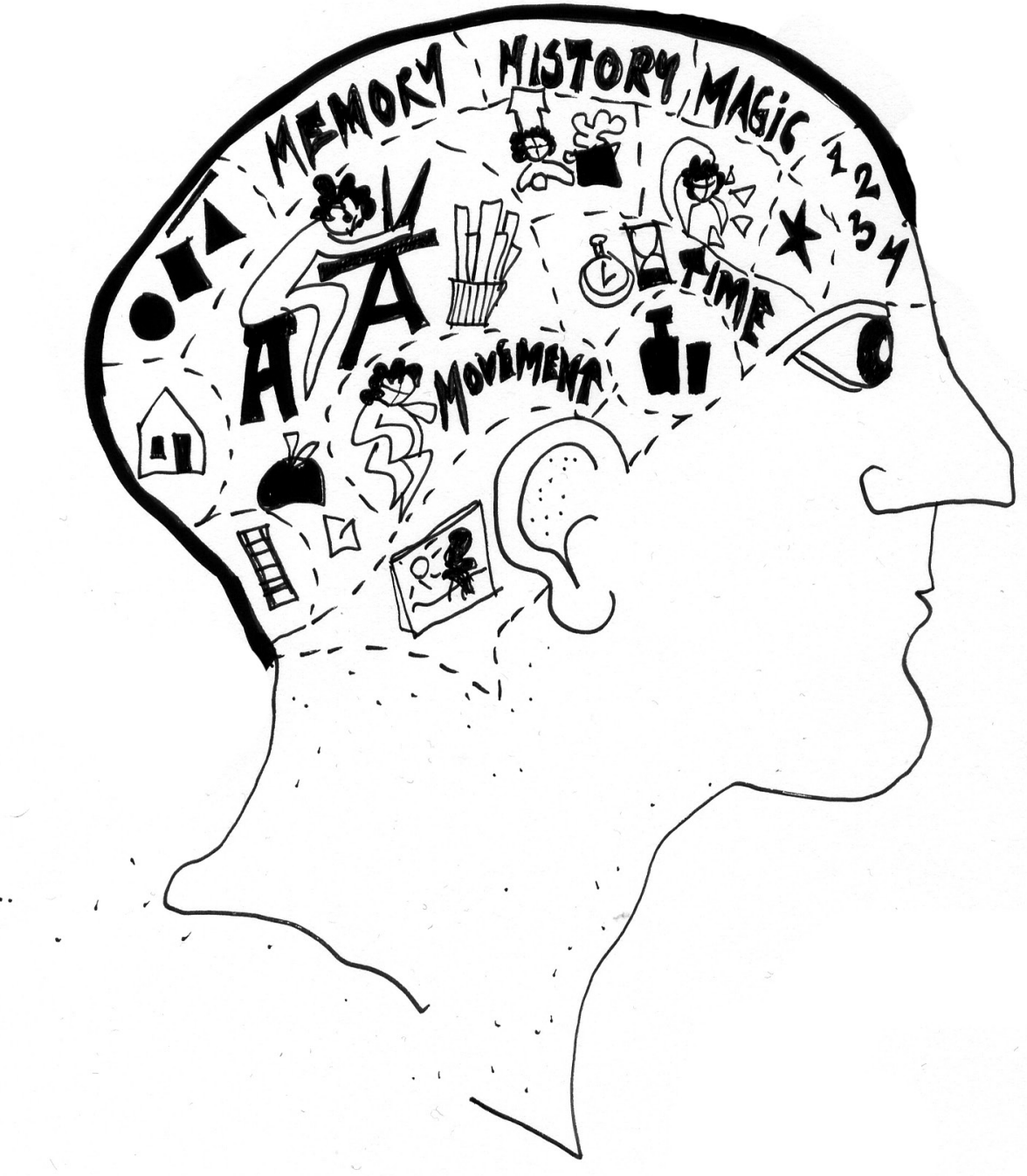

Fig. 2.1

“The Architect's Brain" (Drawing adopted from Frascari 


\title{
2
}

\section{INTRODUCTION}

\author{
ON HEALTH AND ARCHITECTURE
}

More than 250 years ago, precisely around 1750 to follow the thinking of Collins, the old established idea that architecture was primarily an art object was gradually dissolved and replaced by an understanding of architecture as a 'space' framing human activities and social relations, as well as fostering an increased interest in studying social and political ideas as ideals for architectural quality rather than geometrical shapes and specific styles (Collins 1965:xxi,15,22,25; Whyte 2004:43; Bø-Rygg 2004:24; Frisby 2004:5).

Often labels like the 'Industrial Revolution' and the 'Scientific Revolution' are used to describe the radical technological developments and social and political changes that during the late $18^{\text {th }}$ and early $19^{\text {th }}$ centuries influenced and gradually changed everyday life in most Western European societies (Jamison et al. 2011). The Industrial Revolution is characterized by the invention of steam engines, electricity and many other technologies that fostered rapid developments of factories and a huge integration of people in the cities (Bø-Rygg 2004:25). This caused changes in urban structures and often forced people of the working classes to live in dense neighborhoods and poorly built dwellings which would heavily affect the common health and well-being of the people living there. In the book: Cities of Tomorrow, English-American professor in urban and regional planning Sir Peter Hall (2002:18-19) writes how this Industrial era, particularly in grand cities such as London, Paris, Berlin and New York during 1880-1900 had generated "dreadful" places, where the poor and working classes were living in wracked and neglected houses with open sewages, dark back alleys, smoke, filth, vermin and severe crime. The radical changes in societal structures partly caused by the Industrial Revolution not only influenced the dwelling standards of most people, but also demanded new types of buildings such like schools, universities, workshops, apartment houses, public baths, brothels, public museums, theaters, train stations, parliaments, hospitals and restaurants.

According to English Professor in design history Penny Sparke (2008:23), prior the $18^{\text {th }}$ century most European homes had been the major place of daily activities - a place in which work, leisure activities, extended family relations, and making, preparing and preserving of food as well as clothes making and moral education had co-existed. Up until the $18^{\text {th }}$ century, architects had thus mainly worked as masons or clerks occupied with designing for patrons like the church, noblemen, kings and other rich and powerful people. During the late $19^{\text {th }}$ and early $20^{\text {th }}$ centuries, motivated by exactly such things as human needs and fabrication costs, more and more architects became engaged in social responsibilities concerning communities, welfare and public health. Those notions had previously played little or no part in the formation of the architectural ideals, and it caused many architectural thinkers to re-evaluate the design principles defining architectural quality (Collins 1965:15,21,22,25; Eck 2004:56). 
One of these changing ideals in architecture was the English Arts \& Craft Movement led by textile designer William Morris and inspired by writer John Ruskin and architect Augustus W. N. Pugin in the $19^{\text {th }}$ century (Sparke 2008:86). The ideal behind this movement was, based on Ruskin's social criticism, that the moral and social health of people - and of the society - could be related to the qualities of architecture, as well as the skilled and creative workers (Whyte 2004:48). Another example of the changing ideals in architectural quality, in response to improving the qualities of live, is the ideal of the Garden City, a concept developed with English Sir Ebenezer Howard in response to the rapidly increasing problem of smoke, slums and overblown land values in the Victorian city in the late $19^{\text {th }}$ century. The concept of the Garden City proposed to solve this by creating self-sufficient, small circular constellations of towns built in the open countryside (Hall 2002:8). For Howard the provision of good cheap housing freed from the menace of speculation would guarantee a better society by combining the social advantages of the city with the primal innocence of the country. In the concept of the Garden City, the small town is the symbol of society, of mutual help and friendly cooperation, of broad expanding sympathies, of science, art, culture, religion and the nature as the source of all health, wealth and knowledge (Whyte 2004:48-51). Here architecture became a humanistic project occupied with the human scale based on the underlying intensions of improving the everyday life and, as part hereof, the possibilities of improving the general health and well-being of civic people by providing a better architectural frame around living. This was based on a socio-political approach using architecture not only to help improve public health and societal issues, but also to change and improve entire societies (Hall 2002:3). According to Hall (2002:2), the visions themselves, however charismatic, were often utopian ideals that were never realized. Today such ideals as the ones governing the Arts \& Craft Movement as well as the Garden City are often criticized for being so utopian that few were actually implemented in practice. And that those who were implemented in practice often differed from the ideas originally envisaged, and the results were often bizarre, sometimes even catastrophic (Hall 2002:3).

An important aspect that characterizes the utopian ideals and architecture of the Arts \& Craft Movement is the fascination of 'total design' - or what is also often referred to as the architectural 'Gesamtkunstwerk', where architects conceived the exterior and the interior as a single unit and linked the structural aspects of the interior with the non-structural, the practical with the decorative, and the two-dimensional with the three-dimensional (Sparke 2008:40). Here, not only the specific architectural envelope but all scales - from landscape, city, building, gardens, interiors, décor, art, furniture, tapestries, carpets, tableware, probs, clothing, shoes to even jewelry - were used to follow the ideal of creating a better society through design (Bryant 2004:158). Through the idea of the Gesamtkunstwerk, religious or social concepts and political aims were brought into the realm of architecture, and a certain set of ideals were brought upon society to follow (Bryant 2004:158). In that way the architecture became a "carrier" of utopian ideas for transforming society, creating a better way of life and ultimately achieving a new social order (Bryant 2004:158). Different interpretations exist of the meaning of the term, but by some people, the architectural Gesamtkunstwerk has because of the above utopian ideals been called "habitational engineering", "environmental dramaturgy" or the "ultimate myth of the origin" (Bryant 2004:159). And it is criticized as an elitist bourgeois illusion too far removed from the reality it wishes to transform. These critics thus argue that instead of transforming society, the reality of the present was excluded (Bryant 2004:159,161). Part of this critique is based on the circumstance that the occupation with the architectural Gesamtkunstwerk, fostered a very distinct focus on luxurious interiors and the "ensemble" of extravagant furniture, which caused the discipline of Interior Architecture to prosper during the early $20^{\text {th }}$ century.

\section{The emergence of the interior}

Relative to the above-mentioned, it was not until the beginning of the $19^{\text {th }}$ century (1829) that the term 'interior' came to denote the inside of a building (Rice, 2007:2). Before that time, interior, presumably first occurring around the 15th century, had denoted an inside separated from an outside used to describe a spiritual, 
inner character or the soul (Rice, 2007:2). As such various definitions of 'interior' exist. Some writers and architectural theoreticians use 'Interior design', 'Interior Architecture', 'Interior Decoration', 'Spatial Design' or even 'Room' and 'Space'. Others, dependent on what academic background and specific architectural perspective they represent in their writings, use 'Interiority'. Further, parts of the academic world and design practice even argue that the 'interior' is a distinct discipline; separate from the architectural discipline (Sparke 2008:188). I will not engage in an elaborate discussion about the specific meanings and interpretations of the 'interior' here. Instead I would like to point at the writings by Australian architectural theoretician Charles Rice (2007:2), who argues that the original or first use of the term 'interior' in connection with architecture relate to the use of image-based wall decorations. The image-based sense strongly relates to the theatrical world, focusing on the interior's deliberate fabrication and staginess using artistic effect of colors, furniture and probes to make a clear distinction between the interior space and the construction or structure of the building (Rice 2007:2). Rice (2007:2) also notes that the interior developed not only as a 2-dimensional 'image' but further emerged as a 3-dimensional 'space' thereby fostering a type of 'doubleness' of the interior. This 'doubleness' or the mutual connection between 'image' and 'space' reflects the poetic values of a building's interior developed within domestic architecture during the Victorian era in the mid$19^{\text {th }}$ century (Rice 2007:2). This type of interior is often also referred to as 'bourgeois interiors.' The 'bourgeois interiors' of the Victorian home of the upper middle-classes are often characterized by the arrangements of upholstered furniture around small tables, establishing a strong sense of enclosure further articulated with the eclectic mix of "rich" textiles such as velvet and silk, footstools, chandeliers, bibelots on the mantel pieces, rugs, patterned carpets, curtains, potted plants, framed pictures and collections of ceramic artifacts or "knick-knacks", books and perhaps even a religious statue (Sparke 2008:21,24). According to both Sparke (2008) and Rice (2007) the "modern" developments in interiors, as with the development of 'modernity' in architecture, are closely connected to the radical social and political changes occurring in Western societies. Those social and political changes motivated increasing desires and demands for privacy and comfort, but also altered practices of consumption and self-representation (Rice 2007; Sparke 2008).

During the Victorian era within the upper middle-classes, the home turned into a refuge - a shelter dedicated to the privacy of the individual; protected from the public society, with an emphasis on the physical comfort and the home as a "sacred heaven" (Sparke 2008:13,24). However, the home was also simultaneously a place of social interaction where fashion and 'taste' could be displayed, and class could

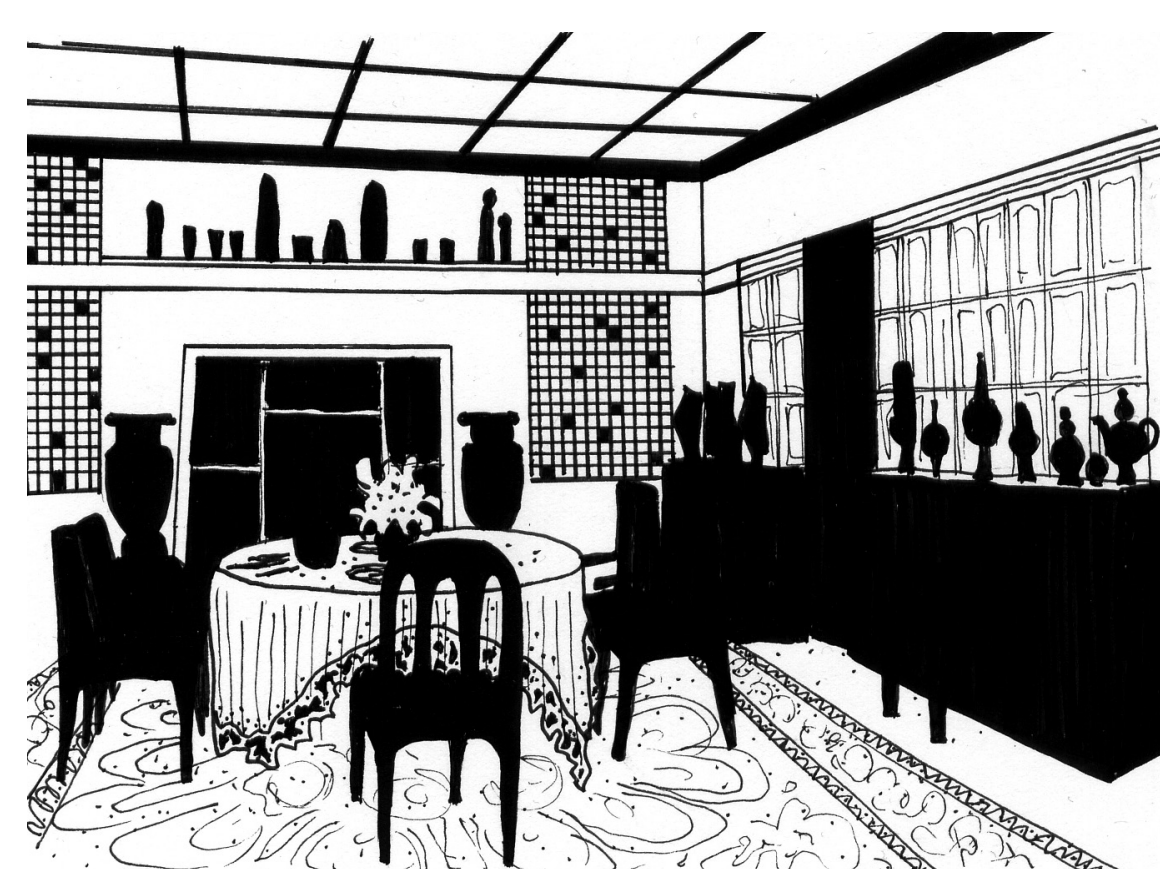

Fig. 2.2

"The bourgeois interior" What today is known as the Newport Mansions in the United States stemming from the "Gilded Age" probably stand as the most luxurious examples of the link between domestic interiors, social aspiration and opulent material display (Drawing adopted from Gannon \& Miller 2010:91). 
be demonstrated through the collection of artifacts. The domestic interior was as such not only an 'image' or 'space', but it also became an 'assemblage' of material objects representing an expression of the 'self' through the choice of décor (Sparke 2008:12,21). Whereas Rice (2007) relates the 'doubleness' in the meaning of the interior to the development of domestic architecture, Spark (2008) has with the book: The Modern Interior investigated the 'doubleness' in the emergence of public interiors.

\section{The public interior}

Sparke (2008:22) argues that during the late $19^{\text {th }}$ century this above-mentioned eclectic Victorian interior as 'assemblage' moved from the homes of the upper middleclasses and into both semi-public and public domains. Because during the $19^{\text {th }}$ century, the growing industrialization and urbanization, as well as the increasing availability in mass-produced goods in the early $20^{\text {th }}$ century, strongly affected European and North American consumers' 'self 'and 'collective' identities (Sparke 2008:9,17). The expanding display of domestic interiors in public domains manifest in window and retail displays in shops stimulated desire and encouraged consumers to construct their own domestic spaces (Sparke 2008:15). These public interiors had a capacity to turn values, desires and aspirations into visual, material and spatial ideals - creating a series of "idealized interiors" and providing glimpses into the homes of the rich which simply seduced the "spectators" emotionally into consuming and buying more (Sparke 2008:15,17). The public interior understood as an 'assemblage' of collective objects thereby changed not only the architectural qualities of both public and private spaces, but also influenced how individuals related to one another in society, as well as saw oneself within the society. According to Sparke $(2008: 12,22)$ the era of 'modernity' thereby encompassed many more "inside spaces" than just those of the domestic. And she notes how the era of 'modernity' pointed at public interiors as a complex phenomenon which could be understood as both 'image, 'space 'or an 'assemblage' of material objects for mass-consumption like: work (factories), mobility (train stations, train carriages, ocean liners/vessels), praying (churches), exhibition (museums), leisure (theatres), retail (shops), hospitality (cafés, restaurants, clubs, bars and hotels) and healthcare (waiting areas and wards in hospitals and health resorts) (Sparke 2008:8,12,22). Sparke thus focuses on the individual vs. the community as well as on differences between house/home and public building/monument, and argues that the public interior is a "home away from home" (Sparke 2008:12,22).

What is important in the arguments put forth by Sparke (2008) in the above-mentioned, is that since the mid-18 ${ }^{\text {th }}$ century - particularly during the period from 1750 to 1950 - architects have assumed that architecture could not only be used to improve our general health and well-being, but it could also be used to communicate our social status and most importantly seduce us emotionally by evoking bodily sensations touching our mind and create memorable experiences that moves us beyond place and time. In that sense, I would like to argue that a series of different disciplines such as exhibition design, retail design, service design, social and psychological sciences, economic sciences, hospitality, sensory and consumer sciences as well as not least neuroscience boarder with the understanding of public interiors. Because these disciplines - and in particular neuroscience - likewise touches on the understanding of how humans not only experience and perceive certain objects such as built environments, but also engages in an the wonders of what sparks human needs and desires for commercial goods such like food. However, before I continue this line of thinking, I find it is important to note that the discipline of neuroscience employ a wide range of specialised academics investigating much more elaborate and profound aspects of the workings of our mind and bodily perceptions, than I as an architect will ever be cable of. Here a wide range of neuroscientists, environmental psychologists, sensory scientists, neurobiologists, physicians and brain researchers have been engaged with research investigating the human perception of the built environment or food for several years, and vast amounts of research-based literature exists elaborating on the findings of such studies. I would therefore like to emphasize, that my interest is not in how and why neuroscience influence our minds and behaviour. But instead, which consequences and what importance the recent neuroscientific findings have for our understanding of the architectural quality, and thereby also for architectural theory and architectural practice in general. 


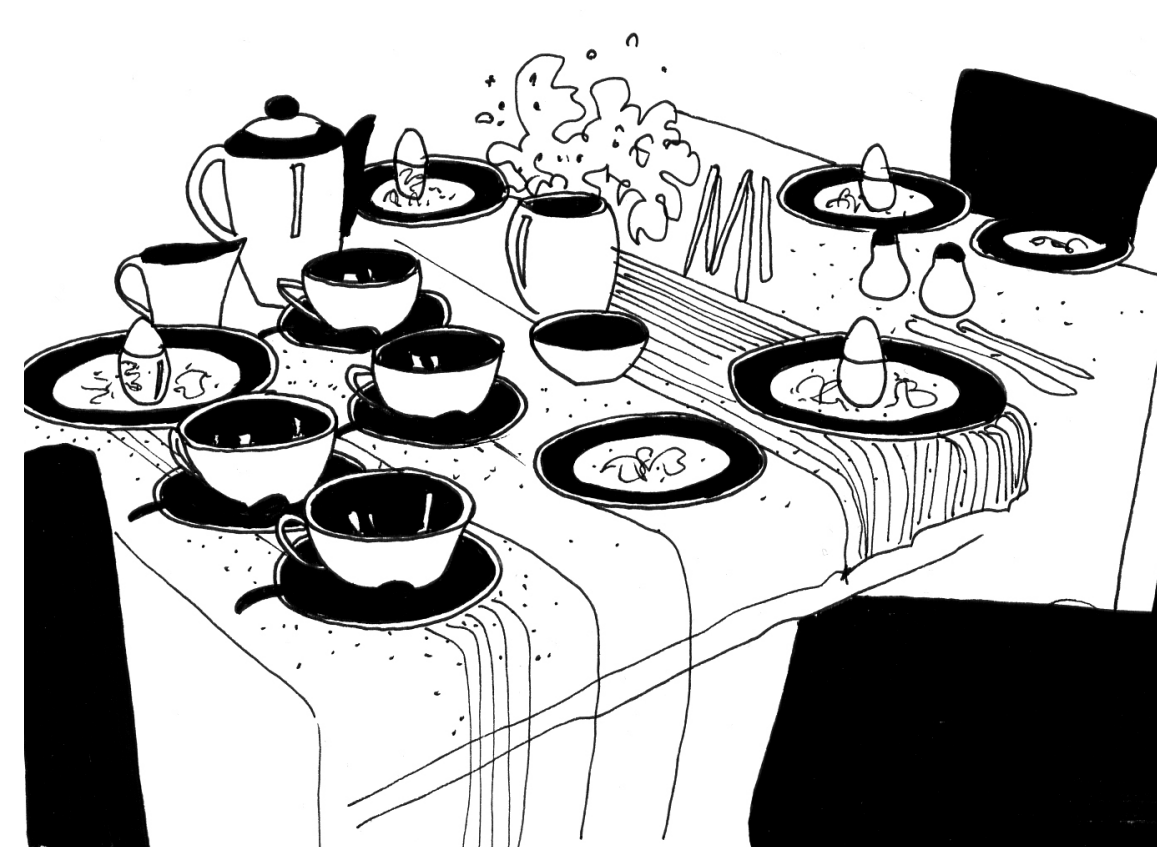

THE WONDERS OF NEUROSCIENCE

\section{A "new" perspective on architectural quality}

In August 2002, a group of North-American researchers from what would later become the Academy of Neuroscience for Architecture (ANFA) gathered at a conference in Massachusetts exploring the interface between architecture and neuroscience. The motivation behind this exploration was that since the 1980s the discipline of neural science had, with the improvement of advanced scanning technologies (such like fMRI, PET, EEG and MEG), achieved elaborate insights into the wonders of the human brain and a more profound understanding of how we experience, perceive, act, move, think, learn and remember (Sternberg 2009:2; Kandel et al. 2000:xxxv; Kandel et al. 2013). In the preface to the book: Principles of Neural Science, American Professor in biochemistry and neurobiology Eric R. Kandel (Kandel et al. 2013) thus write how the neuroscientific understanding of the brain and what is often referred to as the 'mind' has evolved from being addressed in cell biological terms to expanding with the molecular level, later a molecular biological level and today with the branch of computational neural science providing the possibility of gaining insight into the highly complex analysis of the workings of the brain on levels never seen before (Mallgrave 2011:134; Kandel et al. 2013:xlii-xliii).

One of the major features discovered with the recent neuroscientific investigations is that the brain continuously generates its own patterns of information through a series of neural circuits; continually "processing" inputs of e.g. touch, color, form, motion, smell, and sound in different areas of the brain (Mallgrave 2011:128). Another curious feature is that the brain continuously develops throughout life, and its neural complexity is presumably therefore highly influenced and shaped by the environment embracing it (Mallgrave 2011:126,134). What this type of research suggests, according to American architectural theoretician Harry Francis Mallgrave (2011:134-135), is first of all that the human brain is more than electrical and chemical events, more than homeostatic mechanisms - it is not just a "computer" passively processing sense stimuli - but instead it is a fully embodied entity that actively confronts the world with its own representational models. Second, it also suggests that it no longer makes sense to speak of a 'mind' or 'senses' as separate from the brain. Instead the brain consists of a series of "parallel processing" of assemblies of neurons in many different cortical areas (Mallgrave 2011:143). Apparently what is known today as 'perception' is thus formed through a series of "micro-consciousness" being scattered in location and formed over time within distinct areas of the brain (Mallgrave 2011:148).
Fig. 2.3

"Shopping for an Interior" During the turn of the 20th century it became very popular to exhibit entire interior assemblages in the shops, creating "idealised interiors" triggering consumer desires. (Drawing adopted froom Sparke 2008:56) 
With reference to the findings of for instance neuroscientist Semir Zeki Mallgrave (2011:139) exemplifies the above-mentioned with the main argument that neurological investigations have literally changed how we see the world. Traditionally the sense of vision was closely linked to an understanding of the Cartesian model, where sensory vision was compared to camera-like perspective depicting the world as an 'image'. Contemporary neuroscientific investigations suggest a much more complex scenario, where the brain registers and reacts to light, shapes and lines, colors, motion, orientation and depth in distinct parts of the brain. There is as such no single zone that collects all this visual information, and it is not a linear process. Mallgrave (2011:144) emphasizes in continuation hereof that it thus seems like the brain, when faced with new experiences, selects parts of the "new information" and compares it to old memories. Earlier experiences are thus altered with the encounter of new ones, and it turns out that perceptual vision is presumably "processed" in the same areas of the brain as imagined thoughts (Mallgrave 2011:163-164). With reference to neuroscientist Joaquin M. Fuster, Mallgrave (2011:164) concludes that, in that way, all memory is in essence "associative" and an act of re-categorization and construction, because the brain generalizes and categorizes the perceived world into permanent, imagined and essential characteristic properties. In his own terms: "This places all our knowledge of the world under perceptual memory" (Mallgrave 2011:164).

That kind of knowledge is particularly interesting for creative disciplines such like architecture and gastronomy. Because what the above-mentioned neuroscientific discoveries suggest are that humans, due to underlying neural workings of the brain, constantly "search" for "universal aspects of forms" in their experience and perception of objects such as the built environment and food (Mallgrave 2011:146). Despite the arts are often seen in sharp contrast to the sciences, not only Mallgrave (2011:1) but also the American editor and research assistant to Eric Kandel, John Lehrer (2007:vii) argue that the core findings of neuroscience, which suggest an embodied understanding of the brain and an importance of certain 'universal aspects of form' linked to our memories and emotions, were anticipated by artists, such like writers, painters, composers, poets, architects and even chefs more than 200 years ago. As mentioned in the above, before 1750 architects were particularly occupied with the idea that proportions and geometrics provided privileged and harmonic ratios in architecture, and thereby they sparked the idea that architectural quality could be defined by a series of universal or basic design principles (Mallgrave 2011:146).

This idea that the arts could perhaps contribute to greater insight and knowledge about human experience, mind and behavior is indirectly supported by Kandel et al. (2000:407). They begin a chapter on perception with a long quote of one the most famous evocations on sensory experience and remembrance in the history of literature; the description of the 'taste' of a small Madeleine cake dipped in tea that reveals the vivid childhood memories of the entire city of Combray, written by the French author Marcel Proust.

In continuation hereof, Kandel et al. (2000:644) note on the matter of 'taste' that the sensation and perception of flavor of food derives from a combined series of information provided by the olfactory system, gustatory system and somatosensory inputs. What we thus mainly experience as 'taste' in the mouth is really a highly complicated parallel process of perceptions encountered with the different sense modalities of the mouth, nose, eyes, ears, hands, tongue and vision as well. Here the gustatory (mouth), olfactory (nose), tactile (tongue and hands), audio (ear), visual (eyes) perceptions are activated and engaged simultaneously. According to American Professor in food science Harry T. Lawless (2000:92-93), eating can be thought of as a combination of a series of different sensory experiences, and what is so spectacular about eating is that it is probably one of the only experiences that involves all senses simultaneously. Through the acts of looking, grapping, chewing and swallowing the food, the neural cells rooted in our entire body register odours, aromas, colors, light, sounds, flavor, texture, temperature, crispness, softness, creaminess and so on (Lawless 2000:93). In fact, much of what we 'taste' is thus really based on the ability of the nose to pick up the different vapors traveling around in the cavity of the mouth (Lawless 2000:94). The experience of eating and the perception of 'taste' relative to food are something that has been investigated and debated a great deal within culinary circles (see e.g. Korsmeyer (2005), Korsmeyer (1999), Flammang (2009)), and, 


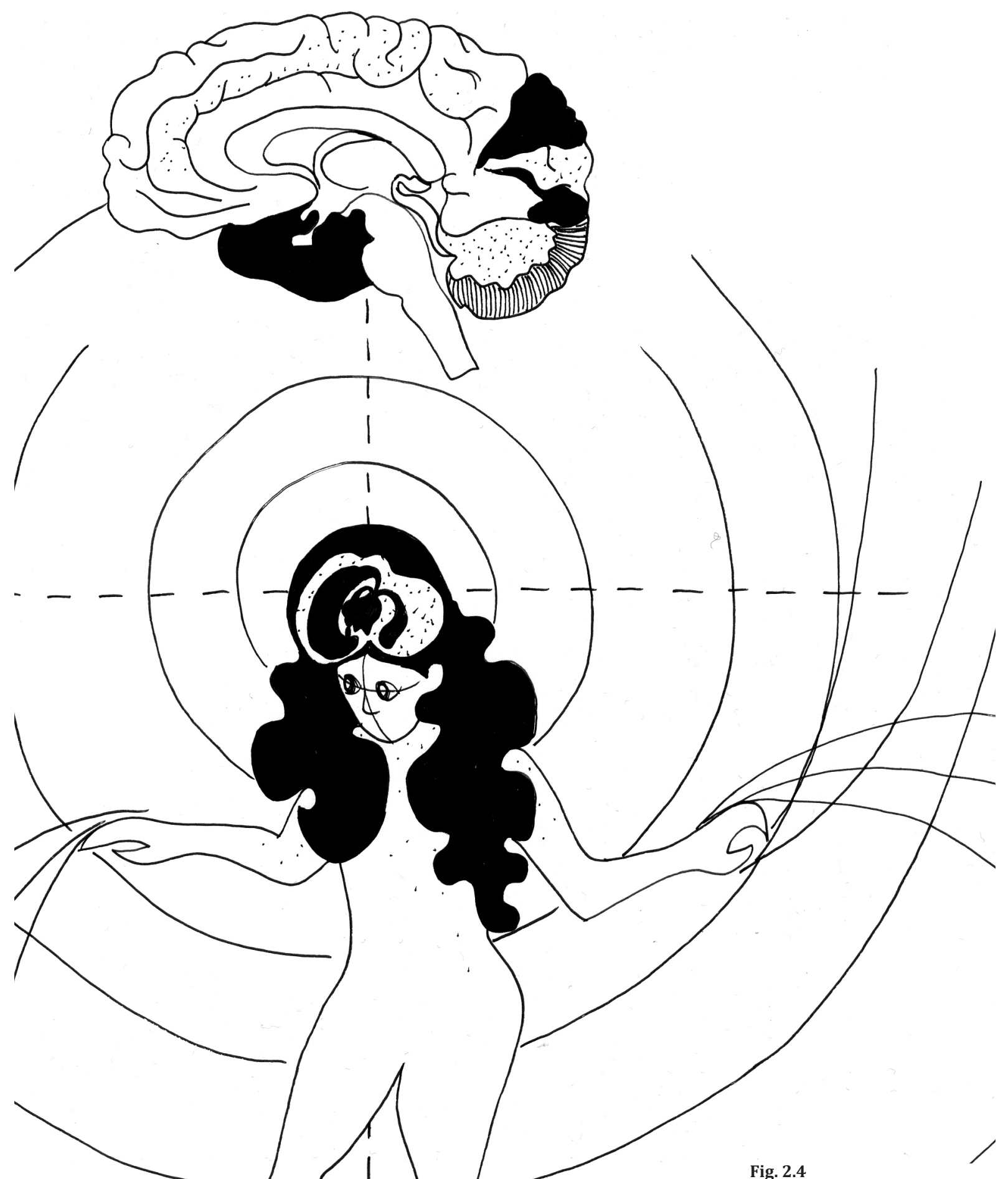

Fig. 2.4

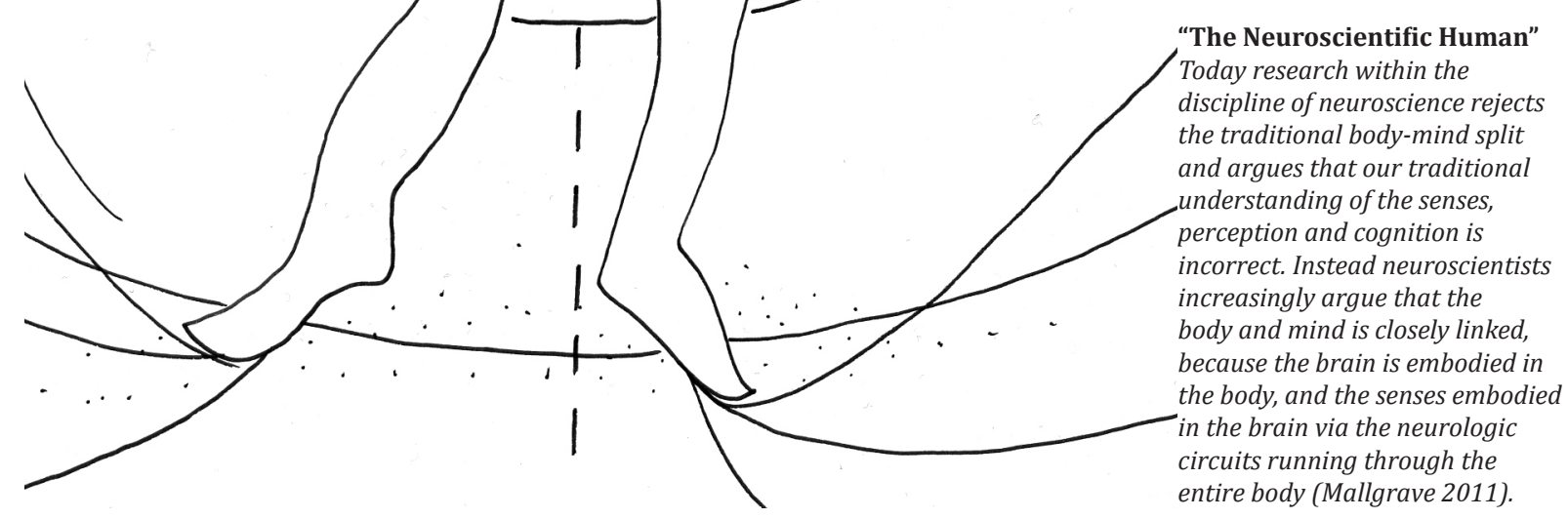


among others, American food scientist Herbert Meiselman (2008:14) has attempted to outline the dimensions that possibly influence the experience of eating and the aspect of a meal. On the background of such discoveries as the above, he argues that the act of eating involves far more dimensions than the physical, sensory and bodily encounter with a specific food item eaten (Meiselman 2008:14). Because the act of eating, as emphasized by Lawless (2000), involves a parallel combination of all the senses at once, the perception of eating must also include the social, psychological and cultural dimensions as well. With this statement, Meiselman (2008:16) even argues that the built environment and surrounding 'space' is important for how we perceive and experience eating.

\section{An insight into the impacts on health and well-being}

If we move away from the culinary perspective back to my main perspective - the architectural perspective, another very interesting discovery made with the advances in neuroscience is the indication that the perception of the built environment is presumably linked with our general health and well-being. The work and investigations done by American neuroscientist Antonio Damasio with the book: Descartes' Error, emotion, reason and the human brain (1994), picks up on these types of discoveries and argues that emotions cause changes in our body's homeostatic conditions. As well as in the supporting brain structures involving 'thought' among others, because emotions and feelings have a pejorative effect on our health (Mallgrave 2011:190). According to Mallgrave (2011:191), the point made by Damasio is that different emotions have different neurological "maps", and on that background suggests that physical and cultural environments promote or reduce pain and thereby affect the overall well-being (Mallgrave 2011:192). The statement that health and well-being is affected by the neurological processes of the body and brain is supported by Canadian Rheumatologist Esther M. Sternberg (2001:7) who continues Damasio's line of thought by adding that illness or the effect of being sick can be described in many ways, but one of them is in the discrete components of fever, fatigue, sleepiness, weakness, sadness, and loss of appetite for food. Sternberg's (2001:7) point is that illness has a sensory component, such as pain, and each of these feelings can be further described by the effects on the various molecules released from immune cells in the brain (Sternberg 2001:7). So the brain and the immune system seemingly "communicate" (Sternberg 2001:xi). Consequently, because 'mind' and 'body' are closely linked, physical changes in the environment could possibly influence our overall health and well-being because the immune system is presumably negatively affected by psycho-social levels of stress (Heslet \& Dirckinck-Holmfeld, 2007:198,248).

In 2002 at the ANFA, among the speakers at the conference held in Massachusetts, USA was American environmental psychologist Roger Ulrich (1984), who presented a study wherein he found that patients recovering from surgery took fewer analgesics and had shorter hospital stays if assigned to rooms with windows overlooking a natural scene compared to rooms with windows facing brick walls (Sternberg 2009:2). This discovery later led Ulrich (Ulrich \& Zimring 2004:2) to suspect that most modern American hospitals were built in such a way that they risked causing stress, anxiety and frustration among patients. The arguments were based on the recent discoveries in neuroscience; that the built environment via sensory perceptions has an impact on the experienced level of stress. The importance of that was that, if the experienced stress level is too high, it will have a reducing impact on the immune system, thus impacting the ability to heal wounds and resist infection diseases (Ulrich 2009a,b; Ulrich 2010). But also impact on the physical and psychological comfort of the patients and the patient's satisfaction with the healing process (Glind et al., 2007:154; Ulrich 2010). The argument thus was that, when considering hospital treatment and recovery processes of patients, it is vital that the immune system has optimal conditions and is not weakened any further than by the prevailing illness, because further weakening of the immune system can cause serious infections and delayed healing of wounds (see e.g. Heslet \& Dirckinck-Holmfeld 2007:200; Sternberg 2009; Ulrich et al. 2008, Frandsen et al. 2009; Lawson 2010). On the background of a new series of research studies Ulrich later identified three important design principles, which he suggested should be followed in future hospital design. Those were: (1) a sense of control with respect to physical surroundings, (2) access to social support, and (3) access to positive distractions such as 'nature views' (Ulrich 1991). This research 
along with other healthcare related research became the outset for the architectural sub-disciplines called Healing Architecture and Evidence-Based Design where various researchers related healthcare, architecture and environmental psychology began investigating the influence of built environment on patient treatment and recovery processes (Glind et al., 2007:154). The sub-discipline of Healing Architecture thus offers answers to how the architectural qualities of hospital environments can have an impact on patient treatment or recovery outcome and can help improve healthcare efficiency and reduce costs. And relative hereto Evidence-Based Design (EBD) was introduced as a kind of research method used in hospital contexts to "scientifically measure" the influence of physical environment on human perceptions, hospital productivity, employee and patient morale, as well as patient treatment outcome (Ulrich et al. 2010:95-96). EBD strongly relates to the terms Evidence-Based Medicine (EBM), Evidence-Based Healthcare (EBH) and Evidence-Based Practice (EBP), which since the 1980s have been developed within medical professional, healthcare and social work practices where research-generated facts and best evidence are used to guide decisions about practice (Rubin \& Babbie 2010:20; Harrison \& Checkland 2009:121).

Today much of the research conducted within the domain of Healing Architecture and Evidence-Based Design, linking health and well-being with architecture, are gathered and published by American Center for Health Design, which also offers extra education and certification in health design to professional architectural practice (see www. healthdesign.org). Furthermore the center provides an electronic library offering access to more than 2,500 references elaborating on relationship between health and architecture. However, in 2004 a research study that was performed across five different hospitals in Denmark indicated that more than $30 \%$ of the patients were suffering from undernutrition (Rasmussen et al. 2004). Because undernutrition is in general defined as a state where someone is not supplied with enough food or other resources such as nutrients; e.g. fat, protein or a vitamin, to provide for a proper bodily growth and health development (DFSN 2006:245). And because undernutrition among hospitalized patients in general can also be associated with increased risk of medical complications, increased length of hospital stay, more medical prescriptions, higher rate of infections, and diminished quality of life as well as produce higher treatment costs, the study suggested that the nutritional well-being of patients was an important but possibly overlooked aspect in contemporary hospital treatment (Rasmussen et al. 2004) [Tvedebrink et al. 2013b].

\section{THE PROBLEM OF PATIENT UNDERNUTRITION}

\section{An overlooked link between health and food}

The above findings of the study performed by researchers from the Danish departments of Gastroenterology in Aalborg, Copenhagen and Roskilde do not stand alone. According to Holst et al. (2011:176) the problem of undernutrition among hospitalized patients has presumably been seen all the time. This is further supported by Hartwell (2004:22-26) and Shepherd (2011:1-2) who both argue with reference to a long list of international literature that malnutrition, which is likewise defined as a condition of not having enough to eat (DFSN 2006:148), in general has been reported in hospitals for over 30 years and still is a prevailing issue in Western societies. With reference to Davis \& Bristow (1999), Hartwell (2004:22) points at how malnutrition among patients possibly cause severe physical damages, such like weight loss, muscle wasting, depleted fat stores, reduced serum albumin levels and impaired immune function. Hartwell (2004:22) further argues how these physical damages result in lowered resistance to infections, delayed wound healing, a general weakness and reduced functional capacity, but also how each of these impairments could possibly cause serious complications and impede recovery. Finally, with reference to Beese (1997), Hartwell (2004:22) argues that malnutrition also has psychological impacts, such as apathy and depression which might risk leading to a loss of morale and a will to recover. Because malnutrition is defined not only as an imbalance in energy, protein and other nutrients but can often be directly linked to measurable effects on tissue and function, it have an extraordinary impact on the clinical outcome of treatment procedures. Hartwell et al. (2007) therefore suggest using food as treatment, and this is supported by Shepherd (2011:2) who concluded that the importance of mealtimes 
should be emphasized (see also Bond 1998; Allison 2003; Davidson \& Scholefield 2005). Particularly Shepherd (2011) rooted this conclusion in the overall hypothesis that an important interrelationship possibly existed between health and food intake influencing the well-being of the patients, as suggested with research performed within different branches of food science. Here various reasons for an insufficient food intake have been heavily debated throughout recent years, not only concerning clinical practice, but also regarding infant eating and problems on obesity (see e.g. Pliner \& Rozin 2000:19; Wansink 2004). And researchers argue that the regulation of food intake is influenced by a highly complex system of interactions of the senses, digestive tract, central nervous system, gut hormones and several psychological and social parameters such as daily activity pattern, body weight, energy density, gastric emptying time, patterns of eating, company for eating, food choice, presentation of food, quality of food being offered, portion size, visibility and availability of food, efforts, preferences, mood, variety, sensory-specific satiety, motivation, distractions, experience, memory and expectations, as well as cultural standards, and location (Pliner \& Rozin 2000:22,27-37; Nieuwenhuizen et al. 2010:161).

Food intake thus depends on a long series of both bodily and mind-related experiences that strongly indicate that overcoming patient undernutrition not only depends on getting the appropriate amount of nutrition and being satiated physiologically, but is as much about the psychological well-being and social satisfaction of enrolling oneself in a community during mealtimes. When the understanding of undernutrition and food intake is thus broadened beyond the act of eating a specific food item to further include the psychological values, cultural norms, social behavior and ritual acts, the eating experience is influenced by the entire eating environment - the surrounding architectural scenery framing the meal [Olsen, 2010:105].

With this particular understanding, I am back not only at the arguments put forth by Sparke (2008) on the ability of the architectural interior to communicate and seduce our minds and power to affect our behavior, but more importantly also back at why I became so interested in the analogy of theatre in the unfolding of the relationship between food and architecture in my Master's thesis. Because even though, most of the above-mentioned societal problems related to common public health and wellbeing that occurred in the Western world during the $19^{\text {th }}$ century today have been eradicated. The ideals of the late $19^{\text {th }}$ and early $20^{\text {th }}$ century focusing on the impact and importance of architecture on health and well-being is still a heavily debated issue among contemporary practitioners and researchers related healthcare, as can be seen with the rapidly evolving discipline of Neuroscience and the two sub-disciplines Healing Architecture and Evidence-Based Design. Furthermore, as argued for above, a series of research studies performed within the discipline of Gastroenterology indicate that health and well-being are closely linked to food intake. Because food scientific research studies then further suggests that food intake is influenced by the communicative significance and theatrical ability of architecture to seduce us, the crucial question inspiring my research is, if this specific problem of patient undernutrition and the contemporary concern with improving the human well-being, by linking respectively health and architecture, health and food, as well as food and architecture can gain any further insight by synthesizing the perspectives of health, food and architecture into one coherent whole?

As mentioned in the Preface, during my time as a research assistant at the Center for Food Science, Design and Experience at Aalborg University, I was introduced to a project called MORE. This project offered in my point of view a possible answer to that specific question about the synthesis of health, food and architecture, and quite early became the key motivation in my research. In the following chapter I will therefore begin the problem definition and unfolding of my research hypothesis and research questions with a brief presentation of project MORE. The presentation is based on my participation in a series of formal meetings held by MORE, insights into the project descriptions and research material developed in MORE, as well as a minor series of more informal visits, conversations and semi-structured observations performed in the specific departments of Infectious Diseases and Haematology involved in MORE (see Bibliography in page 231). 


\title{
PROBLEM DEFINITION
}

\author{
ON HEALTH, FOOD AND ARCHITECTURE
}

Traditionally, the nurses handle the everyday nutritional care of the patients (Holst et al. 2011:176). However, inspired by the international research performed on undernutrition as well as the tendencies in Healing Architecture and on the initiative of the Department of Medical Gastroenterology and Centre for Nutrition and Bowel Disease at Aalborg Hospital in Northern Denmark, a small group of doctors, nurses, dieticians and nutrition specialists established the project MORE. The project MORE tried to break with the propensity of patient undernutrition by focusing more on a holistic approach to patient healthcare, synthesizing health and food by modifying diets and nutrition to support the needs and desires of each patient during eating (MORE 2009; MORE 2010b). The general idea of the project was that patient recovery did not solely depend on medical and surgical treatments, but also on the general wellbeing and health of patients - on the aspects of care and caring provided by the nurses and nutritional staff through everyday activities related to eating (MORE 2010c,d).

In 2009 and 2010 the group involved in MORE conducted a cross-sectional user survey with patient and staff interviews, as well as performed observations, implemented interventions and conducted impact measurements in the three departments: Infectious Diseases (7V), Hematology (7Ø) and Heart-lung (T) at Aalborg Hospital (MORE 2010j; Beermann \& Holst 2010). As part of the intervention studies conducted in MORE, nutritional therapy with direct improvement of the quality of the food served was initiated, as well as a focus was put on how to improve the food intake and the nutritional values obtained by each patient during eating. This was done through initiatives of screening, monitoring and developing individual nutrition plans, as well as introducing "in-between snacking" at the involved hospital departments (MORE, 2009) [Olsen, 2010:103]. Some of the studies, which were performed to obtain knowledge on the patients experience of being undernourished, identified that possible reasons for the patients' low food intake could be related physical and psychological impacts, impacts of medication, motivation and expectations to staff as well as the role of fellow patients or relatives for instance (Holst et al. 2011:179). Here aspects such as nuisance, pain from muscles and bone ledges, as well as a general uncomfortable feeling were found to influence the physical and psychological well-being of the patients, causing a lack of appetite and sense of bad taste, and thereby affecting their ability to eat and obtain a sufficient food intake (Holst et al. 2011:179). However, other internal studies, which were aimed more at identifying main barriers for achieving proper levels of nutrition during mealtimes in the different hospital departments, found that some of the main barriers for low food intake among hospitalized patients could possibly be related aspects such as absent priority and focus on nutrition among staff (especially doctors), absent routines and procedures in departments, difficult to place and locate responsibility, missing knowledge on the importance of optimal nutrition, bad eating environment in the departments, no patient dining room and absent administrative and managerial support (MORE 2009:2). 


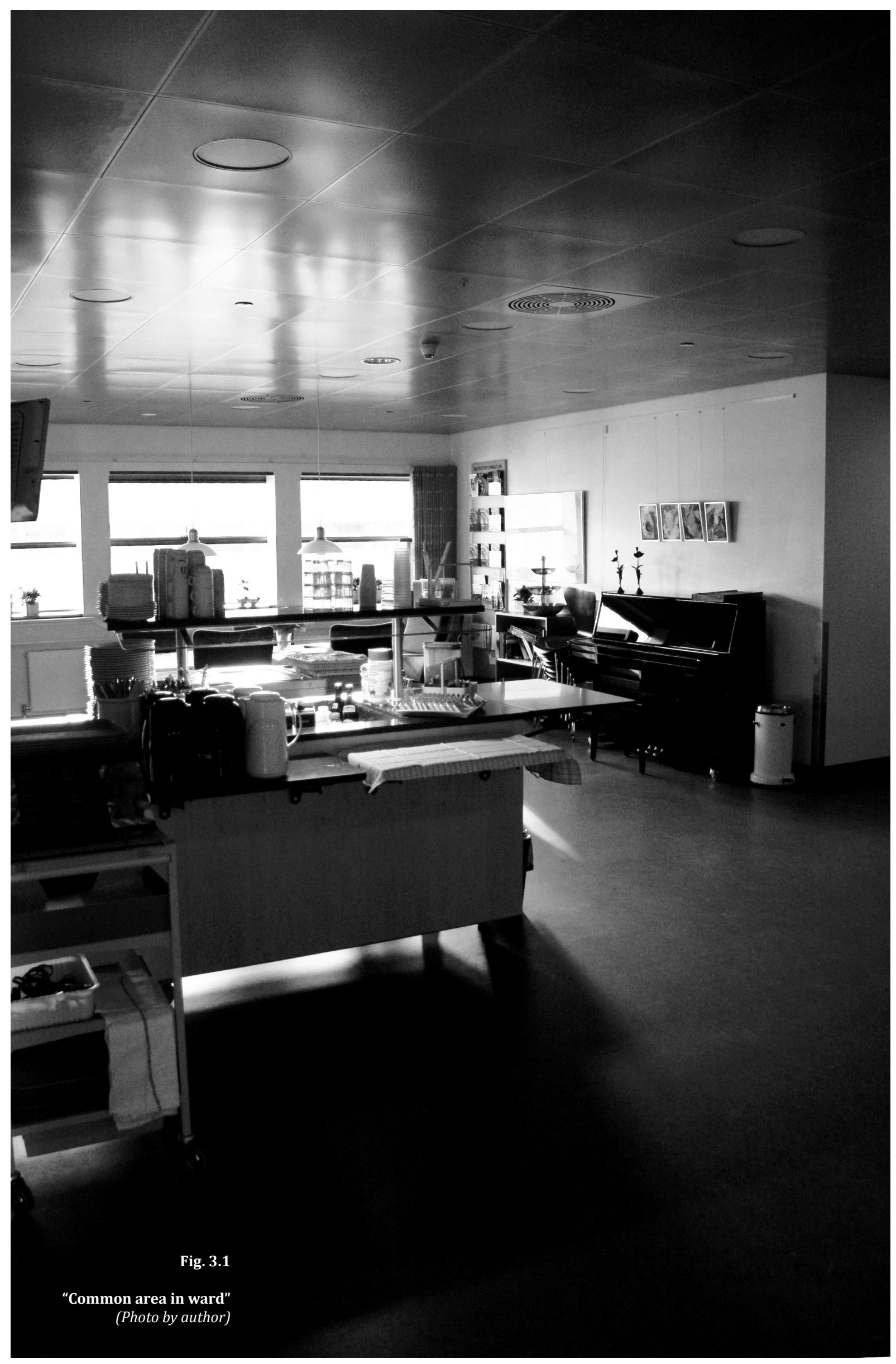




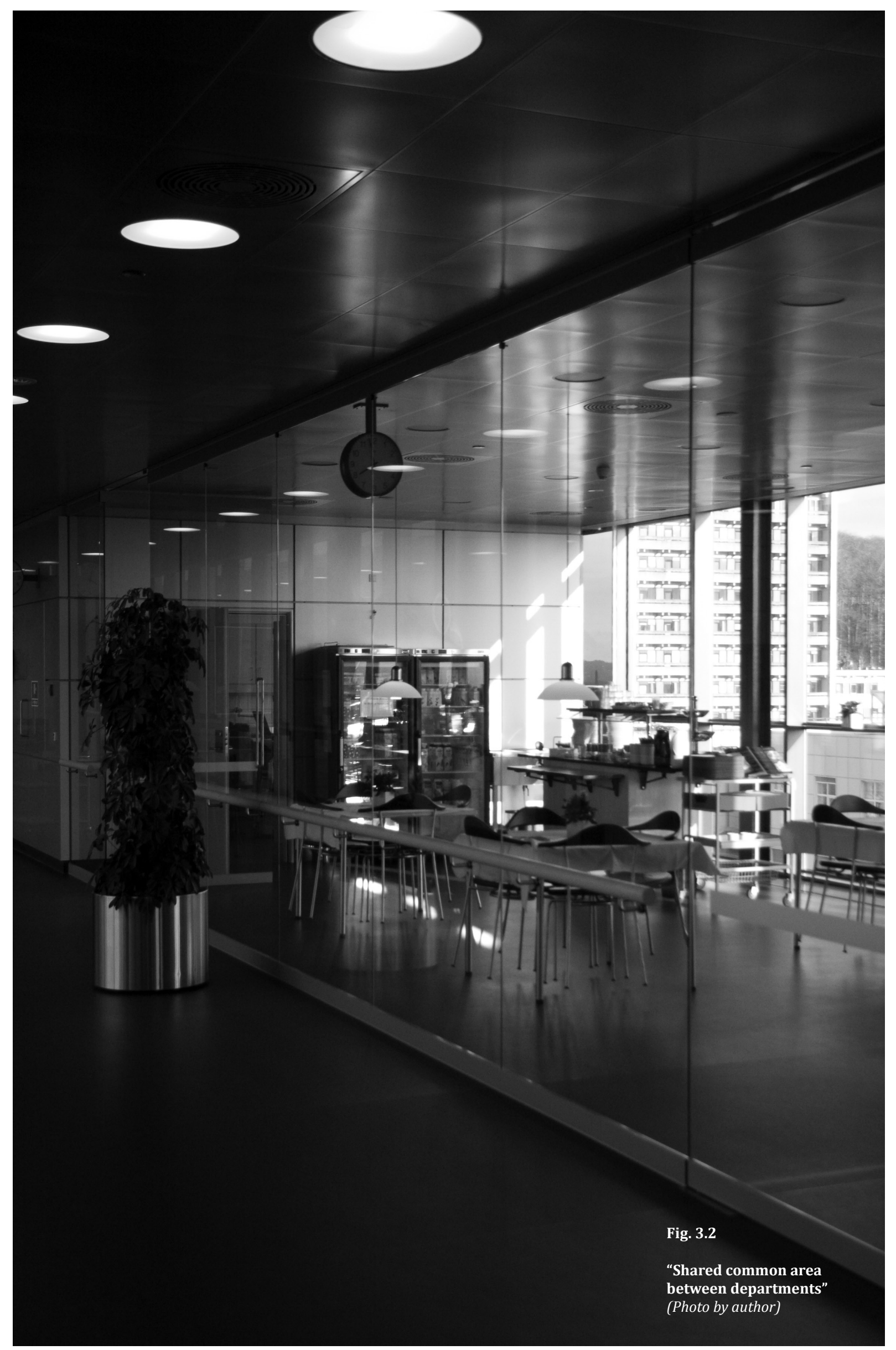


Fig. 3.3

"Department of Infectious Diseases (7V)"

Two of the involved departments in project MORE are located on the 7th floor of a newly built extension (2006) to the original hospital (1970) called: Medicinerhuset. In the 7th floor the departments share centralized kitchen facilities and a larger common area. Each of the two departments furthermore have their own minor common area in the ward, encompassing a small dinner table, some armchairs and a bulk trolley for the food service of patients during mealtimes, as well as for drinks or lighter snacks during the day. Additional to the bulk trolley the departments are part of a sub-initiative of project MORE offering patients drinks, snacks and sweets in-between meals from a small tea trolley strolling around the ward three times a day. All meals are prepared in a large decentralized kitchen located in a separate building in the hospital area. The centralized kitchen facilities are thus mainly used for storing of drinks, snacks, tableware and dishwashing, as well as heating of foods prior to mealtime (Ulrich \& Hurwitz 2009) [Tvedebrink et al. 2012:8].

The below sketches illustrates first the entire floor plan of level 7 at Medicinerhuset, then the specific floor plan for Department of Infectious Diseases, and finally a conceptual floor plan of the common area in the ward. The photos on the opposite page are all from the common area at the Department of Infectious Diseases (photos by Author).
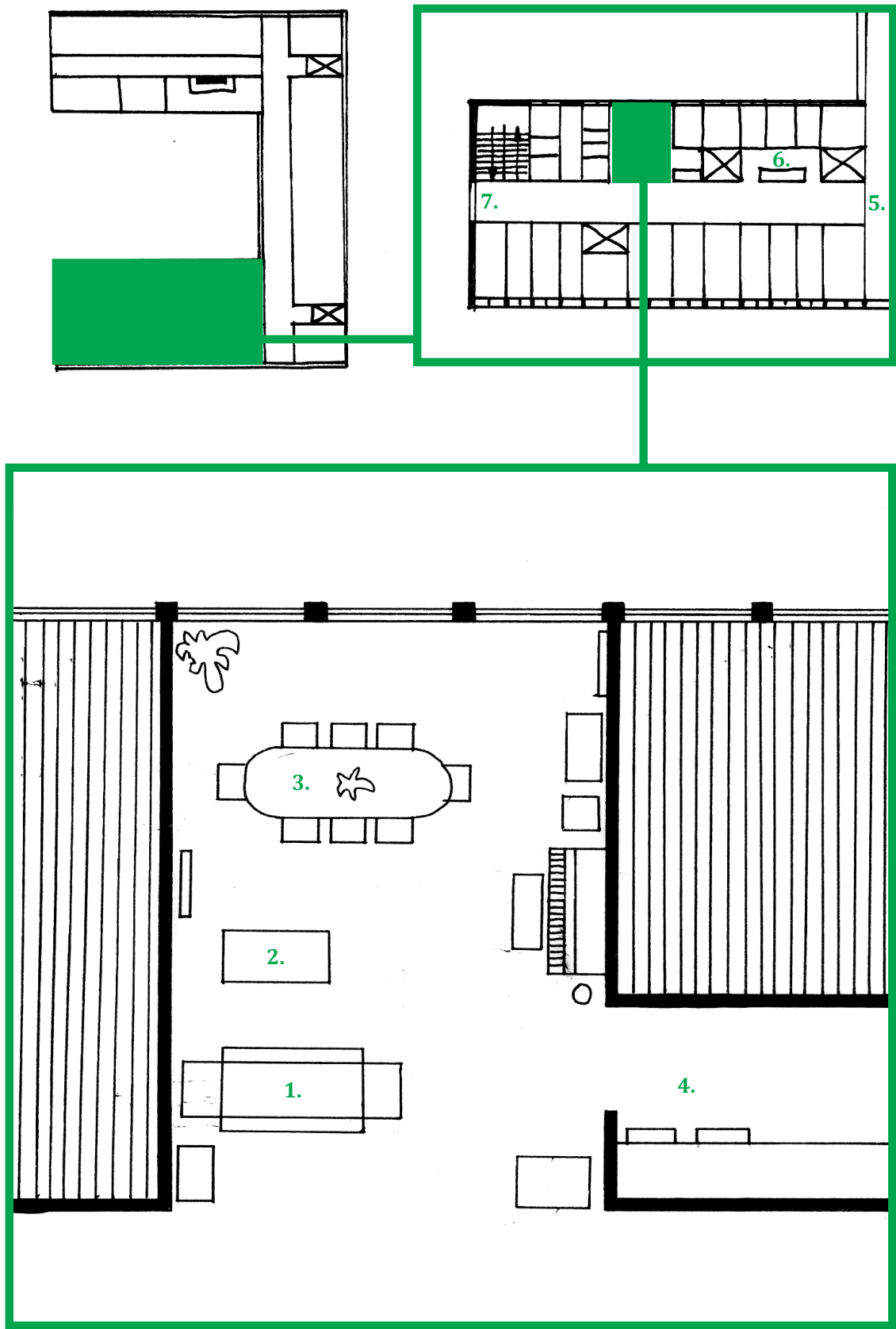


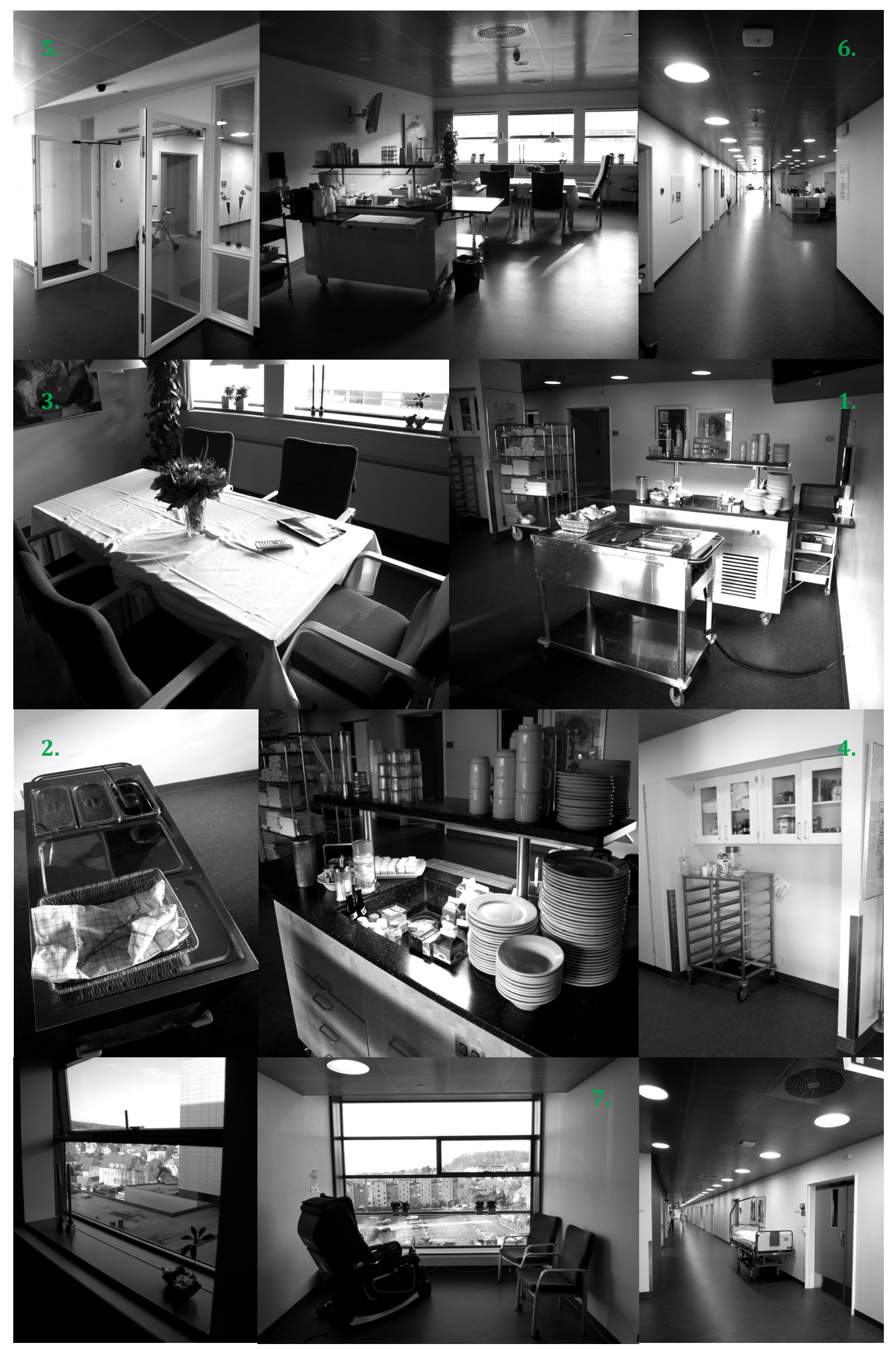


On the above-mentioned basis stakeholders in MORE developed ideas about improving the entire eating situation and patient eating experience by means of partly introducing a patient-centered focus on nutrition, but also by refurbishing the specific eating environments. This idea among others also included an increased focus on the 'hostess' role of the nursing staff during food services (MORE 2010b) [ Olsen 2010:103]. The Department of Infectious Diseases (7V) made applications for funds to alter and refurbish the patient eating environment at the ward, as well as hired a Danish 'food event company' called: Madeleines (who are an offspring of the Danish restaurant called Madeleines Madteater) as a consultant to help develop some of these ideas and specifically make proposals for how to design and implement these refurbishing's (MORE 2010d,g; MORE 2011). A series of interventions were performed, improving the eating environment by adding white tablecloths, napkins, flowers, candle lights, china, and music to the scenery of the "ordinary" food servings. Furthermore, a 'welcome-tray' with special servings and written materials about food and nutrition, as well as "interviews" aiming at categorizing patients into types/ 'personas' associated with a specific menu and serving style was implemented in ward routines. Finally, food menus were improved by adding different "toppings" providing an impression of delicacy on the plate, and the nursing staff made an extra effort of not disturbing while patients were eating (MORE 2010b; Rasmussen 2011)[ Tvedebrink et al. 2013b]. The impact measurements conducted in the involved departments indicated that the interventions affected patients' meal experiences and food intake. However, the studies also indicated that more research is needed to gain insight into these complex relationships of health, food and eating environment (Rasmussen 2011).

What I find is particularly interesting in the example of MORE is that it was acknowledged that food servings in hospitals are not just matters of feeding the patients with appropriate amounts of nutrition such as energy, proteins and calories, but as much about the eating experience and the entire eating environment established around the patients during mealtimes. Consequently, I find that the underlying idea of MORE was to use mealtimes as a positive distraction in hospital treatments, making the eating experience a facilitator for improved life quality, establishing social contact and thus possibly reducing stress levels occurring during the recovery process, just as 'nature views' or 'art' was suggested as positive, healing distractions with the discipline of Healing Architecture. However, what I find is so unique and fascinating about MORE, is that contrary the design principles put forth with Healing Architecture and the research stemming from the food science, this project linked not only the knowledge of health and architecture, health and food or food and architecture. But instead proposed to synthesize the knowledge of health, food and architecture into one coherent whole. They even did so with the help of a food event company strongly relating to the theatrical world. As mentioned in my Master's thesis (see Olsen 2008) the restaurant Madeleines Madteater was one of the first in Denmark to fuse the knowledge of theatre, gastronomy and architecture in their approach to food servings. Yet, the example of MORE is not unique.

\section{A similar project}

In 2009 a similar project was established at another Danish hospital in Vejle. At Department A250 of Orthopedic Surgical Patients on the background of a research survey conducted in their ward, a small group of nurses and nutritional staff made a proposal for refurbishing the patient eating environment (Grønhaug 2011, Grønhaug 2011b; VEJLE 2011). Their overall idea of changing the patient eating environment was originally inspired by research studies performed within the discipline of Healing Architecture, but also because the research study performed at the department showed that most patients felt uncomfortable and "on display" during eating in the old setting (Grønhaug 2011). The eating environment was dull, "institution-like" and unstructured, and mealtimes felt more like an obligation rather than an enjoyment (Grønhaug 2011). Based on some of the same considerations on patient healthcare, a synthesis of health, food and architecture, as well as the social powers of meals as in MORE, the aim of the VEJLE project was to investigate the therapeutic effect of the physical environment on patient nutritional well-being (Grønhaug 2011). Danish design consultant, Kerstin Egelund, was hired to develop the specific design concept for refurbishing the patient eating environment. The design concept was based on inspiration from pictures of a spring-green Danish beech forest, and her intention 


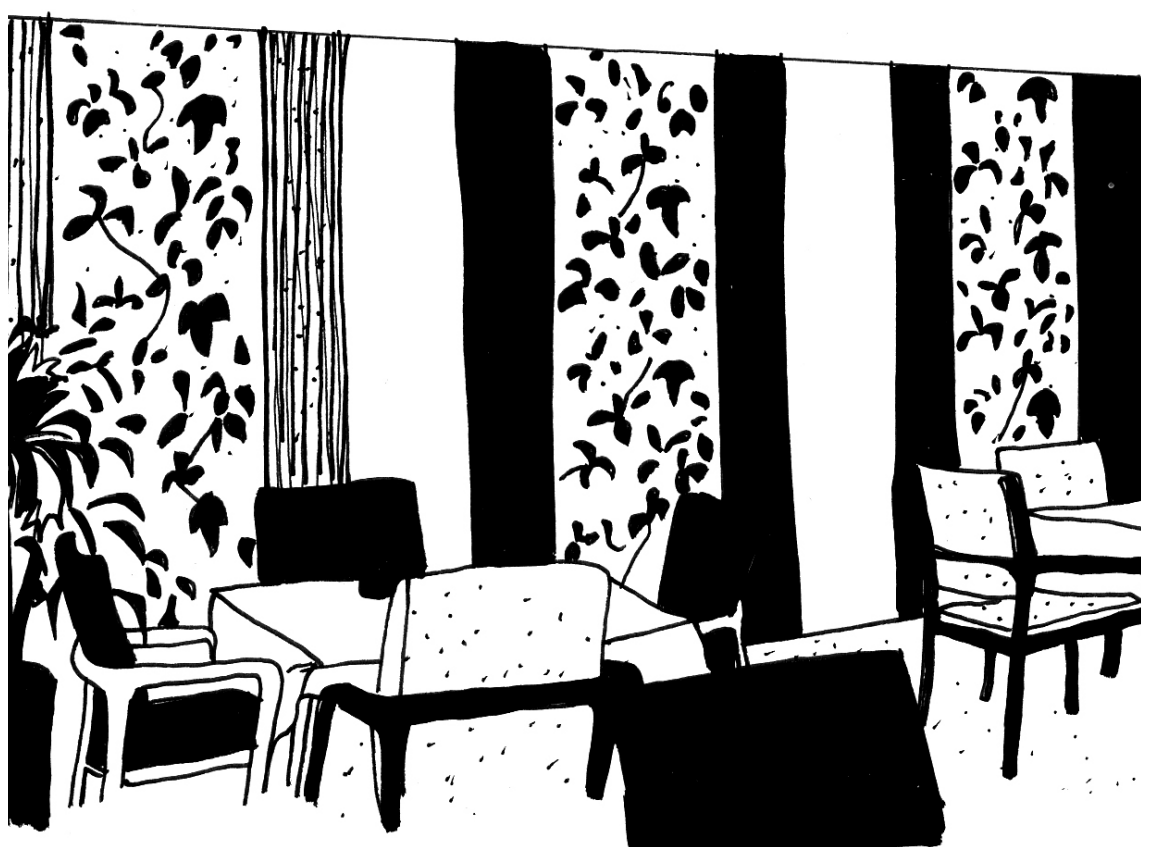

was to imitate nature and create an experience of an outdoor environment - a kind of picnic (Grønhaug 2011:4). The VEJLE project thus focused on how elements of daylight, artificial light, nature (view, plants, paintings, movies and aquarium), color (nature inspired), sound levels (noise and music), social relations and social contact could create a better eating environment so as to influence the satisfaction and food intake of the patients (Grønhaug 2011).

Like in the example of MORE, research based on a quasi-experimental study, which collected data before and after the design intervention through patient interviews, questionnaire and measuring food intake among patients, indicated that a small change in patient meal satisfaction had occurred (Grønhaug 2011). After the design intervention, patients generally experienced more well-being and relaxation. Several patients also visited the setting regularly simply because it was one of the nicest spaces in the entire hospital department (Grønhaug 2011). According to hospital employee and project stakeholder Louise Muxoll Grønhaug (2011:4), patients began to describe the meals as a social event creating a "breathing space" during hospitalization and medical treatments, and thereby the refurbished eating environment provided a space for forgetting about the difficult illnesses. The study in VEJLE implies that an improvement of the interior architectural qualities of the patient eating environment not only causes greater satisfaction with the atmosphere of the setting, but also a much greater satisfaction with the meal situation (Grønhaug 2011:6). There was a slight improvement in food intake, and in general the entire experience of the care and caring during hospitalization was improved (Grønhaug 2011:8).

\section{RESEARCH IDEA \& HYPOTHESIS}

\section{The impact of interior architecture on food intake, health and} well-being

Motivated by the example of MORE and the recent findings in the VEJLE project, as well as within the discipline of Neuroscience, Healing Architecture and Food Science, the overall research idea of this $\mathrm{PhD}$ thesis is that an important interrelationship possibly exists between health, food and architecture, and that the interior architecture of any eating environment therefore influences both our food intake and general health and well-being. From an architectural-theoretical point of view, that idea is based on the underlying horizon of understanding that architectural quality manifests itself not

\section{Fig. 3.4}

“Department of Orthopaedic Surgical Patients (A250)" Refurbished patient eating environment at Vejle Hospital. (Drawing adopted from photo provided by Grønhaug 2011). 
just as a physical built environment or background passively framing our everyday life, but as suggested with the previous chapter an interior assemblage or theatrical scenery actively staging our everyday experiences, emotions and behaviors through the communicative and existential 'doubleness' picked up by our body and mind.

With this research idea and horizon of understanding the research hypothesis is:

\author{
That the interior architectural qualities of eating \\ environments influence food intake, health and well-being \\ of patients.
}

\title{
PATIENT EATING ENVIRONMENTS What is the problem?
}

In both the examples of MORE and VEJLE, I presented how impact measurements indicated that design interventions performed on the eating environment affected not only the food intake and eating experience in a positive manner, but presumably also the general health and well-being of the patients. Despite these indications, some of the nursing staff - particularly in the example of MORE - still felt that the existing hospital design and specific interior architecture did not support the demands and ideals for an improved patient eating experience, and that more could be done to improve patient food intake if greater environmental changes could be implemented; for instance by breaking down walls to reconfigure the interior architecture as well as changing furniture in the existing wards (MORE 2010g,i; VEJLE 2011). Both MORE and VEJLE therefore wished for a more profound understanding of how the interior architectural qualities of the eating environment possibly influenced food intake and nutritional well-being. They also specifically desired more knowledge on what defined the interior architectural qualities of the eating environment to achieve this kind of improvement in the future? Like the above-mentioned architects of the mid- $18^{\text {th }}$ to early $20^{\text {th }}$ century searched for a series of basic design principles defining architectural quality in general to help improve public health and well-being, I find that the stakeholders of MORE and VEJLE in a similar manner desired a series of basic design principles helping them define and "predict" the interior architectural qualities of eating environments to improve patient health and well-being.

\section{Why is the problem relevant?}

The two "problems" raised with MORE are particularly interesting because Denmark is facing the task of constructing and building five new 'super hospitals' as well as renovating several new hospital departments across the entire country during the next ten years (SUM 2009; Arkitektforeningen 2013; SUM 2013). Five to seven of these hospitals are completely new, designed from scratch and planned to be constructed on new building sites in Aalborg (NAUH), Skejby (DNU), Gødstrup (DNV), Odense (OUH), Køge (USK), Hillerød (NHN), and in Herlev (NHH)(Arkitektforeningen 2013; Pedersen 2010). The process is already ongoing. Design briefs have been formulated, competitions have been held, jury reports have been published and several Danish design companies and interdisciplinary consortiums such as Indigo, Rådgivergruppen $D N U I / S$, and Medic OUH are already involved in developing detailed project proposals on the new hospitals in Aalborg, Skejby, and Odense (NAUH 2012; OUH 2011; DNU 2013).

A quick review of the published design briefs, jury reports and project proposals on the 'super hospitals' revealed that most considerations on patient eating related to the logistic challenges of transporting food from a decentralized industrial kitchen facility into the centralized minor kitchen facilities located in or near the different departments. Generally all of the new hospitals plan to exclude primary kitchen facilities from the hospitals. They instead suggest that external decentralized kitchen facilities are used for pre-preparing the food and then the food will be transported in closed, temperature-controlled bulk trolleys to the individual hospital wards where 


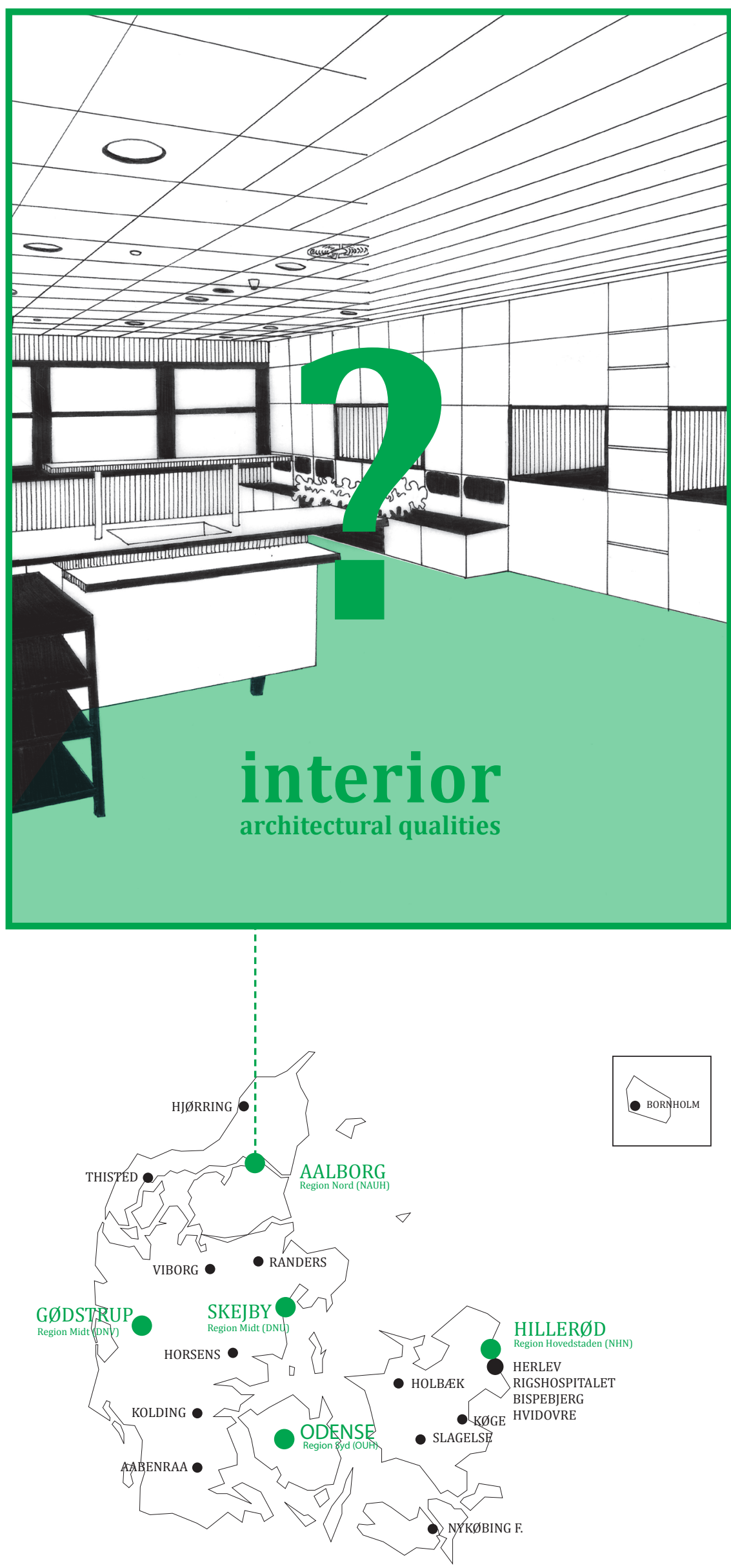

Fig. 3.5

"Problem"

A demand for knowledge on what defines the interior architectural qualities of patient eating environments.

Fig. 3.6

"Future Hospital Design" Suggestions for the location of future super hospital in Denmark and extensions of existing hospitals. 
final preparations and servings are handled from minor centralized kitchen units (OUH 2012:112,113; DNU 2007; DNU 2010; NAUH 2012; NHH 2011). Most often any mention of food or eating is found under "logistic concepts" that position food in line with transportation of waste disposal, medicine, and laundry (OUH 2012:103-104).

Comparing these contemporary developments within hospital design practice with the practice of MORE and VEJLE, I find it quite curious that seemingly no focus is put on the problem of patient undernutrition and the importance and relevance of designing better patient eating environments. Particularly, as shown in the same quick review, when the architects are highly encouraged to work according to the patient-centered mind-set of Healing Architecture in the development of their design proposals. Further supporting this curious observation is the circumstance that several stakeholders involved in the "super hospitals", such as Danish architects Lars Steffensen from Henning Larsen Architects A/S involved in the design of NHH, Tom Danielsen from C.F. Møller Architects A/S involved in the design of DNU and Lars Juel Thiis from Cubo Arkitekter A/S also involved in the design of DNU, describe in different public media how they - opposite the existing "modern" hospitals which are generally considered un-aesthetical because they are centered around rational, technical and logistic aspects of treatment (see Heslet \& Dirckinck-Holmfeld 2007) see the future 'super hospitals' not just as impressive and prestigious buildings able to provide cutting-edge medical care, equipped with the newest technologies, but also as patient-centered and sensuous architecture framing hope, healing and human-ness (HLA, 2011; Thiis 2004; Balle Jensen 2008). So these stakeholders emphasize their desire to correct the dehumanization of contemporary "modern" hospital architecture and embrace the idea of Healing Architecture instead as an integrated aspect of hospital treatment. The Danish architectural firm C.F. Møller Architects A/S has even with inspiration in the findings of Evidence-Based Design developed a specific design tool - a 'healing environment wheel' featuring the following 12 important healing aspects: access to landscape, empowerment and ergonomics, artificial light, information and computer technology, art, design and interior, indoor climate, texture, navigation and logistics, acoustics, daylight and single-patient rooms, that should be incorporated in future hospital design (Balle Jensen 2008; Tougaard 2008). Again, like in the above-mentioned example of the OUH food servings, I find it quite curious that there seemingly is no direct focus on the importance of the eating environment in the treatment of patients and design of hospitals among architectural design practices, when the problem of undernutrition apparently is gaining increasing attention within hospital practices.

According to Danish professor in urban planning Ole B. Jensen (2010:8) and American practicing and teaching architects Linda Groat and David Wang (2002:49), even though many contemporary architectural offices have research divisions and engage with the academic world - either via conferences or teaching associations - historically, the design practice has little tradition of utilizing or applying evidence-based knowledge when developing new designs. Groat \& Wang (2002:49) thus argue that traditionally a designed object such as architecture can be evaluated on its own as an aesthetic artifact with or without reference to research and a larger body of evidence-based knowledge. This because, the design process that characterize most architectural practices primarily draw on normative and polemical knowledge and focus more on the creative, tacit and interpretative actions (Groat \& Wang, 2002:49). The tradition of using evidence-based knowledge in architectural practice, as seen with the above examples of contemporary Danish super hospitals, is as such relatively new, and discussions are still developing on why and how to apply and use the evidencebased knowledge in the professional practice (see e.g. Sailer et al. 2008; Stankos \& Schwarz 2007). However, as seen in the case with the Danish super hospitals from a design practice point of view, the development of Evidence-Based Design and Healing Architecture has already led to some radical changes in the overall planning process and formulation of hospital design briefs. The design briefs and judging reports on the Danish 'super hospitals' as such indicate that a new agenda is emerging in hospital design practice; an agenda where involved stakeholders are increasingly requesting and demanding research-based knowledge to guide the overall design principles in such mega-scale projects. And it is my claim that contemporary hospital design practice is increasingly adopting the concept of Healing Architecture and integrating research-based knowledge developed within the domain of Evidence-Based Design. 
In relation to my above-mentioned curiosity about the missing perspectives on patient eating environments in the otherwise admirable attempt to think holistic in the design of the future 'super hospitals', American researchers in Social Work Allen Rubin \& Earl Babbie (2010:21, figure 2.1) have outlined a diagram illustrating the integrative relationship of Evidence-Based Practice, blending 'best-research evidence' with 'practitioner's expertise' and 'user attributes'. There model is as mentioned originally aimed at social care practice, but I find it valuable to adopt this model to describe the contemporary situation in the design of the Danish 'super hospitals'. In my opinion a similar blending of 'best research evidence', 'practitioner's expertise' and 'user attributes' is evident in the combination of the research-based knowledge adopted from Healing Architecture and Evidence-Based Design, the practical expertise of the architects and design teams, as well as the user attributes of the stakeholders of the hospital (management, staff, patients and so on). When applying the example of the Danish 'super hospitals' to the model developed by Rubin \& Babbie (2010) (see Figure 3.7, Hospital Design Practice), I find that a possible explanation for my curiosity about the missing perspective on patient eating environments is that the problem of undernutrition and patient eating environments are overlooked in the circle of 'best research evidence'.

Even though the example of MORE indicated not only an increasing interest, need and demand among the professional healthcare practices, but also pointed at an immediate demand for knowledge on how the architectural qualities of the eating environment could possibly influence the meal experience, food intake and nutritional well-being among hospitalized patients. I suspect, on the background of the model indirectly describing the application of knowledge to healthcare practices, that if there is no "best research evidence' supporting the ideas developed in practice among the expertise of the architects, or as in the example of MORE - among the 'user attributes' of the clinical staff - apparently that type of knowledge is overlooked in the guidance for future best practice. Therefore, it is my claim that a either a gross research-to-practice gap is preventing stakeholders in contemporary hospital design from implementing research-based knowledge on patient undernutrition in hospital design briefs, design proposals and judging criteria. Or simply, a large knowledge-gap exists in general, so no or very sparse research-based knowledge exists for professional practices to engage in.

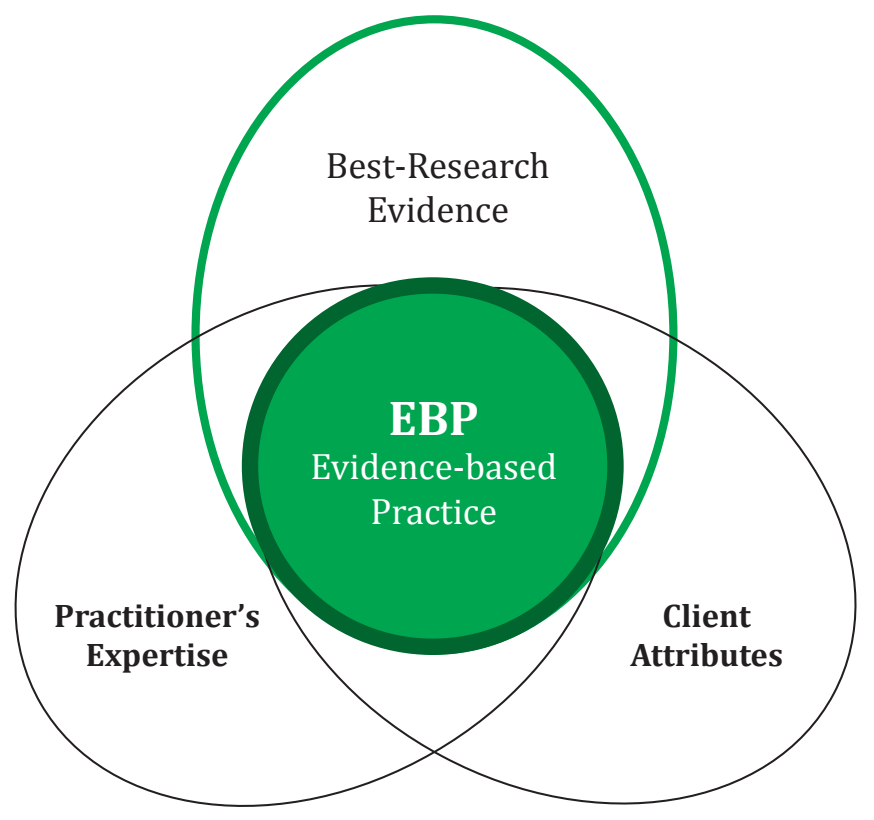

Fig. 3.7

"Hospital Design Practice integrative model"

Model inspired by Rubin \& Babbie (2010:21) describing the integrative relationship between practitioner expertise, user attributes and best research evidence. According to Rubin and Babbie (2010:21) none of the three core elements can stand alone - they work in concert by using practitioner skills to develop a user-sensitive case plan that utilizes interventions with a history of effectiveness. 
Fig. 3.8

"Research Problem: the synthesis of health, food and architecture"

A holistic design perspective including the problem of patient undernutrition is missing and

there is a knowledge gap. What research-based knowledge exists supporting the hypothesis that the interior architectural qualities of eating environments influence patient food intake, health and well-being?

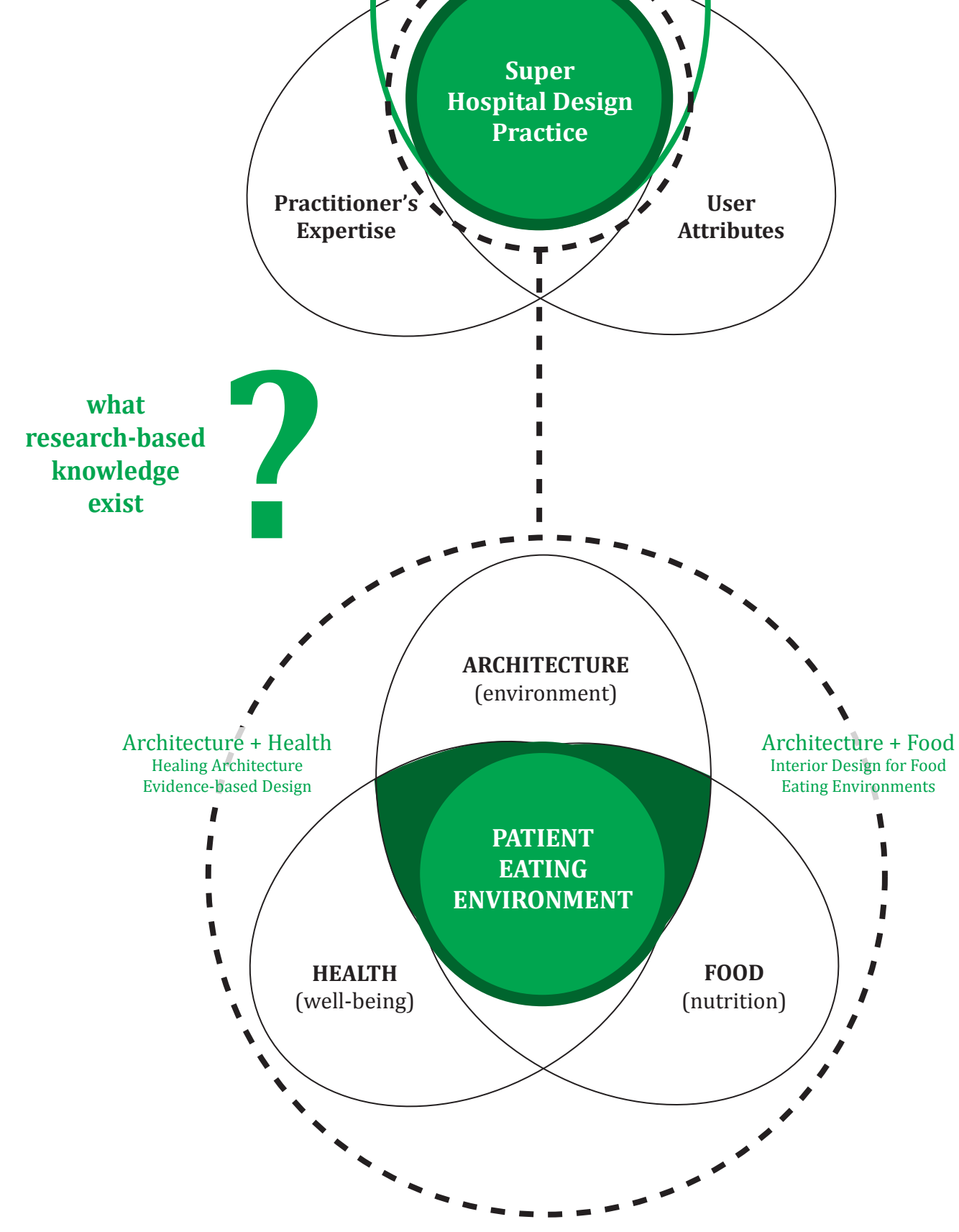


Within the next five years, major decisions on hospital and healthcare practice will be made that presumably are irreversible and that we will probably have to stick with for the next 50 years or so. Consequently, as the process of redefining hospital designs is already on-going, the examples of MORE and VEJLE represent not only a historically and politically important awareness of public healthcare, but further poses a unique - or perhaps last minute - opportunity, from an architectural research point of view, for updating and rethinking hospital designs as well as for establishing researchbased knowledge, extending the contemporary research developed with Healing Architecture and Evidence-Based Design, to help improve the current challenges on patient undernutrition [Olsen, 2010:103].

The crucial problem is, therefore, in my opinion that contemporary hospital design practice is overlooking the potential importance of the direct linking between eating environment and interior architectural scenery in patient healthcare. This is presumably mainly due to a lack of research-based knowledge supporting the argumentation that the interior architectural qualities of eating environments influences the food intake, health and well-being of the patients. On this background, the research goal of this thesis is to widen the existing perspective on hospital design and to do so by investigating whether any research-based knowledge exist which support the hypothesis that the interior architectural qualities of the eating environment influence the meal experiences and overall health and well-being of patients. The research aim is also to bridge knowledge gaps and establish a set of design principles aimed at the increasing practical demands for research-based knowledge about how to design future patient eating environments to facilitate better food intake and nutritional well-being applied in future use of the professional design practice.

So, in continuation of the above problem definition, hypothesis as well as overall aim and goal, this motivates the following research questions:

(1) Is there any research-based knowledge supporting the above-mentioned hypothesis that the interior architectural qualities of eating environments influences patient food intake, health and well-being?

(2) Is it possible on the background of existing researchbased knowledge to outline a set of basic design principles to help "predict" the interior architectural qualities of patient eating settings to be used in future professional practice? 


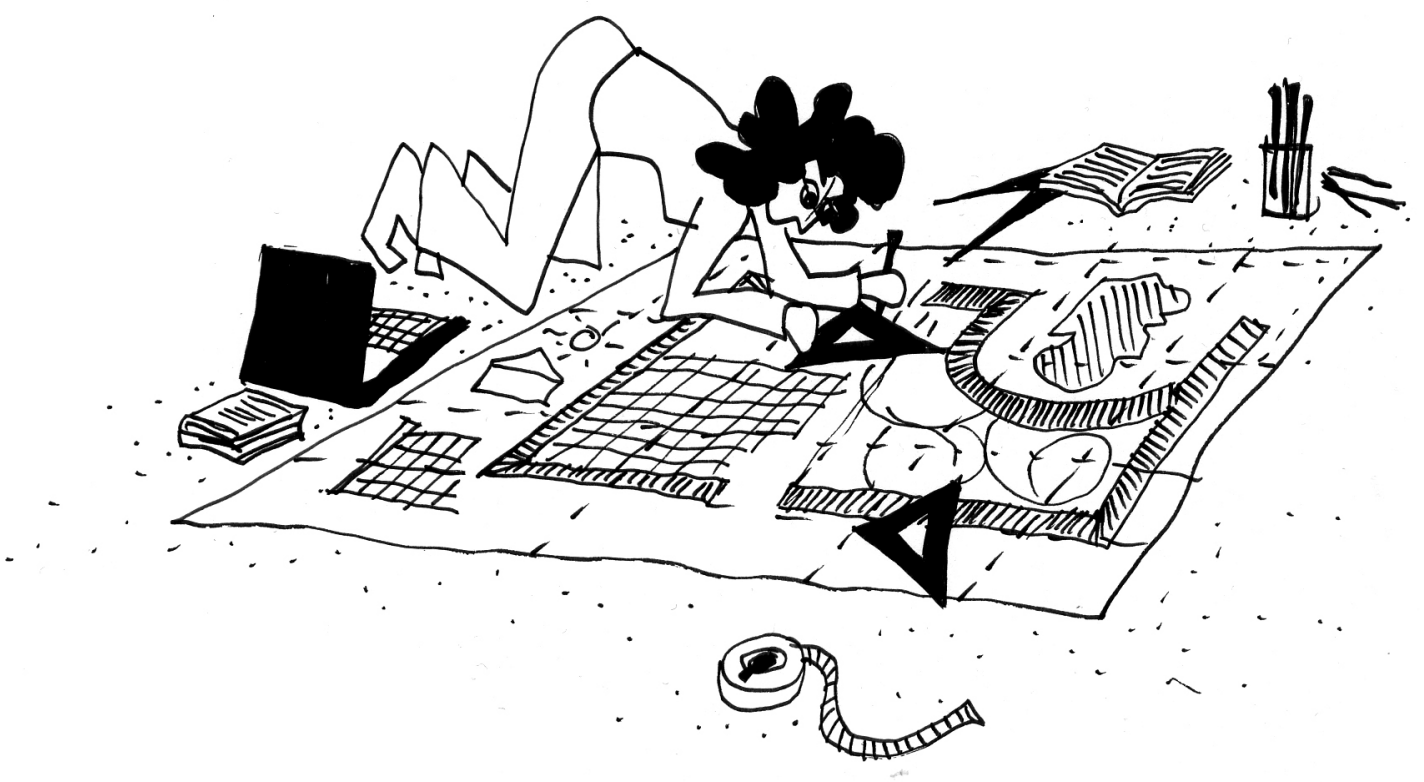

Fig. 4.1

"Research-based knowledge" What can be considered as research-based knowledge? (Drawing adopted from Frascari 2011:107) 
4

\title{
RESEARCH APPROACH
}

\author{
UNFOLDING THE RESEARCH METHODOLOGY
}

As mentioned in previous chapter, my hypothesis that the interior architectural qualities of eating environments influence the food intake, health and well-being of patients was based on my "observation" of the two practice-based examples MORE and VEJLE. Herein my claim that contemporary hospital design practice overlooks the perspective of patient undernutrition in its Evidence-Based Design approach motivated my goal to widen the exiting perspective on hospital design with the synthesized perspective of health, food and architecture. This led to the formulation of two research questions: a) clarify if any research-based knowledge exists, supporting the hypothesis that the interior architectural qualities of eating environments influence patient food intake, health and well-being, b) outline if this research-based knowledge can be used to establish a set of basic design principles used in professional practice to design future patient eating environments.

In this chapter, a methodological discussion of how to approach these research questions in order to meet the requirements of such a practice is unfolded. The methodological challenge with this synthesized perspective is that the different stakeholders of hospital design, as seen in the previous chapter, with their request for research-based knowledge often tend to demand for "hard" 'scientific evidence' put forth for instance with the sub-disciplines of Evidence-Based Design, EvidenceBased Medicine and Evidence-Based Practice. However, as indicated in the examples of MORE and VEJLE and in the arguments put forth by Lawless (2000) and Meiselman (2008) in the previous chapter, complex social, cultural and ritual values, as well as personal emotions, feelings and expectations all govern the meal experience, possibly influence the food intake and strongly affect the overall health and well-being of the hospitalized patients. Understanding the patient eating situation is, therefore, presumably dependent on various qualitative, quantitative and hermeneuticinterpretative parameters, whose interrelationships are very complex and some even still unknown.

Because the framework governing the two examples of MORE and VEJLE are based on both empirical and theoretical knowledge ranging across very different research domains like health, food/nutrition and architecture, I balance many different kinds of information and types of knowledge touching on the paradigms of Natural Science, Social Science and the Humanities simultaneously. Within each of these paradigms, various philosophical stances and very different research perspectives exist on what constitute research-based knowledge, and thus challenging the prevailing contemporary knowledge and methodology established within the more "hard" 'scientific research' disciplines like Evidence-Based Design. In addition to this, architectural researchers and practitioners have begun to argue that EvidenceBased Design research tends to focus too much on measurable single-isolated design elements such as: noise, lack of space, light, ventilation, surface coverings, art, nature 
views, medical equipment and the different aspects of logistics, hygiene, treatment technology, practice, outcome and patient safety, as well as medically related errors ascribed: active failures, mistakes and misunderstandings in medication or surgical procedures, or physical injuries and infections obtained by patients during the healing process. Instead of treating architectural 'space' as a representable object, an interactive medium reproducing social relations or a mental place fostering multiple interpretations and memories like suggested with the epistemology of phenomenology, cultural and social science. Thereby critics of Evidence-Based Design and Healing Architecture claim that the underlying theoretical thinking and methodology of the two sub-disciplines contradict with the holistic perspective and "designerly way of knowing" inherited with the architectural practice (see e.g. Lawson 2010, Stankos \& Swarz 2007, Bromley 2012 and Frandsen et al. 2012:1063). These critics thus point at how a "theoretical dilemma" guides existing studies in Healing Architecture and the related methods of Evidence-Based Design. When American environmental psychologist Roger Ulrich as mentioned in previous chapter, for instance, refers to the use of a 'scientific approach', he elaborates this with the following definition: "Rigorous, in that they use appropriate research methods that allow reasonable comparisons, and discarding of alternative hypotheses...rigor, quality of research design, sample sizes and degree of control..." (Ulrich \& Zimring 2004:3). Whereas, I find that most often he means utilizing quantitative research tactics like microbiological sampling, measuring and monitoring to collect data on days of hospitalization, use of analgesics, cortisol levels, demographics, transport routes, movements, circulation and flow. The data collected in the different empirical studies is, according to American psychiatrist and anthropologist Elizabeth Bromley (2012:1063), both limited and mixed, partly because environments perceived as "healing" by one individual may be experienced as unpleasant to others, but also because measures of patient satisfaction have confounding limitations and, in general, show a weak relationship to the practical quality of the healthcare. Others would argue that architecture as a research discipline is relatively young, and that the appropriate research tactics do not yet exist for gathering the integrated empirical information needed to understand how humans experience and perceive space (see e.g. Heslet \& Dirckinck-Holmfeld 2007) [Olsen, 2010]. In order to develop a more nuanced or holistic perspective, research on health and well-being not only demands qualitative and quantitative research methods, according to Danish physician Lars Heslet \& architect Kim Dirckinck-Holmfeld (2007:274) respectively, but also hermeneutic and phenomenological perspectives including the holistic spatial understandings of architecture.

Fig. 4.2

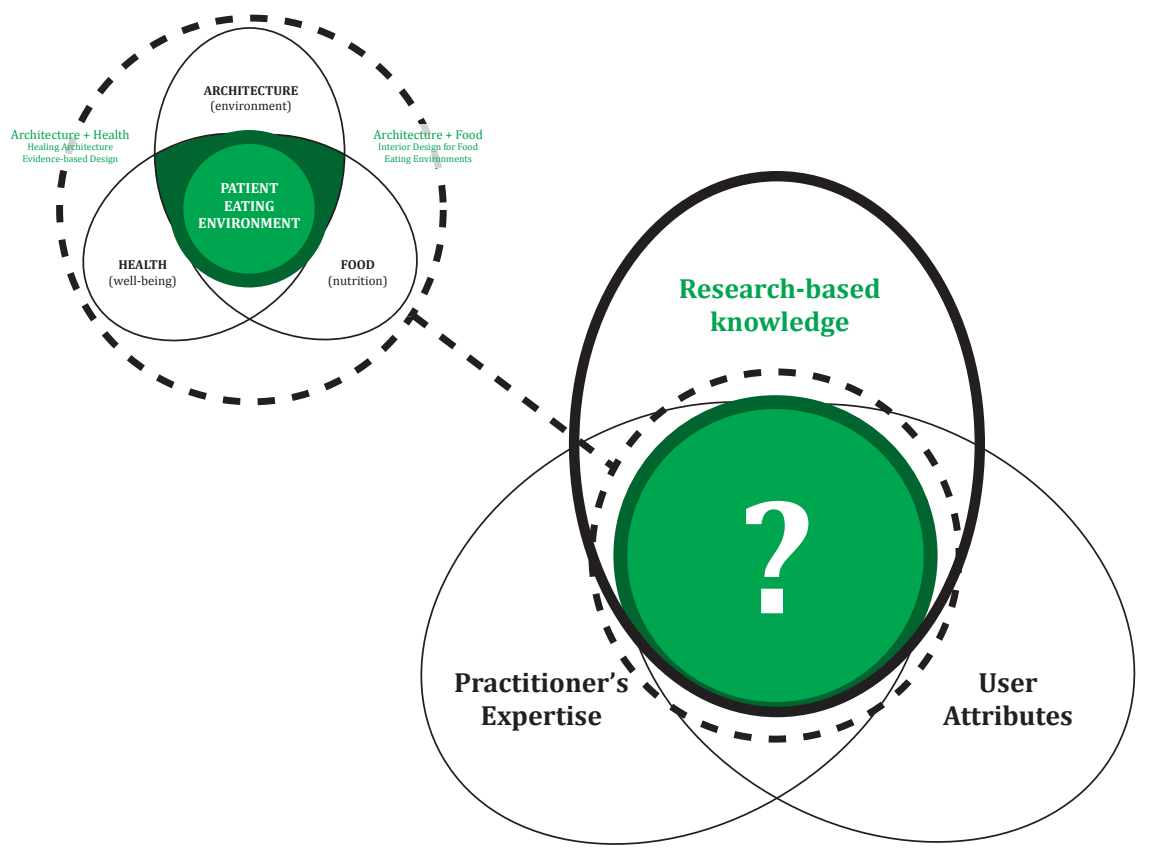
What can be considered as research-based knowledge? 
As stated in the above, the critique of the existing Evidence-Based Design research methodology is that the approach often fails to incorporate the holistic perspective implicit underlying my hypothesis and the practice of the examples of MORE and VEJLE. Consequently, my above framing of the research problem indicate that the "hard" evidence established with contemporary Evidence-Based Design research indirectly governing the understanding of research-based knowledge employed by the practice of hospital design might not be the "right" - or at least the only - solution. Rooted in the methodological unfolding of my two research questions is, therefore, also a more fundamental discussion about what defines research-based knowledge?

\section{RESEARCH-BASED KNOWLEDGE}

In the book: Architectural Research Methods, written by American practicing and teaching architects Linda Groat and David Wang (2002), a scientific body of knowledge is described as a systematic and transparent process of reflection "verifying" or "falsifying" the 'neutrality', 'consistency' and 'applicability' of a specific theory or hypothesis outlined. This description is generally supported by others approaching the subject of conducting research (see e.g. DePoy \& Gitlin 2005:4,7; Sohlberg \& Sohlberg 2001:60). However, according to English-Danish Professor Andrew Jamison, this understanding of building scientific knowledge has changed throughout history, and what today is generally considered as 'scientific' was not developed until the $16^{\text {th }}$ and $17^{\text {th }}$ centuries (Jamison et al. 2011; Jamison 2012).

Jamison et al. argue that the historical development of science can roughly be split into the two categories: Traditional Science and Modern Science. Where Modern Science can further be split into three sub-categories called: Little Science (research mode 1), Big Science (research mode 2) and Techno-science (research mode 3) (Jamison et al. 2011; Jamison 2012a,c,d,e). The birth of Traditional Science is often dated back to the rise of Western civilization and the search for knowledge established with the great thinkers and philosophers of ancient Greece (Jamison et al. 2011:4). During the $16^{\text {th }}$ century, contemporary philosophers of science broke with the prevailing way of building knowledge, arguing that building a scientific body of knowledge should be based on an evidence-based claim instead of an authoritative claim utilizing emotional-spiritual beliefs, distinct regional modes, intuition or secondhand information as had been increasingly the case during the Dark Ages and the dominance of the Christian church (Solhberg \& Sohlberg 2004:139; DePoy \& Gitlin 2005:10). These later authoritative, emotional, intuitive or secondhand ways of knowing are all based on an unsystematic and non-verified nature of reasoning and theorizing, and thus imagination, tradition, common sense and myth were divorced from 'science' (Jamison et al. 2011:4; Rubin \& Babbie 2010:7). From the $17^{\text {th }}$ century Modern Science was developed. This type of 'science' focused on instrumental, rational and universal knowledge that argued that intuitive ideas are turned into scientific knowledge through the process of induction or deduction (Jamison 2012b:3).

The process of induction builds on a "bottom-up" research strategy that moves the researcher from an initiate idea and hypothesis, developed from specific examples, literature and personal experience into a higher and more general level of abstraction (Brodersen 2007:45). It is a systematic process of generalization based on empirical "observations" of a few examples utilizing empirical material to describe and predict "lawfullness" to a specific phenomenon, and on this basis build a general level of abstraction (theory) (Groat \& Wang 2002)[Olsen, 2010:111]. The process of deduction, on the other hand, builds on a "top-down" approach using a general level of abstraction (theory) to explain a new example. Deduction is thus a process often used to "verify" the "lawfulness" of existing theory (see Figure 4.3, Induction - Deduction) (Groat \& Wang 2002; Sohlberg \& Sohlberg 2001; Brodersen 2007) [Olsen, 2010:112]. Whereas the deductive approach is suitable for "testing" theories, for making design intervention or for laboratory simulations producing "evidence" for the experienced phenomenon, the inductive approach instead encourages an investigative or explorative research process, searching for a set of general concepts and notions describing and explaining the experienced phenomenon.

Inductive and deductive reasoning has thus for many years been applied research within the domain of Natural Sciences that are generally considered as "hard" sciences. 


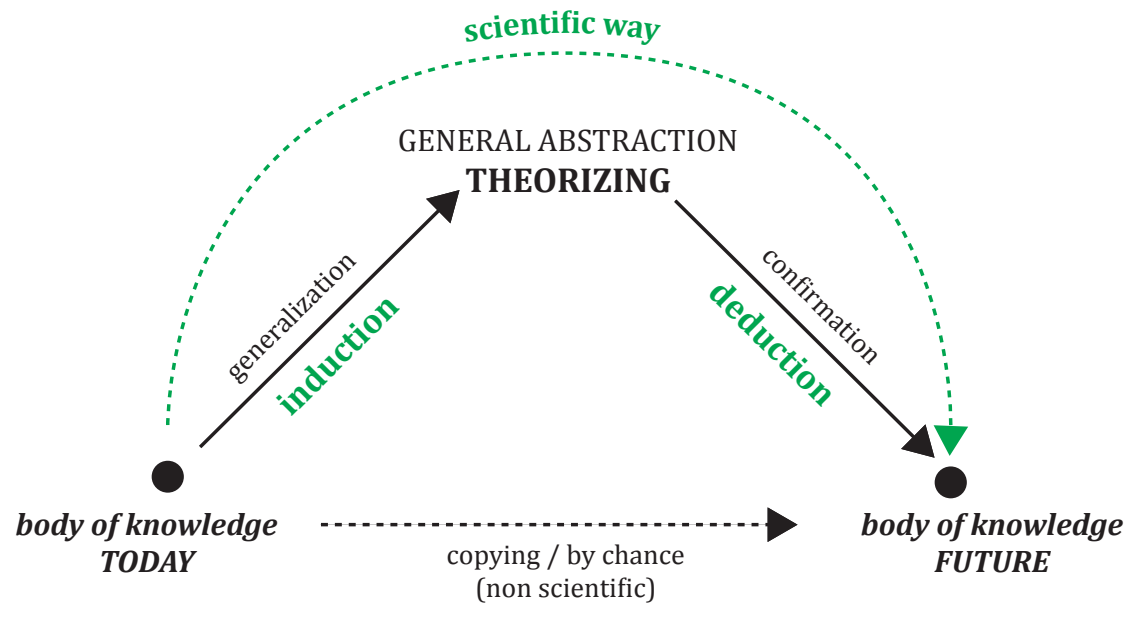

Fig. 4.3

"Induction - Deduction" Building scientific knowledge through the process of induction and deduction. (Model adopted from Brodersen 2007)

Fig. 4.4

"Abduction" Moving into a higher level of abstracting means a research strategy encompassing a combined inductive and deductive way of reasoning allowing the various kinds of knowledge to support each other and build the scientific "evidence" together.

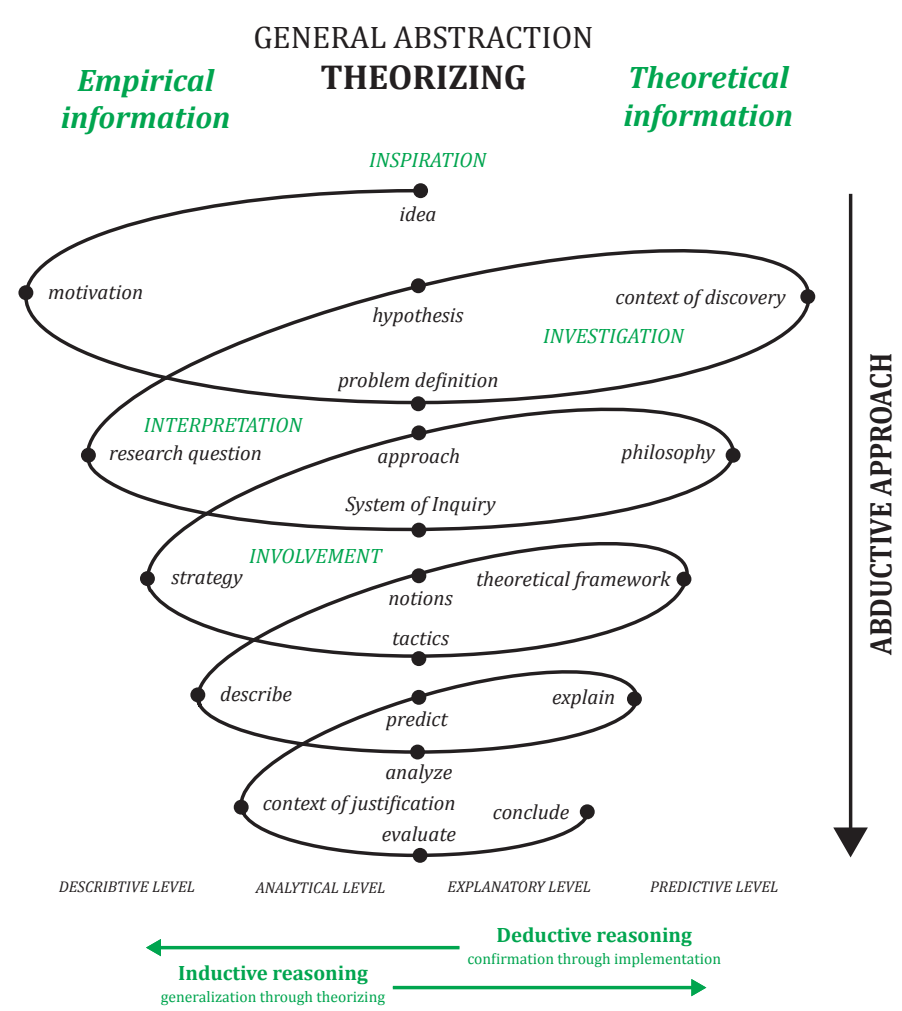


During the Industrial Revolution in the $19^{\text {th }}$ century, changes in research ideals and philosophical thinking were influenced by a criticism of the technological values of the industrial world and its instrumentalism taking numerical values for granted and rejecting or at least suppressing the "soft", more psychological and emotional values (Jamison 2012a:22). During the mid-19 $9^{\text {th }}$ century, the American mathematician, philosopher and scientist Charles Sanders Peirce (1839-1914) proposed a third doctrine called abduction in opposition to the inductive and deductive approaches employed in Modern Science. According to Sterns (1952:196), Peirce advocated that: "the mind is not to be isolated from its place in the whole of nature, and in the behavior of mind we have the right to find clues as to the nature of the world which surrounds $u s$ ". In continuation hereof, Peirce argued that it makes no sense to isolate induction and deduction from each other, because there is never any completely isolated experiment or strict linear research process, but rather a series of loops between inductive generalization and deductive reasoning (Weiner \& Young 1952:197). Peirce advocated that all research inquiries are initiated by a phase of perplexity and wonder; a puzzling situation, which through the process of abduction, induction and deduction is transformed into scientific knowledge (Weiner \& Young 1952:42). Based on our "observations", we formulate a hypothesis. The hypothesis is transmitted into a general theory when confirmed in practice.

This process of abduction or formulating a hypothesis is also what others today call a 'qualified guess' (Brodersen 2007:45). In Weiner \& Young (1952:37), this is reformulated so the motivation for doing inquiry is based on a wonder - just as my wonders about the relationship between food and architecture - and the goal to replace that wonder with a research-based understanding is accomplished by establishing an explanation and the ability to use this explanation to predict. Building scientific knowledge is as such a creative process, comprising a kind of circular process moving from idea (hypothesis); describing and analyzing, into a higher 'level of abstraction' (general theory); explaining and predicting. Which is then applied in practice to specific actions; implementing and testing, in total leading to a constant refinement of the initial hypothesis (Weiner \& Young 1952:37,42).

According to Danish Professor in Planning Lars Brodersen (2007), this process of moving into a higher 'level of abstraction' concerns the process of abstracting from observed "facts" to a general level of theory, theorizing or reflecting on a meta-level. To make an 'abstraction' means to select certain aspects of an observed phenomenon/ object and "cultivate" these to make connections or to systematic account for that phenomenon/object (Sohlberg \& Sohlberg 2001:171; Groat \& Wang 2002:74) However, whereas established theories contain several connected and linked terms, concepts and notions, the 'level of abstraction(s)' concerns "isolated" terms, concepts and notions. 'Abstractions' can thus develop into theories, but are not theories in themselves. Instead 'abstractions' are making a perspective or a specific set of "glasses" to see "reality" with (Sohlberg \& Sohlberg, 2001:172). And here it is the back-andforth process, "jumping" between induction and deduction that is itself key for how the scientific knowledge is built (Groat \& Wang, 2002:56). We could thus argue with inspiration in the theory proposed by Peirce that research is a creative, interpretative and communicative process, transforming individual ideas into general theories and then documenting these through practical implementation.

The theory developed by Peirce strongly influenced the understanding of 'science' and how to build 'scientific knowledge'. Up until World War II, science was dominated by what is defined as Little Science (research mode 1) by Jamison (2012). What occurred between 1940s and 1970s is then what is defined as the movement of Big Science (research mode 2). Finally, Techno-science (research mode 3) has been developing since the 1980s (Jamison, 2012a:2). The major differences between the three different modes, and the reason for splitting 'science' into these three "revolutions", is the distinction in types of 'scientific knowledge' produced, the organizational form and a change in the dominant values behind the 'science' performed. The movement from research mode 1 to research mode 2 was, according to Jamison (2012a), motivated by a change in the size and scale of research. 'Science' became more mission oriented, engaging in external sponsorships with new norms and value systems, as well as engaging in a new role for the state relative to research (Jamison, 2012a:2). Research mode 2 - the Big Science is characterized by the rapid developments in atomic physics and the invention of the A-bomb (Jamison et al. 2011). The movement from 
research mode 2 to research mode 3 was motivated by a change in range and scope of research, where 'science' became more market oriented, focusing on a global reach and, especially, also influenced by a rapidly increasing collaboration between universities and professional industries engaging in more entrepreneurial norms and value systems (Jamison, 2012a:6). Today, the term Techno-science (research mode 3 ) as such indicates a general movement from 'science' into 'research', where the understanding of performing 'research' instead of 'science' emphasizes the elements of uncertainty and the nature of discovering, exploring or trying to unveil complexities and controversies, rather than focusing on establishing certainty and create objective "evidence" or "hard" facts about "reality" (Jamison, 2012b:30; Jamison 2012b:2). This means that today there, apparently, is greater acceptance among academics of the "soft" values, and interpretation is increasingly considered as valid research-based knowledge.

Like Jamison et al. (2011), the architectural theoretician Alberto Pérez-Gómez (2012) argues that instead of assuming that scientific thought and architectural theory are two separate disciplines, we should remember that, since ancient Greek philosophy was derived by Plato, architecture and science have been linked in the overall aim of revealing the "truth" about cosmos. He points at how this is reflected in the writings of architecture ever since the ancient Roman architect Marcus Vitruvius Pollio (c.80-15 BC) (Pérez-Gómez 2012:3). Continuing this line of thought, Pérez-Gómez stresses how at some point in history, architectural theory even was science, and that it was not until the $17^{\text {th }}$ century, when 'Modern Science' arose, that transformations in architectural theoretical treatises and eventually also in architectural practice caused this to change (Pérez-Gómez 2012:3).

\section{Research-based knowledge is...}

As seen in the above discussion, what is important to understand, relative to my research problem and related research questions, is that 'research', 'science, "truth" and 'evidence' are not static terms, but constructed concepts developed throughout history. Research-based knowledge is, therefore, not necessarily defined as "hard" scientific or evidence-based knowledge, but can be achieved and built in many different ways. What all three modes of Modern Science can agree upon is that building a 'scientific body of knowledge' is a social activity where private knowledge is elevated to 'scientific' or research-based knowledge by recognition and appreciation by colleagues or peers, because the researcher has argued so well for his ideas that research societies agree they are "true" until something better and more precise is defined (Brodersen 2007:45). According to Groat \& Wang (2002:7,74), common to all scientific research today is instead defined by the researcher going through a process of reducing lived experience and observed phenomena to "chunks of information" that are noted (described) and categorized (analyzed) and therefore undergo some kind of interpretation (explained). This process of reducing or transforming the information is called 'theorizing', and it is directly related to the research methodology in two ways: (1) research methods used to establish theory that is, in general, trying to 'describe,' 'explain' and 'predict' a given phenomenon; and (2) as a research method testing if the 'descriptions,' 'explanations' or 'predictions' of a given theory hold true in all cases of a phenomenon under study, not just the specific case observed (Groat \& Wang 2002:74; Sohlberg \& Sohlberg, 2001:126). This understanding of research-based knowledge as a process of theorizing is particularly interesting relative to my second research question and the specific requirements of MORE and VEJLE for a set of basic design principles "predicting" the interior architectural qualities of patient eating environments. Because, in the light of the above, this process of theorizing is defined by the ability to 'define', 'explain' and 'predict', as well as establish 'descriptions', 'explanations' and 'predictions' just as I am searching for. In the following I will therefore try to unfold what it means to develop such 'predictions' in a research-based manner:

To 'describe' means to make a 'description' of the observed phenomenon/"raw material" collected by means of empirical or hermeneutic strategies. A descriptive level can thus be understood as the foundation for building up 'explanations' and 'predictions', and thereby theorizing (Sohlberg \& Sohlberg 2001:83,85). Within the empirical-positivist research tradition, the level of description is as objective and 
precise as possible, aiming at operationalizing different variables into numbers on a scale or graph. This operationalization is obtained by use of quantitative research tactics such as laboratory experiments, pseudo experiments and simulations employing advanced technological equipment or questionnaires to measure the "raw material" (Sohlberg \& Sohlberg 2001:83,85). As mentioned in the introductory chapter, today advanced technology can measure phenomena most of us are unable to "observe" ourselves (Sohlberg \& Sohlberg 2001:71). An increased amount of research within disciplines such as food science, sensory and consumer science, Evidence-Based Design and the social sciences are utilizing advanced technological equipment such as GPS, RFI and eye-tracking devices in the attempt to "map", measure and document the tacit dimensions and experience of very complex phenomena (e.g. human movement and visual perception). With both the empirical-naturalist and hermeneuticinterpretative traditions - which the discipline of architecture traditionally belong to it is very difficult to distinguish between the levels of 'describing' and 'analyzing'. Often analyzing is an integrated part of describing, whereas the "role" of the researcher in empirical-positivist research is often seen as more objective. The role of the researcher in empirical-naturalist and hermeneutic-interpretative research is important for how realities are constructed by use of language (metaphors, concepts, notions and rhetoric) and thereby also for how the applied theory determines the character of the description (Sohlberg \& Sohlberg 2001:86-87). Presumably that is also why Groat \& Wang (2002) in the above-mentioned chose not to include the step 'analyze' in their definition of 'theorizing'. However, because I find that this step is exactly what architectural theoreticians such as the previously mentioned Bek \& Oxvig (1999) attempted to unfold with their proposal for an "analysis of space", I have chosen to include it separately in the below.

To 'analyze' is where researchers ideally define and classify the observed phenomenon. Within the empirical-positivist research tradition, this "classification" is done by dividing the material into categories and sub-categories, defining parts and wholes, grouping and creating dichotomies as well as setting up different criteria with the overall aim of establishing or testing a theory (Sohlberg \& Sohlberg 2001:97-108). Defining means outlining the meaning and use of notions and concepts, making implicit knowledge explicit; this is based on a close relation to theory and practice (Sohlberg \& Sohlberg 2001:96). Again, as with the descriptive level, a series of different ways of "defining" exist - such as encyclopedic definitions and persuasive definitions etc. depending on the specific research tradition, strategy and tactics engaged (Sohlberg \& Sohlberg 2001:97-108). The methods of analyzing become very complicated when the observed phenomena relate to human behavior, action and society. This is due to the fact that it is very difficult to determine or define how much is caused by human will, random human acts or consequences of societal structures (Sohlberg \& Sohlberg, 2001:138).

To 'explain' is trying to understand what causes a certain phenomenon. Often the empirical-positivist research tradition is accused of focusing too much on macroexplanations, trying to generalize on such an abstract level that it becomes groundbreaking "lawfulness" that governs all phenomena alike. On the other hand, part of the empirical-naturalist and hermeneutic-interpretative research tradition does not aim at common "lawfulness" or macro-explanations, but rather at micro-explanations, focusing on describing what is experienced from a new perspective and thereby constructing new connections and adding new values to the overall understanding or pointing at deeper levels of understanding in the complexity of the experienced phenomena (Sohlberg \& Sohlberg, 2001:134).

To 'predict' is the level of general 'abstraction' that utilizes the three abovementioned levels of descriptive, analytical and explanatory knowledge, to move from the steps of defining, classifying and outlining concepts and notions to the step of establishing a theoretical framework with a taxonomy employing central terms or metaphors to outline a general set of guidelines 'predicting' the characteristics of given phenomena/object (Sohlberg \& Sohlberg, 2001:172). Brodersen (2007:55) uses the analogy of cooking to describe the relevance of theorizing in a 'general level of abstraction' and elaborate on what it means to 'predict' on a research-based background. Brodersen (2007:55) thus note that cooking is a very complex process with endless variations and individual possibilities, but still it makes sense to develop cooking receipts providing potential users with instructions/guidelines - or what 
Groat \& Wang (2002) in the above also referred to as a 'predictions' - describing and explaining this complex phenomenon. For instance, in cooking recipes, the instruction "boil until tender" is a 'general abstraction'. There are many possible details that are not elaborated upon in this specific instruction. No precise or detailed description on boiling time, but a general instruction to continue the process of boiling until a certain condition is achieved, and the ingredient is no longer half raw (Brodersen 2007:55). The instruction could have been much more elaborate, describing in details how to take the pot out of the cupboard with one's hands, closing the cupboard, moving from the cupboard to the zink by walking; lifting one's leg, putting one's foot in front of the other, and so on (Brodersen 2007:55). Brodersen's point is that you can never fully 'describe' and 'explain' those instructions/'predictions'. It would be both exhausting to read and outlive, but more importantly also impossible to do in practice because you would have to engage into levels of molecular, chemical, physical, biological knowledge - just to mention a few- in the attempt to unveil the "complete truth" (Brodersen 2007:55). The reason why cooking recipes still work - and often work well - according to Brodersen (2007:55), is that they are on such a 'general level of abstraction' that the instructions/'predictions' work even though minor variations might occur and that you can compare or make analogies to similar situations. In line with this argument, Groat \& Wang (2002:78) argue that even though 'theorizing' may have certain common attributes, it is difficult - if not impossible - to conceive it as one conceptual domain. Instead 'theorizing' and the specific act of 'predicting' can be addressed in multiple ways and in different scales. In the attempt to explain this, they define three overall categories: 'positive theory', 'normative theory', and 'polemical theory'.

\section{Different types of theory}

According to Groat \& Wang (2002:78), 'positive theory' is to be understood as a descriptive and explanatory system of research-based knowledge often communicated through 'scientific' journal papers such as the ones published within Evidence-Based Design and Healing Architecture that, because this kind of research identifies causal links, can 'predict' future behaviors of the studied phenomenon. Whereas, 'normative theory' is more related to conventional architectural practice where certain "rules of thumb" based upon tacit and inherited factors rooted in the design are used to 'describe, 'explain' and 'predict' the phenomena studied (Groat \& Wang, 2002:78). In that way, Groat \& Wang (2002:78) argue that 'normative theory' is largely what motivates actions in design practice, and it is therefore often not considered as conductive to rigorous testing as 'positive theory' (see Figure 4.6, Different Types of Theory). However, as also emphasized by Groat \& Wang (2002:82), because 'normative theory' is demonstrated by conventional practice in the built objects that has withstood the test of time, it can be argued that this kind of theory is already empirically tested repeatedly in the field having the entire history of architecture as 'evidence'. Finally, the category 'polemical theory' covers the vast range of literature - treatises, essays and manifestos - written throughout history by architects and architectural thinkers (Groat \& Wang, 2002:82). What characterize most of these 'polemical theories' is the fact that, even though they often draw from other bodies of literature, they tend to promote or defend a very subjective and personal set of opinions - or what I would call intentions - on how to design these objects and 'describe', 'explain' and 'predict' their architectural quality. This definition cause Groat \& Wang $(2002: 56,82)$ to ask if such polemically based theories can even be considered 'scientific' in line with the 'positive theories'?

Based on my above discussion of what defines research-based knowledge, I find that the answer to their question strongly relates to how 'research' is generally evaluated within other disciplines, by use of the above-mentioned standards on 'truth value, 'applicability', 'consistency' and 'neutrality'. Traditionally, if my ontological and epistemological assumptions are guided by the stance of positivism, relating perhaps most to Modern Science - Research Mode 1, we say that the research design for building scientific knowledge is supposed to represent a logical set of statements which quality can be judged by the ability to achieve 'internal validity', 'external validity', 'reliability' and 'objectivity' (Yin 2009:40; Groat \& Wang 2002:35)[Olsen, 2010:116]. Whereas, if my assumptions instead are guided by a more naturalistic stance relating to Modern Science - Research Mode 3, quality can be judged by 'credibility', 'transferability', 


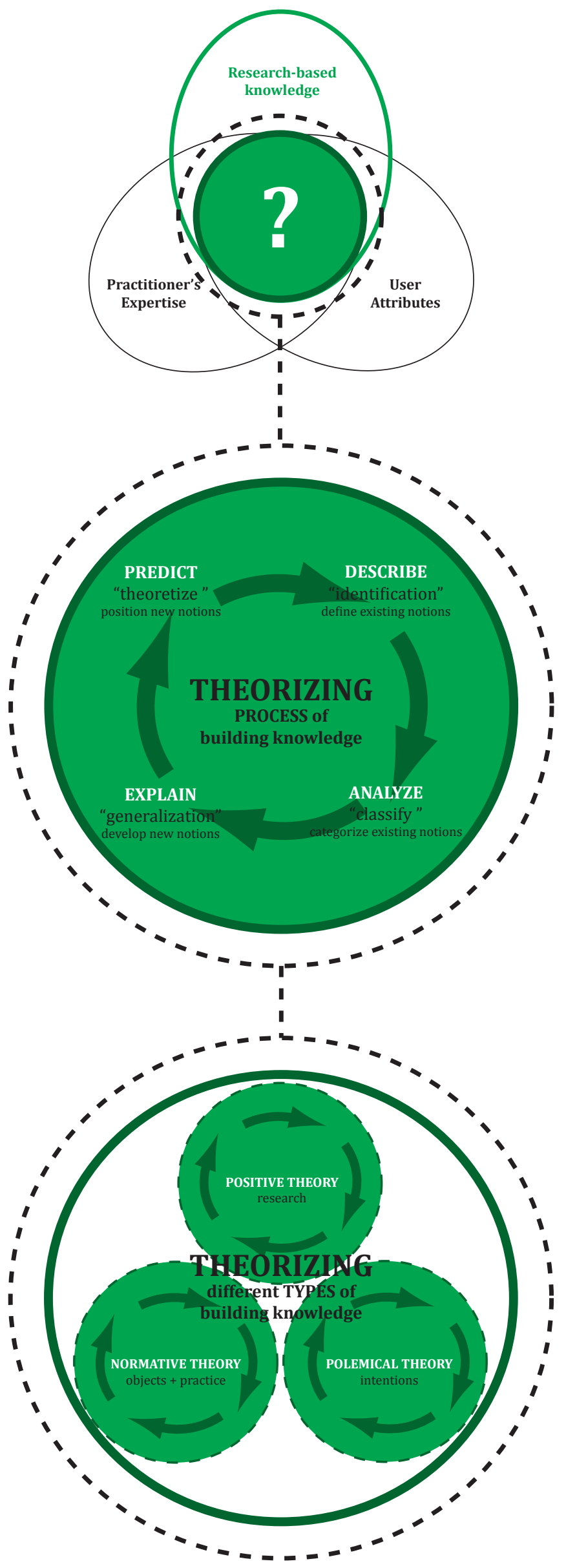

Fig. 4.5

"Theorizing"

To describe, analyze, explain and predict the "observed" phenomenon. On that background I build "scientific" knowledge.

Fig. 4.6

"Different Types of Theory" 'Positive theory' rooted in research, 'Normative theory' rooted in objects and practice, and 'Polemical theory' rooted in the written intentions are different types of theory. 
'dependability', and 'confirmability' (Groat \& Wang 2002:35)[Olsen, 2010:111]. Most important is that the idea behind the research criteria 'credibility', similar to the positivist 'validity', should establish 'truth value' by taking into account the natural complexities inherited in the specific situation studied (Groat \& Wang 2002:38) [Olsen, 2010:111]. Methodologically, this is mainly achieved by building a "thick" set of explanations using a variety of information sources, multiple investigators, and/or a combination of research methods, in order to cross-check information and interpretations as well as to insure a systematic and transparent process verifying the 'neutrality', 'consistency' and 'applicability' of the knowledge developed (Geertz 1973; Groat \& Wang 2002)[Olsen, 2010:111].

What motivated Groat \& Wang's questioning of 'polemical theory' in the first place was that it tend to depend upon personal intentions using rhetoric and persuasive proofs, not empirically testable proofs and further lack the ability to demonstrate causality or 'predict' behavior in the same manner as 'positive theory' (Groat \& Wang 2002:83,84). The 'polemical theory' is as such difficult to position within the above-mentioned traditional 'research quality standards' developed within other, more established, research disciplines. However, Groat \& Wang (2002:84) end up advocating that 'polemical theory' in its own way demonstrate 'truth value' or gain 'validity' when a wide audience is persuaded by the theory. Thereby, the act of persuasion becomes a "test", however, not a scientifically describable or predictable "test", according to Groat \& Wang (2002:84). Instead Groat \& Wang (2002:86) argue, the generalizability (related to 'external validity' and 'transferability') of a 'polemical theory' is heavily dependent upon what can be understood and accepted by a wide community of human beings. The success of "interpretations" and the quality of the theory depend upon the process of peer reviewing and being accepted by a wider academic audience (Groat \& Wang, 2002:86). Because the standards for evaluating research quality today is built on the explication of how and on what basis the knowledge claim is made. Being a researcher thus means that I need to communicate and reflect on the kind of knowledge I contribute with to research in general as a researcher. I need to communicate what motivated and inspired my research, what kind of involvement the research engages in, and what defined the research problem and research questions to begin with as well as the consequences my interpretation, the specific choice of research strategy and research tactics endeavored to investigate the research problem, had on my process of establishing research-based knowledge [Olsen, 2010:116,118]. In an attempt to capture such complex methodological reflections as I am faced with in my overall research process, Groat \& Wang (2002) developed what they called the 'system of inquiry'.

\section{THE 'SYSTEM OF INQUIRY'}

The 'system of inquiry' is constructed by three conceptual levels called: 'system of inquiry', 'strategies' and 'tactics'. Here, the level 'system of inquiry' refers to my underlying ontological and epistemological assumptions. Whereas the 'strategies' and 'tactics' refer to the employed research methods and specific techniques used to collect, describe, analyze and explain the research object, which in my specific case is the interior architectural quality of patient eating environments (see Figure 4.7, System of Inquiry).

\section{Ontological assumption}

Ontology is the teaching of "world views" and the underlying assumptions about the fundamental principles of our world. In that way, a researcher's ontological assumptions relate to the understanding of what constitutes the being and identity of a given phenomenon/object and how we define or classify this (Sohlberg \& Sohlberg, 2001:38). Throughout time, two major ontological world views have dominated scientific research: the philosophies of Materialism and Idealism (Sohlberg \& Sohlberg, 2001:39). The Materialist philosophy accounts for the natural world by means of causal explanations where everything is the result of natural laws. In general, the idea is that the world is made up entirely by 'matter', and that every phenomenon/object, therefore, occurs by means of physical processes and can, thereby, also be reduced to material and physical components like molecules, atoms 
or genes. The world is understood entirely by means of sensory input, and 'matter' can thus be described, analyzed, explained and predicted by means of mechanical and technological measurement (Sohlberg \& Sohlberg, 2001:40-42,51). Opposite to the Materialist philosophy, we find the Idealist philosophy that splits the world into a material world and an ideal world, where both exist. But whereas everything is transitory in the material world, everything is eternal and constant in the ideal world (Sohlberg \& Sohlberg 2001). In the ideal world, we find the archetypes representing the general "idea" of people together with every possible phenomenon/object. In the material world, we only find imperfect or incomplete examples. In that way, the Idealist philosophy denies the reality of the material world. The point is that the researcher does not experience the real world, but only projections of reality. As such we cannot measure "reality" by means of mechanical or technical equipment. To understand a specific phenomenon/object, we need to understand the general "idea" or the archetype of that phenomenon/object. Another point is that the researcher desires and longs for the ideal world (Sohlberg \& Sohlberg, 2001:45-46).

Of course, no absolute Materialist reality or any absolute Idealist reality exists. Instead, several philosophies and paradigms exist in between the two "realities".

\section{Epistemological assumption}

Relative to the ontological assumptions, epistemology is the understanding of how we come to know reality (Sohlberg \& Sohlberg 2001:56). The epistemological assumptions thus relate to the nature of knowing and the conditions for knowing, as well as how we argue for this knowledge or how to validate the knowledge. Being aware of my epistemological assumptions relative to my ontological assumptions is, therefore, a systematic process of reflection of my knowledge (Sohlberg \& Sohlberg 2001:60). As with the ontological assumptions, two main positions have continuously dominated researchers' epistemological assumptions throughout history. Those are the philosophical stances called Empirism and Rationalism. Empiricism is a philosophical stance that claims that our knowledge mainly derives from experience communicated by our senses. The stance in the search for verifiable knowledge focuses on a critical and systematic collection of data, based on systematic observations and thus often investigates the world and given phenomena/objects by means of experiments (Sohlberg \& Sohlberg 2001:60). The important matter within this stance is inter-subjectivity; data and information collected during these experiments and observations must be interpreted in the same way by different researchers. The stance forms the basis for a positivist research paradigm strongly related to the process of induction and use of quantitative research methods in a search for universal "lawfulness" (Sohlberg \& Sohlberg 2001:61). This stance strongly influenced Modern Science - Research Mode 1 and the disciplines of physics, biology (evolutionary theory), medicine, psychology and pharmacology (Sohlberg \& Sohlberg 2001:3951). The stance of Rationalism, on the other hand, focuses on reason when producing knowledge. Here, it is reason that verifies the argumentation, and the researcher can only achieve knowledge by trusting reason or thinking. In this stance, human thinking is the primary tool, more important than the sensory input emphasized with the empirical perspective (Sohlberg \& Sohlberg 2001:61). Rationalism is behind the deductive research process. Based on "ideal" fundamental principles, we can derive general "lawfulness" about phenomena by using logic. This particular stance has close relations to logic and mathematics, but also to the social sciences where the focus on norms as regulators and creators of societies, together with the social construction of realities, interpretations of realities and the importance and meaning of culture, becomes central (Sohlberg \& Sohlberg 2001:48-49). Again, according to Sohlberg \& Sohlberg (2001:63-64), today both the empirical and rational philosophical stances have developed throughout time, and positions between the two exist as well.

\section{THE 'STRATEGIES' AND 'TACTICS'}

The 'strategies' are, according to Groat \& Wang (2002:11), the specific research methods chosen to "transform" private or any other type of knowledge into researchbased knowledge. They define my overall design of the research study and are a kind of "action plan" of how I get from the idea and research questions to the 'scientific' conclusions and "answers" to my research problem [Olsen, 2010:111]. In close relation 


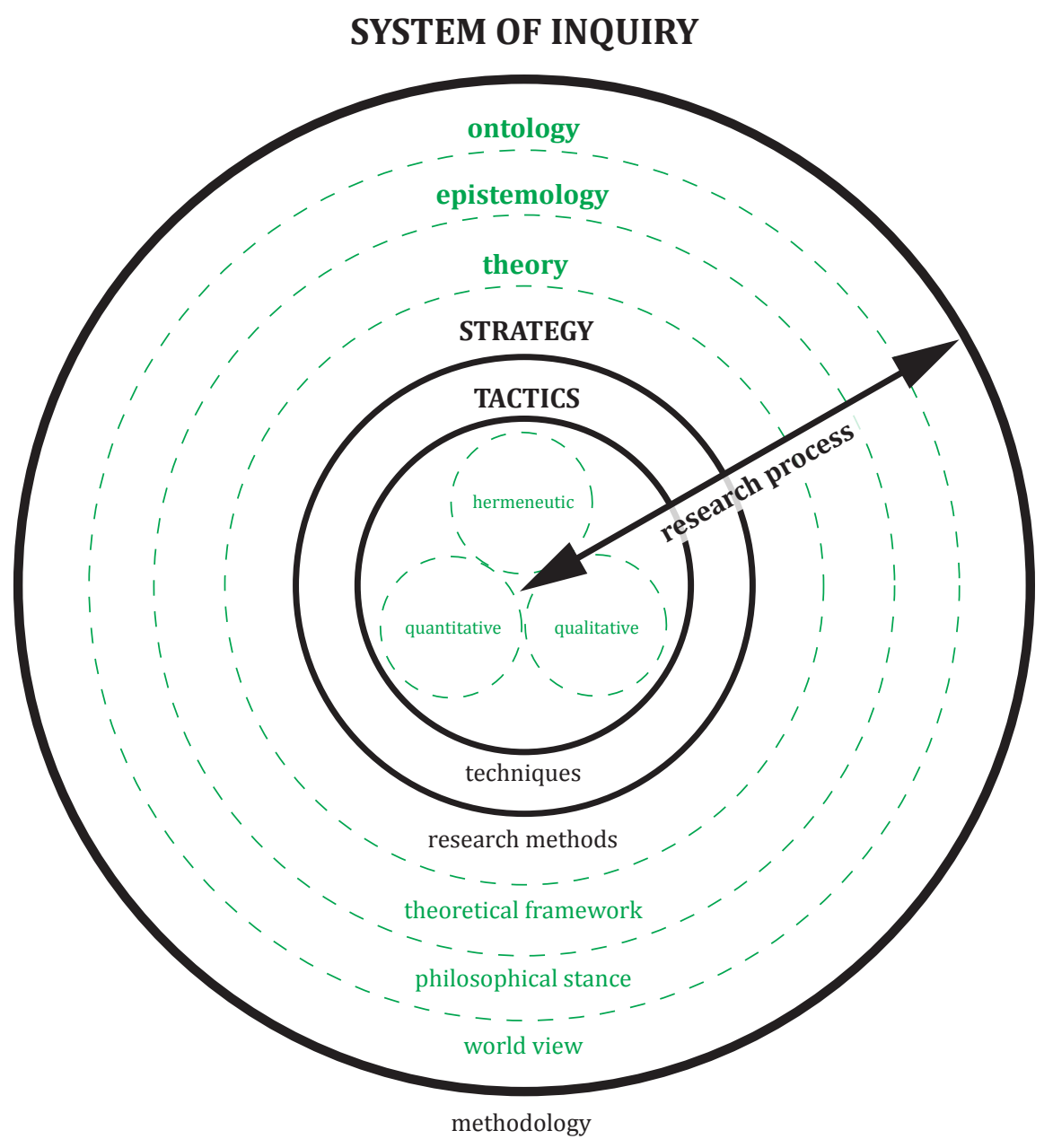

Fig. 4.7

"System of Inquiry" Model inspired by the model developed by Groat \& Wang (2002:10). The model outlines the relationship between ontological and epistemological viewpoints, research strategies and applied 
to the choice of research 'strategy' are the research 'tactics', which are my specific pick of techniques used to collect, describe and analyze the "information" gathered on the interior architectural quality of patient eating environments (Groat \& Wang, 2002:11). Relative hereto, Groat \& Wang (2002:11) emphasize that within any particular 'system of inquiry' there are multiple choices of 'strategies' and 'tactics'. My specific choice of 'tactics' thus depends on what kind of "information" I want to "collect", and presumably, there are strengths and weaknesses of all research 'strategies' (Groat \& Wang, 2002:10,11,31).

Different traditions exist within the different research disciplines on how to describe a given phenomenon/object. Because the practice of architecture requires knowledge of a vast array of phenomena (technology, engineering, art, physical properties of materials, principles of perception, behavioral issues, history etc.), a broad range of paradigms are commonly employed in architectural research and a wide range of different research 'strategies' exists, which covers, among others, qualitative, quantitative, exploratory, interpretative-historical, hermeneutic-interpretative, experimental, simulation, logical argumentation, case study and co-relational research (Groat \& Wang 2002). Depending on which one of these I choose, a similar wide range of quantitative, qualitative and hermeneutic-interpretative research 'tactics' exists ranging from observation to laboratory research (Groat \& Wang 2002:23,24,87). The various 'strategies' and 'tactics' can be combined and mixed in many different ways. For instance, the interpretative-historical research 'strategy' makes use of empirical evidence from the past, which, at the tactical level, can consist of both archival material such as public or private documents, artifactual material such as objects available on site or in museums, verbal material such as oral or written information gained through interviews of eye witnesses (Groat \& Wang 2002:88).

This kind of research strategy strongly relates to the hermeneutic-interpretative research tradition, relating to the Humanities where historians, archeologist, architects and designers in the last 2,000 years have tried to include the methods of interpretation in the investigation of the meanings of texts and artistic works/ objects, or tried to understand the tacit knowledge of human actions such as behavior, language, speech, social institutions and rituals, ceremonies and events, and the significance of the past for the present day as a cultural phenomenon (Eck 2004:57). The 'polemical theory' which governs most architectural theory is thus based on a hermeneutic-interpretative tradition. Ontologically and epistemologically, the strategy is often based on the philosophy of Idealism and the stance of Rationalism where the world is understood on the background of different "realities", different life conditions and perspectives. Methodologically, the strategy draws heavily on interpretation understood as a circular or spiral process (the hermeneutic circle) continuously shifting between wholes and parts, past and present, subjective and objective moving between different analytical levels and levels of abstractions (Sohlberg \& Sohlberg 2001:53-54,204). Most of the existing knowledge in the architectural and culinary discipline is thus rooted in a hermeneutic tradition, going back to the writings of some of the first cookery books and architectural treatises.

Whereas hermeneutic-interpretative research deals with a combination of individualpsychological and historical-empirical evidence from the past, qualitative research deals with the interpretation of contemporary situations (Groat \& Wang 2002:88). According to Sohlberg \& Sohlberg (2001:11), a qualitative research strategy is based on a holistic ontological viewpoint where multiple realities exist, rather than just one single reality. Here individual ideas, language and perceptions cannot be separated from the outside world, and individuals create their own subjective realities (Sohlberg \& Sohlberg 2001:11). It is an ontological viewpoint that belongs to the naturalistic tradition. An important epistemological difference is that the "knower" and "knowledge" are interrelated and interdependent; research methods, therefore, naturally incorporate subjective reasoning and interpretation from the researcher (Sohlberg \& Sohlberg 2001)[Olsen, 2010:111]. Within the empirical-naturalist tradition, the level of description would be more subjective-interpretive utilizing qualitative research tactics to develop "thick" descriptions. As mentioned above, the "thick" description is achieved by means of establishing elaborate descriptions of the framework conditions embracing a given phenomenon - describing the physical environment, the behavior and actions/activities - providing detailed "background information". The important point here is that the empirical material is collected 
from involved parties/persons, and this can be done by employing research tactics like interview, observation, case study, field studies, focus groups or narrative investigations like personal life stories and photos to obtain empirical data and achieve as nuanced and precise a picture of human behavior (intentions, experiences, opinion, emotions, ideas, attitudes and positions) as possible, and to document the specific description of the particular phenomenon (Sohlberg \& Sohlberg 2001:8688,116; Filstead 1970). These kinds of research tactics are good for making inductive conclusions, because they can help identify factors, whereas more quantitative tactics are good for making deductive conclusions and measuring effects of specific changes occurring with interventions and manipulation (Sohlberg \& Sohlberg 2001).

In continuation hereof, Groat \& Wang (2002) situate the entire process of 'theorizing' in the larger context of the 'system of inquiry' and emphasize that research methodologies are ways to test (affirm, modify or reject) those 'descriptions', 'explanations' and 'predictions' and their applicability beyond the particular case studied (Groat \& Wang 2002:74). The point made by Groat \& Wang (2002: 87) is that, on the one hand, 'theorizing' depends on the philosophical foundation for its own "validity" and coherence, and, on the other hand, it posits specific explanations and claims for "testing" and 'analyzing'. So, what I assume in my research process is theoretical whereas what I $d o$, based upon those assumptions, is methodological (Groat \& Wang 2002:74). With these above considerations on what defines researchbased knowledge and methodological discussion about how to approach research in general. I find it is on time, I try to unfold my own research approach and define my own 'system of inquiry'.

\section{RESESRACH APPROACH \\ Reflections and considerations on my 'system of inquiry'}

In my $\mathrm{PhD}$ project, even though my personal inspiration began with the Gastronomic Analogy, my research was motivated by the practice-driven problem of patient undernutrition and challenge of refurbishing the hospital eating environments related to the two examples MORE and VEJLE. The practical problems and challenges led to my overall research idea and hypothesis that the interior architectural qualities of eating environments influence the food intake, health and well-being of the patients. Furthermore, I outlined on top of the discoveries, research and practice developed in the examples of MORE and VEJLE, two research questions investigating if any researchbased knowledge exists supporting my hypothesis, and if it is possible to establish a set of basic design principles 'predicting' future interior architectural qualities of patient eating environments to be used by the professional practice.

With my hypothesis, I automatically adopted the holistic-ontological worldview of MORE and VEJLE where hospital food servings are perceived as more than mere nutrition taking place in a larger context and serving higher means than nutritional satiety [Olsen, 2010:106]. The two examples lean on the tendencies in Healing Architecture and EBD, but, as argued in the introductory chapter, they further lean on existing hermeneutic-interpretative, phenomenological and semiotic epistemological stances on architectural 'spaces' relating to human existence and behavior. They also relate to studies within the social sciences and the epistemological viewpoints where the aspects of human behavior and interaction can help us understand how to design spaces and specific architectural settings to create certain atmospheres inviting for specific social relations [Olsen, 2010:107]. Together these ontological and epistemological assumptions suggest that I am a "research hybrid" who relates both to the sensory-material world and the interpretative-ideal world when trying to understand the complexity of how the interior architectural qualities of eating environment influence patient food intake, health and well-being. I, therefore, need a research 'strategy' and set of 'tactics' allowing for a combination of the "hard" and "soft" values, as well as hermeneutic-interpretative perspectives supporting the already existing empirical qualitative and quantitative outcomes found at MORE and VEJLE, to be able to incorporate the holistic perspective underlying the synthesizing of health, food and architecture [Olsen, 2010:111]. 


\section{Research strategy and tactics}

In the following, my methodological considerations concerning 'strategy' and 'tactics' relative to each of the two research questions outlined above are presented. Beginning with research question (1):

$$
\begin{aligned}
& \text { "Is there any existing research-based knowledge supporting } \\
& \text { the hypothesis that the interior architectural qualities of eating } \\
& \text { environments influence food intake, health and well-being of patients?" }
\end{aligned}
$$

According to Groat \& Wang (2002:45), at occasions when we cannot depend upon the knowledge we already possess but must seek new information as researcher, a possible research 'strategy' is to do a survey of various sources - or what they call a Literature Review. Relative hereto, Rubin \& Babbie (2010:24) argue that two primary procedures exist for performing such a Literature Review. Those employ either a "top-down" or a "bottom-up" search of literature. The bottom-up literature search starts from "scratch" with looking for all sources providing any 'evidence' pertaining to my research question. Each source is then critically read and evaluated, whereas in the top-down approach I must start with reports, books and articles that already provide systematic reviews or meta-analysis of literature on the subject. Then I rely on their judgment and investigation to build my pool of knowledge and review literature (Rubin \& Babbie 2010:24). Compared to the top-down approach, the bottom-up approach can be very time-consuming. However, according to Rubin \& Babbie (2010:24), relying exclusively on a top-down approach has the major disadvantage that I rely on the authority and judgment of the researchers performing those reviews. Groat \& Wang (2002:45) use a slightly different categorization when discussing the use of a Literature Review. They argue that at least two different types of literature reviews exist: the Integrative Literature Review and the Annotated Bibliography. In their argument, the Annotated Bibliography is an intermediate review - based on both the bottom-up and top-down approach - listing all the references obtained from searching the literature relating to a specific field or a predefined topic. Each reference is listed with key-methods, key-theories, key-sources and key-word describing the major issues relating to the investigated topic (Groat \& Wang 2002:47).

The Integrative Literature Review builds on the Annotated Bibliography. Contrary to the mere listing of the Annotated Bibliography, the Integrative Literature Review summarizes past research conclusions and draws "new" overall conclusions from the body of literature found with the Annotated Bibliography on my specific topic (Beyea \& Nichll 1998)[Olsen et al. 2010:5]. Together the Integrative Literature Review and Annotated Bibliography are thus used to synthesize the "scientific" knowledge or 'positive theory' from the different lines of research as well as to sum up methodological developments and, thereby, help frame future research in the complex interdisciplinary area of health, food and architecture.

However, because architectural research is a rather young academic discipline, the weakness of the literature review focusing on 'positive theory' is that most literature and knowledge existing within the architectural domain are not available through these traditional resources. Instead, much architectural knowledge is - as noted in the above and previous chapters - rooted in 'polemical theory' and 'normative theory', with the intentions, practice and objects that has stood the test of time. This kind of normative and polemical knowledge is not automatically found in the kind of researchbased literature such as journal articles and conference papers, but in the history of architectural thinking and doing, in architectural books and in popular media like magazines, advertisements, films, and design reviews. This kind of normative and polemical knowledge can only be "uncovered" by means of a more hermeneuticinterpretative study investigating the knowledge rooted in the polemical writings and the history of architecture. Furthermore, as seen with MORE and VEJLE, much of the knowledge employed to develop the ideas and hypothesis of the influences of interior architectural qualities on patients' food intake, health and well-being is based on tacit knowledge rooted in everyday practices and common perceptions of food, meal rituals, gastronomy, culinary art and nursing, touching on or even being directly based on what Groat \& Wang referred to as 'normative theory'. Furthermore, because my research problem is practice-driven much of the existing knowledge relating to our two research questions would presumably exist tacitly in the built environment - in 
Fig. 4.8

"Explorative System"

The concept of research-based

knowledge is not static, but evolves throughout time.

Today research-based knowledge can be achieved in many different

ways, because the standards for evaluating is built on the explication of how and what basis the knowledge claim is made. Research-based knowledge is thus not only based on positive theory (research), but possibly also include polemical theory (intentions) and normative theory (objects and practice).

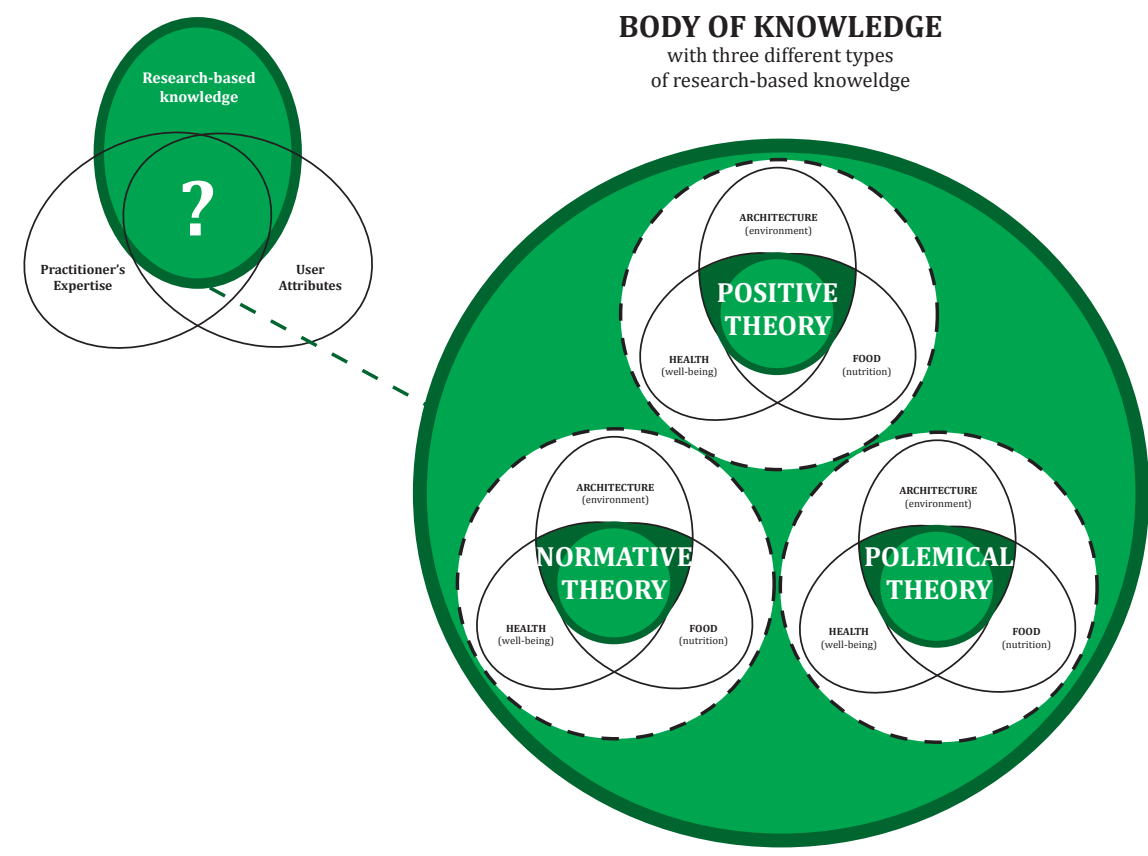

past and present healthcare and eating environments, as well as in the professional practice - among healthcare staff, patients and practicing architects. Presumably, this is not only the case within the discipline of architecture, but it could be the case within disciplines such as healthcare, medicine and nutrition as well, because they all - like architecture - are very practice related. In continuation hereof, it is important to note that Groat \& Wang (2002:46) further define this Literature Review not as a strict search of literature, but instead as an explorative system investigating a general body of information. The strengths of such an explorative system are that it provides the opportunity of a survey of various sources and different types of research-based knowledge. Relative hereto, Rubin \& Babbie (2010:41) argue that an explorative study is ideal when examining a new interest, exploring a relatively new and unstudied topic. The explorative study can help provide a beginning familiarity with the topic and on that basis help plan a large-scale study geared to produce conclusive findings (Rubin \& Babbie 2010:41). Thereby the "Literature Review" could be seen as the totality of activities that I, as a researcher, go through to unfold that body of information and to investigate existing research-based knowledge.

If we thus accept, as argued for in the above, that research-based knowledge can stem from many different types of knowledge, our sources for investigation potentially expand from the contemporary tendencies of favoring scientific literature (positive theory) and evidence-based research produced with methods of EBD in hospital design practice to further including the polemical writings exiting in architectural theory, culinary theory and healthcare theory (polemical theory). Included also is the tacit knowledge presumably being rooted in both professional practices as architectural design, care and caring/nursing as well as simple common knowledge of everyday experiences of eating, being sick and engaging with architecture (normative theory) (see Figure 4.8, Explorative System). On that basis, I have chosen to split my research investigations into three overall parts: (1) investigating 'positive theory' (research), (2) investigating 'normative theory' (practice and objects), and (3) investigating 'polemical theory' (intentions) (see Figure 4.8, Explorative System).

\section{(1) Investigating positive theory (research)}

To gain as much insight and knowledge as possible on already existing scientific literature, I chose to use the tactics of the Integrative Literature Review and Annotated Bibliography. Here, the specific research "tools" employed are either traditional library search and/or the use of a computer with an internet search engine, using e.g. academic web services like Web of Science, Science Direct or SciVerse to help locate the 
literature. In that way, I gain access to a global overview of most Western European literature.

Presuming that the results of the investigations performed with the Annotated Bibliography and Integrative Literature Review are positive and 'scientific' researchbased literature supporting my hypothesis does exist. Then because the Annotated Bibliography and Integrative Literature Review provides a systematical outline of existing concepts and notions employed within the three different domains of health, food and architecture, it would be possible to use this research-based knowledge to begin 'describing' what the key sources, key theories, major issues and debates about the interior architectural qualities of patient eating environments are. As well as 'analyzing' and 'explaining' how they characterize the interior architectural qualities of patient eating environments.

In continuation hereof, to answer research question (2):

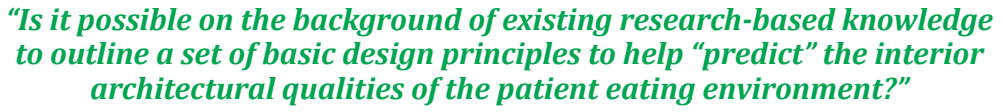

I could use the 'positive theory' derived from existing 'scientific' research-based knowledge and the concepts and notions outlined with research question (1) to produce a taxonomy - or what I have also chosen to call 'basic design principles' which, in an overall deductive manner, 'predicts' the interior architectural qualities of the patient eating environment. This theoretical framework and 'basic design principles' could then hopefully be used by both future professional practice when developing hospital design proposals but also by future researchers when "testing" the impact and influence of the interior architectural qualities of eating environments on patient food intake, health and well-being.

On the other hand, presuming that the results of the Annotated Bibliography and Integrative Literature Review turn out negative and no or very sparse 'scientific' research-based literature exists supporting my hypothesis, I would instead need to continue to one of the two other sources of research-based knowledge: the personal intentions of the architect rooted in 'polemical theory' or the tacit knowledge inherited in objects and practice rooted in 'normative theory' (see Figure 4.8, Explorative System). For instance, if I begin with the 'normative theory', it would be necessary to extend the approach of the explorative system with a research 'strategy' and research 'tactics' that allow for collecting information on more tacitly and empirically rooted knowledge that exists among these practice-related sources as well.

\section{(2) Investigating 'Normative Theory' (practice and objects)}

Whereas the deductive approach is suitable for "testing" theories, making interventions or laboratory simulations producing 'evidence' for the experienced phenomenon, the abductive approach instead encourages an explorative research process - extending the explorative system proposed by Groat \& Wang (2002) - searching for a set of general concepts and notions 'describing' and 'explaining' the experienced phenomenon. The 'scientific evidence' is then created through a triangulation of the different research tactics used in the theoretical investigations. With the 'general level of abstraction' (theoretical framework) established, hopefully in the future, it will be possible for other researchers or practitioners to deduce (specialize) to their specific situation. For instance, other hospital departments or possible other types of healthcare related eating environments (Brodersen, 2007:45). An often utilized abductive strategy within both the social sciences and architectural research - and according to American Dr. Robert K. Yin (2009:18), a possible good way of investigating a complex real-life phenomenon - such as for instance my example of investigating the practice of interior architectural qualities of patient eating environments - in its natural context without manipulating relevant human behaviors - is the research 'strategy' referred to as a case study.

The case study gives the unique capacity to deal with a full variety of hermeneuticinterpretative, qualitative and quantitative evidence together, forming a strong chain of evidence established on the background of information gathered from multiple sources (Yin, 2009:11)[Olsen, 2010:113]. The point is that with this abductive 
Fig. 4.9

"Positive Theory" Using Annotated Bibliography and Integrative Literature Review to investigate what positive theory (research) exist supporting the hypothesis.

Fig. 4.10

"Deduction" Utilizing the theoretical framework from existing research-based knowledge to develop a taxonomy predicting the interior architectural qualities of future patient eating environments.

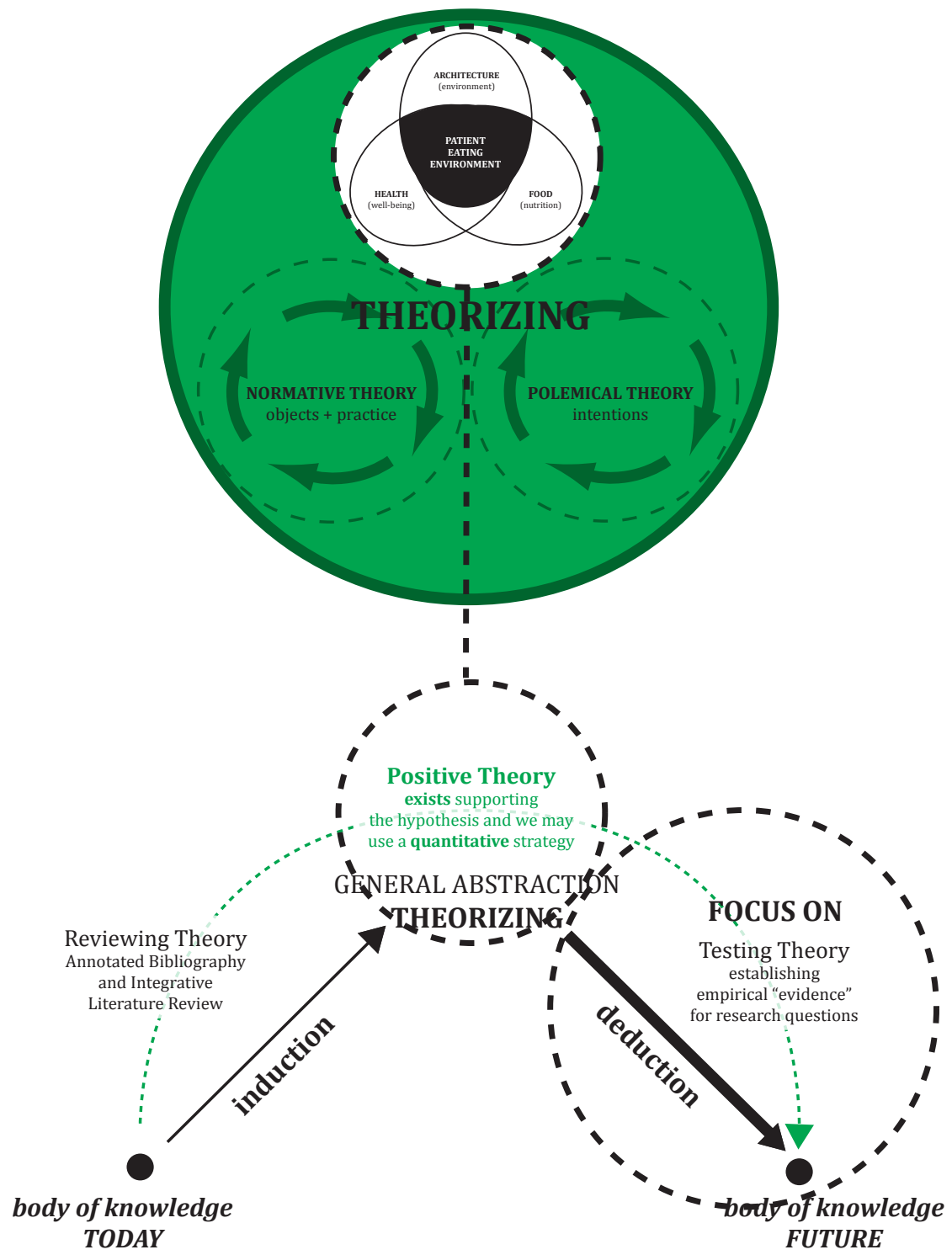


research 'strategy', I continuously move between a deductive and inductive way of reasoning: - from being motivated and inspired by seemingly "unknown" phenomena, to establishing a general hypothesis, to developing a theoretical level of knowledge establishing a general set of guidelines (concepts/notions) on why and how the interior architectural qualities of the eating environment influence the food intake, health and well-being of patients, to "testing" this 'theory' through comparison with hermeneutic-interpretative studies (existing 'polemical theory' and best practice historical design review) and empirical observations conducted on the influence of design interventions (refurbishing interiors in MORE and VEJLE) as well as performing impact measurements, which can all together then be used to develop an evidencebased proposal for a set of basic design principles for implementation in future professional practices (see Figure 4.11, Abduction) (Yin, 2009:18)[Olsen, 2010:114].

However, it is important to note, according to Yin (2009:18-19), that the research strategy of a case study benefit from the prior development of a theoretical proposition to guide the data collection and analysis process, which are otherwise too complex for survey or experimental strategies. This initiative theory is meant as a hypothetical story about why acts, events, structure and thoughts occur, and the result is, according to Yin (2009:38), that the theory development not only facilitates the empirical data collection phase of the case study, but further provides the 'general level of abstraction'. This is characterized by Yin (2009) as 'analytical generalization' as opposed to 'statistical generalization' ordinarily used within the positivist research tradition and can be described as an ongoing circular process [Olsen, 2010:113]. The theoretical knowledge is then used as a practical template on how to "collect" empirical information in the specific field studies, but also on how to compare the empirical knowledge obtained from the different sources (Yin 2009:38)[Olsen, 2010:114]. The 'scientific evidence' will then be created through a triangulation of the different research 'tactics' used in the hermeneutic and empirical investigations. By choosing the case study research 'strategy', I as such utilize a multilayered methodological approach collecting "information" from three different kinds of sources: hermeneuticinterpretative strategy, empirical qualitative strategy, and empirical quantitative strategy, to capture the "characteristics" of the interior architectural qualities of the patient eating environment.

Assuming that my Annotated Bibliography and Integrative Literature Review of 'scientific' research-based literature have turned out negative, I do not have this prior theoretical framework demanded by Yin to engage in a case study. Or, at least, it will presumably not be that different from the knowledge MORE and VEJLE as well as all the professional architects already had when engaging in their design inquiries making proposals for the future super hospitals. To avoid facing the same "theoretical dilemma" and methodological contradictions, as is already the case with existing research-based knowledge relating to the domain of Evidence-Based Design where researches as mentioned in the introductory chapter tend to engage in a strict deductive research process on an "uninformed" theoretical basis, I need to continue from investigating the 'positive theory' and 'normative theory' to investigating the last option of theories - the 'polemical theory'.

\section{(3) Investigating Polemical Theory (intentions)}

Because these sources represent a polemical theorizing contrary the 'positive theory' in the 'scientific' knowledge of research and 'normative theory' in the tacit knowledge of practice, I need to begin at a different level of understanding where I return to the abductive approach using an overall hermeneutic-interpretative strategy to unfold the polemical knowledge related health, food and architecture in order to move towards the building of a theoretical framework and establish a set of design principles 'predicting' the interior architectural qualities of future patient eating environments (see Figure 4.13, Explorative Study) [Olsen, 2010:112]. However, the point of a hermeneutic-interpretive strategy and the tactic of the hermeneutic circle are not to try and understand the spiritual and mental life of the author of the text/designer of architecture, but instead to try and understand the intention of the author/designer (Lübcke 2002:166-167). The circular relationship illustrated in the hermeneutic circle is, therefore, something rooted in the "text/object" - something that exists independent of me as researcher and interpreter. According to the previously mentioned 
Fig. 4.11

"Abduction" Establishing research-based knowledge on the basis of normative theory rooted in objects and practice.

Fig. 4.12

"Multi-embedded Case Study" The overall research strategy is an abductive approach, moving from the hypothesis to a general theoretical framework and then towards a specific set of design principles for future patient eating environments. It as such utilizes a combination of inductive and deductive reasoning.
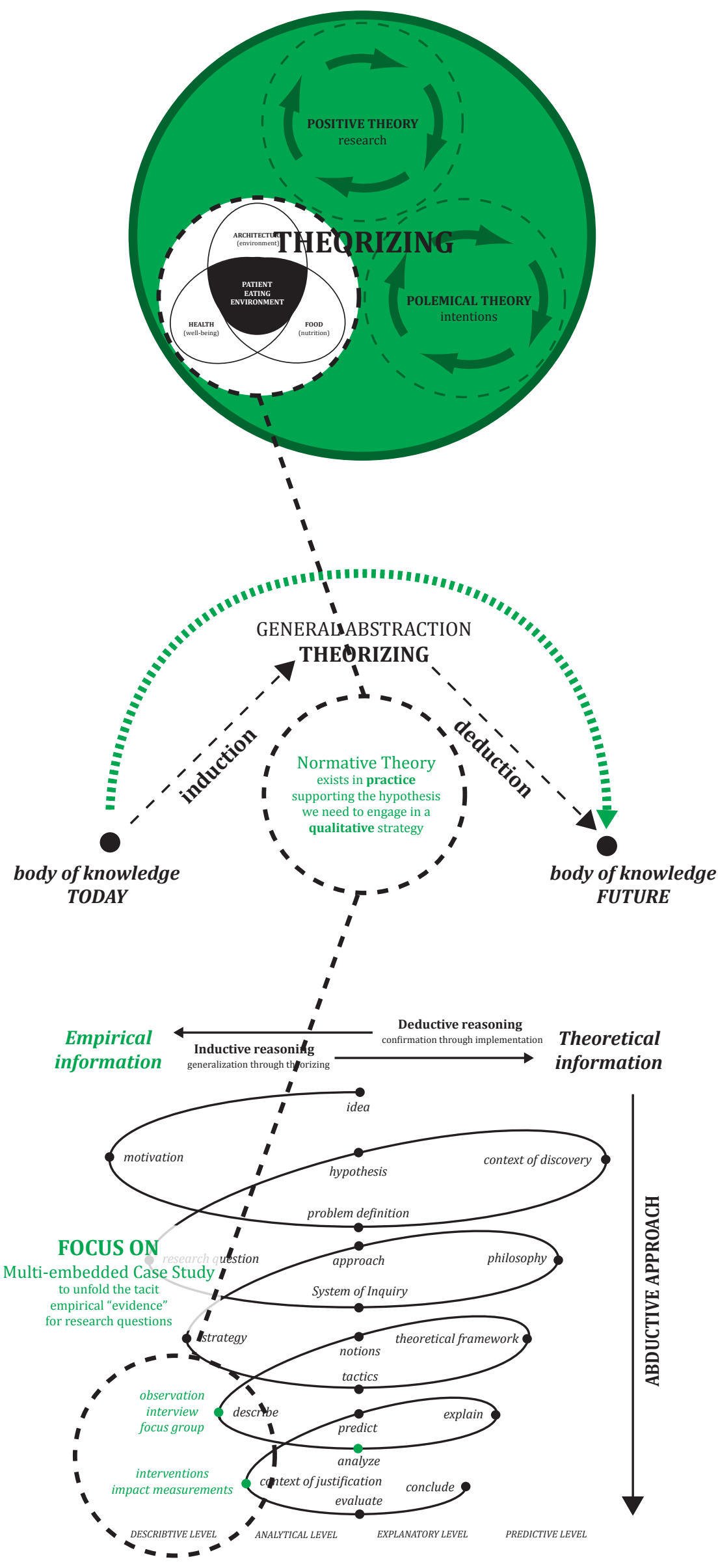


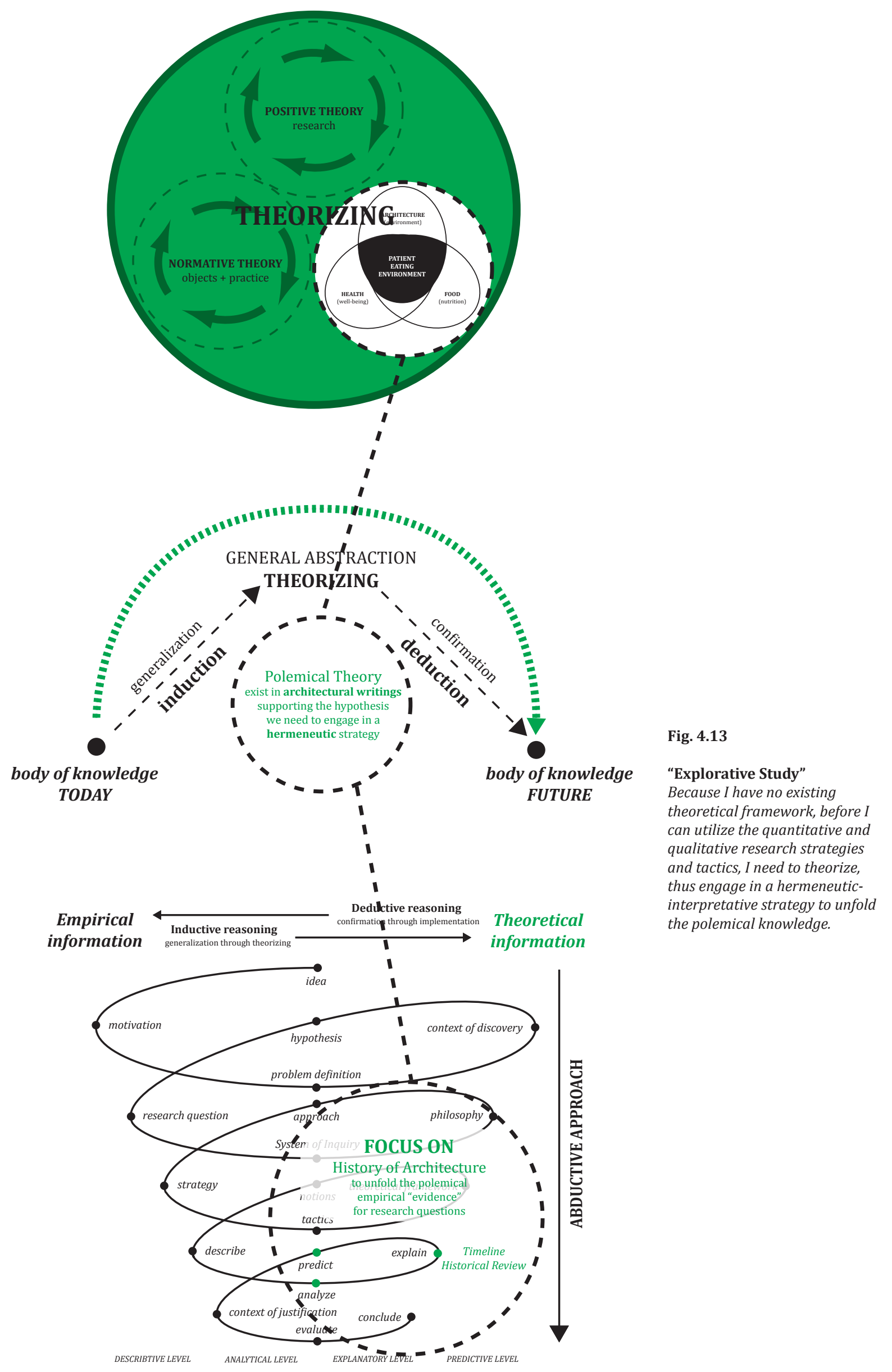


architectural theoretician Kenneth Frampton (2001), the "fusion of horizons" is an essential part of hermeneutical understanding, and he notes that: "understanding does not involve re-experiencing an original understanding, but rather the capacity to listen to a work of art and allow it to speak to one in one's present circumstances" (Frampton 2001:392). His point with this statement is that it simply is no good to consider the text as a finished piece of work - a closed/past event - instead it is part of an ongoing process that includes me as interpreter. Herein the history of the text is mixed with my history as a reader, and this is where the "fusion of horizons" occurs.

Accordingly, previously mentioned architectural theoretician Alberto Pérez-Gómez advocates that the discipline of architecture cannot simply be deduced to a collection of objectified buildings, polemical theories and drawings. He states that architecture is more complex, more than a technical solution to a pragmatic problem, because it is also shifting with the history and culture (Pérez-Gómez 2012). With this statement, Pérez-Gómez challenges the last two hundred years of "instrumental" discourses in architecture which, according to him, were initiated with the attempts to categorize the history of architecture into a series of styles. Pérez-Gómez argues that what I here have chosen to call 'architectural quality' (and what he calls 'appropriateness') was always understood in relation to 'history'. So, he argues that the quality of architecture depend on the ability of the architect (and me as researcher) to understand the work at hand in relation to the context and the preceding architecture - both as written intentions and built objects.

With my initial observations made on MORE and VEJLE, I would argue that I already have begun parts of an investigation and unfolding of the context of my "work at hand". Nevertheless, neither these normative "observations" nor the planned Annotated Bibliography and Integrative Literature Review provide me with the historical perspective emphasized by Pérez-Gómez. On that basis, it seems like I require a kind of Historical Review or Timeline, which, in the same fashion as the Annotated Bibliography and Integrative Literature Review, outlines past and present information on key objects and intentions relating to my perspective on patient eating environments. This Historical Review could be used to introduce a brief outline of existing research, practice/objects and intentions relating to my three key-words: health, food and architecture. Together the Timeline and Historical Review thus aim at creating a "knowledge map" synthesizing the history of interior architecture with the historic development of respectively healthcare environments and eating environments through 'analyzing' the tacit knowledge existing in professional design practice, as well as giving examples on past and present polemical knowledge that could help frame the development of my theoretical framework and a proposal for a set of design principles 'predicting' the future design of patient eating environments. However, most likely an overwhelming and "infinite" amount of polemical and normative knowledge exists within the intentions and objects of the three domains: health, food and architecture. So, as it is almost certainly impossible to try and get an overview of it all, I have decided that the purpose of the Historical Review is not to make a precise and chronological portray of the historical development of interior architecture, healthcare and eating environments, but instead to provide an outline exemplifying which best-practice or state-of-the-art knowledge possibly exists on within each of the domains in our past and present, though with an emphasis on the interior architectural qualities of patient eating environments where possible.

With the historical review, I have, like the Annotated Bibliography and Integrative Literature Review, two possible research outcomes. If the Historical Review is positive - that I succeed in finding existing knowledge among the intentional writings and history of designed objects, so that I, through inductive reasoning, can construct a theoretical framework - then I can, as with the positive answer in research question (1), enter into the next phase: deducing the 'evidence' through a design intervention and impact measurements. However, if the research outcome of the Historical Review turns out negative - that I am not able to find any, or very little, polemical and normative knowledge existing in past and present intentions and objects, then I either have to acknowledge that my hypothesis presumably cannot be supported by a researchbased argument, or I must engage in the strategy of a multi-embedded case study investigating the 'normative theory' inherited in practice, accepting the "theoretical dilemma" of conducting empirical investigations on a seemingly uninformed basis. 


\section{SUB-CONCLUSION ON RESEARCH APPROACH}

Theimportant point and methodological conclusion is that my research project, because of its interdisciplinary character approaching patient eating environments from an architectural perspective, is not a predefined linear process. But instead an ongoing and continuously evolving process where the specific research strategies and tactics are determined and defined with the research outcome of my initiate investigations and, in particular, the outcome of my literature review. The overall research approach is as such not only an explorative study but also very much defined by an eclectic approach which can end in many different ways, because of the interpretative and creative steps rooted in the polemical and normative understanding of the interior architectural qualities. With this final remark, I will continue to the unfolding of my theoretical framework and the first step of the theoretical investigations - the review of 'positive theory' and the history of research relating to patient eating environments.

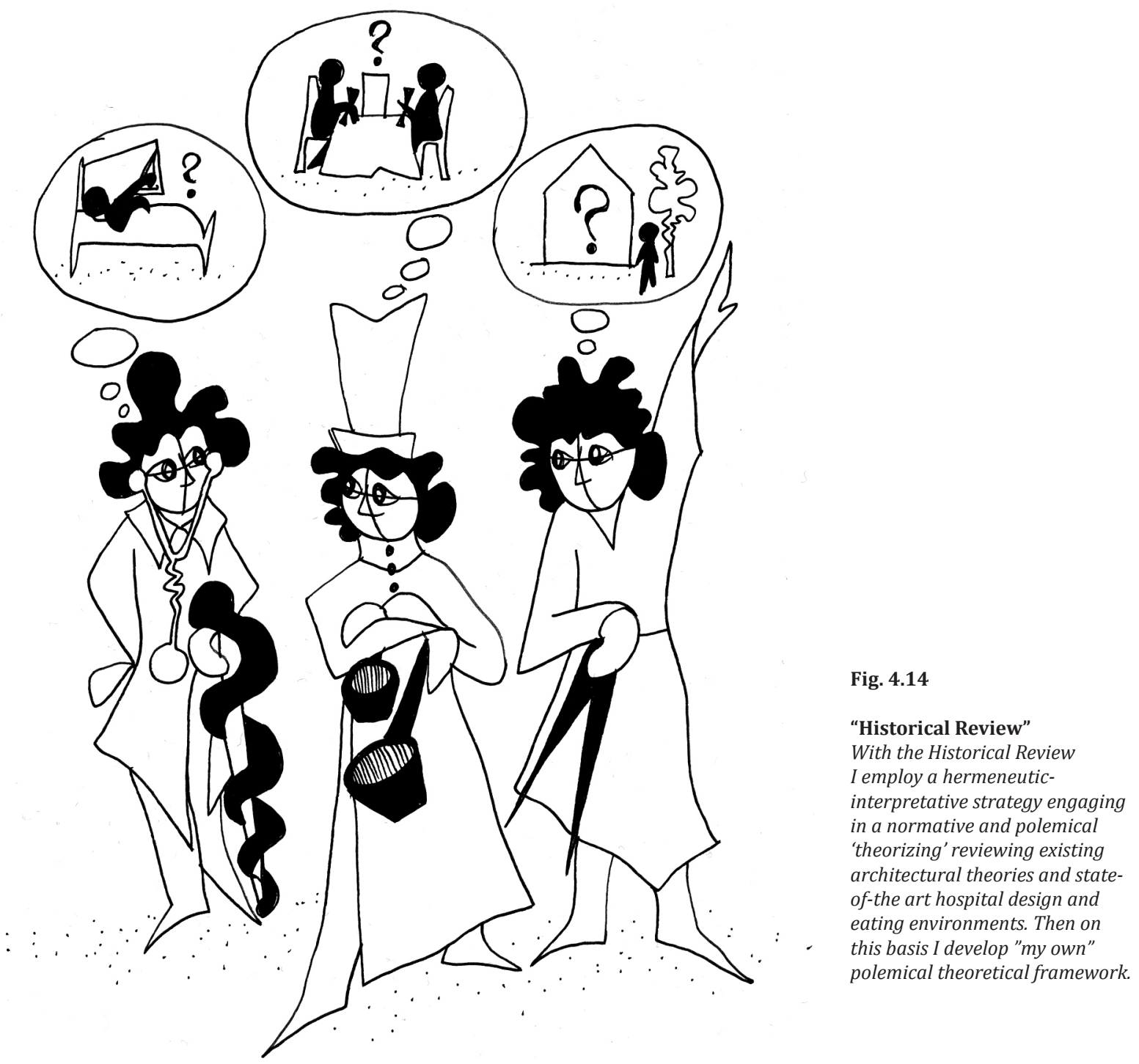




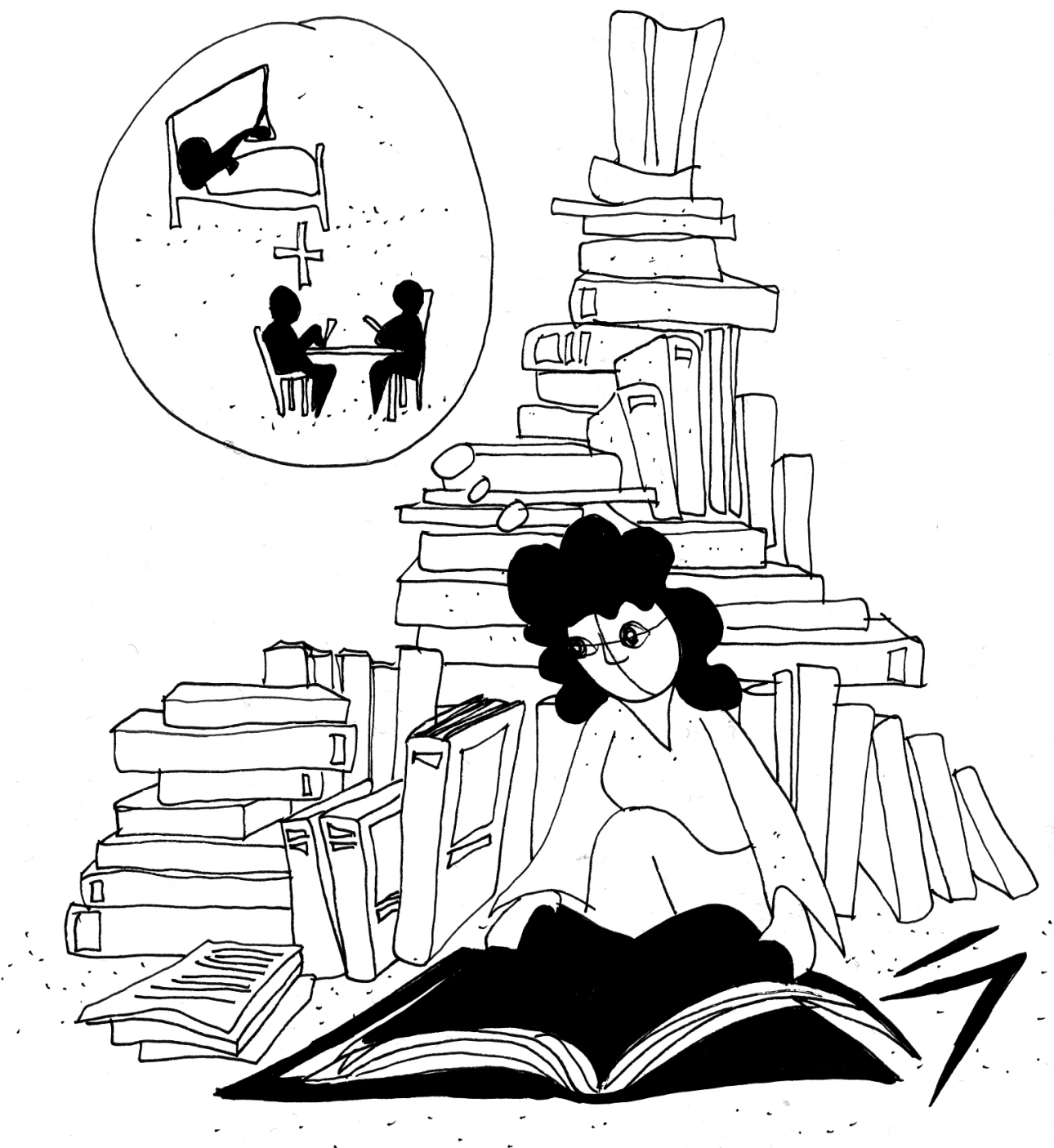

Fig. 5.1

"Search Focus"

The three keywords in the search are: health, food and architecture. These guide a focus on (1) food+architecture (2) health+architecture,. and (3) health+food+architecture 


\title{
POSITIVE THEORY
}

\author{
THE HISTORY OF RESEARCH
}

The purpose of this chapter is first of all to investigate research question (1), outlining the 'positive theory' and 'scientific' literature existing relative to research performed on the interior architectural qualities of patient eating environments. As mentioned in the previous chapter, Research Approach, in order to engage in this type of inquiry, the strategy of an Annotated Bibliography and an Integrative Literature Review were chosen. These were performed as a five-step process:

(1) On the background of the research hypothesis, research question and overall aim of investigating which interior architectural qualities define the patient eating environment, three overall groups of keywords were identified to narrow down my search focus. These were, first of all, a synthesis of the three implicated research domains: health + architecture + food, searching for instance for "hospital eating environments", "patient eating environments", "hospital eating setting" and "hospital dining interior". Next, a broader search was done. Here focusing first on: health + architecture, searching for "healing architecture", "evidence-based design", "hospital interiors", "healthcare environments" and so on, investigating if any additional research showed up elaborating on the influence of interior architectural qualities of healthcare environments on health and well-being. Secondly, focusing on: food + architecture, searching for instance for "eating environment", "meal setting", "food environment", "dining interior" and so on, in a similar manner as the above focus on health + architecture investigating if any additional research showed up elaborating further on the influence of interior architectural qualities of eating environments on food intake.

(2) These three groups of keywords were used to search for relevant literature in research databases such like Web of Science, Scopus, and ISI Knowledge. This enabled a simultaneous search of multiple databases such as MEDLINE, Science Direct and Elsevier which are databases that are generally considered relevant to both medicine and social work (Rubin \& Babbie 2010:24)[Olsen et al. 2010:5]. Limitations in using these databases are, however as mentioned in the previous chapter, that only sparse amount of research in general exists relating to the domain of architecture. To try and widen the architectural search perspective, searches were also performed in Google Scholar and Google, just to see if additional research showed up.

(3) Research published in either English or Scandinavian languages were then selected and ranked so literatures considering the interior architecture or built environment together with eating in hospitals were prioritized.

(4) All references were listed in the Annotated Bibliography in a table according to publication year and reviewed on basis of their abstracts, as well as cited with key methods, key theories, key sources and key words describing the major issues 
relating to the investigated topic of the interior architectural qualities of patient eating environments [Olsen et al. 2010:5].

(5) Afterwards, all the listed literature specifically concerning the impact of built environment relative to patient eating were highlighted and reviewed in detail reading the articles in full length - for the Integrative Literature Review [Olsen et al. 2010:5].

\section{RESULTS OF THE ANNOTATED BIBLIOGRAPHY}

As mentioned in the introductory chapter, since the 1980s a rapidly increasing group of researchers related the architectural sub-disciplines of Healing Architecture and Evidence-Based Design have begun to investigate the influence of built environments on the health and well-being of humans. This type of research is not limited to hospitals, but investigate domains of healthcare and welfare in general - for instance in schools, workplaces and elderly homes. As also stated in the introductory chapter, more than 2,500 references exist, today, in the database of American Center for Health Design elaborating on the relationship between health and architecture. Likewise, the reviewed literature of the Annotated Bibliography showed that, in general, a substantial and overwhelming amount of references exist, spread across the domains of health, food and architecture, relating to research disciplines like Hospital Nutrition, Gastroenterology, Nutritional Science, Health Science, Sociology, Anthropology, Food Service, Consumer Science, Hospitality, Geography, Management, Tourism and Retail [Olsen et al. 2010]. Here, research studies on food, drink and provision; chefs, waiters and professional kitchens; food and meal rituals; roles of host and guests, urban regeneration and commercial space; public space and well-being; lifestyle and consumer culture; space and spatiality; food environments; meal experiences; service and hospitality; human relations, demonstrate the contextual importance and influence of the built environment on consumer food choice, food intake, consumer preferences, satisfaction and food acceptability relative to eating [Olsen, 2010:104]. Based on my review, I find that similar to most of these studies is that they are based on a deductive research approach utilizing quantitative and qualitative research methods investigating the influence of the built environment in laboratories and under freeliving conditions in the natural environment. Epistemologically viewpoints range from sociology and natural criticism to more positivist and statistically based approaches, and research strategies vary from laboratory experiments, field experiments, questionnaires, measuring of dietary intake and surveys, to research tactics utilizing dietary diaries, dietary recall, observations, open-end interviews, in-depth interviews, focus groups to interventions.

In the following I will briefly elaborate on, what I find is, the most interesting references reviewed with the Annotated Bibliography relative to my three specific research focuses. Picking up on the "clues" outlined in the introductory chapter with the research tendencies of Food Science and Healing Architecture, I will begin this elaboration with the focus of food + architecture and health + architecture. Before I narrow down to the synthesized focus of health + food + architecture, and continue with the Integrative Literature Review.

\section{Food + Architecture: influences of eating environment on food intake}

As presented in the introductory chapter, within the disciplines of Food Science and sub-branches of sensory science, consumer behavior and food evaluation, it has been argued for years that eating and having a meal are often made into something more than obtaining mere nutrition (Meiselman 2000). Here, eating is instead partly seen as a social event and cultural situation encompassing a specific meal experience serving higher means than satiety. As noted in Olsen (2008:78), those disciplines engage in investigations of food perception and meal experiences through food evaluation tests and empirical studies performed in restaurants, schools, canteens in the army or at universities, food test laboratories or home environments. Here, they use sensory evaluation techniques such as hedonic scaling and questionnaires to establish a "lawful" relationship between different food product characteristics and human 
LIFE COURSE

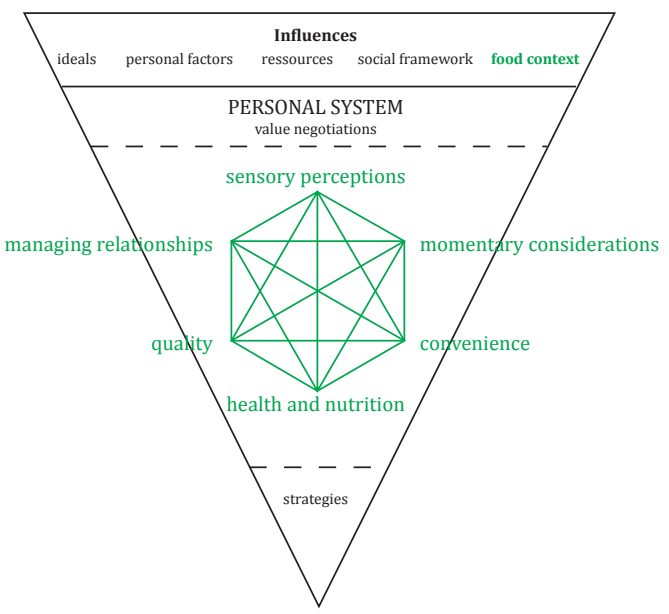

FOOD CHOICE
Fig. 5.2

"Food Choice and Expectations"

Models developed by Delizia \& MacFie (1996) and Furst et al. (1996). Here the quality of a "good" meal experience is based on the underlying significance of food choice and consumer expectations.

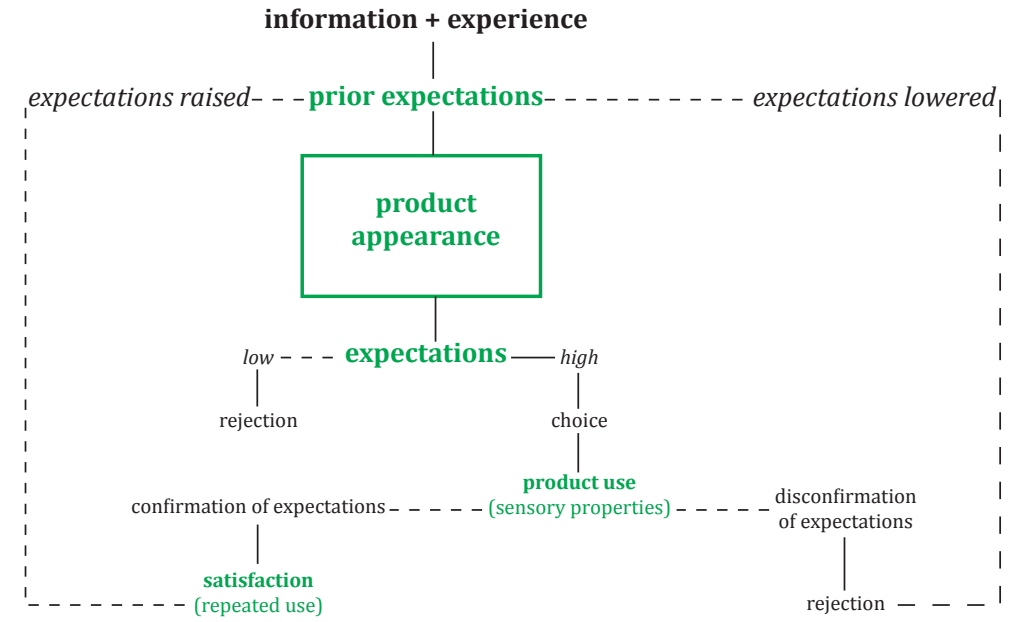

perception [Olsen 2008:78]. A large body of research has thus specifically investigated individual aspects of the built environment relative to food intake, food choice and consumer satisfaction, as well as related this kind of research to health, for instance by focusing on obesity (see e.g. Chang \& Christakis 2002). This is further exemplified with the two consumer related models: The Food Choice Process Model developed by Furst et al. (1996) and The Food Expectations Model developed by Delizia \& MacFie (1996) (see Figure 5.2, Food Choice and Expectations). Furst et al. (1996) describe the complicated psychological, social and physiological aspects interfering with the choice of food, arguing that the process of choosing food is guided by the three major components: life course, influences and personal system operating together. Here, under the category of "influences", the food context is defined as the physical surroundings, convenience and climate that contribute to the final food choice (Furst et al. 1996:247-255). Delizia \& MacFie (1996) clarify the coupling of food choice (and indirectly food intake) with the importance of product expectations, and thus define that the experience of eating is also about understanding the expectations and satisfaction of a meal. These expectations are formed in relation to the memories of earlier meal experiences and directly related to the appearance of a given object 
or product, communicated with the written information, labeling, package, ads and prices relative to or on the object (Delizia \& MacFie 1996:103) [Olsen 2008:84-88].

Another of the often cited studies relating to the interior architectural qualities of eating environments explores the effects of adding an Italian theme to a British restaurant (Hirsch \& Kramer 1993). The study found that, without altering the menu, the pattern of the diners' food choices differed from when the restaurant was decorated in its normal British theme. Likewise, other studies on cognitive information in form of food packing, restaurant menus, visual and auditory stimulation (music, lighting, and decoration), restaurant décor, manipulation of interior and table configurations demonstrate that including flowers, tablecloths, better acoustics, and lighting in eating environments could increase food intake among elderly diners at nursing homes or, for instance, change consumer behavior (Hirsch \& Kramer 1993; Gibbons \& Henry 2005). Relative hereto, research has tried since the 1970 s to describe human eating and meal behaviour from a sociological perspective, primarily debating the importance of eating as a social activity. Several empirical studies across gender, age, social status and civil status suggest that communal eating is healthier because of the social facilitation, and this is very important for the context of health and understanding of how to promote healthy eating (see e.g. Holm 2003; Kleges et al. 1984; Belasco \& Murcott 2008; DeCastro \& DeCastro 1989; Sobal \& Nelson 2003).

Other researchers such as Sobal \& Wansink (2007) in the article: Kitchenscapes, Tablescapes, Platescapes, and Foodscapes argue the influences of micro-scale built environments on food intake. According to Sobal \& Wansink (2007), the built environment provide a context within which food choices are embedded, and they thus argue that food intake is situational influenced by the built environment and objects contained in the built environment. Furthermore, they state that when people eat in particular spaces such as kitchens and dining rooms, they employ a series of specific objects such like chairs, cutlery and plates in the process of eating. These spaces and objects of the built environment all influence the decisions made about types and amounts of food selected and eaten, which again determine food intake and thereby indirectly influence the general health and well-being (Sobal \& Wansink, 2007:125).They thus emphasise how, for instance, kitchenscapes influence food intake through availability, diversity, and visibility of foods; how tablescapes influence food intake through variety, abundance, and accessibility; how platescapes influence food intake through portion and/or package size, arrangement and utensil type; and finally how foodscapes (in their terminology: the space around the food on the plate) through food-items form and mark food intake. Their conclusion is that these spaces and objects of the built environment provide subtle, pervasive, and often unconscious influence on food choices, food intake, obesity, and health. They further suggest that reengineering or refurbishing built environments - just as MORE and VEJLE desire may offer opportunities to shape food intake (Sobal \& Wansink 2007:124). Wansink \& Cheney (2005) has also demonstrated that the size of serving bowls change food intake; for instance, a larger size leads to larger intake. Before Sobal \& Wansink (2007), Mehabrian \& Russell (1974) argued that certain positive behaviors might be directed at a particular place. Holahan (1982) argued that the built environment influence how we think, feel and behave. And Bitner (1992) argued that human behavior is influenced by the built environment, in particular the effect of what she called the atmospherics, physical design and décor elements utilized in e.g. marketing and retailing. Bitner (1992), like later Sobal \& Wansink (2007), used the suffix "-scape" to construct the term: servicescape to describe all the physical factors such as layout, lighting, colour and temperature that can be used to enhance consumer experiences. Research studies performed by Cardello et al. (1996) and Meiselman et al. (2000) show that identically served foods, beverages and smaller meals are perceived differently if experienced in a home compared to an institutional setting such as a hospital. People rate food higher in the home or in a restaurant than in a laboratory or a hospital because of the contextual effects and the different expectations they produce (Cardello et al.1996). Following that Cassidy (1997) argued that the built environment is experienced through all senses at the same time and produces both a physiological and psychological effect.

De Castro \& Stroebele (2002) then suggested in a similar manner that altering social, temporal, environmental and hedonic variables influence food intake. Rozin (1996), Meiselman (2000) and Meiselman et al. (2000) argued that environmental factors are equally important - if not more important than the actual food item itself in 
Foodscape (Object)

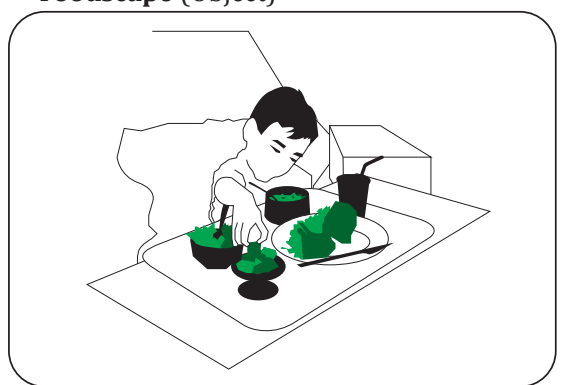

Tablescape (Furniture)

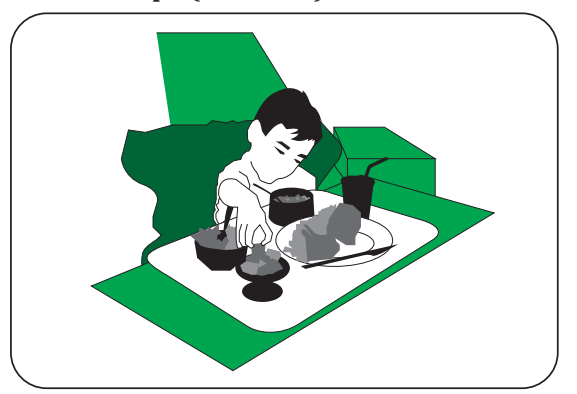

Platescape (Container)

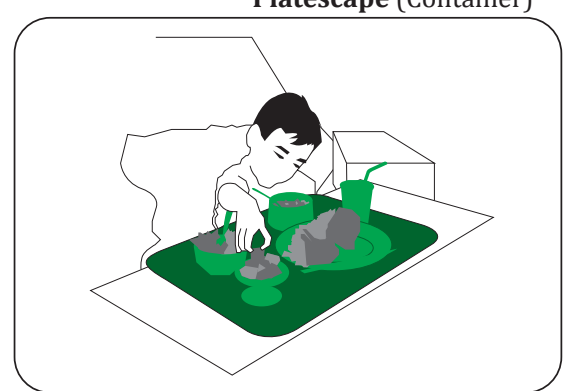

Kitchenscape (Room)

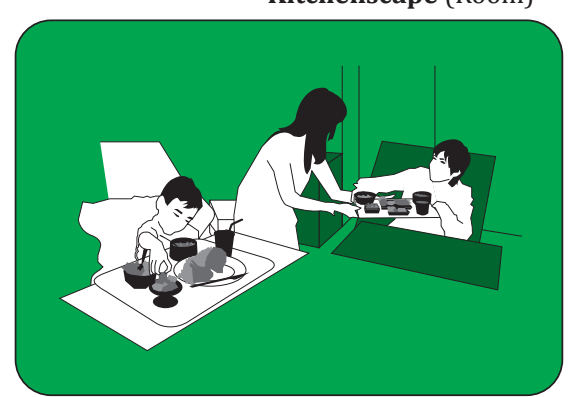

Fig. 5.3

"Kitchenscape, Tablescape, Platescape and Foodscape" The study by Sobal \&

Wansink(2007) suggest that the aspects of availability, diversity, visibility constitute a "micro-environment" where the appearance of room, furniture, containers and food objects influence food choice, food intake and thereby affect the overall health (Model adopted from Sobal \& Wansink 2007:128).

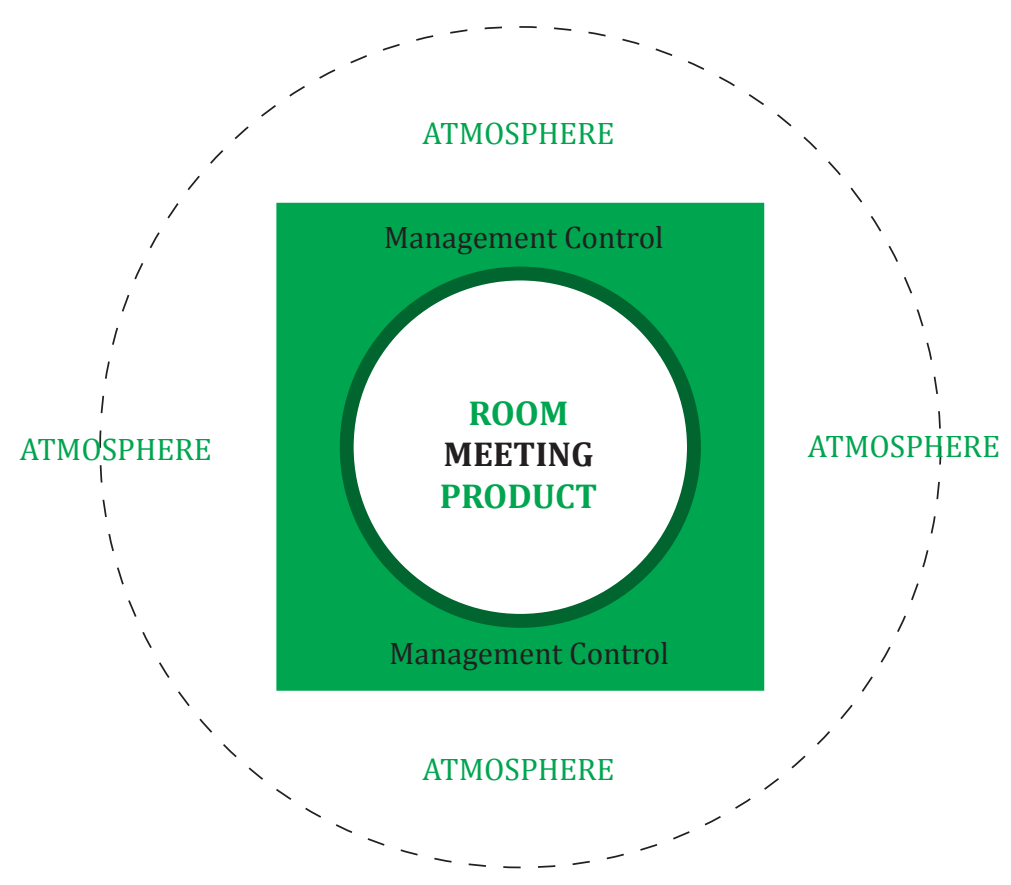

Fig. 5.4

"The Meal Experience" The FAMM-model developed by Gustafsson (2004), which approaches the built environment from both the perspective of Atmosphere and Room. 
food choices. Meiselman et al. (2000), Meiselman (2003) and Edwards et al. (2003) argued that eating locations influence food acceptance. They base this on research indicating that different locations with the same population show differences in food acceptance (Edwards et al. 2003). In continuation hereof Meiselman (2007) argued that situational and social contexts influence eating behaviors. Furthermore, directly related to food consumption, several researchers have investigated the impact and importance of light and sound (see e.g. Bell \& Meiselman 1995, Milliman 1986, North et al. 2003).

What this long list of research indicates is that a rather large body of research-based knowledge, or what I have also called 'positive theory', exists relating indirectly to the search focus: food + architecture. But what I find is most interesting, relative to my specific research problem and challenge of finding research-based knowledge describing the interior architectural qualities of patient eating environments, are the number of researchers who not only state that the built environment influence food intake, but who have further attempted to developed analytical models for evaluating the qualities of a meal and herein the qualities of its built environment (see Figure 5.4, The Meal Experience). An example of this is the culinary model called: FAMM model developed by Swedish researcher Inga-Britt Gustafsson (2004; Edwards \& Gustafsson 2008). The model is based on the evaluation methods of the Michelin Guide on hotel and restaurants, and suggest that every meal is constructed by a synthesis of the qualities of the atmosphere and room in which the meal takes place, the meeting between consumers, other guests and waiters, the products_such as the specific drinks and dishes served, as well as the management control system that is need "backstage" to make the meal possible (Gustafsson 2004; Edwards \& Gustafsson 2008). Together the room (built environment with style history, architectural style, decoration, textiles, design), meeting (interactions), products, management control system (economics, laws and logistics, and atmosphere are the five basic "design principles" for developing meal service (or what I call meal experiences) in restaurants.

Edwards \& Gustafsson (2008) emphasize that those five basic principles need to be considered in an integrated manner and understood by utilizing different types of knowledge such as scientific knowledge, practical-productive knowledge, aesthetic knowledge and ethical knowledge. However, more recently North American researcher Herbert L. Meiselman (2008) argued that the FAMM model put forth by Gustafsson (2004) is not broad enough to fully understand and appreciate the complexity of a meal. Meiselman (2008:14) instead argues that a meal should be analyzed from the following views: history (meal patterns over time), product development (food combinations), food service (food sequences, food compatibilities, sensory themes), designer/artists (meal locations, environments, physical settings), sensory (combination of sensory experiences), biology (food intake, timing and pattern), physiology (internal hunger and satiety, signals), nutrition/dietetics (food intake and macro/micro nutrients), anthropology (cultural differences), sociology (commensality and social rules/rituals), psychology (basic unit of eating), marketing (price, value, brand and satisfaction), and abnormal psychology/health (undernutrition, undereating and overeating) (see Figure 5.5, Meal Experience Extended). Consequently, Meiselman (2008) writes that the design and style of the interior and exterior of, for instance, a restaurant or a eating environment have the ability to communicate comforting traditional food service or provoke interest and present new trends, because the customers expect a certain kind of food, based on the design of the eating environment.

However, despite Meiselman's critique of the FAMM model, he does not himself offer any specific model for how to analyze a meal based on all these different perspectives. According to Edwards \& Gustafsson (2008), certain expectations and demands are related to the meal situation when paying or purchasing in a public domain such as the hospital, and the specific taste and experience of the enjoyment of the meal occasion is, therefore, influenced by additional factors occurring before, during and after the consumption of the food. Both Meiselman (2008) as well as Edwards \& Gustafsson (2008) state that the 'room' and 'atmosphere' framing eating is an important part hereof, and Edwards \& Gustafsson (2008) further write that working with public meals, therefore, requires knowledge not only about the food, preparation and serving, but also about the history of the 'room' and 'atmosphere': the style and architecture, textiles, design, décor, and art [Olsen et al. 2010:3]. Thereby they both indirectly suggest, in my point of view, not only the direct importance of what I have called 
the interior architectural qualities of eating environments on patients' food intake, but also the indirect importance on the health and well-being. And they do so by a synthesis of distinct research disciplines and practices relating to both the arts and the sciences. Still, a major weakness in both the writings of Edwards \& Gustafsson (2008) as well as Meiselman (2008), relative to my specific research focus, is that despite their attention on the aesthetic qualities of the 'room' and the 'atmosphere', neither the FAMM model nor Meiselman's (2008) holistic perspective offer any detailed insight into how I analyze the specific interior architectural qualities of this 'room' or the 'atmosphere' of the eating environment and how that influence the health and well-being of the diners. But perhaps research relating more to the research focus: health + architecture do?

\section{Health + Architecture: influences of built environment on health and well-being}

When I move away from the focus on Food + Architecture into the focus on Health + Architecture, a vast and overwhelming amount of research literature relating to healthcare architecture occurs. Here, some of the first research-based knowledge on hospital design, dating back to the beginning of the $20^{\text {th }}$ century, was articles published in the British Medical Journal in 1908 and in the Lancet in 1909 by a group of researchers who debated the proper design of hospitals (see Ochsner 1902; Ochsner 1907; Thompson 1907; Adams 1908)(Lemche 2012:23). Furthermore, as mentioned previously, within the last years, several literature reviews have been published outlining existing research-based knowledge relating to the domain of Healing Architecture and Evidence-Based Design (see e.g. Delvin \& Arnelli 2003; Ulrich et al. 2004; Ulrich et al. 2008; Frandsen et al. 2009; Xiaobo et al. 2011; Heslet \& DirckinckHolmfeld 2007). These reviews indicate that research-based knowledge relating to this topic has radically increased since 1980s, particularly within a North-American and British context. However, a few Scandinavian references have been included in the review provided for instance by Frandsen et al. (2009).

In general, I find, most of the reviewed literature focus specifically on investigations of private spaces, social spaces, work environments, patient rooms and how noise, daylight, lack of space, (fresh) air, ventilation, surface coverings, art, nature views, access to nature and greens, ambience, sound, ergonomics, and medical equipment possibly affect the stress levels of hospitalised patients, as well as investigate different aspects of logistics, hygiene, treatment technology and patient safety (Glind et al., 2007:154)[Olsen, 2010:104]. Often these references are based on "best-practice" from specific hospitals or clinics, and, so far, these studies indicate that a poor architectural environment can cause e.g. active failures, mistakes and misunderstandings in medication or surgical procedures, as well as risk causing physical injuries and infections obtained by the patients during hospitalization (see e.g. Ulrich et al. 2008; Frandsen et al. 2009)[Olsen, 2010:104]. Other studies suggest that patients have a preference for the private space of a "home-like environment", elements that promote a sense of "normalcy" and with an absence of long corridors (see e.g. Curtis et al. 2007; Douglas \& Douglas, 2005), and these tendencies have, among others, led to more hospitals painting their long corridors with soft colors and decorating with art (Glind et al., 2007:154). Relative hereto Heslet \& Dirckinck-Holmfeld $(2007: 248,275,278)$ argue that art could be important elements in future hospital design, because art - for instance as music, sculpture, painting or even interior decoration and the coherent architectural 'space' - indirectly in line with idea of 'nature views' purposed by Ulrich (1991) constitute 'positive distractions' that help calm down the patients and thereby also stimulate their general well-being. Heslet \& Dirckinck-Holmfeld (2007:278) make a brief description of what they find defines the "proper" choice of art in hospitals and outline three basic 'principles' exemplifying this. Those are: (1) art as an integrated interior aspect of the specific ward context, (2) art as an individual object hung on the wall, and (3) art as a free standing object defining a 'space within the space' (Heslet \& Dirckinck-Holmfeld 2007:278). This type of research is interesting for my specific research problem, because it, in line with the above reviewed references relating to the domain of Food Science, indicate that a relationship possibly exist between the interior architecture and our general health and well-being. However, as can also be seen from my above listing of keywords characterizing the reviewed literature, very few references relating to my focus on health + architecture are as specific in their 
mentioning of the interior qualities of a hospital as an architectural coherent 'space' as Heslet \& Dirckinck-Holmfeld (2007).Instead, it is my claim, that most of the reviewed literature tend to focus on isolated elements of the different hospital interior spaces, forgetting about the interior architectural qualities understood as a coherent whole. Still, a weakness in the writings of Heslet \& Dirckinck-Holmfeld (2007), relative to my specific research focus, is that they do not offer any detailed perspective on what defines these interior architectural qualities or relate them in any sense to the eating environments. But instead write about 'art' and 'space' in a more general and overall sense. Compared to the above review of the references relating to my focus on food + architecture, where Edwards \& Gustafsson (2008) and Meiselman (2008) analyzed eating environments but lacked focusing on the aesthetic qualities, I find it quite curious that Heslet \& Dirkinck-Holmfeld (2007) began analyzing the aesthetic qualities of art but lacked focusing on eating environments. Particularly because all of them, despite their distinct relations to health, food and architecture, related their analyses to the same underlying epistemological understanding of 'space' as a communicative scenery, which in an almost theatrical manner is able to seduce us, touch our emotions and feelings, and thereby also affect our general well-being.

In continuing of the above-mentioned references investigating the relationship between health and architecture, I further found a small group of references relating to my search focus on health + architecture, which did not specifically relate to the disciplines of Healing Architecture or Evidence-Based Design. Instead they were based on research relating more to the social sciences and focused on how the eating environment, through the ability to stage our social relations, influenced the health and well-being of for instance elderly or hospitalized patients. These references are those I find came closest to my narrow research focus searching for a synthesis of health, food and architecture. And they are further elaborated in the following.

Fig. 5.5

"The Meal Experience extended"

Meiselman (2008) argues that the qualities of a meal must be evaluated on the background of history, product development, food service, design/art, sensory input, biology, physiology, nutrition, anthropology, sociology, psychology, marketing and health.

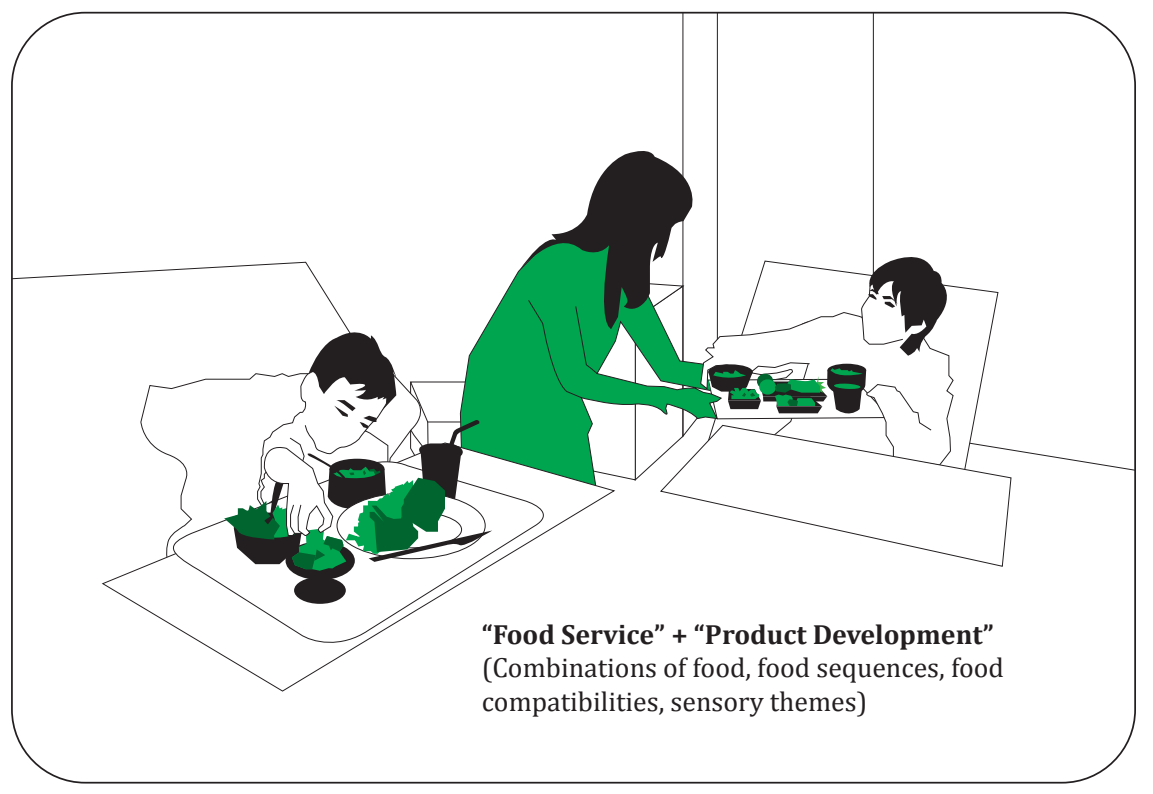


“Health” (under eating or overeating)

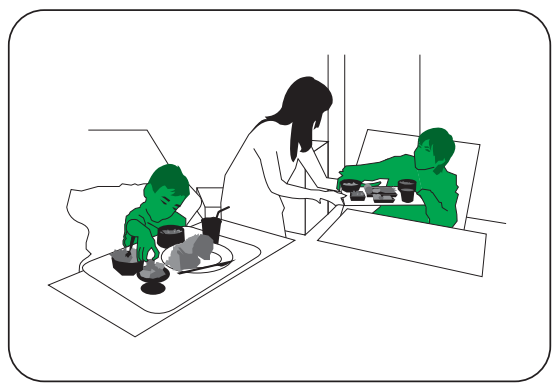

"Designer/Artist" (physical setting)

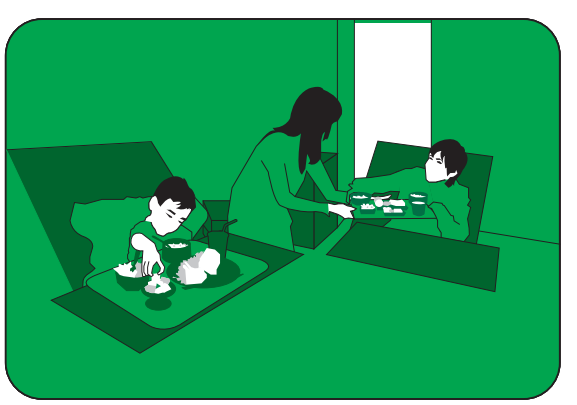

"Atmosphere" (Light + Sound etc.)

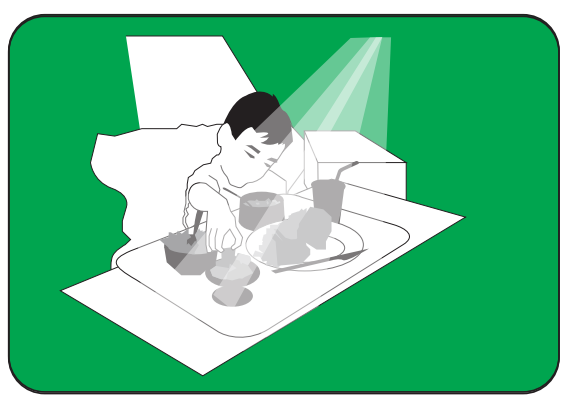

“History" (meal pattern)

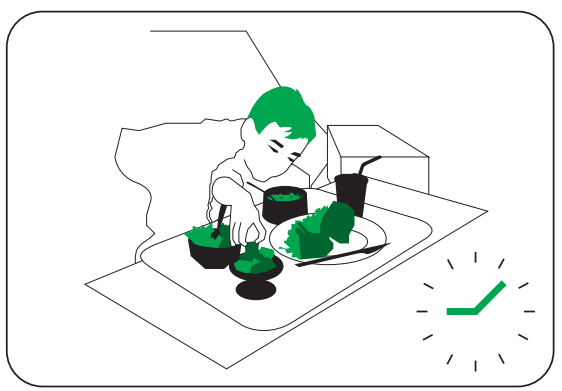

“Anthropology” (cultural differences)

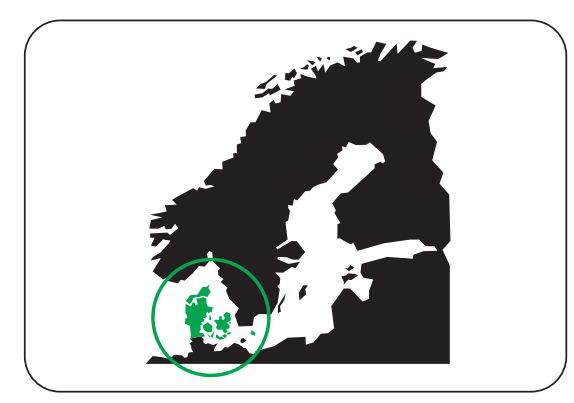

“Physiology" (internal hunger)

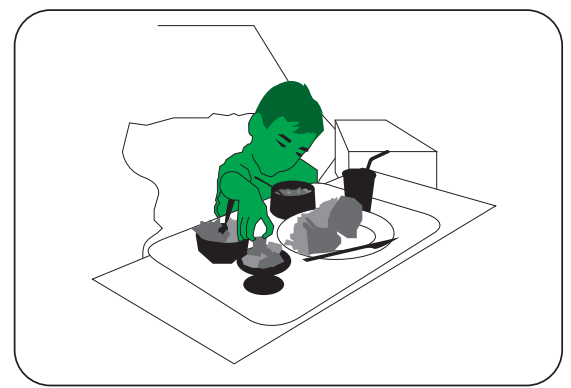

"Sensory input" (comb. of experiences)

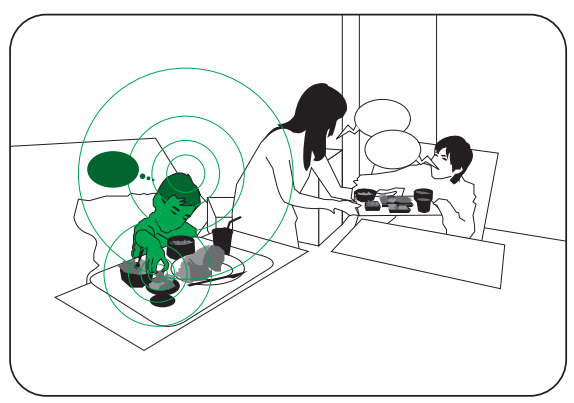

“Biology" (food intake, timing and pattern)

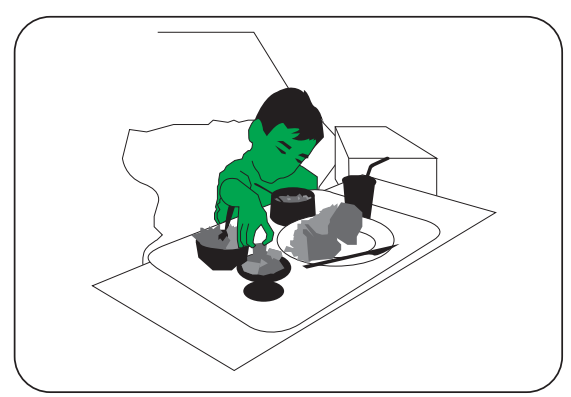

“Psychology" (memory + expectations)

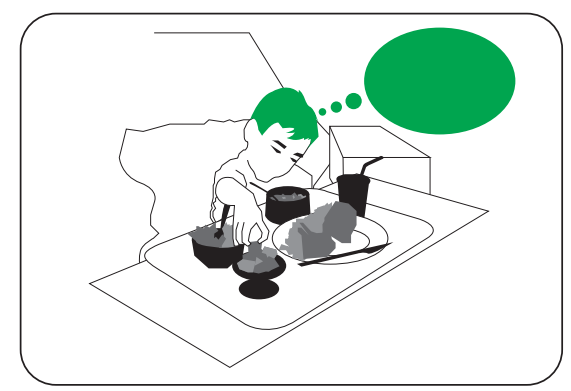

"sociology" (commensality + rituals)

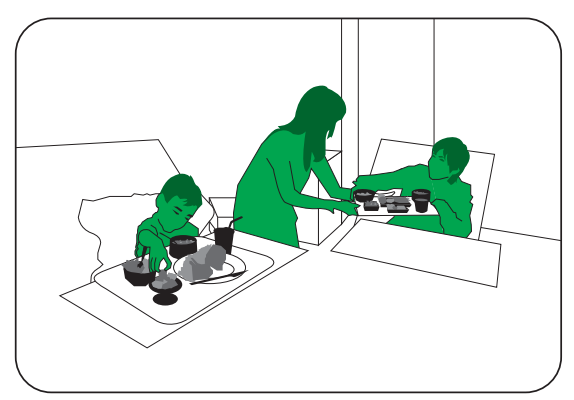




\section{Health + Architecture +Food: influence of eating environments on patient food intake, health and well-being}

A minor series of references relating to research in elderly homes specify that improvements in physical environment and the overall dining ambience has shown significant increase in mean body weight, and thus indicating that food consumption exceeded energy expenditure, which is basically what is also needed at the hospitals to avoid malnutrition and undernourishment among patients (see e.g. Mathey et al. 2001, Gibbons \& Henry 2005). Gibbons \& Henry (2005) served identically prepared meals to elderly people in two different eating environments, the university training restaurant and a staff canteen, where both males and females consumed significantly more in the restaurant environment. According to the research done by Gibbons \& Henry (2005), the situation influences the perception of the individual food items, the drinks and, in general, the entire consumption of the meal. Hoyer \& de Graaf (2004) reported greater intake among elderly people in what they refer to as 'decorated' eating environments. Research performed by Maller et al. (1980) showed that hospital patients rated meals higher when served in a dining room, than in the traditional ward environment. Reed et al. (2005) found that the food intake of long-term care residents was higher among those who had their meals in a public dining area than among those who did not (from Paquet et al. 2008:604). Melin \& Götestam (1981) showed that by rearranging furniture and changing mealtime routines in a way that is more conductive to interactions, staff members found that psychogeriatric patients were communicating more among themselves in addition to showing better eating behavior during coffee breaks. Elmståhl et al. (1987) and Xia \& McCutcheon (2006) found that research conducted to review the mealtime experiences in hospitals showed that placing a dining room in the ward allowed the patients to eat together and thereby provided a more natural mealtime environment similar to a 'home-environment'. This is partly supported by the references Holm \& Jacobsen (1990), Holm (2003), Holm (2003b), Holm et al. (1996), Holm et al. (1998) and Kok et al. (1992) who describe the positive effect of refurbishing a ward kitchen and eating environment in the department for children with cancer. Here the changes interior architecture were found to influence the social relations occurring between patients, family and staff during mealtimes, and thereby indirectly affect the general health, well-being and food intake of the children. Also Hartwell (2004), Edwards \& Hartwell (2004), Hartwell et al. (2006), Hartwell et al. (2007) and Shepherd (2011) have investigated how hospital eating environments and hospital food service systems influence patients' food intake and meal experiences. And suggest relative hereto that patient food satisfaction depends as much on the communicative significance rooted in the entire hospital food service system and eating environment, as the specific quality of the food served.

Continuing this line of thinking, Mamhidir et al. (2007) illustrated that an improved physical dining environment made patients view meals in a more holistic way, increased contact among patients and improved appetite. Bélanger \& Dubé (1996) investigated the relationship between the level of arousal emotions and patient satisfaction, and this study indicated that environmental conditions were essential. Cortis (1997) notes that patients should have the possibility to eat in a dining room or dining area with the possibility to sit at a table when eating their meals. Mathey et al. (2001) argue that creating an enhanced eating environment in a residential care home for elderly people influenced food intake positively. Weber et al. (2004) indicated that people eat considerably more in an enhanced context. Brush \& Calkins (2008) suggest that a modification of the dining environment can improve the eating experience, support rehabilitation processes and enhance food intake. According to Paquet et al. (2008), such findings are consistent with the findings from studies performed with free-living individuals by de Castro \& de Castro (1989), Redd \& de Castro (1992), and Clendenen et al. (1994) for instance. Furthermore, Paquet et al. (2008) refer to studies performed by Clendenen et al. (1994) and de Castro (1994) which demonstrate that the effect of food intake is stronger for interactions with family members and friends than with coworkers and strangers.

When considering the food intake among hospitalized patients, research within the social sciences demonstrate that social facilitation of food intake goes beyond the effect of the presence of dining companions, and that the specific elements of the meal social environment contribute to the social facilitation of patient intake (Paquet et 
al. 2008). Studies within social research found that not only the communal behavior expressed by participants in a meal had a positive impact on the amount of energy consumed, but also the complementarities of participants and other patients' behaviors on the communion and agency dimensions could be seen as predictors of a greater energy intake (Paquet et al. 2008:608). The underlying mechanisms in the effect of social environments impact on energy intake are meal duration, positive perception of food taste in response to mealtime interactions, and change in emotional states in response to mealtime interactions (see e.g. de Castro 1990, de Castro 1994, Feunekes et al. 1995, Pliner et al. 2006). The research performed in the area of social science highlights the importance of the social interaction in the individuals' food intake, and the research provides a valuable insight into the specific social elements of the meal environment that contribute to shape patients' food intake. Pasquet et al. (2008) propose that staff members encourage meal fellowship by rearranging meal environments and minimizing mealtime distractions to facilitate better interaction and specifically suggest this to be implemented via a common table in a public dining room (Paquet et al. 2008:610).

Finally, today a minor group of researchers are focusing on applying concepts of 'hospitality' to hospitals with the aim of making the patients feel at home as much as possible and in the attempt to improve overall patient satisfaction with hospital treatment and recovery procedures (see e.g. Severt et al. 2008; Bromley 2012; Lynch et al. 2011; Hepple et al. 1990; Todres et al. 2009; Patten 1994; Ritzer 2007; Ball \& Johnson 2000; Hemmington 2007; McCree 2004; Lashley 2000). These hospitality studies in hospitals consider the social domain of the staff providing the hospitality, as well as the role and experience of the patients during mealtimes (Shepherd 2011:3). Nevertheless, often when focusing on customizing hospital service levels, such as food servings, to meet patients' needs and desires, the hospitality focus is dominated by debates about hotel metaphors like 'host-guest' and 'service provider/ consumer' relationships or even 'concierge services' (Severt et al. 2008:664). This, despite researchers such as Lynch et al. (2011) recently emphasized that the use of such hotel metaphors extend the hospitality analyses into analyses of human and non-human relationships. Thereby Lynch et al. (2011) also pointed at the mediatory role of non-humans like the broader built environment and its interior architecture. Here hospitality, according to Lynch et al. (2011:8,15-16), does not take place in 'space', but rather produces, constructs and mediates spaces through material objects such as clothing, foodstuffs, cutlery, furniture, light, decorations, interiors, buildings, cities and landscapes [Tvedebrink et al. 2013b]. This kind of research is strongly related to other research domains like Experience Economy, Performance Studies and Experience Design, investigating how sensations enchant and seduce customers (see e.g. Pine \& Gilmore 1999 or Kirshenblatt-Gimblett 2007). Here, the underlying assumption is that the built environment can be used to enhance the experiences of the consumers, because such experiences are understood not just as "services" but also as staged events that not necessarily entertain customers but engage them emotionally, intellectually, physically and spiritually thus turning the experience into a memorable event (Shepherd 2011:35-36).

\section{Concluding on the Annotated Bibliography}

Consequently, because the Annotated Bibliography showed that a rather large amount of references have explored aspects of the built environment and contextual factors of eating relating to patient healing, patient recovery, nutritional well-being, food intake and human eating in general, it is almost impossible to give a comprehensive and detailed account of past and contemporary 'scientific' research-based knowledge related the synthesized domain of health, food and architecture. Therefore, the Integrative Literature Review rather aims at outlining main sources that illustrate key issues and tendencies directly related to the investigated topic, focusing on the interior architectural qualities of patient eating environments and using these to discuss future perspectives related hospital design. And as seen from the above brief outline of the reviews performed, when narrowed down to consider the complex interrelationship of health and food together with architecture, this narrow focus showed that sparse literature exists and possibly even fewer referred directly to the importance of the interior architectural qualities of hospital eating environments on patient food intake, health and well-being [Olsen et al. 2010]. As partly seen in the above outline of the 
Annotated Bibliography, only about 35 references out of several hundred reviewed focused directly on the importance of the hospital eating environment and what I find could be understood as the impact of the interior architectural qualities on patient eating. Of these very few references were available in full length via the research databases, and even fewer references had detailed descriptions of their research methods or, more importantly, noted how the specific interior refurbishments were implemented or what their architectural qualities were. Furthermore, some of the reviewed literature referred to the same research studies. Therefore only 3 research studies have been the object of the Integrative Literature Review, and my attempt towards unfolding a more detailed understanding of how existing 'positive theory' characterize the interior architectural qualities of patient eating environments. Those are presented in the following.

\title{
INTEGRATIVE LITERATURE REVIEW
}

\author{
Rigshospitalet Departments 5053 and 5054, DK
}

One of the reviewed studies that related more directly to the investigated research topic on the interior architectural qualities of patient eating environments is a Danish explorative research study called: Bedre kost til børn med kræft (Better food for children with cancer, red.) that was performed between 1989-1991, investigating malnutrition among hospitalized children. This study is originally described by Danish sociologist Lotte Holm \& psychologist Anne Jacobsen (1990), but has also been more elaborately described in Holm (2003, 2003b), Holm et al. (1996), Holm et al. (1998) and Kok et al. (1992), as well as in a lecture by Holm (2007).

The research study consists of a series of empirical field studies quantitatively and qualitatively investigating the impact of a design intervention performed on the eating environment at the children cancer department at Rigshospitalet in Copenhagen, Denmark. First of all, the quality of the food was improved together with the implementation of a higher degree of freedom to choose among various food items as well as eating when hungry. Furthermore, family members and close relatives were allowed to eat together with the children, and finally refurbishments and interior alterations in the eating environment were conducted as part of the study. This included, among other things, the establishment of a large new kitchen including a grand dining table, new china, and colored cups and glasses, as well as the food previously served in metal containers were now served on china, like in a restaurant or as we would do at home (Holm 2003:291; Holm 2007:7,23). The results of the study showed that before the design intervention, establishing a new kitchen and improved eating environment, the energy intake in \% of recommended daily intake for healthy children was $44.8 \%$. Whereas the same result after the implementation of the new kitchen and eating environment had increased to 70.8\% (Holm 2007:20).

The hypothesis behind the study speculated that the problem of undernutrition might not only depend on physically obtaining the right amount of nutrition but as much on the quality of the food, the food service system and consuming a 'meal' and being part of a larger social context (Holm \& Jacobsen 1990:10)[Olsen, 2010:103]. The results of the study indicated that the problem of malnutrition among hospitalised patients might not just be a matter of wrong nutrition and a poor diet, but also a social and cultural matter bound to the entire eating situation (Holm 2003b:279) [Olsen, 2010:103]. Relative hereto, the research study further speculated that both the social context and the ability to create a meal were strongly dependent on the eating environment - the interior architectural scenery with the specific room configuration framing the meal (Holm 2003b:284,293). These speculations were based on the theoretical writings of, among others, Canadian sociologist Erving Goffman (19221982), who is generally considered a very important figure in sociology with his focus on the world of the everyday and the use of metaphors on the theatre and ritual (Jacobsen 2010), and his text Asylums: Essays on the Social Situation of Mental Patients and Other Inmates (1961). Here he studied the social order in what he referred to as 'Total Institutions. According to Goffman, a 'Total Institution' is a "place of residence and work where a large number of like-situated individuals, cut off from the wider society for an appreciable period of time, together lead an enclosed, formally administered round of life" (Goffman 1961:11). 
Holm \& Jacobsen (1990:18-19) adopt the notion of 'Total Institutions' to describe how a patient during hospitalization is often subject to an "institution" to which he/ she must assign to during the daily procedures and activities taking place there. The argument made by Holm (2003:265) is that very often you, as a patient, have to wear certain kind of clothes, sleep with others in certain kinds of rooms with specific kinds of interior, furniture and equipment. You must further often eat the same as all the others at specific pre-defined times during the day, and sometimes you even have restrictions as to where you can go and move around both indoor as outdoor. As a hospitalized patient, you are, furthermore, often being "violated" mentally by being moved around in the hospital hallways, wearing very little clothes, presumably not feeling very comfortable or being inspected and nursed (changing bandages and being washed) in the room among the other patients (Holm 2003:265-66; Holm \& Jacobsen 1990:18-19). They further argue that during hospitalization patients are often "forced" to eat at least one of their meals in the provided hospital eating environment. If not in the hospital bed, then at the hospital ward, in the department living room or at one of the "public" canteen areas. In some cases, whether intentionally or not, patients are even required to eat food which they do not really like. Being a patient you are thus dependent on the kindness, favor, goodwill and service you meet at the hospital, not only by the specific staff but also to a great extent by the visitors, relatives and co-patients, as well as to some extent the entire management and political authorities behind the hospital who decide how the hospital runs (Holm \& Jacobsen 1990:18-19). In this situation, the patient has lost his or hers independence and selfdetermination, and due to the exposed situation experience a kind of dehumanization which makes them very vulnerable (Holm 2003:265). The interesting point made by Holm \& Jacobsen (1990:18-19), regarding my specific research problem, is that, because hospitals play a great part in consumption of daily meals among numerous patients, the patients' eating situation during hospitalization can be compared to Goffman's concept of the 'Total Institution' where patients become "inmates" because of an exposure to otherwise very private procedures performed by stranger in front of strangers (Holm 2003:266). Holm \& Jacobsen (1990:18-19) further argue that when hospitalized the patient is often separated from his or hers family, friends, and homely environment, taken out of the ordinary life and living situation, as well as removed from the places, objects, and people with whom you normally surround yourself. On top of this, the patient is sick, presumably not feeling well, might be anxious, nervous or fearful, and is often strongly dependent on the treatment, help and care provided by the staff at the hospital, as well as the daily procedures performed around them (Holm \& Jacobsen 1990:18-19). Generally, the patients have no influence themselves on what they are eating, where, when or how. Furthermore, the patients are living in close proximity to strangers and may not have any privacy. From a sociologicaltheoretical point of view, Holm (2003b:284) thus argues that the hospital design has influenced the children's nutritional well-being by staging social relations and creating mealtimes resembling a feeling of "home". Because the hospital interior architecture (or the architects) seemingly had "forgotten" about the mealtimes, the entire eating situation was worsened. Holm (2003b:284) elaborates upon this by pointing at how no specific places had been established to facilitate "proper" eating. Therefore, the patients had to eat either in the patient rooms, in the hallway or at the small tables located around the ward at display to all the persons (staff, co-patients or visitors) passing by. Due to poor interior design, the patients would not be facing each other when seated at these tables, but instead sitting next to each other - in line facing the wall in small kitchens without windows or ventilation.

Furthermore, the kitchens seemed more like storage rooms or transit spaces with visible garbage, dirty laundry, food in stored in large plastic wrappings and a series of "signs" communicating practical information on ward routines and safety (Holm \& Jacobsen 1990:27-29). In that way, the overall eating environment had no or at least very little sense of "home". Holm \& Jacobsen (1990:28), therefore, speculated that the old hospital environment thus typically isolated the children in the wards or in the hallways of the hospital department when eating (Holm 2003b:284). And the specific hospital design and interior architecture, in their point of view, thereby became a physical or material "sign" on the low priorities of patient meal times by the hospital (Holm 2003b:284). On this basis, the study tried to demonstrate that a new "meal space" focusing on encouraging social bonding possibly affected the nutritional wellbeing of the children as much as the specific food intake and food items eaten (Holm 2003:293). 


\section{NHS and Acute Care Hospitals, UK}

As mentioned in the introductory chapter, the problem of patient undernutrition does not only exist in Danish hospitals, but is seemingly a general problem in contemporary Western hospitals. Two English PhD theses called: Patient experience, nutritional uptake and satisfaction with hospital food services written by Heather Hartwell (2004) and: The effects of a hospital ward eating environment on patients' mealtime experience written by Paula Angela Shepherd (2011), respectively, investigate the problem of patient malnutrition in British hospitals. The PhD thesis originally described in Hartwell (2004) is further elaborated with minor studies presented in Edwards \& Hartwell (2004), Hartwell et al. (2006), and Hartwell et al. (2007). The research studies are based on the overall problem that even though substantial research evidence exists showing that eating in the presence of others can actually increase food intake, most patients in UK hospitals consume meals in solitude. The purpose of the research was, therefore, to perform a three step case study: (1) comparing the dietary data collected from patients consuming their meals either in bed, at the side of bed or in the presence of others (Edwards \& Hartwell 2004:324), (2) comparing plated versus bulk trolley food (Hartwell et al. 2007), (3) investigating general patient meal satisfaction (Hartwell et al. 2006). According to Hartwell (2004:18), her thesis focused on an embedded humanistic perspective studying subjects within context, contrary the dominating structuralist perspectives focusing on organizational and system theory. The result of her thesis is the development of a predictive model for patient satisfaction attempting to describe a holistic appreciation of hospital food service (Hartwell 2004:18). The studies performed by Shepherd (2011) focus on investigating the effects that hospital ward eating environments can have on patients' foodservice experience and raises the question of whether or not an enhanced eating environment could possibly help improve nutritional outcomes (Shepherd 2011:i). Shepherd (2011), like Hartwell (2004), based her studies on a case study approach, employing mixed methods in an exploratory research strategy comprising four major phases - patient interviews, patient questionnaires, stakeholder interviews and impact measurements of patients' food intake and mood.

The theoretical background of both Hartwell (2004) and Shepherd (2011) is based on an elaborate overview of the existing literature relating to research studies carried out on patient malnutrition, nutritional risk assessment, hospital food services impact on food intake, patient satisfaction and the importance of the social and eating environment. In continuation hereof, both Hartwell (2004) and Shepherd (2011) point at how several research studies investigating the effects of malnutrition in hospital patients indicate that the meal experience is an important contributor to a patient's morale. Relative hereto, Edwards \& Hartwell (2004) emphasize the importance of social facilitation and the importance and effect of others being present when eating. According to Edwards \& Hartwell (2004), the presence of others can increase levels of arousal and drive, or provide clues as to appropriate or inappropriate eating behavior. Furthermore, they emphasize that when meals are shared or eaten together more food is provided, the atmosphere might be more social, the food might taste better and the meal might last longer (Edwards \& Hartwell 2004:323). They found that the energy intake of UK patients consuming their meals in a social group around a common table was superior to the intake of those patients eating alone either in or at their bed (Edwards \& Hartwell 2004:324). The observation that patients will eat more (increase food intake) sitting around a table in a social situation, than when eating alone, is something, which according to Hartwell (2004:34) has also been suggested by Gibbons \& Henry (2003), Hotaling (1990) and Allison (1999). Thus promoting social aspects of eating can help prevent malnutrition, because mealtimes provide a platform for socialization (Edwards \& Hartwell 2004). However, it is, as Edwards \& Hartwell (2004:324-325) notice, unclear from the study why the social situation increases the energy intake of patients. According to Edwards \& Hartwell (2004:325), it is problematic ensuring that groups are similar when performing research studies in "live settings", where individuals have a free choice and are naturally individual. As argued for in the chapter, Research Approach, despite the researcher's effort not to manipulate the situation and to ascertain patients of similar physical condition, post recovery, and free choice as what to eat and where to sit, the researcher is not able to control every possible variable that influences the overall meal situation. The researcher has very poor chances of determining the influencing aspects like if the patients choosing to sit at the common table were more motivated and predisposed 
towards consumption of more food, or if some patients were more social by nature than others. On that basis Edwards \& Hartwell (2004:325) suggest that, even though space is limited, patients should be encouraged to eat their meals around a table in a social context, and it should be emphasized that social facilitation has the potential to address hospital malnutrition. Furthermore, they found that social facilitation should be used to promote meal times with the creation of what they call: 'ambient dining areas', away from noise, smells and other distractions associated with hospital wards, and where patients could consume their meals in company of others (Edwards \& Hartwell 2004:325). Relative hereto, Hartwell et al. (2007:212) state that in the UK there is no agreement among catering companies as to whether bulk trolley or plated systems are better. They base their statement on a survey performed by Hwang et al. (1999) among 192 acute care hospitals in the UK, showing that the bulk service could increase the quality of the food, the interpersonal aspects of the food service, as well as patients' satisfaction because the meal temperature could be controlled, problems with meal mass production were decreased and it allows patients to select portion sizes according to appetite and preference (Hartwell et al. 2007:212). According to Hartwell et al. (2007:212), in the study of Hwang et al. (1999) some felt though that the plated meal service contrary could ensure higher quality presentation as well as the service was kept at a higher standard. This detailed discussion on food service systems in hospitals, is important for my specific research problem, because it both indirectly and directly influence and the rituals relating to the meal servings as well as the manners in which the patients eat, and thereby ultimately the design of the eating environments. Hartwell (2004:52-54) thus identified and referred to a series of barriers to complete nutrition in hospitals, and pointed, among others, at how one of the major barriers in overcoming undernutrition in hospitals is the failure to deliver food in a manner appropriate to the particular patient. For instance inflexible meal systems, serving the food in an inaccessible manner (being wrapped or placed outside of reach), too large a portion and finally an unpleasant eating environment. Supporting this, Shepherd (2011:10) with reference to Naithani et al. (2008) stated that despite the majority of patients being satisfied with the quality of their meals, almost half of the patients felt hungry during hospitalization due to organisational, physical and environmental barriers like inflexible ordering systems and menu problems, uncomfortable position to eat or food out of reach, as well as interruptions, noise and unpleasant smells.

Shepherd (2011:11) continues her argument by pointing at how recent research suggests that the built environment plays a role in the prevention and reduction of psychological and social problems encountered by patients in acute care. She states that the quality of 'space' is not just created by the built environment but by the events and practices that make the 'space' hospitable and that mealtime provisions in hospitals therefore are crucial (Shepherd 2011:24). She further finds that even though hospitals try to deliver food following individual desires and needs, and the food itself is of the highest quality, if the presentation and delivery of the food is poor, the value is lost if they are not consumed by the patient (Shepherd 2011:11). With reference to Warner (2004), Shepherd (2011:19) argues that these ideas involve setting aside special time to make a ward ready for food services - creating a patientcentered framework for mealtimes, as is for instance in peoples' private homes. A literature review of food service provisions, nutritional care and meal environments in hospitals led Shepherd (2011:22) to conclude that a series of barriers to good nutrition has been identified, and whereas many focus on foodservice and reduced support from hospital staff, poor nutritional education and lack of knowledge, illdefined and ambiguous responsibilities and protocols, inappropriately timed clinical routines, poor nutritional assessment and lack of motivation among clinical staff, some studies also emphasize the importance of communication and the hospital environment (Shepherd 2011:22). According to Shepherd (2011:16), improving standards of patient nutrition and ensuring that patients actually eat thus involves far more than just the quality of the food on the plate. Food servings also involve levels of communication and must be measured by patient satisfaction and how that relates to the presentation and delivery of the food. Furthermore, according to Shepherd (2011:30), it has long been accepted that consumer behavior is influenced not only by tangible services but also by the "total product" being offered, including services, warranties, images and packaging. Relative hereto, Shepherd (2011:30) notes that Kotler (1973) suggested that the atmosphere of the place where the product is purchased can be more influential than the product itself for the consumer decision. 
In this type of research, the term 'atmospherics' or 'atmosphere' is commonly used to describe the sensory quality of the surroundings - the experience as perceived by sight, sound, scent and touch (Shepherd 2011:30).

What is curious from my architectural research point of view is that nowhere in the writings by Hartwell (2004) or Shepherd (2011) do they address the direct influence or arrangement of the hospital design and interior architecture beside the notion of patients eating either in bed, at bed side or at a common table. Nonetheless, in their final remarks and recommendations aimed at policy makers and managers of the hospital eating environment, this is extended to interior guidance - or what I also call 'basic design principles' - on creating 'ambient dining areas' away from noise, smells and other distractions associated with hospital wards. Shepherd (2011) thus highlights in her conclusion how it is clear that (1) malnutrition among hospitalized patients are still of very low priority, (2) the eating environment can influence the foodservice experience, (3) it is important to focus not only on the quality of the food but also on the manner and location in which the food is served, (4) a eating environment should be provided that incorporates elements of protected mealtimes in terms of removing distractions and interruptions, together with providing a space away from "bedrooms" and with opportunities for socializing and sharing mealtimes together, (5) hospitals should have dining rooms and ward hostesses facilitating the meals alongside the nursing staff. What I thus understand from the above-mentioned research studies is that the social facilitation of food intake by means of the architectural design, room configuration, interior layout, and specific choice of furniture guide and influence the social behavior and relations among the patients, also when eating and having a meal. However, as also noted by Paquet et al. (2008:604), although several research findings provide initial evidence for the importance of mealtime social interaction, limited guidance is offered for the development of environmental interventions. Instead of the term 'environmental interventions' from an architectural point of view, I find we could say that limited guidance is offered for how to design dining facilities that could support adequate food intake.

\section{SUB-CONCLUSION ON 'POSITIVE THEORY'}

As seen from the above, the literature review performed, with the Annotated Bibliography, on existing 'positive theory' showed that a vast range of research already exists across the distinct domains of health, food and architecture. All this research covers many aspects already, strongly indicating that something is at stake and that the built environment does influence our meal experiences and food intake and thereby indirectly also our health and well-being. What, for instance, the two models developed by Furst et al. (1996) and Delizia \& MacFie (1996) suggested was that human beings, when they interact with food products through their different sense modalities, receive stimuli that trigger certain memories of past experiences and, on that basis, create specific expectations towards the forthcoming food experience determining their food choice and presumably also their food intake. If these expectations are then met it triggers an eating satisfaction linked to a series of positive emotions and feelings possibly in the future being associated to similar eating situations through their material appearance. Based on the above Annotated Bibliography, which represents a quick review of a broad series of references, I find there are some very strong indications that human digestion - and particularly metabolism - is directly and indirectly affected by a stressing or unpleasant eating environment, and that the experience of this particular eating environment is partly governed by our engagement, perception and understanding of the qualities of the interior architecture. Consequently, the reviewed literature in that way supports my hypothesis that the interior architectural qualities of eating environments have an impact on patient food intake, health and well-being. However, in general only very few of the reviewed references related directly to a hospital context as well as included aspects of health, food and architecture simultaneously. Instead most of the reviewed references related to public eating environments established in restaurants, hotels, schools and universities, which I find constitute a more commercial and consumeroriented context. Therefore the more elaborate Integrative Literature Review was only performed on a very limited group of the reviewed references. 
Even though most of the above, closely reviewed studies mentioned how the interior architecture of eating environment influence patient meal experiences and the social relations established between staff and patients during mealtimes, none of the literature, in my opinion, pay much interest in a profound understanding of how the hospital design framing the eating environments influence the meal experience and sense of commensality among the patients. None of the reviewed literature in my point of view tried to define why the interior architecture of eating environments influence meal experiences, or define what the interior architectural qualities are that have an impact on patient eating experiences, food choices and food intake in general [Olsen, 2010:107]. Fewer refer directly to the importance of the interior architecture qualities of eating environment when considering food intake, health and well-being. They do not theoretically or practically describe or define how the specific interior architectural qualities are relevant for achieving this stage of social well-being and feeling at "home", or how the eating environment should be designed to achieve this feeling. I thus find that most of the reviewed literature missed to answer: Why a single grand table worked better than a small one? Why a common central kitchen worked better than decentralized units? And why colored glasses and china worked better than steal containers? How did these different interior architectural elements relate to the overall atmosphere and social interaction created?

Instead of clarifying some of these questions, it seems to me like most of the research and specific interior interventions conducted in the above-mentioned studies are based on common sense assumptions and a rather latent-intuitive basis, but also grounded in empirical data, rather than including any architectural considerations on the practical decisions on how the interior architectural qualities influence patient food intake, health and well-being. The findings have become research-based understandings that support each other in their common sense assumptions by referring to the same pool of "evidence" and literature. Together these studies provide bits and pieces or "clues" to the relationship of health, food and architecture. So, as with the examples of MORE and VEJLE, it can be argued that the question about what defines the interior architectural quality is still left unanswered, and seemingly a large knowledge gap exists here to be investigated or examined from an architectural research point of view [Olsen, 2010:105].

Research limitations to my literature review are, however, that a comprehensive account of past and contemporary scientific research is almost impossible to provide. In particular within the area of architectural design, very sparse amounts of scientific evidence exist as journal articles [Olsen et al. 2010]. As mentioned in the chapter, Research Approach, I can, therefore, not engage in an overall deductive research strategy employing the case study strategy to empirically verify an existing theory. I need to begin at a different level of understanding where I engage in the hermeneuticinterpretative research 'strategy' theorizing. I must, therefore, continue with an explorative research strategy so as to achieve a higher 'level of abstraction', and then use this theoretical framework in a deductive manner to establish a set of basic design principles [Olsen, 2010:112]. And this begins, as also argued for in the previous chapter, with a Historical Review outlining the highlights of the 'normative theory' rooted in the objects and theoretical practice of health, food and architecture. 


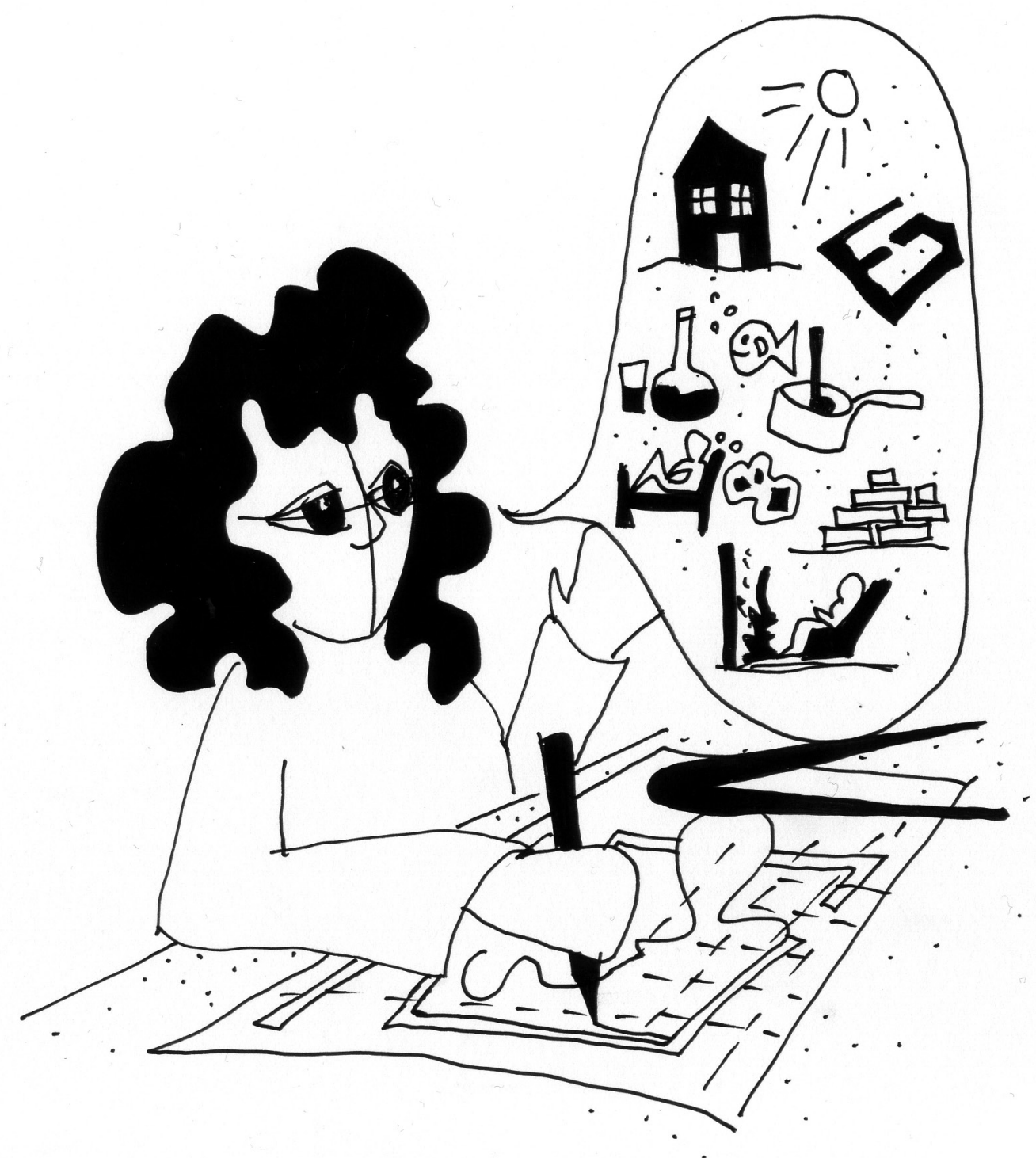

Fig. 6.1

"Normative Theory" Architectural Storytelling with three entries: health, architecture and food outlining key-objects and key-theories (Drawing adopted from Frascari 2011:37). 


\title{
"ANALYZING" \\ INTERPRETATION
}

6

\section{NORMATIVE THEORY}

\author{
THE HISTORY OF OBJECTS
}

In the previous chapter, I investigated how existing 'positive theory' describe the interior architectural qualities of patient eating environments on the background of an Annotated Bibliography and an Integrative Literature Review. As seen from the sub-conclusion of that chapter, a lot of literature exists which supports my hypothesis that eating environments influence food intake, health and well-being, whereas no 'positive theory' seemingly exists describing what the specific interior architectural qualities are of these environments, or how they should be designed to achieve a better food intake, health and well-being. I only have lots of indications and suggestions - or what I called "bits" and "pieces" - of a theoretical framework. Therefore, in this chapter, as argued in the chapter, Research Approach, I need to engage in a more explorative approach trying to establish a theoretical framework that can be used to outline a set of 'basic design principles' to help 'predict' the interior architectural qualities of patient eating environments.

As also argued in the chapter, Research Approach, this explorative approach is based on a hermeneutic-interpretive strategy, utilizing the specific tactics of a Timeline and a Historical Review to "map" the normative and polemical knowledge existing on past and present interior architecture related to health, food and architecture. Relative hereto, I find that a vast amount of literature exists performing a historical analysis of hospitals and relating the development of European hospital design to the progress of medical science and practice in Western medicine or healthcare (see e.g. Henderson et al. 2007; Henderson 2006; Park \& Henderson 1991; Leistikow 1967; Rosenfield 1969; Heslet \& Dirckinck-Holmfeld 2007; Granshaw \& Porter 1989; Adams 2008; Risse 1999; Verderber 2010; Siraisi 1990; Thompson \& Goldin 1975). Parts of this literature refute the arguments put forth by historians of medicine that changes in medical technologies, throughout time, are the only aspects that have influenced hospital designs. Instead these historians, in line with the arguments put forth by architectural historian Alberto Pérez-Gómez (2012) in the chapter, Research Approach, believe that more attention should be paid to the history of the wider context of hospital designs because hospitals as public institutions are the result of a complex "hybrid" of medical, functional, technological, social, cultural, economic, aesthetic and anthropological aspects (Adams, 2008:xviii; Henderson et al. 2007:43).

Furthermore a similar vast amount of literature exist relating to the history of interior architecture and the history of architectural theory, as well as the history of food, the history of gastronomy and the history of culinary theory. There is no way to include everything, and my historical review will, therefore, suffer from obvious biases and omissions no matter what I do. Still, the crucial question is how to choose, and what to choose, in this overwhelming pool of knowledge? Where will I find the normative and polemical knowledge needed to construct a"knowledge map" helping me 'predict' the interior architectural qualities of patient eating environments? 


\section{The history of hospital design}

The previously-mentioned Danish physician Lars Heslet \& architect Kim DirckinckHolmfeld (2007:19) begins their history of Danish hospitals and hospital design in the mid-18 $8^{\text {th }}$ century, with the era of Enlightenment, the French Revolution and the foundation of Det Kongelige Frederiks Hospital (The Royal King Frederik's Hospital) in 1757 . With this chapter, they argue that up until the mid-18 ${ }^{\text {th }}$ century illness and sickness had primarily been a private matter, and what were known as 'hospitals' back then had mainly been public institutions founded to house the insane, poor, leprous or people sick from plague. Otherwise it was an institution reserved the army and navy (Heslet \& Dirckinck-Holmfeld 2007:19). A frequently encountered statement regarding these "institutions" is that they were antechambres de la mort (death chambers) where people only went to die (Henderson et al. 2007:46). Apparently, due to the poor standards of the hospitals, when sick, most people would prefer to stay at home, being treated by family, friends, community members or the local medical practitioner, instead of going to the hospital (Granshaw \& Porter 1989:1). Today that cliché, though, is increasingly being rejected by hospital researchers such as the abovementioned. Because, a rich history exists recording that medical treatments and healthcare presumably were performed in public in the Middle East and Asia (Iraq, Iran, Egypt, Turkey, Japan and China) long before the establishing of the "modern" European hospital (Henderson 2006:339; Horden 2008, Verderber, 2010:19).

According to American Professor in design therapeutics and practicing architect Stephen Verderber (2010:11,19), archival records indicate examples of hospitals in Turkey, Saudi Arabia and North Africa located in urban centers near available water sources with pharmacy, dispensary, a social space, a library, and even a small mosque for patient use. But also because, according to previously-mentioned Rheumatologist Esther M. Sternberg (2009:3), the concept of public healthcare goes back at least to ancient classical times when temples to the Greek god of healing, Asclepius, were built on hilltops overlooking the sea. Here, presumably based on the philosophy of 'Humoral theory', which was established by Hippocrates arguing that disease was cause by an imbalance within the body and the four humours - blood, phlegm, choler and bile (Henderson 2006:304), sophisticated bathing facilities, therapeutic exercise, rest, nature views and nutritional support were vital elements in the treatment of diseases and illness (Verderber 2010:13). Furthermore, according to Sternberg (2001:1-4), challenges of human health and well-being have always been around. In the Western world, there are examples of myths depicting how religious-based medicine and "healing" on the background of a strong belief in the supernatural powers of gods caused ancient priests, oracles, sorcerers and shamans to perform sacred or spiritual rituals using prayer, music, food, sleep and dreams to cure the sick (Sternberg 2001:1; Verderber 2010:13). Relative hereto, Verderber (2010:10) divides his history of western healthcare environments according to the major developments in medical and therapeutic thinking, and arrives at the following primary "movements" of interest for hospital design: The Ancient, The Medieval, The Renaissance, The $19^{\text {th }}$ century (Nightingale movement), The Modern (Megahospital) and The Contemporary (Sustainable Healthscape).

What I understand from the above brief review of the history hospital design is that being treated and cured from sickness has often not only been a matter of medical or surgical treatments performed in a hospital, but a matter of the entire scenery established around the patient; for instance, with the architecture, food and healthcare during hospitalization as well. Furthermore, inspired by Adams' (2008) and PérezGómez's above arguments, I understand that this scenery must be understood on the background of the history of the wider context and the preceding architecture relating not only to hospitals, but presumably also to healthcare, food and architecture in general.

In my Timeline and Historical Review, I must, therefore, in line with the timeline provided by Verderber (2010) ideally begin with the context of the first hospitals and the first eating environments, but also the first examples of architecture and architectural writing to understand the thinking and doing that throughout time has influenced the contemporary interior architectural qualities of patient eating environments. I find this time span is further supported by the series of "clues" provided my in the Preface, Introduction and Research Approach - such as the period between 1750-1950 
emphasized by Collins (1965) as the era of radical changes in architectural ideals. But also the Gastronomic Analogy and the statement put forth by James Fergusson about the writings from Vitruvius to Pugin and practice of the chefs Soyer and Mrs. Glasse, which indicate that I have to investigate the history of architectural theory, the history of gastronomy and the history of culinary theory stemming from the periods of ancient Rome and the $19^{\text {th }}$ century. Finally, the contemporary tendencies in Neuroscience, Healing Architecture and Evidence-Based Design influencing not only architectural theory but also architectural practice, as seen with the example of the Danish super hospitals, indicate that I have to look at the present time.

On the background of the above my Timeline thus outlines major developments in the history of eating environments established both in domestic and public domains, as well as major developments in the history of healthcare design. The history of both eating environments and healthcare design follow the eras suggested by Verderber (2010), thereby being divided into the following five overall periods:

The “Ancient" (c.400,000 BC - 500 AD)

The “Medieval" \& "Renaissance” (c.600 - 1750)

The "19"th century" (c.1750 - 1920)

The “Modern" (c.1920 - 1995)

The “Contemporary” (c.1995 - 2013)

Each period is introduced with a map highlighting the places, which in my point of view, represents a kind of "state-of-the-art" thinking and doing of that specific period. This is with the overall purpose of positioning the 'normative theory' and the 'polemical theory' in a geographical context but also illustrating the, in my opinion, inherited connections possibly existing in architecture across time and place. Furthermore each period in the Timeline is structured by three overall "entries" to the research topic. These are:

\section{“Health"}

Outlines the major developments relative to 'normative theory' on hospital design. Herein breakthroughs in healthcare history with key diseases, key hospitals and key developments in the "styles" of hospital architecture.

\section{"Food"}

Outlines major developments relative to 'normative theory' on eating environments. Herein breakthroughs in culinary history with key chefs, key culinary writers and key developments in the "styles" of dining room interiors.

\section{"Architecture"}

Outlines major developments in 'polemical theory' in architectural history. Herein key writers, key architects and key theories influencing the above 'normative theory' on hospital design and eating environments in the history of architecture. 
The Historical Review in continuation hereof introduces my attempt towards a synthesis of the historic developments of eating environments and healthcare design into a "knowledge map" illustrating the history of the interior architectural qualities that might govern the context of patient eating environments. My "knowledge map" has been created on the background of, first of all, a review of a series of history books covering respectively the history of architecture, interior design, gastronomy and hospital architecture, as well as literature collecting key polemical texts on architectural theory, interior theory and culinary theory. The purpose of my Timeline and Historical Review have, therefore, not been to make a precise and chronological portrayal of the historical development of healthcare design, eating environments or architectural theory, but instead provide a possible outline exemplifying what normative and polemical knowledge possibly exist on the interior architectural qualities of patient eating environments inherited from our past.

With the three entries; health, food and architecture, I have, therefore, tried in a deliberate "eclectic" manner to select examples that by no means are representative for the development of common healthcare design or everyday eating environments around the world. These examples are, in my point of view, state-of-the-art, developed in a European context, chosen for their exceptional approach to healthcare and eating.

However, as noted by Risse (1999:4), it is an almost impossible task to outline the historical development of hospital design - and in my case also of eating environments - without risking portraying each of the topics as over-simplified phenomena. There is not one type of hospital design or eating environment. Presumably every hospital and eating environment is different from each other, specifically by means of their particular context; the location, surroundings, architecture, interior, and users. The different divisions of 'Ancient', 'Medieval \& Renaissance', '19th century', 'Modern' and 'Contemporary' are as such general abstractions or constructed ideas I develop with the Timeline and Historical Review. Thereby the different sources represent normative and polemical knowledge, rather than positive knowledge. 

Fig. 6.2

"The Ancient"

Traces of small huts and cooking on fire position the first civilizations to the time around $7000 \mathrm{BC}$.

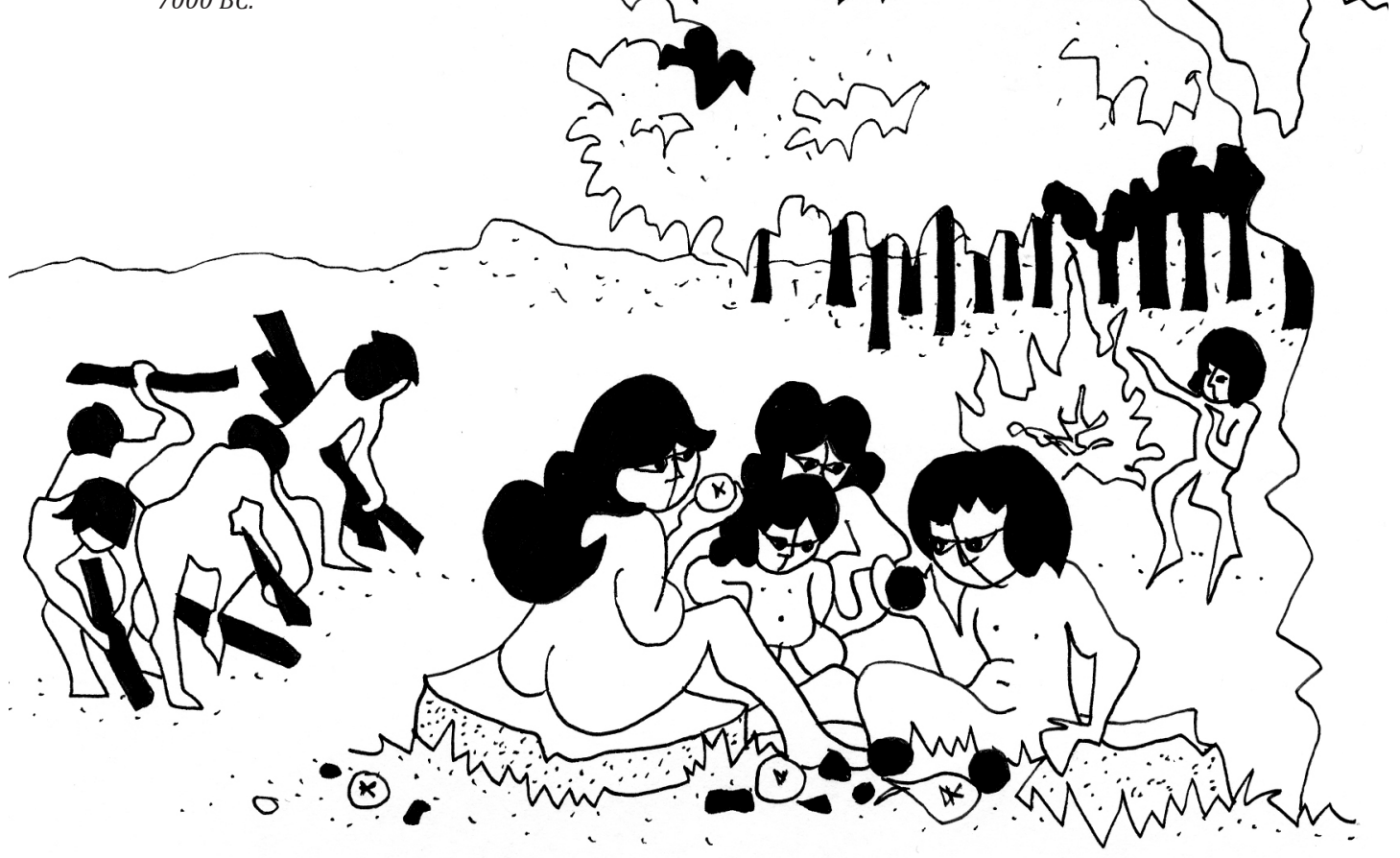

\subsection{0 years old}

Traces of small huts presumably erected in wood are among the oldest signs of human building activity stemming from tribe cultures in Terra Amata in southern France (Pile 2009:15).

\section{c. $150.000 \mathrm{BC}$}

First indications of cooking food by use of baking in the sun and earth ovens (Fernández-Armesto 2002:4).

\section{c. $10.000 \mathrm{BC}$}

Excavations of Ukrainian hearth suggests roasting of meats (Toussaint-Samat 2009:9,66).

\section{c. $7000 \mathrm{BC}$}

Traces of agriculture, farming and pottery vessels for perfume found in Syria, Mexico, Middle East and Asia (Toussaint-Samat 2009:10,37).

\section{c. $4000 \mathrm{BC}$}

The first larger cities with monumental buildings and dwellings were erected in stone and clay, in the area surrounding the Nile (Pile 2009:19; Watkin 2000:9).

\section{Mid-10th century BC}

The Temple of Solomon built in Jerusalem by King Solomon. It was presumably destroyed in $586 \mathrm{BC}$ by Babylonian Nebuchadnezzar. The earliest records of architectural thinking in the Western World relate to the old religious Hebraic traditions recorded in the Old Testament (Mallgrave 2006:xxiii,15).

\section{Late 7th and 6th century BC}

The Old Testament from I Kings constituted one of the eight books of the Prophets in the Hebrew canon. It contains according to Mallgrave (2006:15) some of the oldest descriptions of architecture with the notions on the Temple of Solomon.

\section{c. 5th century BC}

The Greek god Asclepius, son of Apollo, with his two daughters Hygeia and Panacea symbolized all the essential in a balanced health and well-being, and is therefore considered the god of medicine and healing in ancient Greek religion (Sternberg 2001:2; Verderber 2010:10).

\section{5th century BC}

Ancient Greeks believed that emotions and health were linked. The Asclepieion was a healing temple built in favour of the sacred god Asclepius built several places in ancient Greece, for instance the Asclepieion of Epidauros in Athens or the later Asclepieion at Cos and Pergamon. The Asclepia were built on lower slope of hillside, near a water source, with residential and commercial zones situated in-between. Furthermore, some of the Asclepia had sophisticated bathing facilities for patients, a combination of large tubs and mud baths, sacred spring, courtyard heated sub-flooring systems which would presumably closely resemble contemporary wellness (Verderber, 2010:13). Finally, there was a strong emphasis on a regimen of communality with nature and the outdoors, focus on therapeutic exercise, respite, water, vegetation, sunlight, improvements in nutrition and immersion in landscape, as well as bed rest and medications (Verderber, 2010:13). 
Fig. 6.3

"The Temple"

The God Asclepius was a symbol on the balance of a healthy diet, pure water, exercise, and support of friends and family, as well as the calming activities of sleep, music and prayer (Sternberg 2001:3).

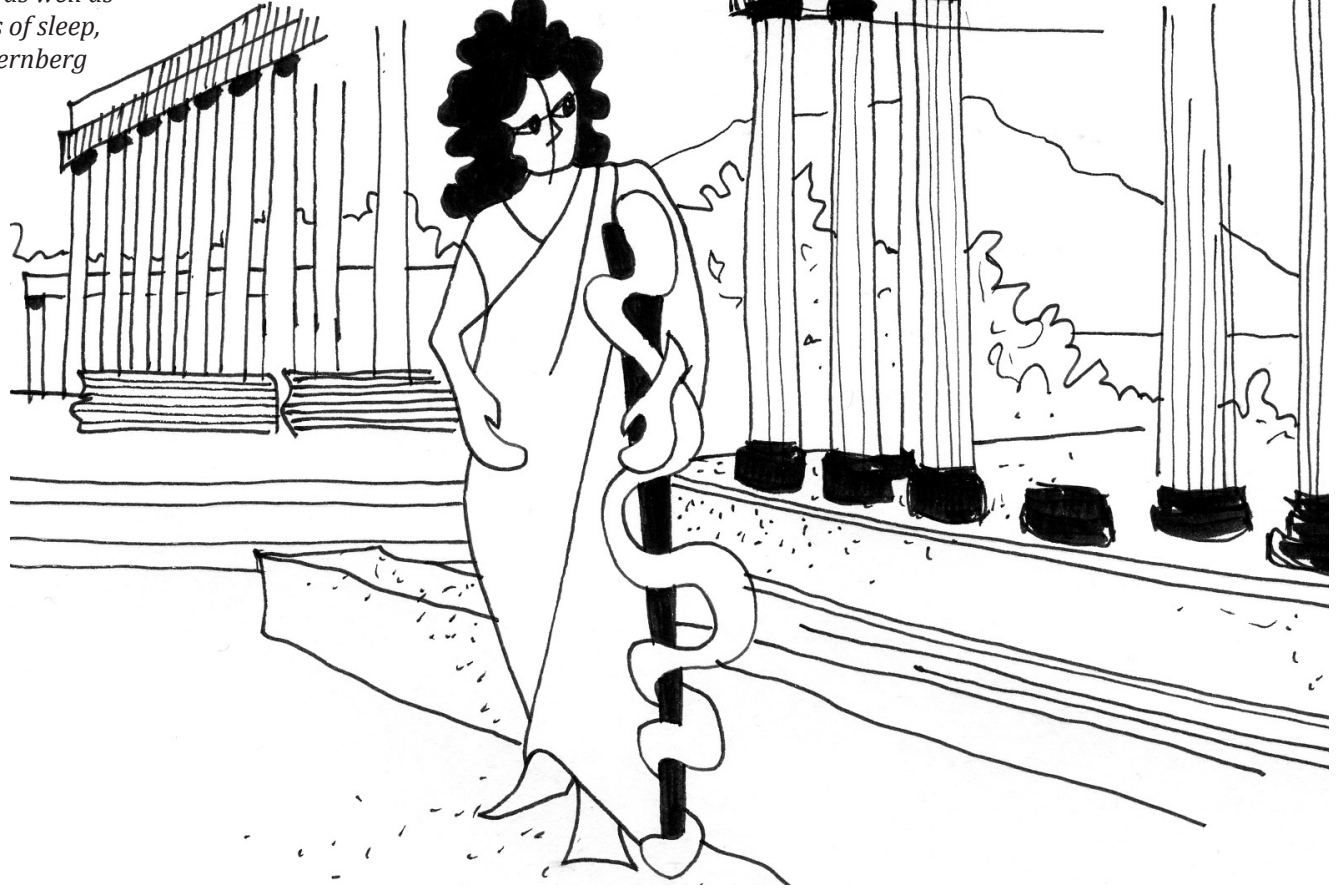

c. $430 \mathrm{BC}$

The Plague of Athens was an epidemic that hit Greece. The Plague presumably returned both in 429 and $427 / 426 \mathrm{BC}$ as well (Wikipedia 2013).

\section{c. 460 - $370 \mathrm{BC}$}

Hippocrates was the first to systematically distinguish medicine from philosophy and is thus considered the "father" of modern medicine. He argued among others that the physician must possess a strong understanding of the climatic and environmental influences upon human health. Furthermore he developed the theory of the Four Humours, and is considered the founder of the Hippocratic Schools of Medicine establish at Cos where his teachings of "physicians" combined the supernatural with the rational (Verderber 2010:10-11).

\section{c. 350 BC}

The Greek philosopher Aristotle (384-322 BC) is considered one of the first to write about aesthetics, science and politics (Oxford Dictionary of Philosophy 1994:24).

\section{c. $300 \mathrm{BC}$}

The Greek mathematician Euclid wrote the book(s): Elements, which describe plane theory and solid geometry. This is considered the foundation of Euclidean geometry and Euclidean space (Oxford Dictinonary of Philosophy 1994:126).

\section{c. $25 \mathrm{BC}$}

The Roman architect Marcus Vitruvius Pollio (c.80-15 BC) writes the treatise: De Architecture (The Ten Books on Architecture, c.25 $\mathrm{BC}$ ) where he identified three guiding principles for the design of architecture: firmitas (durability), utilitas (convenience) and venustas (beauty) (Mallgrave 2006:6). Vitruvius is generally considered the "father" of architectural writing, however, according to Mallgrave (2006:xxiii) Vitruvius was writing on the basis of a theoretical tradition going back at least five centuries before him. Unfortunately all these texts have been lost. In book I he comments on the education of the architect emphasising the importance of knowledge on medicine and the healthiness of sites and waters, and in book VI and VII he made notes on the proper exposure and interior design of the outdoor and indoor dining rooms of the Roman Villas (Triclinium or Stibadium ) (Verderber 2010:13, Morgan 1960:10,181-189,208-210). 


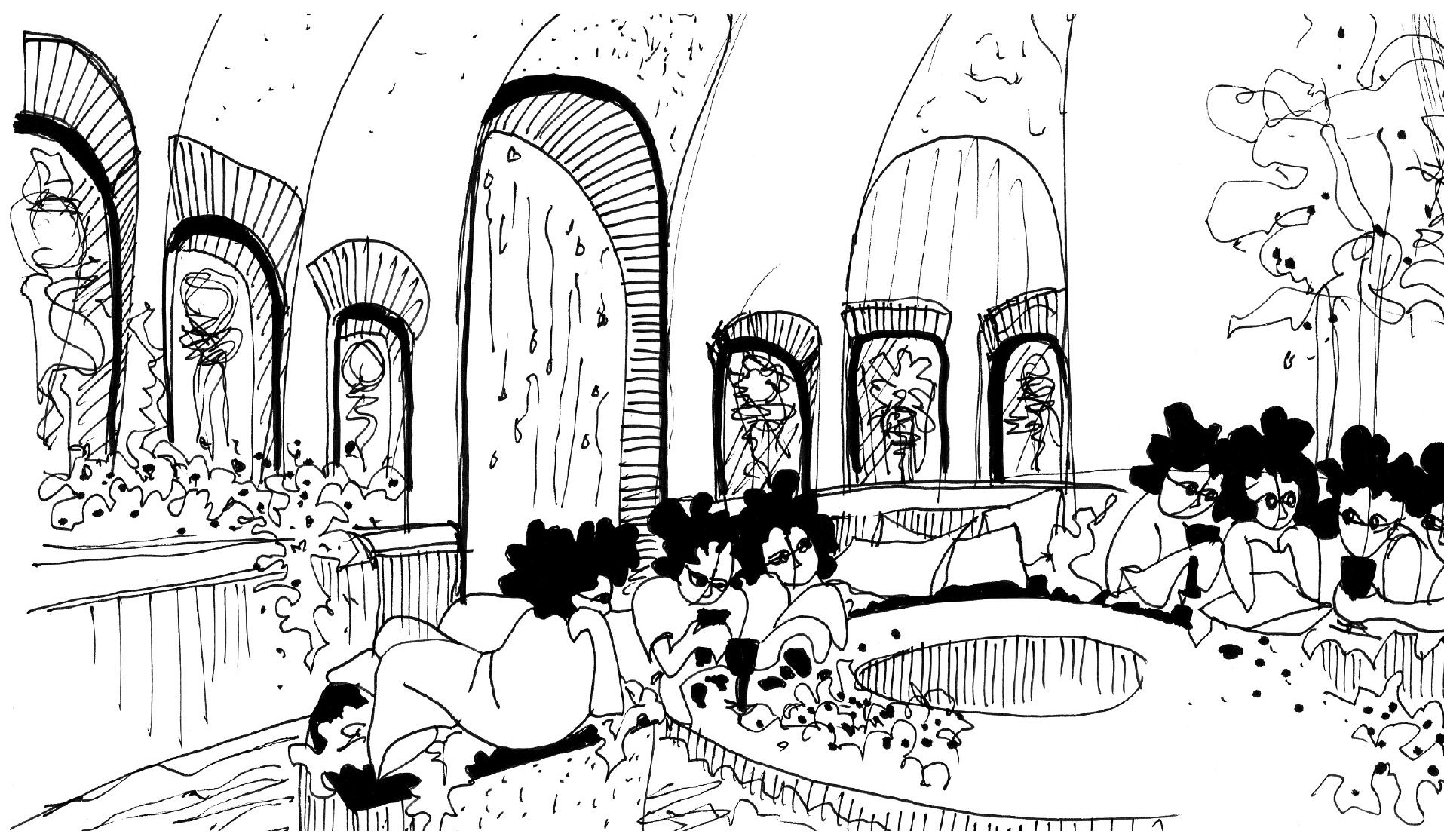

GALEN CLINICAL MEDICINE

\section{c.25 BC -118 AD}

The Triclinium or Stibadium are also known as the formal dining room of the Roman Villas in the Antique era. Here the term triclinium is adopted from the Greek triklinion originally deprived from triand kline- meaning a couch. The Triclinium is characterized by the lecti, which are a formation of three couches forming a horseshoe surrounding a small centered table (mensa). Contrary the Triclinium the Stibadium is a semi-circular formation of in-built couches around a central table. Both the Triclinium and Stibadium allow space for nine persons (three on each couch). The couches slope away from the table and diners would thus recline on the couches in a semirecumbent position. The fourth side of the arrangement was left free to allow for service of food and drinks. The guests were arranged in a prescribed order, emphasizing the social status and division of the attending persons. The left couch (lectus medius) was reserved for the distinguished guests, where the most noble space of the them all was the locus consularis. Usually the host and the most noble of the guests was placed closely to each other, leaving the right couch (lectus summus) for the lesser important persons of the party. Each couch was presumably firmly furnished with pillows and large blankets to assure the comfort of reclining while eating (Curl 1999:682; Fleischer 2007:414; Strong 2002:28; Olsen 2008:320). During the Roman era particular wealthy personalities would entertain important guests (business partners or war associates) with grandiose feasts in such dining rooms. Here food and drinking were part of a spectacular event comprising performances of dancing, music and poetry recitation in highly decorated settings. Archival records and excavations show that these dining interiors were theatrically staged with spectacular views to gardens and atrium with water fountains and pools. The wall surfaces of the dining room were presumably decorated with complex perspective scenes, central paintings and mosaic floorings depicting various spiritual and religious scenes (Strong 2002:28; Hannestad 1979:86-89, Bek 1983:82-85)[Olsen 2008:viii].

\section{c. $79 \mathrm{AD}$}

The Roman city Pompeii is partly destroyed and buried under the ashes of the eruption of Mount Vesuvius. However, aarcheological evidence from the excavations at Pompeii indicate that already during the Roman era street kitchens and public guest houses existed serving a hot meal (Hannested 1979:14-15).

\section{c. 129 - $216 \mathrm{AD}$}

Galen arrives in Rome around $162 \mathrm{AD}$, his writings, influenced by Hippokrates, came to influence an era of rational medical philosophy free from superstition and beliefs in the supernatural up until the Renaissance (Verderber, 2010:13). According Verderber (2010:13) Galen argued that the "physician" had to understand the human physiology, anatomy, and pathology applying logic to be able to analyse "proofs" and to avoid fallacies, as well as be trained in ethics.

\section{c. 165 - 189 AD}

The Antonine Plague was a pandemic that hit the Roman Empire presumably from the Near East which Galen described in his treatise: Methodus Medendi (Wikipedia 2013). 


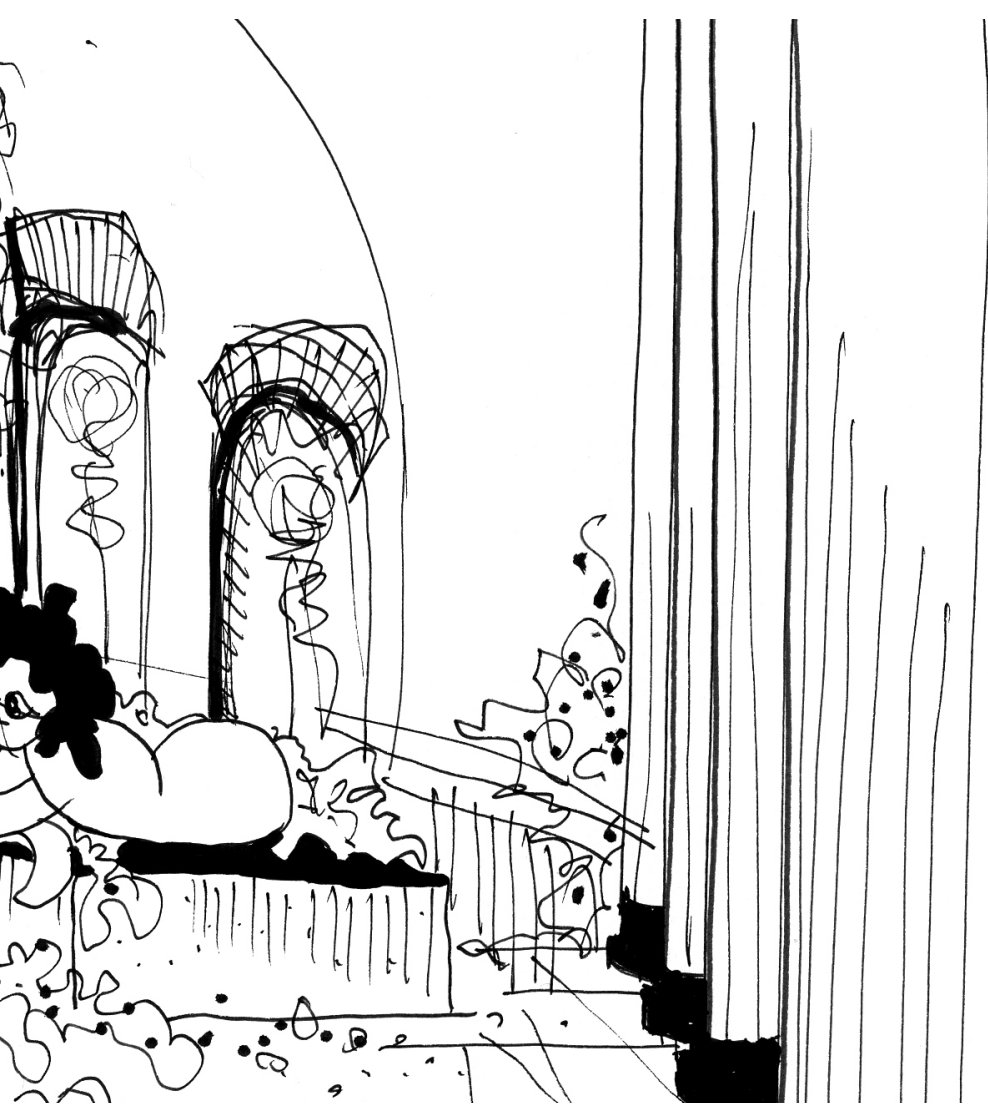

Fig. 6.4

"The Triclinium"

A spectacular example of the Roman dining room is the grand Stibadium established at Hadrian's Villa where cascades of water presumably ran out of the built-in furniture into a large pool and canals surrounding the entire scenery while eating. Here the food presumably was served on the edge of the pool and at small tables flanking each person [Olsen 2008:118].

Late 1st century BC - 3rd century AD

Another health related architectural setting in Roman architecture was the Roman Bath also referred to as the balnea or thermae, such as the Great Baths of Diocletian (late 3rd century AD), Caracalla (early 3rd century $A D$ ) or from Pompeii (1st century $B C$ ). Here a complex mix of courts, atriums, cambers and courtyards framed different types of baths with steam, cold and warm pools with advanced sanitary systems, massive aqueducts and indoor plumbing transporting fresh water from natural hot springs, as well as removal of waste water (Verderber, 2010:13-14). Archival records, from among others Pompeii, indicate that these settings were highly opulent in their ornamentation of wall surfaces, use of materials and architectural detailing. During the Roman era these settings evolved into large-scale building complexes present in most cities. The public baths became important social epicentres in Roman society, combining core civic functions of personal hygiene, spiritual worship, social interaction, enjoyment and entertainment with wellness in one single location. Here patrons stayed on a daily basis, engaging in exercise such like running, weight lifting, wrestling and swimming or body treatments with oil. According to Verderber (2010:14-15) the Roman Bath thus became civic monuments, used by everyone, built by Emperors to create a lasting memory, and a modern equivalent would probably be a combination of library, art gallery, mall, bar/ restaurant, gym and spa.

\section{Late 4th century AD}

The Roman cookery book: De re coquinaria (On Cooking) by M. Gabius Apicius is one of the earliest to survive. It contains 417 recipes divided in 11 books with titles like The gardener, Of Birds, The Sea and The Fishermen which derive from ancient medical sources (Strong 2002:22).

\section{4th/5th century AD}

The fall of the Roman Empire (Verderber 2010:17)

\section{c. 541 - 542 AD}

The Plague of Justinian was a pandemic the hit the Byzantine Empire (Wikipedia 2013). According to Verderber (2010:17) the Medieval era is often characterised not only by the fall of the Roman Empire in the 4th century and the following chaos that this event brought upon Europe, but also by the extremely deadly epidemics and pandemics such as plague that swept through European cities and wiped out entire communities in a very short time. 


\section{FROM HUT AND POT TO TEMPLE AND TRICLINIUM}

As seen in the Timeline, my interpretation of the history of patient eating environments begins with the myths of the hunters and gathers of ancient civilizations. According to most of the reviewed historical literature, very sparse knowledge and empirical evidence exist revealing how the ancient civilizations lived, what they ate and not least what their "interior architecture" looked like. Most architectural literature speculate that they lived either in small huts, caves or even tent-like structures, presumably erected in wooden branches, natural fibers and animal skin (Pile 2009:15). Not until around 4,000 years BC do larger cities with buildings erected in stone and clay appear in the area of the Nile (Pile 2009:19; Watkin 2000:9). Culinary literature in continuation hereof notes that despite bones and burned nut shells have been found on excavated sites, there is no clear evidence of when the ancient civilizations began cooking their food by, for instance, roasting on spits or boiling with hot stones in pots made of skin. Historians thus speculate that before the $15^{\text {th }}$ millennium BC ancient civilizations were primarily hunting for game or gathering foods by picking plants and wild vegetation (fruits, berries, nuts, seeds, roots etc.). Presumably, these plants were then used both for nutritional and medical purposes (Toussaint-Samat 2009:9,35,66). During the $7^{\text {th }}$ millennium BC, agriculture emerges in parts of Asia, and traces of farming and cultivation of beans have been found in both the Middle East and Mexico from around that same period (Toussaint-Samat 2009:37). Throughout the next three millennia, the different ancient civilizations' growth in mechanical advancements, knowledge, skills and craft brings not only an extraordinary development in agriculture and farming but also in cooking, healing and building.

Anecdotal literature and archaeological excavations stemming from the ancient Greek and Roman eras thus demonstrate how the primitive meals prepared in the era of the "hut" and "pot", around the $5^{\text {th }}$ century BC, have been refined into grand banquets and grandiose feasts held among the higher aristocracy in spectacular temples. The Greek Symposium and the Roman Convivium, which were both elegant dining ceremonies with great social importance (Strong 2002:24), are material manifestations of this where lavish interior architecture together with the special arrangement and serving of luxurious foods composed multi-sensuous meals. The Triclinium at Villa Hadrian near Tivoli in Rome, Italy is a significant example of this. Here, landscape, water fountains, choreographed waterworks, grand building structures, spectacular interiors and built-in furniture constitute a semi-open dining hall which main purpose, presumably, was to impress dinner guests with a sublime and extravagant meal experience (see Figure 6.4, The Triclinium) [Olsen 2008:28]. Very little evidence exists providing any precise descriptions of meals taking place in the particular Triclinium or Stibadium of Villa Hadrian. However, archaeological evidence from the Roman cities of Pompeii, Ostia and Herculaneum as well as a series of Roman texts refer to the spectacular feasts held during the Roman era by the Emperors Julius Caesar, Vitellius, and Nero (see e.g. Strong 2002:3-23,28-43; Hannestad 1979:7-9). Concerning the Roman banquets, English art historian and writer Sir Roy Strong (2002:7) and Danish historian and archeologist Lise Hannestad (1979:117-127) tell how recitation, music, dance performances as well as serving luxurious foods and rare delicacies such like oysters, scallops, boar, pomegranate and exotic spices like saffron in an elaborate theatrical manner merged the meal experience with the sensory experience of the interior architecture of the dining hall [Olsen 2008:28-29]. As mentioned in the above, during the Greek and Roman era the healing of illness and diseases was presumably performed in temples based on the ideals of the holistic medical theory of the 'Four Humours' developed by Hippocrates and Galen. Here, the importance of bathing rituals and nutritional support together with a strong sensibility towards climate, nature and built environment guided the everyday healthcare practice. This holistic approach to health and well-being was further seen in the entire set-up of mealtimes where bathing rituals, protection against climate with textiles and fabric screens, stunning nature views and the interior decorations of the Triclinium likewise were closely related to the meal rituals and the desire to achieve a "perfect balance" in life (Strong 2002:24). 
$\underset{\checkmark}{\checkmark}$
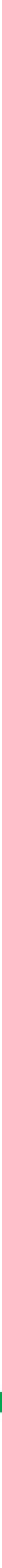


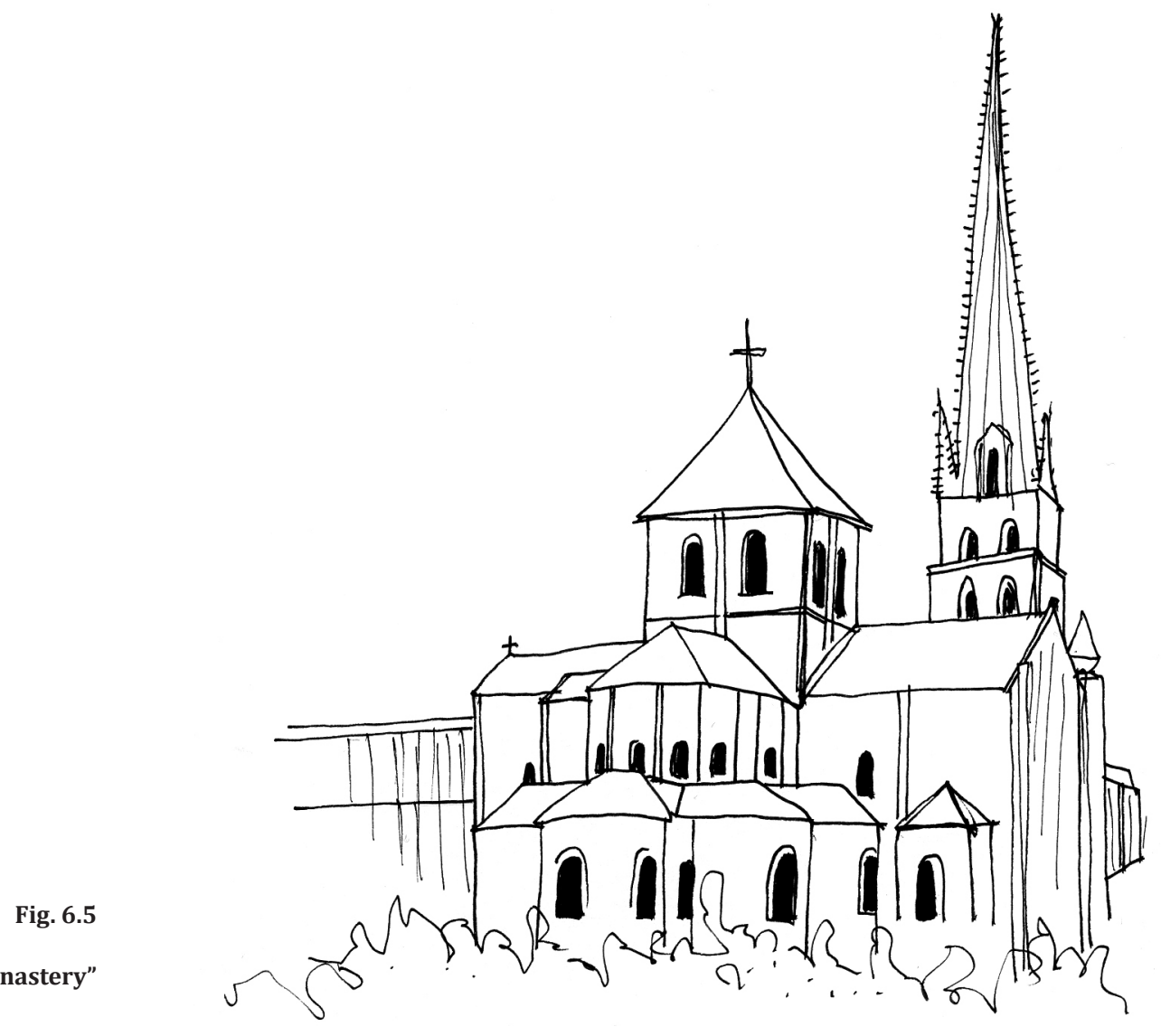

"The Church and Monastery"

\section{c. 707 - $878 \mathrm{AD}$}

Records of Islamic institutes for sick indicate some of the first outpatient hospitals in the Byzantine. Presumably these hospitals covered a broad range of treatments and social healthcare, not necessarily medical or surgical treatments performed by doctors, but resembled more a hospice or asylum working as part Inn/ part infirmary where poor, sick, orphans, pilgrims, mentally ill, insane, leprous and other social outcasts could stay (Horden 2008:I,46-48; Granshaw \& Porter 1989:21; Verderber 2010:17-19).

\section{c. $829 \mathrm{AD}$}

The hospital Hôtel-Dieu in Paris is mentioned in archival records. During the Middle Ages is became the largest hospital in France (Leistikow 1967:26).

\section{0 - 1550}

More than 60 monastery hospitals were founded in Florence. Particularly around 1250-1300 there is an increase in hospitals. About 30 of these 60 hospitals according to Henderson (2006:5) survived well into the 16th century. And one of the largest of these hospitals was Santa Maria Nuova (from 1500), a hospital functioning in Florence into the 21st century (Henderson 2006:5).

\section{c.1136}

Pantokrator established in Constantinople by Emperor John II Comnenus and his wife Irene. Here a hospital was part of a larger monastery supplying sick and injured with clean beds, proper food, care and regular medical treatments (Horden 2008:51-52). However, some researchers think that this building is just an ideal or fantasy never realized, but only existing on a piece of parchment (Henderson et al. 2007:65).

\section{c. 1144}

The French Abbot Sugar (c.1081-1151) with the book: Libellius Alter de Consecratione ecclesiae sancti Dionysii (The Book of Suger:Abbot od Saint-Denis, c.1144). The importance of geometry and proportions, as some of the basic symbolism of the church are evident (Mallgrave 2006:22). With the rebuilding of the Carolingian pilgrimage church, he presumably is part of the birthplace of Gothic architecture (Mallgrave 2006:22).

\section{4}

Records of hospital in Damascus (Verderber 2010:19)

\section{c. 1175}

Records of hospital at the Danish monasteries at Øm in MidJutland and Æbelholt in North-Zealand (Christiansen 1973:5, Leistikow 1967:20).

\section{c. 1181}

The Danish botanical and medical author Henrik Harpestreng (c.1164-1244) wrote Liber herbarum (herb book) which is considered the oldest Danish translation on botany. It included a long list of herbs used both for medical and cooking purposes (Christiansen 1973:5). 


\section{9th century AD}

The plan of St. Gall was a plan presumably made for a grand monastery encompassing a hospital. Various interpretations of this type of monastery were built as medical centers all over Europe, particularly in France, Northern Italy and England during the medieval era (Verderber, 2010:17; Granshaw \& Porter 1989:56). The religious affiliation is reflected in the interior architecture of these hospitals. Here patient wards were based on cross-plan and a church interior encompassing a centrally positioned alter and altarpiece so the patients could overhear mass every day from their bed, and the staff had clear sight of all the patients simultaneously (Granshaw \& Porter 1989:28,76; Henderson et al. 2007:182). Here medical thinking is strongly influenced by the "Christus medicus" and treatments was characterised by bloodletting and a belief in the "Seven Works of Mercy" who governed the religious-based and faith-based care performed by the monks and nuns (Verderber, 2010:17; Henderson 2006:335, Henderson et al. 2007:182). Redemption and salvation (if not recovery) according to Verderber (2010:17) correlated with a diminished belief in nature and landscape as important factors in treatments of the social misfits, undesirables, disfigured, disabled, and infirm who were sentenced to these public health "institutions" by public decree. Most of these hospitals encompass besides the patient ward, a church, monastery, kitchen, pharmacy and were self-sufficient, autonomous institutions producing all their basic necessities of daily life from operated farms onsite or nearby, which raised livestock, had land devoted to agriculture, growing vegetables, fruits and herb-gardens. This self-sufficiency was of critical importance, not only for producing the medicine and food used, but also for securing the income of the monastery (Verderber, 2010:17). Horden (2008:143-144) defines Medieval hospitals as "total non-natural environments".

\section{c. 1286}

The Hospital Santa Maria Nuova was founded in Florence in Italy. Here like in the other monastery hospitals it was the aim of the medical practice to restore the body to its proper balance with the use of the so-called "non-naturals" (such as exercise, food and drink, sleep and emotion). So by providing the right diet and securing air supply, proper temperatures and good physical surroundings the health of the patient could be administered (Henderson 2006:xxix-xxx,14). As also mentioned in Tvedebrink et al. (2013a, see appendix) particularly interesting for Santa Maria Nuova is according to Henderson (2006:65,203-207) that the many account books from the hospital show a large number of chickens used to produce a simple nourishing broth for the sick. This "chicken broth" was regarded as an essential element in the medical treatment procedures. Every day during mealtime, before the regular meals were served, the chicken broth would be served by a servant to the seriously ill by the sound of a bell. Henderson (2006:204) describes how the chicken broth in an almost ritual manner is brought into the patient hall in a grand pot and ladled into cups with a serving spoon. A nurse then has a brass basin that holds a napkin and two cups - one for the broth and the other containing water with lemon and damson. The cups are carried to each bedridden patient, who then drinks the broth, washes his mouth with the water and afterwards wipes it with the napkin (Henderson 2006:204).

\section{4}

Records of hospital in Cairo, Egypt (Verderber 2010:19).

\section{c. 13th century}

A series of monastery hospitals are founded in Western Europe, particularly in England and France. Among the English hospitals are St. John in Canterbury (Kent), St. Nicholas in Salisbury (Wiltshire), monastery of Lewes (Sussex) and St. John in Winchester (Hampsire). Other West European hospitals were Hôspital St. Jean in Angers (Makne-et-Loire), St. Janshospitaal in Bruges (West Vlaanderen), Hôspital La Biloke in Gent (oostVlaanderen), Hôspital Notre Dame des Fontenilles in Tonnerre (Yonne), Heiliggeist-Hospital in Lübeck (Schleswig-Holstein), St. Mary's Hospital in Chichester (Sussex) and Hôtel-Dieu in Beaune (Côte-de'Or) (Leistikow 1967:27).

\section{4th century}

The Black Death, a plague pandemic hitting major parts of Europe and presumably killing between $75-200$ million people (Wikipedia 2013). 


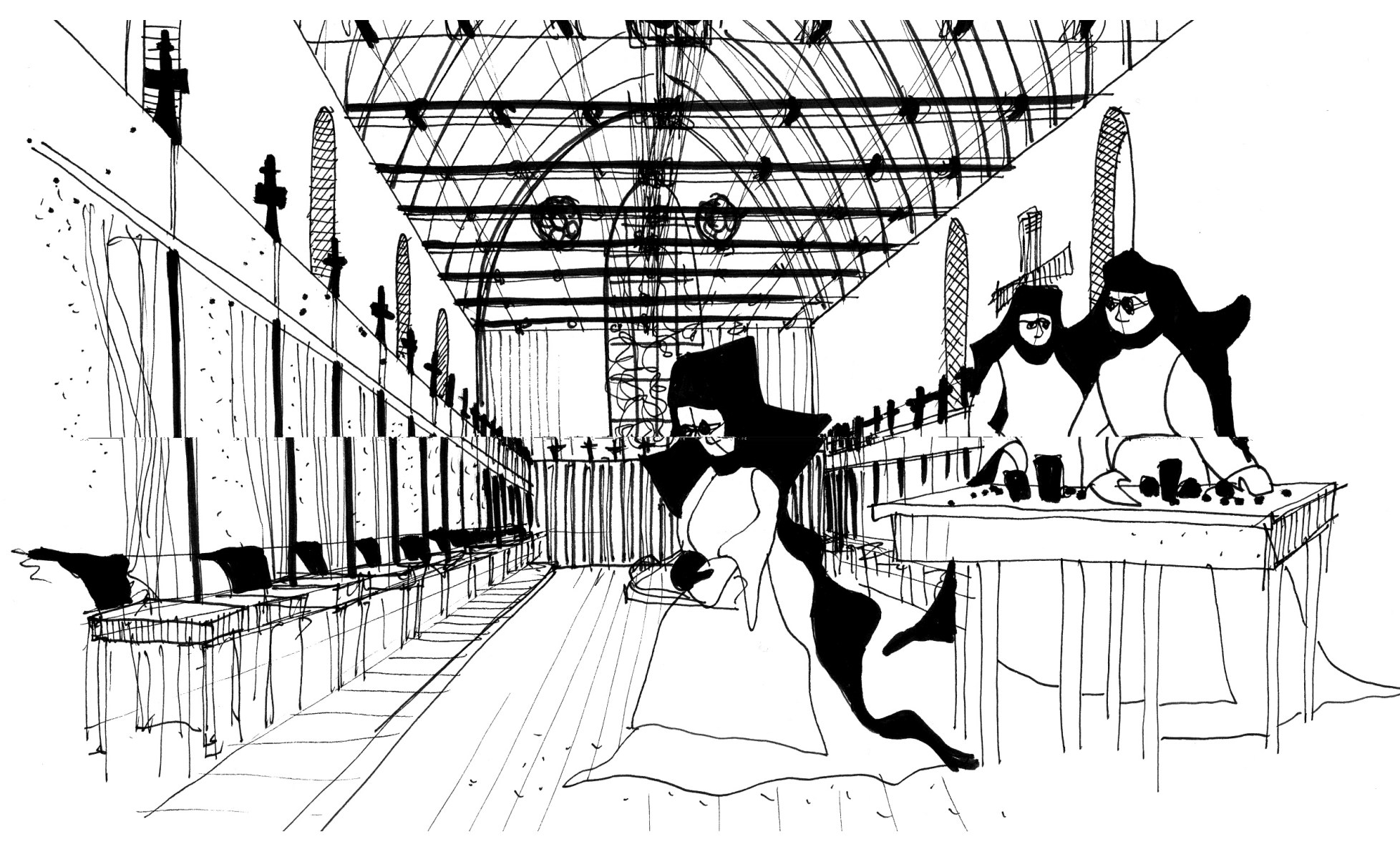

\section{9}

The Ospedale Innocenti (Hospital of the Innocents) in Florence, by the Italian Filippo Brunelleschi (1377-1446). Brunelleschi is also known for building among others the Florence Cathedral (1417-34), reconstructing the church of San Lorenzo (141829) and for being one of the first to study the formal and constructional principles of classical Roman architecture (Mallgrave 2006:28, Rosenfield 1969:24).

\section{0}

Before a Restaurant was a place to eat it was a thing to eat. According to Spang (2000:1) with reference to the renaissance Master Chiquart Amiczo a restaurant was made by taking: "... $a$ freshly killed capon be cooked in an alchemist's glass kettle with sixty gold ducats, and notated that the cook might supplement the fold pieces with diamonds, rubies, sapphires, jaspers, or any other good and virtous precious stones the doctor may order". Thus a restaurant was back then a restorative broth or consommé made from capon or chicken bouillon (Spang 2000:1).

\section{0}

Ospedale della Scala in Sienna (Rosenfield 1969:24)

\section{3}

Hôtel-Dieu de Beaune in France was founded by Nicolas Rolin. The hospital still exists today as a museum where it is possible to see the architectural principles of the interior of the great hospital halls (Leistikow 1967:27,30).

\section{3-52}

The Italian Leon Battista Alberti (1404-72) wrote with the treatise: De re Aedificatoria (On the Art of Building in Ten Books) on the importance of the environment on health in his search for specific guidelines on building design and architectural beauty, as well as the idea that beauty lies in the absolute and fundamental rule of Nature - the mathematical laws and harmonic proportions of how ornament orchestrate the architectural design (Mallgrave 2006:32,34). According to Henderson (2006:xxv) Alberti wrote in his treatise: "In Tuscany, in keeping with the long-standing local tradition for religious piety, wonderful hospitals are to be found, built at vast expense, where any citizen or stranger would feel there to be nothing amiss to ensure his well-being."

\section{c.1450}

The eminent Maestro Martino of Como writes one of the first "modern" cookery books: Libro de arte coquinara, which was a practical manual for courtly cooks (Freedman 2007:198).

\section{1-3}

The Italian Il Filarete (Antonio di Piero Averlino, c.1400-70) wrote an untitled treatise, arguing the superiority of ancient art - classical architecture over gothic architecture and takes the proportions of the Doric order back to the origin of Adam (origin of man in Christian belief). He is also the architect of the Ospedale Maggiore in Milan, Italy (1456-65) (Mallgrave 2006:36, Rosenfield 1969:24). 
Fig. 6.6

"The Monastery"

The Hôtel-Dieu de Beaune had

four wings which were arranged around an inner courtyard. The communal hospital hall was assembled under one roof with the altar and a chapel. The hall has a pointed barrel roof and room for 30 beds (Leistikow 1967:30).

\section{c. 1465}

The humanist writer Bartolomeo Sacchi (also known as Platina) (1421-81) adopts the writings of Martino in his writings: De honesta voluptate et vaetudine, which is a treatise on the correct pleasure and good health. He thus merges medical and moral commentary with recipes on food into a guide for good health and a philosophy of eating (Freedman 2007:199).

\section{Late 15th century}

The Opera Gastronomica was according to KirshenblattGimblett (2007:72) a musical banquet where performance, actors and religious acts blend with eating. Here the center of attention is not the actual play, but instead the patron seated on a throne-like chair. The theatrical stage is thus literally a physical extension of the dining table and the festive meal is not only for satisfying physical hunger, but rather a multisensory event held in the interest of commensality or what could be called a kind of spiritual hunger. The banquet was as such primarily "for show" with an emphasis on the visual language and the physical world made edible by staging the food to be seen, to be touched, inhaled, ingested, absorbed and embodied not only as substance but also as meaning (Kirshenblatt-Gimblett 2007:74).

\section{1}

Hortus Sanitatis is considered the third fundamental botanical work produced in Mainz and printed by Jacob Meydenbach. It is a Latin translation of the German Herbarius and contains a treatise with wood cuts of animals, birds, fishes and stones, but also mythical monsters all together illustrating what to do when ill or sick (Christiansen 1973:7).

\section{7}

At a visit to Florence the artist and scientist Leonardo da Vinci dissected a human body at the Hospital Santa Maria Nuova. Apparently this act was strictly frowned upon by the church (Mallgrave 2011:20). Da Vinci is further known for his anatomical drawings depicting the interior parts of the human body in elaborate details. Presumably such anatomical drawings were part of the great developments in medical thinking during the renaissance era (Pagel 1939:386).

\section{2}

The English Savoy Hospital in London was founded by King Henry VII. It was presumably greatly inspired by Santa Maria Nuova, and should have had luxurious conditions with beds with mattresses, sheets, blankets, pillows, bed covers and curtains to establish privacy. Fruthermore lamps hanging from the ceiling should have provided light in the ward during nighttime (Granshaw \& Porter 1989:29; Henderson 2006:xxvi). 
Fig. 6.7

"The Sugar Banquet"

\section{3}

Catharina de Medici brought the Italian kitchen to France, when she married King Henry II.

\section{4}

Thomas Elyot: Castel of Health. English dietetic manual (Freedman 2007:201).

\section{0-77}

Bartolomeo Scappi (c.1500-1577) worked as a chef for different influential Cardinals of the church and two popes. He is furthermore known for writing one of the first cook books: Opera (1570), as well as cooking during conclave in the winter 15491550, when Julius III was elected pope (Fisker \& Jørgensen 2010).

\section{2}

Andrew Boorde: Compendyons Regyment of a Dyetary of Health, an English dietetic manual (Freedman 2007:201).

\section{9}

The cookery book: Banchetti, composizioni di vivende $e$ apparecchio written by Christoforo da Messisbugo was published (Strong 2002:131).

\section{0}

The cookery book: Opera di Bartolomeo Scappi, maestro dell'arte del cucinare, con laquale fi puo ammaefrarequali voglia Cuoco, Scalco, Trinciante, o Maftro di Cafa (The Opera of Bartolomeo Scappi, the Art and Craft of a Master Cook), written by Bartolomeo Scappi was published. The book is considered as one of the first and most thoroughly prepared cook books. It presents more than 1000 recipes used in 100 meals, and a series of detailed engravings depictinig kitchens, kitchen tools and working chefs. Furthermore, Scappi had a distinct chapter on health and diets for sick people (Fisker \& Jørgensen 2010).

\section{6th century}

Martin Luther on a travel north of the Alps, according to Henderson (2006:xxvi) writes about the magnificent appearance and service of the Italian hospitals. Apparently the rulers of states of other parts of hospitals were so impressed by these reports that they sent for copies of their statues and architectural designs as a basis for the planning of theur own hospitals (Henderson 2006:xxvi).

\section{0}

The Italian Andrea Palladio (1508-80) wrote the treatise: $I$ quatro libri dell'architettura (The four books of architecture, 1570 ) where he states his belief in absolute beauty or cosmic proportions as the guiding principle of all architectural design. Furthermore he is known for the design of among others a series of grand Villas in the Veneto area in northern Italy (Mallgrave 2006:46). 


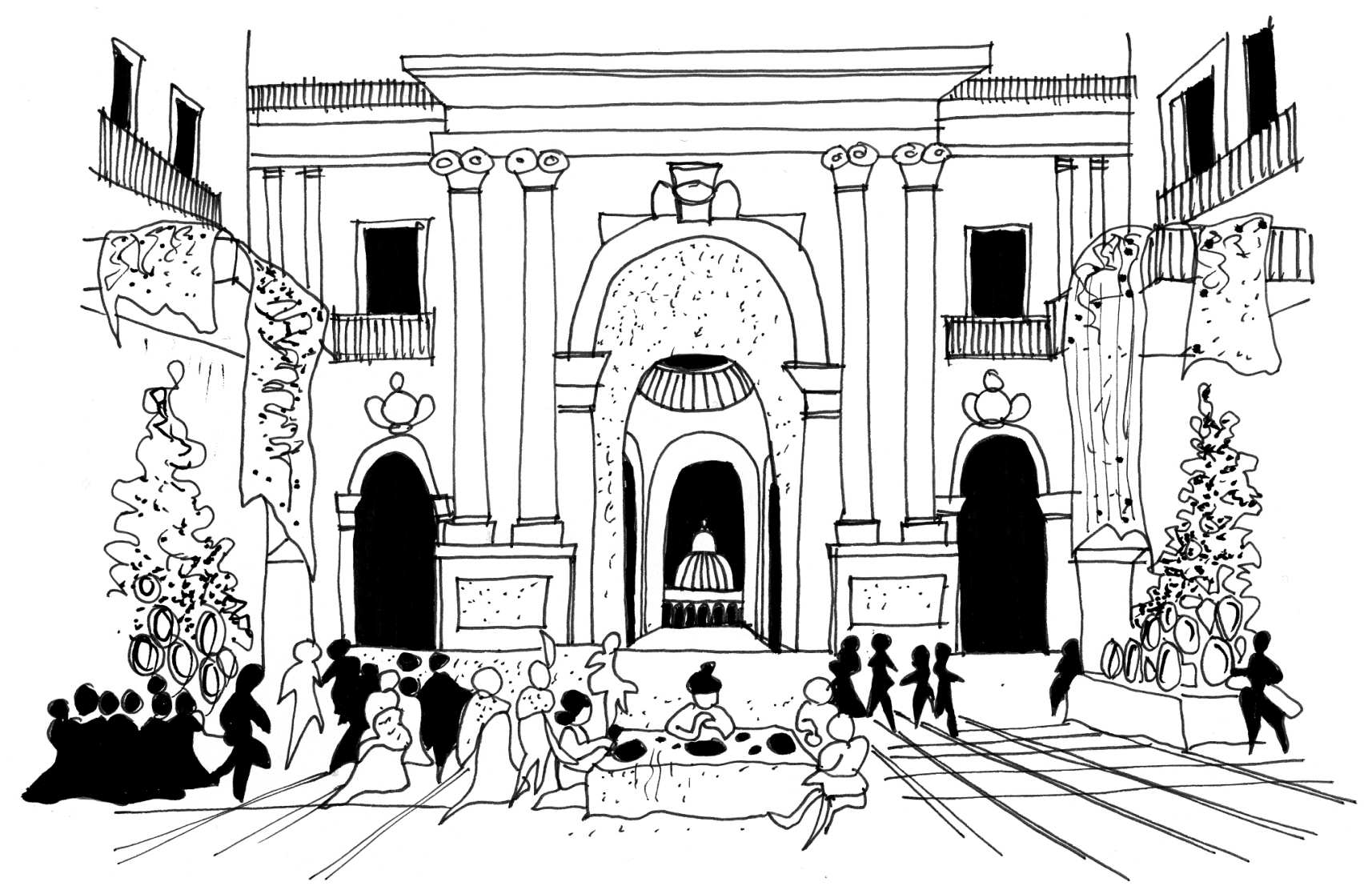

1574

The Sugar Banquet. According to the two documents: Le Feste and L'Hisotria della Publica dating back to 1574 tell how, Henry III - King of France and Poland, when he passed through Venice on a travel with his mother Catharina dé Medici was celebrated with a grand banquet (Benedetti \& Croce 1574; Fisker \& Olsen 2011:6). As written in Fisker \& Olsen (2011:8-10) the banquet was held in the Ducal Palace. Where a grand party of 3000 guests dressed in the finest robes of gilded silk, precious jewels and exquisite golden brocade welcomed the King. Apparently 400 men rowed the royal ship at the Lido followed by a plethora of noblemen in gondolas decorated with gold fabrics, mirrors and coats of arms. An exceptional triumphal arch had been mounted on the Lido along with an open loggia with ten Corinthian pillars drawn by the architect Andrea Palladio.

The story tells that the King was led to the Palazzo, in which the Sala del Maggior Consiglio was decorated with all sorts of textiles, gold figures and glassworks. Fragrant plants and trees had been placed around the room, fruit baskets hung from the ceiling, domesticated hares, rabbits and birds were tied to the trees with silk ribbons. Above it all were the friezes painted on the ceiling, depicting the Doges. Before the meal, acrobats amazed the audience with precarious manoeuvres (Fisker \& Olsen, 2011:8-10).

The material excess knew no restraints and the tables were lavishly set. Finally, a spectacular surprise had been prepared to entertain the King. Henry III was invited to sit at a table, where everything from napkins to plates, knives and forks - even 1260 skillfully crafted mythical figures placed on the table and handed out as gifts for the female guests were made of sugar. The result apparently was so convincing that the king did not hesitate to take his seat. The illusion of the beautiful tableau was obviously noticed when the napkin crumbled in his hand (Fisker \& Olsen, 2011:10). When the king was finally allowed to sit at a more substantial table and served food of a more culinary nature, he was entertained with poetry readings and singing in-between the more than 1000 different dishes and 300 sweets served on gold and silver plates. The banquet lasted for hours, and at the end of the festivities the story tells that a large pie was carved in front of the kingfrom which birds flew out for the guests to chase. The price for capturing the biggest bird was a gilded ostrich egg (Fisker \& Olsen 2011:12).

\section{Early 16th century}

Michel Eyquem de Montaigne (1533-92), according to

Mennell (2003:248) described a conversation with the Italian chef of Cardinal Caraffa. The chef was clearly skilled at judging taste, but working for a single patron and not a public.

\section{4}

Thomas Cogan: Haven of Health, an English dietetic manual (Freedman 2007:201). 


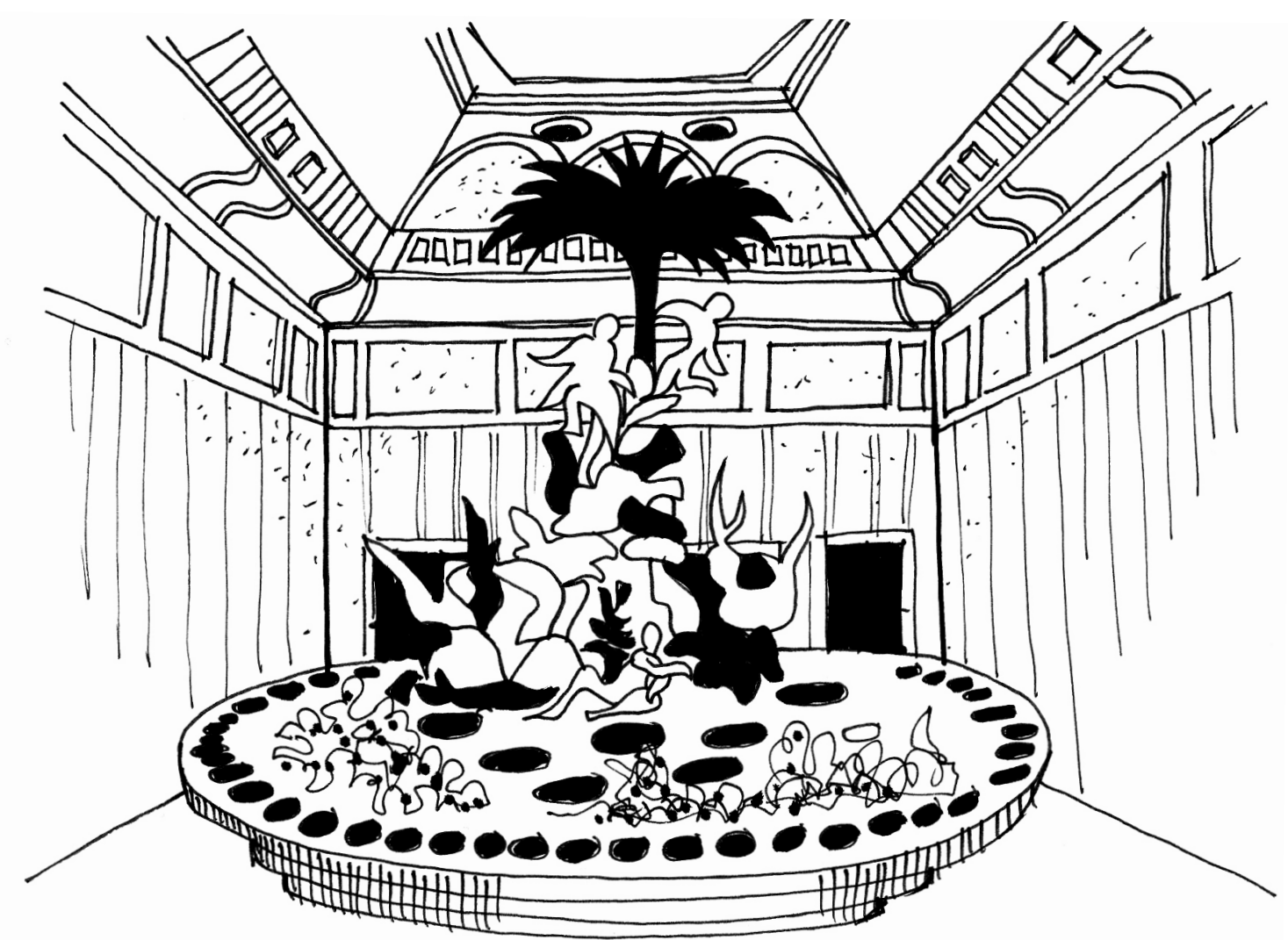

\section{0}

The foundation of the Botanisk Have (Botanical Garden) in Copenhagen at the University. Here herbs and plants used for medication were grown for the use of the medical students (Christiansen 1973:7).

\section{$1628+37+41$}

The French mathematician and philosopher René Descartes (1559-1650) wrote a "notebook" called: Regulae ad Directionin Ingenii (Rules for the Direction of the Mind, 1628). Herein he advocated for a deductive method of reasoning. His logic would later be widely embraced by scientists and also highly influence the understanding of architectural quality, because his main point also was that when investigating objects: "we can only study what we can clerly and evidently intuit or deduce with certainty, and not what other people have thought or what we ourselves conjecture" (Mallgrave 2006:61). In 1637 he published: Discours de la méthode as a preface to a treatise on mathematics and physics. Herein he introduced the concept of Cartesian co-ordinates. In 1641 he published: Meditationes de Prima Philosophia (Meditations on First Philosophy), which is considered his best known work, but where he also presents the famous Cartesian dualism - a separation of mind and matter (body and senses) into two different, but interacting substances. Descartes is thus known for arguing that it takes divine dispensation to certify any relationship between the body and mind. Despite other philosophers attempt to reject this "body-mind split" Descartes's theory became a central point of reference in modern philosophy and science (Oxford Dictionary of Philosophy 1994:101).

\section{$1632+38$}

The Italian scientist Galileo Galiliei (1564-1642) published: Dialogo sopra I due massimi sistemi del mondo (Dialogue Concerning the Two Chief World Systems, 1632) and Discorsi e dimonstrazioni matematiche, intorno à due nuove sciencze (Discourses and Mathematical Demonstrations Relating to Two New Sciences, 1638). With these the "Galilean world view" which is considered the "basis" in modern science and philosophy of space was established (Oxford Dictionary of Philosophy 1994:153).

\section{4}

The first Theatrum Anatomicum (Anatomical Theater) is built in Denmark at the University in Copenhagen by Simon Paulli (Christiansen 1973:10).

\section{7}

The earliest appearance of salle á manger (dining room) in a French architectural book. Here a separate room is designed for dining in the Parisian town houses of the aristocracy (Strong 2002:242).

\section{8}

Simon Paulli writes the first Flora Danica, a book illustrating all the common wild growing herbs in Denmark. Though primarily those used for medication (Christiansen 1973:5)

1651 - The French chef and writer La Varenne published: Le Cuisinier Francois, which according to Mennell (1985:71) is considered as one of the first cookery books to break clear with medieval food instead focusing on what would become known as modern French cuisine. 
Fig. 6.9

"Body and Mind"

Fig. 6.8

"17th century"

"Repas en ambigu" denoted an elaborate formal composition of dishes laid out on a grand table in the center of a room for display especially used at festive banquets held by the European court life during the Baroque era. According to KirshenblattGimblett (2007:74) with reference to el-Khoury (1997:58), this scenery transformed the entire dining room into a culinary theatre or a one-act play. (Drawing adopted from Sabban \& Serventi 1998:117)

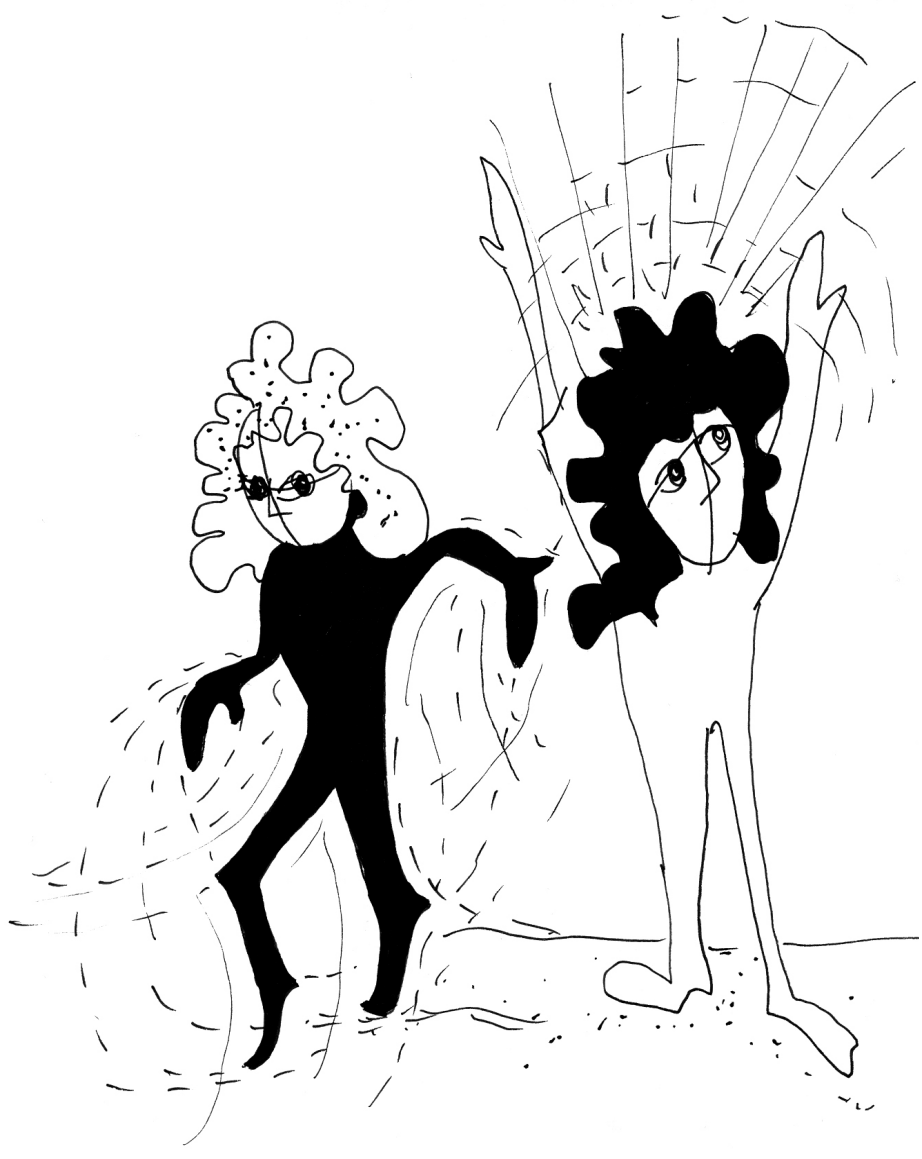

1655

Thomas Moffett: Health's Improvement, an English dietetic manual (Freedman 2007:201).

1665-1666

The Great Plauge of London (Wikipedia 2013).

\section{1}

The French King Louis XIV, also known as the "Sun King" came into office (Mallgrave 2006:70)

\section{$1671+75+83$}

Royal Academy of Architecture was founded with the first director being the French architect Francois Blondel (1618-86). Here he wrote the curriculum for the school, codifying the principles in classical design in line with those taught in the other fine arts. Vitruvian theory and the treatises of the Renaissance, according to Mallgrave (2006:70), constituted the core teachings in a faith in absolute beauty and harmonic proportions. In 1675 Blondel wrote the first architectural textbook of French academic theory: Cours d'Architecture: enseigné dans l'Academie Royale d'Architecture(Architecture course: instruction at the Royal Academy of Architecture). This book was based on his lectures and defined architecture and the architect's role in line with the conceptions of Vitruvius and Alberti. Interestingly enough in the books he further writes: "Architecture is the art of building well... a good building is one that is solid, commodious, healthy, and pleasing." (Mallgrave 2006:72). In 1683 Blondel published part III of his Cours d'architecture (Architecture Course), here he argued against Perrault stating according to Mallgrave (2006:76) that the proportions of "modern" architecture must conform to classical times, and never should incorporate the Gothic style.
$1673+83+84$

The French surgeon, anatomist and architect Claude Perrault (1613-88) translate the Ten Books on Architecture written by Vitruvius into French. According to Mallgrave (2006:74) Perrault undermined the academic teachings put forth by Blondel, by adding a footnote in the translations of Vitruvius stressing the flexibility and openness to innovation and change from the ancient, also suggesting that "a little gothic" in terms of the structural and visual lightness should be added to "modern" architecture. Perrault is thus also known for designing part of the Louvre Palace in Paris incorporating these structural considerations, implementing an innovative system of iron reinforcing the building (Mallgrave 2006:74). In 1683 Perrault published the treatise: Ordonnance des cinq espéces de colonnes selon la method des Anciens (Ordonnance for the Five Kinds of Columns after the Method of the Ancients). Herein he argued that there was no such thing as "harmonic ratios" but that proportions were instead based on custom and habit, thereby suggesting that two kinds of architectural beauty - "positive" and "arbitrary" exists (Mallgrave 2006:78). Furthermore he published the second edition of his translation on Vitruvius (1684). With these two publications he in the words of Mallgrave (2006:77) "join the battle" arguing for the Gothic style against the Classical style. This "quarrel" would continue in architectural theory and thinking during the next two centuries.

Mid-17th century - Coffee-houses and cafés existed in Venice (1645), Oxford (1652), London (1652) and Paris (1672) as popular public meeting places to enjoy tea, coffee and "light" food (Mennell 1985:137). 


\section{THE MONASTERY AND THE BANQUET}

The theatrical approach to food servings at grand feasts and banquets held by the aristocracy continued throughout the Medieval and Renaissance eras according to Strong (2002). As with the Greek Symposium and the Roman Banquet, these banquets were not only meant to provide the dinner guest with a spectacular multi-sensuous experience, but furthermore as a strong "medium" for communicating prosperity, power and social status. Here overwhelming amounts of silverware, crystal, and china were used particularly during the renaissance feasts and banquets not only to serve the food, but simply also as decoration of the grand dining halls [Olsen 2008:29]. As seen from the Timeline, examples from the Renaissance era as well as the period of Enlightenment indicate how dining interiors were generated by means of great ensembles of tableware and even sugar sculptures exhibited on grand tables and built-in wall shelves. According to Strong (2002:189), grand banquets were held as actual theatre plays, orchestrated with a specific plot and dinner guests dressed up in costumes, actors serving food and theatre sets framing the entire feast [Olsen 2008:29]. Back then the sensuous staging of the meal with not only the food servings but also the interior became amusements for all the senses; a meal was made into an event, serving higher means than just satiety and nutrition. As argued for by previously-mentioned American professor in performance studies Barbara Kirshenblatt-Gimblett (2007:23 ), food was for show; it was to be seen, touched, inhaled, ingested, absorbed, and embodied - not only as substance, but also as meaning. The point made by both Strong (2002) and Kirshenblatt-Gimblett (2007) is that with the grandiose feast and banquets, the linking of the interior architecture and the expensive tableware with spectacular meal events made the power of the host (king, nobleman or patron) tangible - it was materialized in the splendor of the visual effects, rarity of food ingredients, opulence and extraordinary performative happenings. The social world was made "edible" through the decorative interiors framing the entire meal event. In that way, I find that, the tableware and the food on display became "furnishing" architectural elements and the dining interior became, not only a background 'image' or framing 'space' but also, a staging 'assemblage' of material objects representing an expression of the host and dinner guests.

This is not only evident in the examples of the luxurious banquets held among the aristocracy and upper classes, but was presumably evident also in the contemporary hospitals - the monasteries, as seen for instance with the example of Ospedale Santa Maria Nouvea in Florence (see Figure 6.6, The Monastery). Here the description of a patient meal provides an example of how not only the specific diet, but also the interior architecture framing the meal through an intentional staging of the meal rituals together with the medical procedures was an essential part of the entire hospital treatment [Tvedebrink et al. 2013:2]. It is exemplified with the rituals of the "chicken broth" and the servings of the bread and wine. Here rituals utilizing the sound of a bell and strict routines guiding the food service are not only framed by the built environment, but possibly magnified and staged by the religious interior atmosphere - the altar, shrines, relics, murals and ornamental interior decoration and the spiritual rituals embracing the meal rituals. Because the religious and spiritual values at that time were important aspects of treating illness, I find that the iconographic value of religious artifacts and the interior architecture of the monastery become essential spiritual and ritual effects in the hospital procedures that materialize the intangible devotion to God (Henderson et al. 2007; Henderson 2006)[Tvedebrink et al. 2013:10]. So, again, as argued in the Introduction, with reference to previously-mentioned English Professor in design history Penny Sparke (2008), the interior architecture framing the meal is in my point of view not only an image-based background or a spatial frame, but it becomes an 'assemblage' of material objects linking together furniture, décor, tableware and food with the social staging and cultural relations governing that time.

If I look into the history of interior architecture and the polemical writings of that particular time, according to previously-mentioned American architectural theoretician Harry Francis Mallgrave (2011:9), architects during the Renaissance such like Italian Leon Battista Alberti (1404-72) primarily understood architecture as a metaphor for the human body, and the human body as a metaphor for architectural design. Architectural quality was thus, according to Mallgrave (2011:9), based on a belief that the human being, by virtue of his divine creation, occupied a privileged place in the world. This belief was manifested in an occupation with linear 
perspective, proportions, symmetry and geometry. To Alberti the mathematical theory underpinning geometry was the representative of a divine ideal that brings an imperfect human being into closer harmony with the divinely created order of the universe, and geometry thus becomes the "humanization of space" (Mallgrave 2011:11). Following the "humanist" perspective in architecture, a similar "humanist" perspective governed the culinary world. As seen from the Timeline, the first printed cookery books or dietary advice manuals on health occur around the turn of the $16^{\text {th }}$ century in England, Italy and France. However, these cookery books and dietary manuals were mainly reserved for the rich and noble (Freedman 2007:198). It was not until the turn of the $19^{\text {th }}$ century that this kind of literature became available for more common people - or what some refer to as the bourgeoisie (Notaker1987:174-183; Spang 2000:1,27). However, with the French revolution and the "liberation" of chefs, a radical change in public meals occurred. What had previously been handled by taverns and coffeehouses was, during the late $18^{\text {th }}$ century and the early $19^{\text {th }}$ century, turned into a glorious business of what we today know as restaurants. 

Fig. 6.10

"The Primitive Hut" During the $18^{\text {th }}$ and $19^{\text {th }}$ century there was a particular occupation within the architectural discipline with finding the "origin" of architecture. This was partly motivated by a search for a taxonomy describing the qualities and purpose of architecture. (Drawing adopted from Hvattum 2004:32)

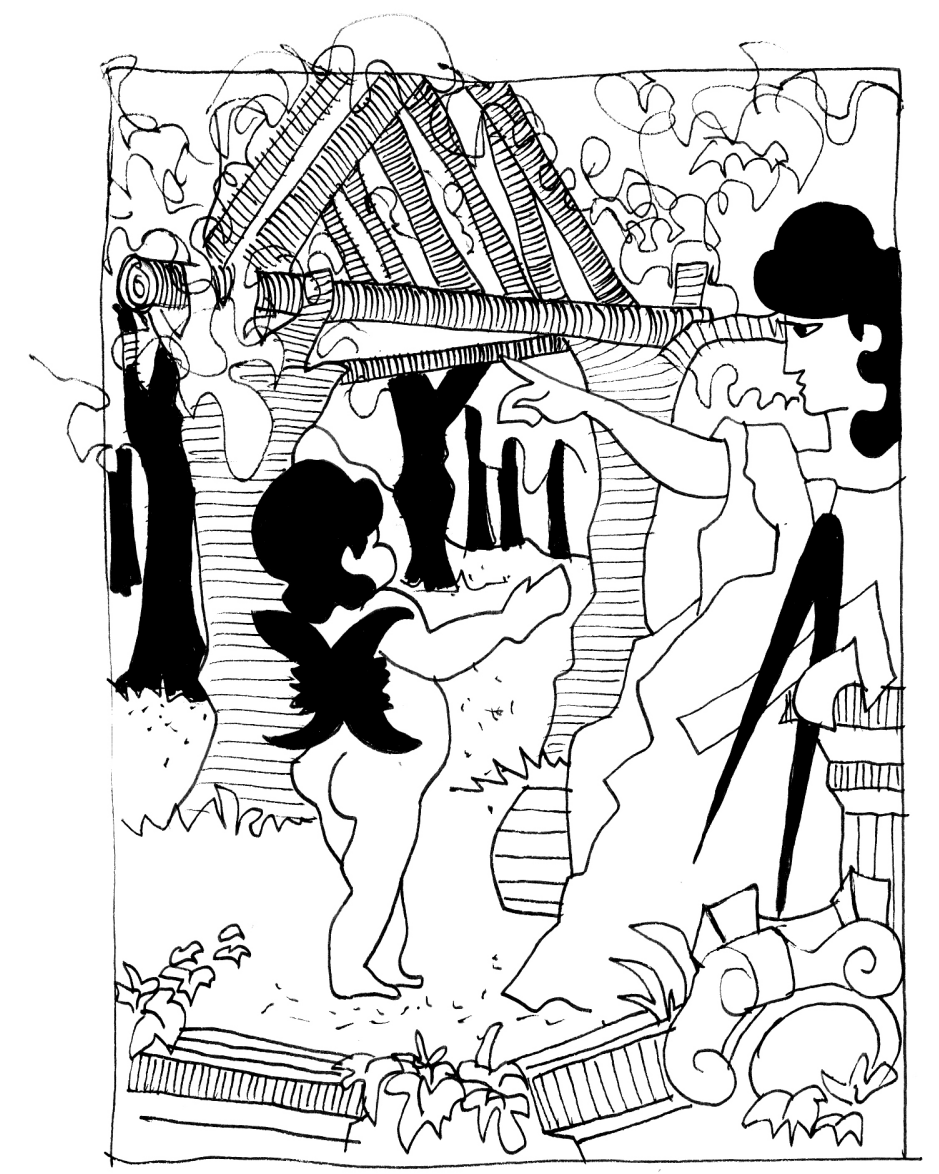

\section{0}

John Locke (1632-1704) published: An Essay Concerning Human Understanding, where he argues that all ideas (knowledge) come from sensation (the senses) and reflection (mental operations) (Mallgrave 2006:225).

\section{2}

The British diplomat William Temple (1628-99), according to Mallgrave (2006:229), with the small essay: Upon Gardens of Epicurus; or, of Gardening in the Year 1685 highly influenced what during the 18th century was known as the "picturesque" aesthetics.

\section{8th century}

Service a' la francaise evolved from earlier Medieval and Renaissance serving models, where tables according to the style were laden with several dishes of food before the guests arrived. On grand tables all the dishes, candles, salts and ornaments had been placed with careful attention to the hierarchy of each dish and its position. However, the dinner was still divided into two or three courses (Visser 1991:198; Franck 2002:59; Olsen 2008:320).

1709+10 - The Irishman George Berkeley (1685-1753) published: Towards a New Theory on Vision and The Principles of Human Knowledge.

\section{5}

The Italian philosopher of history Giambattista Vico (16681744) published: Scienza nuova (New Science). According to Frampton Vico presents the concept of enactment and reenactment of man through history not only as metaphor and myth but also corporeal, in that the body reconstitutes the world through its tactile appropriation of reality (Frampton 2001:10). During the late 18th - early 19th century Vico's work is picked up by the German Romanticism. Vico detached himself from the Cartesian doctrine and rejected the role Descartes had put on mathematical and physical science. Instead he emphasized the possibility of social and historical knowledge - the languages, the myths and the traditions that are handed down through generations. Vico is thus considered one of the "forefathers" of later works of Dilthey (Oxford Dictionary of Philosophy 1994:393).

\section{8}

The British architect Batty Langley (1696-1751) published: New Principles in Gardening, where he defined a new garden style imitating nature, emphasizing the visual experience of irregularity and exploration of dales, canals, grottos and serpentine meanders (Mallgrave 2006:241).

\section{9}

The book: Le Dons de Comus by Marin. Herein a "restaurant" is described as:" that which restores or repairs strength", thereby denoting a semi-medicinal preparation or restorative food (Spang 2000:1).

1739-40 - The Scottish philosopher David Hume (1711-76) published: A Treatise of Human Nature. 


\section{7}

The English housewife and cookery writer Hannah Glasse (1708-1770) published her cookery book: The Art of Cookery made Plain and Easy. The cookery book was presumably one of the most read cookery books in England and America at that time, and presumably both George Washington, Benjamin Franklin and Thomas Jefferson owned a copy (Hess 1997:v). Mrs. Glasse is considered a pioneer in her recipes, for instance writing about how to make ice cream, as well as using chocolate, vanilla and even tomatoes in her recipes aimed at the homes and households of fairly ordinary people in England (Hess 1997:viii). In 1747 Mrs. Glasse began working as a dressmaker (Hess 1997:iv-x).

\section{8}

Baron de Montesquieu (1689-1755). According to Mallgrave (2006:131), his writings analyzed the difference between nations and different cultures, searching for an explanation of on the premises of human culture. He argued that human culture is a product of nature - the geographical and climatic conditions, and thus made an early search for the science of history and for an anthropological model to evaluate human culture (Mallgrave 2006:131).

\section{8 - Rediscovery of the lost Roman city Pompeii.}

1750 - Jean-Jacques Rousseau (1712-88) with: Discours sur les sciences et les arts (Discourse on the sciences and arts, 1750) advocated that man was free, virtuous and happy but had ben corrupted by society and city life. Man had to return to the simple life in harmony with nature (Watkin 2000:406). According to Mallgrave (2006:132) these writings were part of a "broad attack" on the king, the aristocracy, the church, education and art that later culminated in the French Revolution.

\section{5}

The German Johann Joachim Winckelmann (1717-68) published: Gedanken über die Nachahmung der griechischen Werke in der Mahlerey und Bildhauer-Kunst (Reflections on the Imitation of Greek Works in Painting and Sculpture, 1755). He is generally considered the "father" of modern art history because of these writings, where he argued the superiority of Greek art over Roman art (Mallgrave 2006:159-160). His framework presents a stylistic evolution, where he argues that there exist four phases for classical art: the Ancient Style, the Grand Style, the Beautiful Style and the Style of the Imitators. Art passes from one to the other in an evolutionary manner into the higher ideal of beauty, where it borders on excessive refinement and overelaboration, and therefore the last phase is by definition a phase of decline (Mallgrave 2006:176-77).

\section{7}

David Hume published the essay: Of the Standard of Taste. Here he states that "Beauty is no quality in things themselves, it exists merely in the mind which comtemplates them" (Mallgrave 2006:271).

\section{1-1883}

The Second Flora Danica was published in the end including more than 3240 illustrations of wild growing flowers, herbs, plants, mushrooms, ferns, moss and algae (Christiansen 1973:5).
1753

The French Jesuit (later Benedictine) Abbé Marc-Antoine Laugier (1713-69) published the polemical book: Essai sur l'architecture (Essay on Architecture, 1753). According to Mallgrave (2006:141) It had a great effect on architectural theory, both inside and outside France, and is generally considered a very important book from the 18th century. He is one of the first Frenchmen to deny the relevance of Vitruvius writings. Instead he introduces the notion of "reason" to be the guide of architectural quality. Based on the logical and rational arguments of the ideal of the "primitive hut", he deduces the three essential elements: the column, the entablature and pediment, guiding architectural quality. He argues that by imitating the natural process art was born and all the splendors of architecture ever conceived have been modeled on that little hut. From his "purist" point of view, Laugier thus also deny the extravagance of the periods of Baroque and Rococo architecture (Mallgrave 2006:142)

\section{5}

The term Dining Room appears officially in England in a dictionary (Strong 2002:244).

\section{Mid-18th century}

Cotton, coal and textile industries occur (Engholm \& Michelsen 2000:18).
$1761+65$

The Italian artist Giovanni Battista Piranesi (1720-80) published a visual and polemical work: Della magnificenza ed architecttura dé Romane (On the magnificence and architecture of the Romans, 1761). Known for his engravings on Roman antiquity, depicting picturesque gardens and buildings (Watkin 2000:369; Mallgrave 2006:178-79). In 1765 Piranesi's writings: Parere su l'Architetture (Opinions on architecture, 1765) argues for the architect's freedom to invent and re-use traditional forms as he likes. With this he thus introduces eclecticism (Mallgrave 2006:185).

\section{3-8}

The brothers Robert and James Adam published: Works in Architecture of Robert and James Adam (Mallgrave 2006:287).

\section{5}

The establishment of Den Kongelige Priviligerede Danske

Porcelænsfabrik (Royal Copenhagen) (Christiansen 1973:47; Fisker \& Olsen 2008:2). Producer of Danish porcelain - among others the china service called 'Flora Danica' , a spectacular set of tableware comprising 1802 pieces, each element decorated with golden brims and detailed hand-painted botanical illustrations copied from the Flora Danica plant encyclopedia. The company later becomes known for the production of 'Musselmalet' and 'Mågestellet' (Christensen 1973:52).

\section{7}

Marquis Girardin published: De la composition des paysages (On the composition of landscapes, 1777). Inspired by Rousseau he emphasized the power of the landscape and how it appealed to the senses and the soul (Watkin 2000:406). 


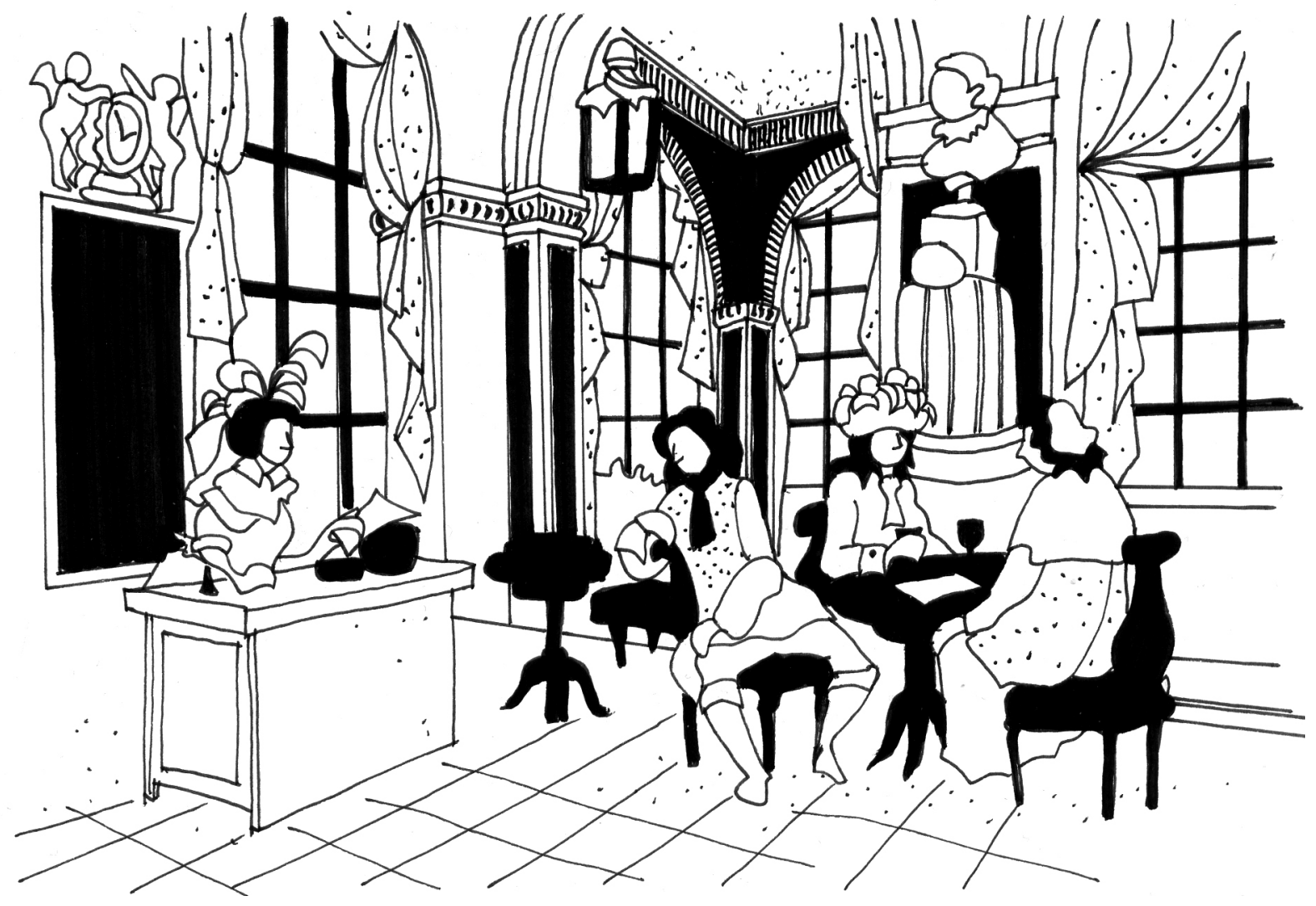

HOMEOPATHY

1780

Nicolas Le Camus de Méziéres published: le genie de

l'architecture; ou, l'analogie de cet art avec nos sensations (The genius of architecture or the analogy of that art with our sensations, 1780). Writes about the psychological experience of moving through space and how all the senses can be exploited in a successful design (Mallgrave 2006:199), Furthermore according to Watkin (2000:406) he evoke sentiments and creates an associational mingling of architecture and landscape, and argues that the principles of architectural quality should be based on the effect on our souls in accordance with the sensations we experience (Mallgrave 2006:200).

\section{0s-90s}

The French Etienne-Louis Boullée (1728-99) with the explanatory essay: Architecture, Essai sur l'art (Architecture, Essay on Art, 1794), he argues critical against Vitruvius writings, considering them too technical, instead focusing on architecture as poetry composed of symmetry, regularity, varied form and character. Furthermore he is known for the the megalomaniac scale of his design on libraries, museums, tombs, pyramids and gate towers (Watkin 2000:406; Mallgrave 2006:210).

\section{1}

The German philosopher Immanuel Kant (1724-1804) published: Kritik der reinen Vernuft (Critique of Pure Reason). Here he defined space as a form of intuition (Böhme 2002:1).

\section{Early 1780s}

Records show that in 18th century England Taverns and Inns existed where travelers could buy an "ordinary" daily meal at a fixed price. Taverns and Inns were furthermore considered as public guest houses were you could stay overnight, and were people would meet for social gatherings (Mennell 1985:136).

\section{Late-18th century}

Iron foundries, steel production, railways and steamboats occur (Engholm \& Michelsen 2000:18).

\section{The French Revolution}

\section{c.1789}

The first modern restaurant was presumably, according to Spang (2000:79), invented by Roze de Chantoiseau, who frequented the aristocratic and administrative circles of Paris to be able to accomplish his idea of the "public dining room". The first public restaurants sold little food, but instead were public spaces or 'restaurateur's rooms' were people too frail to eat a regular evening meal, went to drink restorative bouillons (a restaurant). At these places one could "restore" or "rest" one's body from hunger or fatigue, and this "restoring" or "resting" is according to Finkelstein (1989) the reason why they came to be known as "restaurants". Until the middle of the nineteenth century these restaurants were mainly a Parisian phenomenon (Spang 2002:2; Olsen 2008:320).

\section{$1794+98$}

The writer Uvedale Price (1747-1829) wrote the threevolume study: Essays on the Picturesque, as Compared with the Sublime and the Beautiful and An Essay on Architecture and Buildings as connected with Scenery. Here he argues for the picturesque as a notion in architecture and aligns architectural beauty it with convenience and asymmetry in plan (Mallgrave 2006:307,319). 
Fig. 6.11

"The Bourgeois Restaurant" (Drawing adopted from Spang 2000:120)

\section{1}

Joseph Berchoux according to Mennell (1985:266) derived the word 'gastronomy' from Greek and used it in a title of a poem. This term was afterwards rapidly adopted in England and France to label "the art and science of delicate eating" and was yet another contribution to the grand "battle" in the shaping of taste and gastronomic writings occurring during the 18th and 19th century (Mennell 1985:266).

\section{$1802-05$}

The French architect Jean-Nicolas-Louis Durand (1760-1834) published: Précis des lecons d'architecture données à l'Ecole Royale Polytechnique (Précis of the Lectures on Architecture). Herein he developed a novel system of "building blocks" or series of typological elements - such like "facades", "floor plans", "porches", "vestibules", "staircases", "elevations" and "roof shapes" the architect/engineer could pick and choose from when designing and composing larger units such like buildings, streets and cities. Furthermore Durand introduced a series of archetypical design principles for "libraries", "justice ministries", "museums", “colleges" and "hospitals". This is the first time that architecture had been reduced to such a closed syntactic system completely free of stylistic or historical interest (Mallgrave 2006:335). Another characteristic is Durand's rejection of Laugiers and Quatramére de Quincy's primitive hut and that architectural beauty lies in the visual appearance - Durand instead argues that architectural beauty should be guided by the two principles of: fitness to purpose and economy of means (Mallgrave 2006:335; Malnar \& Vodvarka 2004:x).

\section{3}

The French Antoine Chrysosthôme Quatremére de Quincy published: De l'architecture égyptienne considerée dans sa origine, ses principes et son gout (On Egyptian architecture considered in its origins, its principles, and its taste, and compared on the same points with Greek architecture, 1803). Herein he suggested three primary architectural archetypes; the tent, the cave and the hut. The three was correlated to three different ways of obtaining food; hunting, gathering and farming, as well as with three different seats of civilization; the Orient (China), Africa (Egypt) and Caucasia (Greece). He argued that only the Greek hut had the possibility of rich architectural development (Mallgrave \& Robinson 2004:44; Mallgrave 2006:338).

\section{3-12}

The French Alexandre Balthazar Laurent Grimod de la Reyniére wrote: Almanach des gourmands, which is one of the first cookery books to evaluate food stores and public restaurants (Mennell 2003:247; Notaker 1987:199).

\section{4}

The French architect Claude-Nicolas Ledoux (1736-1806) wrote: L'architecture considérée sous le rapport de l'art, des moeurs et de la legislation (Architecture considered in relation to art, morals, and legislation). It is according to Mallgrave (2006:216) a utopian and utilitarian theory that challenged classicism by introducing architecture as the shaping of morality and happiness of humans. 
“Carême's pieces montées"

(Drawing adopted from Kelly

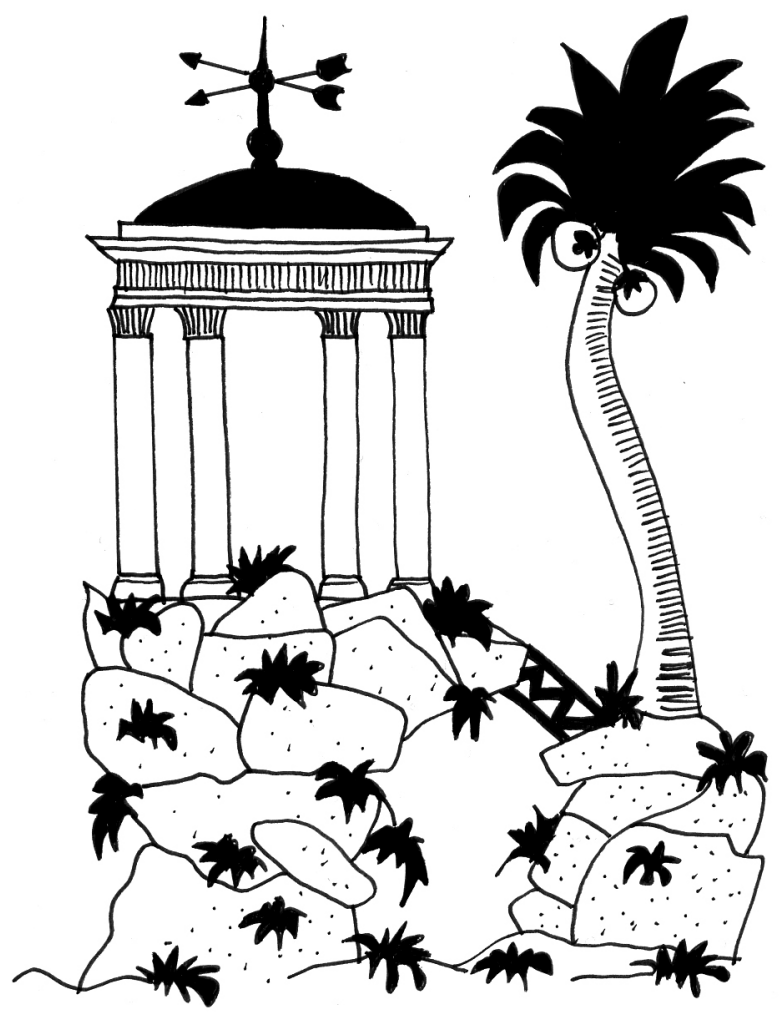

2003:23)

\section{Mid-19th century}

Service a' la russe was introduced with the arrival of feasting and dining a' la russe, where each dish is cut up in the kitchen and served directly to the guests instead of arranging it on grand tables with centerpieces and extravagance achieved by the number and quality of dishes served in succession of each other (Mennell 1985:150; Visser 1991:203; Franck 2002:61; Olsen 2008:320).

\section{0s}

The Russian mathematician N.I. Lobachevsky (1792-1856) is considered as one of the first to develop non-Euclidean geometry (hyperbolic geometry) (Oxford Dictionary of Philosophy 1994:156).

\section{$1821+33$}

Marie-Antonin Carême (1784-1833) created the concept of Grande Cuisine with specially designed pieces montées, which were impressive ornamental displays and elaborate socles on which food was mounted and served service á la francaise (Franck 2002:60). Here food was turned into architectural feasts for entertainment of the guests. Those were characterized by the large food sculptures for display, merging the interior and décor of the dining room in multi-sensuous meal experiences (Fisher 1954). Carême already in the 19th century pointed out the importance of décor and a total designed interior environment surrounding a meal (Finkelstein 1989:37-38). From 1815-1835 Carême published a series of cookery books, among others: $L a$ Pâtissier pittoresque (1815) and L'Art de la cuisine francaise au XIX siècle (1833-35) (Mennell 1985:145).

\section{5}

The French Jean Anthelme Brillat-Savarin (1755-1826) was a lawyer and mayor of profession, but with a grand passion and interest in gastronomy. He became famous for writing his book: Physiologie du goût (The physiology of taste, or meditations on transcendental gastronomy, 1825). With his aphorisms and 30 meditations on the senses, taste, gastronomy, appetite, food in general, theory of frying, thirst, drinks, end of the world, gourmandism, gourmands, gastronomical tests, pleasures of the table, hunting-luncheons, digestion, rest, sleep, dreams, influence of diet, obesity, treatment of obesity, thinness, fasting, exhaustion, death, cooking, restaurateurs, classical gourmandism in action and bouquet, he is considered as a unique theoretician endeavoring the field of gastronomy from the perspective of both lust, health, history, science, sociology, passion and philosophy (Brillat-Savarin 1949; Olsen 2008:321). BrillatSavarin is furthermore by some acknowledged as one of the first to define the term 'gastronomy', describing eating and having a meal as something more than mere nutrition. 


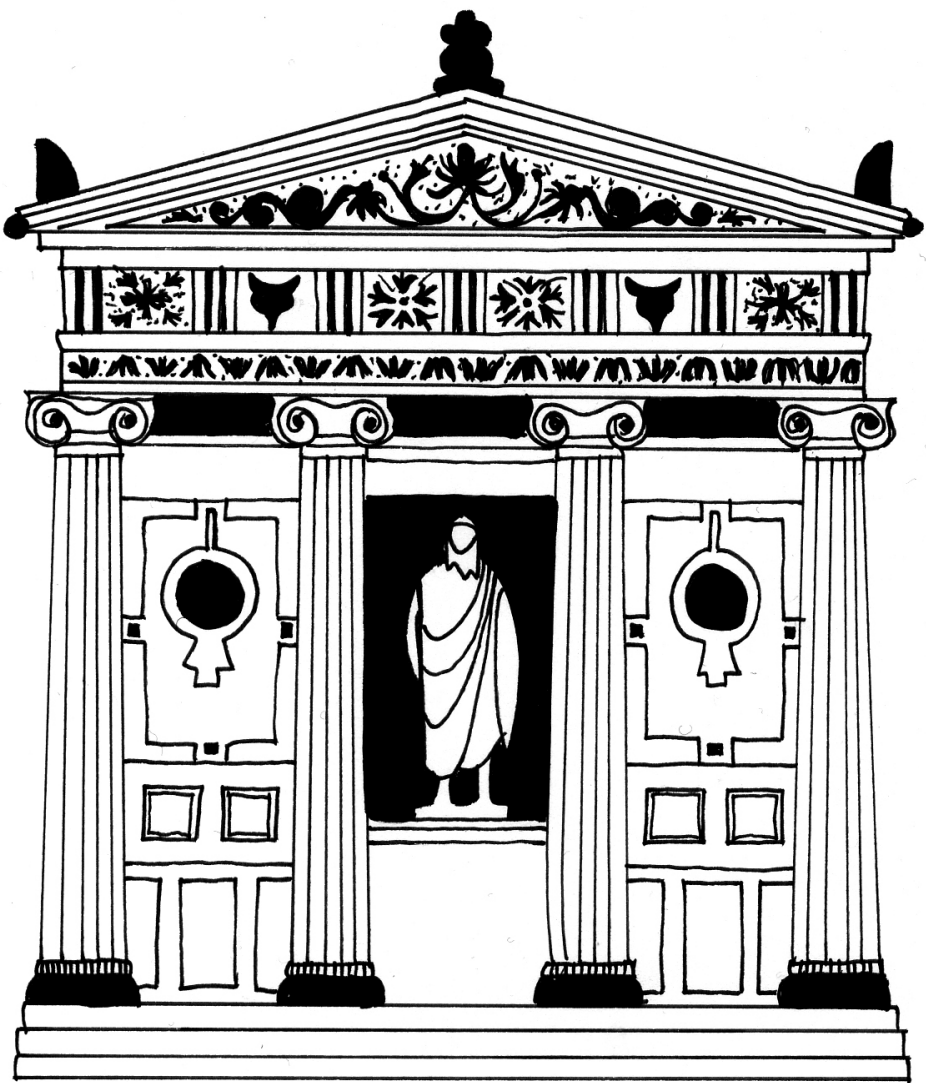

Fig. 6.13

"Polychromy"

(Drawing adopted from

Mallgrave 1996:37)

\section{$1829+34+35+36$}

The German architect Gottfried Semper (1803-79) makes a design proposal for a Irrenanstalt (Insane hospital) in Hamburg (Nerdinger \& Oechslin 2003:138,163). Semper also published the polemical pamphlet: Vorläufige Bermerkungen über bemalte Architecture und Plastik bei den Alten (Preliminary Remarks on Polychrome Architecture and Sculpture in Antiquity, 1834). Here he challenges the "white" aesthetics of classicism by arguing that Greek architecture was polychrome (multi-coloured) (Mallgrave 2006:349). In 1835 Semper makes a design proposal for the famous Hoftheater in Dredsen, but he also makes a design proposal for the café Baldini - a small "coffeehouse" owned by the confectioner Aug. Baldini. As well as a proposal for a Maternihospital in Dredsen (1835), and a proposal for the Saalumbau Hotel in Dredsen (1836) (Nerdinger \& Oechslin 2003:138,163).

\section{0}

The German scholar Karl Otfried Müller (1797-1840), published: Handbuch der Archäologie der Kunst (Handbook of the Archaeology of Art). According to Frampton (2001:4) he is one of the first to use the notion 'tectonic' relative to architecture.

\section{5}

According to Dictionnaire de l'Académie Francaise (1835) "restaurateur" meant: "He or she who repairs or re-establishes" (Spang 2000:1).

\section{$1836+41$}

Augustus Welby Northmore Pugin (1812-52) writes a short polemical book: Contrasts; or, A Parallel between the Noble Edifices of the Middle Ages, and Corresponding Buildings of the Present Day; Shewing the Present Decay of Taste. Herein he by means of drawing compared his view on "modern" neoclassical versus medieval architecture. According to Moffett et al. (2004:429) Pugin's comparison is particular manifest in two drawings of the ancient and modern town. Here the ancient medieval town is illustrated as a grand monastery were the "poor" receive kindness through a "hearty diet of beef, mutton, ale, cider, milk, porridge, bread, and cheese" further dressed in clean garments and given a decent burial. Whereas, in contrast, in the modern neo-classical town the "poor" are kept in small cells in large prison-like buildings with a temple-front portico. They are fed a diet of small amounts of potatoes, gruel, bread and oatmeal, as well as dissected when dead instead of given a proper burial (Moffet et al. 2004:429). The point presumably made by Pugin was that the modern industrial and neo-classical town was dominated by a greedy capitalism and degradation of human existence, rejecting all moral and religious values from the medieval period. Pugin is thus considered as one of the leading Gothic Revivalists in England, and is particularly known for designing a series of English cathedral, chapel and church interiors, as well as the House of Parliament, wherein he emphasized the beauty, craft and honesty of the construction. In 1841 he published: The True Principles of Pointed or Christian Architecture, which was a manifest of this belief in the honesty of gothic buildings (Moffett et al. 2004:429; Collins 1965:108). 
1851

In 1851 Soyer was asked by the Executive Committee to "cater" at the Great Exhibition held in London, but he turned it down, presumably because he had the idea of opening his own restaurant next to the Crystal Palace. This restaurant was thought as a large "theme restaurant". But the restaurant was not enough - Soyer also (like Gottfried Semper) submitted a design proposal to the Building Committee of the Great Exhibition (Clement-Lorford 2012:103). Soyer established his restaurant - the Universal Symposium - in a large house called Gore House he had leased only a hundred feet from one of the entrances to the Great Exhibition and seemingly Soyer was so interested in interior decoration that he designed most of the restaurant himself (Morris 1938:56). The restaurant comprised a series of spectacularly decorated dining rooms - among others the Le Salle de Noces de Danaé (the Shower of Gems or Danaes Abode), La Salle du Parnasse (the Blessington Temple of the Muses), La Chambre Ardente D'Apollon, La Grotto des Neiges Eternelles (the Grotto of Eternal Snow), Le Pagode du Cheval de Bronze, La Forét Péruvienne (the Night of Stars), Encampment of all Nations, Baronial Hall, Temple of Phoebus, Bower of Ariadne, Hall of Golden Lilies and Enchanted Fountain. In one room the ceiling was made of latticework with glittering foiled raindrops made of gold and silver descending from the ceiling to the floor, in another craggy masses of rock and stalactite were made of crystallized ice, and a third was "dressed" completely in black and white silk, black velvet and silver lace. But the symposium also contained an entire hall called: Hall of Architectural Wonders where designs from several architects such like Christopher Wren was on display (Clement-Lorford 2012:108-111). The first months of the restaurant went well, it was greatly visited by the aristocracy of rich, noble and famous people, but after some months people began complaining that the food was cold and tasteless and that the service was generally poor. As the restaurant was further too expensive to keep running it closed after only 3 months of service

"The Universal Symposium" (Drawing adopted from ClementLorford 2012:111)
(Clement-Lorford 2012:116).

\section{$1836+43$}

The Danish archaeologist Christian Jürgensen Thomsen outlined the history of mankind into the chronology of a Stone Age, Bronze Age and Iron Age. This was confirmed in 1843 by the Danish Jens Jacob Asmussen Worsaae who aligned these periods with stratigraphic succession (Mallgrave \& Robinson 2004:27-28).

\section{7}

Madam Mangor writes the Danish bestseller cookery book: Kogebog for smaa Husholdninger (Cookery Book for small households) (Dybdahl \& Engholm 2008:12).

\section{c. 1840}

One of the first Pavilion Hospitals was built in Paris. This type of hospital is characterised by the series of individual buildings, isolating patients in separate wards according to their type of disease or illness, in the attempt to decrease contamination risks (Adams 2008:xvii; Heslet \& Dirckinck-Holmfeld 2007:56-58). The Danish Bispebjerg Hospital (1913) designed by the architect Martin Nyrup is built in this manner.

\section{3-52}

The German Karl Bötticher (1806-89) wrote: Die Tektonik der Hellenen (The Tectonic of the Hellenes), where he presents the concepts of Kernform and Kunstform distinguishing between material craft and artistic representation. According to Frampton, Bötticher used the term 'tectonics' as signifying a complete system binding all the parts of a building into a single whole including relief sculptures (Frampton 2001:4).

\section{5}

The German architect Gottfried Semper (1803-79) makes a design proposal for a Hospital for Fürsten Ghica in Bucharest (Nerdinger \& Oechslin 2003:245-47).

\section{9}

The Scottish architect James Fergusson (1808-1886) published: An Historical Inquiry into the true Principles of Beauty in Art: More especially with reference to Architecture. Herein he on the basis of a series of travels and empirical studies of Egyptian, Asian, Grecian, Etruscan and Roman art, as well as a great inspiration in the writings of Rousseau presents his argument that all man are born equal and that the true mission of art should be to improve knowledge in the public mind (Fergusson 1849:6).

\section{9-51}

The composer Richard Wagner taking his point of departure in Opera and the unique combination of music, theater, dance, literature and the decorative arts is often credited with formulating the concept of the Gesamtkunstwerk in a series of publications published during this period (Kallir 1986:22).

\section{c. 1850}

The Danish Royal collection of Copper ware was begun which comprise around 800 pieces spread at 45 different types - pots, pans, kettles, boilers, saucepans, casseroles, frying pans, bain-marie's, casks, dishes, cake tins, lids, containers, colanders and cauldrons. The first elements crafted by hand and the newest industrially fabricated (Krog \& Dahl 2003). 


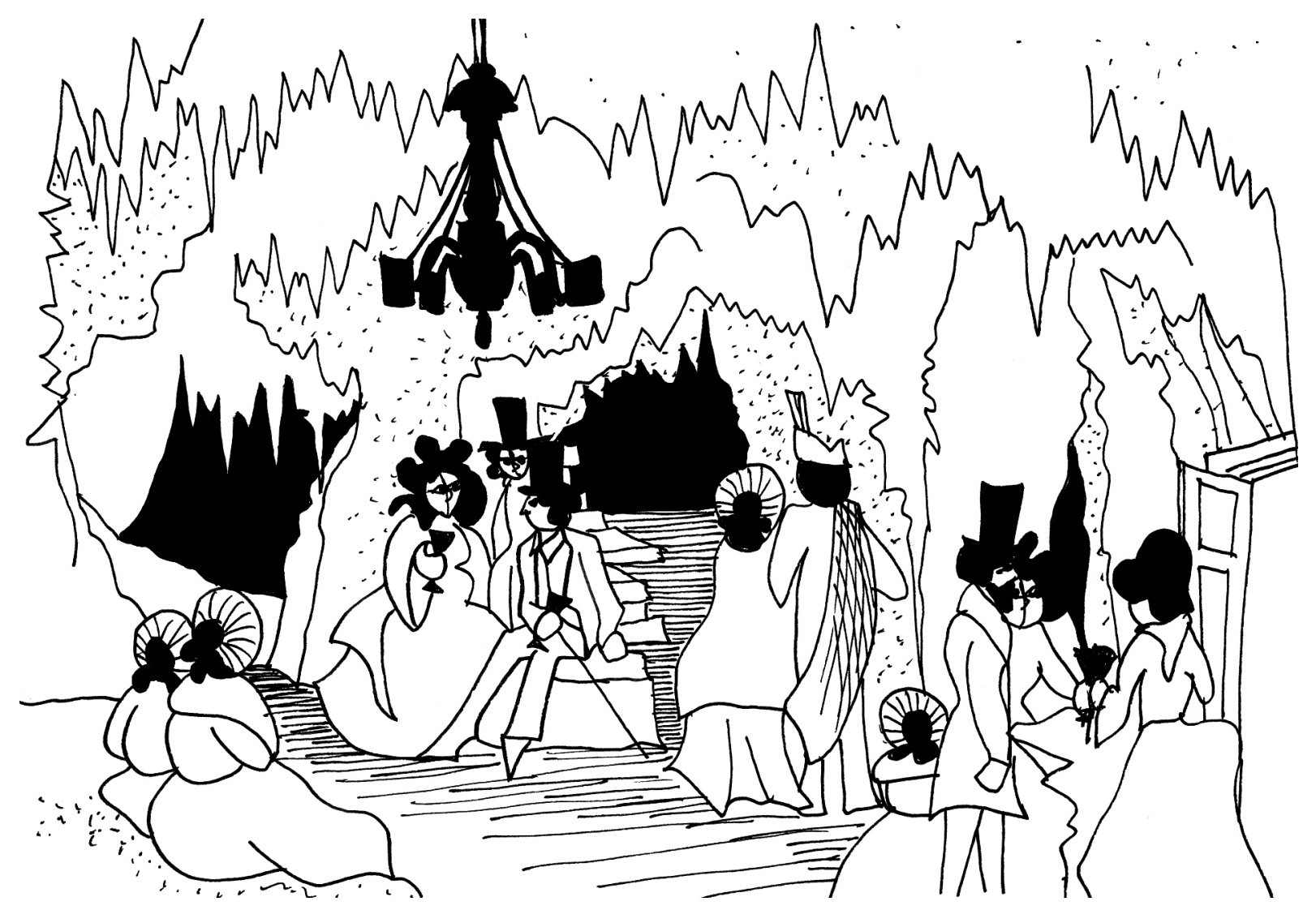

\section{0}

The German architect Gottfried Semper (1803-79) makes a design proposal for a café/coffeehouse. At the same time he also makes a proposal for a Salon in Schloss Bois-le-Roi (Nerdinger \& Oechslin 2003:269,272).

\section{1}

The Great Exhibition held in London, Crystal Palace exterior designed by the gardener Joseph Paxton. It is one of the first exhibitions of industrial production (Engholm \& Michelsen 2000:16). Gottfried Semper designs the interiors displayed at the exhibition for Canada, Sweden and Denmark (Nerdinger \& Oechslin 2003:276-77).

\section{$1851+53+63$}

Gottfried Semper writes: Die vier Elemente der Baukunst (Four Elements of Architecture, 1851) and Style (1863). According to Frampton (2001:5) indirectly challenged the neoclassical primitive hut as presented by Laugier. This is based on an actual Caribbean hut Semper saw at the Great Exhibition in London in 1851. Semper's hut is instead divided into the four elements: hearth, flooring, walling and roofing. On the basis of this taxonomy Semper, according to Frampton classify building crafts in two fundamental procedures - the tectonics of the frame and the stereotomics of the earthwork (Frampton 2001:5). Semper further makes a design proposal for a Spa (Wasch- und Badeanstalt) in London and in 1853 he makes a design proposal for an Auswandererhospiz (Nerdinger \& Oechslin 2003:79,281).

\section{1}

The restaurant Universal Symposium was opened by the French chef Alexis Soyer (1809-1859). Between 1821 to 1837 Soyer served as a cook to several French and English nobles, but he is perhaps most known for his time as a master chef at the London Reform Club and the grand banquets he held for hundreds or even thousands of people during 1838 and 1846. Furthermore Soyer published several cookery books - among them: The Gastronomic Regenerator: a simplified and new system of cookery (1846), The modern Housewife, or Ménagére (1849), Soyer's Charitable Cookery, or the Poor Man's Regenerator (1855) and A Shilling Cookery Book for the People (1855). Hence, Soyer devoted his culinary talent to both the very rich and the poor (Soyer 1977:i). Soyer was also a humanitarian organizing soup kitchen for the poor during the Irish famine of in the late 1840s and who during the Crimean War provided soldiers with nourishing foods on the battlefields in collaboration with the nurse Florence Nightingale and her medical staff in Balaklava. Finally, Soyer helped reorganizing food provision in hospital kitchens and invented a magic stove as well as a modern gas cooking apparatus (Soyer 1977:ii; Cowen 2006:213-215). In his book: The Pantropheon or a history of food and its preparation in ancient times (1853), Soyer writes about agriculture, kitchen gardens, a series of different types of foods, the dining room, the table, table seats and the Roman supper, as well as finishes off with a section on "modern" banquets (Soyer 1977). 


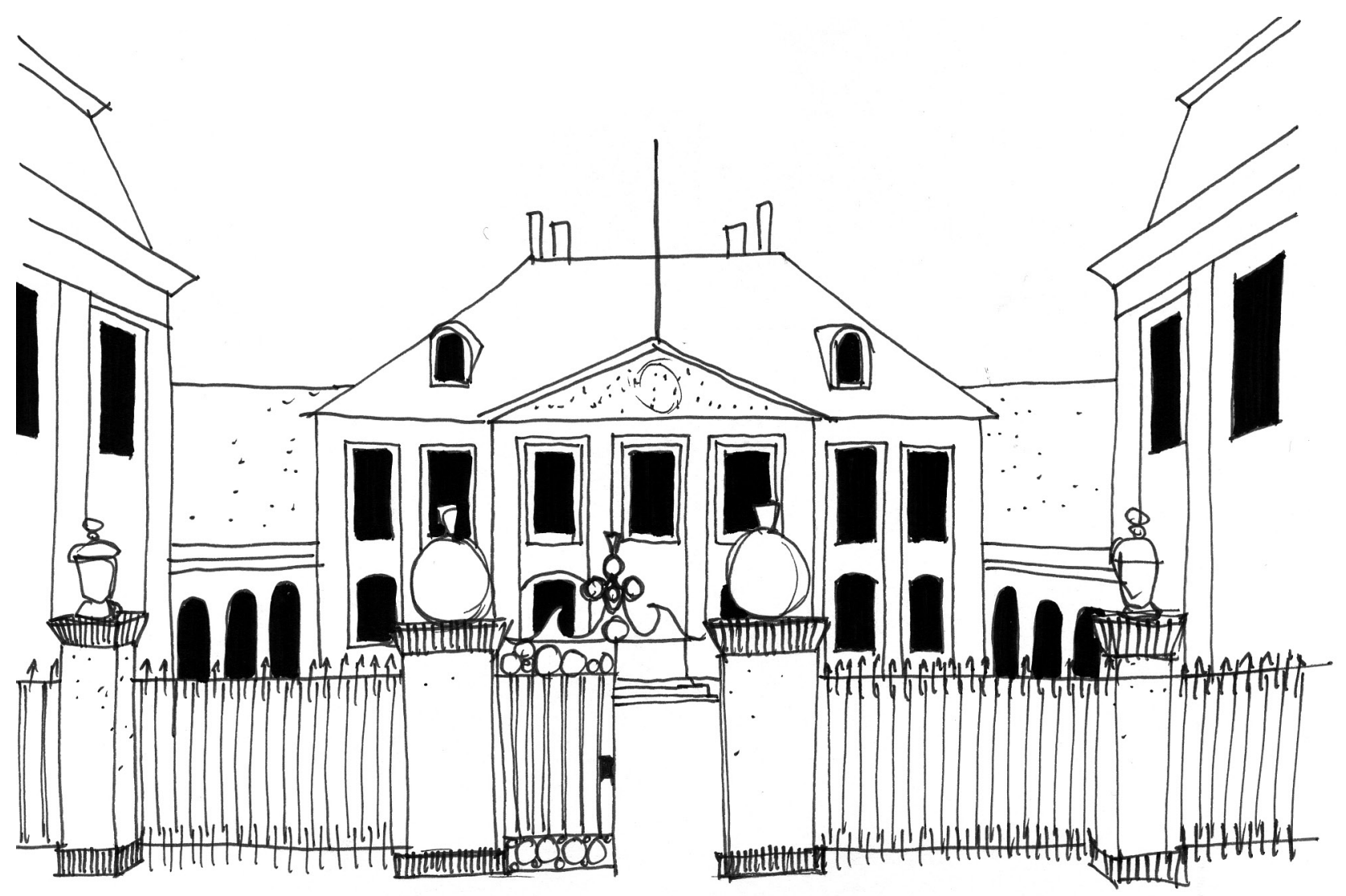

TUBERCULOSIS

\section{5}

The English nurse Florence Nightingale (1820-1909) was send off as "lady in chief" to the front lines of the Crimean War in Turkey from 1853 to 1855 in an attempt to reform barrack hospitals nursing the wounded English soldiers (Verderber, 2010:20; Bäüner 1952:14). Here Nightingale encountered a very high mortality rate among the wounded soldiers. In the attempt to changes this she transformed the entire hospital facility by improving among others hygiene conditions and diets (Verderber, 2010:21). Later Nightingale published: Notes on Nursing (1858) and Notes on Hospitals (1859) advocating for an improved education for nurses, as well as emphasising that natural daylight, fresh air, clean water, efficient drainage and proper food servings were important parts of the medical and surgical treatment procedures. Presumably this also in continuation of the tendencies with the Pavilion Hospital lead to the development of the Nightingale Ward where 26 to 30 patient beds were aligned in two long rows in an open hall further encompassing bathrooms, sculleries and nurse stations strictly separated from other wards and different patient groups (Bäüner 1952:20-21,27; Verderber, 2010:21; Heslet \& Dirckinck-Holmfeld 2007:58).

\section{6}

Félix Urbain Francois Dubois, a student of Carême, published: $\mathbf{L a}$ Cuisine classique. According to Mennell (1985:150) he became even more famous for his architectural creations and his dishes were even decorated with inedible details and reinforcement. But he is also known for moving the food service style from service á la francaise to service á la russe, thereby promoting the serving of hot food (Franck 2002:60; Mennell 1985:150).

\section{7}

The skeleton of a Neanderthal man is found by Johann Karl Fuhlrott (Mallgrave \& Robinson 2004:27).

\section{9}

English naturalist Charles Robert Darwin (1809-1882) published: On the origin of Spicies, this became the outset for the idea of evolution.

\section{Late 19th century}

Service á l'assiette followed the emergence of restaurants taking the servings of food into plate servings delivered directly from the kitchen to the individual diner. This scaled down the artistic presentation of the food even more, but thereby also making the chefs responsible for the arrangement and portion size to each guest instead of the waiters (Franck 2002:61; Olsen 2008:320).

\section{9-66}

The German architect Gottfried Semper (1803-79) makes a design proposal for the Kurhaus und Badhotel in Bad Ragaz (spa and health resort). Simultaneously during 1861-62 Semper also makes a design proposal for Kranken- und Irrenanstalt Königsfelden (Hospital and Insane hospital), a proposal for Waschschiff Treickler (Public laundry boat) in Zürich, as well as a design proposal for the Konversationshaus Baden (health resort) in Bäderstrasse. Here he combines health treatments with a restaurant, a café, a theatre and a grand garden with a small zoo (Nerdinger \& Oechslin 2003:352,364-66,424-28).

\section{2}

The Gastronomic Analogy was put forth by the Scottish architect James Fergusson (Collins 1965:167). 
Fig. 6.15

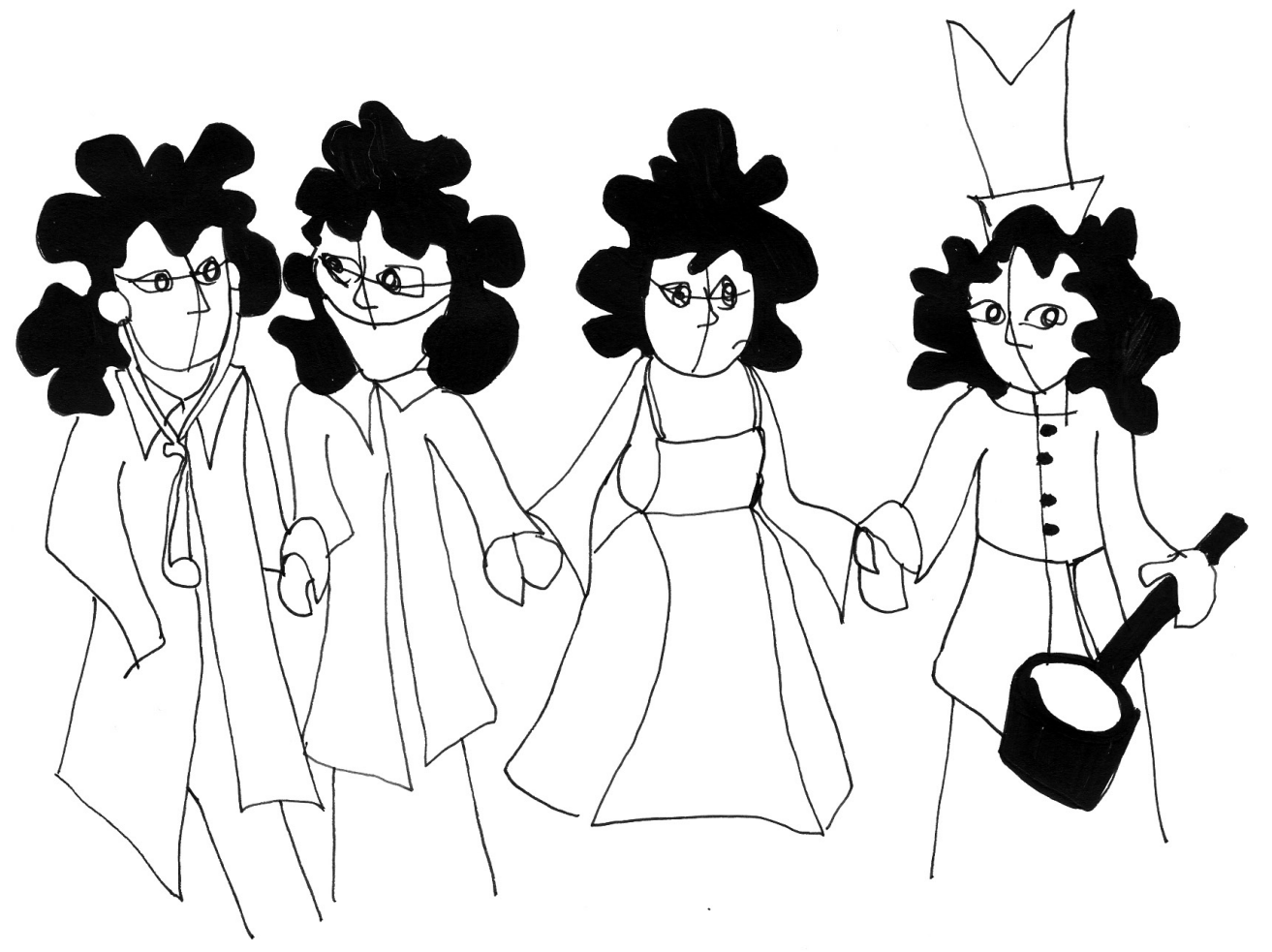

"A Holistic view “

Frederiks Hospital in Copenhagen

(Drawing adopted from Heslet \&

Dirckinck-Holmfeld 2007:33)

1867

The French chef and confectioner Jules Gouffé (1807-77) published: Le Livre de cuisine (The Royal Cookery Book) and later also: Le Livre de Pâtisserie (The Royal Book of Pastry and Confectionery). He was the student of Carême and skilled maker of pieces montées (Mennell 1985; Fisker \& Jørgensen 2010c).

\section{2}

The book: Le Grand Dictionnaire de cuisine (Great Dictionary of Cuisine) written by the French fictional writer Alexandre Dumas (1802-70) was published. The book reflects Domas' great interest in cooking and skills as a gourmet (Fisker \& Jørgensen 2010d).

\section{6}

The British writer John Ruskin published: The Stones of Venice. Herein Ruskin blamed industrialization and machinery for the many social ills flourishing the workers during the 19th century (Whyte 2004:48).

\section{7-1931}

The German philosopher Edmund Husserl (1859-1938) who is considered the "father" of phenomenology published a series of writings wherein he among others broke with the positivist philosophical stance dominating science, instead giving weight to subjective experiences as a source of knowledge (Oxford Dictionary of Philosophy 1994:181; Olsen 2008:321).

\section{8}

Louise Nimb writes the Danish cookery book: Fru Nimbs Kogebog (Mrs. Nimb's Cookery Book) introducing culinary recipes for both every day and festive occasions (Dybdahl \& Engholm 2008:12).
1889

World Exhibition in Paris with among others the erection of the Eiffel Tower.

1889

Moulin Rouge, a Parisian cabaret with courtesans in exotic feathers and fur dancing can-can was founded by Charles Zidler and Joseph Oller. The cabaret was part of the Belle Époque era where we see a rapid development in public entertainment such like casinos, music halls and theatres with extraordinary interior designs (Shattuck 1955:4; wikipedia.org 2012).

\section{9}

Hotel Savoy replaced the Hospital Savoy in London with a luxury hotel built by impresario Richard D'Oyly Carte presenting entertainment and elegant dining within stateof-the-art interior architecture (Henderson 2006:xxvi; Freedman 2007:323-24).

\section{9+1915}

The Swiss art historian Heinrich Wölfflin (1864-1945) published: Klassische Kunst. Eine Einführung in die italiensche Renaissance (1889) and Kunstgeschichtliche Grundbegriffe (1915). In the later book he presents the comparative method of analyzing art objects as interdependent on contrast and opposition (Bek \& Oxvig 1999:113). 
c. $1890 \mathrm{~s}$

The invention of the diesel engine, oil engine, modern automobile, telephone, typewriter and tape recorder (Engholm \& Michelsen 2000:22).

1893

Restaurant Maxim's was founded as a bistro in Paris by former waiter Maxime Gaillard. The second owner, Eugene Cornuché, gave the restaurant its Art Nouveau interior décor (Wikipedia. org 2012; Shattuck 1955:4). Maxim's is part of a movement in the Belle Époque era, were restaurants became the scene or forum for complex social interactions, cultural influences and for showing personal identity, as well as expression of individual desires and moods through choices of eating, drinking and entertainment.

\section{$1893+94+1905$}

The German art historian August Schmarsow (1853-

1936) gave a lecture where he rejected the "art of dressing" (decoration in architecture). In 1894 he published: Das Wesen der architektonischen Schöpfung (The Essence of Architectural Creation) and in 1905 he published: Grundbegriffe der Kunstwissenschaft. In the first text Schmarsow on the background of theory developed by Semper advanced the primitive hut as the primordial shelter, and according to Frampton makes an interesting distinction between Raumwissenschaft being the mathematical science of space, and Raumkunst being the architectural art of space. Furthermore he used the notion Raumgestalterin to denote the "createness" of space - seeing the evolution of architecture as the progressive unfolding of man's feeling for space (Frampton 2001:1,18,389; Mallgrave 2008:82).

"Willow Tea Rooms" (Drawing adopted from Billcliffe 1979:153
1893

Artist and sculptor Adolf von Hildebrand (1847-1902) published: Das Problem der Form in der Bildenden Kunst (the problem of form in painting and sculpture, 1907)(Frampton 2001:notes)

\section{3}

The Austrian art historian Alois Riegl (1858-1905) published: Stilfragen, Grundlegungen zu einer Geschichte der Ornamentik (Bek \& Oxvig, 1999:46)

\section{5}

The method of producing X-ray images was discovered by German physicist Wilhelm Röntgen (Wikipedia.org 2013).

\section{6+1903-4}

The Buchanan Street Tea Room and Willow Tea Rooms in Glasgow, Scotland designed by the architect Charles Rennie Mackintosh (1868-1928). Mackintosh is known for his complete interior spaces. The tea rooms are designed as a response to a social problem plaguing Glasgow in the late 1880s, where the increasing heavy industry led male shipbuilders to severe drunkenness during daytime because there were no places to go during lunch but bars and public houses (also including drinking). With the design of the tea room they daughter of a wealthy Glasgow tea importer tried to changes this by offering a rival to the public "drunk" houses. Mackintosh designed everything rooms, furniture, china, and murals (Kurtich \& Eakin 1993:10)
$1898+1910$

The Austrian-Hungarian born Adolf Franz Karl Viktor Maria Loos (1870-1933) published the essay: Das Prinzip der Bekleidung (The principle of Cladding). He is also known for the essay: Ornament und Verbrechen (Ornament and Crime) where he rejects ornamentation from useful objects (Frampton 2001:18).

\section{8}

Hotel Ritz, a grand Hotel in Paris was founded by the hotelier César Ritz and the chef Auguste Escoffier. The hotel is part of a huge development in hotels, bistros, salons and restaurants occurring in New York, London and Paris during the era of Belle Époque, where French haute cuisine was modernized by chefs like Escoffier (Mennell 1985:157; Freedman 2007:325; wikipedia.org 2012)

\section{0}

The French chef Prosper Montagné (1864-1948) returned to Paris, where he worked in several restaurants and Grand Hotel, before he began writing his own cookery books (Fisker \& Jørgensen 2010b).

\section{1}

The Danish classical cookery book: Frøken Jensens Kogebog is published (Dybdahl \& Engholm 2008:12). 


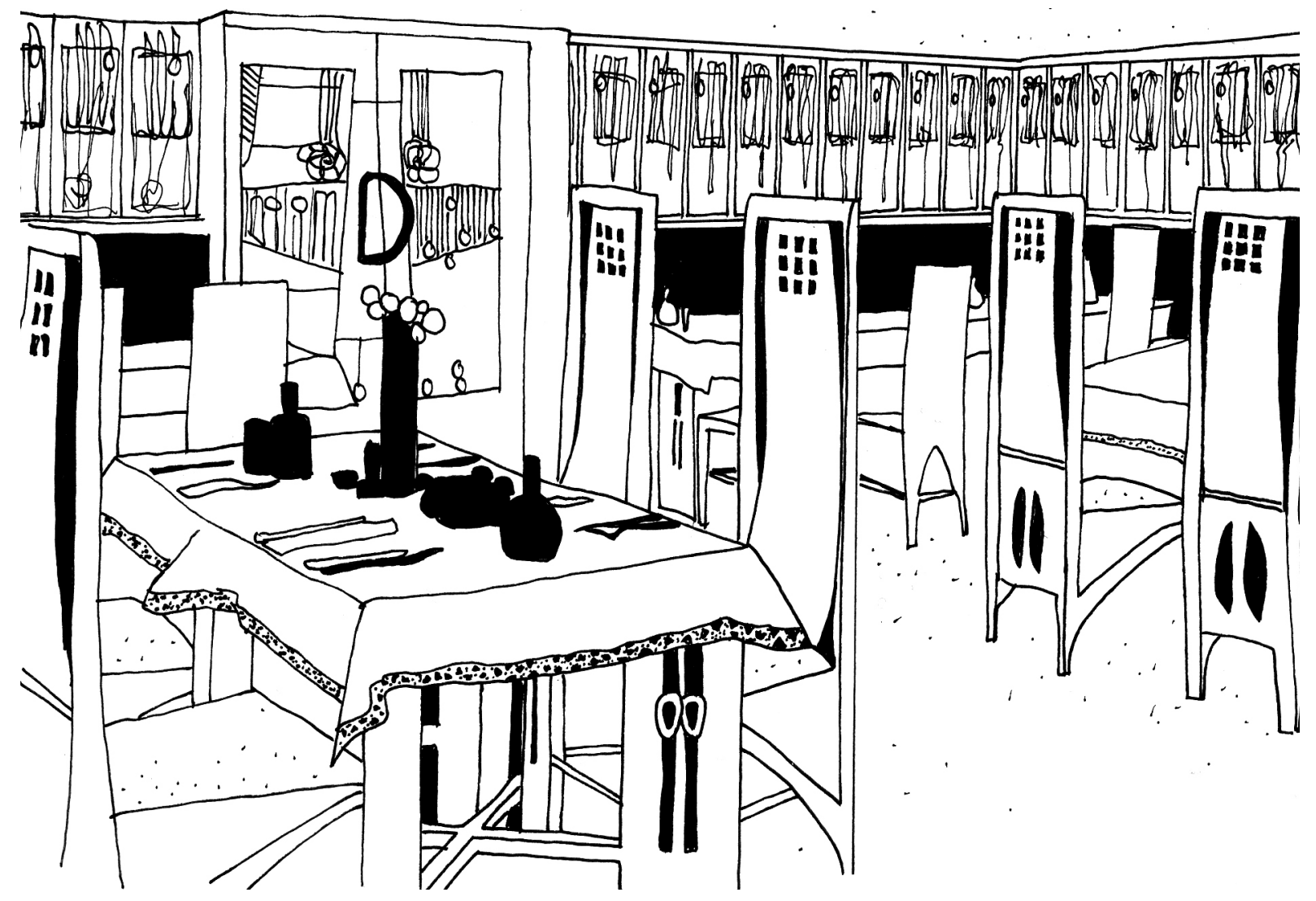

\section{3}

The first attempts towards flying by the brothers Wright (Engholm \& Michelsen 2000:22)

$1903+17$

The French chef Georges Auguste Escoffier (1847-1935) published: Le Guide Culinaire (1903) and Le Livre des menus (1917). He was first chef at Hotel Savoy, London and later at Hotel Ritz, Paris where he became highly esteemed among gourmets for cutting down on the "clumsy" garnishes. Instead he insisted that all food had to be edible and focused on the perfect balance of a few superb ingredients, simply-cooked vegetables. In that way he is considered one of the developers of modern French cuisine (cuisine classique) and the introduction of service á la Russe. Escoffier is furthermore known for introducing the rational techniques of mass-production and divisions of labor associated with factories into the large restaurant and hotel kitchens introducing the concepts of a "culinary battery" or what is also known as the Brigade de cuisine with five interdependent parties segmenting the various tasks in the cooking process into different stations and work divisions (Mennel 1985:157-59; KirshenblattGimblett, 2007:76-77).

\section{4-17}

The designer Tony Garnier (1869-1948) designed the proposal for: La Cité Industrielle (The Industrial City). A scheme illustrating a modern city built on a neo-classical plan featuring a monumental civic city center with cultural buildings, single-family houses with Roman atria and garden terraces. Garnier emphasized unornamented walls and hygienic aspects such as sunlight and fresh air to penetrate the interior spaces (Moffett 2004:506).

\section{$1904+05$}

The Dutch-born Hendrik Petrus Berlage (1856-1934) gave a lecture defining architecture as the "art of spatial enclosure". According to Frampton (2001:18) Berlage argued that the nature of the wall was surface flatness and those constructive parts such as pillars and capitals should be assimilated into it without further articulation (decoration and ornament). In 1905 he published the text: Gedanken über Stil in der Baukunst (Thoughts on Style) inspired by the writings of Semper. Here he encouraged the architects to devise the decorative motives in architecture directly out of the construction itself (Mallgrave 2008:118).

\section{$1905+16$}

The German physicist Albert Einstein (1879-1955) discovered the Theory of Relativity. The general theory is not published until 1916. Einstein was known for his strong interest in philosophical thought, among others Hume, and apparently this influenced his reflections on the nature of the world leading him to suspect that a "marble" of space, time and geometry existed (Oxford Dictionary of Philosophy 1994:115-116). 


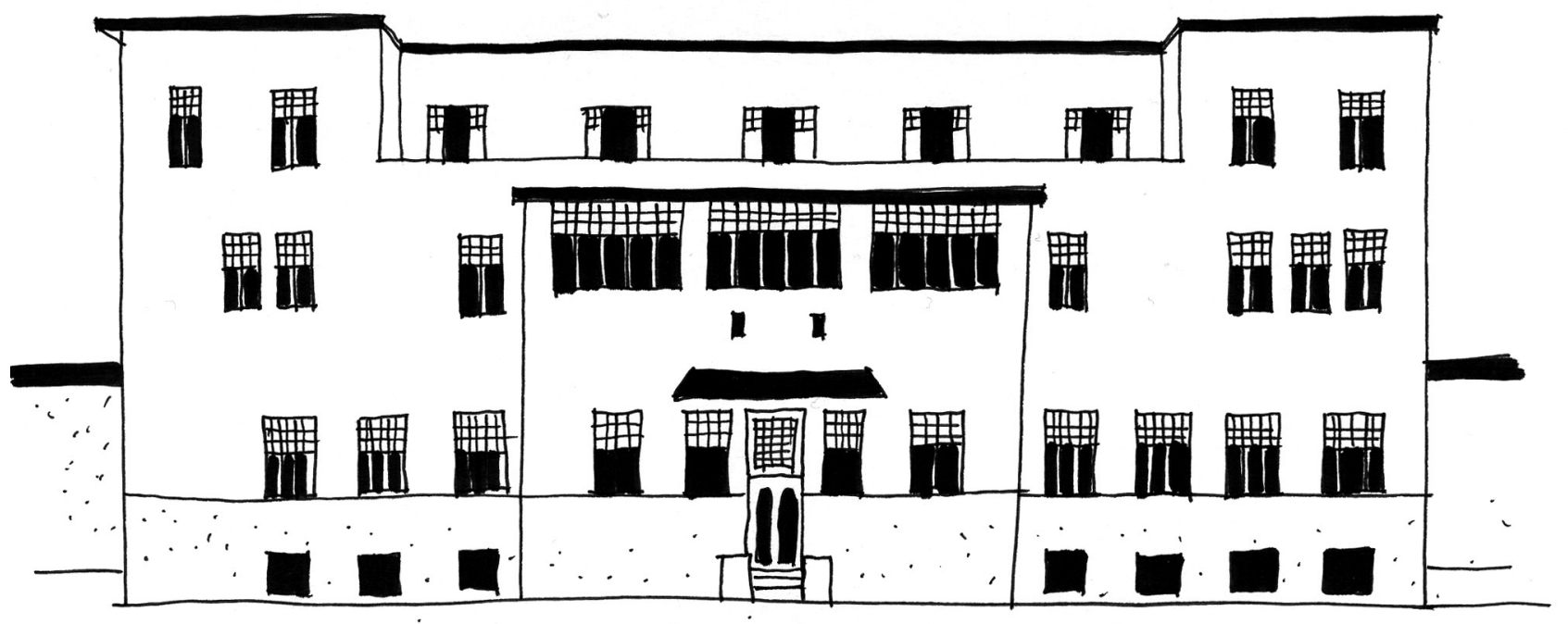

Fig. 6.17

"The Sanatorium"

(Drawing adopted from Sarnitz

2007:46,49)

\section{4}

The Sanitarium Purkersdorf designed by architect Joseph Hoffmann (1870-1956) was a spa built for the treatment of nervous disorders among the European upper classes, thus functioning as part health resort, part hospital. The interior design of the building is very detailed and is one of the earliest major examples of the "total designs" made by the Wiener Werkstätte (Kallir 1986:53).

\section{7}

The Japanese chemist Kikunae Ikeda writes about the

"deliciousness" of taste in Journal of Chemical Society of Tokyo. It is considered a seminal finding in the physiology of taste, later leading to the discoveries of Umami (L-glutamate) (Lehrer 2007:57-58).

\section{$1910+35$}

The first electrical refrigerators occur in the US during the 1910s. In 1935 the American designer Raymond Loewy designs the legendary French-American refrigerator 'Coldspot Super Six'. Introducing an aerodynamic look to kitchen utensils (Dybdahl \& Engholm 2008:74).

\section{3-27}

The French novelist Valentin Louis Georges Marcel Proust (18711922) writes: À la recherché du temps perdu (In Search of Lost Time/Remembrance of Things Past).

\section{$1912+15$}

The American housewife Christine Isobel McGaffey Frederick (1883-1970) publishes among others the article: Household Engineering: Scientific Management in the Home, which is a text dedicated to applying the rational efficiency of industrial production to the domestic kitchen (Dybdahl \& Engholm 2008:17).

\section{c.1914}

The car company Ford develops the principle of the assembly line (Engholm \& Michelsen 2000:22).

\section{6}

The lectures held by the Swiss linguist Ferdinand de Saussure (1857-1913) who is generally considered the "father" of structural linguistics and of structuralism in its wider application were published (Oxford Dictionary of Philosophy 1994:340; Olsen 2008:322).

\section{1}

The Swiss architect Adolphe Appia (1862-1928) published: L'oeuvre d'art vivant. Previously he had written: La mise en scene du theater Wagnerien (1891). Herein he wrote on spatio-corporeal connotations which were a distinction on the interplay between body and form on the stage (Frampton 2001:11).

1923

Haus am Horn is built at Bauhaus in Weimar. Here the kitchen designed by Benitta Otte and Ernst Gebhardt is decorated with an almost "clinical look" and it is considered one of the most innovative interiors in the test house, and a direct forerunner for the standardization kitchen elements found in the modern kitchens (Dybdahl \& Engholm 2008:34).

\section{$1923+66$}

The architect Charles-Edouard Jenneret-Gris, also known as Le Corbusier (1887-1965) published Vers une architecture (Towards a New Architecture). In 1966 Corbusier also made a rather remarkable proposal for a grand new hospital in Venice, Italy (Sarkis 2002). 


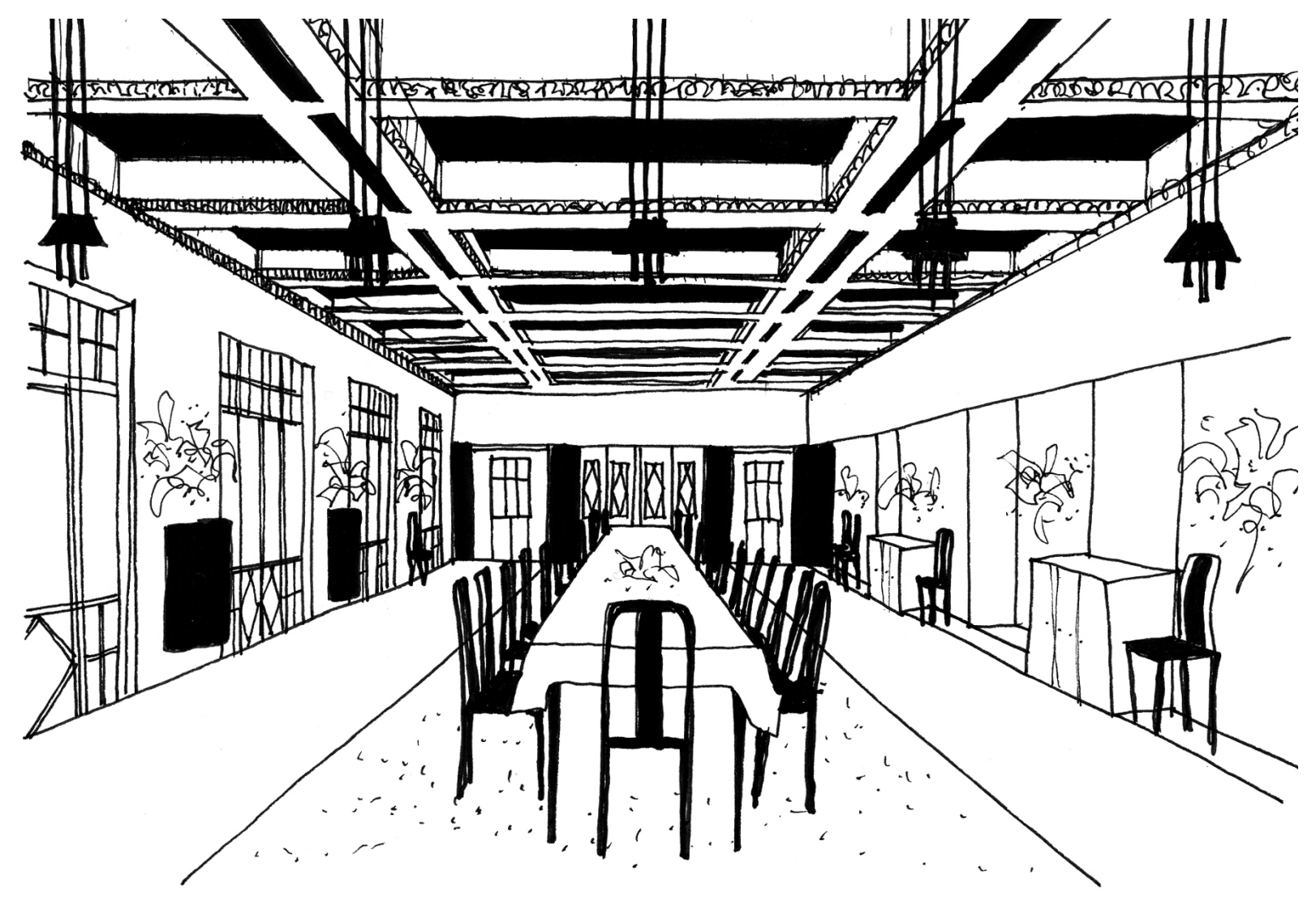

\section{4}

The Austrian art historian Max Dvorák (1874-1921) was published in: Kunstgeschichte als Geistesgeschichte Studien sur abendländischen Kunstentwicklung, here he linked an art object with the time it had been produced, thus making the artifact a representative of a specific era (Bek \& Oxvig 1999:70).

\section{6-27}

The Austrian architect Margarete Schütte-Lihotzky (1897-2000) designed the Frankfurt Kitchen, which is today considered a milestone in domestic architecture, and the forerunner of modern kitchens. Here she optimized the movements of the housewife as much as possible and improved sanitation conditions/hygiene, by re-organizing the interior parts according to the use of the different functions during the process of cooking. (Dybdahl \& Engholm 2008:17).

\section{7-40}

The German literary critic Walter Bendix Schönflies Benjamin (1892-1940) works on the collections of writings on the Arcades Project (Hartoonian 2010; Benjamin \& Rice 2009).

$1927+51$

The German philosopher Martin Heidegger (1889-1976) published: Sein und Zeit (Being and Time) and later Bauen, Wohnen, Denken (Building, Dwelling, Thinking).
1927-29 - The Paimio Tuberculosis Sanitarium designed by the Finish architect Alvar Aalto (1898-1976) was built. Despite the building's high-rise exterior style, each level included balconies for exploiting the curative powers of sunlight and fresh air. Furthermore patient rooms were designed to foster a communal atmosphere and special attention was given to interior detailing such as locating artificial light behind patients' heads to reduce glare, as well as incorporating wall-hung cabinets to ease cleaning, washbowls designed to control splashing together with ergonomic shaped door handles and custom designed furniture (Moffett et al. 2004:533; Verderber 2010:35).

\section{7-30}

The Cornell Medical Center of New York Hospital is built. It is one of the first hospitals to be built as a "skyscraper" or what is also called high-rise urban hospitals. Contrary the pavilion hospital, the rational, technological and industrial building developments provided modern high-rise hospital with the possibility to "stack" patient wards on top of each other, allowing for hundreds and thousands of beds in total on much fewer squaremetres and at a much lower cost (Heslet \& Dirckinck-Holmfeld 2007:92; Verderber 2010:34). According to Bromley (2012:1059) the modern hospital also adopted rational techniques of standardization and accountability to address the problems of inconsistency and human errors in the quality of medical care.

1929

The architectural historian Henry-Russel Hitchcock published: Modern Architecture: Romanticism and Reintegration. 


\section{THE HOSPITAL, HEALTH RESORT AND RESTAURANT}

With the French Revolution (1789-1799), the courtly banquets previously practiced were replaced by new forms of festivity and sociability (Kirshenblatt-Gimblett 2007:75). During the late Renaissance, the power of the aristocratic households was largely reduced and many cooks were left unemployed. Presumably, this meant that many skilled cooks established other places to work and serve meals for the new class: the bourgeoisie who could pay for such meals. And cooks were turned into a professionalization of 'chefs' and the emergence of "modern" restaurants. In 1789, the shared revolutionary optimism presumably led the proprietors of the new cirque de Palais Royal (a multi-venture center of enlightenment and entertainment) advertised that their ample establishment included both a café and a restaurant (Spang 2002:79; Mennell 2003)[Olsen 2008:320]. According to sociologist Joanna Finkelstein (1989:3839 ), the diners at some of the first restaurants did not come there for fine eating, but instead it was a commercial enterprise imitating the fashionable style and form of life associated with the declining aristocracy. They wanted to appear as the new social elite, and dining at restaurants thus became a status symbol and a way to display a new and fashionable lifestyle (Gustafsson et al. 2008:85). Finkelstein (1989:37) notes how restaurateurs in their competition for business fostered a particular interest in the "theatricality of gastronomy and the drama of the restaurant". Meaning that restaurateurs employed the design and presentation of food, décor or service as a mean to attract and distract customers (Finkelstein 1989:37). Relative hereto, one of the characteristics of the banquets held during the Roman, Medieval and Renaissance era is the vast amount of dishes served to the dinner guests during the feast.

As seen from the illustrations (see Figure $6.8,17^{\text {th }}$ century and Figure 6.7, The Sugar Banquet), numerous plates and dishes are lined up on grand tables in front of the guests while they feast. During the period of Enlightenment and particularly in the $18^{\text {th }}$ century, this method or style of serving food was referred to as service á la française. In the early $19^{\text {th }}$ century, this style of food serving culminated with the "culinary designs" of the French chef Marie Antoine Carême (1784-1833). Greatly inspired by the contemporary architectural styles, he apparently went to the Bibliothéque Nationale to copy the prints of classical monumental architecture as inspiration for his spectacular pieces montées which were ornamental displays and decorative socles or pedestals on which food (most often pastry or sponge cake, nougat, almond flour and sugar) was sculpturally mounted (see Figure 6.12, Carême) (Franck 2002:59). The specific placement of the pieces montées and the different dishes with food followed a very precise geometric and often symmetrical arrangement (Franck 2002:60). Carême's books: La Pâtissier pittoresque (1815) and L'Art de la cuisine francaise au XIX siècle (1833-35) is full of directions for how to arrange these dishes, plates, candles, salts and other decorative elements on the table (Mennell 1985:145). Each element was placed with careful attention to the hierarchy of each dish and its position within the overall system, and often special containers, tureens and sauce boats had been invented for displaying the foods at these events (Franck 2002:60). Furthermore, according to Strong (2002:282), Carême synthesized gastronomy not only with the arts (architecture, sculpture, painting, literature and poetry) but also the sciences (physics, chemistry, political economy and commerce) in his control with every detail and aspect of the culinary events - from the choice of dishes to the display of food, table layout and decoration of the entire room.

By the 1740s, such an occupation with the interior architecture of eating environments as material 'assemblages' had already sparked an "industry" where entire dinner services in silver were being commissioned by the European Courts and aristocracy, and quickly spread into the middle classes and the bourgeoisie (Strong 2002:233-38). Later on, during the mid- $19^{\text {th }}$ century and the culinary style fashioned with Carême, there is a shift from silver to faience and porcelain, as well as copper ware, where thousands or hundreds of pieces decorated with wild game or flowers like the Danish Flora Danica or Danish Royal collection of Copper completely changed the visual impact of what Strong (2002:239) refers to as the 'tablescape' of the eating environment. The great displays of porcelain, silver and copper and figurative presentation of dishes laid out not only on the dinner tables, but also displayed in cabinets and side buffets moved the meal from the regular eating context into a cultural sphere where the connotative meaning of the design of the porcelain takes on an importance equal to - or greater than - the practical edible function of food during the meal. Consequently, the 
porcelain and entire interior 'assemblage' functioned as a political and social display of power or a symbol of wealth in addition to serving as practical tableware [Fisker \& Olsen 2008:2]. In continuation hereof, Strong (2002:242-45) notes that the modern understanding of a dining room as a separate space for eating does not officially appear in French literature until around mid- $17^{\text {th }}$ century as a 'sale á manger' and in English literature until the mid- $18^{\text {th }}$ century as a 'dyning room' [sic!]. However, in 1773 the Scottish-born architect and interior designer Robert Adam supposedly highlighted a series of fundamental differences distinguishing French and English dining rooms. In England, men stayed behind to talk and drink, whereas in France they withdrew into the salon to have conversations (Strong 2002:245). Strong (2002:245) notes that this leads Adam to conclude that the English dining room must, therefore, be elegant and splendid in its interior style - and "instead of being hung with damask, tapestry etc., they are always furnished with stucco, and adorned with statues and paintings, that they may not retain the smell of the victuals". And Strong (2002:245) continues his reference to Adam stating that "it was essential for the architect to have total control over the whole mise-en-scéne down to the curtains and the silver". What is important to notice, according to Strong (2002), is that even though by the late $18^{\text {th }}$ century that a special room for eating was established in domestic houses, it did not mean that the interior was permanently set up. Instead the chairs stood against the wall and were only brought forward for the meal. The table was the only permanent and central element of the 'tablescape' remaining in position in the room when not eating (Strong 2002:245). Nevertheless, by the 1850s, Strong (2002:290) notes that the occupation with the choreography of bourgeois domestic everyday eating and dinner parties had turned into a major preoccupation for architects, who not only designed special breakfast or luncheon rooms and state dining rooms, but who also engaged in an orchestration of spaces and movements of dinner guests that ensured they would never cross paths with the servants bringing food from the kitchen. The dining room, thereby, according to Strong (2002:290), became a "clear symbol of class distinction, an embodiment of the separation of the owners and the family from the servants and the practicalities of cooking. It was a room for display...".

In the late $19^{\text {th }}$-early $20^{\text {th }}$ century with the French chef George Auguste Escoffier (1847-1935) who is considered the "father" of cuisine classique, the food serving style had transformed from service á la française to service á la russe (Franck 2002:60). Here, in the opulent and exclusive eating environments of Hotel Ritz and Hotel Savoy, dishes were presented one after another in sequence directly to each guest individually by a waiter, instead of being located on a grand table before the meal. In that way, the food would presumably remain hot and keep its flavor longer than previously (Franck 2002:60; Strong 2002:284-85). However, according to Franck (2002:60), elaborately constructed cold dishes, often in aspic, could still be used as display. With the transition from service á la française to service á la russe, the spectacular grand tables and interior landscapes of different tableware dating back to medieval and renaissance eras were rejected - leaving the 'tablescapes' quite empty [Olsen 2008:32]. Instead the 'tablescapes' and interior, according to Strong (2002:298-99), were decorated with real flowers and plants in "fancy flower pots", silver centerpieces and candelabra. Despite the transition from service á la française to service á la russe, due to the large amount of different courses served during a meal (hors d'oeuvre, soups, fish, entrée, piece de résistance, sorbet, roast and salad, vegetables, hot sweet, ice cream, dessert, coffee and liqueurs) still demanded a plentitude of porcelain service, tableware, damask tablecloth and cutlery for display which was further emphasized and empowered by the increasing industrialization, mass production and franchise of such handicrafts (Strong 2002:299). In that way, some of the earliest interiors of restaurants and hotels closely imitated the domestic bourgeois dining room tendencies with distinctive interior 'assemblages' of delicate porcelain, copper ware, grand mirrors, landscape paintings and candlelit tables dressed in damask (see Figure 6.11, The Bourgeois Restaurant).

In continuation hereof, I find it quite interesting that Spang (2002:1) notes that originally the term 'restaurant' did actually not refer to the interior architecture of an eating environment, as it does today, but was instead a medical term used to denote the actual object eaten - a restorative broth or bouillon made from capon or chicken. As mentioned in the Timeline, according to Spang (2002:1), in the $15^{\text {th }}$ century a recipe for a 'restaurant' instructed that "a freshly killed capon be cooked in an alchemist's glass kettle with sixty gold ducats, and noted that the cook might supplement the gold pieces 
with diamonds, rubies, sapphires, jaspers, or any other good and virtuous precious stones the doctor may order". In the $17^{\text {th }}$ and $18^{\text {th }}$ century this description of a 'restaurant' is altered into a medical term offering bouillon-based preparations or consommé restore health to suffering invalids in French cookery books and the Encyclopedia (Spang 2002:1,3). Simultaneously with the increasing amounts of restaurants in larger cities like Paris and London, an escalation occurred in culinary literature.

Even though the term 'gastronomy' presumably does not occur until around the early $19^{\text {th }}$ century with the writings of French lawyer Jean Anthelme Brillat-Savarin (1755 - 1826), according to Professor of History Paul Freedman (2007:199), what is very interesting about most of the first cookery books, like the one written by Platina (1421-81), published in Rome, Florence, Venice and later Paris and London is that they tried to balance both the dietetics and the science of eating for good health with gastronomy. Freedman (2007:201) notes that the rationale behind this was that back then a belief that healthy diet was good for you and thus understanding how food worked to nourish the body would also lead to healthier lives, together with a happier and more prosperous society. With Platina's writings, the concern for dietetic healthiness was combined with culinary pleasure, and thus health and well-being were closely linked to the art of eating well for pleasure and the signs of cultural refinement already closely linked with eating through the interior architecture staging the meal (Freedman 2007:199). These ideals, like the fashion of the previouslymentioned Roman Convivum, show a strong link back to the prescriptions of Galenic physiology and his medical model of the 'Four Humours' used throughout antiquity and medieval times where the well-being of the human body was based on a balancing of 'the humours' by regulating the impact of the surrounding environment and the consumption of food (Freedman 2007:202). In the early $19^{\text {th }}$ century, this dietetic advice is, on one hand, followed up by Brillat-Savarin who, among others, writes about the origin of fire, the restaurants in Paris in-between 1810 and 1820, and makes an elaborate attempt towards merging gastronomy with notions on chemistry and medicine, physics and anatomy trying to develop the taxonomy of culinary 'taste' in a scientific manner. On the other hand, these dietetic advice and holistic thinking aiming at balancing life, is followed up by the English noble lady and later nurse Florence Nightingale (1820-1909) who radically changed not only the hospitals, but the entire healthcare system in Victorian England with her healthcare practice and writings.

According to Bäüner (1952:5), Nightingale was a well-educated young lady born into the more noble circles, which is why it was heavily frowned upon by her parents when she chose to occupy herself with the duties of healthcare. Around the mid-19 century, there was still no specific education for nurses in England. Nightingale is, therefore, considered a forerunner because she studied at hospitals in London, Dublin and Edinburg, but also went to France, Italy and Germany to learn about the practice, skills and knowledge of nursing (Bäüner 1952:7-8). These personal investigations and an education in a German hospital in Kaiserwerth led to Nightingale establishing an education for nurses in England during the early $19^{\text {th }}$ century. Later, during the Crimean War fought in Turkey from 1853-56, Nightingale was appointed "the lady in chief" in nursing of the wounded and diseased English soldiers in Scutari. Apparently, the army barracks and hospital conditions were so poor that thousands of men were left dying without any proper healthcare (Bäüner 1952:14). To overcome this, Nightingale gave instruction for an improved hygiene e.g. by use of clean water and clean sheets, as well as use of partition screens during operations. Another radical turning point in her changes in the healthcare of the wounded and ill soldiers was when she together with the French chef Alexis Soyer who, as seen from the Timeline, was famous for his spectacular restaurants, also transformed the entire kitchen domain and food service area, putting focus on the quality of the food served to the soldiers (Bäuner 1952:21). Together these holistic healthcare initiatives would later become the part of the development of the 'Nightingale Ward' and 'Pavilion Hospital' where natural daylight, fresh air, clean water, efficient drainage together with servings of proper food became standards in English hospitals during the late $19^{\text {th }}$ century (Verderber 2010:20-21,27). In my opinion, both the writings of Brillat-Savarin and Nightingale illustrate a holistic thinking encouraging a restoring of one's health through improved physical and spiritual well-being materialized with the built environment, nature and food. This is an ideal that heavily inspired and motivated the particular view on healthcare that emerged among the upper and middle classes in Western societies during the turn of the $20^{\text {th }}$ century when a series of health resorts, spas, retreats and tuberculosis 


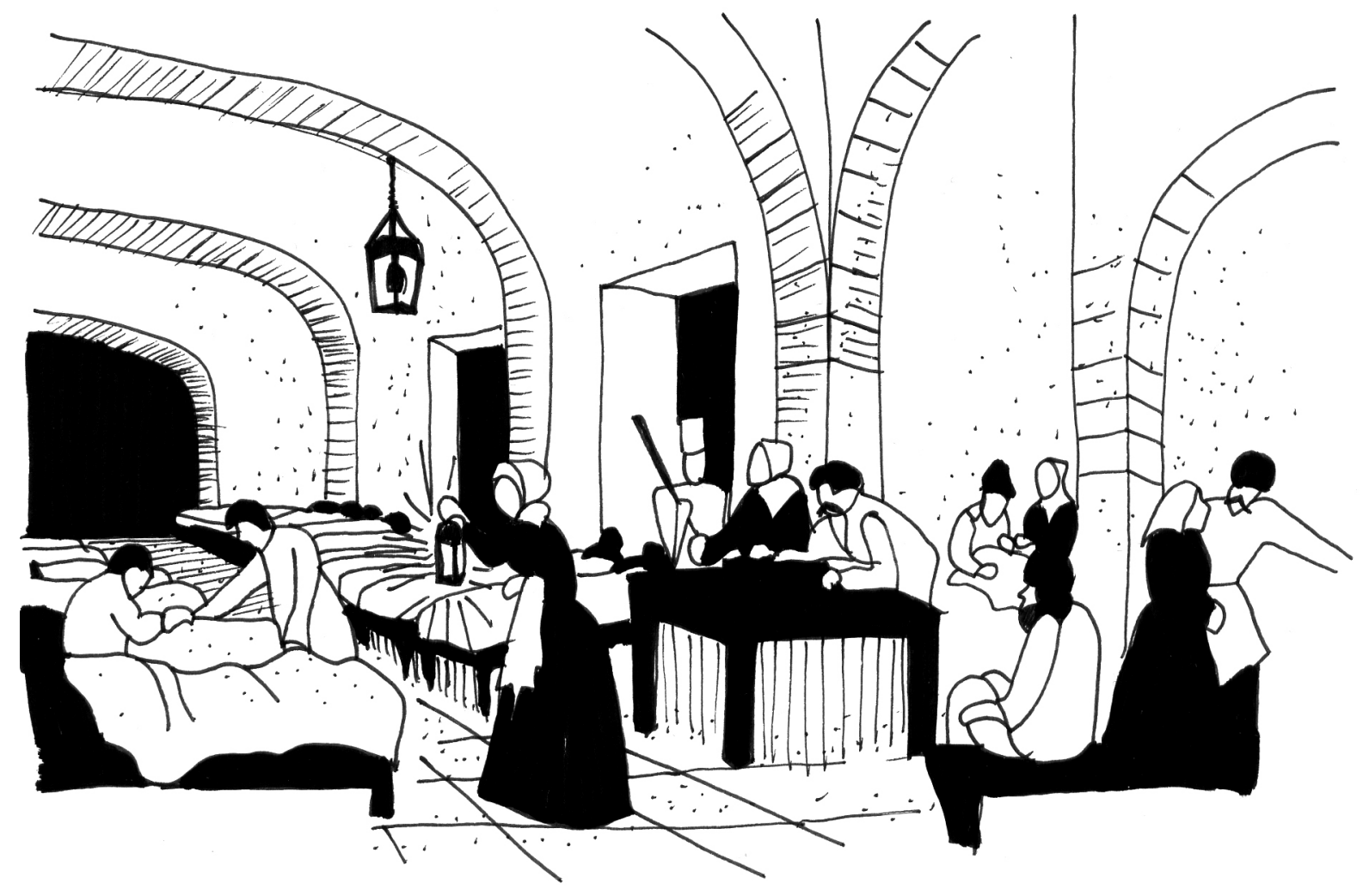

Fig. 6.18

"The Nurse"

Drawing inspired by picture in Bräüner (1952:21). 
sanatoria were designed and built in parts of England, France, Germany, Switzerland and the United States combining health and well-being with the therapeutic effect of exercise, healthy nutrition, fresh air, pleasure, enjoyment and entertainment in luxurious architectural settings and extravagant gardens in the countryside surrounded by stunning mountain landscapes and "pure water" from natural mineral springs (Verderber 2010:27). Some of these design proposals were put forth by German-born architect Gottfried Semper who was engaged in several design proposals for health resorts combining hotel-like healthcare facilities with landscape views, garden promenades, animal zoo, theater and restaurant (Nerdinger \& Oechslin 2003). Others again combined the restoring of health with museums, vegetable gardens and drinking houses (for drinking mineral water) (Verderber 2010:28). Those ideas of the "healthy Gesamtkunstwerk" fusing well-being with mind, food, architecture and social community through pleasure, experience and leisure were highly motivated by the belief that the increasing polluted air, poorly drained lowlands and crowded tenements of the previously-mentioned "dreadful" grand urban cities of, for instance, London and Paris caused severe diseases that could be cured by moving into the open countryside enjoying the natural elements (Verderber 2010:28; Hall 2002).

Part of these ideals presumably relate to the emergence of Romanticism and the picturesque adornment of nature introduced by among others the writer and philosopher Jean-Jacques Rousseau during the late $18^{\text {th }}$ century in opposition to the advancing Industrialization (Collins 1965:21-61; Moffett et al. 2004:415-417). During the late $19^{\text {th }}$ century, the rapid developments in iron structures and prefabrication materialized first with the erection of the Crystal Palace at the World Exhibition in London in 1851, and then with the Eiffel tower in Paris at the World Exhibition in 1889 (Moffet et al. 2004:441,444). Within the discipline of architecture a "quarrel" evolved between architectural thinkers and practitioners regarding the use of iron. Some argued that the articulation of the iron structure, like in the Gothic period, articulated a structural transparency and "lightness" in the building, which others merely saw as a crude "nakedness" abandoning all the cultivation inherited with the walls covered in brickwork or clattered with gypsum (Frampton 2001; Collins 1965, Mallgrave 1996). Likewise within the culinary discipline, the 'Industrialization', with the development of prefabricated and processed foods, sparked the creation of technologies to "fake" the production of certain food products, but also the use of technology to ease the production of food, thus encouraging mass-production of food (Fisker 2003:236). According to Verderber (2010:29), by 1927 and through to 1930 s, presumably partly due to the 'Great Depression', most health resorts, retreats and spas in the United States closed. Another possible explanation is that at the turn of the $20^{\text {th }}$ century a strict division between physiological and psychological aspects of health emerged in hospital treatment procedures. Sickness had a causal, objective explanation either being a matter of chemical or physiological dysfunctions (somatic diseases). Hospital procedures stripped off any treatment or care involving subjective or emotional awareness on sickness, patient treatment was a matter of strict surgical or medical treatments (Gabe \& Calnan 2009; Sohlberg \& Sohlberg 2001:141)[Olsen 2010:109]. This division further influenced the kitchen and patient eating. Contrary to the Medieval monastery hospital, the 'Modern Hospital' is far from self-sufficient. Often the reliance of hospital supplies depends on shipments from far away - not only basic ingredients, but perhaps even the food and the dishes served for the patients are cooked and prepared at different locations than the hospital itself. In this hospital, physicians and nurses know much more about mode of transmissions and routes of infections than ever before. 


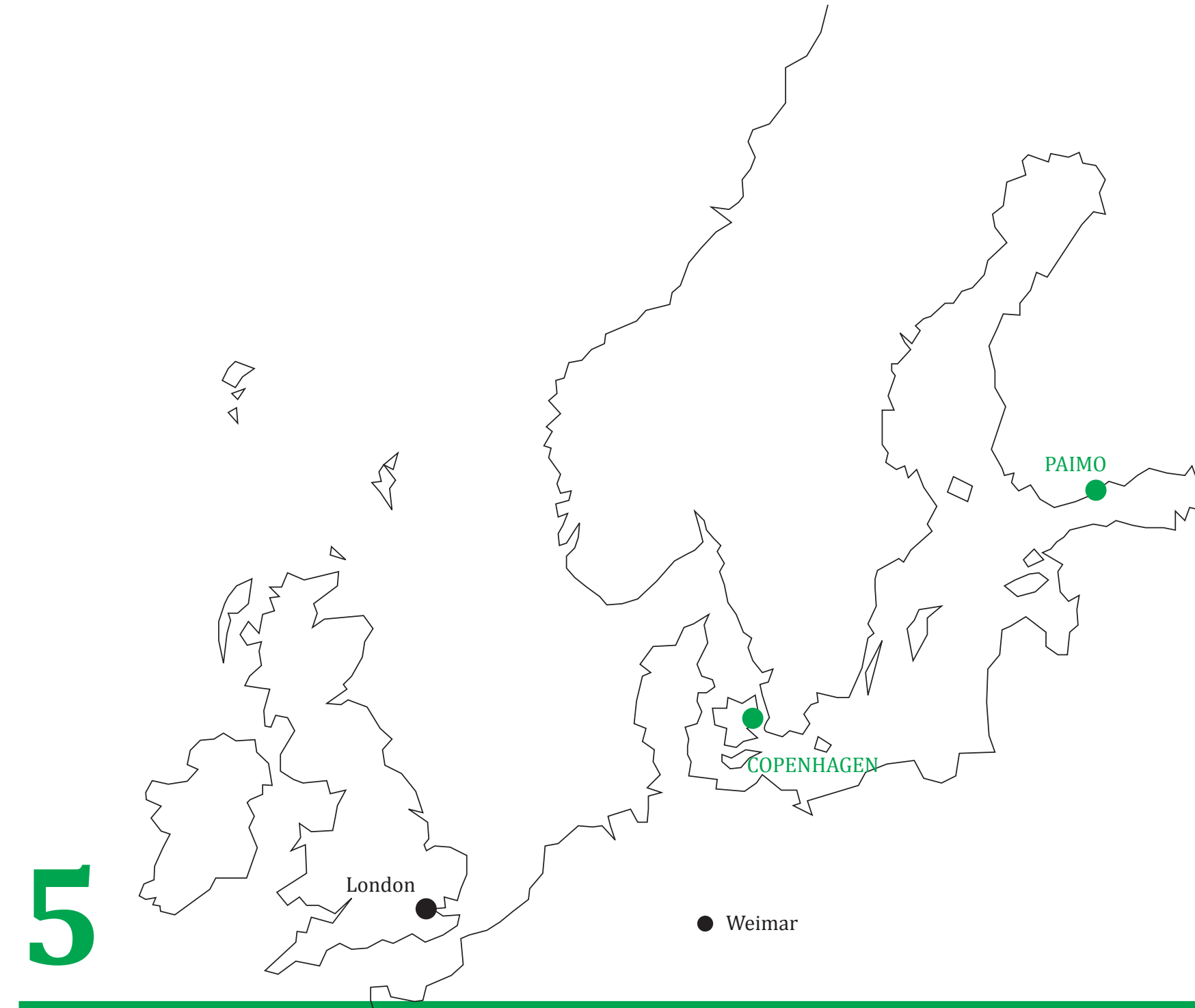

\section{THE "MODERN"}

c. 1930 - 1995

Paris

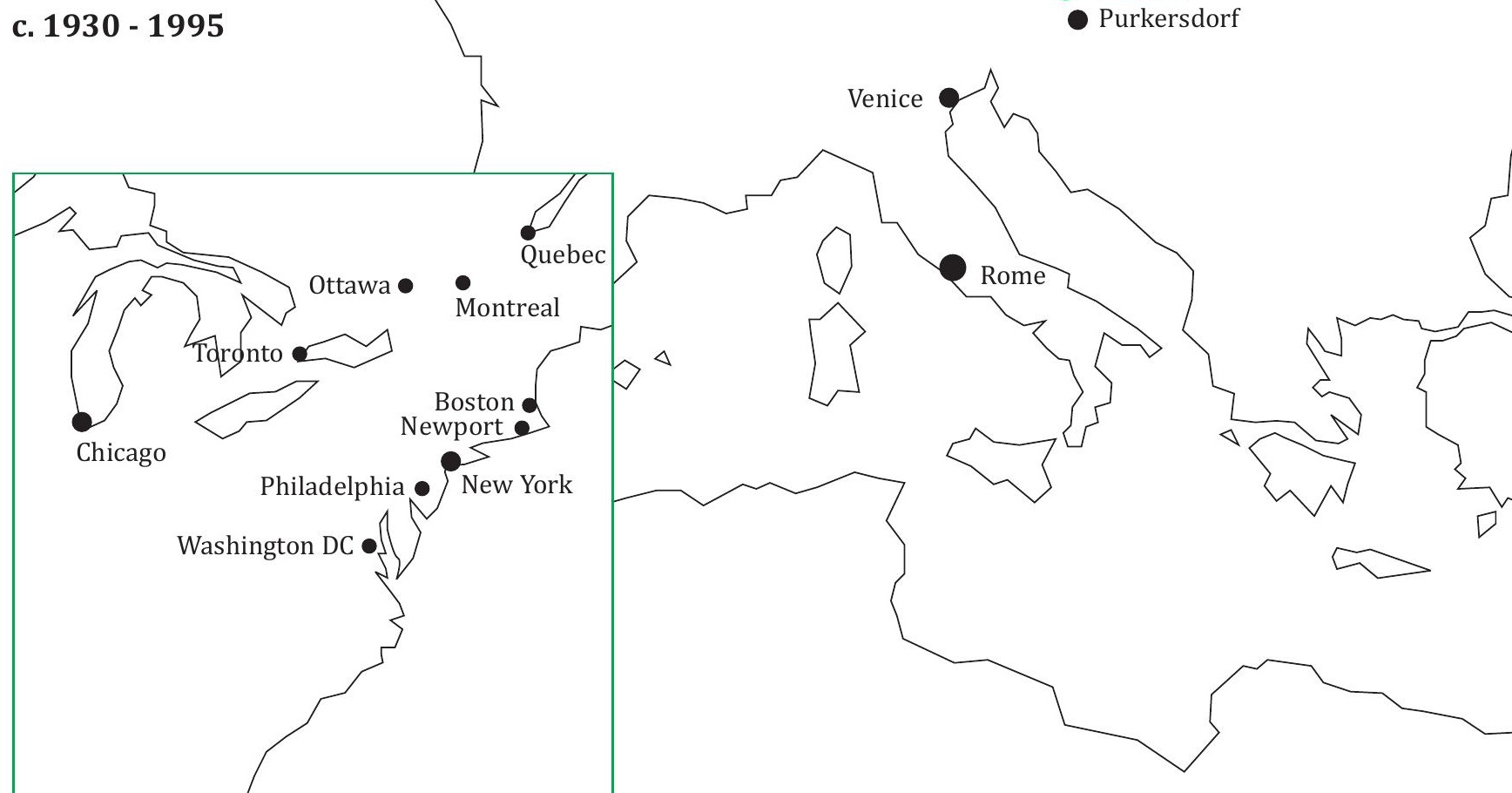


Fig. 6.19

"The Hotel" (Drawings adopted from Christensen 2008:38; Sheridan 2003:156)

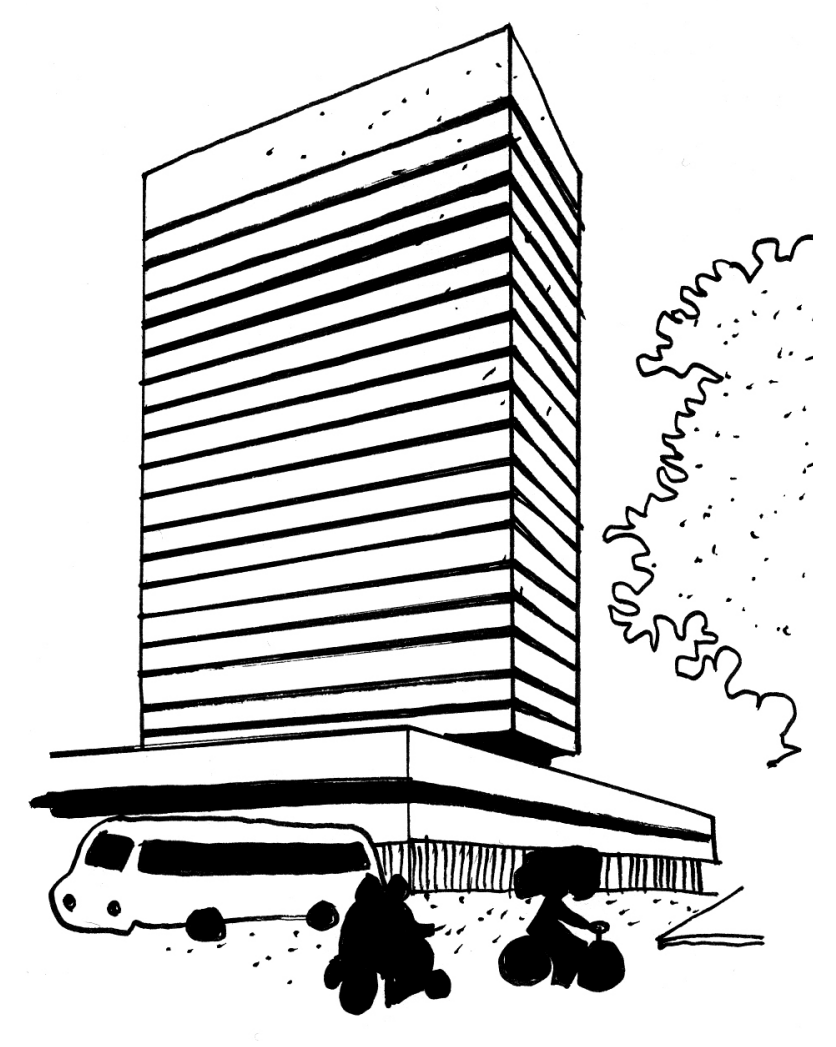

\section{Early 1930s}

The first Drive-In Restaurants occur in Southern California. Here Barbecue, beef, pork and chicken were the typical menus (Jackle \& Sculle 1999:143).

1931 Frank LIoyd Wright: Modern Architecture 1935 Walter Gropius: The New Architecture and the Bauhaus 1936 Nikolaus Pevsner: Pioneers of the Modern Movement

\section{6}

The German philosopher Edmund Husserl published: Die Krisis der europäischen Wissenschaften und die transzendentale Phänomenologie: Eine Einleitung in die phänomenologische Philosophie (The Crisis of European Sciences and Transcendental Phenomenology: An Introduction to Phenomenological Philosophy).

\section{c. 1937}

The German-American architect Ludwig Mies van der Rohe (1886-1969) was employed as head of department of architecture at the Illinois Institute of Technology in Chicago. Here he continued with practicing and teaching architecture under the motto: "Less is More" (Nygaard 2011:255).

\section{8}

Larousse Gastronomique considered the world's greatest cookery encyclopedia was edited by Prosper Montagné (Fisker \& Jørgensen 2010b).

1940 James Maude Richards: An Introduction to Modern Architecture

1941 Sigfried Giedion: Space, Time and Architecture 940+48
The first McDonald hamburger restaurant opens in the US operated by Richard and Maurice McDonald. In 1948 the reorganized their concept into using production line principles when cooking, and during the 1950s and 1960s the architecture and interior design of the restaurants were increasingly used as advertising (Jakle \& Sculle 1999:153; Dybdahl \& Engholm 2008:111).

\section{4}

Discovery of a definitive antibiotic for Tuberculosis (Verderber 2010:35).

\section{5}

The French philosopher Maurice Merleau-Ponty (1908-1961) published: Phénoménolgie de la perception (Phenomenology of Perception)

\section{6}

WHO (World Health Organization) defined that 'health' is a matter of physical, mental and social well-being (Horden 2008:21).

1948 Bruno Zevi: Sapere vedere l'architetture (Architecture as Space: How to look at architecture)

1950s

The Danish Supermarket chain FDB launches the series of FDB Furniture in co-operation with modern furniture designers like Børge Mogensen, Finn Juhl, Hans Wegner, Arne Jacobsen and Poul Kjærholm had been begun before World War II, but during 1950s it increasingly sells quality furniture from department stores such like ANVA in Copenhagen (Engholm \& Michelsen 2000:80-83). 


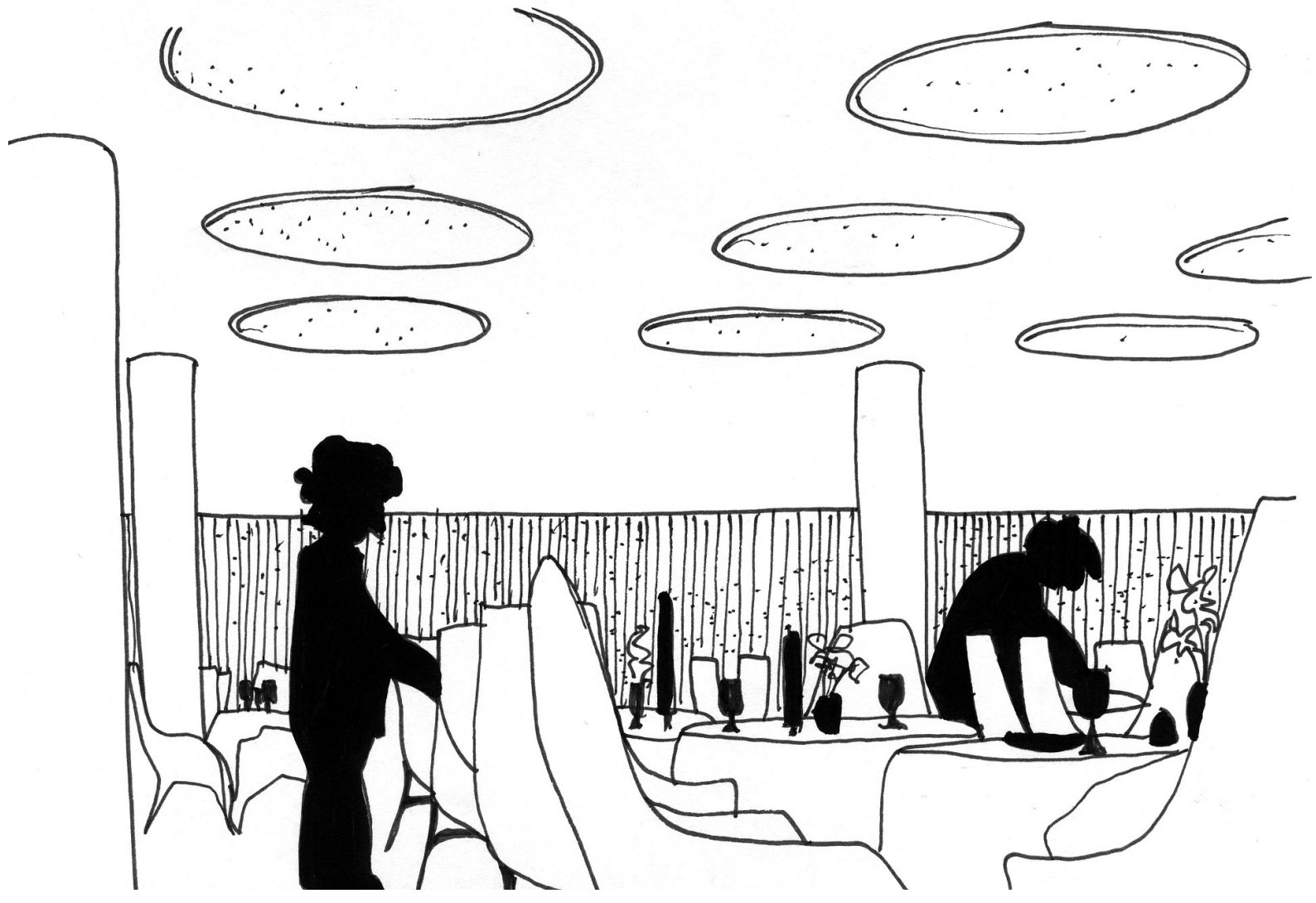

1958 The French philosopher Gaston Bachelard: La poétique de l'espace (The Poetics of Space, the classical look at how we experience intimate places)

\section{9+61}

Erving Goffman (1922-1982) published: Asylums: Essays on the Social Situation of Mental Patients and Other Inmates (1961) and The Presentation of Self in Everyday Life (1959)

\section{9-61+67}

The SAS Royal Hotel designed by Arne Jacobsen was built in Copenhagen. The hotel, as well as the restaurant located in the top-floor of the hotel is a modern Gesamtkunstwerk. Here everything was designed from the smallest details of the pattern on the curtains and other textiles, to the door handles and even caviar wrappings or the cutlery, glasses, ash trays, table lamps - everything except the soft green version of the Danish china called Mussel specially provided from Royal Copenhagen. The SAS hotel is considered one of Jacobsen's masterpieces because is comprises a complete interior architectural settings melding interior, furniture and finishes of tableware and textiles (Sheridan 2003:9; Olsen 2008:45). The SAS Hotel restaurant, together with the Royal Conditori (confectionary) and Royal Bar located at street level in the SAS Hotel was the highest fashion in food and drinks in Copenhagen during the 1960s (Christensen 2008:37).

\section{$1960 s$}

The two Danish chefs Conrad Bjerre-Christensen \& Aksel Larsen were the first to present a culinary TV-show in Denmark (Christensen 2008:31).

\section{0s}

The Danish Hospital "Riget" in Copenhagen was built in the modern high-rise style (Heslet \& Dirckinck-Holmfeld 2007:92,97).

1963+71

Christian Norberg-Schulz: Intentions in Architecture (1963) and Existence, Space and Architecture (1971)

\section{4}

Det Danske Gastronomiske Akademi (The Danish Culinary Academy) was founded by Mogens Brandt, Mogens Lind, Christian Elling and Jens Kruuse (Christensen 2008:22). 1964 Mario Praz published: History of Interior Decoration 1964 Bernard Rudofsky: Archtiecture without architects 1965 Peter Collins: Changing Ideals in Architecture

\section{6}

Robert Venturi (born 1925-) published: Complexity and Contradiction in Architecture. Herein he announced the end of Modernist dominance (Moffertt et al. 2004:476). Made the case for non-straightforward architecture and glorified the baroque and Palladio architecture, the theatrics and the atmosphere, but also celebrated the ugly and ordinary aspects of the roadside strips in the US with the neon advertising signs and billboards and instead encouraged a pluralistic architecture (Moffett et al. 2004:542). His own dining room designed in the 1980s introduce a design idiom mixing traditional with modern, even classical elements such as a painted frieze and built-in cabinets is part of the interior (Pile 2009:428). 
Fig. 6.20

"The Mega Hospital" (Drawing adopted from Heslet \& Dirckinck-Holmfeld 2007:107)

1970s

The Danish chef Søren Gericke (born 1947) began his culinary career at Restaurant Copenhague in Paris. According to Christensen (2008:58) Gericke socialized with the French chefs Taillevent, Verge and Vivarois.

\section{3}

The Austrian-born architectural historian Eduard Franz Sekler published the essay: Structure, Construction and Tectonics. Here he according to Frampton defined the tectonic as: "an expressivity arising from the statical resistance of constructional form in such a way that the resultant expression could not be accounted for in terms of structure and construction alone" (Frampton 2001:19).

\section{Malcolm MacEwen: The Crisis in Architecture}

\section{6}

Herlev Hospital in Copenhagen was opened. Here the kitchen is designed as a rational industrialized production line with quick distribution of the food (Dybdahl \& Engholm 2008:105). Otherwise the hospital interiors are elegantly decorated with colorful art made by the artist Poul Gernes (Heslet \& DirckinckHolmfeld 2007:108).

\section{6}

The French culinary writers Henri Gault and Christian Millau established the magazine: La Nouvelle Cuisine, herein they on the background of the cooking practice of among others the French chef Paul Bocuse identified 10 commandments for Nouvelle Cuisine (the new gastronomy) (Mennell 1985:163).

1977 Christopher Alexander (1936-): A Pattern Language 1977 Kent C. Bloomer \& Charles W. Moore: Body, Memory and Architecture

\section{7}

Charles Jencks: The Language of Post-Modern Architecture. Herein he investigated architecture as a language, using the signs and symbols as a way of reading the building (Moffett et al. 2004:544).

1981 Joseph Rykwert: On Adam's House in Paradise, the idea of the primitive hut in architectural history

1983 Alberto Péréz-Gómez: Architecture and the Crisis of Modern Science

1984 Marco Frascari: The Tell-the-Tale Detail

\section{0s}

The discipline of Neuroscience radically developed and gained improved insight into the wonders and workings of the brain with advanced scanning technologies such like fMRI, PET, EEG and MEG (Kandel et al. 2013). 


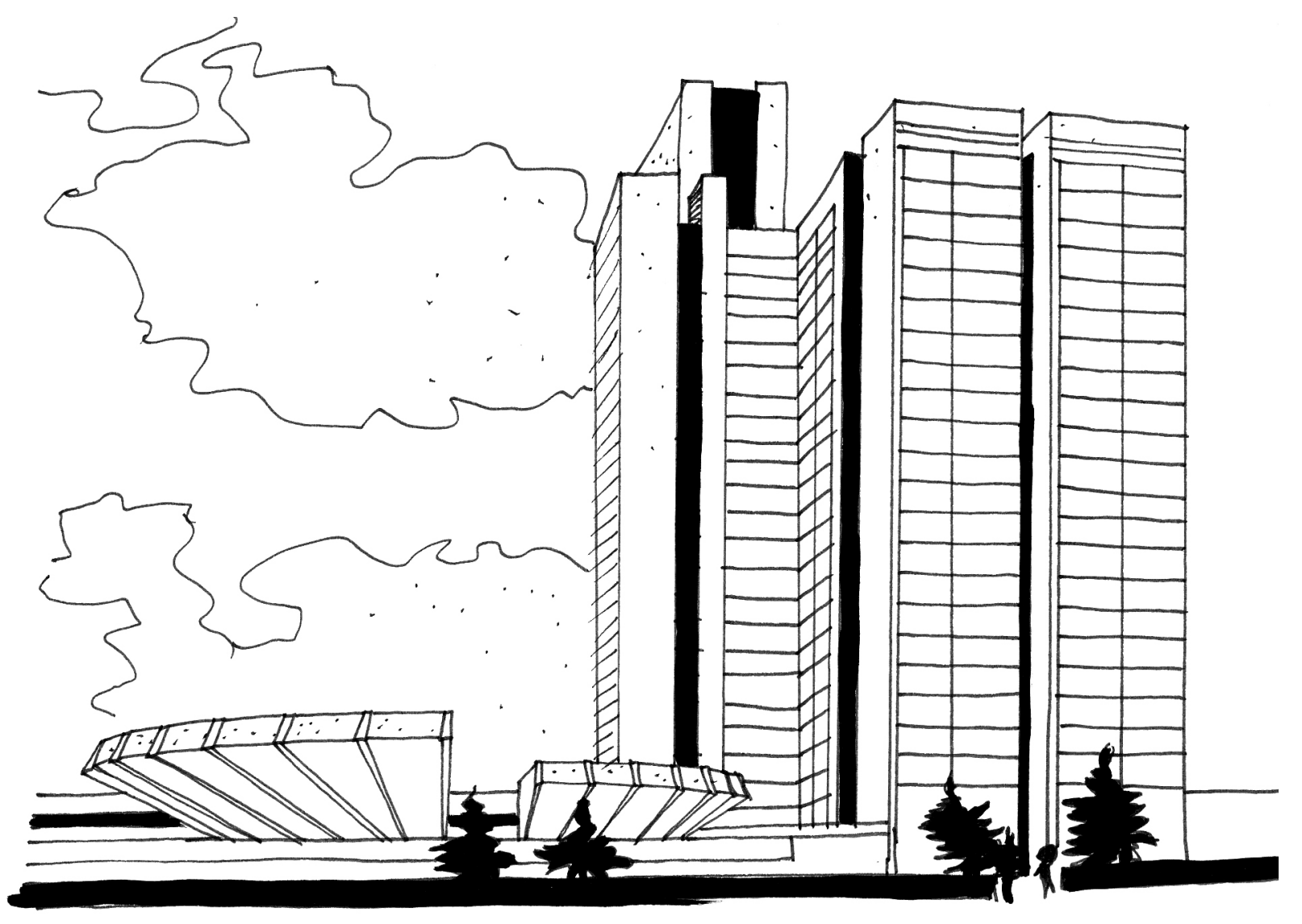

1981 Joseph Rykwert: On Adam's House in Paradise, the idea of the primitive hut in architectural history

1983 Alberto Péréz-Gómez: Architecture and the Crisis of Modern Science

1984 Marco Frascari: The Tell-the-Tale Detail

1984 Roger Ulrich: View through a Window May Influence Recovery from Surgery

\section{c.1987}

The restaurant El Bulli owned by the Catalan chef Ferran Adriá and Juli Soler launched a new culinary concept with snacks, avant-desserts and morphing's, later evolving into the discipline of Molecular Gastronomy (Adriá 2008).

\section{Late 1980s}

The Slow Food movement was initiated by a group of inspired Italian gastronomes in a small town in Bra. The group wrote a culinary manifesto devoted to protecting the right to eat and enjoy good food. The manifesto criticized the speed of the world - the use of machines and heavy industry to manufacture and standardize food products. Their claim was that this food industry with its sterile concepts of productivity and focus on quantity, mass consumption and economy was destroying healthy eating habits, meal traditions, ways of life as well as ultimately also the environment (Petrini 2007:138). Instead the movement through social, political and economic initiatives wanted to consolidate a future were sustainable principles, ethics, morals and fairness governed eating and food production.
1990+2001 Kenneth Frampton: Rappel á l'ordre: The Case for the Tectonic (1990) and Studies in Tectonic Culture (2001)

\section{0s}

The term Evidence-Based Medicine (EBM) is increasingly used in Canada to denote sources of valid knowledge about the effectiveness of healthcare and clinical practice among medical students (Gabe \& Calnan 2009:124).

\section{0s}

The term Evidence-Based Practice (EBP) gained widespread acceptance in the US and UK in clinical practice and healthcare (Gabe \& Calnan 2009:121).

\section{2}

The Danish culinary entrepreneur Claus Meyer (born 1963) presented his culinary television show Meyers Køkken

(Meyers Kitchen). It became a huge success and since he has become a very successful and innovative force in developing the manifests of the Nordic Kitchen, promoting Nordic cuisine and among others establishing the restaurant NOMA. Furthermore he owns a series of Deli's and Bakeries as well as companies importing chocolate and coffee (Christensen 2008:128).

1992 Joy Monice Malnar \& Frank Vodvarka: The Interior Dimension 1993 John Kurtich \& Garret Eakin: Interior Architecture 


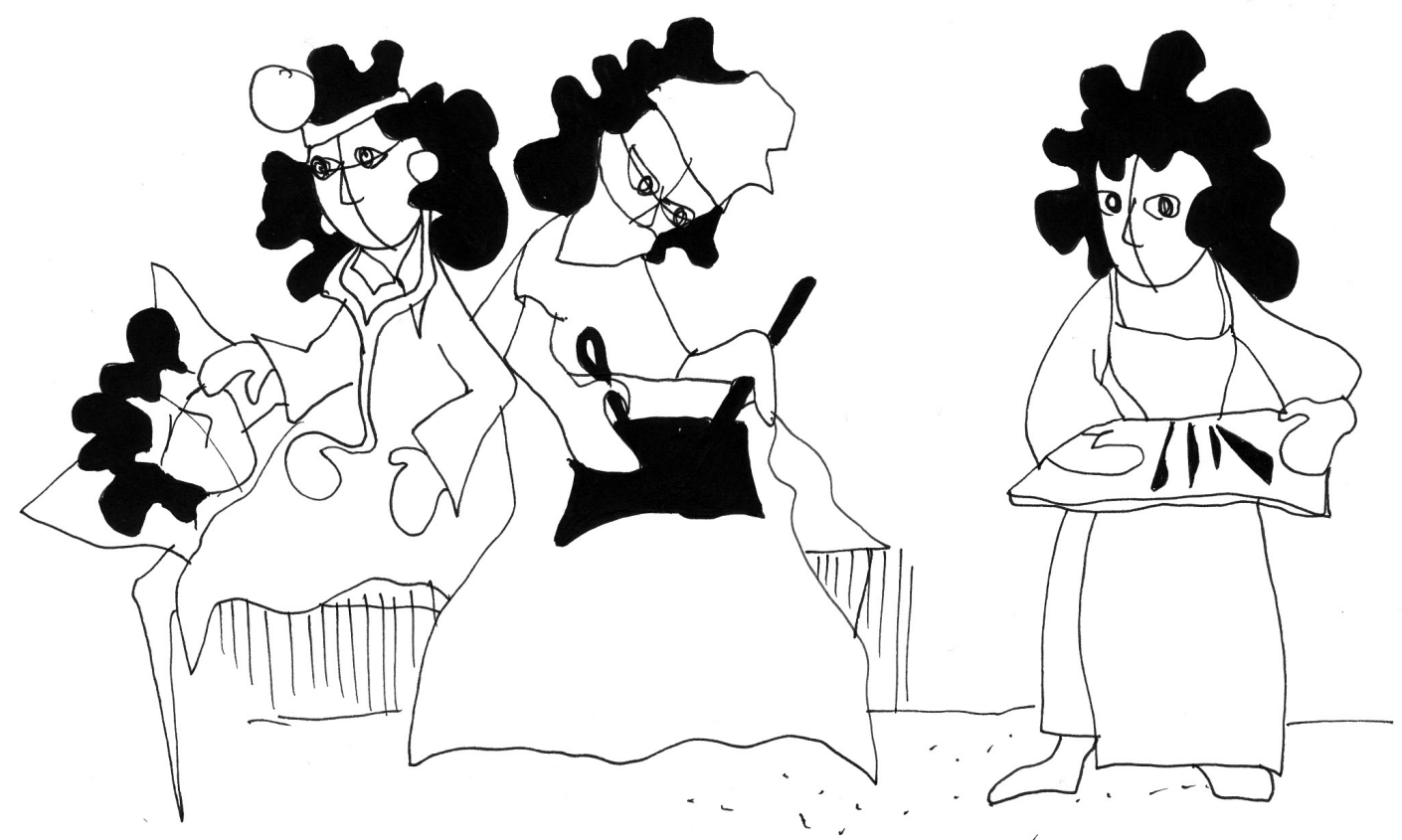

Fig. 6.21 


\section{THE MEGA MACHINES AND FAST FOOD}

As seen from the Timeline, the method of producingx-ray images was discovered in 1895 . This method gained increasing interest in the early $20^{\text {th }}$ century and soon made it possible for doctors, through use of advanced radiology, to provide much more precise diagnoses than ever before. According to Heslet \& Dirckinck-Holmfeld (2007:10), this is presumably an important aspect in the final rejection by the somatic physicians with any aspects of spirituality and mythology relating to the ancient holistic theories of Hippocrates and Galen. Instead medical diagnoses in the Modern times are based on reason, sense and logic as derived within the natural sciences with the philosophers Isaac Newton, John Locke and David Hume. I find, these changes in hospital treatment ideals presumably also meant patients' meals were no longer considered an important part of the actual treatment procedures. Instead the food may have been seen more as an everyday necessity - providing the patients with the sufficient amount of nutrition to keep the body going, and which had to be dealt with in the same manner as other logistic everyday activities like handling laundry and waste. Hence, the kitchen is located in the basement together with the other service functions and the food is transported in large steel containers through an elaborate tunnel system (Adams 2008:123). According to Heslet \& Dirckinck-Holmfeld (2007), the architectural idea governing the modern hospital can be compared to the rational planning of an industrialized production line in any modern-day factory.

The same kind of rational efficiency had, to some degree, already been introduced in the restaurant and hotel kitchens with the Brigade de Cuisine developed by French chef Auguste Escoffier (1847-1935), which was a hierarchical system describing the particular role and function of the chef, but also within the interior of domestic kitchens. As seen from the Timeline, during the early $20^{\text {th }}$ century, the housewife Christine Fredericks "rationalized" domestic kitchen design to fit and optimized culinary production line. This is later followed up by designers from Bauhaus designing an innovative kitchen at the Haus am Horn and the design of the Frankfurt Kitchen (Dybdahl \& Engholm 2008). However, I find, these developments - particularly the hospital kitchens - stand in stark contrast to the contemporary developments in large-scale restaurant and hotel kitchen where culinary practice is taking a new turn. During the mid-20 $0^{\text {th }}$ century, with prominent French chefs like Poul Bocuse, Roger Vergé, Michel Guérard, Jean and Pierre Troisgros and, in Denmark, Søren Gericke, Erwin Lauterbach, Jan Pedersen and Roy Hurtigkarl, the style of Nouvelle Cuisine emerged (Franck 2002:61; Fisker 2003:58). The emergence of Nouvelle Cuisine was, among others, based on the development of ten "commandments" for the new gastronomy, pinpointing: (1) simplicity - avoiding unnecessary complications, (2) reduced cooking time - not overcooking food products, (3) fresh produce - follow season and local availability, "real" foods not processed or manufactured, (4) shorter menus, (5) rejection of "strong" marinates served with meats and poultry - instead fresh meat, (6) rejection of the "rich" and "heavy" sauces - especially the espagnole and béchamel - instead butter, fresh herbs, lemon juice and vinegar, (7) inspiration in regional dishes, rejecting Parisian Haute Cuisine, (8) inspiration in avant-garde techniques - ultra modern kitchen equipment (e.g. Poul Bocuse using the micro-oven) and using technology in an intelligent way, (9) a focus on dietetics, (10) a focus on inventiveness (Mennell 1985:163-64). According to Franck (2002:61) and Fisker (2003:58) respectively, the nouvelle style of cooking not only emphasized the use of fresh ingredients and "old" neglected foods, but also stressed the visual presentation - not through ornamental inedible sculptures like with Carême or elaborative decorative garnishes like with Escoffier, but by artistically arranging the food itself in small portions on individual plates. This food service style is what Franck (2002:61) refers to as service á l'assiette. The ten "commandments" put forth by the chefs in the era of Nouvelle cuisine should be seen as an opposition to the style developed with chefs like Escoffier, where meats, fish and poultry were covered in "heavy" or "rich" sauces and decorated with elaborately carved ice sculptures. 
The tendencies in the culinary practice, with Nouvelle Cuisine, moving from an opulent use of ornamentation and decoration in the $19^{\text {th }}$ century to a rejection of unnecessary extravaganza, happens simultaneously within the architectural practice. Here, the function and use of a building during the early $20^{\text {th }}$ century becomes more important than the decoration and ornamentation. Perhaps one of the best known clichés is the statement on minimalism put forth by German-American architect Ludwig Mies van der Rohe (1886-1969) arguing that: "less is more", presumably in strong opposition to teachings of the old École des Beaux-Arts, but also the unnecessary extravaganza of Neoclassicism and Art Nouveau dominating the late $19^{\text {th }}$ century (Nygaard 2011:255). If we look at the developments in architecture and particularly in interior architecture, framing the meals or health of that same time, the early or mid- $20^{\text {th }}$ century is rich with examples of domestic and public eating environments or healthcare interiors. Again as seen from the Timeline, there is the design of the SAS Royal Hotel by Arne Jacobsen (1959-61), Paimio Sanatorium by Aalvar Aalto (1932), American Bar by Adolf Loos (1908), Tea Rooms by Charles Rennie MacKintosh $(1893+1903)$, Purkersdorf Sanatorium by Josepf Hoffmann (1904-5), and many more that I have not mentioned or included in the Timeline (see Figure 6.16, Willow Tearooms, Figure 6.17, The Sanatorium and Figure 6.19, The Hotel). Those specific examples are depicted in various architectural and interior magazines and books and, therefore, stand as significant examples not only of interior 'assemblages' with particular focus on the social responsibilities and a profound sensibility to materials, but also of the ideal of the Architectural Gesamtkunstwerk, as mentioned in the Introduction.

Simultaneously, some of the first design proposals for 'Skyscraper Hospitals' using the structural principles of curtain walls and a steel frame occur in grand cities like Chicago, USA (1905) and in Paris, France (1932-35) (Verderber 2010:34-35). Here the 'Pavilion Hospital' is replaced with high-rise urban hospitals with high density, designed as a 10-story "city" with 'Nightingale Wards' in layers providing the template for what is today known as the 'Modern Hospital' (Verderber 2010:34-35). In 1944, scientists discovered an antibiotic against Tuberculosis, and so the need for tuberculosis sanatoria and the demands for natural daylight and fresh air were outdated (Verderber 2010:35). Instead, an increase in urban hospitals resembling mega-scale building complexes like airports and shopping malls located outside the cities occurred during the 1950s and 1960s. Particularly in the United States, this was manifested in large sterilized ward environments, illustrating a scientific approach to healthcare (Heslet \& Dirckinck-Holmfeld 2007:92; Verderber 2010:38). In the United States, where the healthcare system is more divided into private and public hospitals than in Denmark, the wealthy patients were privileged with private single rooms designed with a series of domestic "homely" or "hotel-like" features like reading tables, lounge chairs, lamps and a television, wood paneling, travertine fireplaces, sculptures, indoor trees and flowers, carpeting and colored walls, compared to the economic four-bedded patient room in the public facilities where wards were crowded with equipment and often designed without any considerations for natural daylight or fresh air from windows (Sloane 1994:85,87,90). According to Sloane (1994:90), in the United States, in the attempt to create a more pleasant, informal and comforting patient-centered environment in the best private hospitals, hospital designers had been drawing on inspirations not only from hotels, but also restaurants and retail design. In Denmark, we have Rigshospitalet and Herlev Hospital, built during the 1950s - 1970s, as examples of industrialized "skyscrapers". According to Heslet \& DirckinckHolmfeld (2007:102), particularly in the example of Rigshospitalet, the rational, functional, technical and economic aspects of the hospital treatments and building costs dominated over the previous holistic focus on natural daylight, spatial patient wards and nature views emerged with the Nightingale Ward and Pavilion Hospital. Contrary to Rigshospitalet, Herlev Hospital illustrates a much greater sensitivity to the human scale and desire for artistic adornment in the interior architecture according to Heslet \& Dirckinck-Holmfeld (2007:106-109). In line with the previously-mentioned contemporary tendencies of 'Nordic' or 'Scandinavian Design', the architecture at Herlev Hospital is more "democratic" in the way it, for instance, introduces a very colorful decoration of the walls in the different departments, hallways and wards (Heslet \& Dirckinck-Holm 2007:106-109). 


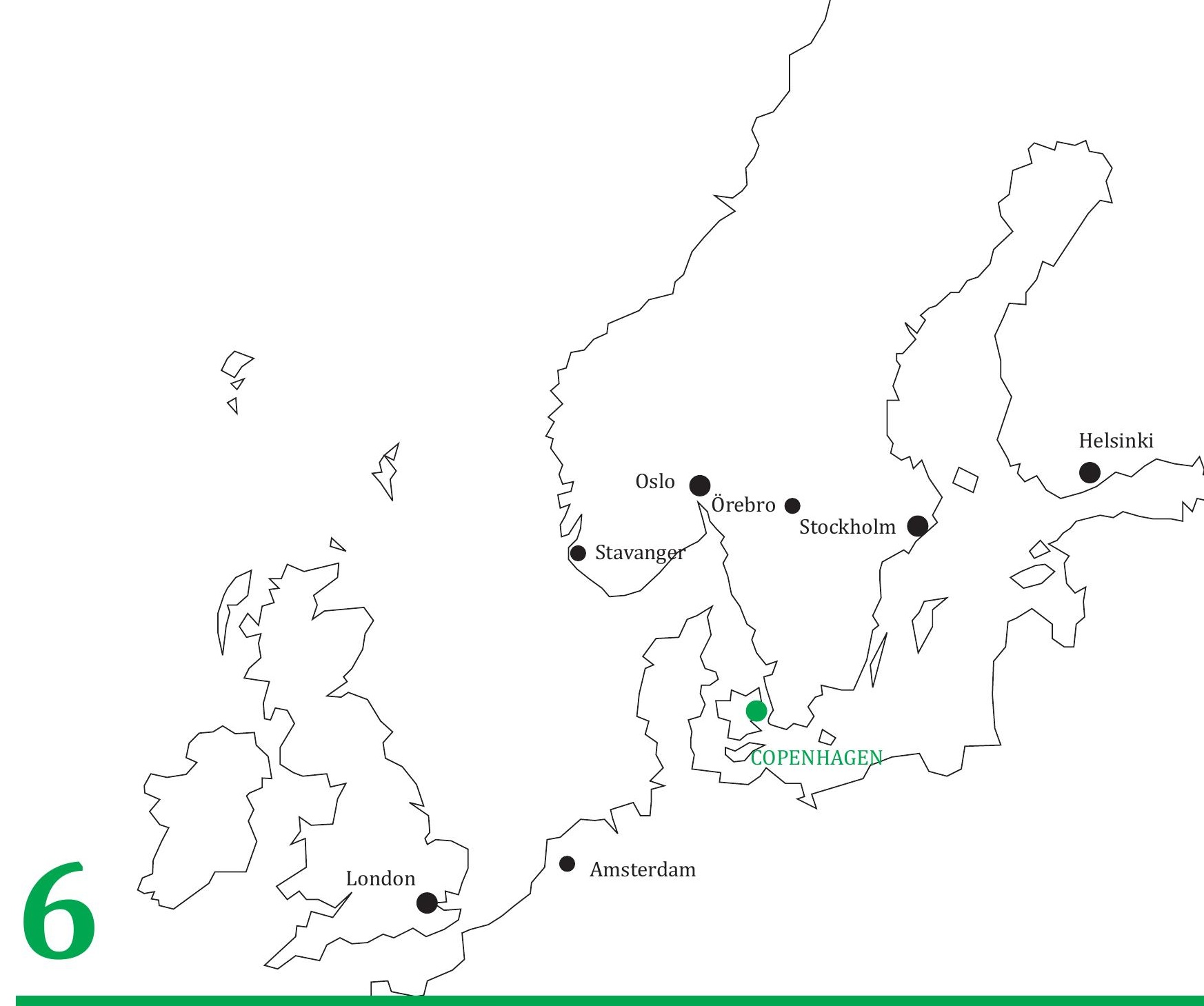

\section{THE "CONTEMPORARY”}

\section{c. 1995 - 2013}

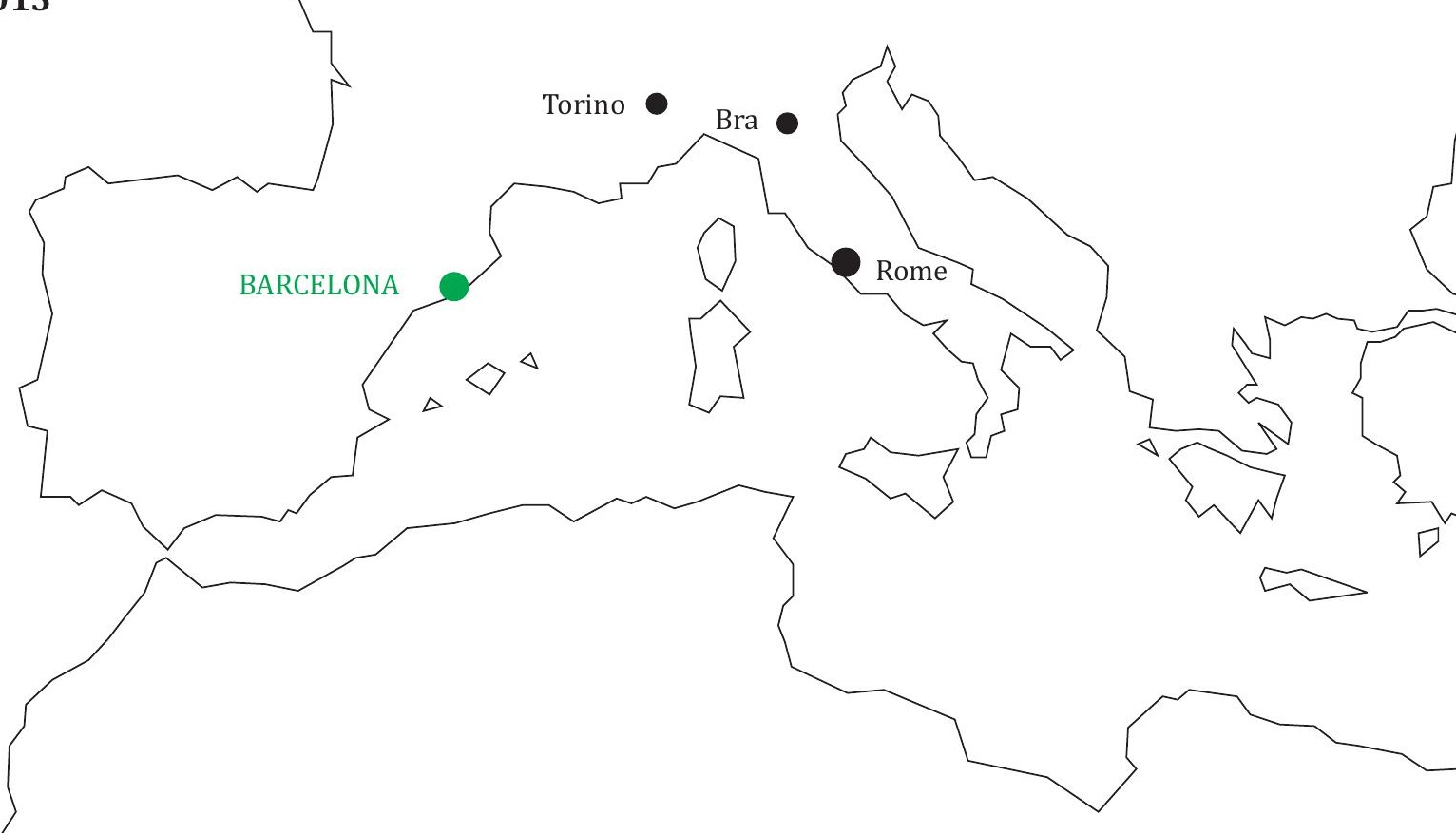




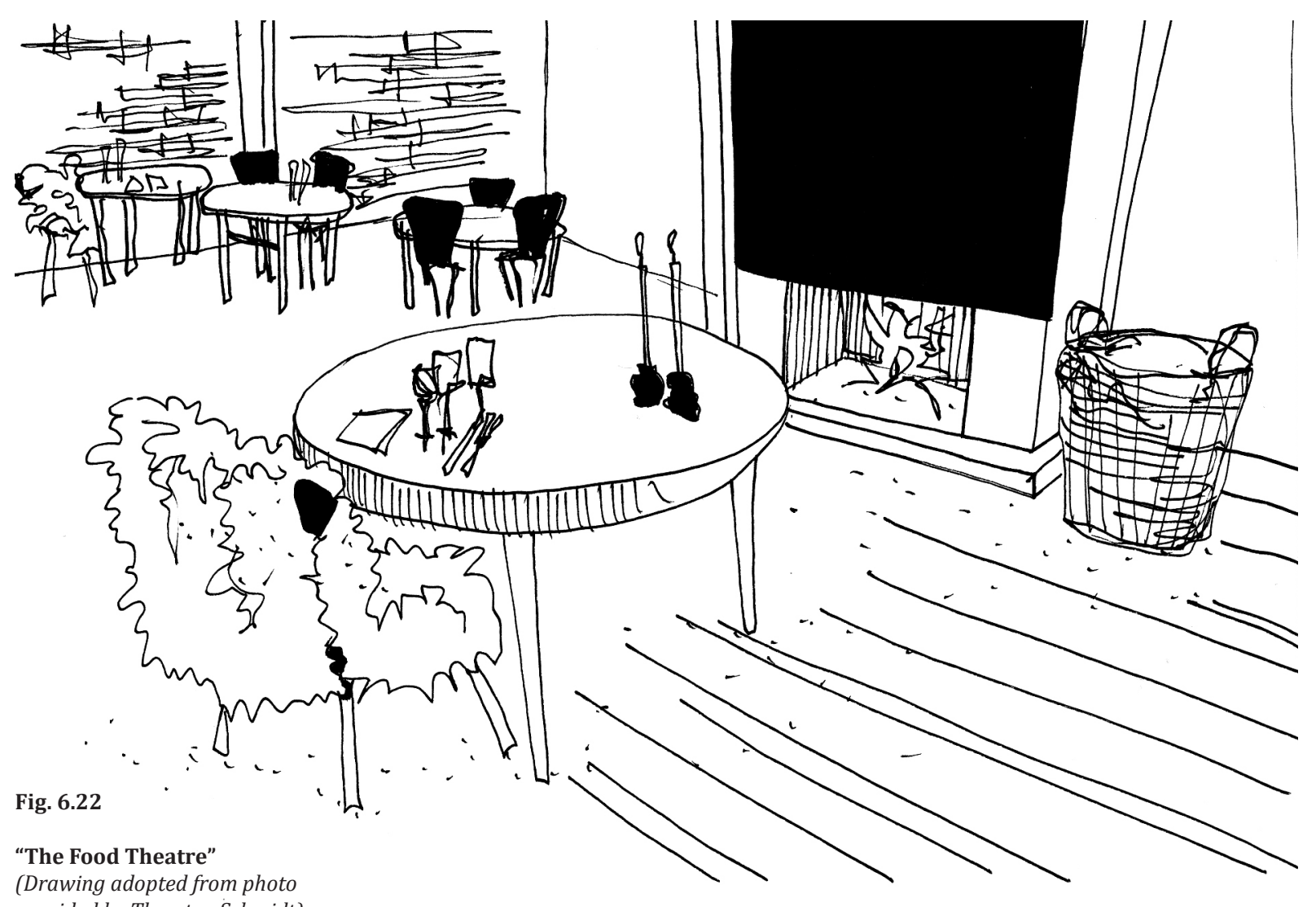

provided by Thorsten Schmidt)

1994 Gevork Hartoonian: Ontology of Construction 1994 Bell et al.: The effects of adding an Italian theme to a restaurant on the perceived ethnicity, acceptability and selection of foods

\section{5}

The restaurant the Fat Duck was opened by the English chef Heston Blumenthal (born 1966). Throughout the years the restaurant has become very known for its molecular cooking style challenging ordinary food combinations and meal rituals, as well as utilising advanced cooking techniques such as liquid nitrogen and slow-cooking in mineral water. The restaurant was awarded three Michelin stars in 2004 (en.wikipedia.org 2013).

1996+2005+2009 Juhani Pallasmaa published: The Eyes of the Skin, Encounters and The Thinking Hand

1999 Lise Bek \& Henrik Oxvig: Rumanalyser (Analysis of Space) 1999 B. Joseph Pine \& James H. Gilmore: The Experience Economy

2000+2002 - Glutamate and Umami receptors discovered (Lehrer 2007:61)

2000 Karen A. Frank \& R. Bianca Lepori: Architecture Inside Out 2000 John Pile: A History of Interior Design

2001 Anne Massey: Interior Design of the 20th Century

2002 - The Academy of Neuroscience for Architecture gathered at a conference in North America. This would later evolve into the disciplines Healing Architecture and Evidence-Based Design (EBD) (Sternberg 2009:2).

\section{$2002+2004$}

The German philosopher Gernot Böhme (1937-) published the paper: The Space of Bodily Presence and Space as Medium of Representation and Atmospheres: The Connection between Music and Architecture beyond Physics. Here he argued that there are many concepts of 'space', and question whether there is a unified space in the background or some common element that group them together? Relative hereto, he distinguishes between space as "outer" and "inner" perception, and argues that the notion "atmosphere" is that unified concept in architecture that not only changes our understanding of how we experience space, but also how we behave in space (Böhme 2002:1; Oxvig et al. 2007:34).

2002+2005 Karen A. Franck: Food+Archtiecture and Food + The City.

2003 Anna Marie Fisker: Mad og Arkitektur

\section{4}

The book: Eating Architecture edited by Jamie Hortwitz and Paulete Singley was published. Herein appeared the text: Semiotica ab Endendo, Taste in Architecture written by Marco Frascari.

2004 H. Hartwell: Patient Eating Experience, nutritional uptake and satisfaction with hospital food services

\section{4}

The University of Gastronomic Sciences located in Bra in Northern Italy was founded by Carlo Petrini and the Slow Food Movement. 
Fig. 6.23

"The Food"

(Drawing adopted from photo provided by Thorsten Schmidt)

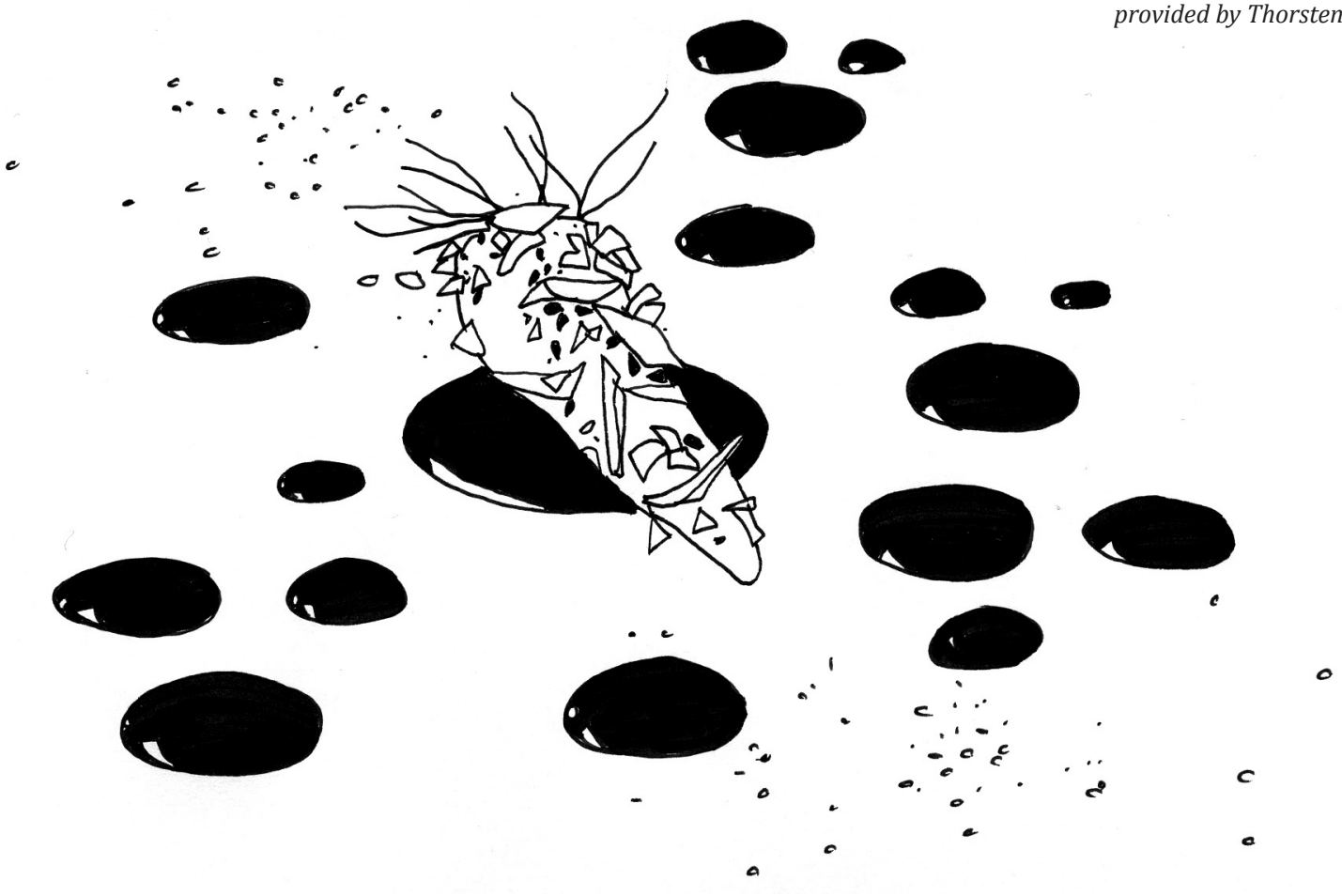

\section{4}

The manifesto for the New Nordic Kitchen was written down by a small group of innovative culinary personalities from Iceland, Sweden, Norway, Finland, Faroe Islands and Denmark. The manifest presented ten "commandments" dictating that new Nordic cuisine (Christensen 2008:171).

2004 Inga-Britt Gustafsson: Culinary Arts and Meal Science, a new scientific research discipline.

2004 Rasmussen et al.: Prevalence of patients at nutritional risk in Danish Hospitals

2004 Ulrich et al.: A Review of the research literature on evidence-based healthcare design.

\section{5}

The French physical-chemist Hervé This (born 1955) published: Molecular Gastronomy: Exploring the Science of Flavor, where he described the science of the culinary phenomena of cooking. He was particularly interested in the mechanisms describing the culinary transformations occurring doing boiling and frying etc. But already since 1993 he had been writing about the "secrets" of gastronomy and cooking (en.wikipedia.org 2013; This 2006).

\section{5}

The Danish restaurant Malling \& Schmidt was opened by Rikke Malling (born 1975) and Thorsten Schmidt (born 1976). In 2010 the restaurant moved to new and larger facilities just outside Aarhus. Here it temporarily closed down in 2012, but re-opened in December 2012 in a third version called "Villa Dining" in close co-operation with the Danish ceramics firm Kähler Design (Malling\&Schmidt 2013). The kitchen is highly inspired by the advanced cooking techniques and visual-technical expression of Molecular Gastronomy. But also very passionate in using locally or regionally grown organic produce, as well as following the seasonal changes. In this restaurant the meal begins when entering the front door, and continues as a carefully planned "journey" or event until you exist again later in the evening. This is further accentuated with the series of "surprising" elements or challenging experiments that aim at bringing guests out of their comfort zone, ordinary meal rituals and ways to eat the food served (Schmidt 2008). The restaurant interior is primarily held in bright and wooden colors, arranged around a centrally located kitchen, which appear as a chemistry laboratory encapsulated in glass to allow the dinner guests to follow every move the chefs in the specially designed and handbuilt kitchen made in Scandinavian wood and steel - of cause supplemented by the various elements of Kähler design. The furniture and tableware of the restaurant is thus primarily classical Danish or Scandinavian design - some of the plats and serving containers specially designed by Thorsten himself in corporation with Kähler (Schmidt 2008; Christensen \& Bech-Poulsen 2012:170-185). 


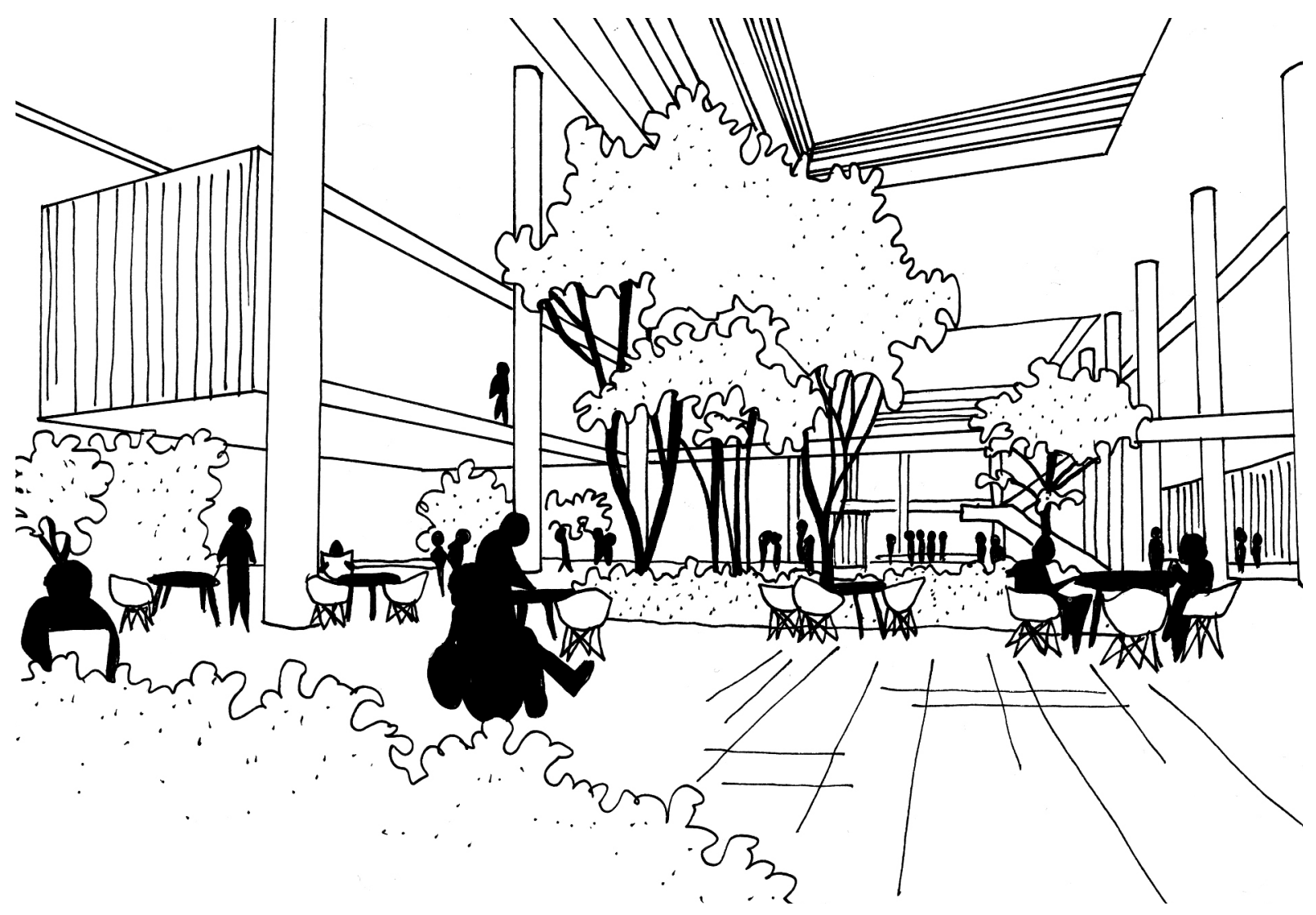

SUPER HOSPITALS

\section{$2006+2010$}

The Helsingør Psykiatriske Hospital (Helsingør Psychiatric Hospital) was build. It was developed by the PLOT - a Danish architectural firm today called BIG led by architect Bjarke Ingels. In 2010 BIG published the book: Yes is More, presented among others the design proposal for the hospital, but also arguing with reference to Mies van der Rohe's 1950s quote "Less is More", Venturi's 19770s quote "Less is a Bore”, Koolhaas' 2001 quote "More and More, More is More" and Barack Obama's 2007 quote "Yes we can" argued for a pragmatic utopianism in both architectural thinking and practice. An approach that rather than choosing between avant-garde utopias or pragmatic boring boxes chooses to combine the two into an architecture that takes on the creation of socially, economically and environmentally perfect places as a practical objective (Big 2010:intro).

2007 The English physical-chemist Peter Barham became a visiting professor of Molecular Gastronomy at the University of Copenhagen, Denmark. Barham as among others worked with the English chef Heston Blumenthal (Barham 2007).

2007 Lars Heslet \& Kim Dirckinck-Holmfeld: Sansernes Hospital 2007 Jeffry Sobal \& Brian Wansink: Kitchenscapes, Tablescapes, Platescapes and Foodscapes, influences of microscale built environments on food intake

\section{7}

The Danish restaurant Madeleines Madteater was founded by chef Mette Sia Martinussen and product designer Nikolaj Danielsen. Highly inspired by the writings of Marcel Proust on Remembrance of things Past, they executed restaurant meals as a thoroughly planned theatre play using stage sets, actors, artificial light, media and sound to extend the perception of the food served, as well as advertising the restaurant in line with other theatrical plays. This was further underlined with the fact that costumers had to buy a ticket at an online ticket sale for concerts, art museums and theatres (Lorenzen 2005:34-37; Danielsen 2007; Olsen 2008:36).

2007 Charles Rice: The Emergence of the Interior

2007 The book: The Architect, The Cook and Good Taste edited by Petra hagen Hodgson and Rolf Toyka was published.

c.2007 Restaurant of the Future was established at Waagningen Unviersity in the Netherlands

2008 Edwards \& Gustafsson: The Five Aspect Meal Model 2008 Edwards \& Gustafsson: The room and atmosphere as aspects of the meal: a review

2008 Carolyn Steel: Hungry City

2008 Annemarie Adams: Medicine by Design, the architect and the modern hospital 1893-1943

\section{8}

11th International Architectural Biennale in Venice here several exhibition designs were occupied with the relationship of food and architecture 
Fig. 6.24

"The Super Hospital"

(Drawing adopted from $\mathrm{NAUH}$

2012, juni:21)

2008 Project MORE at Aalborg Hospital 2009 Penny Sparke: The Modern Interior

2009 Frandsen et al.: Helende Arkitektur (Healing Architecture)

\section{9}

The Danish Government launches a welfare program planning a series of Super Hospitals

\section{Verderber: Innovations in Hospital Architecture}

\section{$2010+11+12$}

The Danish restaurant NOMA led by chef René Redzepi was ranked as no. 1 in the San Pellegrino Award: 50 Best Restaurants in the World (Christensen \& Bech-Poulsen 2012:11) . NOMA was opened in 2003 in co-operation with among others the culinary entrepreneur Claus Meyer. Today it is though primarily led by René Redzepi (born 1977) (Christensen \& Bech-Poulsen 2012:203). NOMA received two Michelin stars in both 2011 and 2012. The kitchen is characterized by its almost militaristic conducted cadence and the artistic presentation of numerous small or medium-sized food creations presenting innovative and spectacular compositions of Scandinavian foods and produce. The "Nordic" spirit is reflected into every detail of the restaurant interior and staff dressing. Wood, earthly colors, leather, fleece and an articulation of the raw materials is evident both in the architectural design as in the presentation of the food (Christensen \& Bech-Poulsen 2012:200-21). Finally, NOMA through the participation of René is involved in several experimental projects such like the NOMA Test Kitchen, Nordic Food Lab and MAD Symposiums (NOMA 2013).
2011 Shepherd: The effects of a hospital ward eating environment on patient's mealtime experience

\section{1}

The Danish chef Rasmus Kofoed (born 1974) from restaurant Geranium won the gold at the World Cup at Bocuse d'Or held in Lyon. The kitchen at Geranium is based on a highly technical, multi-sensuous and artistic expression, promoting organic and biodynamic produce. The multi-sensuous approach in the kitchen is also reflected in the restaurant interior which is characterized by an open view into the kitchen, bright and earthly colors, as well as a grand fireplace. Even the waiters' clothes are specially designed to fit the overall theme of the restaurant. Geranium received a Michelin star in 2012 (Christensen \& Bech-Poulsen 2012:110-127; Geranium 2013).

2011 Marco Frascari: Eleven Exercises in the art of architectural drawing: slow food for the architect's imagination

2010+2011+2012 The International Food Design Society (IFDS) is established and the first two international conferences are held in 2011 and 2012.

2012 M.Sc. in Intergrated Food Studies established at Aalborg University in Denmark.

2012 Bromley: Building Patient-centeredness, Hospital design as an interpretive act

2012 Marco Frascari \& Adriana Ross: Drawing in Silence 


\section{THE HEALTHSCAPE, FOOD THEATRE AND NORDIC KITCHEN}

In my opinion, the particular occupation with the 'Nordic' was re-introduced at the turn of the $21^{\text {st }}$ century with the manifesto for 'New Nordic Cuisine' established in 2004. Here, led by Danish culinary entrepreneur Claus Meyer among others, a group of chefs and food enthusiasts wrote down, in a similar manner as the manifest of the Nouvelle Cuisine, ten "commandments" for 'New Nordic Cuisine'. The manifest was motivated by an increasing opposition to the French and Italian kitchens and their use of foie gras, truffles, tomatoes, red wine and olive oil that was increasingly dominating Scandinavian eating habits and culinary practices. Instead these "commandments" included the use of clean, unspoiled and unpolluted nature; the four seasons that accentuate the taste and character of fresh produce; and an articulation of the Nordic region's unique and positive characteristics (Christensen \& Bech-Poulsen 2012:11; Christensen 2008:170). Like with the Nouvelle Cuisine, this manifesto has led to a rediscovery of "timeworn" and "abandoned" foods such like porridge made on buckwheat kernels, wild plants and sour or pungent berries like stewia, ramson, sea buckthorn, blackberries, sorrel, yarrow, fern, pine; edible flowers like geranium; "uneven" cuts of meats such like using neck, brain, jaws, kidneys, liver, testicles, sweetbreads from rain deer, boar, rabbit and musk ox, rooster combs and feet from poultry (previously these were used for cattle feeding according to Christenen \& Bech-Poulsen (2012:203)); milk and skyr; cod, mackerel, turbot, brill, oysters, langoustines; hazelnuts; rye bread; potatoes, scorzonera, cabbage, horseradish, turnips and seaweed (Christensen \& Bech-Poulsen 2012). These types of foods have been promoted internationally by Danish chefs like Thorsten Schmidt (Restaurant Malling \& Schmidt), Rasmus Kofoed and Søren Ledet (Restaurant Geranium) and René Redzepi (Resturant NOMA). A very interesting aspect about the manifesto of the 'New Nordic Kitchen' is not only the ethical and moral aspects of local or regional foods and the well-being of the animals and nature, but also, in my point of view, the particular occupation with the health and well-being of the consumers.

According to Christensen \& Bech-Poulsen (2012:11), this is achieved in the ability of the 'New Nordic Kitchen' to give the general consumer a relationship to healthy, regional produce by highlighting the short distances from "farm to table", but also by the elite restaurants telling the stories of the produce and their connection to the specific meals eaten by the consumers. This tendency stands, according to Christensen \& Bech-Poulsen (2012:11), in stark contrast to the procedures of the food industry, which often tend to neutralize the use of fresh produce, as well as make the process of processing and cooking anonymous, thus possibly alienating the consumers from the foods' "true origin". I find, this ideal of using regional materials is further manifested in a rediscovery of the 'Nordic Design' traditions in the "Nordic restaurants". Here, chefs such as Thorsten Schmidt in his restaurant Malling \& Schmidt with a newly established concept called 'Villa Dining' intentionally used furniture designed by the Danish architect Arne Jacobsen together with 'Musselmalet' tableware designed by Danish porcelain company Royal Copenhagen and pottery designed by Danish ceramics company Kähler (See Figure 6.22, The Food Theatre) (also see photos in Christensen \& Bech-Poulsen 2012:175,182). Another tendency that has emerged with the 'New Nordic Kitchen' is the "artistic" focus in the arrangement of the dishes, particularly seen in the restaurants Malling \& Schmidt, Noma and Geranium, where the dishes and presentation of the food become small art pieces in themselves (see Figure 6.23, The Food). In my opinion, often this "artistic" arrangement results in a very vague recognition of the original food products, instead putting a strong emphasis on the elements of storytelling and poetic narratives accompanying the dish. Simultaneously with these developments, we see from the Timeline that during the 1990s the Catalan chef Ferran Adria with the restaurant El Bulli sparked a new trend in culinary practice called 'Molecular Gastronomy'. Here the French scientist Herve This and English scientist Peter Barham working together with English chef Heston Blumental at the restaurant The Fat Duck and above-mentioned Danish chef Thorsten Schmidt from restaurant Malling \& Schmidt were forerunners in a new much more technological and scientific tendency in cooking that likewise introduced a revival of the importance of the visual appearance of the food and on the theatrical presentation of dishes in front of an "audience".

Relative hereto, already in 1987, the Norwegian-born cookery writer Henry Notaker (1987) notes in his book Gastronomi - til bords med historien (Gastronomy - dining 
with history) that vast amounts of cookery books describing everything from cooking specific ingredients like eggs and garlic to recipes for skinny/fat, young/old, children, families/singles, how to use a micro-oven or barbeque, and how to stay or become healthy are published each year. Those books contain recipes made by professionals, gastronomes and star chefs, and recipes published for plain everyday meals (Notaker 1987:192-193). Notaker's point is that the "boom" in contemporary culinary literature is generated by an increasing interest among the general public to read about the culture and history of food, but also because notions such like 'foodie' and 'foodism' has emerged since the early 1980s, describing persons that are not only interested in eating food, or talking about food, but which also have to display and expose their relationship to food in far more exhibitionist manners than previously seen (Notaker 1987:195). According to Notaker (1987:195), the notion 'foodie' is perhaps not so different from what was called a 'gourmet' in the era of Brillat-Savarin; however, still he points at one characteristic he finds separates the 'foodie' from the 'gourmet'. With reference to an article written by Ann Barr and Poul Levy published in Harper \& Queen in 1982, Notaker (1987:195) argues that a 'gourmet' typically was a rich, male food lover who saw food as a passion, whereas the 'foodie' instead is typically an ambitious married couple seeing food as a fashion. This is supported by Finkelstein (1989:3) who notes that most dining out in our contemporary society is closely linked to the bourgeois notion of self-presentation and the material mediation of social relations through 'images' of what is fashionable, as also argued for with Sparke (2007) in the Introduction. Thereby, public spaces, like restaurants through their iconic represented ambiances, decors, furnishings, lighting, tableware and food, are regarded as places of personal experience, excitement, pleasure and well-being that are strongly governed by the tendencies of the fashion. Finkelstein (1989:3) even concludes: "The physical appearance of the restaurant, its ambiance and décor, are as important to the event of dining out as are the comestibles...the restaurant has the double function of being an architecture of desire and an inventory of the private, subjective world". Without doubt, these tendencies Notaker and Finkelstein described in 1987 and 1989 have increased rapidly throughout the last ten years. Today - in 2013 - I find even more cookery books exist describing all manners of cooking and eating, and with the emergence of the 'New Nordic Kitchen' 'foodism' has reached higher levels of fashion in Denmark than ever before.

In continuation hereof, lately an increasing globalization has also made any type of food available any time, all year round. There are no limits. Today food is available via the internet, and we can have it brought directly to our home with delivery from large grocery stores within a few hours. Strong (2002:311-12) further argues that the social abilities of both the domestic and public dinner table have partly been replaced today by other media and a different kind of "social filtering". First, it was television and lately other electronic online media services like Facebook and YouTube that have the ability to stage and display idols, trends and fashion. As a result of this, restaurateurs, store managers, food producers, and several other stakeholders related the food sectors are increasingly competing for costumer/consumer attention. With the perspective of the concept of 'Experience Economy', as put forth with Pine \& Gilmore (1999), public food offerings have the potential of being part of more fashionable cultural offerings. What you eat and where you eat is today interpreted by sociologists as ways of personal identity and social affiliation (Holm 2003)[Olsen 2008:35]. According to Franck (2005:2) even plans to regenerate urban economy have throughout the last ten years, heavily inspired by the concept of the 'Experience Economy', increasingly been concentrated around using food as means to generate cultural experiences and reestablish old worn-out city areas. The opening of new cafes, restaurants and luxurious food shops in old harbor and factory neighborhoods are used to create attention and lure new user segments to inhabit the city domains. Relative hereto, it is my claim, that enrolling the meal and food products in cultural and performative experiences creates an extra emotional layer or narrative to the nutritional value of the food and opens op to a more personal and individual engagement in the identity of each consumer [Olsen 2008:35].

In opposition to the rapid technological mechanization and tendencies of dehumanization in the increasing industrial offerings on Fast Food, Convenience Food, Functional Food, and to some extent also the chemical and artificial tendencies of Molecular Gastronomy, I find the emergence of the Slow Food movement stemming from Italy encouraging a return to a slower lifestyle. Here quality in food is achieved 
through three equally important categories: good, clean and fair, which refer to the moral, ethics and sustainability of the production, preparation and gustatory taste of regional foods as well as a responsibility and awareness towards the general environment (Petrini 2007:138-140). In that way, Petrini (2007:139-140) argues that gastronomy becomes a holistic synthesis of tradition, cultural folklore and the scientific disciplines of agriculture, politics, social sciences, anthropology, engineering, etc. Based on the above Historical Review and the outline of Healing Architecture in the introductory chapter, it is my claim that the contemporary hospital practice, research and studies performed viewing patient treatment as healing instead of recovery are

based on a similar "slow tendency" occurring within the medical world. Here patient recovery depends not only on medical and surgical treatments, which are traditionally considered as "hard" physiological aspects of recovery, but on a return to the holistic values and humanistic qualities linked to the general well-being of patients. Here, among others, the "soft" psychological aspects of recovery, like the social affiliation and mental state-of-being, are presumably lost or displaced with the specialization of medicine and the emergence of the 'Modern Hospital' as argued for by respectively Bromley (2012:1058) and Heslet \& Dirckinck-Holmfeld (2007). If I thus return to my Timeline and consider the three "entries" or "layers" of health, food and architecture separately, I have tried to provide an overview of some of the major developments within the history of hospital design, eating environments and architectural 'polemical theory', respectively. Still, I find that it is the merging of the three "layers" into one "knowledge map" that is most interesting. Here I begin to see the contours of a possibly new theoretical discourse and paradigm, investigating the synthesis of health, food and architecture and a link in the underlying theoretical thinking and philosophical perspectives governing the practice as the above examples of the Slow Food, the 'New Nordic Kitchen' and the contemporary healthcare tendencies.

However, I had hoped that the three "layers" in their merging had also revealed a series of best-practice examples illustrating how health, food and architecture in a holistic fashion had already been synthesized in the past. Thereby providing me a practical example illustrating the interior architectural qualities requested by MORE and VEJLE today. But as it later occurred to me, I was searching for an ideal that most likely has never existed. The "highlights" and state-of-the-art developments in the history of health, food and architecture are not necessarily linked in place or in time. Instead, the outline of the history of healthcare design depicts how hospitals have developed from ancient temples, monasteries and hospices into health resorts, sanatoriums, and what is known today as the 'Modern Hospital'. Relative hereto, I find it interesting how the medical thinking and practices developed with Hippocrates, Galen and Nightingale throughout time influenced the development of the hospital architecture and the specific topic of patient eating. The outline on of the history of dining room interior, in a similar manner, depicts how eating environments have developed from ancient fireplaces, Roman Triclinia and lavish banquets into private dining rooms and modern restaurants, as well as having provided an outline of culinary thinking - from the first cookery books written by gastronomes and housewives to the contemporary manifestos written by movements like Slow Food and the 'New Nordic Kitchen' governing contemporary culinary practice.

\section{SUB-CONCLUSION ON 'NORMATIVE THEORY’}

What I can conclude on the background of this Timeline and Historical Review is that the quality of the practice of health, food and architecture is not static. There is seemingly not one set of principles 'describing', 'explaining' or 'predicting' how food should be cooked, how health should be treated or how architecture should be designed. As seen in the above, the interiors of the different environments alter throughout time according to changes in the cultural context - the society, the fashion and the technological developments among others. The specific 'descriptions' of the different qualities are context and time dependent. Of course I should - or at least could - have known that before even engaging in such an elaborate historical investigation. Still, despite this result, I find that, the Historical Review and Timeline did reveal that throughout history certain spectacular examples have existed like the Roman Triclinium, Renaissance monastery, $19^{\text {th }}$ century early restaurants and health resorts, 
'Nightingale Wards', Soyer, and Brillat-Savarin, touching aspects of my "ideal" on synthesizing aspects of health, food and architecture into a coherent whole. Here, we see during the ancient Roman era, the Renaissance and particularly in the $19^{\text {th }}$ century how the architects are not the only ones doing interior architecture, but how also gastronomes, chefs and nurses occupy themselves with the elements and appearance of the built environment. In the most extreme example the chef almost becomes the interior architect himself (for instance Soyer and Carême) in the way they adopt the methods of designing and presenting their food as objects of art or 'total design'. These examples are thus "hybrids", representing, in my point of view, a particular holistic thinking and humanistic world perspective through their occupation with creating multi-sensuous events or healthy environments that not only frame good meal experiences but also spark social interrelations, personal comfort, enjoyment, health and well-being.

Despite the observation that there presumably is not one static answer to the question of what described the architectural quality of patient eating environments, it still seems to me, particularly in the era of the $19^{\text {th }}$ century with the above-mentioned examples, that there are some common underlying features characterizing or at least linking the thinking behind the particular interior environments. However, it is important to be aware that it is a "construction" or an interpretation I make on the history of the different disciplines through my specific selection of practical examples and written words. Despite this, I find that there might in these "hybrid" examples exist some underlying basic architectural qualities describing the patient eating environment. Contrary the above claim, put forth in the chapter, Literature Review, that existing 'positive theory' and 'scientific' research-based literature theoretically fail to consider the interior architectural qualities of the eating environment, as can be seen from the Timeline, vast amounts of polemical literature exist within the architectural discipline trying to explain the same speculations as mine about the quality of architecture and 'predict' how to design good environments. As the Timeline indicates, the discipline of architectural writing span more than 500 years and encompasses a grand mixture of treatises, manifestos, books, book chapters, editorials, journal articles, lectures, interviews, and even poems. There are, as mentioned in the Preface, polemical theories that view architecture from a historical or cultural perspective that explain architecture on the background of phenomenology, structuralism, behaviorism, existentialism, psychology, economy or even neurology. There are thus many perspectives, narrow or wide reflections. For each book and writer, architecture is regarded from a different perspective, creating a new theoretical and practical discourse.

Nevertheless, as mentioned in the Prologue, the architectural theoretician Peter Collins, in 1965, argued opposite contemporary architectural historians that 'modernity' in architecture emerged in 1750. According to Frampton (in Collins 1965), Collins insisted on this specific year, because this was the moment in history when architecture first of all broke with civil engineering, but it was also the year when both the disciplines of architecture and gastronomy, according to Collins, radically expanded their theoretical thinking and polemical writing in the search for a "scientific explanation" of good 'taste' (Collins 1965:viii). This kind of thinking is quite extraordinary, because contemporary major architectural historians like Hitchcock (1929), Pevsner (1936) and Giedion (1941) had mainly evaluated the quality of architectural practice in their historical reviews by reviewing the physical appearance of existing buildings. When Collins (1965:15-16) suddenly insisted on linking the history of architecture with the evaluation of the ideals on quality governing the thinking, intentions and writing of the architects drawing the buildings instead, it was pioneering. The mid- $18^{\text {th }}$ century in Collins' book thus marks the beginning of an era of radical changes in the ideals defining architectural quality, but it also indirectly marks the division of architectural thinking and polemical writing into two major phases - a before and an after the changes in the definition of architectural quality. On that basis, I find that, in my search for an answer to the research question about what 'basic design principles' 'predict' the interior architectural qualities of the patient eating environment, I need to gain a better understanding of these changing ideals in the understanding of architectural quality in general and, therefore, return to the importance of the polemical architectural writings of the era in-between 1750 and 1950. 


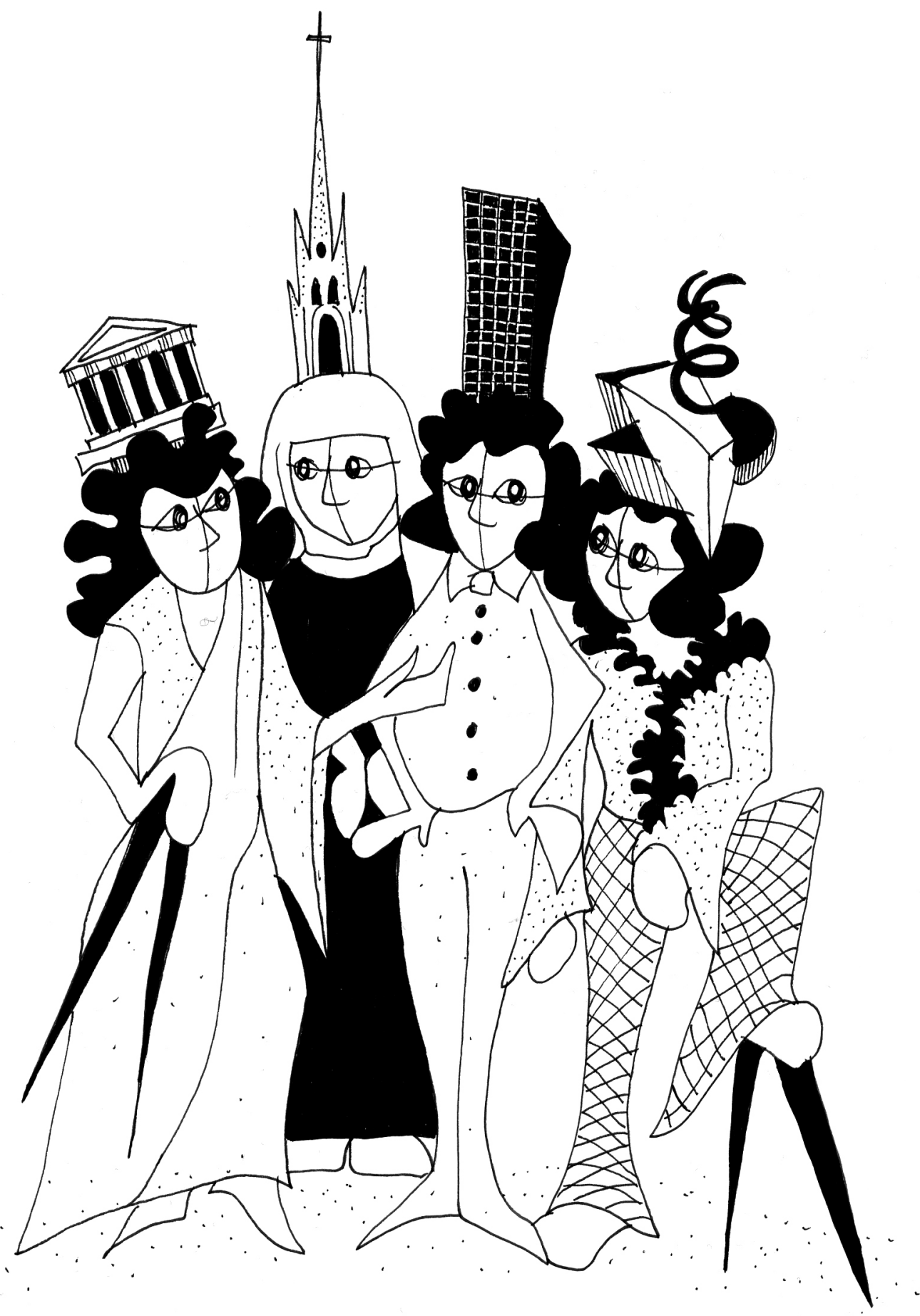

Fig. 7.1

"Architectural Hats"

(Drawing inspired by Frascari 2011:79) 


\title{
POLEMICAL THEORY
}

\author{
THE HISTORY OF INTENTIONS
}

As mentioned in the previous chapter, in his book Changing Ideals in Modern Architecture, architectural theoretician Peter Collins argued that around the year 1750 the thinking and later the practice of the architectural discipline was radically changed. According to Collins $(1965: 15,22)$, these changes were sparked partly by the "quarrels" between ancient and modern architecture, but also by a fundamental change in a number of notions continuously recurring when talking and writing about architecture and thereby a change in the overall ideals governing the thinking of architectural quality (or what he also referred to as the idea of architectural beauty) throughout the period from 1750 to 1950.

According to Collins (1965:22) and as can be seen from the Timeline in the previous chapter, the architectural writings published before 1750 were mainly occupied with studying architectural quality as a matter of Classicism based on the 'beauty' of order, symmetry, harmony, geometry and proportion. Here, what architectural theoreticians call the 'Vitruvian Ideal', defined by three basic principles called: utilitas (convenience), firmitas (durability) and venustas (beauty), had dominated the thinking and writings of renaissance architects like Alberti and Palladio. However, as noted by Mallgrave (2006:4-5), another major cornerstone in Western architectural theory before 1750 was the dominance of Christianity and the medieval thinking sparking the Romanesque and Gothic eras. According to Mallgrave (2006:xxiii-xxiv) the Western history of architectural theory, before the period of Enlightenment (c.1750), is defined first by the ancient religious Hebraic traditions recorded in the Old Testament, then in a series of ancient Greek and Roman treatises among which only the writings of Vitruvius exist today, a series of texts from Late Roman and medieval times mainly based on the Christian classical traditions and the Renaissance which is characterized by rediscovering the lost ideals of the classicism (ancient Rome and Greece). Indirectly linking the two traditions, Professor in History and Theory of Architecture Caroline van Eck (2004:60) suggests that the era before 1750 was primarily concerned with unfolding the meaning and purpose of the principles guiding architectural 'beauty' (venustas). She argues that these ideals were primarily based on the symbol of the highest order (a divine order), religion, myth and ideology. A tendency that was partly inherited in the ideals of later Renaissance architects as well. Up until around 1750, the ideals governing architectural quality were, thereby, very much an iconological object linked to the divine beliefs and social practices of the surrounding world (Eck 2004:60). For that reason, Collins (1965:22) further argues that the three essential principles of the 'Vitruvian Ideal' can never be rejected or replaced by anything else because they simply define the obvious importance of "commodious planning, sound construction and pleasing appearance", and he concludes that any revolutionary or innovative thinking in architecture, like during both the Gothic and Renaissance eras, must therefore essentially be based on notions added to these three basic principles. At the turn of the $19^{\text {th }}$ century - after $\mathbf{1 7 5 0}$ - the theory of evolution and the claim 
that early man, contrary to biblical writings, did not descend from Adam and Eve but had evolved from animals emerged. This was sparked among others with the theory on human evolution developed by the scientist Charles Darwin (1809-1882) who, in his book The Origin of Species by means of Natural Selection (1859), formulated the early ideas of the "biological body" focusing on nature, anatomy, medicine and biology rather than the "spiritual body" which was based on the belief that man originated from God, through Adam, and therefore was destined to a placed in the lost ideal of Paradise (Mallgrave 2011). These transformations, in the understanding of the origin of humankind, highly influenced the understanding of the 'origin', meaning, quality and purpose of architecture as well. The time after 1750 is, therefore, often referred to as an era of "anxiety" - a time where the essence of human nature was being questioned. As mentioned in the above, architectural quality had previously been based primarily on a divine belief in forces more powerful than natural human talents. The radical discoveries in science had "killed" the immortal soul when claiming that humans had evolved from apes instead of fallen angels (Lehrer 2007:viii). According to Professor in Architectural Theory and History Mari Hvattum (2004), the new bourgeois society of the mid- $18^{\text {th }}$ century and forth can thus be characterized by the growing interest in nature, a search for the 'origins' of things and the obsession from scholars, scientists and philosophers within almost every discipline to "scientifically" re-explain the world by discovering "first causes", revealing "certainty" and return to "natural" form. Nature was simply understood as a source of historical legitimacy (Hvattum 2004:30,34). This "obsession" with the natural origin and the scientific is also reflected in the discipline of architecture.

At the turn of the $19^{\text {th }}$ century, architectural thinkers began considering architecture not as a divine temple but as a natural response to the evolution of the basic generic needs of man. The "belief" was that architecture originated with the first primitive huts built by man to protect him and his family from the dangers of the surrounding environment - the climate and the wild animals (Rykwert 1972). Thereby, architecture became a natural response to a specific function and pragmatic need instead. That transition in "beliefs" demanded a different type of vocabulary with different notions to describe the quality, meaning and purpose of architecture than previously seen. The era from 1750 to 1950 is, thus, defined by an almost "desperate" or "obsessive" search among architectural thinkers to define the "new language" of architecture. According to previously-mentioned architectural theoretician Alberto Pérez-Gómez (2000:472), this resulted in a "scientification" of the design process and a dividing of architectural quality into historic periods and distinct architectural styles, as well as describing and explaining the differences between these periods and styles by means of a categorization of the material structure, a system of judgment - or series of design principles - primarily based on rational terms.

As seen from the Timeline in the previous chapter after 1750, in the time following up to the mid- $20^{\text {th }}$ century, the discipline of architecture grows into a series of different styles or periods "labeled" by later architectural historians and theoreticians as: Eclecticism, Historicism, Romanticism, Picturesque, Neoclassicism, Gothic Revival, Engineering Architecture, Arts \& Crafts, Art Nouveau, Viennese Secession, American Style, Deutscher Werkbund, De Stijl, Art Deco, Futurism, Constructivism, Avant-Garde, International Style and Modernism. Here architectural thinkers, according to Collins (1965:15), in the search for notions that define and describe the fundamental qualities of architecture became particularly fond of analogical justifications, comparing architecture to different scientific disciplines and arts. Just as Fergusson compared architecture to gastronomy. They also became fond of historical allusions employing notions like 'beautiful', 'sublime', 'taste', 'style', 'decorum', 'sympathy' and 'space' to describe the quality, meaning and purpose of architecture (see e.g. Mallgrave 2006; Mallgrave \& Contandriopoulos 2008; Collins 1965). With these notions, a particular distinction between taste/tasteless, good/bad, quality/poor quality or beauty/ugly was often implicitly introduced, suggesting that there was a distinction and fine balance between the qualities of plain, ordinary building and the qualities of architecture. But also an implicit assumption that some design principles were "correct" and others not, fostering a belief that architectural quality had to be based on a series of moral and ethical judgments, and that by following these ideals and basic design principles architects could improve the future (Collins 1965:29,41). As noted by Frampton in the foreword to Collins (1965:xiii), the biggest question relative hereto was - and still is - what defines that balance, and is any architect ever able of attaining any kind of 


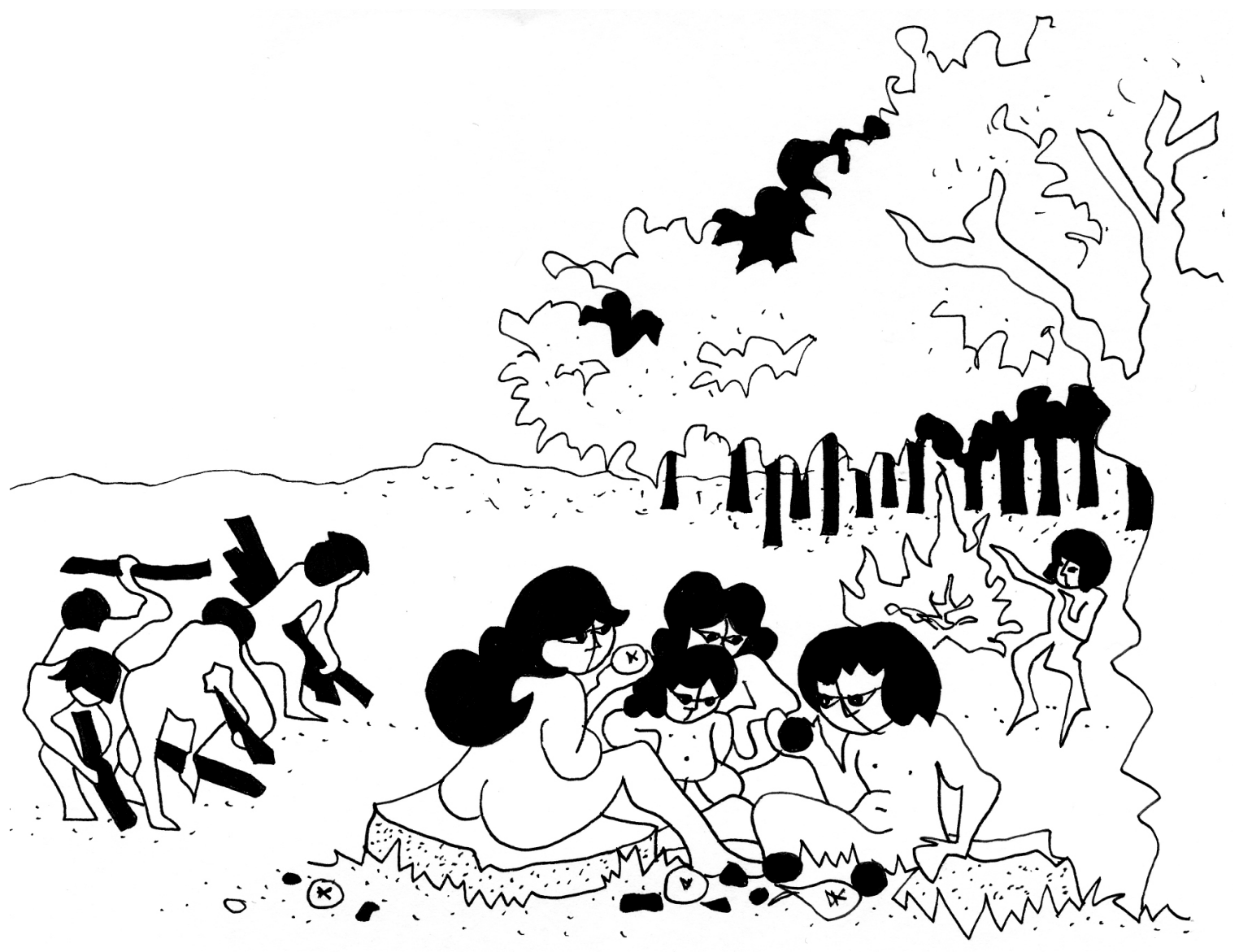

Fig. 7.2

"The Origin"

During the 18th and 19th century, there was a particular occupation within the architectural discipline with finding the "origin" of architecture. This was partly motivated by a search for a taxonomy describing the qualities and purpose of architecture. 
balance? Will it not always be either over-articulated or under-articulated? The answer, according to Collins (1965:26), possible lie in the architectural qualities linked to the emergence of the new notion on 'space'.

\section{The emergence of 'space'}

In his book, Collins (1965:26-27) notes that before the mid-18 $8^{\text {th }}$ century: "the interior of a building was essentially a kind of box-like enclosure, or a series of box-like enclosures, either divided by visibly solid walls, or else interspersed by colonnades. But after about 1730, this attitude changed...the change which occurred...concerned new devices for achieving parallax". First of all, according to Collins (1965:27) the term 'parallax' is defined as the "apparent displacement of objects caused by an actual change in the point of observation". In architecture that means, that as one moves through or past an object, the object not only appear to change position relative to you as a spectator, but also appear to change position relative to whatever is perceived through or behind that object (Collins 1965:27). It is a "multiplication of real effects" in opposition to illusionistic effects achieved by for instance image-based wall paintings. An effect of constantly changing views that for instance is achieved by use of large mirrors placed opposite each other on the walls of a room (Collins 1965:27). The point made by Collins (1965) relative hereto is that, whereas architectural thinkers before 1750 were primarily concerned with the ideals of the shape of the building as a solid object with surfaces and a kind of structure, here the ideals were understood as the specific design of the walls, the columns and the ornamentation. After the mid-18 ${ }^{\text {th }}$ century, these ideals transform into an occupation, particularly among the German writers, with the space-enclosure denoting a spatial significance and "mystical" notion of 'space' as the essential enclosing of "soul-life" (Collins 1965:286). Collins (1965:28788) notes that, whereas the previously-mentioned architectural historian Sigfried Giedion (1941) uses the notion 'Space-Time' to distinguish between cultures of twodimensional, three-dimensional or four-dimensional or any other $n$-dimensional space, the meaning can be expressed more accurately in much simpler terms. Collins (1965:290-91) states that such an understanding of architecture is only possible if we consider the creation of space to be indistinguishable from the depiction of space, and he finds this type of thinking is to deny the words of any "real tectonic meaning". Instead he suggests that the quality of the notion 'space' lies in the understanding of what he calls 'parallax' and our bodily encounter, perception and interpretation of these 'spaces' (Collins 1965:292).

In continuation hereof, Pérez-Gómez (2000:471) argues that the sacred relationship of divine orders that had governed architectural ideals since ancient Greek and Roman times were forgotten or overruled by the revolutionary speculations on geometrical space and "mathematization" of the physical world put forth with the Italian scientist Galileo Galilei (1564-1642) in the mid-17 ${ }^{\text {th }}$ century (Oxford Dictionary of Philosophy 1994:152). With the theories of Galileo, the "rules" for thinking and gaining knowledge changed, and geometry, as well as numbers, became valuable instruments for technical control of practical operations instead. In addition to Collins (1965), Pérez-Gómez (1983/2000) thus advocates that this particular era is where mathematics and geometry dismiss or reject the transcendental dimension of Renaissance cosmology, and where the link between the human and the divine is cut off by modern philosophy and modern science. And these radical developments in philosophy and science paralleled, according to Pérez-Gómez (2000:471), with a development in architectural practice where architects began considering their discipline as a technical endeavor relating to numbers and geometry, instead of a craft and technique with innate magical associations. This fate of architectural thinking was further upheld during the late $18^{\text {th }}$-early $19^{\text {th }}$ century when a number of different spatial positions occurred not only in science but eventually also in architectural thinking and writing. One of these was, the development of 'Euclidean space' around the 1820s. Here, the mathematical development of Euclidean geometry leads to the ideas of analytic geometry and most importantly to a three-dimensional description

of physical space by use of Cartesian coordinates (Lefebvre 1974:1-2). However, this notion of architecture as 'space' has by others been dated to the Renaissance when painters, philosophers and scientists discovered or invented the method of geometric perspective. The geometric perspective made the visible, three-dimensional world systematically comprehensible and measurable on a two-dimensional plane by means 
of a mathematical understanding. Relative hereto were the systematic methods for drawing architecture such as the plane, elevation, and section to render 'space' intelligible (Malnar \& Vodvarka 2004:11). This understanding of architecture as a kind of mathematical 'space' is, by Frandsen et al. (2012:1063), referred to as 'space as distance', because the understanding of the 'space' in line with Euclidian geometry suggests that 'space' is the measurable distance between two or more points (Taylor and Spicer, 2007: 327). Here, proximities can easily be measured, constructed and even calculated with a high level of objectivity (Taylor \& Spicer 2007:329).

So, Pérez-Gómez (2000) argues that this assumption that the meaning of architecture can be derived from functionalism, formal games of combinations, the rationality of a style understood as ornamental language or the use of type as generative structure which evolved in western architectural thinking in-between the mid- $17^{\text {th }}$ and $19^{\text {th }}$ century is a kind of "algebraization" of architectural theory. He claims that it is a reduction of architecture to rational theory. Pérez-Gómez (2000:466) specifically points to the architect Jacques-Nicolas-Louis Durand (1760-1834) who developed a theory of architecture composing a series of basic design principles of an exclusively prescriptive character avoiding all reference to philosophy or cosmology. Here architectural theory was reduced to self-referential system whose elements must be combined through mathematical logic. The values and meaning of the architecture are therefore, according to Pérez-Gómez (2000:466), derived from the system itself . According to Pérez-Gómez (2000:467) this tendency in architectural thinking arose simultaneously or parallel with the rise of Positivism in the Natural Sciences, and with reference to Husserl he further argues that this also marks the beginning of the "crisis" of European science. The point made by Pérez-Gómez (2000:467) is that this development limits architectural theory to a set of operational rules, or what Péréz-Gómez (2000:467) calls a "tool of exclusively technological character", where the main concern is how to build in an efficient and economic manner. Throughout the mid- $19^{\text {th }}$ century, this understanding of 'space as distance' is challenged by the deep political rifts as well as social and political struggles dominating Western Europe. As mentioned in the Introduction, from the Renaissance and onwards, an increase in technological and scientific progresses sparked what is often referred to as the 'Industrial Revolution' and the beginning of an era of high capitalism. Here a rational division of labor together with an increase in the general population gradually led to urban expansions, rapid developments of infrastructure, and communication - in total, altering social life and eroding traditional culture (Bø-Rygg 2004:25). These radical changes motivated by social, economic, political and cultural transformations also led to the dissolution of classical notions and concepts of architectural quality, as noted in the above with the writings of Collins.

Perhaps this is why architectural theoretician Kenneth Frampton (in Collins 1965:vii) notes that Collins' book is a hermeneutical classic which is a neglected or perhaps even forgotten pioneering piece of work? Because, in my point of view, on the background of the above, it provides an ideological history of the modern movement, and, also, it is a multi-faceted interpretation of the theoretical roots of European architecture that challenges and questions the fundamental role played by structural form in the growth of modern architecture since 1750. Collins, according to Frampton (in Collins 1965:vii), pinpoints the beginning of 'modernity' to the start of history as an epistemic discipline. The point made by Frampton is that, during the $19^{\text {th }}$ century, architectural history was established as an academic discipline. This meant that architectural thinkers began studying the relationship between the theory and history of architecture and its practice. Before the birth of modern classical archaeology and historiography in the 1750s, the remains of Greek and Roman architecture had mainly been studied to establish firm principles of classical design (Mallgrave \& Robinson 2004:22; Collins 1965:vii). However, "educational journeys" and "measuring excursions" to study the ancient Greek and Roman executed by the young men of the rich upper class meant that contradictions were found in the treatises and former reconstructions by the students at the Ecole des Beaux Arts (Eck 2004:57; Mallgrave \& Robinson 2004:4). For centuries, architects had turned to history and a copying of the classical ancient Greek or Roman styles to solve their search for beauty. This was followed up by early-19 $9^{\text {th }}$ century architects like Durand who even went as far as to develop a series of "typological elements" and "archetypical buildings" - or what I have called 'basic design principles' - elaborately describing how and what different 
types of architecture such look like (Mallgrave 2006:335). Before 1750, it had thus been unthinkable to start a design from "scratch" (Eck 2004:57).

After 1750 and during the $19^{\text {th }}$ century, this connection between history, practice and theory was significantly altered. The main point of historical investigation was no longer to illustrate, explain or support the 'Vitruvian Ideal'. Instead, it became an academic discipline on its own, closely linked to archaeology and other disciplines such as linguistics and anthropology within the social sciences and the humanities (Eck 2004:57). According to Eck (2004:58), architects continued to write about the history of classical architecture, but during the course of the $19^{\text {th }}$ century their writings changed to reflect how historicism as a viable and meaningful design option was overtaken by 'modernity's' sense of the past as a foreign and fundamental inaccessible territory. This can be seen, for instance, with German-born architect Gottfried Semper (1803-79) who, on the background of a series of travels to Italy and Greece visiting among others Pompeii, Sicily and Athens, did a series of colored sketches depicting how ancient classical monuments had been extensively painted (Mallgrave \& Robinson 2004:5-7). Later on, Semper used this work to introduce a systematic reflection or fundamental taxonomy analyzing the ideal qualities of architectural thinking together with the form. That approach was revolutionary because it removed the understanding of architectural quality from previous considerations on "correct" measurement, 'beauty', proportion, orders, geometry and symmetry into considerations on context, spatiality, time and culture instead. In the introduction to the book Style, Mallgrave \& Robinson (2004:48) thus describes how 'space', in terms of using the German notion Raum, was always an underlying topic in the writings of Semper. They argue that particularly with the theory on the Four Elements of Architecture stemming from 1851, Semper's motive referring to the 'walling' and its inherited concept of 'dressing' (which I will elaborate on later) was an enclosing spatial element which outlined an interior world separate from the outside (Mallgrave \& Robinson 2004:48). In that way Semper, according to Eck (2004:60), made an important theoretical contribution portraying an early version of the modern notion of 'space' as it developed during the early $20^{\text {th }}$ century in the architectural thinking related to the era of Modernism.

\section{The modern notion of 'space' in architecture}

According to Frampton (2001:1), the specific notion of 'space' did not enter architectural theory until it was unfolded in the writings by the two German artist Adolf von Hildebrand (Das Problem der Form in der Bildenden Kunst, 1893) and art historian Auguste Schmarsow (Grundbegriffe der Kunstwissenschaft, 1905) around the turn of the $20^{\text {th }}$ century. However, these writings were in German, thus utilizing the German notion Raum instead of 'space'. Relative hereto, Frampton (2001:1) in line with Mallgrave \& Robinson (2004:49) stresses that Schmarsow was greatly inspired by the writings by Gottfried Semper. Frampton (2001:1) thus notes how Schmarsow, between 1893 and 1914, identifies 'space' as the driving principle between all architectural forms. This is simultaneous with the emergence of the above-mentioned scientific theories on 'space-time' foremost put forth by the scientist Albert Einstein. Within the Natural Sciences, researchers investigating quantum physics literally discovered a whole new world - a series of subatomic particles - which, according to Moffett et al. (2004:543), did not behave by the laws of the prevailing Newtonian mechanics. The emerging theories developed by Einstein on this basis suggested that ultimate truths about the natural world were ungraspable, thus indirectly questioning the prevailing 'scientific' methods and "laws" that govern not only the sciences, but to some extent also architectural thinking, as mentioned above with Collins (1965) (Moffett et al. 2004:543). Frampton (2001:1), in continuation hereof, notes that today the concept of 'space' together with the ideas of levels of speed, time and movement are an integral part of our thinking about architecture. During the turn of the $19^{\text {th }}$ century, the concept was new, and it gave priority to a "spatio-plastic" unity of interior and exterior space, as well as a continuous 'space-time' experience that had not been seen before (Frampton 2001:1-2). These ideals of modernist architecture developed in opposition to the eclectic style and the extravagant use of ornamentation and decoration inherited by the teachings in the Ecole des Beaux-Arts (Moffertt et al. 2004:476). According to Moffett et al. (2004:475), after World War I many architects believed that the European culture had failed and that society needed to change once more, and that the architecture, as in the late $18^{\text {th }}$ and early $19^{\text {th }}$ century, was an important "instrument" in this societal transformation. 
After 1950, the International Style and Modernism in architecture were increasingly being accused of being superficial with a reductionist or "stripping off" of all parts except the essentials, as well as considered to be inhumane, neglecting human values and belief systems because its design principles often tended to prioritize the objective aspects above the more subjective (Moffett et al. 2004:475, 543). Often modernist architects are as such accused of believing in a rational approach to design, emphasizing the "mechanization" and efficiency of machine-made buildings. This is particularly evident in the use of building materials and the process of assembly. According to Moffett et al. (2004:533), most developments in architecture from 1945 through the 1980s were, therefore, motivated by reactions to the International Style and the occupation with rational thinking. These accusations led to a general decline in Modernism in architecture, and instead a "shift" or transformation emerged towards an opposite movement called Post-Modernism.

Post-Modernism was led by architects like American architect Robert Venturi (1966) who was triggered by various ideas occurring in both the humanities and the sciences. Venturi (1966) was especially inspired by structuralism, and he began arguing that architecture could also be seen as a "language" or as a 'space as sign of power relations' relative to 'space as distance' (Frandsen et al. 2012:1066; Moffett et al. 2004:543). Simultaneously, as mentioned in the chapter, Research Approach, around the turn of the $20^{\text {th }}$ century the humanities move towards hermeneutics and interpretation of texts and objects, while the Natural Sciences with Research Mode 1 still emphasized more positivist approaches, basing the understanding of the world on empirical "facts". Often structuralism and semiotics are considered as being in opposition to hermeneutics, because semiotics looked at the text and objects themselves for signs and symbols, where the objects and texts took on meanings never intended by the designer, contrary to hermeneutics which were very occupied with understanding the intent of the author or maker of the objects (Moffett et al. 2004:543). During the early $20^{\text {th }}$ century, the idea of architecture as a 'space of distance' further developed into the theories of phenomenology and the understanding of 'space as lived experience' (Frandsen et al. 2012:1066). According to Moffett et al. (2004:543), the writings of, for instance, philosophers like the philosopher Edmund Husserl (1859-1938) who is generally considered as introducing the concepts of phenomenology and the concept of an embodied experience of space should probably be seen as an attempt to approach a systematic investigation of human consciousness, combining the humanistic and the natural scientific endeavors.

In the late 1990s, Finish architect Juhani Pallasmaa (1996:2), in continuation of the phenomenological trends, wrote the book Eyes of the Skin in opposition to the culture of globalized consumerist values, speed, photographic representation, computerization and growing visual aspects which he found dominated, dematerialized and dehumanized architecture at the turn of the $21^{\text {st }}$ century. Herein, he pointed at the bodily perception as the basis for our inhabitation of the world and, on that basis, advocated for the perception of space as decisive for our experience of architecture (Frandsen et al. 2012:1067-68; Pallasmaa 1996). According to Pallasmaa (1996:2), images of form are peripheral to architecture, because they are unable to address the gravitational centre of our own self-experience. Architecture is an art form for all the senses, whereas a picture or image is merely an empty stage set for the eye. Instead he argues that architecture is an art form that addresses our bodily being in space, time and place. It mediates basic existential causalities and helps define the horizon of meaning (Pallasmaa 1996:2). He continues with arguing that physical structures are grasped as embodied sensations and an unconscious bodily encounter. Every art form echoes its ontological beginning; the art form of architecture was born in the acts of ritual, and architecture disappears when it loses its connection with its "mytho-poetic" beginning (Pallasmaa 1996:2). Besides Pallasmaa, today a series of hermeneuticphenomenologists like the previously mentioned architectural theoreticians Kenneth Frampton, Marco Frascari and Alberto Pérez-Gómez, in opposition to among others post-modernism and structuralism, emphasize the importance of the "whole-body", its senses and the bodily experience. One of their common claims is that by the mid- $20^{\text {th }}$ century mystery in architecture seemed to be on the retreat, and life itself had been reduced to chemistry, biology and physics by the sciences. In fact, PérezGómez (2012:5) claim that what he refers to as the architectural "crisis" must be seen in parallel to the beginning of 'Modern Science' itself and how that development 
impacted on architectural discourses. The point is that much contemporary thinking lean on the early $19^{\text {th }}$ century model of Natural Sciences. Therefore most theory in any research discipline is identified with methodologies that are based on a specialized set of prescriptive "rules" concerned with technological values - with process rather than the mythos and transcendental dimensions of human being (Pérez-Gómez 2000:467). Pérez-Gómez (2000:468) finds that the problem is that modern science does not explain the real issues of human behavior, because positivism rejects the richness and ambiguity of symbolic thought and rejects mystery and poetry. For many researchers, as well as architects today, Pérez-Gómez (2000:468) notes that myth and poetry are considered synonymous with dreams and lunacy, and architecture should not partake in the "escapisms" of the arts but strictly relate to efficient and economical construction. Completely deprived of the poetic content, architecture was destined to reject its position among the arts and instead, according to Pérez-Gómez (2000:472), be reduced to mere technological process and decoration.

As a solution to the "crisis", splitting the arts from the sciences, Pérez-Gómez (2012:3) suggests an architectural theory as hermeneutics. In continuation hereof, he argues as previously-mentioned - that what I here have chosen to call 'architectural quality' was always understood in relation to 'history'. Consequently, Pérez-Gómez (2012:2) reasons that the appropriateness of a chosen architectural order depended on the capacity of the architect to understand the "work at hand" in relation to the context and the preceding architecture, and that aspects of proportion served as an "ontological bridge" between the works of man and the observable world. In Pérez-Gómez's (2012:2) words, the practicing architect always had to "adjust" the dimensions of the work according to a specific task and a particular site, rather than strictly follow the "rules" of a certain theory. In this argument, Pérez-Gómez (2012:2) notes the mythical beginnings and advocates that an original capacity for storytelling, a potential of articulating meaning - a "space of experience" and a "horizon of expectations" - is rooted in architecture. Pérez-Gómez (2012:2) writes: "the projections of the architect's imagination construe a better future for the common good". Pérez-Gómez (2012:2) concludes this line of thinking by noting that today more architects are becoming aware of the shortcomings or limitations of functionalism and formalism, and they are trying to avoid reducing architecture to mere decoration, sensation, sociology or psychology. However, he also notes that, with the rapidly increasing developments of computer methodologies trying to develop geometrical strategies or mathematical solutions to planning problems, architects should be more concerned with meaning as not to make the "rift" between mind and body larger in architecture. And he ends up pointing at the movement of phenomenology within architecture as the only contemporary type of architecture that seems to go beyond positivistic prejudices to find a new metaphysical justification in the human world (Pérez-Gómez 2000:473).

With the book The Poetics of Construction in Nineteenth and Twentieth Century Architecture, Frampton (1995/2001) attempted to "reground" architecture in the poetics of construction. He addressed the same era and 200 years as Collins (1965) did in his book. Contrary to Collins (1965), Frampton (2001) introduced the notion 'Tectonics' and investigated the rise of architectural quality as a result of tectonic form. According to Frampton (2001:3-4) the etymological meaning of the term 'tectonic' derives from the Greek tekton, signifying a carpenter or a builder, but it also relate to the craft of carpentry and the use of an axe, or simply construction in general. However, Frampton (2001:3-4) further notes that the term also has a more poetic connotation, where the tekton refers to a carpenter being a poet. Frampton continues the etymological trace into recent times, where tekton refers to the master builder or the architekton, which today eventually aspire to a more aesthetic meaning rather than a technological category (Frampton 2001:4). The point is that Frampton (2001) focuses on the constructional and structural modes of architecture, and the expressive potential of these two modes. But, he also emphasizes that the concept of tectonics should not just be understood as a technical or material mode, but also as poetic art (Frampton 2001). And he states that this 'poetic art' is not understood as something figurative or abstract. To Frampton (2001:2) architectural quality is both tectonic and tactile in character as it is scenographic and visual, and none of these deny its spatiality. Frampton (2001) thus ultimately defines architecture as the 'poetics of construction', suggesting that architectural quality can be evaluated by criteria such as the appreciation of craft and the tactile dimensions of tangible materiality. Thereby, he makes the overall point that an architect with a profound understanding of how a 
building is constructed is presumably a better architect than one without. However, as emphasized by the previously-mentioned architectural theoretician Harry Francis Mallgrave in the foreword of the book, architects in the $19^{\text {th }}$ century like Karl Friedrich Schinkel (1781-1841) or Gottfried Semper (1803-79) accepted that a building conveys meaning on various levels not only in the capacity of tectonic form to portray constructional logic, but also in the iconographic and didactic functions (Frampton 2001:x). Mallgrave points at how neo-classical architecture with terra-cotta tapestry woven into the surrounds of doors and principal windows and a series of narrative panels depict the mythological and constructional history of this art or the painting of colossal murals - seemingly "ancillary" added ornamentation (Frampton 2001:x). Other $19^{\text {th }}$ century architects such as Augustus Welby Northmore Pugin (181252) and Eugène-Emmanuel Viollet-le-Duc (1814-79), according to Mallgrave, are rationalists that reject this "ornamentation", and he argues for a logic of construction overshadowing these other forms of tectonic expression (Frampton 2001:x).

As mentioned in the Introduction, architectural theoretician Harry Francis Mallgrave has in his book The Architects Brain (2011), in a similar fashion as Collins (1965), Pérez-Gómez (2012) and Frampton (2001), challenged contemporary architectural thinking. But he does so with the compelling discourse outlining the history of architectural thinking from the perspective of Neuroscience. Mallgrave (2011:2) is trying to overcome the, according to him, long-standing distinction between body and mind, but also "split" in architecture between the arts and the sciences. The book is divided into two distinctive parts; with part one presenting a quick overview of polemical theories and intentions of selected writers, from past to present day; and part two introducing the findings of Neuroscience, as well as trying to provide a deeper significance and rooted understanding of architectural quality. In part one, Mallgrave (2011) investigates a series of "moments" in architectural thinking, arguing that 'modernity' and the "modern" understanding of 'space' emerged with the cognitive manifestation of philosophical, psychological, and physiological theory presented in the writings of the architect Marcus Vitruvius Pollio (c.80-15 BC) over 500 years ago. Mallgrave (2011), contrary Collins (1965) and Mallgrave (2006), divides the history of architectural thinking into nine sub-categories: the humanist brain (Leon Battista Alberti, Marcus Vitruvius Pollio and Leonardo da Vinci), the enlightened brain (Claude Perrault, Marc-Antoine Laugier and Julien-David Le Roy), the sensational brain (Edmund Burke, Uvedale Price and Richard Payne Knight), the transcendental brain (Immanuel Kant and Arthur Schopenhauer), the animate brain (Karl Friedrich Schinkel, Karl Bötticher and Gottfried Semper), the empathetic brain (Friedrich Vischer, Heinrich Wölfflin and Adolf Göller), the Gestalt brain (the dynamics and sensory field), the neurological brain (Friedrich Hayek, Donald O. Hebb and Richard Neutra), and finally the phenomenological brain (Maurice Merleau-Ponty, Steen Eiler Rasmussen and Juhani Pallasmaa). The outlined thinkers are grouped according to their ideals and intentions as well as the underlying assumptions about the brain and its workings. Herein, Mallgrave (2011) demonstrates the neurological justification of a series of timeless architectural ideals ranging from the multisensory nature of the architectural experience to the essential relationship of what he calls 'ambiguity'. In part two, some of the scientific findings produced with the discipline of Neuroscience are used to confirm the theoretical ideals outlined in part one. However, the findings of present Neuroscience are, as indicated with the Introduction and review on Healing Architecture, in their "premature" state. Despite this, I find that, one of the interesting points made by Mallgrave (2011:4) is that scientists, psychologists, religious leaders, philosophers, architects and artists have been telling us - since the beginning of recorded time - that there is no "split" between body and mind. But that the brain is embodied, and this understanding influences our understanding and experience of 'space'.

As mentioned in the Introduction, Mallgrave's (2011) conclusion suggests that the importance of "universal aspects of forms", such as considered by Renaissance architects Leon Battista Alberti (1404-72) and Andrea Palladio (1508-80), was perhaps not completely irrelevant. Furthermore, he also strongly suggests that what defines architectural quality is a matter of embodied experiences, and that what some tend to call "good" architecture is instead a quality that fills us emotionally with a sense of happiness and gratification, which can be physically measured in the limbic centers of the brain, while what some tend to call "bad" buildings instead denotes qualities that activates the motor cortex (Mallgrave 2011:184). The claim made by 
Mallgrave (2011:187) relative hereto is that contemporary neuroscientists view the brain as a rhythmic and holistic neural activity that is not only imbued with sensory and emotional coloration, but is also structured by a kind of "metaphoric patternmaking". I find that the interesting point made with his above arguments is that people experience both buildings and architecture emotionally through the multi-sensuous bodily encounters, and, therefore, aspects such as 'materiality', 'intimacy', 'hapticity' and 'nearness' are much more interesting architectural qualities than a discussion about "good" or "bad"(Mallgrave 2011:188).

As further mentioned in the Introduction in chapter 2, the writer and researcher Jonah Lehrer (2007) has followed the neuroscientific idea in a similar approach as Mallgrave in his book Proust was a neuroscientist, arguing that late-19 ${ }^{\text {th }}$ and early$20^{\text {th }}$ century novelists and artists like Walt Whitman, George Eliot, Paul Cézanne, Igor Stravinsky, Gertrude Stein, Virginia Woolf, Marcel Proust and even the chef Auguste Escoffier understood the wonders, poetics and magic of the brain and the intertwined relationship between body and mind. By rediscovering the unconventional thinking established in the mid-19 ${ }^{\text {th }}$ and early $20^{\text {th }}$ century, Lehrer $(2007)$ points at how memory and 'taste' are linked with our senses, and how art and science are not separated but part of the same "story". Lehrer (2007), like Mallgrave (2011), Frampton (2001) and Péréz-Gómez (2012), thus tries to re-establish the link of the sciences and the arts by tracing some of the philosophical roots in science, and some of the more scientific roots in the arts. Thereby touching upon the core understanding of how we perceive and understand the world. To Lehrer (2007:vii), the writer Marcel Proust and the discipline of Neuroscience share a vision of how our memory works, and the other writers, artists and chefs presented in Lehrer's book apparently anticipated the discoveries of Neuroscience with their artistic intuition.

In line with the thinking of Lehrer (2007), Frampton (2001), Pérez-Gómez (2012) and Mallgrave (2011), the architectural theoretician Marco Frascari (2011) has also found inspiration in the theories of Neuroscience. Yet, he uses this knowledge not only to argue for the qualities of architecture, but further to relate the quality of architecture to our general health and well-being. According to Frascari (2011b:27): "Architecture can modify bodies and minds compel them to wellness or diseases. Architecture impressively shapes brains and bodies and conversely brains and bodies shape architecture". This statement is part of a brief text written about the research performed at Azrieli School of Architecture, Ottawa in Canada in 2011. In continuation of the above statement, Frascari (2011b) notes how it is a general assumption within contemporary architectural thinking that physical and material sciences have defeated past architectural procedures. Frascari (2011) believes, like Pérez-Gómez (2012) and Mallgrave (2011), that architecture was unconsciously understood in the past and controlled by what he calls a tacit "neuro-understanding" of its artifacts and genetic processes (Frascari 2011b:27). He thus advocates that by paying close attention to the "neuro-knowledge" rooted in the architectural environment, architects may help improve health and ease diseases. So, in that way, architects and architectural researchers need to engage in an understanding of the findings of Neuroscience to understand the quality of architecture.

However, I find that an important point by Frascari (2011b) relative hereto is that he finds that the majority of the studies made on what others have called "neuroarchitecture", but what I have also presented as Healing Architecture and EvidenceBased Design in the Introduction, are presently based on behaviorist methods. Those methods are mainly based on pre- or post-occupancy of buildings-in-use, focusing on scores of "comfort", which again is primarily based on statistical analysis of 'air quality', 'thermal comfort', 'spatial comfort', 'visual comfort', 'workspace comfort', 'lighting quality', 'office noise control', 'building noise control', and 'security' (Frascari 2011b:27). According to Frascari (2011b:27), these types of scores "do not transact the ineffable nature of architecture as neurobiological presence". Thereby, I find that, he positions himself in the middle of the contemporary debates about Healing Architecture and Evidence-Based research. Frascari (2011b:27) suggests that there are two overall ways to verify the neurological presence and define quality in architecture: (1) either engaging in what he refers to as a "top-down" approach using neurological experiments - such as I would claim most Evidence-Based Design research is trying to do today, or (2) a "bottom-up" approach utilizing the traditional methods rooted in the discipline of architecture like drawings, models or polemical writings. 
One of the points made by Frascari (2011b:27), relative hereto, is that he finds that the architect - or at least himself - is not qualified to perform the top-down approach engaging neurological theory and perform evidence-based experiments. He emphasizes that traditional architectural tools like drawings, models and polemical writings can be interpreted in the light of the most advanced neuroscientific discoveries instead (Frascari 2011b:27). Another point made by Frascari (2011b:27) is that, as seen from the Research Approach and Historical Review as well as the above presentations of the writings of Pérez-Gómez (2000), Mallgrave (2011) and Lehrer (2007) respectively, long before any contemporary scientist had identified neurology, magicians, architects and cooks were taking advantage of such cognitive conditions as highlighted with neuroscience through the normative and polemical knowledge rooted in the creative approach of their disciplines (see Figure 7.3, The 3). According to Frascari (2011:25): "The body and its desires for both food and architecture immerse us in the world, engage us in all sorts of interactions, and blur rigid boundaries between our surroundings and ourselves". His point, relative hereto, is that the problem with the denigration of the corporeal dimension in architecture is not simply that inhabitation fails to get the attention that it deserves, but rather that present architects are "offtrack" (Frascari, 2011:25).

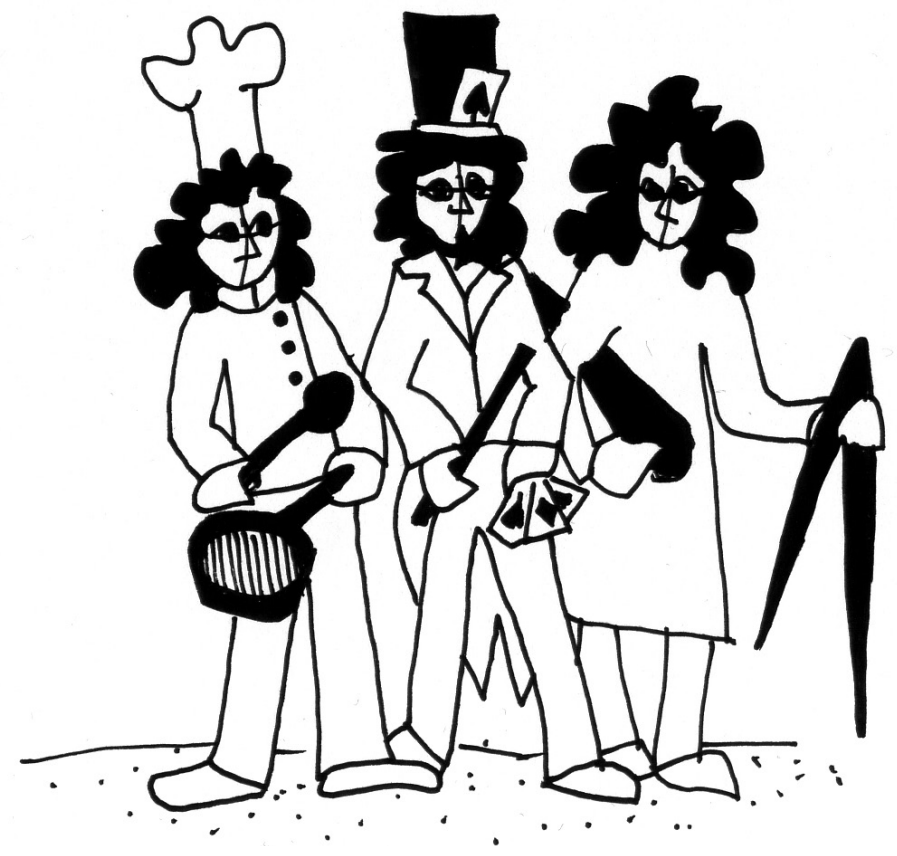

Fig. 7.3

"The 3"

Illustration inspired by drawing made by Marco Frascari

depicting the three best friends: architecture, cuisine and magic. According to Frascari, the three have much in common - they turn seemingly inexplicable events and procedures into elegantly simple answers, and do so be use of neurological conditions known since the birth of human kind (Frascari 2011b:27). 
With this exact statement, I am back at the beginning. Back at my wonders and curiosity about the magic relationship of health, food and architecture, presented in the Preface. Because, in his book Eleven Exercises in the art of architectural drawing: slow food for the architect's imagination (2011), Frascari begins the second chapter with an introduction to the Gastronomic Analogy put forth by the architect James Fergusson in 1862 (Frascari 2011:21). Here Frascari (2011:22) notes that several architectural critics and theoreticians have referred to the Gastronomic Analogy, but seemingly always used it as a way to reveal a significant intuition, characterizing the skills of an architect and a chef. This appreciation of the Gastronomic Analogy applies, as mentioned in the Preface, to Frascari himself as well. In an essay published in 2004, Frascari, in my opinion, seems to arrive at the same conclusion stating that:

"Architecture and gastronomy employ similar procedures of production...in both disciplines taste, an interpretative procedure, is at the base of sign production. In their doing and making, both disciplines face ill-defined problems and solve them using conjectural procedures. Judging by the signs, both disciplines apply the "rule" of taste to solve their ill-defined problems in a non-trivial manner."

(Frascari 2004:199)

There are many complex layers in the above statement put forth by Frascari (2004), but it is still my overall judgment that Frascari (2004) mainly addresses the first part of the Gastronomic Analogy:

"The process by which a hut to shelter an image is refined into a temple, or a meeting house into a cathedral, is the same as that which refines a boiled neck of Mutton into Côtellettes á l'Imperiale or a grilled fowl into Poulet á la Marengo.

So essentially is the case that if you wish to acquire knowledge of the true principle of design in architecture, you will do better to study the words of Soyer and Mrs. Glasse than any or all of the writers on architecture, from Vitruvius to Pugin."

(Collins, 1965:167)

As written by Collins (1965:168-69), the point presumably made by Fergusson with this part of the analogy is that the comparison between architecture and gastronomy possesses so many close similarities that cannot be displayed by music, literature, biology, mechanical engineering or any other of the arts or sciences so often compared to architecture before 1862 in the attempt to describe, explain and predict what back then was called "good" 'taste! The better analogy between gastronomy and architecture is due to the circumstance that both disciplines position themselves in-between art and science. They do so because neither architecture nor gastronomy is pure art or mere science. Instead they are both theory and practice; both knowledge and craft; both need and desire; both function and luxury; both beauty and technique. Contrary to the other arts like music, poetry and sculpture, which architecture has been compared to by renaissance architects, both gastronomy and architecture touch on elements of everyday rituals and their needs and purpose. Music is notes, rhythm, bars, and time - both visual and audial. Literature is words, letters, sentences, grammar, punctuation, sections, chapters, stories and poetry. It could thus be claimed that architecture has far more serious and lasting consequences than the publication of novels or music plays (Zevi 1957:15). In a similar fashion, as Brillat-Savarin (1949:3) in his fifth aphorism noted that humans need to eat to survive, humans interact with architecture on a daily basis and need shelter to protect them from environmental conditions and the circumstances of wild nature. So both gastronomy and architecture, through their functions as food and shelter, touch on the fundamentals of humanity.

In continuation hereof, I would like to argue that the point put forward by Fergusson is ultimately that the notions 'architecture' and 'gastronomy' themselves demonstrate a distinction between the quality of plain, ordinary, straightforward building and 'Architecture', like a distinction in quality between plain, ordinary, straightforward cooking and 'Gastronomy' So, when Fergusson was making the Gastronomic Analogy, he was presumably attempting to define the qualities of architecture by comparing 
it to that which defines quality in gastronomy. To emphasize his point, Fergusson compared the architectural archetypes: the hut and the temple/meeting house and cathedral to "culinary archetypes" - the grilled fowl and the Poulet a'la Marango/ boiled neck of mutton to Côttellettes á l'Imperiale.

What I see from the above examples with the architectural and gastronomic archetypes and the arguments put forth by Fergusson in his book is that both architecture and gastronomy emerge out of something basic and raw. According to Collins (1965:168), scientifically or technically, gastronomy demands the combination of a number of prepared materials of known strength, arranged according to an ideal sequence or plan, for instance using chemistry and physic to obtain a boiled, baked or fried object of food, and with which the efficiency can be analyzed and tested by means of measurements and calculations. However, artistically, gastronomy goes far beyond the "rules" of scientific analysis; "it requires intuition, imagination, enthusiasm, and an immense amount of organizational skill" (Collins 1965:168). Furthermore, it is often, as is seen for instance with the work of the previously-mentioned chefs Thorsten Schmidt and Ferran Adria engaging in the techniques of Molecular Gastronomy, a far more complex process than the plain, honest, straightforward everyday cooking I perform in my own kitchen at home. It involves raw ingredients, materials, techniques, and skills, but also a sense of what Fergusson presumably would have called 'taste' (Collins 1965:168). However, as pure art, food becomes inedible or indigestible - in worse cases it kills you - and thereby completely loses its functional value of providing nutrition. Whereas, as mere function, it is reduced to nutritional values in terms of being vitamins, calories, proteins, and energy. It becomes a list of ingredients. As argued for by Collins (1965:168-169), gastronomy and architecture are both applied sciences and applied arts that are to be enjoyed. Furthermore, what makes them both arts and sciences is that they emerge from a technique into something more.

So, maybe the clue is that the scale for 'describing', 'explaining' and 'predicting' culinary quality become more tangible, than that of evaluating and balancing architectural quality, because the process of evaluating food and gastronomy is very closely linked with physical consumption and bodily digestion. Whereas architecture is obviously not. Or, perhaps the point made by Fergusson with the first part of the Gastronomic Analogy is that the discipline of gastronomy can help us 'describe', 'explain' and 'predict' what the fundamental qualities of architecture ought to be?

In 2011, Frascari (2011:22) has instead become interested in what he calls the "critical content" of the Gastronomic Analogy, focusing more on the second part the statement put forth by Fergusson:

\section{"The process by which a hut to shelter an image is refined into a temple, or a meeting house into a cathedral, is the same as that which refines a boiled neck of Mutton into Côtellettes á l'Imperiale or a grilled fowl into Poulet á la Marengo.}

So essentially is the case that if you wish to acquire knowledge of the true principle of design in architecture, you will do better to study the words of Soyer and Mrs. Glasse than any or all of the writers on architecture, from Vitruvius to Pugin."

(Collins, 1965:167)

Frascari emphasizes relative hereto, that Fergusson did not compare the architects Vitruvius or A.W.N. Pugin with possible corresponding characters in the history of gastronomy or culinary theory, like the famous chef Antoine Carême. Instead Fergusson preferred to compare the architects with the two less celebrated English chefs/cooks: Alexis Soyer and Mrs. Glasse who had shown pioneering approaches to the definition of the qualities of food (Frascari 2011:22). Perhaps by engaging into a more profound understanding of what motivated the Gastronomic Analogy in the first place, as well as trying to understand what is the morale of Frascari (2011), but also of the analogy and point made by Fergusson in this particular era in history, I can also understand if there could be more precise answers to what the fundamental architectural qualities are? 


\section{THE GASTRONOMIC ANALOGY - RECONSIDERED The writings of Alexis Soyer \& Mrs. Glasse}

As can be seen from the Timeline and Historical Review, the French-born chef Alexis Soyer stems from the $19^{\text {th }}$ century, and the English cook or housewife Mrs. Hannah Glasse stems from the $18^{\text {th }}$ century. They are both very popular in Victorian English culture during the period around Fergusson's Gastronomic Analogy. As seen from the above description of Soyer, the French chef was rather extravagant in his Universal Symposium at the Great Exhibition in London in 1851 (see Figure 6.4 in Timeline). However, as also emphasized by Frascari (2011:22), Soyer also invented his own stove to be used by soldiers in wartimes, as well as participated in the Crimean War, where he together with the English nurse Florence Nightingale reorganized the provisioning of the army hospitals and helped improve the nutritional basis of all the patients. Furthermore, he created soup kitchens to supply the poor with proper food during the Irish Potato Famine, and even wrote a series of cookery books sold to raise money for charity (Frascari 2011:22; Morris 1938:1). Soyer was apparently not only occupied with extravagant haute cuisine, but also, with supplying the poor and needy with proper meals as well as preventing soldiers from dying of food poisoning or malnutrition. In a similar manner, Mrs. Glasse, an English housewife, addressed not the professional cook, but what she instead called the "ignorant and unlearned" in the manners of domestic quality cooking with good ingredients and by simple techniques in her cookery book The Art of Cookery: made Plain and Easy (1747/1805:A). Mrs. Glasse instructed to follow the seasons of the year both when choosing vegetables and greens, but especially also when choosing butchers' meats, poultry and fish. In her book she thoroughly describes how to determine the age and quality of meats like mutton and what kind of fowl to choose in different seasons (Hess 1997:4-5,7-8). What I find is particularly interesting is that Mrs. Glasse provides the reader with some very detailed instructions or you could say 'basic principles' in how to analyze the culinary quality of the raw food ingredients by means of a close body-mind relationship. Both in the case of the Mutton and Fowl, she notes how the texture, viscosity, scent, visual appearance and behavior of the skin and meat together are "signs" that will warn you about the quality of the food product at hand. Furthermore, in her long line of recipes, she in general used remarkably few references to the specific quantum used, but instead uses approximations and terms like: "a little butter" and "when they are enough" (Hess 1997:36). Even though Mrs. Glasse is not using these above terms directly, she is instructing the "ignorant and unlearned" in the complexities of creating culinary quality. Something, which the contemporary disciplines of Molecular Gastronomy and Sensory Science have been struggling hard with defining, both on a practice and research-based background, throughout the last twenty years. However, by presenting a rather simple vocabulary and instructing us to use not only our bodily senses but also common sense - thus linking body and mind - Mrs. Glasse managed to do so quite well back in 1747 .

Nonetheless, besides the critical content emphasized by Frascari (2011) relating to Soyer and Mrs. Glasse, I find that there are several other keywords worth noticing in the Gastronomic Analogy, possibly helping me in my search for answers to the question of what defines the fundamental architectural qualities of the patient eating environment. Those are:

"The process by which a hut to shelter an image is refined into a temple, or a meeting house into a cathedral, is the same as that which refines a boiled neck of Mutton into Côtellettes á l'Imperiale or a grilled fowl into Poulet á la Marengo.

So essentially is the case that if you wish to acquire knowledge of the true principle of design in architecture, you will do better to study the words of Soyer and Mrs. Glasse than any or all of the writers on architecture, from Vitruvius to Pugin."

(Collins, 1965:167) 


\section{From Vitruvius to Pugin}

The comment: "writers on architecture, from Vitruvius to Pugin" made by Fergusson is, in my point of view, quite curious - not only because he seemingly rejects the entire history of architectural thinking before 1862 with this statement. But particularly because he emphasized that it is the history of polemical writing spanning between the two architects Vitruvius and Pugin.

As seen in the Timeline and the Historical Review, the Roman architect and engineer Marcus Vitruvius Pollio (c.80-15 BC) is considered the "father" of architectural writing. Vitruvius wrote about construction of machinery and the design of aqueducts, as well as fountains and the Roman Triclinium. He defined architecture as a complex matter incorporating pretty much everything designed and built - from houses and roads, to hydraulics and clocks (Sykes 2007:14; Morgan 1960). However, before Vitruvius engages in such elaborate discussion about the detailed qualities of architecture in his writings, he begins a different place. He begins with the education of the architect, the fundamental principles of architecture, the departments of architecture, the site of the city, the directions of the streets and remarks on the winds, as well as the origin of the first dwelling house (Morgan 1960:vii). And it is in particular the last - the notions on the origins of the first dwelling house - that is important. Because, according to Hvattum (2004:29), ever since Vitruvius began his writings with a reference to the hut as the first gathering of men, he not only suggested that the hut is a fundamental part in the origin of society and a precondition of the Greek temple, but he also indicated that man's need to communicate through artistic and religious 'images' made language and architecture the two primordial civilizing institutions. Hvattum (2004:30-32) suggests on that basis that Vitruvius with the hut as both a meeting house for gathering men and a shelter of cultural 'images' made the quality of architecture the expression of human culture. English architect August Welby Northmore Pugin (1812-52), on the other hand, stems from the mid- $19^{\text {th }}$ century, where he is considered one of the leading architects in England, arguing heavily against neo-classical architecture and instead idealizing the Christian ideals of the Medieval era and particularly encouraging a revival of Gothic architecture (Frascari 2011:22, Collins 1965:100-112, Moffett et al. 2004:429-430). In a series of polemical writings, A.W.N. Pugin argued that the Gothic ideals were the "true principles" in design, because they were a result of an honest use of materials where the structure and function of the structure were exposed (Watkin 2000:468). A.W.N. Pugin practiced these ideals in a series of design proposals for church interiors and other public buildings like the Palace of Westminster, House of Parliament and Big Ben in London as well as chapels, cathedrals, schools, colleges, and a hospital appearing in Gothic style in Southern England (Moffett et al. 2004:429). So, as also seen from the Timeline, the comment "writers on architecture, from Vitruvius to Pugin", indicates a timespan of almost 2000 years, as well as denotes a pool of polemical writings which Fergusson himself contributed to in 1849 with the book An Historical Inquiry into the True Principles of Beauty in Art: More Especially with Reference to Architecture.

\section{The writings of Fergusson}

Fergusson wrote in his own polemical book that he had been acting more in a large mercantile establishment, writing and teaching more about the state of the money market, indigo, silk and sugar than the fine arts of sculpture, painting and architecture (Fergusson 1849:xi). His studies on architecture were, therefore, based on travels performing empirical observations of the buildings and art at first hand, instead of as he stated: "... read as much as many of my contemporaries" (Fergusson 1849:xiv). His approach was to try and understand what he saw - read the crafted marks on the buildings and, on that basis, try to understand the idea and intentions that guided the artist in the design (Fergusson 1849:xiv). Greatly inspired by the writings of Swissborn Jean-Jacques Rousseau (1712-78) Fergusson (1849:4) argued that all man are born equal, and, therefore, each has the power to enjoy, improve or deteriorate their own condition. Fergusson (1849:5-6) further argued that the true mission of art should be to improve knowledge in the public mind, and he also stated that, instead of focusing on the "truths" of sciences, architects ought to employ an architectural quality cultivating intellectual beauty instead of following the temptation of wealth and luxury inherited in material beauty. In continuation hereof, Fergusson (1849:59) classified 
the different disciplines and knowledge fields in two major opposing stances: the sciences and the arts. In this classification lays implicit that man is the highest and most perfect of animals, and together with this there is a kind opposition to the 'theory of evolution' proposed by Charles Darwin and the degrading of man and especially his religion with the belief in God and the divine (see Fergusson 1849:59). However, Fergusson (1849:59) does acknowledge that man must presumably be considered in two distinct perspectives: (1) the physical where man is considered as an animal that is object to zoology and the sciences, and (2) the opposing anthropological where man is considered as a human being possessing material goods and talents of which no animal is capable, thus relating to the arts. Man is thus object of instinctive and bodily sensations like animals, but he is also object to emotions, reason, moral, religion, and ethics with a sense of right and wrong (Fergusson 1849:63). Fergusson (1849) comments on the division in labor, on the division between the corporeal and the spiritual, the division of classes into rich and poor, the luxurious classes of consumers, and he concludes that every civilization and community can be divided into many different classes distinctive in functions and activities relating to the material world. Despite this, he emphasized that man is still one species, and he finds that it is in this "unity in multiplicity, and multiplicity in unity" that provides man with the power of the material world and sparks the continuously effort towards increasing knowledge and power (Fergusson 1849:64-65). Fergusson (1849:65-66) finds that the essential characteristics of humankind compared to animals are that he prepares his own food, builds his own home, provides his own clothing, and thereby establishes all the intellectual enjoyments and refinements of civilized life.

Relative hereto, Fergusson (1849) sub-divides the sciences into: universal sciences, physical sciences and anthropic sciences, as well as the arts into anthropic arts and political arts. In this classification, he positions architecture in the sub-category of anthropic arts, and herein again in the sub-sub-category of technic-refined arts together with, among others, the disciplines of gastronomy, wine-making, confectionary, ceramic and upholstery. Whereas cooking, baking, brewing, weaving, felting, lighting, ventilating, civil engineering and building are classified as applied arts, a level or sub-sub category prior to the refined arts, and medicine including hygiene, surgery and pharmacy is classified under politic arts, and the sub-sub category of Physiology (Fergusson 1849:79). On that basis, he provides an elaborate description of the primary knowledge and "laws" of each of the disciplines endeavored in the book. An interesting point made by Fergusson regarding the classification of Medicine is that it should not be confused with the scientific branch of Physiology, because the latter is only the discipline of curing diseases engendered in our bodies or illnesses achieved by accidents. Whereas the other kind of Medicine is then one on which man's happiness and health depends. He, therefore, argues that accidents and diseases might even be prevented if greater attention was put on how the general health of mankind was promoted through better sanitary conditions, cleanliness and ventilation, as well as exercise and recreation in public domains were masses of men are congregated (Fergusson 1849:129). And he ends up stating:

"...these would, I believe, have a more beneficial effect on the general health of
mankind than all the drugs that ever were concocted; and an opinion to this
effect seems now to be gaining ground...we, up to this time, have always paid
our doctors for curing diseases, not for preventing them, and, consequently,
very little of this unprofitable Hygiene has been taught in our schools, or is to be
found in our medical treatises"

(Fergusson 1849:129)

With this statement, I find, Fergusson (1849) is touching on the core "dilemma" in the "quarrels" of the $19^{\text {th }}$ century, and the point made with his statement in the Gastronomic Analogy that we should reject all the polemical architectural writings from Vitruvius to Pugin.

As mentioned in the above, the period from around 1750 to 1950 is an era dominated by "anxiety", radical changes and "quarrels" about architectural styles. It was an era where many architects were inspired by the developments in the sciences and were looking for a set of fundamental principles 'describing', 'explaining' and 'predicting' the "lawfulness" of architectural quality. Before that time, architects from the renaissance 
and period of enlightenment had been almost obsessed with finding precise "rules" to 'describe', 'explain' and 'predict' architectural quality as a matter based on specific numbers, ratios, and proportions. For several centuries, architectural thinking, writing and practice had, just like A.W.N. Pugin and Fergusson, been occupied with defining the "true principles" in design. And in the attempt to uncover these principles describing the quality in architecture, they had either been obsessed with copying the past either in terms of favoring the Classical forms of the 'Vitruvian Ideal' or the Gothic forms of the Christian Medieval times. Throughout the $19^{\text {th }}$ century, these "quarrels" over "true principles" of architectural quality, furthermore, often came down to a discussion about the proper articulation of ornament. Here Fergusson, according to Collins (1965:125), defined architecture as: "nothing more or less than the art of ornamental and ornamented construction". And Collins (1965:125) notes that Fergusson thus claimed that the ornamentation was what distinguished architecture and mere building. Hence, also suggesting that the main error in the discipline of civil engineering was that it did not include the artistic treatment of ornamentation. Collins $(1965: 124,127)$, with reference to German architect Gottfried Semper and his polemical writings Style from 1863, then notes that this striving for individuality in the architecture tended and still tend to express itself in the adornment of ornamentation, because it was symbolic and had the ability to articulate the social and cultural power

relations. He argues that ornament was the "dress" that: "separated the intelligence of man from that of the lower animals, and urged him to strive after perceptual novelty... what people had been in the habit of calling the principles of architectural design were... simply the principles of architecturesque treatment" (Collins 1965:125). Around the mid- $19^{\text {th }}$ century in the exact years of the Gastronomic Analogy, this "quarrel" between the Classical and Gothic ideals on style reached a climax, which made architectural thinkers like Fergusson reject any considerations on "true principles" based on the ideals of one type of architectural style and ornament. Instead a demand for a new and original kind of architecture that was not based on copying the styles or imitating the forms and ornaments of the past arose (Collins 1965:127-30). Here, among others, Fergusson and Semper began arguing that the quality in architectural 'beauty' should instead be based on a response to the social and technological changes prevailing in the present (Collins 1965:130; Hvattum 2004:156). According to Collins (1965:132), architects like Fergusson did thereby ask for a set of basic design principles which would help describe the fundamental architectural quality expressed in a series of ornamental and tectonic details, which similar to the genetic material of a bone or fossil would be identifiable from a few fragments.

Apparently, according to Collins (1965:144-45), Fergusson himself, despite his original comparison of gastronomy and architecture, does not provide a practical answer for how to achieve a set of basic design principles defining or describing what these fundamental architectural qualities then are. Fergusson himself, during his elaborate argumentation for the different classifications, even came to realize or admit that his strict division of the sciences and arts into even stricter sub-categories of technical, applied and aesthetic arts does not work in practice, simply because the boundaries between the different categories are fluent. He writes: "It is impossible to insist on the arts I have grouped under these heads as strictly belonging to either class" (Fergusson 1849:93). Therefore he instead ends up anticipating that someone else comes up with a system or arrangement that avoids these "anomalies". And as can be seen from the previous chapters and above review of polemical theories, one of his contemporaries - the German architect Gottfried Semper - did.

What is so remarkable about Semper, according to Eck (2004:63), compared to others such as Fergusson and A.W.N. Pugin, is that, in the mid-19 $9^{\text {th }}$ century, he adopted a strategy to define the quality of architecture not in a concern for certain styles, 'beauty' and 'taste'. But in a search for something more profound, where the characteristics of the qualities passed across individual human judgment into a collective understanding. He introduced an understanding that moved the dilemma of the balance of architectural quality, as put forth by Collins (1965), away from the debate about styles into a solution focusing on the design process as a "process of refinement" balancing 'space' as a result of an analysis of the context. And he did so by reconstructing the history of architecture, and by restricting the range of meaning to the purely architectonical, as well as by considering architecture as a representation of significant human action - the acts that give buildings their meaning (Eck 2004:63). Therefore, Semper contributed to the development of a formalism in design theory 
and art history, which was further developed later on by art historians Heinrich Wölfflin (1864-1945) and August Schmarsow (1853-1936) (Eck 2004:63). The reason, according to Eck (2004:63), why architectural theoreticians today see Schmarsow, and not Semper, as one of the developers of the idea of architecture as 'space', is that the art historian Alois Riegl (1858-1905) misrepresented Semper as a materialist. Eck (2004:63) argues that in his writings, Riegl accused Semper of reducing the meaning of architecture to an expression of materials, techniques and functions. Whereas today, I would argue, some instead sees him as a hermeneutic pointing more at how architecture represents itself and its meaning (see e.g. Mallgrave 1996). On that basis, I can sub-conclude that by rejecting all architectural polemical writing in-between Vitruvius and Pugin, Fergusson seemingly rejects the style and ideals governing the architectural qualities from the Roman, Medieval and Renaissance eras, as well as the late $18^{\text {th }}$ century and not necessarily the historical knowledge rooted in the treatises stemming from those eras.

Perhaps here I begin to find a better understanding of the Gastronomic Analogy?

\title{
What can be learned from the gastronomical analogy?
}

What can be seen from the previous chapter and the Timeline is that this occupation with establishing "lawfulness" is happening simultaneously within the domains of gastronomy and culinary theory. Here Mrs. Glasse, Brillat-Savarin, Soyer and later Escoffier were developing taxonomies describing the "rules" or "lawfulness" of gastronomy and thus outlining criteria for culinary quality. Like these chefs were developing recipes for "good taste" in food, the architects of the $19^{\text {th }}$ century were attempting to develop "recipes" for "good taste" in architecture. However, based on the above, I would argue that the "good taste" developed in $19^{\text {th }}$ century architecture was based on very detailed and specific "recipes", instructing the architect on precise measurements, proportions and symmetry compared to the multi-sensuous and embodied understanding of "good taste" in food introduced by Mrs. Glasse.

Frascari's above point, when referring to the "critical content" of the Gastronomic Analogy is that, although at first sight seemingly representing two very different approaches to the art of cookery, Mrs. Glasse and Soyer were both concerned with a "secularization of cooking" and a "prudent gastronomy", as well as they were against the glorification of what Frascari (2011:23) calls 'simulacra'. Frascari writes:

\begin{abstract}
“...they are for a weak gastrophy. A strong gastronomical notion aims to impress through outstanding singular images and consistent articulation of dishes, whereas, a weak gastronomy is contextual and responsive and, as in the present-day Slow Food crusade, recognizes a precise, but gently prudent, material association between the conceiving and making of plates within a regional cosmopoiesis."
\end{abstract}

(Frascari 2011:23)

And he continues:

\begin{abstract}
"Weak cosmopoietic gastronomy is concerned with real sensorial exchanges instead of idealized and conceptual manifestations. These later forms are manifested in the art of cuisine initially elaborated by Carême, carried by the "haute cuisine", and brought to its extreme by the formal appearances of lightness carried on by the "nouvelle cuisine". A weak gastronomy grows and opens up from details of food elaboration, rather than the reverse process of closing down from concepts to the details."
\end{abstract}

\section{(Frascari 2011:23)}

The major conclusion made by Frascari is that contemporary gastronomy, like contemporary architecture, tends to be dominated by a "photographic" bias with a focus on mere visual representation and physical structure. When, according to the Gastronomic Analogy, it should instead focus on so much more. So, in my opinion, what Frascari (2011) argued in the above was that the $19^{\text {th }}$ century "recipes" on culinary quality, contrary most of the $19^{\text {th }}$ century "recipes" on architectural quality, were focusing on the needs of the everyday and common, on the plain and honest, 
but also on the embodied cross-modal sensorial experiences. And that the quality of "weak" architecture lies in the articulation of what Semper refers to as the "dressing" of the interior spaces instead of just the visual values of a certain past style and the ornamentation of a given structure.

In the above outline of the polemical knowledge inherited in the writings from Vitruvius to Pugin, the keywords: "Hut, shelter, image, temple, meeting house and cathedral", "process and refinement" and "true principle of design" was already rooted in this understanding. Or I would even claim these keywords were the core of this understanding.

\section{SUB-CONCLUSION ON 'POLEMICAL THEORY'}

The mid-19 ${ }^{\text {th }}$ century stands for the culmination of the Enlightenment where philosophy and science increased in prominence, and where radical changes in human society and urban environments occurred. It was also an era where technological advances and the 'Industrial Revolution' emerged with the Great World Exhibition held in London in 1851. It is an era of exploration, invention and discovery where medicine and healthcare with, among others, the English nurse Florence Nightingale take some radical steps towards modern hospital design, though still emphasizing the humanistic values of meals and the built environment. What I find is exceptional and worth studying about this specific era and the Gastronomic Analogy is that knowledge on the aspects of human environment has not yet been split into separate research disciplines like anthropology, interior design, medicine, civil engineering and gastronomy. Instead, it was acceptable to integrate and synthesize these domains in the search for a fundamental understanding of our being in the world.

Looking back at the history of health, food and architecture, I would argue that today, we stand in a similar position as the researchers, chefs, hospital stakeholders and architectural thinkers did between 1750 and 1950 - and in particular in the mid$19^{\text {th }}$ century. During that era, the rapidly increasing industrialization offered new and innovative ways to build, to heal and to cook. People like A.W.N. Pugin were afraid of these consequences and reacted by opposing the technology, instead favoring the ideals of medieval times, nature and craft. A.W.N. Pugin was later accused of being romantic and utopian. However, today we once more - or perhaps more likely still see the two opposing directions of the "technological" and the "natural", as well as the "scientific" and "artistic". Today, it is perhaps not so evident within the architectural discipline as theoretical debates here tend to focus more on phenomenology versus structuralism, as seen with for instance the arguments of Pallasmaa (1996), and practice focuses more on functionalism versus holism, as seen with the examples of the new super hospitals and the discipline of Healing Architecture. However, within the discipline of food - particularly the Slow Food movement, but also the two movements of respectively 'Molecular Gastronomy' and the 'New Nordic Kitchen' there are, in my point of view, clear examples of this "modern-scientific technological" against "holistic-artistic nature".

As seen from the above, the hut was never mere technique or science to Semper, but already a kind of architecture balancing both science and art simultaneously. A point often neglected or ignored in the comparisons of architecture to the other sciences and arts. The point of the Gastronomic Analogy is thus about finding this "balance". The history of health, architecture and gastronomy - in my opinion best illustrated with gastronomy - shows an oscillation between purist and sumptuous tendencies. History also suggests a constant refinement of this "balance", or the qualities of this balance indicate building on top of the knowledge from the past towards an ideal in the future. Presumably because the quality is not a static thing and our desires and needs change or evolve, we will never reach that ideal. The quest for the utopian ideal is what keeps both the disciplines of health, gastronomy and architecture going.

Does the Gastronomic Analogy then provide the desired knowledge and an answer for how to "balance" these opposite tendencies of the arts and sciences, as asked for by Collins in 1965 and now me? Does the Gastronomic Analogy 'describe', 'explain' and 'predict' the fundamental architectural qualities? No not directly. But, in my opinion, it does provide us with some important "clues". 
Based on the above considerations, I find that Fergusson's main point with the Gastronomic Analogy was that architectural quality lies not in the specific choice of a certain architectural style, but should be found beyond that. In the Gastronomic Analogy Fergusson uses the two keywords: process and refinement. And these are what, so far, brings me closest to an answer to my question about what defines the architectural qualities of the patient eating environment.

As seen from the above outline of the polemical architectural writings as well as with the previous chapter and the review of normative knowledge rooted in built environments and culinary practice, there are many directions relative to these two keywords that have been pointed out that I could pursue or follow. Notwithstanding, many of the concepts and notions established by architects like Frampton, Mallgrave, Péréz-Gómez and Frascari are very intriguing and would potentially be interesting to continue with in the development of a set of basic design principles describing the architectural qualities of the patient eating environment. Still, in the above attempt to unfold partly the Gastronomic Analogy but also partly the history of polemical architectural writings, I arrive at the sub-conclusion that architectural quality is strongly related to the matter of 'taste' and herein the process of refinement. And here there is one name and a series of writings which continuously - both directly and indirectly - comes up in the contemporary polemical theory as the underlying source of my understanding and definition of architectural quality. - A name and a series of polemical writings which, in my point of view, indirectly links the writings of Frampton, Frascari and Mallgrave. But which also links with Fergusson and the Gastronomic Analogy. That is the name and writings of German-born architect Gottfried Semper.

As mentioned previously, what is so unique about Semper's struggle with balancing the seemingly incompatible demands of science and art, in his attempt to move beyond the copying of past styles, is that he instead defined a new approach to architecture (Mallgrave 2011:188,244). Furthermore, his polemical writings stem from an era quite advanced in science, research and technology, and he was considered a significant contributor to the building of museums and theatres, as well as made several design proposals for cafes, hotels, spas, health resorts and various types of hospitals in the exact same period as the growth of new health initiatives by the nurse Florence Nightingale, the culinary interior initiatives taken in restaurants and festive banquets by the chef Alexis Soyer, the gastronomic theoretical writings outlived by the lawyer Jean Anthelme Brillat-Savarin and finally the emergence of the discipline of interior architecture. Finally, Semper's historical investigations are partly based on the writings on ancient Assyrian architecture done by James Fergusson during the mid$19^{\text {th }}$ century, and just as Semper was very interested in Polychromy so was Fergusson. Records show they even met in a discussion of Polychromy in RIBA in London at the $26^{\text {th }}$ of January 1852 (Mallgrave 1989:19; Herrmann 1984:140). Semper also notes in his manuscript for the third volume of Style that: "among the English there are a few modern writers, like Fergusson... who try to understand the theory of building from a more general viewpoint, yet, as is often the case with them, when they proceed from matters of fact into the speculative realm, they lose themselves in oddities and reveries" (Mallgrave 1989:169). And, as Mallgrave (1989:304) notes, at that date of writing for Semper, Fergusson had already published his book, with which Semper, therefore, presumably was familiar with.

Therefore, I find that Semper with his polemical writing on architectural quality not as a style, but as context and time dependent "process of refinement" possibly represents the holistic perspective on health, food and architecture that I need to try and 'describe', 'explain' and 'predict' the fundamental interior architectural qualities of patient eating environments. So, in the next chapter, I will continue with a study of the polemical theoretical writings of Semper, in the search for a set basic design principles defining architectural quality. 


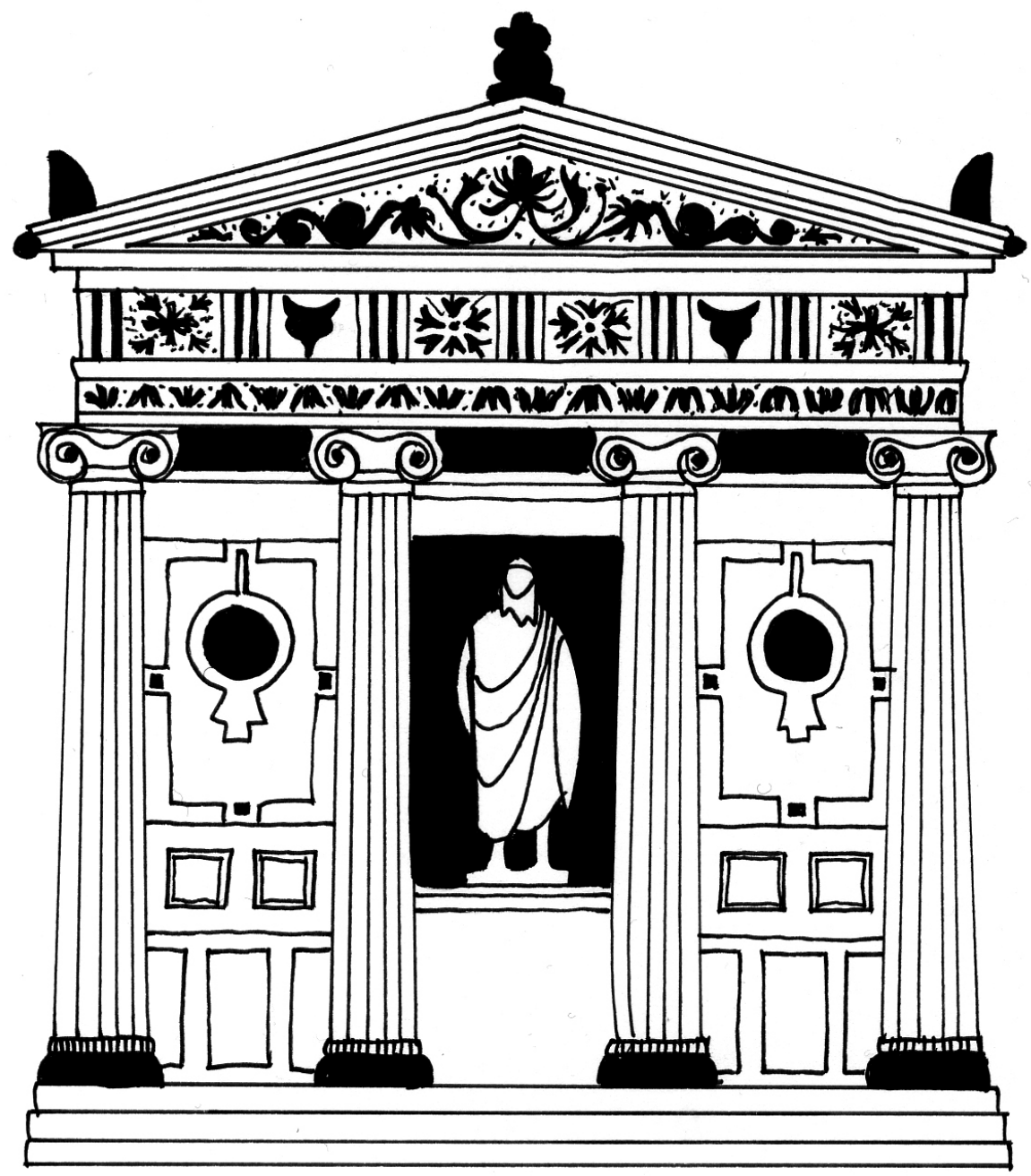

Fig. 7.4

"The Temple of Polychromy" (Drawing adopted from

Mallgrave 1996:37) 


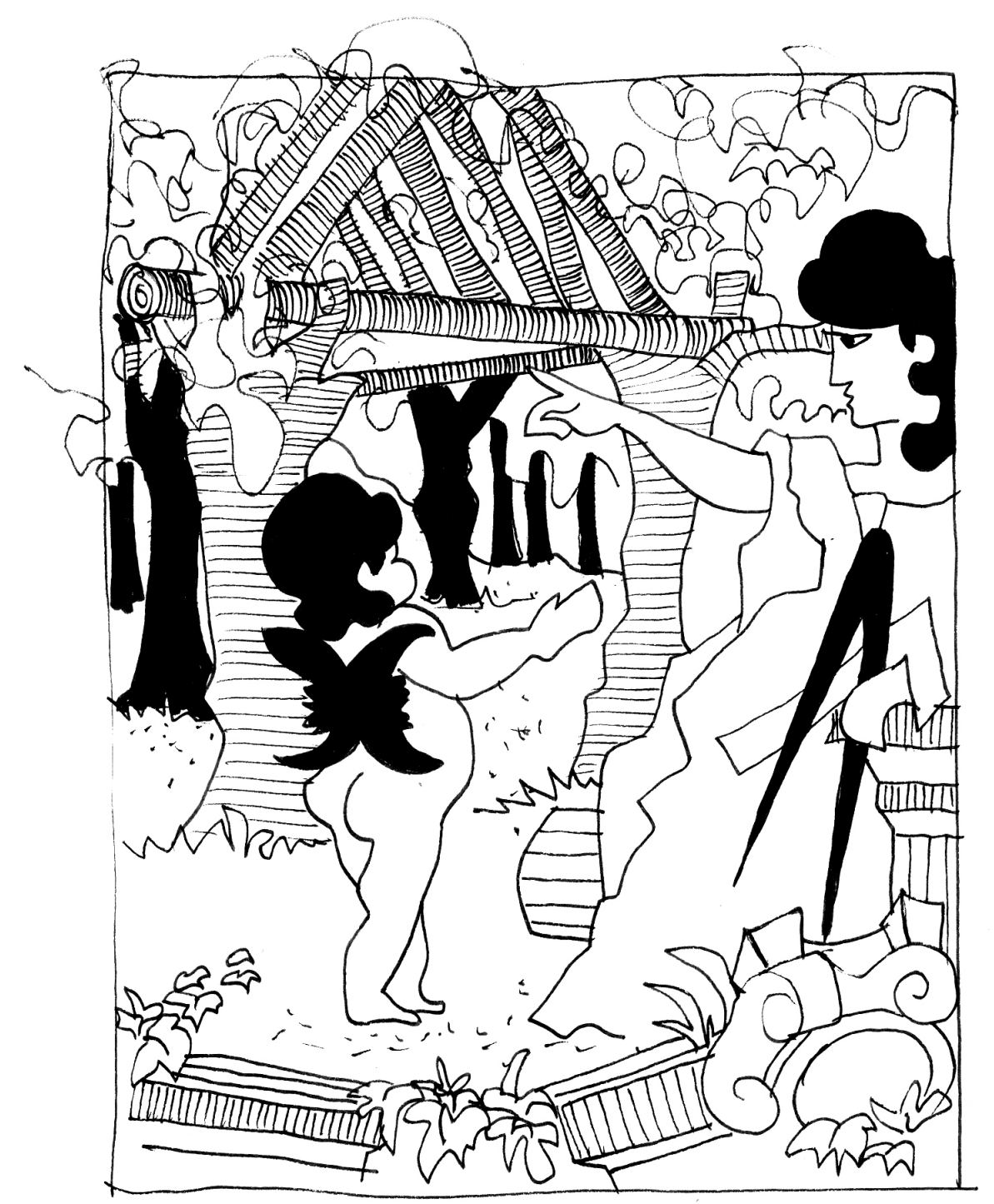

Fig. 8.1

"The basic principles of design" Semper is one of the first during the 19th century to break with the obsession with defining "true styles" and "good taste". Instead he offered a perspective on architectural quality as a contextual ever changing phenomenon, based on some few fundamental motives. (Drawing adopted from Hvattum 2004:32) 


\title{
"PREDICTING" INTERPRETATION
}

8

\section{DESIGN PRINCIPLES}

\author{
UNFOLDING SEMPER'S POLEMICAL THEORY
}

For many years, according to architectural historian Harry Francis Mallgrave (1996:3), German-born architect, engineer and historian Gottfried Semper (1803-79) had some very detailed analyses of the history of arts that were almost completely overlooked by writers of architectural history like Sigfried Giedion (1941), Nikolaus Pevsner (1936) and Peter Collins (1965). For instance, Collins $(1965: 112,124)$ only referred to Semper two times. One was with brief reference to his texts on polychrome architecture (see Semper 1833, Semper 1834, Semper 1851 and Semper 1854), where Collins (1965:112) ends up calling Semper an amateur and an extremist. The other was with reference to Semper's book Style and his remarks on the individual strive for adornment (Collins 1965:124). In a similar manner Giedion (1941:181,338) mentioned Semper very shortly two times in his book Space, Time and Architecture. Both times it was without referring to Semper's theories or built works. Finally, Pevsner $(1936: 56,122)$ also mentioned Semper twice, here with reference to two buildings by Semper and his text Wissenschaft, Industrie und Kunst: Vorschläge zur Anregung nationalen Kunstgefühles, bei dem Schlusse der Londoner IndustrieAusstellung (Science, Industry and Art, proposals for the development of a National taste in Art at the Closing of the London Industrial Exhibition, 1852). However, like Giedion (1941) and Collins (1965) without going into any further mentioning of Semper's own theory or other buildings. In continuation hereof, Mallgrave (1996:4) argues that Semper has been accused of conforming to everything from Materialism and Functionalism to Romanticism and Historicism. All these different interpretations - or lack of the same -could be linked with Semper's very diffusive style of writing according to Mallgrave (1996:5). Nonetheless, Mallgrave (1996) like Eck (2004:63) finds that Semper's thinking is significant and almost revolutionary for his time, and today he is increasingly seen as an important figure in the 'polemical theory', relating to the practice of art, architecture, art history, archaeology and anthropology (Mallgrave 2011, Mallgrave 1996:3).

Throughout his life, Semper published a rather long series of papers, lecture notes and a few books (see Mallgrave \& Robinson (2004:947-950)). Those were primarily published in German, and not until recent times have Semper's writings been translated into English and thoroughly debated by e.g. Herrmann (1984), Mallgrave \& Herrmann (1989), Mallgrave (1996), Hvattum (2004), Mallgrave \& Robinson (2004), Frampton (2001) and Hartoonian (2006). But also in Danish by Bek \& Oxvig (1999:352-384). Still, one of the most important writings by Semper is the book Die vier Elemente der Baukunst (The Four Elements of Architecture) published in 1851. With this book, Semper developed a model for four basic elements underlying the making of architectural form. This model was based on the theoretical understanding that the design of architecture, like nature, is based on the endless variation of a few basic elements of high quality. Those basic elements are what Semper chose to call 'motives'. In an almost evolutionary manner, Semper proposed that architectural 
quality stems from infinite variations of these motives and that contemporary differences in building style and interior design are the evolutionary result of these motives responding to contextual circumstances like topography, climate, and culture (Semper 1863, Mallgrave 2011) [Tvedebrink et al. 2012:4].

As previously mentioned, up until the mid-19 $9^{\text {th }}$ century, the understanding of architectural quality had mainly been dominated by laws of proportion, symmetry, and harmony based on a strong interest in the styles of classical Greek and Roman or Gothic architecture. Nevertheless, influenced by contemporaries like Immanuel Kant (Kritik der reinen Vernunft/Critique of Pure Reason, 1781), Charles Darwin (The Origin of Species by means of Natural Selection, 1859), and Gustav Klemm (Allgemeine Kulturgeschichte der Menschheit/ General Cultural History of Mankind, 1843), Semper grows an interest in anthropology and the early prehistoric societies as motivation for understanding the origin of and quality in architecture (Mallgrave 2011). The studies by Darwin and Klemm are some of the first in western history to study man outside the religious framework, as mentioned in the previous chapter. The entire foundation for how human beings perceive, read, understand and appreciate the external world is up for debate. The anthropological idea that man is defined by his family, social life, eating and burial habits, dwelling, clothing, decoration, tools, weapons, utensils, religion, and language are groundbreaking and world-shattering [Tvedebrink et al. 2012:4-5].

Inspired by the novel anthropological definitions of 'culture' and 'man', Semper adopted the anthropological idea that no human culture has ever managed without fire for heating, light, cooking or defense, and that fire is, therefore, the force that stands at the beginning of all cultural development (Mallgrave 1985, Mallgrave 2011). The idea is that around the fireplace early human beings gathered for food and relaxation after hunting. In this way, language developed, small communities unfolded, the first religious rites were performed and so customs, traditions as well as celebration came into being. From there on society developed, including the act of building shelters. The fireplace, in Semper's thinking, is therefore not only a functional element for heating, light or cooking, but a communal forum being simultaneously a social gathering point, spiritual anchor point and cultural focal point on human settlement and the establishment of communities. It is the "germ" of tribal life and the "embryo" of social forms in general (Herrmann 1984:198)[Tvedebrink et al. 2012:5].

\section{THE UNDERLYING MOTIVES IN ARCHITECTURE}

To capture this higher significance and epistemological role of the fireplace, Semper (1989; 1853, November) introduces the notion 'hearth'. The hearth should here be understood as a metaphor for the social, spiritual, and cultural values which the primordial fireplace encompasses as a communal forum and origin of human settlement [Tvedebrink et al. 2012:5]. Semper (1853, November) makes the hearth the first motive of building and of architectural quality, and claims that all other elements of architecture only exist as defenders of the hearth. These other elements can, in Semper's viewpoint, be narrowed down into three basic motives, protecting the sacred forum and underlying the creation of architecture. Those motives are: 'flooring', 'walling' and 'roofing' (Semper 1863:666). Within the discipline of architectural theory many different interpretations of Semper's four motives exist. Some researchers refer to them as 'mounding', 'earthwork' and 'terracing' instead of flooring, others use 'enclosure' instead of walling and 'roof' or 'ceiling' instead of roofing (see e.g. Mallgrave 2011; Mallgrave 1985; Semper 1853, November; Semper 1989; Semper 1863; Herrmann 1984; Hvattum 2003). Nevertheless, the important point is that the motive of flooring raises the hearth of the ground, and joins it with the walling and roofing. The motive of roofing is an overhead protection of the hearth. The motive of walling is the vertical spatial divider, which should not just be understood as ordinary floors, walls and ceilings, but as an enclosure defining a new spatiality or an inner world separated and protected from the outer (Mallgrave 1985; Semper 1989:102103). The numbers of possible combinations for these four motives are manifold. The motives could be altered or transposed between both elements and materials, evolving into more elaborate metaphors and symbols. What is important, according to Semper, is that the different variations of the motives evolve according to the special contextual influences they are under. How the motives are shaped and ordered accordingly is a 
result of the context - the differences in time, differences between races and nations, political and religious tendencies as well as changes in nature and climate. Relative hereto, Semper (1854) emphasized that sometimes parts of the motives are more developed than others or perhaps just maintained symbolically [Tvedebrink et al. 2012:5].

\section{Textiles, Ceramics, Tectonics and Stereotomics}

Almost ten years later, in the book Der Stil in den technischen un tektonischen Künsten; oder, Praktische Aesthetik: Ein Handbuch für Techniker, Künstler und Kunstfreunde (Style in the Technical and Techtonic Arts; or, Practical Aesthetics, 1860-63), Semper developed a taxonomy on the background of his theory on the four motives of the hearth, flooring, walling and roofing, classifying the four building motives with four fundamental aesthetic crafts. Here hearth-making was linked with the craft and techniques of 'ceramics', flooring with 'masonry', roofing with 'carpentry', and walling with 'textiles' (Mallgrave \& Robinson 2004:13). Where 'ceramics' is defined as the soft, malleable or plastic substances that are easily shaped and harden in the open air through drying or by fire. Carpentry, or what Semper also referred to as 'tectonics', is all structural wooden frameworks that are elastic and of relative strength, resistant to forces working vertically along the length. Masonry, or 'stereotomics', is defined as the small dense aggregates that are piled together and are strong in compression. Finally, 'textiles' are made of strong, tensile and pliable materials highly resistant to tearing (Mallgrave \& Robinson 2004:13,21; Semper 1960:109). As mentioned above, according to Semper, the idea with these four parings was that every classification was to be understood in its broadest sense. So despite each of the above materials seemingly has its own domain of forms which is most natural to the inherited technique and craft, an infinite number of combinations can still occur across materials, crafts and techniques. Semper (1863:109) thus emphasized that, for instance, 'ceramics' in not restricted to clay vessels, but can also be related to glassware, stoneware, metalwork, barrels, baskets, and so on.

Semper continues his historical investigations on the origin of building forms and building materials, arguing on the background of Assyrians wall decoration that the development of the walling can be traced back to the characteristic features of the hurdle, mat and carpet (Herrmann 1984:204). Here Semper claimed that the wild tribes originally used the wooden fence or a primitive hurdle as means of enclosing space, and that the weaving of the fence led to weaving of carpets made of animal or vegetable fibers. This led Semper to argue that the essence of the walling throughout the history of architecture thus is the wickerwork, and that the hanging colorful carpets remained the "true" walling; the visible boundaries of a room, despite the often solid walls behind them for necessary structural and climatic reasons that had nothing to do with the creation of space (Herrmann 1984:205). This occupation with the colorful primordial motif of mythical animals and religious characters, according to Semper, gives rise to "interesting reflection" on the importance and quality of ornamentation, decoration and symbols in architecture (Herrmann 1984:208, 224). One of the points put forth by Semper in his elaborate study of textiles and walling is that he finds there can be no doubt that the first principles of 'style' are bound up with the earliest textile techniques, and he argued that the basic objectives of the textile technique were to string and to bind, in the attempt to cover, to protect and to enclose - or what he also later refers to as 'dressing' (Semper 1863:113).

\section{THE DRESSING OF THE ENCLOSURE}

Semper's notion of dressing is partly based on his belief that some of the first human beings learned to recognize the essence and purpose of natural covers like animal skins and tree bark and began using them for protection, cover and spatial enclosure. But partly also on the belief that our own skin - or what he refers to as the most "natural cover" and "hide" - has been the object of surface ornamentation in line with clothing since the ancient customs of tattooing and painting the skin (Semper 1863:123,172). By which he means that the decorative symbols used in architecture presumably derived from the textile arts (Semper 1863:247). With detailed descriptions of many different types of fabrics ranging from wool, velvet, silk, satin and golden brocade, damask to felt, and embroidery, stitching, weaving, drapery and other materials such 


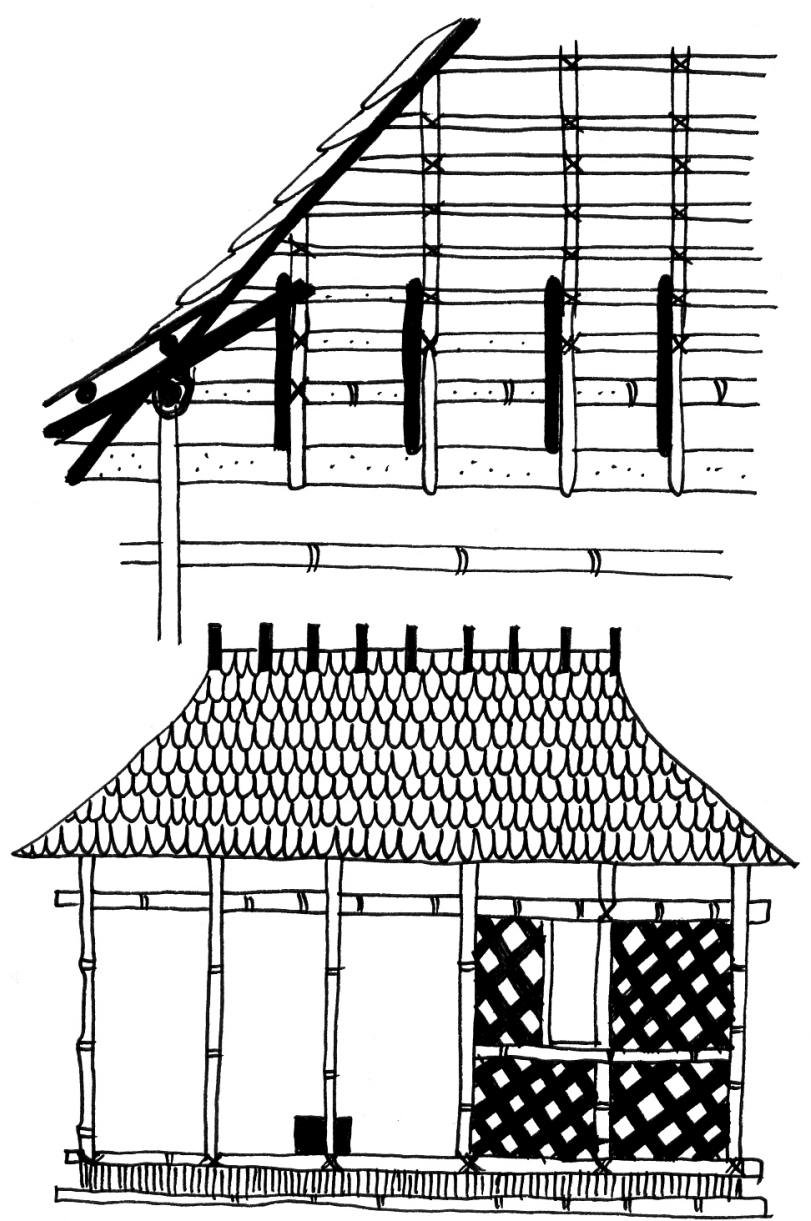

Fig. 8.2

"The Caribbean Hut" In the Colonial division of the Great Exhibition in 1851 Semper

is faced with the core of his theoretical speculations. Here he sees a full-scale model of a small Caribbean hut, originating from the island of Trinidad. The hut displays the four motives in their simplest expressions and combinations; hearth, mounding, enclosure and roof (Semper 1853,

November][Tvedebrink et al. 2012:5] (Drawing adopted from Hvattum 2004:36).

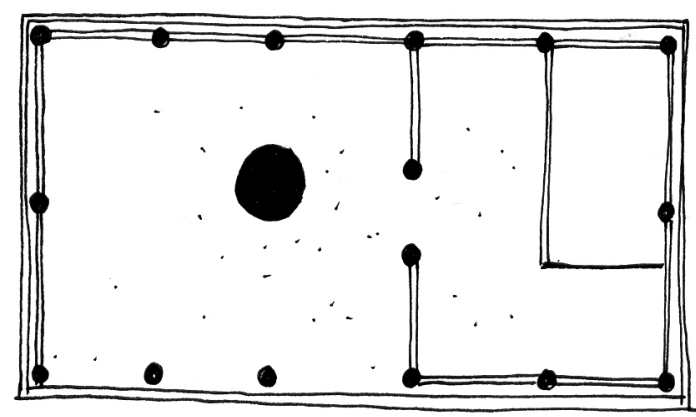


like animal skins, tree bark, leather, furs, rubber, lacquering, papier-mâché, fibers and cotton, he argued how the relation of the human hand and the craft and process of weaving led to making carpets for wall dressings and floor coverings working as spatial enclosures, dividing the "inner life from the outer life, as a formal construct of the spatial idea" (Semper 1863:247-48). Consequently, Semper also notes that the scaffolds that potentially served to hold, secure or support this enclosure had nothing to do with the architectural idea; "they were never form-determining and never directly involve with space and the division of space" (emphasis from original text)(Semper 1863:248). And he ends up concluding on this matter:

"It was therefore the covering of the wall that was primarily and essentially of spatial and architectural significance; the wall itself was secondary. The covering of the wall that retained this meaning even when other materials than carpets were used either because these materials lasted longer or because they were cheaper, easier to clean, or more magnificent, as for instance when carpets were replaced by stucco, paneling, alabaster or metal plates.... Walls never appeared in their structural nakedness; they were always covered on the inside as well as on the outside...On festive occasions the display of carpets would have recalled the original motif in its proper form"

(Herrmann 1984:206,208-209).

There might be a hidden critique of the ideals of the Gothic Revival as put forth by architectural thinkers like A.W.N. Pugin herein. But in continuation of these elaborate writings on walling and textile materials, Semper also moves on to argue that the most important general aspect influencing the 'style' of these bodily enclosures is the appearance of the surface and the particular dressing of this surface. With reference to the ancient Roman floors, despite criticizing the more realistic ones imitating fruit, shells and bouquets of flowers because they constitute visual obstacles that make the walking look down on the floor and thus potentially fall, he argued how in ancient Rome the use of surface ornamentation in mosaic floors were not intended to be walked on. But instead were horizontal surfaces, similar to ceilings, intended to create a central focus working as a conclusion to the overall sense of 'space' (Semper 1863:124,131).

Semper also has a detailed discussion of what kind of ornamentation is then suitable for respectively walling surfaces, flooring surfaces and roofing surfaces. And he notes, among other, that nature's carpet - the lawn with flowers - presents the most gracious analogy to ornamental treatment of floorings, whereas the roofing should be the climax of the effect and it should exceed the decoration of the walling and the flooring in its splendor (Semper 1863:132,147). When writing about the walling, Semper has a rather long passage on the use of tapestries and drapery in ancient Roman buildings, both domestic and public. He specifically mentions the interior of the Roman Triclinum, and how he finds that the ruins of Pompeii show clear evidence that tapestries, drapery, curtains and mobile screens were used extensively, not only in addition to the masonry walls as protection against rain, wind, cold and direct sun, but primarily also for reasons of comfort creating an enclosure for adornment, referring presumably to special spiritual or religious significances (Semper 1863:277279). Semper, therefore, states that these kinds of "light walls" were applied both in the everyday and for special festive occasions, as the completions of the architectural work and were simply what made the spaces "inhabitable" (Semper 1863:284).

\section{The importance of the central focus}

According to Semper, the surface did so by the particular articulation of the form, structure, material and color to give "prominence" to a central focus within the neutral, framed area, and thereby achieving a coherent whole working together. And he emphasized that the surfaces are thus more "correct" if they strengthen rather than weaken the unity arising from the "center" (Semper 1863:131). The surfaces of the walling, flooring and roofing together thus work as a spatial 'enclosure' and as a background to the furniture, the objects of art, as well as the occupants of the 'space' (Semper 1863:128). Consequently, Semper also emphasized that this can only be achieved by a concentric arrangement and subordinating of everything that fills the 'space' between the enclosure and the central focus to the overall effect (Semper 1863:131). 
Fig. 8.3

“The Roman Dining Interior"

The 'dressing' of the surfaces enclosing the Roman Triclinium,

the House of Venus, Pompeii.

Here the central focus was the position of the patron during the dinner (Drawing adopted from photo in Bek 1983:144).

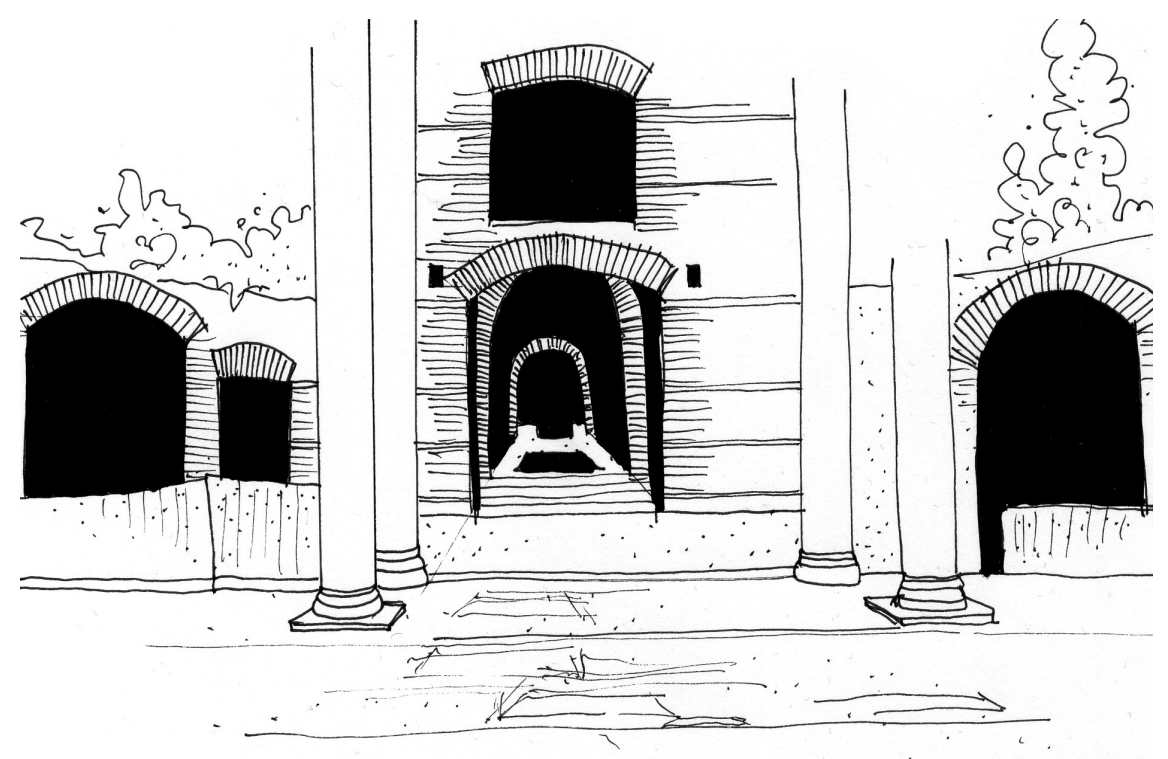

Fig. 8.4

"The Hearth"

The hearth was for many years a central focus, which despite geography, climate, topographyarchitecture (cave, tent or hut)

linked the everyday activities of cooking and eating with social gatherings and spiritual rituals. And thereby it became an essential element in the everyday lives of human being and a "first motive" in the order of the built environment (Drawing adopted from photo in Bek 1983:144).

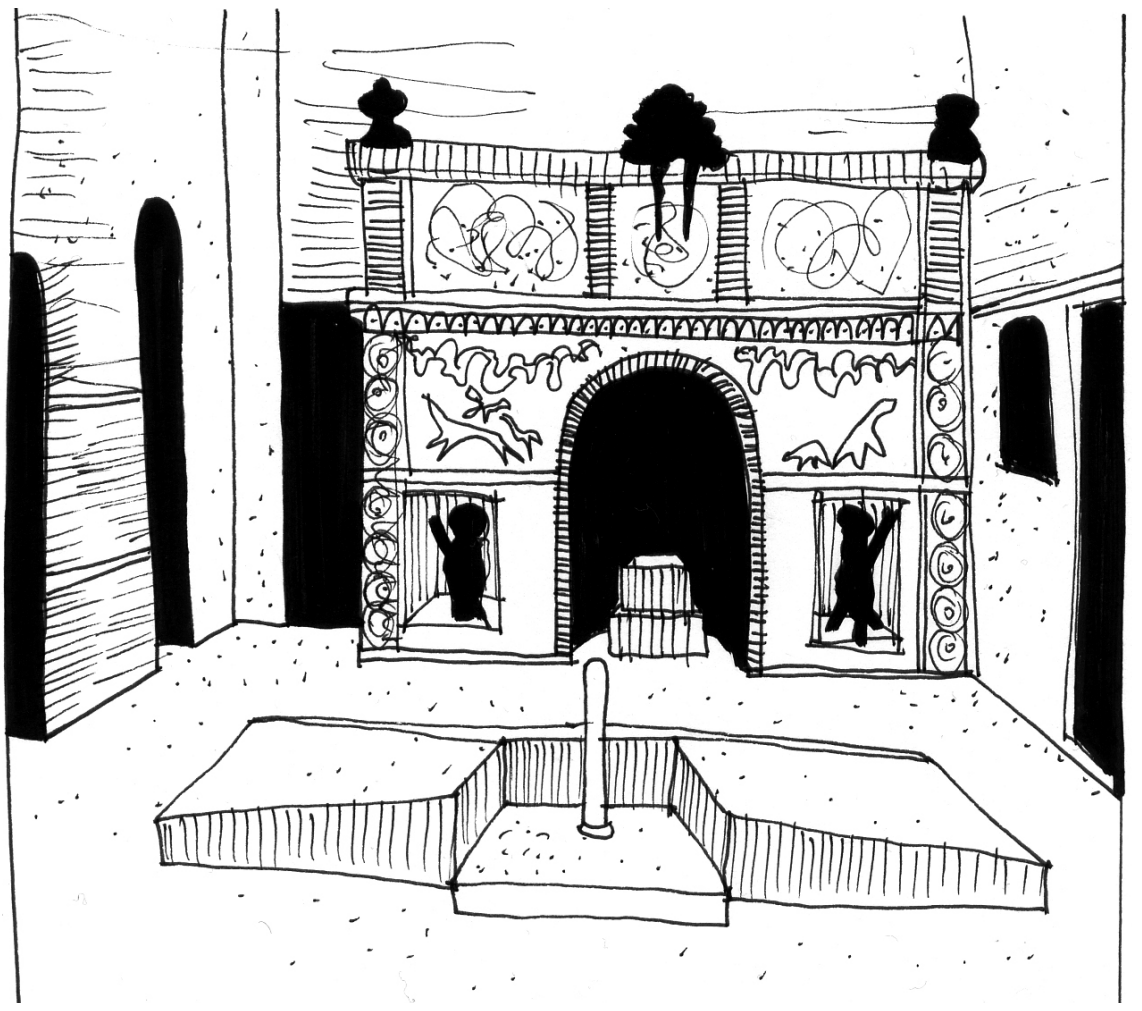


Based on the above, I find that if we compare the notion of the dressing and the enclosure with the above perspective of the four basic motives of architecture - the hearth, flooring, walling and roofing. It is possible to argue, even though Semper never really directly describes it himself, that this central focus enclosed by the surfaces of the flooring, walling and roofing is the metaphorical significance of the hearth. Thereby, the hearth truly becomes the first motive - or what I would also call the main idea and basic principle guiding the entire architectural design.

What is thus important in Semper's theory is that the hearth is the only part of the architectural design which is self-existing and has a meaning without the coexistence of the other three motives (Mallgrave 1985). The hearth can exist without the protection of the roofing, without being included by walling, or elevated on flooring. However, I find that it is not to be confused with mere function. The hearth constitutes the fundamental idea of a communal forum in itself. It is, in its highest significance, the central focus where to all other things relate, both the elements of architectural construction as well as the forces of society. The hearth is, therefore, an epistemological object working as the guiding principle of architecture [Tvedebrink et al. 2012:6]. Inherited in Semper's definition of dressing is the point that the dressing of the enclosure of the hearth is what produces what other later have called 'architectural space' rather than just being an interior decoration (Bek \& Oxvig 1999:368; Semper 1854). Here I thus return to the comment on the 'architecturesque' treatment made by Collins (1965:124-127) in the previous chapter, where he argued that the ornament was the "dress" that articulated the social and cultural power relations, and what ultimately sets the intelligence of man above that of animals. Because, neither Mallgrave (1996:7) nor Hartoonian (2006:xv) uses the term 'architecturesque' to denote the communicative and seductive ability of the dressing to articulate the social and cultural power relations like Collins (1965) did. Instead they use the notion of 'theatricality'.

\section{THE NOTION OF THEATRICALITY}

This notion of theatricality is something Mallgrave (1996:7), with reference to Michael Fried (1967), argues should not be understood in the negative sense as "theatricalization". He finds that negative understanding was a notion which emerged in the Barouqe era signifying illusional or staged effects produced by different angled perspectives and stage scenery, and which therefore suggests a sense of superficial scenography that offers little beyond the spectacular artistic "mirage" (Mallgrave 1996:7, Fried 1998:160-66). Instead Mallgrave (1996:7-9) argues that the notion of theatricality relative to Semper's theory could be understood as a primeval and innate human sentiment that manifests itself whenever two or more people come together in any setting, thus instead signifying the kind of regressive relationship potentially occurring between a work of art/architecture and the spectator/beholder in a given situation (Mallgrave 1996:7). Here Mallgrave (1996:7) furthermore refers to the meaning of the Greek word théatron, meaning "a place to view, to behold", and he relates it to Semper's own analogy of the dressing as a "theatrical mask". Semper writes:

"I think the 'dressing' and the 'mask' are as old as human civilization and that the joy in both is identical to the joy in those things that led men to be sculptors, painters, architects, poets, musicians, dramatists - in short, artists. Every artistic creation, every artistic pleasure, presumes a certain carnival spirit, or to express it in a modern way, the haze of carnival candles is the true atmosphere of art. The destruction of reality, of the material, is necessary if form is to emerge as a meaningful symbol, as an autonomous human creation."

(Semper 1863: 438-9n85)

As presented above, Semper argues that, throughout all phases of society, the hearth formed the sacred focus around which the whole took order and shape. He exemplifies this by posing that in prehistoric times, the hearth was perhaps just defined by a small fireplace on the ground, but throughout history it evolves into a religious object and transitions into an altar (Semper 1854). On the background of a study of classical Greek architecture, Semper argues that not only tribal dwellings but entire cities originally developed on the model of the hearth as the central motive. In the development of the 
city, the hearth is then a public communal forum, such as the classical Greek temple, set apart from the private dwellings of the individual families (Mallgrave 1985). According to Semper, this is an abstraction of the early shelters or primitive huts originally established around the sacred fire of the hearth. He argues that the cella which is the sacred inner chamber of a Greek temple and which often contained a cult image or statue representing the goods worshiped was meant to symbolize the state of the universe before the act of creation, and was thus considered the most important and sacred communal forum in ancient Greek culture (Semper 1854). This was further emphasized spatially by the use of a table or plinth to receive offerings, and the cella often working as a treasury. Following Semper's thinking, the cella is the hearth in classical Greek society and the first motive of ancient Greek architecture, domestic as well as urban [Tvedebrink et al. 2012:6].

The above example of the Greek temple put forth by Semper, in my point of view, touches on the core of all the architectural keywords - 'hut', 'temple', 'meeting house', 'image' and 'shelter' - I highlighted in the Gastronomic Analogy in the previous chapter. With the argument that the ultimate purpose of architecture is to appeal to the higher laws of humanity, Semper suggests that the process, by which the primitive hut developed into imposing Greek temples, is the result of the human desire for refining our environment through ornament and decoration, as a kind of "communication" to each other (Mallgrave 1996:7). Contrary to Vitruvius and even Fergusson, Semper here, in my opinion, makes the specific design of the ornament and architectural quality not depend on the style, but instead on the sense of theatricality in the communicative significance of the hearth as the central focus in society. The importance of the hearth as the first step in any architectural design is thus, in my interpretation, the understanding of this society - understanding the context and analyzing the social, cultural and spiritual norms and values related to a specific place and time.

With reference to the architect Charles Garnier, Mallgrave (1996:7) argues that Semper's sense of theatricality relates to the anthropological discourse emerging in the $19^{\text {th }}$ century that reduced architecture into two primary building types: the church and the theater. The first built for the "divine spectacle" and the second for the "human spectacle", which ultimately are both places to "see and be seen" (Mallgrave 1996:7). However, Charles Garnier and Mallgrave (1996) are not the only ones being occupied with this comparison. In between all, his almost mathematical classifications of disciplines belonging to the sciences and arts as well as conforming $19^{\text {th }}$ century view on 'taste', Fergusson (1849) had a specific section commenting on the 'beauty' of Greek Drama. Here he argued that the temple and the theatre were the two most essential buildings in Greek societies. And he notes that if we did not preconceive these two worlds - the church/temple and the theatre - so differently, we would find that temples share many of the same architectural qualities as theatres. With their draped and masked figures, sculptures, mythical characters, music, recitation and poetry, they both present a spectacular scenery created with the architecture (Fergusson 1849:427-428). In continuation hereof, Mallgrave (2011:74) in the book The Architects Brain writes how, to Semper, the Greek monumental architecture, such as temples, arose simultaneously with the creation of Greek drama. Therefore, the drama and the temple were born out of the same artistic instinct. The point made by Mallgrave (2011) relative to the quotes and perspectives above is thus that he finds that to Semper: "...the purpose of monumental architecture is quintessentially theatrical and - through an extraordinary extension of the metaphor - the painted dressing of the Greek temple are now transformed into a theatrical (Dionysian) mask, which no longer simply "dresses" but purposefully disguises both the material and thematic content..." (Emphasis from original text)(Mallgrave 2011:74). Relative hereto Semper writes on festive celebrations:

"The festival apparatus - the improvised scaffold with all its splendor and frills that specifically marks the occasion for celebrating, enhances, decorates, and adorns the glorification of the feast, and is hung with tapestries, dressed with

festoons and garlands, and decorated with fluttering bands and trophies - is the motive for the permanent monument, which is intended to proclaim to future generations the solemn act or event celebrated" (Emphasis from original text)

(Semper 1863:249) 


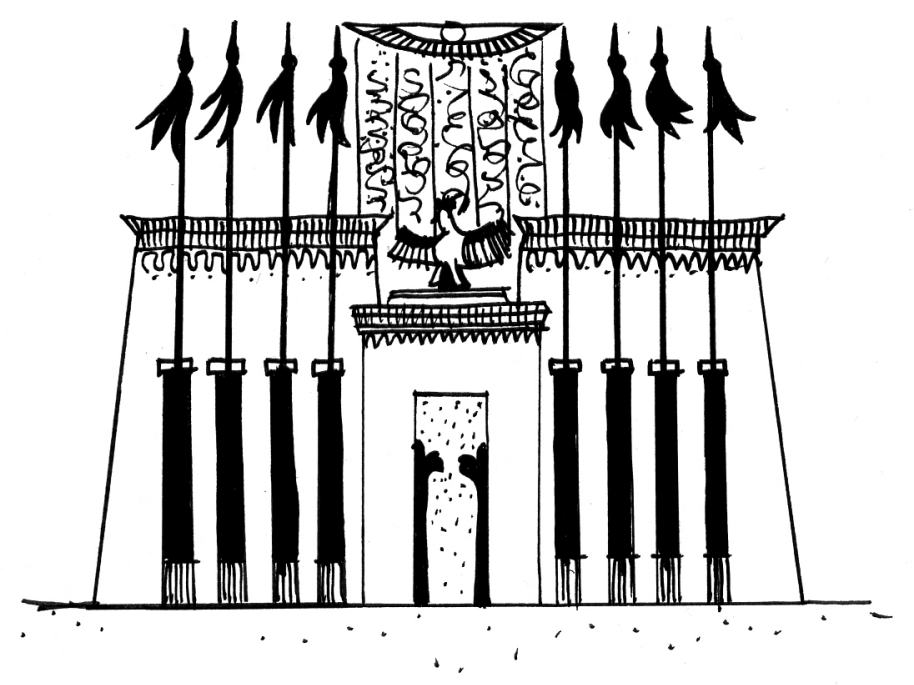

Fig. 8.5

"The Temple"

One of the archetypes presented in Semper's writings is the Temple.

The temple is not only a sacred religious monument and spiritual focal point, but also a cultural

center, a communal forum and a social gathering point, that has been celebrated since the birth of human civilization.

(Drawing adopted from Semper 1863:119)

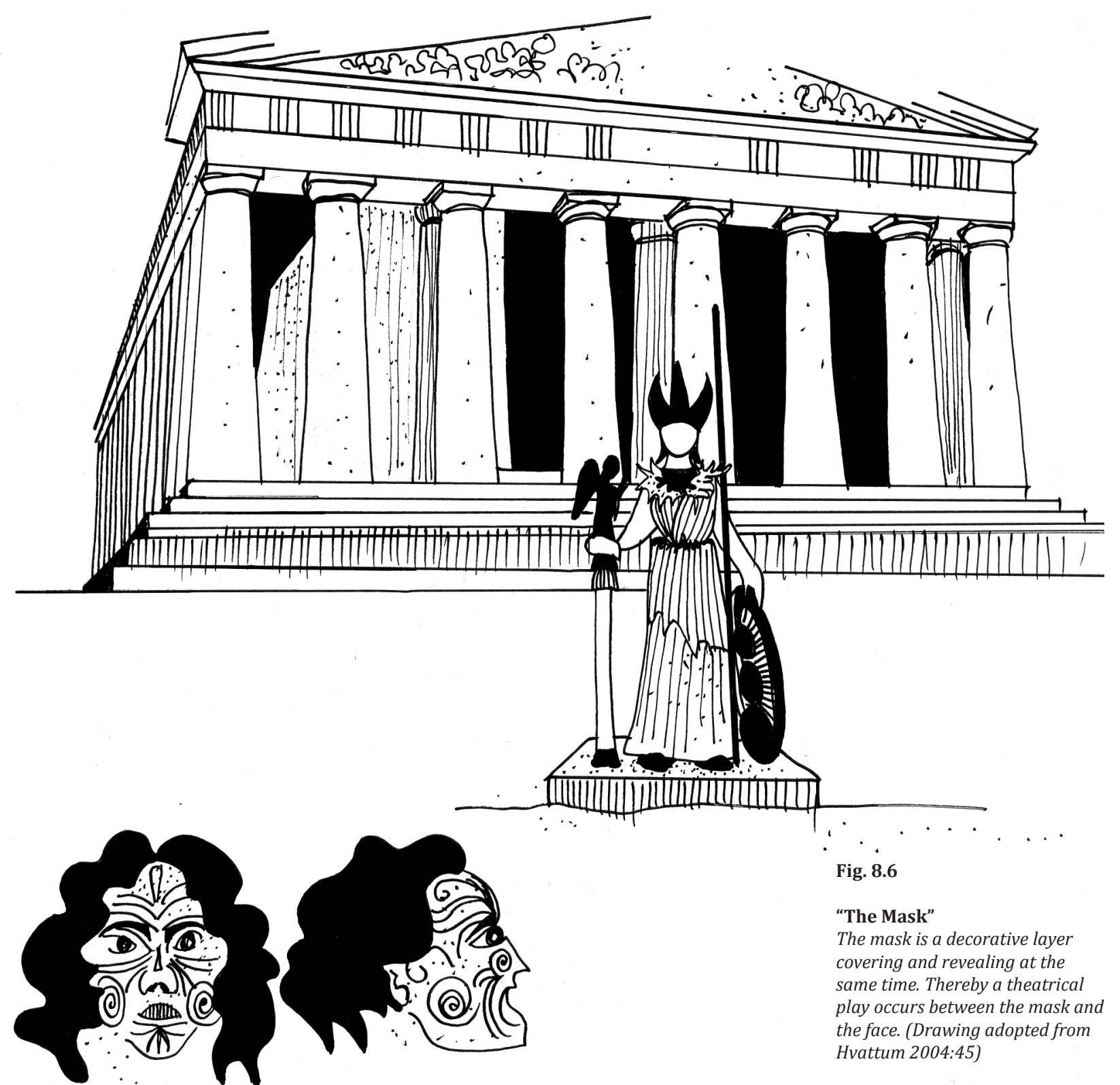


As mentioned previously, Semper most likely knew Fergusson's writings, partly because they met and debated on topics such as polychrome architecture, but also because he refers to Fergusson's writings elsewhere in his own writings (see e.g. Semper 1863:325-326). In Semper's writings, the "theatrical mask" could, therefore, be seen as something which both physically masks the structural material beneath the surface as well as simultaneously being a representative mask that conceals and reveals social, cultural and spiritual norms, values and rituals. What is interesting is that Semper not only links the architectural quality of the temple and theatre, but does so with the celebration of the ancient feast as the central motive.

On that basis, I find that there are two interesting points made by Semper with the descriptions of the Greek temple, ancient feast and extended classification of the four technical arts: the ceramics, carpentry, masonry and textiles. One is that the four technical arts reveal a great deal about the development of art works throughout history (Mallgrave \& Robinson 2004:15). This is further exemplified with Semper's analysis of the two vessels: Egyptian situla and Greek hydria, where he claims that: "ceramic artifacts are among the oldest and the most eloquent of historical documents" (Mallgrave \& Robinson 2004:36). Mallgrave \& Robinson (2004:36) emphasize that is was not particularly innovative to investigate a nation's larger cultural context through analyzing artifacts such as the situla and hydria, but it was groundbreaking to start associating these material objects with a collective psychological behavior that characterizes a given nation, and potentially also ultimately suggesting that material objects through their form and style were able to express and communicate an emotion or mood (see Figure 8.6, The Mask). However, in the introduction to Style Mallgrave \& Robinson (2004:20) notes that Semper never quite made his definition of 'style' explicit, except from one manuscript of 1856 where he defined 'style' as: "giving emphasis and artistic significance to ....all intrinsic and extrinsic coefficients that modify the embodiment of the theme in a work of art". Mallgrave \& Robinson (2004:20) interpret this as Semper's essential idea was that every piece of art, and herein architecture as well, consists of a series of first and second categories. The first categories consist of those circumstances which affect a work from within - such as the purpose or function of the work, the material of which the work is made, and the technique employed to make it. The second categories consists of those variables which affect the work from without - such as the local, social and personal influences, climate, topography, politics, religion, and cultural traditions (Mallgrave \& Robinson 2004:20). What I find is curious with these two categorizations is that architectural quality arises as a product of not only the specific time, but also the specific availability of building materials, available technology, craft and knowledge, influence of climate, topography and specific site. As well as the everyday social actions and spiritual rituals governing the given culture and society the architecture is part of. Therefore, a very important point, I find, is that Semper, compared to some of the other $19^{\text {th }}$ century architectural thinkers, is neither sentimental nor nostalgic in his thoughts on architectural quality and architectural design. His intention is not to return to the form, shape and order of neither the primitive hut, nor any other past architectural style. Instead, I find Semper emphasized the importance of the contextual understanding and how architecture must adapt to the present time, surrounding topography, specific location, climate, techniques, craft, materials and methods available, as well as social, spiritual and cultural traditions it is to be part of. The other more essential point is, therefore, the importance of the context in the meta-physical and physical manifestation of the "collective-self" and "private-self" as a result of the hearth, and the idea that architecture everywhere is based on those four motives initiated with the establishment of the hearth.

\section{The Context}

The point made by Semper with the above is that the context with its inherited intrinsic and extrinsic knowledge influenced and continuously influences the development of architectural form. In order to develop architectural quality, I need not to copy past examples or use precise geometrical rules, but must instead try to understand the specific context for which I am designing. Semper thus indirectly argues for a kind of architectural evolution - a continuously refinement of the ideals guiding the architectural qualities. In that way, Semper presents some very early hermeneutic considerations on how the elements of architecture become material devices through which we experience, perceive, read, interpret and predict culture. The hearth is as 
such not a specific interior or structural element, like the three other motives, but instead a fundamental design principle, suggesting the importance of a meta-physical and physical scenery with higher theatrical significance and a representative role as the "original forum", which is the driving force of social family life, establishing communities and fostering human civilization. This is what Semper himself calls not a 'polemical theory' but an "Empirical Theory of Art" that sees architectural quality not as formal 'beauty' expressed through harmony, eurhythmy, proportion, symmetry and so on, as in the time until the mid- $19^{\text {th }}$ century, but instead as an idea - the force, material and the means, in terms of the basic preconditions of the theatrical significance of the architectural scenery (Semper 1863:72). As in the natural evolution, there are some key elements and fundamentals always present, despite the evolution. They just transform in their physical appearance. This is what I so far, with indirect reference to the history of architecture, have been calling 'basic design principles'. However, this is what, I find, Semper coins so well with the notion of motives and his awareness on the fundamental importance of the social, cultural and spiritual values represented with the theatricality of the hearth, the flooring, walling and roofing, the enclosure, the dressing as well as the intrinsic and extrinsic contexts as basic preconditions for the architectural expression and style.

As presented in the previous chapters, the idea of architecture as 'space' - is generally not considered to be developed until the late $19^{\text {th }}$ century with German artist Adolf von Hildebrand and the art historians August Schmarsow, Alois Riegl and Heinrich Wölfflin (Frampton 2001:1; Bek \& Oxvig 1999:15). However, based on the readings of Mallgrave (1996), Bek \& Oxvig (1999), Hartoonian (2012) and Hvattum (2004), I find that the theoretical work and writings developed by Semper during the period of 1833-1879 and the notion of theatricality incorporate the idea that the social, cultural, and spiritual values embodied in the built environment are important for how we experience architecture. But, also, for how we 'describe', 'explain' and 'predict' architectural quality in general. Thereby, even though Semper does not directly use the term theatricality, he, in my opinion, moves the prevailing contemporary understanding of architecture from being an 'image-based' background or framing 'space' assigned strict geometry and proportions towards the notion of architecture as a scenery which in a theatrical sense embodying not only the persons and objects present, but also the interactions and ideas occurring between these persons and objects, for instance, during a feast [Tvedebrink et al. 2012:6]. Thereby Semper, in my point of view, not only used the analogy of theatre to explain the fundamental qualities in architecture, but possibly also introduced a concept signifying the coherence between the motives of the hearth, flooring, walling and roofing with the enclosure, dressing and context, which I find should be called architectural theatricality.

Based on my readings of Fried (1998) my claim is that the significance of, what I would call, the architectural theatricality of the scenery offers a kind of heightened perceptual experience. The point is that everything counts - not as part of the scenery, but as part of the entire situation (Fried 1998:155). It is the experience of this situation that is most interesting, that is the aim of the architecture, because that is what persists in time. That is what has a duration beyond the bodily engagement with the scenery (Fried 1998:166-167). Here the concept architectural theatricality, thus covers the same kind of 'doubleness' as argued for by Rice (2007) and Sparke (2008) in the Introduction.

This 'doubleness' refers to a semantic development that, according to Rice (2007:2), marks the emergence of the interior in the late $15^{\text {th }}$ century. Here, as mentioned in the Introduction, the notion 'interior' could be understood as both the "inside" as a divide from the "outside", but also to "describe the spiritual and inner nature of the soul" (Rice 2007:2). Which later, in the beginning of the $19^{\text {th }}$ century, evolved into an understanding of the 'interior' as both a three-dimensional physical 'space' as well as a two-dimensional representational 'image', according to Rice (2007:2). But, the term, 'doubleness', further relates theoretically to the writings by German philosopher and literary critic Walter Benjamin (1892-1940). According to Sparke (2008:13), Benjamin understood the Victorian home as place of 'dwelling' and 'inhabitation' opposed to the commerce and communal leisure of public spaces (Sparke 2008:13,22). This was based on the understanding of the need of the individual for a place to bring together the "far away" and the "long ago" in the "fuzz" of the 'modern' world (Sparke 2008:23). However, it also led Benjamin to state that the private living room"... is a box in the 
Fig. 8.7

"The Origin"

A primitive scenery. The 'Hearth' as social gathering point, spiritual ancher point and cultural focal point arises.
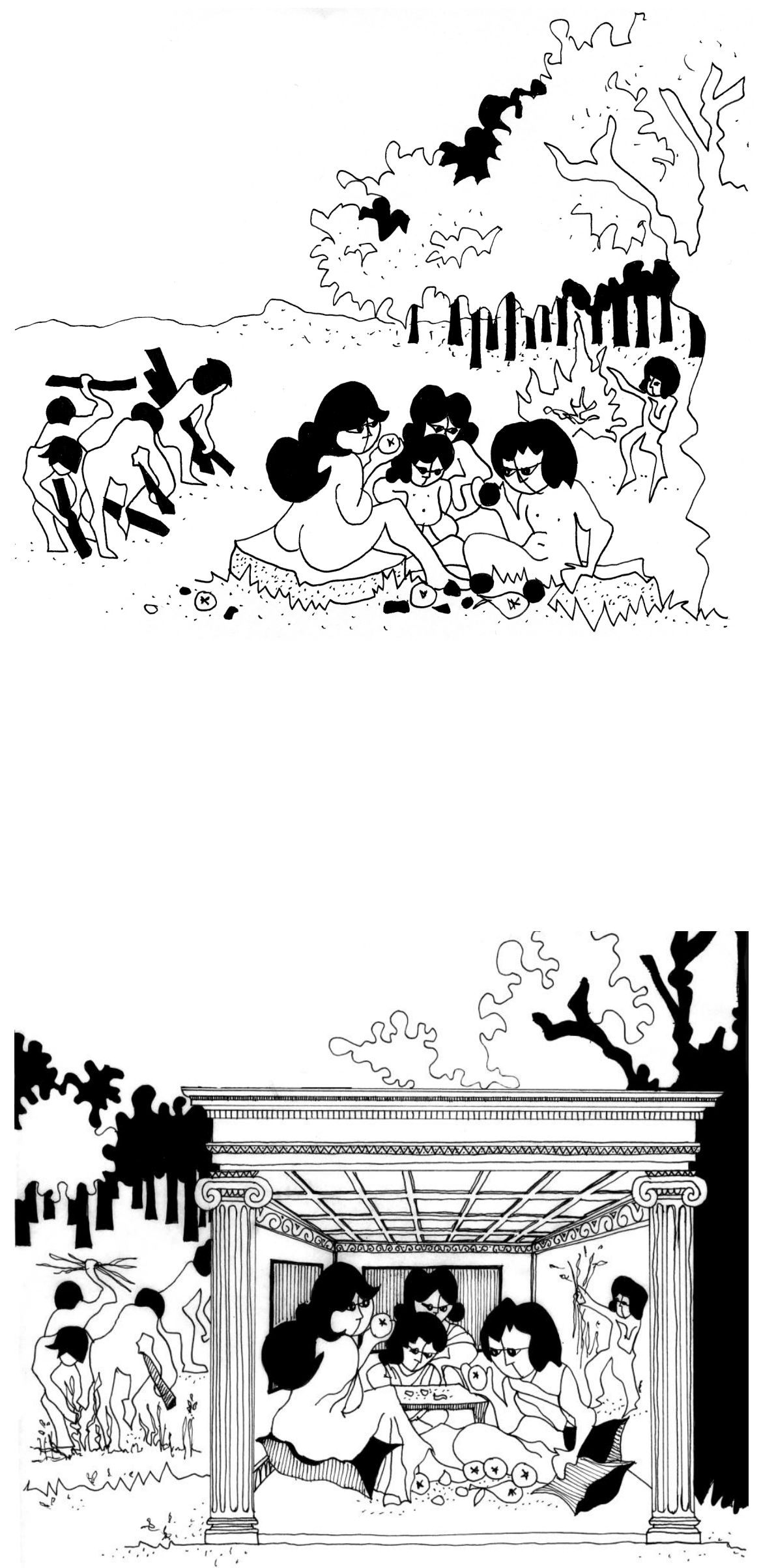
theatre of the world" (Sparke 2008:23). In that way, Sparke (2008:23,38) and (Rice 2007:9) argue that Benjamin looked beyond 'style' to cultural meanings of material objects - just as I find Semper did - and accordingly encouraged us to consider the interior in terms of a "soft" and impressionable "surface" that protects the private life and conceals the "private self" against the public society, but simultaneously through the communicative significance rooted in the "surface" represent and reveal the "private self" to the public. Inspired by the writer Marcel Proust and his telling of the Madeleine cake that transported him back to the past and the vivid memories of Combray, Benjamin writes about the mémoire involontaire and use it to denote how the interior works "as a space for the registering of traces" (Rice 2007:15-16). Rice (2007:16) notes that the material objects, just as with Marcel Proust's Madeline cake, become ways of opening up traces of the unconscious and revealing the past, and the point is that the material objects becomes "bridges in time" that links the individual with past experiences through memories and associations.

According to Rice (2007:16) this longing for the "far away" and "long ago" - or what he also refers to as the 'long experiences' - is what gives rise to the private individual as a "collector", and consequently also what during the $19^{\text {th }}$ century gave rise to the bourgeois interior. And this "collection" of material objects is presumably what makes Sparke (2008:11-12) introduce the notion 'assemblage' as a third interpretation of the 'interior' emerging during the $19^{\text {th }}$ century. However, what is important to note relative hereto is that, it is not the Madeleine cake itself that is significant, according to Rice (2007:17). Instead it is the trace in memory that is opens up. For Benjamin the interior - whether 'image', 'space' or 'assemblage' - is thus revealed as a 'dreamimage' that unfolds a kind of "dream space" where scales and time shifts, and thereby the interior architectural qualities become bigger than the architecture itself (Rice 2007:18,33). What I find is significant about this relative to my research focus, is that here the writings of Semper, Mallgrave, Benjamin, Rice and Sparke (2007) blend. Despite their slightly different use in terms, the difference in time and purpose, I find that these statements draw on the same pool of theoretical knowledge that, to me, suggests that the architectural theatricality of the scenery of the interior is what provides the heightened perceptual experience that is so significant for our emotional and physical well-being.

In continuation of hereof, I would argue that the notion architectural theatricality can be understood as a fundamental interior architectural quality and a basic design principle encouraging a poetic, careful and skilled dressing of the enclosure of the hearth intended specifically to touch, move, seduce, inform and make the "spectator" aware of his presence within a larger communal ritual as the feast. But most importantly also what, I find potentially, can be used to provide better meal experiences encouraging an increased food intake.

\section{From basic motives to a design method}

Based on the above, I would argue that Semper, in the same manner as Mrs. Glasse thoroughly elaborated upon almost every single raw food ingredient and their material qualities and gastronomic use in her revolutionary cookery book, approaches architecture in his theories not only from a perspective of form expressed through style, proportion, harmony and geometry, but also as an assemblage of material objects and their embodied knowledge, crafts, techniques and multi-sensuous qualities. In comparison, contemporary architectural writers like Fergusson, as previouslymentioned, approached architectural quality from a slightly different perspective. Fergusson split the bodily physical characteristics from the aesthetic spiritual characteristics in his classification. With this "split" between the sciences and arts, Fergusson adopted the 'body-mind split' introduced by French mathematician and philosopher René Descartes (1596-1650). A "split” which separated the physical body and spiritual mind. However, I find that Semper "escaped" this split in his theory, and instead he achieved a synthesis of the body and mind into an embodied experience with the elaborate classification of the architectural theatricality of the basic crafts, materials, techniques and motives composing the scenery of any built environment.

Thereby, it is my claim that the motives of the hearth, enclosure and dressing as well as the sense of theatricality are early anticipations of the contemporary findings of Neuroscience, as argued for with Mallgrave (2011) in the Introduction. In my opinion, 
Semper's basic motives and sense of theatricality in architecture are part of the key to understanding what contemporary neuroscientists, according to Mallgrave (2011:146), defined as "primary neurological forms" or "universal aspects of forms". Relative hereto, Mallgrave (2011:197,201) notes that the recent discoveries within the discipline of neuroscience reveals that the brain, when encountering spatial experiences, presumably creates a kind of "topographic map" wherein detailed information about certain material objects are used as navigation and basis for orientation. Therefore, humans are presumably extraordinary sensitive to the detailing and material articulation of architectural enclosures (Mallgrave 2011:201). This recording of specific scene details are important to the significance of Semper's notion on the relevance of the dressing and the sense of theatricality as a mask both revealing and concealing the 'doubleness' in the architectural scenery. I would even go as far as claiming that the 'doubleness' of the dressing as both a cultural layer and multi-sensuous layer is, what makes human beings recognize, orient, position, and move in 'space'.

Thereby, Semper, was a few steps ahead of Fergusson back in the 1860s in that he actually managed, in my point view, to embody and materialize the morale of the Gastronomic Analogy in a series of basic motives that describe the fundamental qualities of architecture, as a response to the context of the present instead of copying the style of the past. Thereby, in my opinion, he also suggests that what gastronomy and architecture really share is that they are both sciences and arts, and that the process of refinement is a matter of synthesizing the complex contextual aspects of crafts, technology and knowledge rooted herein. Consequently, he also acknowledges that interior architectural quality is a matter of synthesizing bodily, cultural, social and spiritual engagements and interactions, as well as acknowledges that sensations, emotions, feelings, memories, imagination, customs, traditions, myths and rituals are closely intertwined and cannot be separated. This was instead of doing what Fergusson did: using the Gastronomic Analogy primarily as a metaphor to explain the process of refinement as a matter of judgment of different levels of "bad", "poor", "descent", "fine", "good" or "sublime" 'taste'. In that way, I also find, that Semper was decades ahead of his time in proposing how to approach architectural design in general. His theory on the four motives in architecture was an almost revolutionary example of a hermeneutic approach to architectural design, emphasizing the poetic value of legends and myths together with the cultural, ritual and social values of the built environment, and did so with specific reference to the ancient festive celebrations merging entertainment and communal eating in one theatrical scenery. Thereby, in my point of view, he was suggesting a method for a design process utilizing the knowledge of the context that continuously invites new expressions rather than a specific style and prescriptive "rules" or formal "laws" to be followed when designing.

With the above interpretation of Semper's theories and the concept of embodying in mind, from my point of view, the fundamental principles defining interior architectural quality in general are defined by the significance of the notion of the hearth as a metaphor for the inhabitation of a particular piece of ground or site, maybe marked simply by sitting directly on the earth, establishing a place, creating a space, marking an outer frame, establishing a background, and thereby also indicating an interior and exterior world. Perhaps later on these interior and exterior spaces are further defined by the material appearance of the walling, flooring and roofing that shelter, cover and enclose the interior spaces from the exterior. Thereby, the theatricality of the surfaces of these enclosing surfaces are articulated with a dressing manifested through the particular contextual choice of materials and detailing in form, structure, construction, joining, ornamentation and decoration. All together this establishes a unified and coherent scenery. So, in my point of view, Semper's concept of the four motives of architecture very much relates to architecture growing from the "insideout", denoting an architecture which, with the concept of the hearth and the inherited values of a "private-self" and "collective-self", revolves around human-centeredness and an embodied experience.

The question is if this concept of architectural theatricality and the fundamental principles of hearth, enclosure, dressing and context, developed with inspiration in Semper's 'polemical theory', can be used not only to define interior architectural quality in general, but also be used to define the interior architectural quality in patient eating environments? 


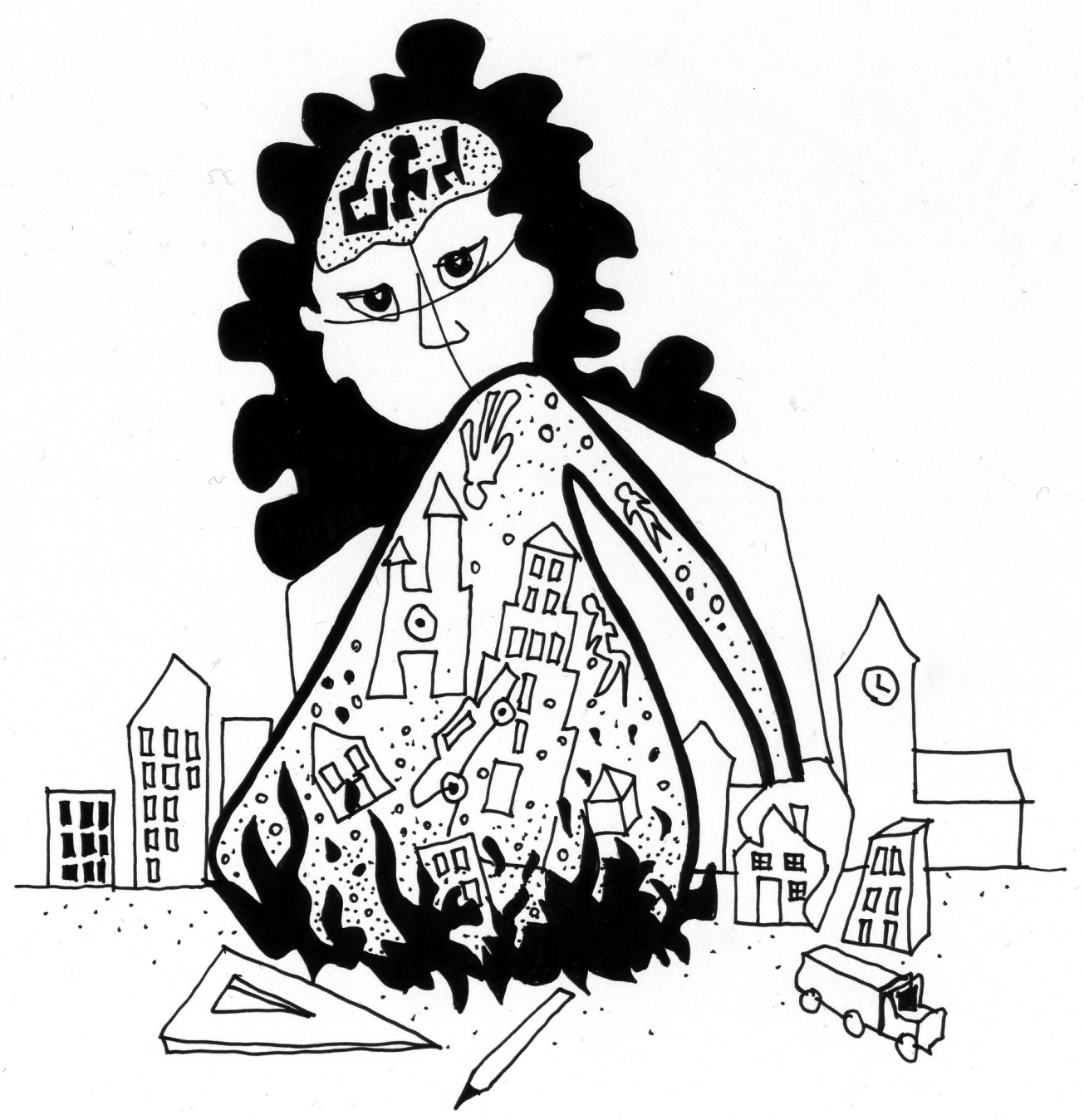

Fig. 8.9

"The Design Process"

Semper was decades ahead of his time in proposing how to approach architectural design in general. He suggested to utilize the context rather than a specific style and prescriptive "rules" or formal "laws". (Drawing adopted from Frascari 2011b:26) 


\section{THE CONCEPT OF ARCHITECTURAL THEATRICALITY The Interior Architectural Quality of Patient Eating Environments}

As argued in the previous chapters, since the writings of Vitruvius, the origin and purpose of architecture has, especially during the $19^{\text {th }}$ century, been ascribed the prehistoric fireplace and the making of the first primitive huts. As noted by Professor of Architecture Simon Unwin (2007:28), these writings often depict a prehistoric family or tribe making its way through a forest landscape still unaffected by human activity and actions. At some point the group decides to stop for a rest, and perhaps they light a fire for warmth and for eating. By doing so, they establish not only a small campsite, but a 'place'. Regardless of whether they intend to stay there permanently or just for a few hours, this 'place' has become the center of their lives. With the specific choice of 'site', the making of the fire, the eating and the creating of 'place', they have begun to organize the world around them with specific purposes and, thereby, also created a series of 'spaces'. They have, as Unwin (2007:28) writes: “...begun to do architecture". But they have also, as suggested with the Timeline and Historical Review, begun the evolution of the kitchen and the dining room. They have begun to do gastronomy.

The theoretical importance relative to patient food servings is that, whether we like it or not, a meal is a constructed phenomenon and a situation which influences our meal experiences. As seen in the arguments put forth in the chapter, Positive Theories, with the researchers Sobal \& Wansink (2007) and Gustafsson (2004), meal experiences and food intake are presumably highly influenced by the eating environment. Taking a point of departure in the core concept of the word "landscape", one of the points made by Sobal \& Wansink (2007) was that the eating environment provides subtle, pervasive, and often unconscious influences on our food choices, food intake, obesity, and health. On that basis, they suggested that we could, therefore, re-engineer and intentionally design eating environments that might offer opportunities to shape food intake and influence meal experiences. They suggested a division into four scales to define the different scales of an eating environment: the roomscape, tablescape, platescape and foodscape (Sobal \& Wansink 2007). Gustafsson (2004) suggested in a similar manner that the eating environment could be defined by the specific 'atmosphere' and 'room' which the built environment articulated through the history, style, decoration, textiles, 'products', 'interactions' and 'management systems'. Contrary to the model developed by Sobal \& Wansink (2007) and Gustafsson (2004) dividing and separating the eating environment into minor elements, I find that Semper argued for a coherent and unified scenery.

However, just as the 'polemical theory' developed by Semper was not directly aimed at patient eating environments, the 'positive theory' developed by Gustafsson (2004) and Sobal \& Wansink (2007) are aimed at eating environments in restaurants, hotels or private homes, and not hospitals. Nevertheless, because the Annotated Bibliography and the Integrative Literature Review indicated that a very limited amount of 'positive theory' relate directly to patient eating environments and that these references - such as Shepherd (2011) - already drew on research developed in restaurants and hotels, I find that it is necessary to use the positive, normative and polemical theory developed outside the context of the hospital to provide a broader perspective and inspiration on the interior architectural qualities of patient eating environments. Following the above interpretation of Semper's theory, defining the interior architectural qualities of the patient eating environment must, therefore, begin at a slightly different level than the four different 'scapes' proposed by Sobal \& Wansink (2007) or the 'room' and 'atmosphere' suggested by Gustafsson (2004).

Instead, the interior architectural qualities of the patient eating environment is ordered and shaped by the scenery established with the four underlying motives of the hearth, flooring, walling and roofing enclosing the meal, as well as the dressing of that enclosure, furthermore taking its point of departure in the contemporary context. A scenery which stages the meal situation and influence the expectations, choices and satisfaction that we experience during eating from the smallest architectural scale of presenting the food, laying the table with plates, bowls and glasses, into the spatial arrangement of table and chairs, to the enclosing dimension of wall, floor and roof because of the architectural theatricality inherited in these material objects [Tvedebrink et al. 2012:7]. What Gustafsson (2004) and Sobal \& Wansink (2007) 
perhaps did not express so clearly with their models, as Semper, is that the significance of the hearth as the first motive in the creation of this unified scenery is the 'doubleness' and sense of architectural theatricality rooted the physical and meta-physical qualities of the ensemble of objects present in the scenery. Semper links the order and shape of the architecture with the cultural and anthropological understanding of a communal forum, like the situation of a feast or meal, through the concept of the hearth and the three motives of walling, roofing and flooring. In that way, I find that Semper's theory provided important "clues" on architectural perception and creation which elaborate on some of the tacit and symbolic dimensions of architecture and how the scenery of a given built environment is an assemblage which both is a framing 'space' and a representational 'image' that support our collective cultural memory and private self [Tvedebrink et al. 2012:11]. So even though Semper's 'polemical theory' was not specifically aimed at eating environments, I find that his notion of the dressing could be what Gustafsson (2004) refers to as the 'atmosphere'. However, with Semper's model, it becomes evident how the 'room' and the 'atmosphere' are not only linked, but are basic architectural motives that foster each other. As long as eating and having a meal is not consummated in pure nature, there will always be some kind of architecture present enclosing and dressing the entire situation. This is whether it is the 'interior' of some indoor setting or the 'exterior' or landscape of an outdoor setting, or it is the specific material objects like furniture and tableware used in the process of eating. The 'polemical theory' of Semper, thereby, not only unfold the interior architectural qualities of the 'room' and 'atmosphere' as outlined with the model developed by Gustafsson (2004) and the 'scapes' outlined with Sobal \& Wansink (2007), but extend their qualities with the architectural perspective that the eating environment is not to be understood as a series of separated elements, but instead as an unified scenery enclosing the material objects, persons, ideas and interactions present during a meal.

Based on my interpretations of Semper's theory, I find that the following four principles could describe the fundamental interior architectural qualities in patient eating environments:

- HEARTH

Articulates social gathering point, spiritual anchor point and cultural focal point.

The meal as a communal forum and first motive for the scenery of eating.

- ENCLOSURE

Articulates flooring, walling and roofing.

The interior and exterior elements working as shelter and cover responding to the social, cultural and spiritual ritual behaviors relating to a meal and eating.

\section{- DRESSING}

Articulates the architectural theatricality of the interior.

The detailed, symbolic and material masking of the surfaces establishing a unified scenery enclosing the hearth while simultaneously revealing and concealing an embodied perception of the cultural, spiritual and social norms and values inherited in the rituals, myths, customs and traditions of a meal.

- CONTEXT

Articulates the extrinsic and intrinsic contexts.

The extrinsic context as the present site of a meal or eating - the topography, nature, climate, landscape, environment, surroundings and materials available. The intrinsic context as the adaption to present time - the cultural, social and spiritual knowledge rooted in state-ofthe-art technologies, tools, methods, practices, crafts, sciences, arts, styles, taste and aesthetics relating to meals and eating. 


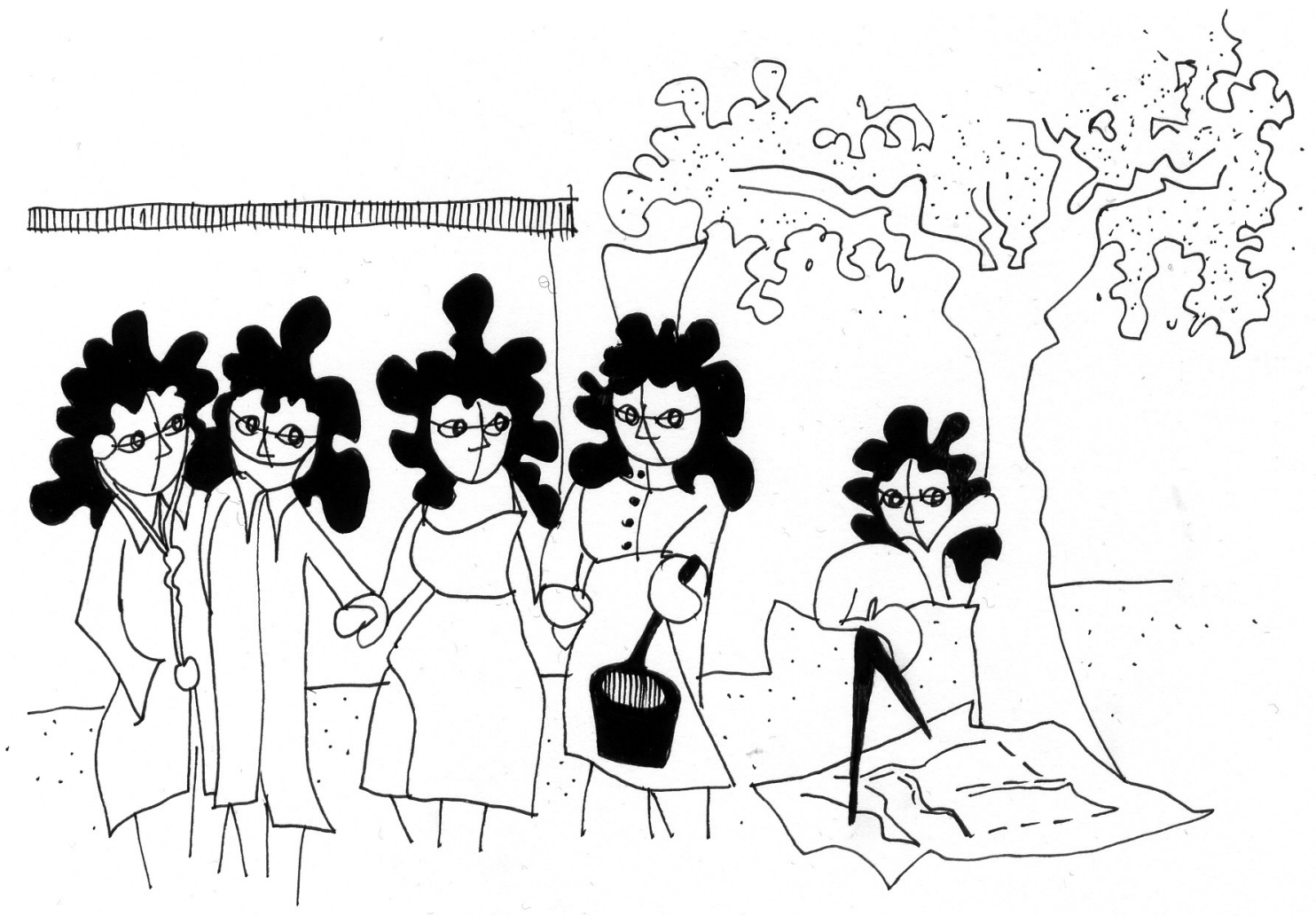

Fig. 9.1

"Inspiration"

A new theoretical discourse

focusing on patient eating environments from the perspective of architecture and thereby integrating health, food and architecture. 
9

\title{
PATIENT EATING ENVIRONMENTS
}

\author{
RETURNING TO PROJECT MORE
}

With the unfolding of the 'polemical theory' of Semper and an interpretation of his suggestion for a series of fundamental motives and basic design principles guiding architectural quality in general, I will return to project MORE and the specific example of the Department of Infectious Diseases to see if I can use these fundamental principles to 'evaluate' the interior architectural qualities of that specific patient eating environment.

As presented in chapters 1 and 3, the Department of Infectious Diseases was one of the forerunners in project MORE, who wanted to improve the overall treatment outcome and recovery process of the patients by focusing more on the importance of eating during hospitalization and how to encourage food intake through a holistic approach to food servings. The Department of Infectious Diseases among others hired the Danish "food event" company and restaurateur Madeleine's to develop a design proposal for an interior refurbishing, as part of a series of general improvements in the patient food services. During the first year of my PhD project (2009-2010), I followed the progress with project MORE as well as "observed" moments of the everyday life in the Department of Infectious Diseases. That resulted, as mentioned previously, in a small series of informal and formal visits and observations, talks and interviews, as well as meetings with the different involved staff in the department. It also led to a series of photos and sketches of some of the everyday mealtimes at the department. This material is what I have used, together with the four principles outlined in the previous chapter, to 'analyze' the interior architectural qualities of the patient eating environment. With the overall aim of possibly also being able to point at or 'predict' what the interior architectural qualities could be in future patient eating environments.

I have chosen the project MORE and the specific Department of Infectious Diseases, because, as mentioned in chapter 3 , this project stands, together with the example of VEJLE, as the first contemporary examples trying to synthesize health, food and architecture into a coherent whole. However, contrary to the example of VEJLE which completed an interior refurbishing with the help of a design consultant, the departments involved in project MORE have not been refurbished. The design proposal made by Madeleine's was never realized. Instead a series of attempts have been made by the nursing staff in the different wards to transform the patient eating environments. The nursing staff's initiatives indicate that something is "missing", is "wrong" or is not "optimal", today, but they cannot define what it is. They suspect it is closely related to the interior architecture framing the eating environment. The nursing staff have, therefore, questioned if any research-based knowledge exists supporting that suspicion. Furthermore they have requested for a series of basic design principles that can assist them in 'predicting' what the future interior architectural qualities of patient eating environments could be, so that they can use these to apply for funds to 
refurbish the existing wards. But most importantly, so the nursing staff can also use this knowledge to 'describe' and 'explain' the importance of a focus on the interior architectural qualities of patient eating environments in the design of the new super hospital, planned to be built in Aalborg during the next 10 years. In continuation hereof, it was my overall aim and goal to widen the existing perspective on hospital design in Denmark and contribute with research that could help bridge the knowledge gaps relating to patient eating environments in general in the challenge of designing the future Danish super hospitals.

Clearly the specific Department of Infectious Diseases is a unique example, that cannot automatically be compared to other patient eating environments, because there is a difference in what I have called the extrinsic context such as user groups, patient diseases, surroundings, environment and hospital architecture. Nonetheless I find that a majority of the intrinsic context - the present time and the cultural, spiritual and social norms and values that relate to meals and eating in a hospital are fundamental and therefore general within a Danish context. Potentially, they are, therefore, the same, whether it is a patient eating environment at a super hospital in Aalborg or a super hospital in Skejby, Gødstrup, Odense, Køge, Hillerød or Herlev. So, it is these fundamental interior architectural qualities, relating to the intrinsic context, that I will try and address in the following 'analysis' of the patient eating environment in the Department of Infectious Diseases, at Aalborg Hospital.

\title{
The Department of Infectious Diseases
}

As presented in the previous chapter, with my interpretation of Semper's theory, the sense of community rises with the higher significance of the hearth as a communal forum and its ability to gather people around for activities like celebration, cooking, feasting or eating. As seen in the drawing of the floor plan of project MORE (see Figure 3.3, Department of Infectious Diseases (7V), p. 32), the layout of the ward is based on an archetypical model of a 'Modern Hospital', where patient rooms are aligned on one side of the ward, separated from staff and service functions like elevators, staircases, washrooms, nurse offices, and the nurse station by a long hallway. In this specific department, the only patient-related facility located in the right side of the ward is the small common area. Here, a few chairs and a table substitute a "semi-private" local eating environment, reserved for the minor group of patients hospitalized at that specific department and ward. Otherwise, patients have to eat in bed or go to the "semipublic" canteen area located in-between the two wards, where others are "allowed" as well. From the few observations made in the explorative field study, it became evident how the patients in this specific ward, by the means of the overall architectural scenery, were often indirectly "forced" to eat alone. This is, for instance, seen with the behavior during mealtime, as recorded with the notes from the observation:

\begin{abstract}
"During the day, the bulk trolley is used to store all relevant kinds of tableware and china...furthermore, the bulk trolley is equipped with a wide range of soft drinks available for the patients. However, they are not allowed to touch it themselves due to danger of contamination. ...During mealtime, an additional bulk trolley with hot food is brought in and placed in the small living area. The patients slowly trickle in and align in front of the bulk trolley. ...food is served from large steel containers... and handled to each individual on plastic trays... Each patient can then choose to sit in the living area in the ward, in the patient rooms or in the common eating facilities of the overall department. ... there is only room for about 4-5 patients. The rest look rather nervous and in doubt where to go? Some return to the patient rooms... an old man heads for the common area...others quietly wait for a free seat, or sit at the end of the hallway in the armchair..."
\end{abstract}

[Tvedebrink et al. 2012:9]

As seen from the field study notes, there is seemingly not enough room for all the patients to sit down and eat together in the ward. Consequently, several patients chose to wait or eat alone in other locations and, thereby, became "detached" from the overall ward community. Furthermore, the eating environment is part of a small common area located in-between elevators, storage rooms, offices and the nurse station. Here trolleys with dirty laundry, cleaning utensils or medical equipment 
are often temporarily stored, despite the nurses' attempt to keep it away during mealtimes. So, even though the space physically is located in the middle of the ward, it quickly becomes concealed in the daily activities of busy nurses and doctors or in the scenery of visitors and co-patients watching TV.

Finally, the patients are not invited to interact, as it is not even allowed for them to touch parts of the meal-scenery, and each patient meal is sharply separated by the boundaries of the serving trays. I would argue that, as we saw in the cases of Holm \& Jacobsen (1990), the activities of patients, staff and visitors are mixed, and there is no communal forum fostering social events and revealing the sense of a community during mealtimes. If I use the notions inspired by Semper's 'polemical theory', there is seemingly no hearth-of-the-meal [Tvedebrink et al. 2012:9].

If I continue with the notions inspired by Semper's 'polemical theory', the hearth is not only defined as a social gathering point, but also as a spiritual anchor point and a cultural focal point. These are often indirectly defined by the cultural and spiritual significance of the enclosure of the three other motives; the flooring, walling and roofing, as well as the particular dressing of the surfaces of these elements. With this perspective, it becomes evident that it is not so much about the missing sense of a hearth-of-the-meal or a scattered sense of a communal-meal-forum, as it is the impression that there is no specific dressing or enclosure articulating or revealing the existence of a hearthof-the-meal. As seen in the photos (see Figure 9.2, Patient Eating Environment), the existing meal-scenery is primarily concealed in-between other ward activities and their sceneries as described above. Consequently, the overall architectural scenery is not providing any coherent sense of an underlying motive for the order and shape of the interior architecture staging the patient mealtimes and meal experiences. Instead, there is a series of other, more permanent hearths. There is the nurse station serving as the central focus and social gathering point for the staff and visitors to the ward; there is the television serving as a communal forum, spiritual anchor point and cultural focal point for the patients with the different shows broadcast during the day; as well as there is the small arrangement of the table and five chairs serving as a social gathering point for those patients that for instance would like to play cards during daytime. All these hearths relate to separate activities not directly involving patient mealtimes or encouraging communal eating during food servings. The one interior "element" I would claim come closest to enclose a sense of a permanent hearth-of-themeal, in a similar fashion as the residual hearths are permanent interior elements, is the bulk trolley. However, I think it is difficult to claim that the bulk trolley serves as a social gathering point, spiritual anchor point or cultural focal point, because it does not articulate the sense of a communal forum or central focus inviting the patients to interact in the same fashion as the other hearths. On the contrary, it stands as a representation of the regulations and control of the hospital as a system permitting the patients to touch the bulk trolley or the food themselves due to contamination risks, but it also stands a representation of the dependability on service and help from the staff to be able to eat and drink. So if any social gathering point or sense of communal forum were to occur during mealtimes, it would in my point of view, have to be a result of random coincidences or casual meetings happening on the effort and initiative of the patients and staff, rather than a fundamental design motive incorporated in the hospital design.

Furthermore, in continuation hereof, it is my claim that the dressing of the flooring, walling and roofing enclosing the meal-scenery are, like the rest of the ward and the entire hospital, dominated by white or greyish colors, industrialized materials like steel, gypsum and lino, technical installations and what could seem as very sparse attempts of indicating any sense of cultural or spiritual affiliation. Despite the decorative attempts of adding different colors and art-pieces to selected walls. Clearly, the underlying architectural intention is instead an optimization of space, ordered to facilitate the rhythm and demands of the hospital treatments and the procedures by its staff relative hereto. This can be seen from the obvious distribution of space in the hallway, allowing for clear passage as well as quick and efficient transport of patient beds or the hasty movements of medical personal in case of emergency. I cannot claim that there is no dressing, because, as mentioned in the previous chapter, there always is. But I could claim that the interior architectural quality and specific architectural theatricality of the present dressing is not centralized and articulated around the focus of mealtimes. Instead, the architectural theatricality rooted in the present dressing of the 
Fig. 9.2

"Patient Eating Environment"

The Department of Infectious

Diseases, part of project MORE

at Aalborg Hospital (photos by

author).
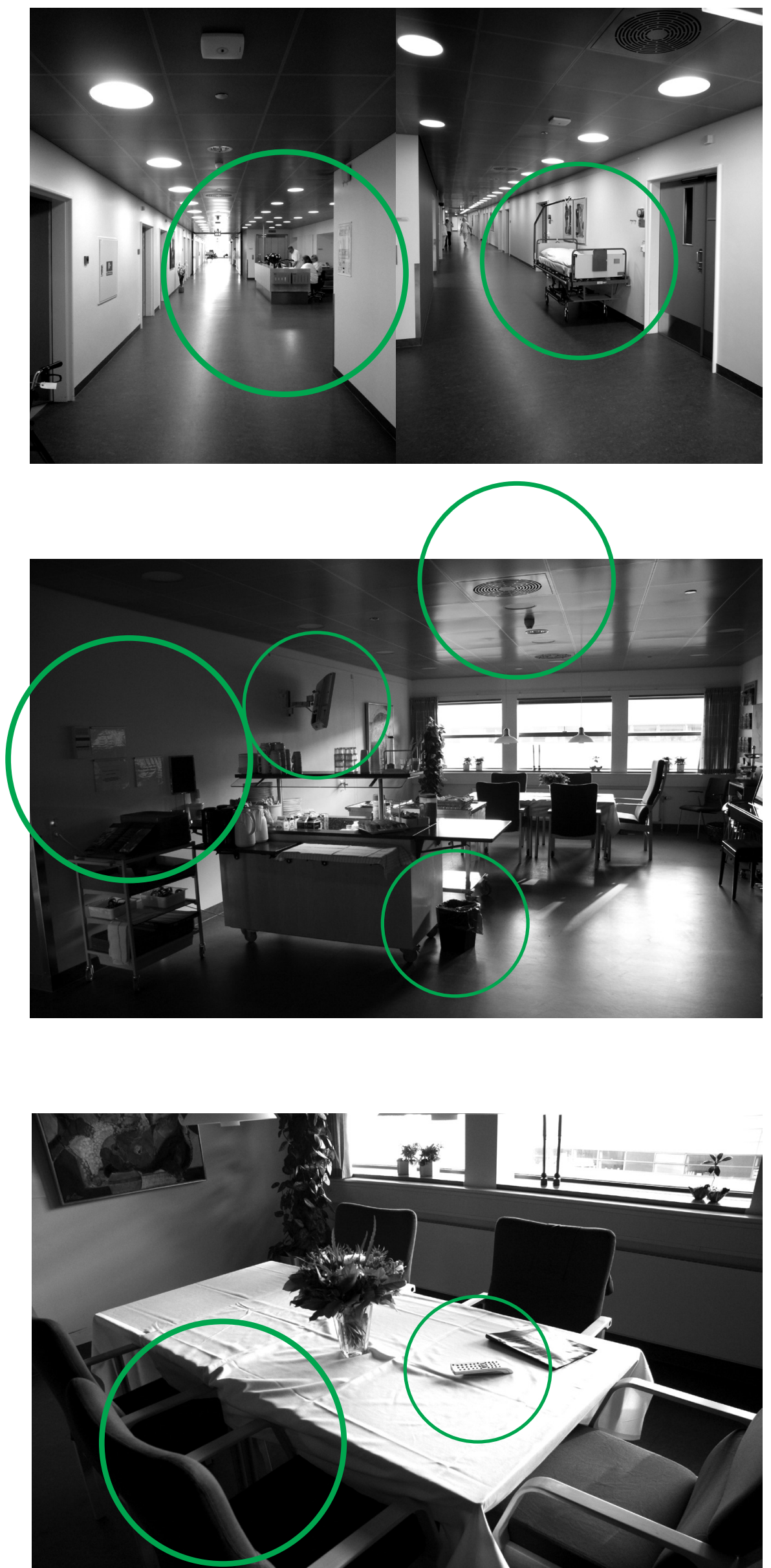

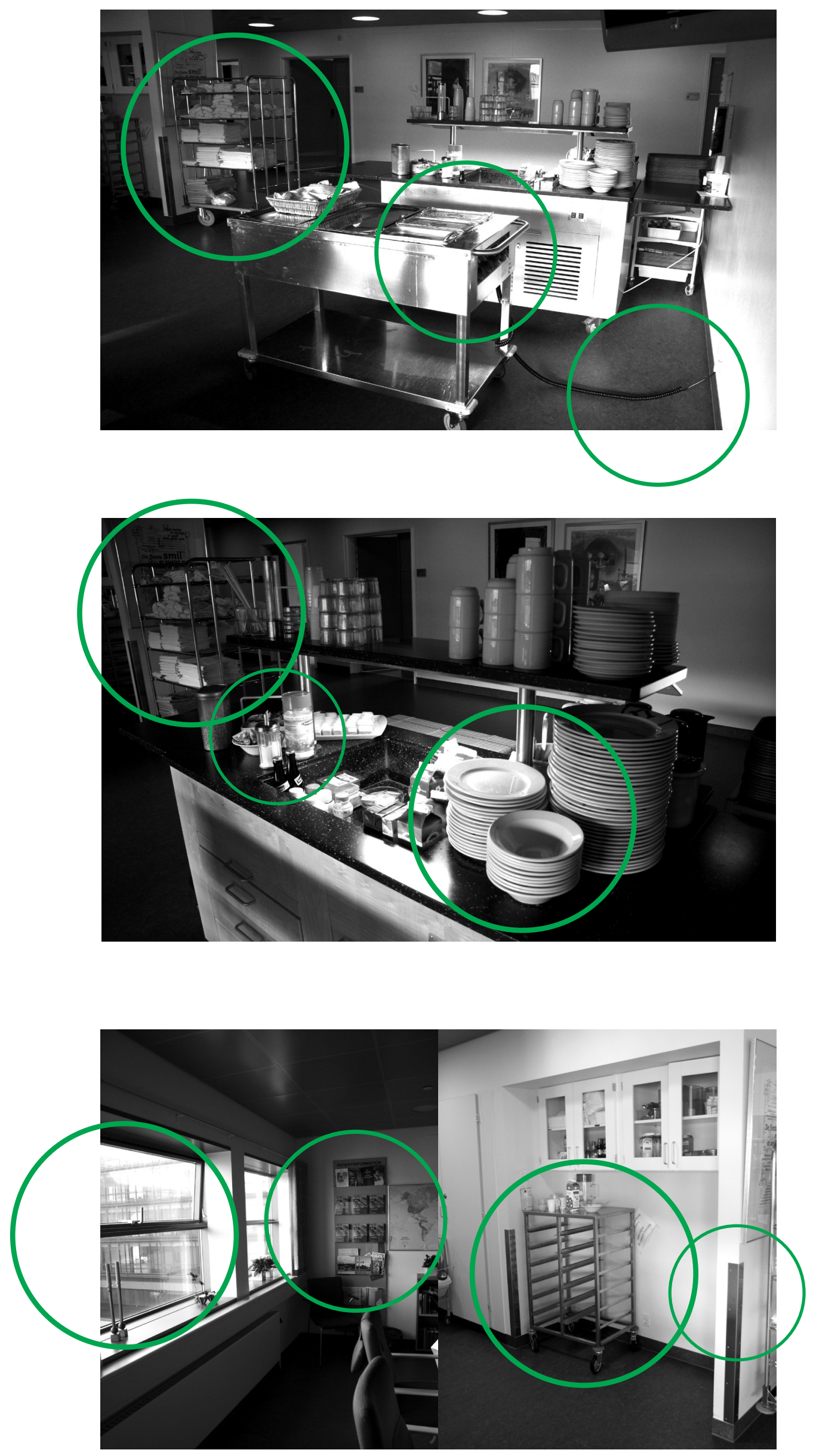
enclosure of the ward is optimized and articulated for the rational, functional, logistic, technical and hygienic procedures and activities of the 'Modern Hospital', striped down to the minimal requirements of interior decorations and furniture. So, despite the staff's deliberate efforts during mealtimes to "add" an architectural theatricality by use of white table cloths, napkins, candles, flowers and small decorative artifacts, I find on the background of the above that the overall meal-scenery is dominated by the overall hospital-scenery and the dressing of the hospital-enclosure with the white-greyish walls, ceilings and floor, as well as the standardized hospital furniture; armchairs, small coffee tables, the bulk trolley and tableware specially manufactured for these kinds of public institutions [Tvedebrink et al. 2012:9-10]. When I compare the contemporary dressing of the enclosure of the Department of Infectious Diseases with the fundamental principles describing the interior architectural quality as put forth with my interpretation of Semper's theory, it is therefore my claim that the contemporary patient eating environment has not been staged for a meal situation. The interior architectural qualities and architectural theatricality that potentially could signify the meal as a scene fostering a communal forum and social gathering point, as we for instance saw it with the examples highlighted in the Timeline and Historical Review, are missing - or are overruled by the overall scenery of the hospital. So, again, as argued for in the above, if any sense of a communal forum were to occur during patient mealtimes, it would, in my point of view, have to be a result of random coincidences rather than a fundamental design motive intentionally incorporated in the hospital design.

With the moral of the Gastronomic Analogy in mind, I would argue that it is, therefore, the equivalent of what culinary theory would call "mere nutrition". In the specific case of project MORE, it is my claim that the hospital-scenery and meal-scenery currently work as two oppositions or contradictions, with the patient eating environment appearing in a "sub-optimal" form. In that way it seems, in my opinion, like the specific facilities for eating and social gathering have been given low priority in this hospital ward. No architectural attention has been put to the careful design of the ward to establish a scene for eating. They simply lack to establish the scenery that supports the social, spiritual and cultural qualities associated with the significant values of a meal as argued for in the above [Tvedebrink et al. 2012:10].

If I evaluate the interior architectural quality of the hospital with the narrow focus of patient eating environments in mind, maybe that is the problem? Maybe the problem is that the contradictions and tensions between the hospital-scenery and meal-scenery occur because no special attention is paid to the eating environment in hospital design? As I have argued throughout the previous chapters, both with the Literature Review, Historical Review and particularly the Gastronomic Analogy as well as the 'polemical theory' of Semper strong indications exist, throughout history, suggesting that the particular dressing of the surfaces and of the interior architecture as a unified scenery is possibly very important for how we experience and perceive a meal. And several researchers suggest that the communicative significance rooted in the interior architecture of eating environments is important for our food choices and food intake, as well as our general health and well-being. The question is, therefore, how we can turn these contradictions of the hospital interior architecture? How can we make the meal-scenery respond to the social, cultural and spiritual rituals of the patient mealtimes while simultaneously still respond to the strict, contradictory hygienic needs and technical demands of the treatment procedures and safety relating to the hospital-scenery?

Indications from the chapters, 'Positive Theory' and 'Normative Theory' as well as the polemical theoretical perspectives developed with Semper, suggest that a potentially "optimal form" would be to articulate the architectural theatricality by an inclusion of a communal forum establishing a sense of a hearth, and doing so by refining and articulating the dressing of the enclosure, the surfaces of the flooring, walling and roofing enclosing the social, cultural and spiritual values related to the hearth-of-themeal. Following this idea developed on the background of Semper's theory, it makes no sense to try and re-introduce the fireplace as an interior element in the hospital ward to foster social events around eating and motivate dining room architecture. Today, the primordial significance of the fireplace as hearth, sacred altar, and cooking utensil has been taken over by various other means. Time has provided us with the knowledge to invent devices for heating, electric lighting, and for cooking. So, the fundamental needs 
of the fireplace are replaced by technical devices, often built into different rooms not being physically or epistemologically connected any more. The fireplace has lost its significance as communal forum and as hearth [Tvedebrink et al. 2012:10]. Instead, it is my claim that, we must find out what constitutes the significance of the hearth in the patient meal-scenery today, and do so by analyzing the intrinsic and extrinsic contexts of the patient mealtimes: the site, place, surroundings, time, knowledge, technologies, materials, rituals, social, spiritual and cultural tendencies of eating and having a meal in the hospital [Tvedebrink et al. 2012:10].

As indicated from the study performed by Holm \& Jacobsen (1990) and the example of VEJLE, today the dinner table is seemingly a significant interior element in the staging of a communal forum during mealtimes. The scene of the dinner table offers a unique possibility at a hospital for gathering patients around and fostering a situation of relaxation and a sense of community. This can be achieved either in "public", encouraging patients able to move to eat together in the ward or in some of the larger canteen areas. But it can perhaps also be achieved in "private", offering the bedridden patients who are not able to move around the opportunity to eat with relatives or others in the patient room in a closer proximity to the bed. During mealtime, the patients have time to talk and interact without necessarily having to think about or being reminded about the downsides of being hospitalized. The dinner table thus maybe has the potential of becoming the 'communal forum' or hearth that creates a moment of spare time and enjoyment in the everyday of being hospitalized?

In the specific case of the Department of Infectious Diseases, it could perhaps be achieved by articulating the dressing of the flooring, walling and roofing, enclosing the dinner table so it stands out from the rest of the hospital interior, whether it is in the patient room, common area in the ward or the canteen area located in-between the two departments. Perhaps we do not need to establish a separate eating environment, perhaps just a distinct type of dressing through specific use in materials, technique, form and style would be enough?

For instance, as I presented in the Introduction with the example of VEJLE, the designer Kerstin Egelund used a series of hanging wall curtains in different textures and colors decorated with patterns of leaves to cover the standard hospital-scenery, as well as enclose and dress the patient eating environment, thereby physically and mentally separating and districting the meal-scenery from the other hospital-scenery. I could easily imagine how, if the future hospital architects were encouraged to engage in such detail interior designs that the hanging curtains could transform and evolve into many different solutions. Because, there are many different ways of enclosing and dressing the scenery of a meal, as well as there are potentially many different kinds of hearthsof-the-meal. I find that it does not necessarily need to be the dinner table that is the hearth-of-the-meal, and it does not need to be curtains that constitute the dressing. In the contemporary 'Nordic restaurants' that I presented in the Timeline and Historical Review, the kitchen areas were the hearth, and the dressing was articulated in the materiality of the food and the materials used during servings. As many patients, furthermore, are forced to stay in bed due to their illnesses during mealtimes, the hearth-of-the-meal in hospitals could perhaps be the bed table, the serving tray or even the plate?

My overall point with this sub-conclusion is that this is exactly the idea with Semper's four basic motives. They are fundamental and general principles. The detailed discussion of what constitutes the hearth and how the specific architectural theatricality of the enclosure and dressing are articulated and should be designed is still up to the individual architect's interpretations of the given assignment and contemporary context. 


\section{THE FUTURE SUPER HOSPITALS \\ Discussing the relevance of the concept of Architectural Theatricality}

In light of the previously-mentioned contemporary tendencies where both hospital staffs and contemporary high-end restaurants increasingly engage in detailed orchestrations of meal experiences - intentionally altering the scenery of the eating environment, the quality of the food served and even the manners in which the food is served - I find that my concept of architectural theatricality and the four basic principles as an underlying theme for patient eating environments present a great opportunity for a grand "reconciliation" and synthesis of knowledge areas like health, food and architecture. But also offers valuable insight into a less debated, but important, topic of patient undernutrition in the planning and design of the future Danish super hospitals.

However, as mentioned in the Introduction, hospitals are adaptive and responsive sites and places that embody the interactions of a wide range of persons, artifacts and activities. Hospital design is, therefore, a very complex assignment that includes many different stakeholders with various political, medical, economic, social, human and aesthetical ideals to be incorporated. Relative hereto, previously-mentioned Danish partner in Henning Larsen Architects A/S and leading architect in the proposal for the new Herlev Hospital, Lars Steffensen, even refers to the complexity of hospital architecture as a "Gordian Knot" (Blankholm 2011). Despite my intensions of improving healthcare through the great opportunity for synthesizing health, food and architecture, as noted at the webpage of the Danish Herlev Hospital (2013), hospital design must first and foremost prioritize patient safety and treatment. Herlev Hospital, therefore, find that in some cases this main ideal of patient safety and treatment work against the ideals of patient-centeredness and the desires for creating more "home-like" or "hotel-like" environments, because these types of environments often create poor working conditions for the staff, but also because they complicate hygienic control and other logistic challenges (Herlev Hospital 2013). According to researchers from Danish Building Research Institute Anne Kathrine Frandsen, Stefan Christoffer Gottleib and Chris Harty (2012: 1069), making a design proposal for a hospital is, to some extent, a compromise or a negotiation between various interests and experiences of multiple stakeholders which have to be juxtaposed and balanced through the process of design. But, the point made by the Herlev Hospital, is that hospital planners are often "forced" to prioritize among opposing and contradictory design principles, and what happen in practice is that the necessary prioritization rules in favor of production management and work environmental considerations, consequently undermining the ideals of the patient-centeredness (Herlev Hospital 2013). And therefore, initiatives like in my proposal are often deprioritized. Relative hereto, Steffensen does not see the current design principles of Healing Architecture and Evidence-based Design as final solutions to be applied - that would be impossible or at least very expensive and therefore unrealistic because of the extremely strict financial governmental regulation (Blankholm, 2011). So, the question is whether or not such a narrow perspective as my interior architectural qualities on patient eating environments is acceptable and relevant in the greater picture of the contemporary need for sufficient and flexible super hospitals?

With the risk of misinterpreting contemporary debates, my major concern is that today there is an increasing amount of fingers pointing from parts of the academic world, accusing the tendencies in the 'New Nordic Kitchen' with some of the most celebrated chefs and restaurants of enrolling a kind of totalitarian regime in their aesthetic approach to food, health and well-being (see e.g. Søndergaard 2012; Talberg 2010; DR P1 2013). The underlying claim is that, in the elaborate attempt to improve meals and eating experiences not only in restaurants but also in schools, kindergartens, workplaces and domestic kitchens, the ideals of the 'New Nordic Kitchen' are so luxurious, delicate and spectacular that they come very close to outliving the same tendencies of 'total design' reserved for "the few", as I presented in the previous with some of the architectural utopian ideals defining the emergence of 'modernity' at the turn of the $20^{\text {th }}$ century. Here, as mentioned in the Introduction, architects like A.W.N. Pugin believed they could change not only the health and well-being of individuals through design but entire societies. The world famous architect Le Corbusier (1887- 
1965) even went as far as to claim that "architecture holds the key to everything" (Whyte 2004:47). This statement would later, according to Professor of Architectural History Ian Boyd Whyte (2004:47), become a perfect coining of the "hubris" partly defining 'modernity' in architecture, because if architecture holds the key to everything, as stated by Le Corbusier, then the architect is quite powerful and faces an enormous responsibility when he engages in public affairs. History indicates these "dark sides" of the Gesamtkunstwerk quite clearly with the developments of different dictatorships during the 1920s and 1930s in Russia, Germany and Italy where an inseparable link was established between monumental neo-classic architecture, stylistic conservatism and totalitarianism (see e.g. Whyte 2004:48). In the words of Whyte (2004:49), the idea of the Gesamtkunstwerk was thus: "a holistic ideal that ultimately worked against the good of mankind".

My point with the comparison of the statement put forth by Le Corbusier and the 'total design' of the 'New Nordic Kitchen' is that when I, inspired by the theories of Semper, argue for an architectural theatricality articulating the scenery of patient eating environments, I inevitably engage in a similar understanding of the meal as a piece of 'total design'. Nevertheless, because a meal is not only about the architectural theatricality of the scenery staging it, but most importantly, also, a piece of "design" physically being consumed and digested - because you are actually meant to eat the food served - it borders on being the ultimate Gesamtkunstwerk. Therefore, the crucial questions are: where does hospital design stop? How much can the architectural theatricality ideally staging a meal-scenery be allowed to suppress the overall hospital-scenery? How relevant is my research topic in practice? Should the stakeholders, architects and designers incorporate the idea of a distinct architectural scenery staging the patient eating environment in the future hospital planning, or should the topic remain a deprioritized logistic challenge?

\section{The staging of a meal as part of the need for treatment}

In a recently published article, the previously-mentioned American psychiatrist and anthropologist Elizabeth Bromley (2012:1057-58), in line with my above concerns, criticizes modern trends in hospital design of being too influenced by consumerism, hospitality, and business-oriented perspectives on patient-centeredness. Her claim is that the focus on hospitality related concerns for the patients' individual needs, desires, and preferences challenge the role of the hospital staff and the healthcare treatments. Apparently, the problem is that instead of using the patient-centeredness to involve patients more in decision-makings and supporting staff-patient relationships, the result is often instead that healthcare treatments become service products and the staff service providers that must satisfy the patients' personal and individual desires at any cost rather than being a community service (Bromley 2012:1057-59). Bromley (2012) finds that particularly hospitals in the United States, but also in the United Kingdom and increasingly in European countries, are transformed into "5-star hotel-like" environments in the aim of improving patient comfort, cleanliness, and safety by increased infection control. Here hospital wards are designed with singlebedded patient rooms incorporating "living room-style" furniture, private bathrooms, television, radio, wireless internet, space for family members, room service-meals served by meal "ambassadors" and even an emphasis on non-medical services like welcoming coffee, extra pillows or altering staff "uniforms" and "attitudes" to address patients with courtesy and in a polite "hostess way"(Bromley 2012:1057, 1061-63). According to Bromley (2012:1061), the nature of the hospital food service changed dramatically with the new room service meals, because the patients' meals were no longer about managing dietary rules, but rather about attending to patients' individual likes and dislikes. This coins my main problem quite precisely, which Bromley (2012:1057-59) argues is that this transformation in environments increasingly distances the patients from the realities of medical care, and in the most extreme cases turns the patients into consumers and a kind of "healthcare tourists".

\section{The risk of consumerism in hospital hospitality}

As can be seen from the above outline of Bromley's arguments, the concept of patientcenteredness, and herein hospitality in hospitals has been subject to compelling critiques and concerns about the influence of consumerism on healthcare and overemphasis put on the orchestration and 'total design' of the overall patient eating 
experience, instead of the specific healthcare treatments. Bromley (2012:1058-59), however, is not only against hospitality in hospitals. She argues that today opinions arguing both for and against patient-centeredness exist, as well as emphasize that it is a subject that is still heavily debated among medical anthropologists and sociologists. One of the more interesting positions presented in her article is that, in this debate, some critics even go as far as compare hospitals with Disneyland theme parks arguing that the 'space' of the hospital is divided into "front stage" areas focusing on the patients having a good experience, and "backstage" areas where all the "hospital business" goes on in order to create the good patient experience (Bromley 2012:1060). Rather surprisingly, Bromley (2012:1060), inspired by senior-level hospital executive Fred Less (2004), emphasizes that the comparison between Disneyland theme parks and hospital architecture is not necessarily a trivializing and bad theatrical comparison. Instead, she finds that the theatrical metaphor adopted from Disneyland reflects serious design intents (Bromley 2012:1060). Bromley (2012:1060) advocates that the ability of the theme parks layout or design to generate a seamless fantasy world "hiding" visitors from machinery, infrastructure and human action is what makes the park function. And she notes how these basic theatrical principles of concealing, from the public, the techniques that constitute the work that produces or defines the setting are increasingly important in healthcare design (Bromley 2012:1060).

In hospital design this can be applied to the careful positioning of central elements such as elevators, entrances, exits, treatment rooms, medical equipment and supplies as well as concealing the work of the hospital "system" from patients and visitors - for instance by locating staff, medical chores, interpersonal aspects of care and technical materials "backstage" behind unmarked doors (Bromley, 2012:1060). In that way, the "front stage" areas are kept as the patient rooms and common rooms free of medical supplies and treatment related equipment as much as possible (Bromley 2012:1060). As was seen in the first chapter with the introduction of Healing Architecture, the idea behind such initiatives is presumably part of the general hypothesis that the stereotype of a sterile, unfriendly and cold atmosphere often associated with modern hospital environments is not really the optimal place for healing. Instead, hospital architects devoted the aspects of Healing Architecture, like the previouslymentioned Danish architects Lars Steffensen, Tom Danielsen and Lars Thiis, often strive for a more warm, inviting and comforting environment, preventing the patients from feeling hospitalized (Bromley 2012:1061). The conclusion made by Bromley (2012:1058,1062) is that the answer to the above critique of hospitality in hospitals as such largely depends on how and for what underlying reasons patient-centeredness is interpreted and implemented in the specific contexts, and on the moral, social and ethical reasons governing the approach to hospitality and as part hereof the influences of managerialism and consumerism on healthcare.

Relative hereto, I, first of all, find that it is quite curious that Bromley (2012) is seemingly positive about the theatrical metaphor applied to hospital architecture. However, I also find that Bromley's "Disneyfication", with the above-mentioned morals, ethics, and social reasons for engaging in the theatrical approach, is coined much better with the theatrical analogy and notion on architectural theatricality inspired by Semper's theory. Personally, I prefer to use the notion: architectural theatricality, as a more subtle, humanistic and less consumer-oriented analogy, not necessarily inviting for "frontstage" and "backstage" areas in hospital design, but still encompassing the fundamental motives of intentionally staging a unified architectural scenery aiming for certain experiences by paying close attention to the careful dressing articulated by the detailing, materiality and idea guiding the design of the hospital and particular the enclosure of the patient eating environment.

As seen from the above short outline of the contemporary debate on Danish hospital architecture presented in the Introduction in chapter 2, not only architects but to great extent also other stakeholders like regional politicians and decision-makers in charge of the hospital building projects draw on the research-based knowledge and design principles published with Evidence-based Design and Healing Architecture. As noted by Blankholm (2011), it could seem like the term 'Healing Architecture' has, in some cases, almost become a mantra used again and again to ensure some kind of architectural quality in the hospitals. The focus on Healing Architecture has undoubtedly helped put a focus on the overlooked importance of architectural quality in hospital design, as well as encouraged a greater awareness on the importance 
of interior architectural qualities supporting human needs. Thereby, some very important steps have been taken both on a political level as well as in the minds of staff, patients, architects and researchers. Nonetheless, I find that strikingly few of the many briefs and proposals on future Danish super hospitals elaborate on the interior architectural qualities of the different inpatient wards or patient rooms, despite this knowledge and the focus on patient-centeredness emphasized by the Danish practicing architects Tom Danielsen and Lars Steffensen in the above. As mentioned in the Introduction based on a review of this material, I find that the focus is primarily put on the large-scale facilities of the hospital architecture - the exterior views and the interiors of public hallways related to entrances and central waiting areas. In that way, I find that the communication of the future super hospitals overlooks the human scale and patient-centeredness so heavily debated. This is especially regarding the mealtimes and the different categories of patient eating environments.

Therefore, I cannot but help wonder if this should be changed? If we should strive for a synthesis of knowledge so that a design approach encouraging the different ward designs was given larger priority?

Relative hereto, as mentioned in the chapters, Research Approach and 'Polemical Theory', one of architectural theoretician Alberto Pérez-Gómez's major claims is that 'Modern Science' has forced architectural thinking and practice into a "crisis", ignoring the essential continuity existing between thought and action, between mind and body. What Pérez-Gómez referred to as the "crisis" was that both theory and practice were reduced to a system of rational prescriptive "rules" like for instance the guidelines of Evidence-Based Design, which I find are examples of this kind of thinking with precise technical prescriptive "rules". As outlined with the Introduction and argued in Olsen [2010:109-110], within parts of the academic world, arguments exist against the use and implementation of evidence-based knowledge strictly obtained from experimental studies utilizing quantitative research methods like the above performed within Evidence-Based Design. This is primarily because the Evidence-Based Design researchers performing studies on different effects of the built environment on patient healing processes draw on quantitative research methods to collect empirical data on different environmental variables studied [Olsen, 2010:109]. Furthermore, despite the radical developments in Neuroscience, increasing insights in the links of mind and body, and the influences of the environments on our immune system, the characteristics of most of the studies investigating eating or healthcare environments are based on research strategies employing traditional quantitative or qualitative tactics developed within the natural and social sciences, also when investigating dimensions relating to the interior architectural qualities. In my point of view, experimental studies on influences of the built environment, both within Evidence-Based Design and research on nutrition and food, often hold the implicit assumption in their quantitative research methods that as long as the spatial settings of each experiment are kept stable, the appearance of physical space is not a disturbing variable [Olsen, 2010:110]. But, considering the architecture of the eating environment as a "single collective variable" strongly interferes with the complex understanding of the interior architectural qualities, as seen with my interpretation of Semper's theory, from an architectural theoretical point of view.

My critique of the existing hospital design practice, research strategies and quantitative or qualitative research tactics is that they often fail to incorporate the holistic and integrated perspective presented with the above hypothesis and theoretical framework in their focus on Evidence-Based Design. In my opinion, contemporary research often fail methodologically to incorporate the ability to 'describe' and 'explain' the architectural context not just as a material object, but as a unified scenery communicating the poetics and magic rooted in the cultural, spiritual and social norms and values staging human action and interaction. There are of course valuable and very good intentions behind Evidence-Based Design. However, my point is that if these "rules" are used as primary design principles in practice, overruling any further aesthetic attempts, then the architecture has been reduced to a series of building blocks, as architectural thinkers like Pérez-Gómez were accusing the geometrical systems of the Ecole des Beaux-Arts of being. Maybe some would argue that this is a situation that is more evident in North American architectural domains, as Scandinavian architectural practice seems to be aware of the more poetic and human-centered dimensions of architecture. However, as seen from the Introduction, 
contemporary Danish architectural practice is in my opinion being challenged by a political demand for research-based knowledge which is indirectly - or even directly demanding Evidence-based methodologies in the new hospital design proposals. What is seemingly happening is that the "crisis" governing North American architectural thinking is currently being applied to a Danish context.

Without considering both the historical and the contextual implications, this "crisis" can, in my opinion, have fatal consequences for the interior architectural quality of hospitals - if we are not careful in how this research-based knowledge is created and implemented. In the specific case of patient eating environments, I suspect that the "building standards", the general legislation of handling foods and food servings in public, and the hygiene standards of a hospital, as well as the economic and political context are so complex that it does not leave "room" for much poetry, magic and aesthetic interpretation in small domains as eating. As seen in the Introduction, food, food service and eating environments are today treated as "logistic" functions both in the design briefs as well as in the design proposals. The eating environment seemingly only exists at the level of "necessity" - it is mere nutrition, not an integrated element in the overall hospital treatment and strategy for creating "healing environments". To overcome this kind of thinking in future hospital design practice, I think we, first of all, should reconsider what the terms used in the judging criteria and design briefs are when 'describing', 'explaining' and 'predicting' the interior architectural qualities of future hospital design. Maybe we should not only use terms as 'nature view' and 'art', but encourage an integrated design solution which also considers patient eating environments and the social, cultural and spiritual perspectives these sceneries offer. For instance by encouraging a focus on the architectural theatricality rooted in the unified scenery established by terms such as the four motives: hearth, enclosure, dressing and context.

\section{SUB-CONCLUSION ON PATIENT EATING ENVIRONMENTS}

What is significant about Semper's theory, in my opinion, and the reason why I have investigated his writings is how he tried to avoid this above-mentioned formal level, avoided prescribing "rules" for how to design, but instead engaged in motives for why to design. Then the "how to design" is still left open for creative interpretation by the individual architect, securing that the architecture can develop in time and adapt to new contexts, new technologies, new materials, new user groups, new functions, new traditions, new cultures, new rituals and new social orders. I find that the other systems, like parts of the Evidence-Based Design methods, despite their good intentions, are less capable of providing this "freedom" of creative interpretation. It is, therefore, my claim that we should consider using terms in style with Semper in the future, working on a meta-level not prescribing "rules" relating to formal elements and a certain style. But instead use motives for the design of an interior architecture, growing from the "inside-out" based on the awareness of the hearth, enclosure, dressing and an analysis of the context with the intrinsic social, cultural and spiritual norms and values inherited herein. I understand this kind of task is like walking on the edge of a knife. There is a fine balance and a thin line to be followed, and I will not claim that I on the background of my research on the interior architectural qualities of patient eating environments have the final answer for how to handle this in the future. My research, alone, cannot solve the problem of patient undernutrition and contemporary challenges on hospital design. Still, on the background of my investigations presented throughout the previous chapters, I have to conclude that something very important is at stake.

Historically, the management of patient food service has been the responsibility of the nurses. But as seen in the examples of MORE and VEJLE, that responsibility is being challenged today. In both MORE and VEJLE an integration of workforce activities and knowledge from a group of doctors, nurses, diet technicians, nutrition care assistants, kitchen staff, designers and even a "food event" company have been coordinated with the argument that patient nutrition and managing patient food service is a multidisciplinary responsibility as well as an integral and central element of patient treatment and care. The food service is, therefore, no longer the individual responsibility of the nurses, but a joint collaboration reaching far beyond the daily challenges of cooking and serving the food. This type of collaboration reaches all the 
way into the planning and design of the hospital architecture and the furnishing of patient eating environments. Thereby, this type of collaboration synthesizes researchbased knowledge with practice-based knowledge, synthesizes health, food and architecture, and most importantly integrates disciplines from the sciences with the arts. However, this type of collaboration represents not only an experimental and novel perspective on hospital treatment, but it also outlines a general knowledge gap on the effects of synthesizing health, food and architecture, which raises more questions than my research can answer. Therefore, I must conclude that we need more research and practice engaging in the understanding of how health, food and architecture is linked, and how the interior architectural qualities of eating environments influence patient food intake, health and well-being. So we do not risk losing our chance of improving hospital architecture, instead of repeating the "crisis" of the early $20^{\text {th }}$ century.

Based on that sub-conclusion, my recommendation for the future super hospitals would, therefore, be to include a focus on, first of all, patient eating environments but also on the specific four design principles, outlined with inspiration in Semper's theory, in the criteria for hospital ward layouts. But, I would also, based on my investigations relating to the two analogies of gastronomy and theatre and their holistic morale, encourage a synthesis of positive, normative and polemical knowledge across domains of health, food and architecture during the contextual analysis and design process of planning the eating environments. For instance by joining workforces from the different disciplines, much more than is the case today. So, in that way the practicing architects are provided with the best possible theoretical and practical knowledge for the future hospital designs.

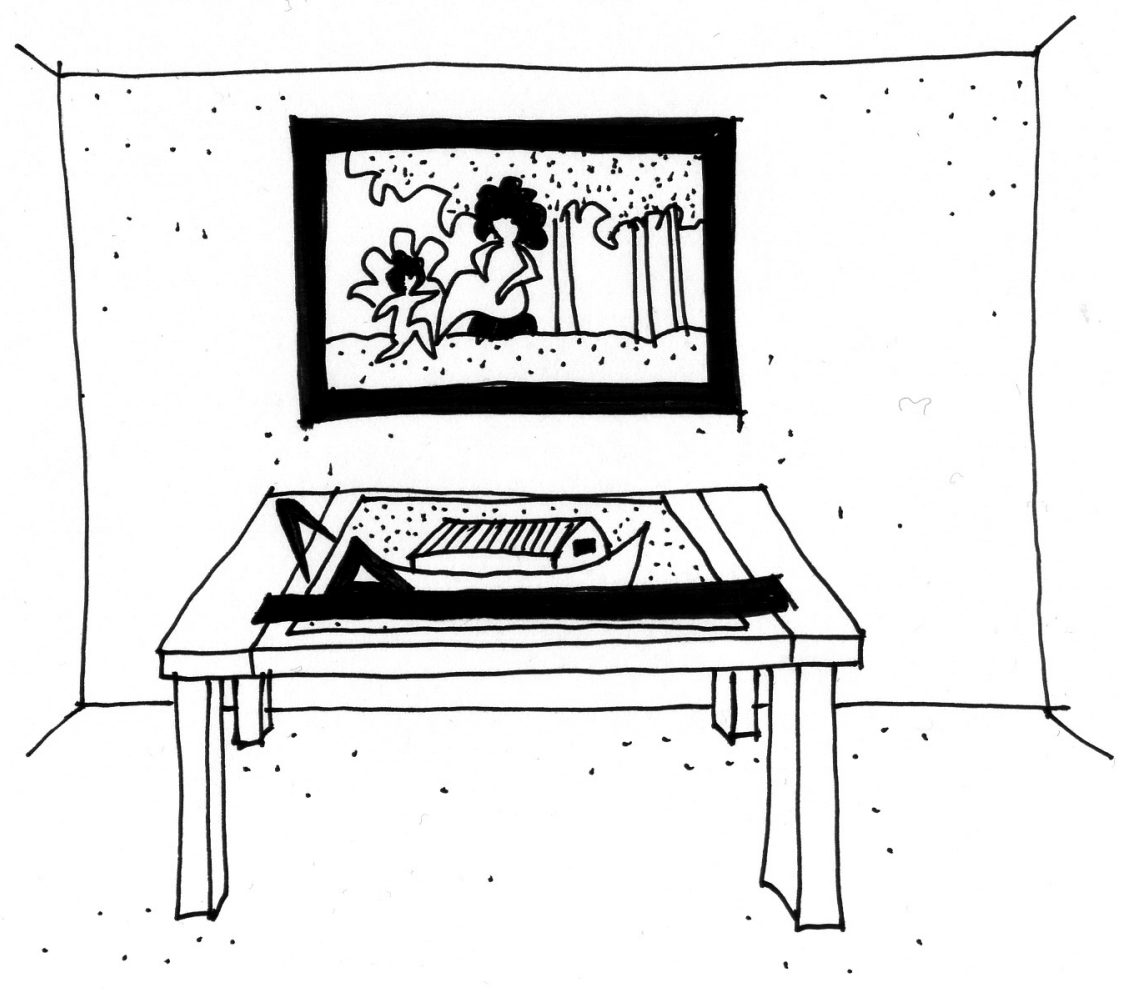

Fig. 9.3

"The Architect's Table" Perhaps in the future we should encourage a synthesis of positive, normative and polemical knowledge across domains of health, food and architecture during the design process of planning the hospital eating environments. (Drawing adopted from Frascari 2011:126) 


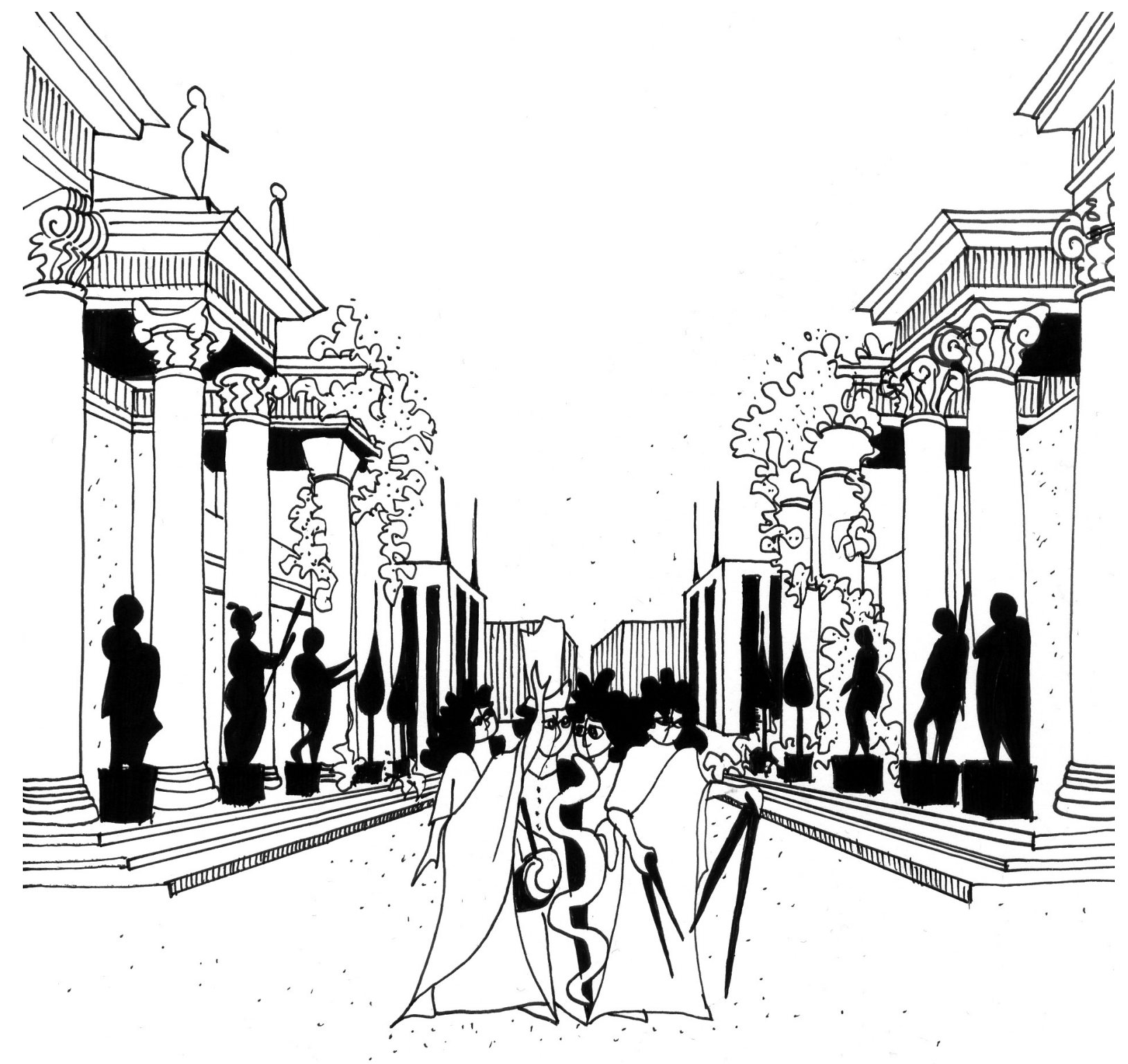

Fig. 10.1

"Architectural Theatricality" Future perspectives 


\title{
10
}

\section{REFLECTIONS \& PERSPECTIVES}

\author{
THE RELEVANCE OF MY RESEARCH
}

There are many ways of both writing and performing a $\mathrm{PhD}$ thesis. During the last four years, I have often been reminded that a PhD project is both about the research education, the specific task of building scientific knowledge as well as, most importantly, the kind of knowledge I as a researcher contribute with to increase the general body of knowledge within the specific research area and research topic approached.

My research area was, first of all, motivated by the personal curiosity and wonder about the relationship between food and architecture. This curiosity and wonder was sparked by an introduction to the Gastronomic Analogy put forth by James Fergusson in 1862. Still, the specific research topic was motivated with the specific examples of the project MORE and VEJLE and the present initiatives to overcome patient undernutrition by means of synthesizing health, food and architecture into a refurbishing of the patient eating environments. This contemporary and practical example indicated that perhaps my curiosity and wonder about the relationship between food and architecture was relevant not only for "the few", but for the common health and well-being of "the many" in public institutions such as hospitals.

Particularly because Denmark during the next 10 to 15 years is building a series of brand new 'super hospitals' in several different regions all over the country. Relative hereto, the present focus on how to improve and optimize not only future patient healthcare but particularly also the future hospital designs has sparked an increased focus in architectural practice on the research-based knowledge produced with the two architectural sub-disciplines Evidence-Based Design and Healing Architecture. The relevant problem and core of my research topic is that the contemporary research performed within Evidence-Based Design and Healing Architecture does seemingly not focus on patient eating environments. There is a knowledge gap in contemporary research, and I find that there is a high risk of missing the synthesized perspective of health, food and architecture in future hospital design. Furthermore, as argued for throughout the thesis, today no theoretical framework exists that defines the basic principles for how to investigate the impact of the architectural scenery on patient health and well-being, without compromising the normative and polemical knowledge rooted in the more hermeneutic-interpretative ways of architectural reasoning. Hence, there is also a knowledge gap in contemporary research methods.

My overall goal with this $\mathrm{PhD}$ thesis has, therefore, been to widen existing architectural theoretical perspectives on hospital design and to increase the underlying methodological knowledge supporting future hospital design practice, by contributing with a research-based development of a theoretical framework that defines the interior architectural qualities of patient eating environments. I did this with the overall aim of bridging the contemporary theoretical and methodological knowledge gaps relating to Evidence-Based Design and Healing Architecture, but 
also to demonstrate that contemporary tendencies in the practice of hospital design are about to forget - or at least overlook - the importance and effect of synthesizing health, food and architecture.

On that basis and with great personal inspiration in the theatrical analogy, I developed the hypothesis that patients' food intake, health and well-being are influenced by the staging of meal experiences with the interior architecture framing the entire scenery of the eating environment. Aalborg hospital and the specific example of project MORE, thereby, became both my 'context of discovery' and 'context of justification', and the objective and research purpose of this $\mathrm{PhD}$ thesis became to investigate if a research-based body of knowledge existed which supported my hypothesis that the interior architectural qualities of eating environments influences food intake, health and well-being of patients. And on that basis, investigate if it was possible to outline a set of basic design principles which in the future could potentially be used by professional practices to help 'predict' the interior architectural qualities of patient eating environments.

Because this PhD thesis thus positioned itself in the intersection of health, food and architecture, I was faced with the challenge of combining an obvious hermeneuticinterpretative understanding of human existence and behavior, where significance is ascribed to spaces and objects we encounter on behalf of our multi-sensuous bodily contact together with the perception of our inherited social, spiritual and cultural norms and values, with existing research disciplines such like nutrition, medicine, healthcare and Healing Architecture which strive for a more evidence-based approach. Thereby, I challenged the contemporary knowledge and methodology, as well as the prevailing hospital design practice, on their understanding of patient eating environments [Olsen, 2010:118]. The main ontological, epistemological and methodological importance for this thesis has, therefore, been the divergence from the positivist research tradition - that I find often dominate food science, nutritional science and health science - into a more naturalistic inquiry where the legitimacy and value of normative knowledge rooted in the built objects and especially polemical knowledge rooted in the architect's written intentions are recognized as valid ways to develop research-based knowledge [Olsen, 2010:118]. To overcome that methodological challenge, I engaged in an abductive research approach employing a hermeneutic-interpretative strategy and a series of theoretical research tactics like the Annotated Bibliography and Literature Review to investigate the existing 'positive theory' rooted in research, the Timeline and Historical Review to investigate the existing 'normative theory' rooted in objects, and finally the Gastronomic Analogy to investigate the 'polemical theory' rooted in intentions as means to investigate if I could find any knowledge supporting my hypothesis. But it was also to help answer the research questions and, thereby, outline a series of basic design principles 'predicting' the interior architectural qualities of patient eating environments.

With the Annotated Bibliography and Literature Review, I stated that sparse amounts of 'positive theory' which synthesize health, food and architecture in hospitals exist, despite a substantial body of research-based literature demonstrating the contextual importance and influence on human eating and meal behavior being available. It turned out that very little - if any - 'positive theory' existed which directly supported my hypothesis. Instead, a vast amount of fragmented indications and "clues" on the possible synthesis of food and health, health and architecture, as well as architecture and food was found. This was, for instance, in the research produced by food scientists Herbert Meiselman and Inga-Britt Gustafsson, as well as food sociologist Lotte Holm. Nevertheless, in all of these combinations, I found that a specific definition of the interior architectural quality was absent. So, instead of engaging in a series of empirical interdisciplinary investigations and interventions "testing" my hypothesis in practice, as initially expected. I was "pushed" into an explorative and eclectic research process theorizing on a more abstract and general level about the interior architectural quality of patient eating environments. Therefore, this thesis turned out being much more theoretical and disciplinary than initially intended.

The explorative research process is particularly evident in how my theoretical investigations, in continuation of the Annotated Bibliography and Integrative Literature Review through the Timeline, Historical Review and Gastronomic Analogy, were used in an eclectic manner to engage in the history of architecture and establish 
little "bits" and "pieces" of information together supporting the hypothesis and constructing an answer to my two research questions. The aim of the Timeline and Historical Review was to create a "knowledge map" which, in the same fashion as the Annotated Bibliography and Integrative Literature Review, provided me with a historical perspective on past and present 'normative theory' relating to patient eating environments. The "knowledge map" synthesized the normative knowledge rooted in the objects relating to health, food and architecture, but simultaneously also created an overview of the architectural 'polemical theory' and intentions of the key theoreticians influencing my theoretical framework and my epistemological perspective. These investigations revealed that throughout history the material objects relating to health, food and architecture alter. Therefore, there is not one ideal architectural style or object that defines the interior architectural qualities of patient eating environments. Still, in my point of view, a series of spectacular examples existed like the Roman Triclinium and Renaissance monastery Santa Maria Nouva as well as, most importantly, the first restaurants, health resorts and Nightingale ward of the $19^{\text {th }}$ century. They all synthesized aspects of health, food and architecture into a multi-sensuous, almost theatrical interior architectural scenery that not only framed extraordinary meal experiences, butalso staged social interrelations, personal comfort, enjoyment and well-being. These spectacular examples of the $19^{\text {th }}$ century, I found, are linked with the Roman Triclinium and Renaissance monastery in their adoration of the classical and ancient philosophies, and they share an underlying holistic and humancentered thinking that guided their specific theatrical interior architectural qualities. The result of the Timeline and Historical Review was, therefore, that I had to engage in an investigation of the underlying intentions and 'polemical theory' of the architecture stemming from that particular era in architectural history.

To do so, I chose to return to the writings of the architectural theoretician Peter Collins and his inclusion of the Gastronomic Analogy in 1965 when he attempted to describe the radical changes occurring in the ideals that define architectural quality and thinking, but also to guide the design principles of architectural practices between 1750 and 1950. Here, I found that the years 1750 to 1950, and particularly the era of the $19^{\text {th }}$ century, stand in architectural history as the culmination of the "quarrels" between "the ancient" and "the modern", as well as between the arts and the sciences. The importance of that "quarrel" has recently been re-addressed by acclaimed contemporary architectural theoreticians like Kenneth Frampton, Alberto Pérez-Gómez, Harry Francis Mallgrave and Marco Frascari. I thus used their writings to interpret Collins' writings and to unfold the significance of the more than 150 years old Gastronomic Analogy. I found that the lesson to be learned is that architectural thinking and practice is about balancing both science and art simultaneously. So, the point of the Gastronomic Analogy is, therefore, in my opinion, that architectural quality does not lie in the specific choice of a style or scientific evidence established, but should be found beyond that in the combination of the seemingly incompatible research and evidence-based knowledge of the sciences and more mystical and poetic knowledge of the arts.

My investigations and endeavors in the Gastronomic Analogy and particularly in the difficult balancing of the sciences and arts led me to a profound study of German architect Gottfried Semper's 'polemical theory'. Here, on the background of the books Style and The four Elements of Architecture, I outlined the concept of Architectural theatricality and a set of four basic design principles that use the notions 'hearth', 'enclosure,' 'dressing' and 'context' to 'predict' the interior architectural qualities of the patient eating environment. This concept and set of basic design principles were based on my interpretations of Semper's linking of the fundamental architectural qualities with the characteristics of a theatre and 'doubleness' of the mask.

What I have chosen to call Architectural Theatricality is thus based on the understanding that architecture bears a resemblance to the theatre and mask, because it is simultaneously a frame, background and stage as well as protective shelter, spatial enclosure and representative image. It is adoration, enhancement, decoration, and ornamentation as representation of mythological and poetic rites relating to the legacy of human culture intended to entertain, astonish, please and school the "spectator" - as well as refuge, shell, cover and skin intended to protect and create a sense of dwelling for the "inhabitant". The theatrical analogy thus suggests an architecture encompassing both a communicative semiotic and 
existential phenomenological significance together with the pragmatic function. It signifies a complex 'doubleness' that represents the mutual connection between twodimensional 'image' and three-dimensional 'space', as well as between the privacy and comfort of the 'shelter' that offers protection to the individual from the public society simultaneously as being a place of social interaction where the display and self-representation of the 'image' offering an exhibition of the 'self' in public. Together the 'image' and 'space' form an 'assemblage' of material objects which, through their embodied knowledge, craft, techniques and detailed multi-sensuous qualities, are able to seduce us, spark our imagination and move us beyond time and place, bridging the past and present. The elements of architecture, thereby, become material objects through which we experience, perceive, read, interpret, recognize, orientate, position, navigate, and move in space, as well as ultimately imagine, dream and predict our culture. In my interpretations of Semper's 'polemical theory', I concluded that part of the interior architectural quality lies in the constant revealing and concealing of the interplay between the 'private-self' and 'collective-self' and the complex combinations of carefully woven cultural, social and spiritual underlying intentions that guide the design of 'spaces' such as patient eating environments.

Semper's 'polemical theory' was not specifically aimed at patient eating environments. So, I did not find any specific architectural object or 'space' which defined the interior architectural qualities of patient eating environments or manifested my idea of Architectural Theatricality. Instead, I did find, however, a series of intentional motives in a polemical fashion describing architectural quality in general. Accordingly, what is clear from all of my investigations is that no single existing theory or research-based knowledge - neither positive, normative nor polemical - provides a complete answer to my two research questions. Consequently, a specific set of basic design principles that 'predict' the interior architectural quality of patient eating environments is almost impossible to establish on a 'scientific' research-based background. However, despite this, I find that it is in the synthesis of the many different "bits" and "pieces" that I can begin to construct an answer. Inspired by Semper's thinking, I outlined the concept of Architectural Theatricality, and through a return to the example of project MORE I suggested that the order and shape of the theatrical architectural scenery of a meal can be predicted with the four basic design principles: hearth, enclosure, dressing and context [Tvedebrink et al. 2012:11]. This resulted in a proposal which, I find, could relate not only to the specific function of patient eating environments and hospital design, but to healthcare architecture and eating environments in general.

Nonetheless, on the background of the above-mentioned theoretical investigations and particularly the Integrative Literature Review, the question occurred if the vague amount of research-based knowledge that exists on this topic of the interior architectural qualities of patient eating environments was simply a result of an absent need or desire for this kind of knowledge? Perhaps very limited knowledge relating to the subject in 'positive theory', 'normative theory' and 'polemical theory' exists, because it is an utopian ideal I am searching for, which may never have or does exist? Or perhaps this kind of knowledge simply just existed tacitly in the professional practices instead?

When realizing that there was a gross knowledge gap in contemporary research, a fourth research strategy to investigate and unfold the practice-based knowledge instead of the research-based knowledge, therefore, suddenly became very relevant. Based on my explorative theoretical investigations, it will hopefully, as mentioned in the chapter, Research Approach, be possible to engage in a case study, empirically investigating the research topic, because I here have contributed with a theoretical framework and a series of predefined notions and concepts working as guiding principles in the research, thereby "completing" the 'circle of inquiry'. Relative hereto, the main question is how to encapsulate the ontological and epistemological perspective, considering that the theatrical architectural scenery of a meal is also part of an imaginary world and about making images as well as creating memorable perceptions. Based on my research and the above investigations, I find that - from an architectural-theoretical point of view in the specific case of trying to improve food intake among hospitalized patients, the meal experience strongly depends on the architect's intentional ability to design an theatrical architectural scenery staging a meal, rather than just providing a common living area framing a meal in hospital wards. Future methodological challenges for similar research projects are, in my opinion, therefore, to develop a specific research 
approach considering the complexity of the social, cultural and spiritual qualities inherited in the scenery of interior architecture when performing the empirical research on how eating environments impact on patient meal experiences, food intake and well-being.

\section{LIMITATIONS TO THE RESEARCH}

Because I did not have any predefined research discipline or paradigm relating to the interior architectural qualities of patient eating environments, there was no predefined theoretical framework to help define my research strategies and tactics. Instead existing knowledge - both in research and practice - touch upon a vast range of affirmed and well-established research domains like food and consumer studies, hospitality studies, social science studies, nutritional studies and behavioral studies, as well as healthcare studies whose epistemological backgrounds often stand in stark methodological contrast with the branches of architectural theory and architectural practice. Within each of these disciplines, a wide spectrum of research strategies and tactics exists. For instance, the discipline of Civil Engineering often focuses on experimental research, utilizing on-site, laboratory-based or computer-based simulations of structural realities. Food \& Consumer Science focus on experimental research with field studies and laboratory tests. Meal Science and Food Sociology focuses more on qualitative research methods, emphasizing interviews, focus groups and video documentation. Finally, the architectural discipline, presumably because of its hermeneutic-interpretative character, is often less aware of the specific research methods and tactics utilized in the research as the other disciplines. Instead, vast amounts of written and built material exist which can be analyzed and interpreted for its normative and polemical content when trying to understand its importance and relevance.

My research process being a "hybrid" of all these disciplines, made it very difficult and extremely challenging for me to balance and find my way through all the knowledge, theories, strategies and tactics from all those disciplines at once. I think that perhaps it became more and more complex to balance the ontological world view, the epistemological philosophies and the specific research strategies and tactics throughout the process as my awareness towards this "hybridization" grew. And I felt like moving more towards "hubris thinking" because I wanted and was often also expected to by the 'context of discovery' - now being the 'context of justification' - to think holistically and take all these perspectives into consideration simultaneously. This meant that I spent a lot of time outlining and reviewing existing 'positive theory', 'normative theory' and 'polemical theory' in the attempt to clarify the theoretical foundation. Research limitations or implications to the work presented in this monograph are, therefore, first of all the hermeneutic-interpretative character of the descriptive, analytical, explanatory and predictive chapters, as well as the crude claim to propose a new discourse in hospital interior architecture. Furthermore, most of the reviewed literature - whether it is positive, normative or polemic - is either in Danish or English/American, even though a lot of material also exists in e.g. German and Italian on respectively interior architecture and hospital history. Finally, I have not even touched on the history of health and well-being or eating in, for instance, Asian or third-world countries. Here, further knowledge on food rituals and health treatments presumably exists that could be valuable for future considerations. Relative hereto, I have mentioned that hospitals are very complex phenomena that not only frame treatments of out and inpatients, but also the everyday working activities of a broad range of staff. So, hospital design relates to many different interlinked functions and various stakeholders. My specific research is just a small contribution to that very complex phenomenon, focusing specifically on patient eating environments and the synthesis of health, food and architecture - from an architectural perspective.

Of course such a description of the interior architectural qualities as put forth here, inspired by Semper, can never be complete or exhaustive. The history of architectural theory and the theoretical engagements of Semper himself show this quite clearly. But also because this thesis only represents a very small part of Semper's elaborate theory on form making. There are other parts of his 'polemical theory' that would perhaps be highly relevant to include in my definition of the Architectural Theatricality and a discourse in the interior architecture of patient eating environments. Also, 


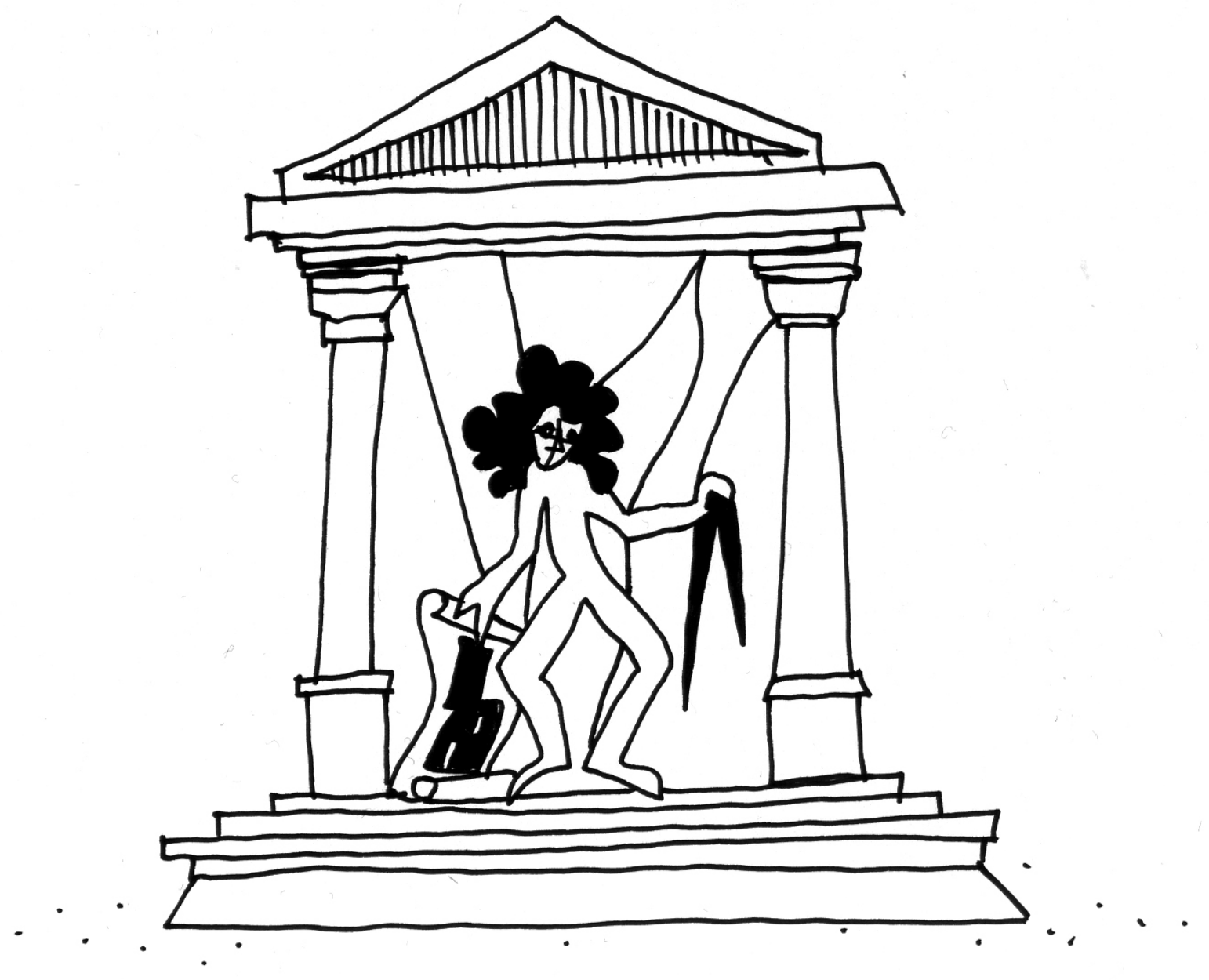

Fig. 10.2

"Architect and Architecture"

(Drawing adopted from Frascari 
there are some lacking aspects in Semper's theory. The anthropological interests and close examination of style overtook his architectural study, and he never got to write more specifically about relating the four 'motives' to the development and design of architecture. How the more social, spiritual and cultural values of the 'hearth', 'walling,' 'flooring' and 'roofing' influence the specific making of the architectural scenery are left rather untouched in Semper's theory [Tvedebrink et al. 2012:11].

With my stay at the Azrieli School of Architecture, Ottawa, and participating in the $\mathrm{PhD}$ master classes held by Professors Marco Frascari, Roger Connah, Steven Fai and guest lectures like Alberto Pérez-Gómez, I was encouraged to try and comprehend the complexity of architectural history and engage in the profound meaning of each of the treatises and polemical writings put forth by the different architectural thinkers, as well as try to understand their inherited connections. It was an overwhelming and very intriguing task that would probably endure a lifetime. I still feel like I have only scratched the surface of the architectural canon, and that I have only outlined fragments of the history of healthcare and food. Perhaps rather obviously, there are many perspectives I have not even mentioned. Presumably, there are many theories I am not aware of that would be highly relevant to investigate in the future and to elaborate on in the researched topic. In the present $\mathrm{PhD}$ thesis, I chose to go with the Gastronomic Analogy and a detailed unfolding of the polemical theory developed by the $19^{\text {th }}$ century architect Gottfried Semper. In relation hereto, I briefly touched on the writings of the $19^{\text {th }}$ century architectural thinker James Fergusson, the $20^{\text {th }}$ century architectural thinker Peter Collins and the contemporary $21^{\text {st }}$ century architectural thinkers Kenneth Frampton, Alberto Pérez-Gómez, Harry Francis Mallgrave and Marco Frascari. However, the Historical Review and the attempt to outline the polemical architectural theories in particular revealed the existence of a gross amount of knowledge that potentially could be interesting within other parts of the architectural discipline but also within the social sciences and hospitality, elaborating on elements of experience, dwelling, sense of place, space and well-being. A series of $19^{\text {th }}$ century thinkers like John Ruskin, Marcel Proust, Friedrich Wilhelm Nietzsche, Charles Sanders Peirce, Erving Goffmann, and Edward Hall, not to mention Martin Heidegger and Gaston Bachelard were in the back of my mind the entire time. Then there is the whole debate about 'taste'; the 'taste' in architecture as an aesthetic aspect and the 'taste' in culinary theory, and how these two are linked and intertwined. But I did not have the courage nor the time and space to include and unfold that kind of thinking here. Looking back, obviously because food, health and architecture ultimately touch on the fundamental and core aspects of life itself, I found that vast amounts of normative and polemical knowledge was available particularly stemming from the turn of the $20^{\text {th }}$ century if I allowed myself to look beyond the 'positive theory' synthesizing these three disciplines. This is something I would like - and could - spend much more time investigating and unfolding.

\section{FUTURE CONSIDERATIONS}

So, I find that if we accept that research-based knowledge does not necessarily have to be "positive" in an evidence-based manner, being deduced on the background of empirical research investigations, but that it can relate to more normative knowledge rooted in the analysis of built objects and the polemical writings presenting the underlying intentions, there are vast amounts of research-based knowledge both past and present to be investigated which can help us understand how to describe, explain and predict the future interior architectural qualities of patient eating environments. Based on this argument, I further find that the content of the thesis is of value to architectural theoreticians, food designers in general, interior designers, hospitality researchers, food and consumer researchers, as well as professionals' related hospitality, hospital design and patient care [Tvedebrink et al 2012:1112]. As mentioned by Lehrer (2007:x), perhaps because the natural sciences have explained so much, today we still tend to assume that the strict scientific approaches can explain everything. But on the background of my investigations, I think we need to start acknowledging that every method, even the experimental ones, has limits. Also, as mentioned previously, one of the essential points and morals put forth with Neuroscience is that we need a continuous dialog between art and science. As I have tried to outline in the previous chapters, Semper saw that already back in 1852, when he tried to synthesize the knowledge and methods of art and science in his theories 
of The Four Elements of Architecture and Style. Nevertheless, more research obviously needs to be done in order to better understand the relationship between intentionally staging patient's meal experiences and food intake by means of Architectural Theatricality. It is important from both a design practice and research point of view to further study the relationship between eating environment and human nutritional well-being in order to be able to build a sufficient body of evidence to support the development of future hospital design. This must include both developments within research methods, strategies and tactics, a preferably larger sample of patient eating environments in the field study, as well as the possibility to perform design interventions within this particular research area in the future.

Still, I find that the particular exploratory effort to apply the architectural 'polemical theory', as developed for instance with Semper, to better understand the architectural means and interior effects on patient eating behavior has been fruitful and original. As I have shown in the previous chapters, today there is a tendency to reductionism in the complexity and value of human experience - to remove the arts from the sciences. The more I have read on the subject of the century old "quarrel" between the sciences and arts, the more I was baffled by the fact that in the $21^{\text {st }}$ century stakeholders involved in the design of future 'super hospitals' would still increasingly demand such a thing as research-based knowledge in an evidence-based manner, when almost 200 years of architectural thinking and practice have been arguing against exactly such things. My initiate suspicion that there is a knowledge gap in the contemporary theory and practice regarding patient eating environments was confirmed with my investigations. They also further indicated that we are about to, once more, forget and overlook the fundamentals that define architectural quality. However, I also find that recent discoveries within the discipline of Neuroscience have brought interesting new light on how humans experience and perceive different phenomena. Discoveries that seem to strongly affect the research-based knowledge rooted in not only architecture but also gastronomy and healthcare, where sub-disciplines like neuro-aesthetics and neuro-gastronomy have emerged within the last five to ten years. What links these fields together is the profound understanding of human experience - how we experience not only through our senses, body and mind, but with our brain as an embodied corporeal organism. Both gastronomy and architecture are able of triggering forgotten or hidden old memories on a tick of time. The material appearance of the objects communicate a narrative or a story and, thereby, becomes bridges in time, space and place as seen with Marcel Proust's story of the Madeleine cake. That is exactly what I found to be the lessons to be learned from the Gastronomic Analogy: that both the arts and the sciences are linked, that architects draw on what Frascari called 'magic' and Frampton referred to as the 'poetics' rooted in the craft of building, the technique of structures, the multi-sensuous perception of materials and the communicative significance of ornamentation which together create an architecture that is able to stimulate imagination and memory.

My claim is that architecture, due to that 'magic' and 'poetic' relationship, can be used to enhance the experience of eating and to promote patient food intake. Because it has the ability to move time and space, and bring to live, in our mind, things that do not even exist. In my opinion, the social, spiritual and cultural values in architecture implied with concept of Architectural Theatricality affect the standards of how we as researchers and practicing architects investigate, describe, analyze, explain and predict the patient eating environment. I, therefore, suggest that my interpretation of architecture as scenery, elaborated here with my concept of Architectural Theatricality, can be used to synthesize the disciplines of health, food, and architecture into a theoretical discourse. This discourse will acknowledge not only the importance of multi-sensuous experiences which are revealed with the material appearance of objects, but also the imaginary world of dreams and memories which are concealed with the communicative significance of intentions when designing the future super hospitals. 


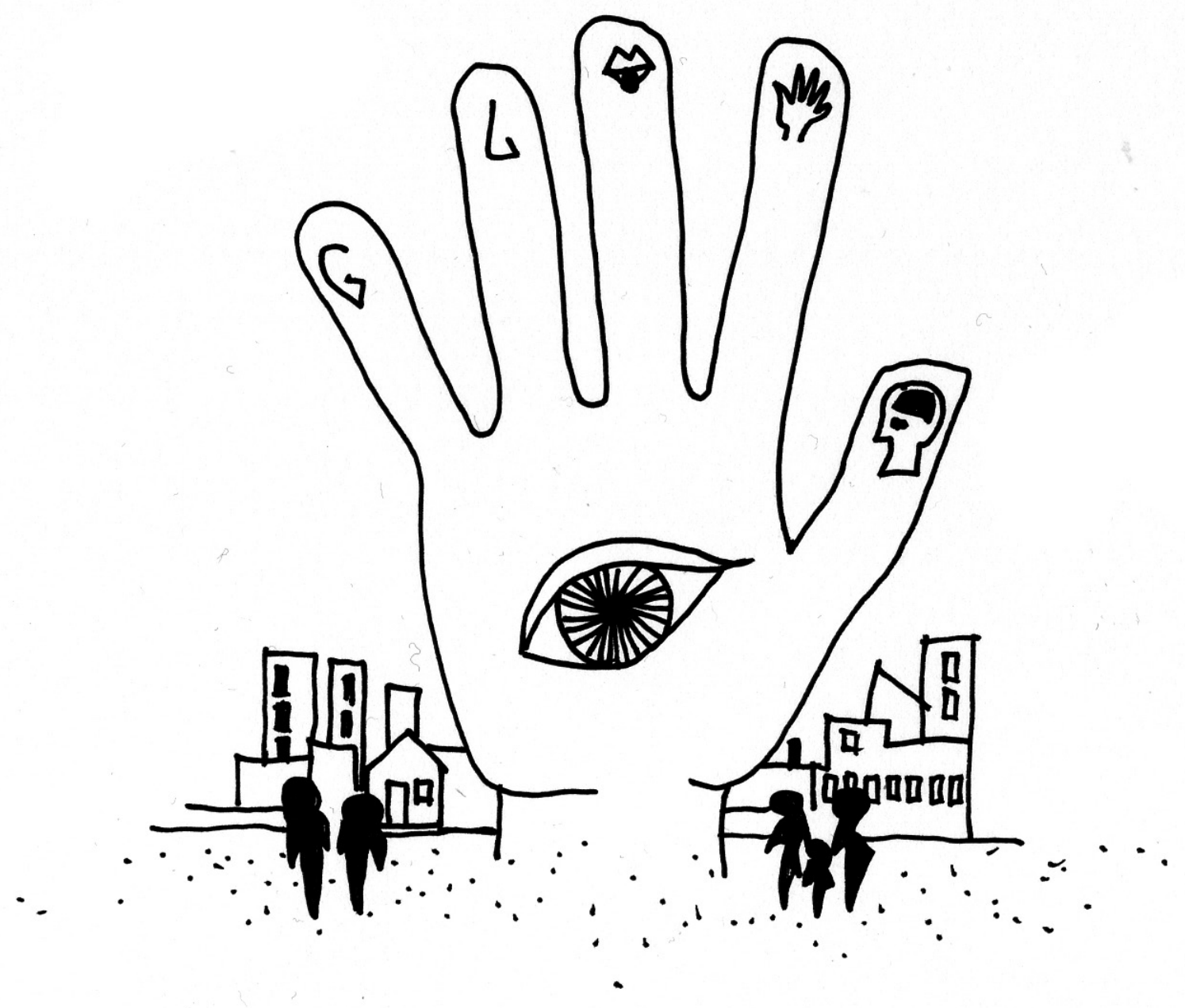

Fig. 10.3

"The Future"

(Drawing adopted from Frascari 2011:147) 



\title{
EPILOGUE
}

\author{
THE MAGIC OF ARCHITECTURE
}

Two years ago, halfway through my $\mathrm{PhD}$ project, I was rather unexpectedly hospitalized because my baby son - barely one day old - underwent a complicated abdomen surgery, which made us stay in two different Danish hospitals for several weeks. I still clearly remember the scent of cleaning detergents, methylated spirits and disinfectants in the wards, as well as the scent of food that spread every day, during mealtime, at these two different hospitals.

In the first hospital, I was located in a four-bedded room together with three other mothers and their premature babies. The room was one among many in the long narrow hallway. My husband was only allowed to visit at certain times during the day, and my newborn son was positioned in a couveuse in a different room constantly surveyed by nurses. If we wanted to spend time together, it was in the company of several strangers. Hospital policies requested my husband to eat elsewhere and, therefore, I had to eat alone - either in bed, back in the patient room, or in the common area at the ward. During meal time all "mother-patients" were lined up in front of the bulk trolley waiting to be served. We were not allowed to touch anything ourselves. We were handed a dark grey plastic trey with plate, cup/glass and cutlery. In the common area there was only room for five or six persons, if I chose to eat there I would be seated among visiting relatives with computers, co-patients watching TV, staff informing each other on different ward duties, or looking on the long list of information folders on hospital procedures and bereavement counseling hanging on the wall next to the table. The entire situation and my worries over my son's complicated condition strongly affected my desires for food. I have never felt so confused, completely lost, alone and physically ill as when staying there. I could not eat - was not hungry at all, and the mere vision of the food served to me, from the bulk trolley, made me feel worse. For almost two days I ate nothing but a small piece of bread. And I was not even the one being sick.

At the other hospital I stayed at a recently newly built department designed for families hospitalized with small children. Here every family had their own small "apartment" with private bathroom, a couch and a small dining table with two chairs facing a large window overlooking a garden with apple trees and roses. The small couveuse was allowed to stay in the apartment, the nurses though still surveying it by means of advanced technological equipment. At this hospital there was no bulk trolley or plastic trays, instead we had the possibility of cooking and preparing our own food in a kitchen, located at the end of the ward, or use the restaurant facilities at the patient hotel located next door. In this particular hospital, even though it was not so different in treatment procedures and hospital clinical services, the architectural scenery made me relax, feel safe and anticipate recovery improvements.

As I am writing this, my son is playing in a sunbeam on the floor in our dining room. 
He is on the edge of learning how to speak his first real words in full sentences. During these first two years, he has undergone an amazing growth and extraordinary advancement. He is no longer a fragile utterly helpless baby strongly dependent on the primordial instincts of grasping for bodily contact - touching and tasting everything with his mouth - but is slowly growing into a small child with his own personal characteristics suddenly confidently encountering the world on his own will.

Retrospectively, I find that the scenery staging the dining table has in many ways been the center of his radical development and growth. Here he has learned about our culture, rituals, traditions and habits. By listening, trying, thinking, analyzing and judging what others (mostly his parents) are doing, he has developed his capacities from relying on his sense of scent to help him judge situations, to identify directions with his ears, recognize objects and persons with his eyes, as well as steer arms, hands, fingers, legs - sit, crawl, jump, walk, run, sing, dance and talk. At mealtime he thus proudly walks to his special high chair, placed at the end of the dinner table. He eagerly grabs his fork, knife or spoon and gets ready to eat. He has his own miniature plate, cutlery, glass and cup. He knows the difference between his and ours, he knows the "rules" of the meal and he feels most comfortable if everything follows the ordinary. With these everyday ritual acts he creates his own place, organizes his own space and situates himself as a member in our little family. If he is not satisfied the verdict is crucial - the food is rejected and he leaves the table very disappointed, sometimes even very unhappy and crying, pushing his chair and tossing around plate, cutlery and food.

The reason why I am writing this, is that today, despite the knowledge I have gained with my research, I still cannot describe or explain in a 'scientific' or evidence-based manner what it was that made this significant difference in the two different hospitals. I still cannot provide a 'scientific' or evidence-based set of design principles predicting the interior architectural qualities of patient eating environments. But, even though critics would probably argue that those two hospital situations are not comparable that my personal state-of-mind strongly affected my judgment - I know from personal lived experience that the quality of the hospital design and the specific interior architecture staging the eating environments played a tremendous role - just as it afterwards has done in general in the raising of my son.

I am not the only one knowing this. As I wrote in the Acknowledgements, one year ago, I was invited by Marco Frascari to participate in the newly established PhD program at Azrieli School of Architecture in Ottawa, Canada during the winter semester 2012. Before my stay we had a brief mail-correspondence, wherein Marco expressed his high interest in the topics of Neuroscience and "neuro-architecture", as can also be seen from his writings presented previously on the importance of the relationship of the architect, the magician and the cook.

Unfortunately, before I arrived in Ottawa. Marco was hit by a major stroke. He was hospitalized immediately, but after some weeks he regained enough strength for me to visit him in the hospital. Even though he was quite tired and exhausted from the hospital treatment procedures, he took his time to talk to me about my particular interest in the relationship of health, food and architecture. As a last gesture before I left, he handed me the week-menu he had been given describing what he could expect to eat during mealtimes in the next six days. Accompanying the menu, Marco said in a silent voice: "They don't even cook the food here. It is delivered with trucks from an industrialized kitchen located far away. I will not eat that. So, when possible, I have my wife bring me some of her home-cooked food instead". A few days later Marco suffered another major stroke. This time he did not recover quite as well. Sadly, he was paralyzed and thereby had lost his ability to speak, as well as to use the right arm and hand.

In the beginning of March 2013 - at the time of writing - I received a small book called: Drawing in the Silence, written by my friend Adriana Ross and a PhD student of Marco's. Herein she presented a series of hand-drawn sketches produced by Marco, in the hospital, with his left hand during recovery. 
The drawings are both sad and very beautiful. Sad because they tell the story of a highly esteemed professor in architecture that most of his grown-up life had been drawing, writing and speaking of the magical wonders of architecture, but who suddenly became very ill and was deprived of the exact same skills - the ability to draw, write and speak. But also beautiful, because Marco despite the limits put on him by his severe illness, took everybody with surprise when he began sketching with the left hand, and thus began reconfiguring and recovering not only his health and well-being, but also his communication with the world. It was a neurological wonder. In this little book, in one of the very last pages, in a drawing following a series of blurred self-portraits, architectural hats and Babel towers, Marco had drawn a magician clearly holding hands with a cook standing together with an architect. I recognized the drawing immediately, because as Adriana also notes in the book, it is a motive Marco has drawn before, when speaking about the Gastronomic Analogy; about the magical relationship binding architecture and food together as well as about the importance of the normative and polemical knowledge rooted in the objects and the intentions of our past.

I hope that this kind of knowledge will not be forgotten in the designs of future hospitals and their patient eating environments.

\section{Tenna Doktor Olsen Tvedebrink}




\section{BIBLIOGRAPHY}

REFERENCES

Adams, H.P. (1908). Notes on the construction of cottage hospitals. British Medical Journal, pp. 1476-1479.

Adams, A.M., (2008). Medicine by Design, the architect and the modern hospital 18931943. Minneapolis, USA: University of Minnesota Press.

Adrià, F. (2008). A Day at elBulli, an insight into the ideas, methods and creativity of Ferran Adrià. New York: Phaidon.

Allison, S.P. (1999). Hospital food as treatment. Maidenhead, UK: British Association for Parenteral and Enteral Nutrition.

Allison, S.P. (2003). Hospital food as treatment. Clinical Nutrition, 22, pp.113-114.

Almdal T., Viggers L., Beck AM. Et al. (2003). Food production and wastage in relation to nutritional intake in a general district hospital - wastage is not reduced by training the staff. Clinical Nutrition, 22, pp. 47-51.

Aron, J.P. (1975). The Art of Eating in France: Manners and Menus in the Nineteenth Century. New York: Harper \& Row.

Bachelard, G., (1994). The Poetics of Space. Boston: Beacon Press.

Ball, S. \& Johnson, K. (2000). Humour in commercial hospitality settings. In: Lashley, C. \& Morrison, A. (ed.), In search of hospitality: Theoretical perspectives and debates. Oxford: Butterworth-Heinemann.

Balle Jensen, K. (2008). Hospital i Skejby bygges på nyt begreb: Evidence Based Design. Ugeskrift for Læger, 170(12), pp. 1010.

Bäüner, J. (1952). Florence Nightingale. Hellerup, Denmark: Aug. Olsens Bogtrykkeri.

Beese, G. (1997). Energy crisis. Nursing Times, 93, pp. 55-57.

Bek, L. (1983). Arkitektur og Livsmønster. Danmark: Borgen.

Bek, L. \& Oxvig, H., (1999). Rumanalyser. Århus: Fonden til udgivelse af arkitekturtidsskriftet B.

Bélanger, M.C. \& Dubé, L. (1996). The emotional experience of hospitalization: it's moderators and it's role in patient satisfaction with foodservices. J Am Diet Assoc, 96, pp. 354-360.

Belasco, W. \& Murcott, A. (2008). Food, culture and Society, an international Journal of multidisciplinary research. Berg Publishers.

Bell, R., Meiselman, H.L., Pierson, B.J. \& Reeve, W.G., (1994). Effects of adding an Italian theme to a restaurant on the perceived ethnicity, acceptability, and selection of foods. Appetite, 22, pp. 11-24. 
Bell, R. \& Meiselman, H.L. (1995). The role of eating environments in determining food choice. In: Marshall, D.W. (ed.), Food Choice and the Consumer. Glasgow: Blackie Academic \& Professional.

Bell,R. \& Pliner, P.L. (2003). Time to eat: the relationship between number of people eating and meal duration in three lunch settings. Appetite, 41, pp. 215-218.

Benjamin, A. \& Rice, C., (2009). Walter Benjamin and the Architecture of Modernity. Melbourne: re.press.

Benedetti, R. \& Croce, M.D. (1574). Le Feste and L'Historia della Publica. Venice Public Library.

Bere E. \& Brug J., (2009). Towards health-promotion and environmentally friendly regional diets - a Nordic example. Publich Health Nutrition, 12, pp. 91-96.

Beyea, S. \& Nichll, L.H. (1998). Writing an integrative review. AORN Journal. Available from: BNET [accessed 23.09.2010]

BIG (2010). Yes is More, an archicomic on architectural evolution. Köln: Evergreen $\mathrm{GmbH}$.

Billcliffe, R. (1979). Charles Rennie Mackintosh, the complete furniture, furniture drawings and interior designs. London: Cameron \& Hollis.

Bistrian, B. R., Blackburn, G.L., Vitale, J., Cochran, D. \& Naylor, J. (1976). Prevalence of malnutrition in general medical patients. Journal of the American Medical Association, 235, pp. 1567-1570.

Bitner, M.J. (1990). Evaluating Service Encounters: The Effects of Physical Surroundings and Employee Responses. Journal of Marketing, 54, pp. 69-82.

Bitner, M.J. (1992). Servicescapes: The impact of physical surroundings on customers and employees. Journal of Marketing, 56, pp. 57.

Bollett, J.B. \& Owens, S. (1973). Evaluation of nutrition status of selected hospitalized patients. American Journal of Clinical Nutrition, 26, pp. 931.

Bond, S. (1998). Why eating matters. Nursing Standard, 12, pp. 26-27.

Brillat-Savarin, J.A. (1949). The Physiology of Taste: or Meditations on Transcendental Gastronomy. (ed.) Fisher, M.F.K., New York: Counterpoint.

Brockett, O.G. (1968). History of Theatre, fourth edition. Boston: Allyn \& Bacon.

Brockett, O.G. \& Findlay, R.R., (1973). Century of Innovation: A History of European and American Theatre and Drama since 1870. Englewood Cliffs: Prentice Hall.

Brodersen, L., (2007). Geokommunikation: et synspunkt om indholdsarkitektur for geokommunikation, om betingelser og muligheder for at opnå enighed om sag og sted som grundlag for beslutning på et fænomenologisk, kommunikativt, semiotisk og retorisk grundlag. Danmark: Forlaget Tankegang.

Bromley, E. (2012). Building patient-centeredness: Hospital design as an interpretive act. Social Science \& Medicine, 75, pp.1057-1066.

Brush, J.A \& Calkins, M.P. (2008). Environmental Interventions and Dementia: Enhancing Mealtimes in Group Dining Rooms. The ASHA Leader. June 17.

Bryant, G., (2004). Timely untimeliness: Architectural modernism and the idea of the Gesamtkunstwerk. In: Tracing Modernity - Manifestation of the modern in architecture and the city. Hvattum, M. \& Hermansen, C. (ed.). London: Routledge, pp.156-172. 
Bø-Rygg, A,. (2004). What modernism was: art, progress and the avant-garde. In: Tracing Modernity - Manifestation of the modern in architecture and the city. Hvattum, M. \& Hermansen, C. (ed.). London: Routledge, pp.23-42.

Cardello, A.V., Maller, O., Kluter, R. (1984). Multi-user assessment of a hospital cookfreeze food service system. Journal of Foodservice Systems, 3, pp.153-169.

Cardello, A.V. (1994). Consumer expectations and their role in food acceptance. In: MacFie, H.J. \& Thomson, D.M.H. (ed.), Measurement of food preferences (pp. 253297). London: Blackie Academic.

Cardello, A.V., Bell, R. \& Kramer, F.M. (1996). Attitudes of consumers toward military and other institutional foods. Food Quality and Preference, 7(1), pp. 7-20.

Cassidy, T. (1997). Environmental Psychology; Behaviour and experience in Context. Hove: Psychology Press.

Chang, V.W., \& Christakis, N. A. (2002). Medical modeling of obesity: A transition from action to experience in a 20th century American medical textbook. Sociology of Health and Illness, 24(2), pp. 151-177.

Chatillon-Plesis (1894). La Vie á table á la fin du XIXe siécle théorie practique et historique de gastronomie modern: Physiologie, discussions, moeurs et mode pratique, service de la table et des receptions, le boire, la cuisine, grandes recetts culinaires du siècle, la patisserie, les restaurants, nouveaux classiques de la table, mélanges et fantaisies. Paris: Firmin-Didot.

Chipperfield, D, Long, K. \& Bose, S. (ed.)(2012). Common Ground, a critical reader. $13^{\text {th }}$ International Architecture Exhibition at La Biennale di Venizia. Venice: Marsilio.

Christiansen, M.S,. (1973). Historien om Flora Danica: to bogværker og et porcelænsstel. København: Dansk Esso A/S.

Christensen, B., (2008). Gastronomien I Danmark, historien om de største kokke og de bedste restauranter. København: Lindhardt og Ringhof.

Christensen, B. \& Bech-Poulsen, C., (2012). Ny nordisk gastronomi, new nordic cuisine. København: Politikens Forlag.

Clement-Lorford, F.J., (2012). Alexis Soyer. The First Celebrity Chef. Unpublished (provided by author via email 30.05.2012 - and with permission to use pictures).

Clendenden, V.I., Herman, C.P. \& Polivy, J. (1994). Social facilitation of eating among friends and strangers. Appetite, 23, pp.1-13.

Collins, P., (1965). Changing Ideals in Modern Architecture: 1750-1950. Montreal: McGill-Queen's University Press.

Correia, M.I.T.D. \& Campos, A.C.L. (2003). Prevalence of hospital malnutrition in Latin America: the Multicenter ELAN study. Nutrition, 19, pp.823-825.

Cortis, J.D. (1997). Nutrition and the hospitalized patient: implications for nurses. British Journal of Nursing, 6, pp. 666-674.

Cowen, R., (2006). Relish, the extraordinary life of Alexis Soyer victoiran celebrity chef. London: Weidenfeld \& Nicolson.

Curl, J.S. (1999). Oxford Dictionary of Architecture. Oxford: Oxford University Press.

Curtis, S., Gesler, W., Fabian, K., Francis, S., \& Priebe, S. (2007). Therapeutic landscapes in hospital design: a qualitative assessment by staff and service users of the design of a new mental health inpatient unit. Environment and Planning C: Government and Policy, 25, pp. 591-610. 
Damasio, A. (1994). Decartes' Error: Emotion, Reason and the Human Brain. New York: G.P. Putnam's Sons.

Davey, P. (2007). Hearth and Home. In: Hodgson, P.H. \& Toyka, R. (ed.), The Architect, The Cook and Good Taste. Germany: Birkhäuser, pp. 100-109.

Davies, M., (2008). Why Do we need doctoral study in design?, International Journal of Design, vol. 2, No. 3, 2008, pp. 71-79.

Davis, A.M. \& Bristow, A. (1999). Managing Nutrition in Hospital. London: The Nuffield Trust.

Davidson, A. \& Scholefield, H. (2005). Protecting mealtimes. Nursing Management UK, 12, pp. 32-36.

Delizia, R. \& MacFie, H.J.H. (1996). The Generation of Sensory expectation by external cues and its effect on sensory perception and hedonic ratings: a review. Journal of Sensory Studies, 11, pp. 103-128.

de Castro, J.M. \& Brewer, E.M. (1992). The amount eaten in meals by humans in a power function of the number of people present. Physiology and Behavior, 51, pp.121125.

de Castro, J.M. (1990). Social facilitation of duration and size but not rate of the spontaneous meal intake of humans. Physiology \& Behavior, 47, pp. 1129-1135.

de Castro, J.M. (1994). Family and friends produce greater social facilitation of food intake than other companions. Physiology \& Behavior, 56, pp. 445-455.

de Castro, J.M., (2000). Eating behavior, lessons from the real world of humans. Nutrition, 16(10), pp. 800-813.

de Castro, J.M \& de Castro, E.S. (1989). Spontaneous meal patterns of humans: influence of the presence of other people, Am.J.Clin.Nutr., 50, pp.237-247.

de Castro, J.M. \& Stroebele, N. (2002). Food intake in the real world: implications for nutrition and aging. Clinics in Geriatric Medicine, 18(4), pp. 685-697.

Delvin, A.S. \& Arnelli, A.B. (2003). Health Care Environments and Patient Outcomes: a review of literature. Environment and Behavior, 35(5), pp. 665-694.

DePoy, E. \& Gitlin, L.N., (2005). Introduction to Research: understanding and applying multiple strategies. US: Elsevier Mosby.

Desmet, P. \& Hekkert, P., (2007). Framework of Product Experience. USA: Elsivir.

Douglas, C. H., \& Douglas, M. R. (2005). Patient-centered improvements in healthcare built environments: perspectives and design indicators. Health Expectations, 8, pp. 264-276.

Douglas, M. (1975). Deciphering a Meal, in Douglas, M. (ed.), Implicit Meanings, London: Routledge and Kegan Paul, pp. 249-75.

Dybdahl, L. \& Engholm, I., (2008). Design: Køkkenet. København: Gyldendal.

Eck, C.V., (2004). Modernity and the uses of history: understanding classical architecture from Bötticher to Warburg. In: Tracing Modernity - Manifestation of the modern in architecture and the city. Hvattum, M. \& Hermansen, C. (ed.). London: Routledge, pp.56-68.

Eco, U., (1992). Interpretation and overinterpretation. Cambridge: Cambridge University Press. 
Edington, J., Boorman, J., Durrant, E.R., Perkins, A., Giffin, C.V., James, R., Thomson, J.M., Oldroyd, J.C., Smith, J.C., Torrance, A.D., Blackshaw, V.,Green, S., Hill, C.J., Berry, C., McKenzie, C., Vicca, N.,Ward, J.E. \& Coles, S.J., (2000). Prevalence of malnutrition on admission to four hospitals in England. Clinical Nutrition, 19(3), p. 191-195.

Edleman, B., Engell, D., Bronstein, P. \& Hirsch, E. (1986). Environmental effects on the intake of overweight and normal weight men. Appetite, 7, pp.71-83.

Edwards, J.S., Meiselman, H.L., Edwards, A. \& Lesher, L. (2003). The influence of eating location on the acceptability of identically prepared foods. Food Quality and Preference, 14, pp. 647-52.

Edwards, J.S.A. \& Gustafsson, I.B., (2008). The five aspects meal model. Journal of Foodservice, 19(1), pp.4-12.

Edwards, J.S.A. \& Gustafsson, I.B.,(2008b). The room and atmosphere as aspects of the meal: a review. Journal of Foodservice, 19(1), pp.23-34.

Edwards, J.S.A. \& Hartwell, H.J., (2004). A comparison of energy intake between eating positions in a NHS hospital - a pilot study. Appetite, 43, pp. 323-325.

El-Khoury, R., (1997). Delectable decoration: taste and spectacle in Jean Francois de Bastide's La Petite Maison. In: Taste and Nostalgia (ed.) Weiss, A.S., New York: Lusitania Press, pp. 49-62.

Elmståhl, S., Blabodil, V., Fex, G., Kuller, R., Steen, B. (1987). Hospital nutrition in geriatric long-term care medicine, effects of a changed meal environment. Comprehensive gerontology, section A, Clinical and laboratory sciences, 1(1), pp.2933

Engholm, I. \& Michelsen, A., (2000). Designmaskinen. København: Gyldendal.

Erlhoff, M., Heidkamp, P. \& Utikal, I. (eds.), (2008). Designing Public. Perspectives for the public. Basel: Birkhäuser

Fergusson, J. (1849). An Historical Inquiry into the True Principles of Beauty in Art: More especially with reference to Architecture. London: Longman, Brown, Green and Longmans.

Fernández-Armesto, F. (2002). Near a Thousand Tables, a history of food.USA: Simon \& Schuster Inc.

Feunekes, G. I., de Graaf, C. \& van Staveren, W.A. (1995). Social facilitation of food intake is mediated by meal duration. Physiology \& Behavior, 58, pp.551-558.

Filstead, W.J. (ed.) (1970). Qualitative Methodology: firsthand involvement with the social world. Chicago: Markham.

Finkelstein, J. (1989). Dining Out, A Sociology of Modern Manners. Oxford: Polity Press.

Fisker, A.M. \& Jørgensen, R.L., (2010a). Bartolomeo Scappi. Denmark: Aalborg University.

Fisker, A.M. \& Jørgensen, R.L., (2010b). Montagné. Denmark: Aalborg University.

Fisker, A.M. \& Jørgensen, R.L., (2010c). Jules Gouffé. Denmark: Aalborg University.

Fisker, A.M. \& Jørgensen, R.L., (2010d). Alexandre Dumas. Denmark: Aalborg University.

Fisker, A.M. \& Olsen, T.D. (2008). Vegetables as a symbol in Design and Art. In Proceedings of the Oxford Symposium on Food and Cookery 2008, Vegetables. Oxford: Prospect Books. 
Flammang, J.A. (2009). The Taste for Civilization. USA: Illinois.

Fleischer, J. (2007). Arkitektur Leksikon. København: Nyt Nordisk Forlag, Arnold Busck.

Foucault, M., (1991). Discipline and Punish: The Birth of the Prison, London: Penguin Books.

Frampton, K. (1995/2001). Studies in Tectonic Culture: the Poetics of Construction in Nineteenth and Twentieth Century Architecture. Cambridge, Massachusetts: The MIT Press.

Frandsen A.K., Ryhl C., Folmer M.B., Fich L.B., Øien T.B., Sørensen N.L., \& Mullins, M. (2009). Helende Arkitektur, Institut for Arkitektur \& Design, Skriftserie nr. 29, Danmark.

Frandsen, A.K., Gottlieb, S.C. \& Harty, C. (2012). Spatial configurations of healthcare practices. [Available through:VBN-aau]

Franck, K. \& Lepori, B., (2000). Architecture Inside Out. Great Britain: Willey-Academy.

Franck, K. (ed.), (2002). Food + Architecture. Architectural Design, vol. 72, no. 6, Great Britain: Willey-Academy.

Franck, K. (ed.), (2005). Food + the City. Architectural Design, vol. 75, no. 3, Great Britain: Willey-Academy.

Frascari, M. \& Ross, A., (2012). Drawing in Silence. US: Lulu.com.

Frascari, M. (1986). Semiotica ab Edendo, Taste in Architecture. Journal of Architectural Education, 40(1), pp. 2-7.

Frascari, M. (2004). Semiotica ab Edendo, Taste in Architecture. In: Horwitz, J. \& Singley, P., Eating Architecture. Cambridge, Massaschusetts: The MIT Press.

Frascari, M., (2011). Eleven Exercises in the art of architectural drawing, slow food for the architect's imagination.New York: Routledge.

Frascari, M., (2011b). Marco Frascari. In: Azrieli Architecture Grimoire 2011-2012. (ed.) Fok, V. \& Ross, A., Ottawa: Azrieli School of Architecture and Urbanism.

Freedman, P. (Ed.), (2007). Food, the history of Taste. London: Thames \& Hudsom Ltd.

Fried, M., (1998). Art and Objecthood: Essays and Reviews. Chicago: The University of Chicago Press.

Frisby, D,. (2004). Analysing modernity: some issues. In: Tracing Modernity Manifestation of the modern in architecture and the city. Hvattum, M. \& Hermansen, C. (ed.). London: Routledge, pp.3-23.

Frayling, C, (1993). Research in Art and Design. Royal College of Art Research Papers, $1(1)$, pp. $1-5$

Furst, T., Connors, M., Bisogni, C.A., Sobal, J., \& Falk, L.W. (1996). Food Choice: $a$ conceptual model of the process. Appetite, 26(3), pp. 247-266.

Gabe, J. \& Calnan, M., (2009): The new sociology of the health service. Routledge, USA, New York.

Gannon, T. \& Miller, P. (2010). Newport Mansions. China: The Preservation Society of Newport County.

Geertz, C., (1973). Thick Description, toward an interpretive theory of culture. In: Culture, critical concepts in sociology, ed. Jenks C., 2003, Routledge, USA, New York, pp. 173-196. 
Gerteis, M., Edgman-Levitan, S., Daley, J. \& Delbanco, T. (ed.) (1993). Through the Patient's Eyes: Understanding and Promoting Patient-Centered Care. San Francisco: Jossey-Bass Inc.

Gibbons, M.R.D. \& Henry, C.J.K., (2005). Does eating environment have an effect on food intake in the elderly? The Journal of Nutrition, health and aging, 9, pp. 25-29.

Gibbons, M., Limoges, C., Nowotny, H., Schwartzman, S., Scott, P. \& Trow, M., (1994). The new production of knowledge: the dynamics of science and research in contemporary societies. Stockholm: SAGE Puiblications Ltd.

Giedion, S. (1941). Space, Time and Architecture, the growth of a new tradition. Cambridge, Massachusetts: Harvard University Press.

Glind, I.V.D., Roode, S.D. \& Goossensen, A. (2007). Do Patients in hospitals benefit from single rooms? A literary review. Health Policy, 84, pp. 153-161.

Goffman, E. (1961). Asylums: Essays on the Social Situation of Mental Patients and Other Inmates. A Pelican Notebook.

Goffman E. (1967). Interaction Ritual: essays on face-to-face behaviour. New York: Pantheon Books.

Grabar, O. (1992). The Mediation of Ornament. Bollingen Foundation.

Granshaw, L. \& Porter, R. (eds.),(1989). The hospital in history. London: Routledge.

Green, D.M. \& Butts, J.S. (1945). Factors affecting acceptability of meals served in the air. Journal of the American Dietetic Association, 21(8), pp. 415-419.

Groat, L. \& Wang, D., (2002). Architectural Research Methods. New York: John Wiley and Sons Ltd.

Gustafsson, I.B., (2004). Culinary arts and meal science, a new scientific research discipline. Food Service Technology, 4, pp. 9-20.

Gustafsson, I.B., Öström, ̊̊, Johansson, J. \& Mossberg, L. (2008). The Five Aspect Meal Model: a tool for developing meal services in restaurants. Journal of Foodservice, 17, pp. 84-93.

Gänshirt, C., (2007). Tools for Ideas. An Introduction to Architectural Design, Basel: Birkhäuser.

Hall, E.T., (1966). The hidden dimension. New York: Anchor Books.

Hall, P., (2002). Cities of Tomorrow. Oxford: Blackwell Publishing.

Hannestad, L. (1979). Mad og Drikke I det Antikke Rom. Copenhagen: Nyt Nordisk Forlag.

Hansen, T. (2002). The effect of physical surroundings in usage situations on consumer perception of food quality and on consumer emotions. Journal of International Consumer Marketing, 15, pp. 31-51.

Harlang, C., (2001). Nordic Spaces. Barcelona: Elisava Edicions.

Harrison \& Checkland (2009). Evidence-based practice in UK health policy. In: Gabe, J. \& Calnan, M. (ed.), The New Sociology of the Health Service. New York: Routledge, pp.121-142.

Hartoonian, G. (2006). Crisis of the Object: the Architecture of Theatricality. New York: Routledge.

Hartoonian, G., (2010). Walter Benjamin and Architecture. New York: Routledge. 
Hartoonian, G. (2012). Architecture and Spectacle: A Critique. Burlington: Ashgate.

Hartwell, H.J., Edwards, J.S.A., \& Symonds, C. (2006). Foodservice in hospital -

development of a theoretical model for patient experience and satisfaction using one hospital in the UK National Health Service as a case study. Journal of Foodservice, 17, pp.226-238.

Hartwell, H.J., Edwards, J.S. \& Beavis, J. (2007). Plate versus bulk trolley food service in a hospital, comparison of patients satisfaction. Nutrition, 23, pp.211-218.

Hays, K.M. (ed.), (2000). Architecture Theory, since 1968. Cambridge, Massachusetts: The MIT Press.

Hemmington, N. (2007). From Service to Experience: Understanding and Defining the Hospitality Business. The Service Industries Journal, 27(6), pp. 747-755.

Henderson, J., (2006). The Renaissance Hospital, healing the body and healing the soul. London: Yale University Press.

Henderson, J., Horden, P. \& Pastore, A. (eds.), (2007). The impact of hospitals 300-2000. Bern, Switerland: Peter Lang AG, International Academic Publishers,ch.1,2,7,8,14.

Hensel, M., Menges, A. \& Hight, C., (2009). Space Reader : Heterogeneous Space in Architecture. Chichester: John Wiley \& Sons.

Hepple, J., Kipps, M. \& Thomson, J. (1990). The concept of hospitality and an evaluation of its applicability to the experience of hospital patients. Int. J. Hospitality Management, 9(4), pp. 305-318.

Herrmann, W., (1984). Gottfried Semper, In search of Architecture. Cambridge, Massachusetts: MIT Press.

Heslet, L. \& Dirkinck-Holmfeld, K., (2007). Sansernes Hospital. Danmark: Arkitektens Forlag.

Hess, K., (1997). The Art of Cookery made Plain and Easy, excelling anything of the kind ever yet published. Bedford, Massachusetts: Appelwood Books.

Hirsch, E.S. \& Kramer, F.M., (1993). Situational influences on food intake. In: B.M. Marriott, Editor, Nutritional needs in hot environments, National Academy Press, Washington DC, pp. 215.

Hitchcock, H.R. (1929), Modern Architecture: Romanticism and Reintegration. Hacker Art Books.

Holahan, C.J. (1982). Environmental Psychology. New York: Random.

Holm, L. \& Smidt, S., (1997). Uncovering social structures and status differences in health systems. European Journal of Public Health, 7, pp. 373-378.

Holm, L., (2003). Måltidet på hospitalet. In: Holm, L., Mad, Mennesker og Måltidet - samfundsvidenskabelige perspektiver. Munksgaard, Denmark, ch. 18, pp. 263-278.

Holm, L., (2003b). Madens betydning for patienterne. In: Holm, L., Mad, Mennesker og Måltidet - samfundsvidenskabelige perspektiver. Munksgaard, Denmark, ch. 19, pp. 279-294.

Holm, L. \& Jacobsen, A., (1990). Mad-og spisemiljø på hospitalet, en psyko-social vurdering af et traditionelt kostsystem på en afdeling for kræftsyge børn. Kræftens Bekæmpelse, Denmark, Copenhagen. 
Holm, L. Smidt, S. \& Michaelsen, K.F., (1996). Socio-Psychological Significance of Hospital Meals - the impact of the Introduction of a New Food System in a Children's Cancer Ward. Scandinavian Journal of Nutrition, 40,pp. 6-10.

Holm, L. Smidt, S. \& Michaelsen, K.F., (1998). Madens socio-psykologiske betydning på hospitalet. Evaluering af et nyt madsystem på en afdeling for kræftsyge børn. Ugeskrift for Læger, 160(30), pp. 4415-4418.

Holst, M., Rasmussen, H.H. \& Lauersen, B.S., (2011). Can the patient perspective contribute to equality of nutritional care? Scandinavian Journal of Caring Sciences, 25, pp.176-184.

Horden, P., (2008). Hospitals and Healing from Antiquity to the Later Middle Ages. Variorum Collected Studies Series, Ashgate Publishing, Hampshire, Great Britain, ch. I, pp.45-74 + ch.V, p. 133-145.

Horwitz, J. \& Singley, P. (2004). Eating Architecture. Cambridge, Massechusetts: The MIT Press.

Hotaling, D.L. (1990). Adapting the mealtime environment: setting the stage for eating. Dysphasia, 5, pp.77-83.

Hoyer, S. \& Graaf, C.D. (2004). Influence of context and environment. Food Quality and Preference, 15, pp.910-911.

Hvattum, M., (2004). Gottfried Semper, and the problem of historicism. Cambridge, UK: Cambridge University Press.

Hwang, L.J.J., Desombre, T., Eves, A. \& Kipps, M. (1999). An analysis of catering options within NHS acute hospitals. Int J Health Care Qual Assur, 12, pp. 293-308.

Jamison, A., Christensen, S.H. \& Botin, L., (2011). A Hybrid Imagination: Science and Technology on Cultural Perspective. Ebook: Morgan \& Claypool.

Jacobsen, M.H. (ed.),(2010). "The Contemporary Goffman”. New York: Routledge.

Jakle, J.A. \& Sculle, K.A., (1999). Fast Food: roadside restaurant sin the automobile age. Baltimore, Maryland: The John Hopkins University Press.

Jensen, O.B., (2010). Design Research Epistemologies. In: O.B. Jensen, ed., Design Research Epistemologies I, Aalborg University, pp.8-20. Available through: www.vbn. aau.dk

Kallir, J. (1986). Viennese Design and the Werkstätte. George Braziller Inc.

Kandel, E.R., Schwartz, J.H. \& Jessell, T.M., (2000). Principles of Neural Science. New York: McGraw-Hill Companies.

Kandel, E.R., Schwartz, J.H., Jessell, T.M. \& Siegelbaum, S.A. (2013). Principles of Neural Science. New York: McGraw-Hill Companies.

Kelly, I. (2003). Cooking for Kings, the life of Antonin Carême, the first celebrity chef. UK: Bloomsbury Publishing.

Kesten, D., (1997). Feeding the Body Nourishing the Soul, essentials of eating for physical, emotional and spiritual well-being. US: Conari Press.

Kirshenblatt-Gimblett, B. (2007). Making Sense of Food in Performance: the table and the stage. In: Banes, S. \& Lepecki, A., The Senses in Performance. New York: Routledge, pp. 71-90.

Kirshenblatt-Gimblett, B. (1999). Playing to the senses: food as a performance medium. Performance Research, 4(1), pp. 1-30. 
King S.C., Weber A.J. \& Meiselman H.L., (2004). The effect of meal situation, social interaction, physical environment and choice on food acceptability. Food Quality and Preference, 15, pp. 645-653.

King, S.C., Meiselman, H.L., Hottenstein, A.W., Work, T.M. \& Cronk, V., (2007). The effects of contextual variables on food acceptability: a confirmatory study. Food Quality and Preference, 18, pp.58-65.

Klesges, R.C., Bartsch, D., Norwood, J.D. (1984). The effects of selected social and environmental variables on the eating behavior of adults in the natural environment. Int J Eat Disord, 2, p. 35.

Knudstrup, M., (2005). Arkitektur som Integreret Design. In: Phil, O. \& Jørgensen, L.B. (ed.), 2005, Pandoras Boks. Metodeantologi, Aalborg University Press, pp. 13-29.

Kok, K., Michaelsen, K.F., Vestergaard, H. \& Jørgensen, P.S., (1992). The Effect of a New Meal Delivery System on the Energy Intake of Children Admitted with Cancer. Clinical Nutrition, 11, pp. 67-68.

Kondrup, J. (2001). Can food intake in hospitals be improved? Clinical Nutrition, 20, supplement 1, pp.153-160.

Kondrup, J., Rasmussen, H.H., Hamberg, O. \& Stanga, Z., Ad Hoc ESPEN Working Group (2003). Nutritional risk screening

(NRS 2002): a new method based on an analysis of controlled clinical trials. Clin Nutr, 22, pp. 321-36.

Korsmeyer, C. (2005). Delightful, Delicious, Disgusting. The Journal of Aesthetics and Art Criticism, 60 (3), pp. 217-225.

Korsmeyer, C. (1999). Making Sense of Taste. USA: Cornell University Press.

Kotler, P. (1973). Atmospherics as a Marketing Tool. Journal of Retailing, 49(4), pp. 48-64.

Krog, O.V. \& Dahl, K., (2003). Kobbertøj fra Det Konglige Køkken: Historien om De Kongelige Middage. København: Den Kongelige Udstillingsfond.

Kuhn, T. (1962). The Structure of Scientific Revolutions. Chicago: The University of Chicago Press.

Kurtich, J. \& Eakin, G., (1993). Interior Architecture. New York: Van Nostrand Reinhold.

Köster, E.P., (2009). Diversity in the determinants of food choice, a psychological perspective. Food Quality and Preference, 20(2), pp.70-82.

Lashley, C. \& Morrison, A. (ed.) (2000). In Search of Hospitality. Oxford: Butterworth Heinemann.

Lashley, C., Morrison, A. \& Randall, S. (2004). My most memorable meal ever! Hospitality as an emotional experience. In: Sloan, D. (ed.), Culinary Taste: Consumer Behaviour in the International Restaurant Sector. Oxford: Elsevier ButterworthHeinemann, pp. 165-183.

Lawless, H.T. (2000). Sensory Combinations in the Meal. In: Meiselman, H.T. (ed.), Dimensions of the Meal, the science, culture, business and art of eating. USA: Aspen Publishers Inc., pp. 925-106.

Lawson, B. (2001). The language of space. China: Architectural Press (Elsivier)

Lawson, B., (2004). What designers know, London: Architectural Press.

Lawson, B., (2006). How designers think. The design process demystified, London: Architectural Press, 4th Edition. 
Lawson, B. (2010). Healing Architecture. Arts \& Health, 2(2), pp. 95-108.

Lefebvre, H. (1991). The Production of Space, Oxford: Blackwell.

Lehrer, J. (2007). Proust was a neuroscientist. New York: Mariner.

Leistikow, D. (1967). Ten Centuries of European Hospital Architecture, a contribution to the history of hospital architecture. Ingelheim am Rhein, Germany: C.H. Boehringer Sohn.

Less, F. (2004). If Disney ran your hospital: 91/2 Things you would do differently. Bozeman, MT: Second River Healthcare Press.

Lindorff-Larsen K., Rasmussen H.H., Kondrup J., Staun M., Ladefoged K., The Scandinavian Nutrition Group, (2007). Management and perception of hospital undernutrition - a positive change among Danish doctors and nurses. Clinical Nutrition, 26, pp.371-378.

Lorenzen, H. (2005). Kokken, designeren, lidenskaben og videnskaben. In: Designmatters, 12, pp.34-37.

Lund, N.O. (2008). Nordisk Arkitektur. DK: Arkitektens Forlag.

Lynch, P., Molz, J.G., McIntosh, A., Lugosi, P. \& Lashley, C. (2011). Theorizing hospitality. Hospitality \& Society, 1(1), pp.3-24

Maller, O., Dubose, C.N. \& Cardello, A.V. (1980)- Demographic and environmental factors: consumer opinions of hospital food and foodservice. Journal of the American Dietetic Association, 76(3), pp. 236-242.

Mallgrave, H.F. (1996). Gottfried Semper: Architect of the nineteenth century. New Haven: Yale University Press.

Mallgrave, H. F. (2011). The architect's Brain - Neuroscience, Creativity, and Architecture. West Sussex: Wiley-Blackwell Publishing.

Mallgrave, H. F. (Ed.), (2006/2011b). Architectural Theory, volume 1 an anthology from Vitruvius to 1870. Australia: Blackwell Publishing.

Mallgrave, H. F. (1985). Gustav Klemm and Gottfried Semper: The Meeting of Ethnological and Architectural Theory. Anthropology and Aesthetics, 9, pp. 68-79.

Mallgrave, H.F. \& Herrmann, W. (trans.) (1989). Gottfried Semper, The Four Elements of Architecture and other writings. Cambridge: Cambridge University Press.

Mallgrave, H.F. \& Contandriopoulos, C. (ed.). (2008). Architectural Theory, volume II, an Anthology from 1871-2005.0xford: Blackwell Publishing.

Mallgrave, H.F. \& Robinson, M. (2004). Gottfried Semper, Style: style in the Technical and Tectonic Arts; or, Practical Aesthetics. Los Angeles: Getty Publications.

Malnar, J.M. \& Vodvarka, F. (2004). Sensory Design. Minneapolis: University of Minnesota Press.

Mamhidir, A., Karlsson, I., Norberg, A. \& Kihlgren, M. (2007). Weight increase in patients with dementia, and alteration in meal routines and meal environment after integrity promoting care. Journal of Clinical Nursing. 16, pp. 987-996.

Marsilio (2008). Out There: Architecture Beyond Building - Installations, volume 1. $11^{\text {th }}$ International Architecture Exhibition at La Biennale di Venizia. Venice: Marsilio.

Massey, A., (2001). Interior Design of the 20th Century. London: Thames and Hudson. 
Mathey, M., Vanneste, V.G.G., de Graaf, C., de Groot, L. \& van Staveren, W.A. (2001). Health effect of improved meal ambience in a dutch nursing home, a 1-year intervention study. Preventive Medicine, 32(5), pp.416-426.

McIntyre, A., (2008). Participatory Action Research. USA: Sage Publications, Inc.

Mehabrian, A. \& Russell, J.A. (1974). The Basic Emotional Impacts of Enviroment, Perceptional and Motion Skills, 38(1), pp. 283-301.

Mehabrian, A. \& Russell, J.A. (1974). An Approach to Environmental Psychology. Cambridge, MA: M.I.T. Press.

Meiselman, H., (1992). Obstacles to studying real people eating real meals in real situations. Appetite, 19, pp. 84-94.

Meiselman, H.L., (2000). Dimensions of the meal. Maryland: Aspen Publishers.

Meiselman H.L., Johnson J.L., Reeve W. \& Crouch J.E., (2000). Demonstrations of the influence of the eating environment on food acceptance. Appetite, 35, pp. 231-237.

Meiselman, H.L.,(2008). Dimensions of the meal. Journal of Foodservice, 19(1), pp.1321.

Melin, L. \& Götestam, K. (1981). The effects of rearranging ward routines on communication and eating behaviors of psychogeriatric patients. Journal of Applied Behavior Analysis, 14, pp. 47-51.

Mennell, S., (1985). All manners of food: eating and taste in England and France from the Middle Ages to the Present. Oxford: Blackwell.

Mennell, S. (2003). Eating out in the Public Sphere in the Nineteenth and Twentieth Centuries. In: Jacobs, M. \& Scholliers, P. (ed.), Eating Out in Europe: Picnics, Gourmet Dining and Snacks since the Late Eighteenth Century. Oxford: Berg, pp. 245-60.

Mennell, S. (1981). Montaigne, Civilisation and Sixteenth-Century European Society. In: Cameron, K.C. (ed.), Montaigne and His Age. Exeter: University of Exeter, pp. 67-85.

Middleton, M., Nazarenko, G., Nivison-Smith, I. \& Smerdely, P. (2008). Prevalence of malnutrition and 12- month incidence of mortality in two Sydney teaching hospitals. Internal Medicine Journal, 31, pp. 455-461.

Mikkelsen, B.E. (2011). Images of foodscapes: introduction to foodscape studies and their application in the study of healthy eating out-of-home environments. Perspectives in Public Health, 131, pp. 209-216.

Milliman, R. (1986). The influence of ancienne music on the behavior of restaurant patrons, Journal of Consumer Research, 13, pp. 286-289.

Mo, L. (2003). Philosophy of Science for Architects, Oslo: Kolofon.

Moffett, M., Fzio, M. \& Wodehouse, L. (2004). A World History of Architecture. London: McGraw-hill Companies Inc.

Morgan, M.H. (trans.) (1960). Vitruvius, the ten books on Architecture. New York: Dover Publications Inc.

Morris, H. (1938). Portrait of a chef, the life of Alexis Soyer. Oxford: Oxford University Press.

Moy, R.J.D., Smallman, S. \& Booth, I.W. (1995). Malnutrition in a UK childrens hospital. Journal of Human Nutrition and Dietetics, 3(2), pp.93-100. 
Naithani, S., Whelan, K., Thomas, J., Gulliford, M.C. \& Morgan, M. (2008). Hospital inpatients'experiences of access to food: a qualitative interview and observational study. Health Expectations, 11, pp. 294-303.

Nerdinger, W. \& Oechslin, W. (ed.) (2003). Gottfried Semper 1803-1879: Architektur und Wissenschaft. Zürich: gta Verlag and Prestel Verlag.

Nevile, J. (1990). The musical banquet in Italian Quttrocento festivities. In: Corones, A. Pont, G. \& Santich, B. (ed.), Food in Festivity: Proceedings of the fourth Symposium of Australian Gastronomy . Sydney: Symposium of Australian Gastronomy, pp. 123-135.

Neumeyer, F. (2007). The Homely Hearth - Building a Living, Eating and Drinking, Considered in Terms of Architectural Theory. In: Hodgson, P.H. \& Toyka, R. (Ed.), The Architect, The Cook and Good Taste. Germany: Birkhäuser.

Nieuwenhuizen, W.F., Weenen, H., Rigby, P. \& Hetherington, M.M. (2010). Older adults and Patients in need of nutritional support: Review of current treatment options and factors influencing nutritional intake. Clinical Nutrition, 29(2), pp.1-10.

Norberg-Schulz, C. (1996). Nightlands, Nordic Building. Cambridge, Massachusetts: The MIT Press.

Norberg-Schulz, C. (1965). Intentions in Architecture. Cambridge, Massachusetts: MIT Press.

Norberg-Schulz, C. (1985). The Concept of Dwelling : On the way to Figurative Architecture. New York: Rizzoli.

North, A.C., Shilcock, A. \& Hargreaves, D.J. (2003). The effect of musical style on restaurant customers' spending. Environment and Behavior, 35, pp. 712-718.

Notaker, H. (1987). Gastronomi, til bords med historien. Viborg: Holkenfeldts Forlag.

Nygaard, E. (2011). Arkitektur Forstået. Danmark: Bogværket.

Ochsner, A.J. (1902). Essentials in the construction of hospitals for large cities. Journal of American Association, 39, pp. 1315-1321.

Ochsner, A.J. (1907). Practical points of economy in hospital construction. Journal of American Association, 49, pp. 990-993.

Olsen, T.D. (2008). Millennium Triclinium, staging Figgjo meal experiences. Master's Thesis, Aalborg University. [not published, but available through university web: www.aau.dk]

Olsen, T.D. (2010). Hospital Foodscape Design - considering if dining environment influence patient healing? In: Jensen, O.B. (ed.), Design Research Epistemologies I: Research in Architectural Design. Aalborg University, Departmental Working Paper Series, pp.101-121. [Available through: www.vbn.aau.dk]

Olsen, T.D., Kirkegaard, P.H. \& Fisker, A.M. (2010). Healing Architecture: How hospital food environments can help improve patient recovery - an integrative literary review. Green Mega Foods, Conference Proceedings. [Available through: www.vbn.aau.dk]

Olsen, T. D. \& Fisker, A. M. (2011). Madens Rum: Handler patienternes spiseoplevelse ikke også om arkitekturen omkring måltidet? Tidsskrift for Forskning i Sygdom og Samfund, 14, pp. 75-85.

Oxvig, H., Rivad, K. \& Thau, C. (2007). Atmosfære, Den kropslige tilstedeværelses rum og rummet som fremstillingsmedium, Gernot Böhme. Denmark: Kunstakademiets Arkitektskole.

Pagel, W. (1939). Prognosis and Diagnosis: A Comparison of Ancient and Modern Medicine. Journal of the Warburg Institute, 2(4), pp. 382-398. 
Pallasmaa, J. (1996). The Eyes of the Skin : Architecture and the Senses. London: Academy Editions.

Pallasmaa, J. (2005). The Eyes of the Skin. Architecture and the Senses. New York: John Wiley.

Park, K. \& Henderson, J. (1991). The first hospital among Christians: the Ospedale di Santa Maria Nuova in early sixteenth-century Florence. Medical History, 35, pp. 164188.

Patten, C. S. (1994). Understanding hospitality. Nursing Management, 25(3).

Paquet, C., St. Arnaud-McKenzie, D., Ma, Z., Kergoat, M.J., Ferland, G. \& Dubé, L. (2008). More than just not being alone, the number, nature, and complementarity of meal-time social interactions influence food intake in hospitalized elderly patients. The Gerontologist, 48(5), pp.603-611.

Peirce, C.S. (1998). The essential Peirce selected philosophical writings. Bloomington: Indiana University Press.

Pérez-Gómez, A. \& Pelletier, L. (1997). Architectural Representation and the Perspective Hinge. Cambridge, Massachusetts and London: The MIT Press.

Pérez-Gómez, A. (1983/2000). Introduction to Architecture and the Crisis of Modern Science. In: Hays, K.M. (ed.), Architecture Theory since 1968. New York: Columbia Book of Architecture, pp. 462-475.

Pérez-Gómez (2012). The Historical Context of Contemporary Architectural Representation. Unpublished paper handed-out as part of PhD course at Azrieli School of Architecture and Urbanism, Carleton University, Ottawa, 17.03.2012.

Petrini, C. (2007). Slow Food. In: Hodgson, P.H. \& Toyka, R., The Architect, the Cook and good Taste. Basel: Birkhäuser Verlag AG.

Pevsner, N. (1936), Pioneers of Modern Design, from William Morris to Walter Gropius. Middlesex, England: Penguin Books Ltd.

Pile, J.F. (2009). A History of Interior Design. London: Laurence King.

Pine, B.J. \& Gilmore, J.H. (1999). The Experience Economy. Boston: Havard Business School.

Pliner, P. \& Rozin, P. (2000). The Psychology of the Meal. In: Meiselman, H.L., Dimensions of the Meal: the science, culture, business and art of eating. Gaithersburg, Maryland: An Aspen Publication, pp.19-46.

Pliner, P., Bell, R., Hirsch, E.S. \& Kinchla, M. (2006). Meal duration mediates the effect of 'social facilitation' on eating in humans. Appetite, 46, pp.189-198.

Praz, M. (1964). An Illustrated History of Interior Decoration: From Pompeii to Art Nouveau, London: Thames and Hudson.

Prevost, E.A. \& Butterworth, C.E. (1974). Nutritional care of hospitalized patients. Clinical Research, 22, pp. 50-54.

Prior, L. (1988). The architecture of the hospital: a study of spatial organization and medical knowledge. British Journal of Sociology, 39(1), pp. 86-113.

Prior, L. (1992). The local space of medical discourse: disease, illness and hospital architecture. Med. Gs. Gesch. Beih., 1, pp. 67-84.

Rasmussen H.H., Kondrup J., Staun M., Ladefoged K., Kristensen H., \& Wengler A. (2004). Prevalence of patients at nutritional risk in Danish hospitals. Clinical Nutrition, 23, pp. 1009-1015. 
Rasmussen H.H., Kondrup J., Staun M., Ladefoged K., Lindorff K., Jørgensen L.M., Jacobsen J., Kristensen H., Wengler A. (2006b): A method for implementation of nutritional theraphy in hospitals. Clinical Nutrition, 25, 515-523

Rechel, B., Buchan, J. \& McKee, M. (2009). The impact of health facilities on healthcare worker well-being and performance. International Journal of Nursing Studies, 46, pp. 1025-1034.

Redd, M. \& de Castro, J.M. (1992). Social facilitation of eating, effects of social instruction on food intake. Physiology \& Behavior, 52, pp.749-754.

Reed, P.S, Zimmerman, S., Sloane, P.D:, Williams, C.S. \& Boustani, M. (2005). Characteristics associated with low food and fluid intake in long-term care residents with dementia. The Gerontologist, 45, pp.74-81.

Rice, C. (2007). The emergence of the Interior: Architecture, Modernity. Domesticity. New York: Routledge.

Richards, J.M. (1940), An Introduction to Modern Architecture. Baltimore, Maryland: Penguin Books.

Risse, G.B. (1999). Mending bodies, saving souls: A history of the hospital. New York: Oxford University Press.

Ritzer, G. (2007). Inhospitable hospitality? In: Lashley, C., Lynch, P. \& Morrison, A. (ed.), Hospitality: A Social Lens. Oxford: Elseiver.

Rosenfield, I. (1969). Hospital Architecture and Beyond. New York, USA: Van Nostrand Reinhold Company.

Rozin, P. (1996). The Socio -cultural context of eating and food chioce. In: Meiselman, H.L. \& Macfie, H.J.H. (ed.), Food Choice Acceptance and Consumption. Glasgow: Blackie Academic and Professional, pp. 83-104.

Rozin, P. \& Tuorila, H. (1993): Simultaneous and temporal contextual influences on food acceptance. Food Quality and Preference, 4, pp.11-15.

Rubin \& Babbie (2010). Essential Research Methods in Social Work

Rykwert, J. (1981). On Adam's House in Paradise: the idea of the primitive hut in architectural history. Cambridge, Massachusetts: The MIT Press.

Sabban, F. \& Serventi, S. (1998). La Gastronomie au Grand Siécle, 100 recettes de France et d'Italie. Paris: Stock.

Sailer K., Budgen A., Lonsdale N., Turner A., Penn A. (2008): Evidence-Based Design: Theoretical and practical reflections of an emerging approach in office architecture. Available via web: http://eprints.ucl.ac.uk/13297/1/13297.pdf

Santich, B. (1990). Metamorphoses of the banquet In: Food in Festivity: Proceedings of the fourth Symposium of Australian Gastronomy (ed). Corones, A. Pont, G. \& Santich, B., Sydney: Symposium of Australian Gastronomy, pp. 108-114.

Sarkis, H. (2002). Le Corbusier's Venice Hospital. USA: Prestel.

Sarnitz, A. (2007). Hoffmann. Köln: Taschen.

Schifferstein, H.N.J. \& Hekkert, P. (2008). Product Experience. USA: Elsevier. Schön, D. A. (1983/2001). Den reflekterende praktiker: Hvordan professionelle tænker, når de arbejder. Århus: Klim.

Semper, G. (1853, November). London Lecture of November 11. (ed.) Rykwert,J., (Trans.) Mallgrave, H. F. (1983), Anthropology and Aesthetics, 6, pp. 5-31. 
Semper, G. (1853, December). On the Origin of Some Architectural Styles. (Trans.) Mallgrave, H. F. (1985), Anthropology and Aesthetics, 9, pp. 53-60.

Semper, G. (1854). On Architectural Symbols. (Trans.) Mallgrave, H. F. (1985), Anthropology and Aesthetics, 9, pp. 61-67.

Semper, G. (1863). Style. Style in the Technical and Tectonic Arts: or, Practical aesthetics. (Trans.) Mallgrave, H. F. \& Robinson, M. (2004). Los Angeles: Getty Publications.

Semper, G. (1989). The Four Elements of Architecture and other Writings. Cambridge: Cambridge University Press.

Senelick, L. (2004). Consuming passions: eating and the stage at the fin-de-siécle. Gastronomica, 5 (2), pp.43-49.

Severt, D., Aiello,T., Elswick, S . \& Cyr, C. (2008). Hospitality in Hospitals? International Journal of Contemporary Hospitality Management, 20, pp. 664-678.

Shattuck, R. (1955). The Banquet Years, the origins of the avant-garde in France 1885 to World War I. Toronto: Vintage.

Sheridan, M. (2003). Room 606, the SAS house and the work of Arne Jacobsen. New York: Phaidon.

Silverman, M.R., Gregoire, M.B., Lafferty, L.J. \& Dowling, R.A. (2000). Current and future practices in hospital food service. J Am Diet Assoc, 100, pp. 76-80.

Siraisi, N.G. (1990). Medieval \& Early Renaissance Medicine - An Introduction to Knowledge and Practice. Chicago, USA: The University of Chicago Press.

Sloane, D.C. (1994). The Evolving Design of the Hospital, 1885-1994. Journal of Architectural Education, 48(2), pp. 82-98.

Sobal, J. \& Nelson, M.K. (2003). Commensal eating patterns, a community study. Appetite, 41(2), p. 181-190.

Sobal, J. \& Wansink, B. (2007). Kitchenscapes, Tablescapes, Platescapes and Foodscapes- Influences of microscale built environments on food intake. Environment and Behavior, 39, pp. 124-142.

Sohlberg, P. \& Sohlberg, B.M. (2004). Erkendelsesformens former - videnskabsteori og forskningsmetode. Klim: Århus.

Sommer, R. \& Ross, H. (1958). Social Interaction on a Geriatrics Ward. International Journal of Social Psychiatry, 4, pp.128-133.

Soyer, A. (1977). The Pantropheon or a history of food and its preparation in ancient times. London: Paddington Press Ltd.

Spang, R.L. (2000). The Invention of the Restaurant: Paris and Modern Gastronomic Culture. Cambridge: Harvard University Press.

Sparke, P. (2008). The Modern Interior. London: Reaktion Books Ltd.

Stankos, M. \& Scwarz, B. (2007). Evidence-Based Design in healthcare: a theoretical dilemma. IDRP e-journal, 1(1), 12.03.2010

Steel, C. (2008). Hungry City: how Food Shapes Our Lives. London: Chatto \& Windus.

Sternberg, E. (2001). The Balance Within, the connecting health and emotions. New York: W.H. Freeman and Company.

Sternberg, E. (2009). Healing Spaces, the science of place and well-being. Cambridge, Massachusetts: Harvard University Press. 
Sterns, I.S. (1952). Firstness, Secondness, and Thirdness. In: Studies in the philosophy of Charles Sanders Peirce. Cambridge, Massachusetts: Harvard University Press, pp. 195-208.

Stevens, G. (1998). The Favored Circle. The Social Foundation of Architectural Distinction. Cambridge, Massachusetts: The MIT Press.

Strong, R. (2002). Feast, a history of grand eating. London: Pimlico.

Stroebele, N. \& Castro, J.M. (2004). Effect of ambience on food intake and food choice. Nutrition, 20(9), p. 821-838.

Sykes, A.K. (ed.) (2007). The Architecture Reader: essential writings from Vitruvius to the present. New York: George Braziller Publishers.

Swan, J.E., Richardson, L.D. \& Hutton, J.D. (2003). Do appealing Hospital Rooms Increase Patient Evaluations of Physicians, Nurses and Hospital Services? Health Care Management Rev., 28(3), pp. 254-264.

Taylor, M. \& Preston, J.(2006), INTIMUS : Interior Design Theory Reader. Chichester: John Wiley.

Taylor, S. \& Spicer, A. (2007). Time for space: A narrative review of research on organizational spaces. International Journal of Management Reviews, 9(4), pp.325346.

Thiis, L.J. (2004). Helbredende arkitektur = fremtidens sygehus. Ugeskrift for Læger, 166(51), pp. 4702-4705.

Thompson, W.G. (1907). Modern Hospital construction. Journal of American Medical Association, 49, pp. 993-998.

Thompson, J. D. \& Goldin, G. (1975). The Hospital: a social and architectural history. New Haven, USA: Yale University Press.

Todres, L., Galvin, T. \& Holloway, I. (2009). The Humanization of healthcare: a value framework for qualitative research. International Journal of Qualitative Studies on Health and Wellbeing, 4(2), pp. 68-77.

Toussaint-Samat, M. (2009). A History of Food. USA: Wiley-Blackwell Publishing Ltd.

Tresidder, R. (2011). Reading hospitality: the semiotics of Le Manoir aux Quat'Saisons. Hospitality \& Society, 1(1), pp. 67-84.

Trubek, A. (2000). Haute Cuisine: How the French Invented the Culinary profession. Philadelphia: University of Pennsylvania Press.

Tuan, Y.F. (1977). Space \& Place: the perspective of experience. Minneapolis: University of Minnesota Press.

Tvedebrink, T.D.O. (2012). The Research Process: unfolding the methodological layers of my PhD project. [unpublished paper for PhD course, Aalborg University]

Tvedebrink, T.D.O., Fisker, A.M. \& Kirkegaard, P.H. (2012). Architectural Mealscapes a paradigm for Interior Design for Food. London: Conference proceedings from the International Conference on Designing Food and Designing for Food, IFDS.

Tvedebrink, T.D.O., Fisker, A.M. \& Kirkegaard, P.H. (2013b). Architectural Theatricality: A design perspective in hospitality studies. International Journal of Hospitality \& Society, 3 (3), pp. 189-211.

Tvedebrink, T.D.O., Fisker, A.M. \& Kirkegaard, P.H. (2013). Sygdommens Spiserum: Har arkitekturen en overset eller glemt betydning her? Tidskrift for Forskning i Sygdom og Samfund, 18(1), p.21-38. 
Ulrich, R. S. (1984). View through a window many influence recovery from surgery. Science, 224(4647), pp. 420-421.

Ulrich, R. S. (1991). Effects of health facility interior design on wellness: Theory and recent scientific research. Journal of Health Care Design, 3, pp. 97-109.

Ulrich, R. \& Zimring, C. (2004). The Role of the Physical Environment in the Hospital of the $21^{\text {st }}$ Century: a once-in-a-lifetime opportunity. The Center for Health Design.

Ulrich, R., Zimring, C., Zhu, X., DuBose, J., Seo, H.B., Choi, Y.S., Quan, X. \& Joseph, A. (2008). A Review of the research literature on evidence-based healthcare design. Healthcare Leadership, White Paper series no. 5

Ulrich, R.S., Berry, L.L., Quan, X. \& Parish, J.T. (2010). A conceptual framework for the domain of Evidence-Based Design. Research Paper no. 2012-69, May Business School, Texas A\&M University.

Unwin, S. (2007). Analysing Architecture. New York: Routledge.

Venturi, R. (1966). Complexity and Contradiction in Architecture. New York: The Museum of Modern Art.

Verderber, S. (2010). Innovations in Hospital Architecture. New York: Routledge.

Visser, M. (1991). The Rituals of Dinner. New York: Grove Weidenfeld.

Wansink, B. (1994). Advertising's Impact on Category Substitution. Journal of Marketing Research, 31(4), pp. 505-515.

Wansink, B. (1994). Antecedents and Mediators of Eating Bouts. Family and Consumer Sciences Research Journal, 23(2), pp. 166-82.

Wansink, B. (2004). Environmental factors that increase the food intake and consumption volume of unknowing consumers. Annu. Rev. Nutrition, 24, pp. 455-479.

Wansink, B. \& Cheney, M.M. (2005). Super Bowls: Serving Bowl Size and Food Consumption. JAMA, 293(14), pp. 1727-1728.

Watkin, D. (2000). A History of Western Architecture. New York: Watson-Guptill Publications.

Weber, A.J., King, S.C. \& Meiselman, H.L., (2004). Effects of social interaction, physical environment and food choice freedom on consumption in a meal-testing environment. Appetite, 42, pp. 115-118.

Weiner, P. \& Young, F.H. (1952). Studies in the philosophy of Charles Sanders Peirce. Cambridge, Massachusetss: Harvard University Press.

Wheaton, B. (1983). Savoring the Past: The French Kitchen and the Table from 13001789. Philadelphia: University of Pennsylvania Press.

Whyte, W.H. (1948), Human Relations in the Restaurant Industry, New York: McGraw Hill.

Whyte, I.B. (2004). Modernity and architecture. In: Tracing Modernity - Manifestation of the modern in architecture and the city. Hvattum, M. \& Hermansen, C. (ed.). London: Routledge, pp.42-56 
Wiener, P.P. \& Young, F.H. (ed.), (1952), "Studies in the philosophy of Charles Sanders Peirce", Cambridge, Massachusetts: Harvard University Press.

Winter, I.W. (2006). Hjemlighed - kulturfænomenologiske studier. København: Danmarks Pædagogiske Universitets Forlag.

Wyszynski, D., Perman, M. \& Crivelli, A. (2003). Prevalence of hospital malnutrition in Argentina: Preliminary results of a population- based study. Nutrition, 19, pp. 115119.

Yin, R.K. (2009): Case study research - design and methods. SAGE publications Inc., USA

Xia, C. \& McCutcheon, H. (2006). Mealtimes in hospital - who does what? Journal of clinical Nursing, 15, pp. 1221-1227.

Xiaobo, Q., Jospeh, A., Malone, \& Pati, E. (2011). Healthcare Environmental Terms and Outcome Measures: an evidence-based design glossary. Phase 1 report, The Center of Health Design.

Zevi, B. (1957). Architecture as space - how to look at architecture. USA: Da Capo Press.

\section{PhD Thesis and Master's Thesis}

Àvila, M. (2012). "Devices On Hospitality Hostility and Design”. PhD Thesis, Sweden: University of Gothenburg.

Botin, L. (2008). "A Humanist in the Hospital: Cultural Assessments of Electronic Health Records". PhD Thesis, Denmark: Aalborg University.

Elle, J.C. (2006). “Det velduftende plejehjem: på spporet af en ny mad- og omsorgskultur i den offentlige sector". PhD Thesis, Denmark: Danmarks Tekniske Universitet (DTU).

Fisker, A.M. (2003). "Mad og Arkitektur". PhD Thesis, Denmark: Aalborg Universitet.

Hartwell, H. (2004). "Patient experience, nutritional uptake and satisfaction with hospital food services". PhD Thesis, England: Bournemouth University.

Lemche, J. (2012), "Den gode sundhedsarkitektur: Patienternes, arkitektens og bygherrens italesættelse af fremtidens sundhedsbygninger", Phd thesis, Denmark: Syddansk Universitet.

Shepherd, P.A. (2011). "The effects of a hospital ward eating environment on patients' mealtime experience". PhD Thesis, England: Bouremouth University.

Silberlein, S.C. (2012), “Tilgængelighed i det offentlige rum - wayfinding på hospitaler", Phd thesis, Denmark: Arkitektskolen Aarhus.

Søndergaard, M. (2012). "En analyse af dækningen af ny nordisk mad i BT, Politiken og Weekendavisen fra 2003 til 2010". Master's Thesis, Denmark: Center for Journalistik, Syddansk Universitet.

Talberg, M.V. (2010). “Ny Nordisk Mat I kontekst - profilering av det nordiske fellesskapet”. Master 's Thesis, Denmark: Copenhagen Business School.

Walter, U. (2011), "Drivers of customers' service experiences: A customer perspective on co-creation of restaurant services, focusing on interactions, processes and activities", Phd thesis, Sweden: Ôrebro University. 


\section{Encyclopedia}

en.wikipedia.org

Gads Litteratur Leksikon, (ed.) Rasmussen, H., Jakobsen, K.H. \& Berman, J. (2005).

2.udgave, 1.oplag (oprindeligt 1999), Copehagen: Gads Forlag.

Politikens Filosofi Leksikon (ed.) Grøn, A., Husted, J., Lübcke, P., Rasmussen, S.A., Sandøe, P. \& Stefansen, N.C. (2004), 1 udgave, 16. oplag (oprindeligt 1983). Copenhagen: Politikens Forlag.

Vor tids filosopfi, engagement og forståelse. (red.) Lübcke, P. (2002, 1982), 1.udgave, 8. oplag, Copenhagen: Politikens Forlag.

ODP (1994). Oxford Dictionary of Philosphy, Blackburn, S., Oxford: Oxford University Press.

DFSN (2006). Dictionary of Food Science and Nutrition. London: A\&C Black Publishers Ltd.

\section{Webpages}

AAU Food Research (2010). Nyt Fødevareforskningscenter går på tværs. Ingeniøren. aau.dk, 02.09.2010 [Accessed: 03.12.2012]

Archinet.com (2013). NOMA Lab: An Architectural Cookbook for the Nordic Cuisine. Archinect. Available from: http://archinect.com/firms/ release/12533/noma-lab-an-architectural-cookbook-for-the-nordiccuisine/39725817 [Accessed 13.03.2013]

Arkitektforeningen (2013). Guide til Sygehusprojekter i Regionerne. Arkitektforeningen. Available from: http://arkitektforeningen.dk/Guide $\% 20$ til\%20sygehusprojekter\%20i\%20regionerne [Accessed 01.02.2013].

Benedetti \& Croce (1574). Le Feste - L'Historia della Publica. Available from: http:// special-1.bl.uk/treasures/festivalbooks/BookDetails.aspx?strFest=0033 [Accessed 25.01.2010]

Blankholm (2011). Gordisk knude løst. Berlinske Tidende,

Business Ejendomme. Available from: http://www.e-pages.dk/

berlingskesektioner/209/20 [Accessed 16.01.2013]

DR P1 (2013). Er ny nordisk mad kun for eliten?. By Schou, C. , 19.03.2013 at 09:10, P1, Denmark: DR. Available from: http://www.dr.dk/P1/Ordeterdit/ Udsendelser/2013/03/20130319125601.htm [Accessed 07.04.2013]

DNU (2007). Det Nye Universitetshospital I Aarhus - vinderprojekt December 2007, Region Midtjylland. Available from: http://www.dnu.rm.dk/presse/ download+publikationer? [Accessed 01.02.2013]

DNU (2010). Dialog med patienter og pårørende - en inddragelseshistorie om fremtidens universitetshospital i Aarhus - DNU, Region Midtjylland. Available from: http://www.dnu.rm.dk/files/Sundhed/DNUDNU/Presse/ Download\%20publikationer/60490_DNU_Magasin_PRINT.pdf [Accessed 01.02.2013]

DNU (2013). DNU, det ny universitetshospital i Aarhus. C.F. Møller. Available from: http://www.cfmoller.com/p/projects?l=.....14 [Accessed 16.01.2013]

Eater.com (2013). Here's a Look Around Noma's New Test Kitchen. Eater. Available from: http://eater.com/archives/2012/02/29/here-are-photos-of-nomas-new-testkitchen.php [Accessed 13.03.2013] 
ETYM (2013). Online Etymological Dictionary. Available from: http://www. etymonline.com [Accessed 21.01.2013]

Geranium (2013). Geranium. Available through: http://geranium.dk/\#/da/ restauranten/velkommen/ [Accessed 13.03.2013]

GSHB (2013). Godt Sygehus Byggeri - de danske sygehusbyggerier. Available from: http://www.godtsygehusbyggeri.dk/ [Accessed 17.05.2013]

HA AAU (2013). Healing Architecture. Aalborg Universitet. Available through: http:// vbn.aau.dk/en/projects/arkitektur-af-helbredelse-optimering-af-arkitektoniskeog-rumlige-rammer-i-hospitaler(5c965d03-dc19-48b8-bc26-a94c0ee862c4).html [Accessed 17.01.2013]

Hermitary (2007). Book Reviews: Rykwert, Joseph, On Adam's House in Paradise: the idea of the primitive Hut in Architectural History. Hermitary resources and reflectiosn on hermits and solitude. http://www.hermitary.com/bookreviews/rykwert.html [Accessed 15.02.2012]

NHH (2011). Konkurrence, udbygning af Herlev Hospital: Dommerbetænkning - april 2011. Region Hovedstaden. Available from: http://www.herlevhospital. dk/NR/rdonlyres/E84FE253-A88E-40E8-85C5-A37D86F41B33/0/ Dommerbetaekningendeligudgavetilnet.pdf [Accessed 01.02.2013]

Herlev Hospital (2013). Helbredende Arkitektur. Herlev Hospital, Region Hovedstaden, Denmark. Available from: http://www.herlevhospital.dk/nythospital/ Menu/projektet/temaer/helbredendearkitektur.htm [Accessed 16.01.2013]

HLA (2011). Helbredende Arkitektur vinder i Herlev. Henning Larsen Architects, Denmark. Available from: http://da.henninglarsen.com/nyheder/ nyhedsarkiv/2011/04/helbredende-arkitektur-vinder-i-herlev.aspx [Accessed 16.01.2013]

ifooddesign (2011). International Food Design Society - food design sub-categories. International Food Design Society. Available from: http://ifooddesign.org/food design/subcategories.php [Accessed 04.09.2011]

Kähler (2013). Kähler Design- history. Kähler Design. Available from: http://www. kahlerdesign.com [Accessed 13.03.2013]

Kroll, K. (2005). Evidence Based Design in Healthcare Facilities. Available from: http://www.facilitiesnet.com/healthcarefacilities/article/Better-Health-FromBetter-Design--2425\# [Accessed 17.05.2013]

LEV (1997). Offentlig kostforplejning I Danmark, Bind I-II, betænkning fra udvalget om offentlig kost-forplejning. Fødevaredirektoratet, Levnedsmiddelstyrelsen, Betænkning nr. 1334. Available from: http://www. statensnet.dk/betaenkninger/1201-1400/1334-1997-1/1334-1997-1_pdf/ printversion_1334-1997-1.pdf [Accessed 17.05.2013]

McCree, A. (2004). Improving patients' nutritional care. Catering. Available from: http://www.publicservice.co.uk/pdf/health/issue3/H3\%201001\%20Alison\%20 McCree\%20ATL.pdf [Accessed 16.05.2013]

Madfood (2013). MAD Symposium - about. MAD Symposium. Available from: http:// madfood.co/the-story/ [Accessed 13.03.2013]

Malling \& Schmidt (2013). Villa Dining, Restaurant Malling \& Schmidt med Kähler Design. Available from: http://www.villadining.dk/ [Accessed 13.03.2013]

Mattana (2011). Wikimedia Commons. Available from: http://commons.wikimedia. org/wiki/File:Pistoia_ospedale_del_Ceppo_008.JPG_[Accessed 01.02.2012] 
MORE (2010). "MORE - Mennesker Og Rigtig Ernæring", Center for Ernæring og Tarmsygdomme, Aalborg Sygehus, Århus Universitetshospital. Available through: www.aalborgsygehus.rn.dk [Accessed 13.04.2010]

NAUH (2012, marts). “Indbudt projektkonkurrence Nyt Aalborg Universitetshospital: Dommerbetænkning - marts 2012", Region Nordjylland, http://www.rn.dk/NR/ rdonlyres/889F0C1E-57C2-4BC3-B6F6-358BA8900A45/0/Dommerbetænkning hjemmeside.pdf [Accessed 01.02.2013]

NAUH (2012, juni). “Udbud med forhandling Nyt Aalborg Universitetshospital: Evalueringsrapport juni 2012", Region Nordjylland, http://www. rn.dk/NR/rdonlyres/89F3C246-6850-4F89-9179-E09750945D1B/0/ Evalueringsrapportjuni2012.pdf [Accessed 01.02.2013]

NHH (2011). Nyt Herlev Hospital. Herlev Hospital, Region Hovedstaden. Available from: http://www.herlevhospital.dk/menu/Om+Herlev+Hospital/ Fremtidensherlevhospital/projektet/ [Accessed 01.02.2013]

NHN (2013, January). Projektkonkurrence, Region Hovedstaden. Available from: http://www.regionh.dk/nythospitalnordsjaelland/menu/Raadgivere_ Entreprenoerer/Projektkonkurrence/?printpage=true [Accessed 01.02.2013]

NOMA (2013). Noma - news. NOMA. Available from: http://noma.dk/news/ [Accessed 13.03.2013]

Nordicfoodlab (2013). Nordic Food Lab - who we are. Nordic Food Lab. Available from: http://nordicfoodlab.org/nordicfoodlab/ [Accessed 13.03.2013]

OUH (2011, januar). Nyt Odense Universitets Hospital, Syddansk Universitet Sund: Indbudt projektkonkurrence - dommerbetænkning januar 2011, Region Syddanmark. Available from: http://www.nytouh.dk/wm343136 [Accessed 01.02.2013]

OUH (2011, juni). Nyt Odense Universitets Hospital, Syddansk Universitet Sund: Vinderprojekt juni 2011 - efterskrift til dommerbetænkning, efter afholdt udbud med forhandling, Region Syddanmark. Available from: http://syddanmark.nyhedsbrev. peytz.dk/v.php?mailinglistId=230\&newsletterId=266167 [Accessed 01.02.2013]

OUH (2012). Nyt OUH Byggeprogram - november 2012. Region Syddanmark. Available from: http://www.nytouh.dk/wm405321 [Accessed 01.02.2013]

Pedersen, F.S. (2010). Her ligger dit super-sygehus, Pedersen, F.S., 8 marts 2010, Berlingske Business. Available from: http://www.b.dk/danmark/her-ligger-ditsuper-sygehus [Accessed 01.02.2013]

SUM (2009). Sundhedspakke 09 - Handout 1. Sygehusinvesteringer. Ministeriet for Sundhed og Forebyggelse. Available from: http://www.sum.dk [Accessed 09.10.2009]

SUM (2013). De 16 projekter - Kvalitetsfonden medfinansierer 16 hospitalsprojekter. Ministeriet for Sundhed of Forebyggelse. Available from: http://www.sum.dk/ Sundhed/Sygehusinvesteringer/De-16-projekter.aspx [Accessed 16.01.2013]

Søeborg, I.M. (2013). Fremtidens Hospital har mennesket i centrum. Jobindex. Available from: http://www.jobindex.dk/cms/Fremtidens-hospital-har-mennesket-icentrum [Accessed 16.01.2013]

Tougaard, H. (2008). Arkitektur kan helbrede. Jyllandsposten. Available from: http:// jyllands-posten.dk/ditliv/sundhed/article3938335.ece [Accessed 16.01.2013]

USK (2013). Dommerbetænkning Universitetssygehus Køge - januar 2013, Region Sjælland. Available from: http://www.regionsjaelland.dk/nyheder/ pressemeddelelser/Documents/Dommerbetænkning-USK-10januar2013-RegionSjælland-2013.pdf [Accessed 01.02.2013] 
Warner, N. (2004). Speech by Lord Warner, Parliamentary Under-Secretary of State in the Lords, 21 January 2004: Better Hospital Food Programme. Available from: http://wwww.dh.gov.uk/en/News/Speeches/Speechlist/DH_4071796 [Accessed 28.01.2009].

\section{Powerpoint presentations}

Beermann, T. \& Holst, M. (2010). MORE: Et interventionsprojekt målrettet spiseudfordringer hos syge, Beermann, T. \& Holst, M., Center for Ernæring og Tarmsygdomme, Aalborg Sygehus, Region Nordjylland, Slides from the conference: Rundt om Fremtidens Sygehusmåltid Videns- og Idédag, [Powerpoint provided: 18.08.2010].

Grønhaug, L. M. (2011). Et helbredende spisemiljø - afdækning af miljøets terapeutiske effekt, Grønhaug, Louise Muxoll. Vejle Sygehus [Powerpoint provided: 26.01.2011]

Grønhaug, L. M. (2011b). Fra idé til produkt - baggrundsmateriale til etablering af et helbredende spisemiljø på A250. Grønhaug, Louise Muxoll. Vejle Sygehus [Powerpoint provided: 25.01.2011]

Holm, L. (2007). Mad på hospitalet. Slides from lecture in the course: Madens Sociologi, October, Copenhagen University.

Jamison, A. (2012a). Research as a Process: Different Modes and Styles. Slides from PhD-course: The Research Process, November, Aalborg University.

Jamison, A. (2012b). From Science to Research: An Historical Introduction. Slides from PhD-course: The Research Process, November, Aalborg University.

Jamison, A. (2012c). Academic Research: Mode 1. Slides from PhD-course: The Research Process, November, Aalborg University.

Jamison, A. (2012d). Commercial Research or Mode 2. Slides from PhD-course: The Research Process, November, Aalborg University.

Jamison, A. (2012e). Change-Oriented Research or Mode 3. Slides from PhD-course: The Research Process, November, Aalborg University.

Jamison, A. (2012f). The Common Denominators: Inspiration, Investigation and Interpretation. Slides from PhD-course: The Research Process, November, Aalborg University.

MORE (2009). Værtskab og trygge måltidsoplevelser - et delprojekt under MORE på Aalborg Sygehus, protokol projektbeskrivelse, Center for Ernæring og Tarmsygdomme, Aalborg Sygehus, Århus Universitetshospital. [Powerpoint provided from e-mail: 05.02.2009]

MORE (2011). 8 gode måltidsvaner af Madeleines, Center for Ernæring og Tarmsygdomme, Aalborg Sygehus, Århus Universitetshospital. [Powerpoint provided from e-mail: 26.01.2011]

Murcott, A. (2009): Qualitative research approaches to food and eating, an intermediate level PhD research workshop. PhD seminar, Helsinki September 2009

Rasmussen, H.H. (2011). Innovation i mad på sygehus-projektresultater fra Danmark Center for Ernæring og Tarmsygdomme, Aalborg Universitetshospital, Danmark. Available from: http://nynordiskmad.org/fileadmin/webmasterfiles/Projects/ Diverse/Rasmussen.pdf [Accessed: 30.01.2013] 


\section{Emprical material (visits, conversations, observations and interviews)}

Danielsen (2007). Visit at Madeleines Madteater. Madeleines Madteater, Nikolaj Danielsen from Madeleines, Denmark: Copenhagen (28 October 2007).

MORE (2010b), Meeting (afdelingsledelsen) involved in project MORE and Madeleines, Aalborg Hospital, Denmark: Aalborg. (08 Marts 2010)

MORE (2010c), Meeting, Aalborg Hosptial, Denmark: Aalborg. (06 April 2010)

MORE (2010d), $1^{\text {st }}$ observations and meeting Jytta S.M. Højsleth; Bitten Gøtzsche; Anette Damgård , Aalborg Hosptial, Department 7Ø, 7V and T, Denmark: Aalborg. (13 April 2010)

MORE (2010e), $2^{\text {nd }}$ observations, Aalborg Hosptial, Department 7Ø, 7V and T, Denmark: Aalborg. (20 April 2010)

MORE (2010f), Meeting Henrik Højgaard Rasmussen, Aalborg Hosptial, Department (Medicinsk center), Denmark: Aalborg. (16 June 2010)

MORE (2010g), Meeting nursing staff department 7V, Aalborg Hospital, Medicinerhuset, Denmark: Aalborg. (16 September 2010)

MORE (2010h), Meeting Region Nordjylland, Aalborg Hospital and Syghus Vendsyssel, Region Nord, Denmark: Aalborg. (17 November 2010)

MORE (2010i), Meeting Lone Frandsen 7Ø, Aalborg Hosptial, Medicinerhuset, Denmark: Aalborg. (12 January 2011)

MORE (2010j), Raw material provided from Interviews and Observations conducted in Project MORE, Marie Nerup Mortensen, Aalborg Hospital, Region Nordjylland, Denmark: Aalborg (Provided by mail 18 January 2010)

Ulrich, R. (2009a), Ph.D. seminar held by Roger Ulrich , Aalborg University, Department of Architecture, Design and Media Technology, Denmark: Aalborg. (1516 Marts 2009)

Ulrich, R. (2009b), Lecture held by Roger Ulrich, Aalborg University, Department of Architecture, Design and Media Technology, Denmark: Aalborg. (18 Marts 2009)

Ulrich, R. \& Hurwitz, P. (2009), Meeting and Guided tour at Medicinerhuset with Roger Ulrich \& Palle Hurwitz, Aalborg Hospital, Denmark: Aalborg. (19 Marts 2009)

Ulrich, R. (2010), Ph.D. seminar held by Roger Ulrich at Aalborg University, Department of Architecture, Design and Media Technology, Denmark: Aalborg. (1011 August 2010)

VEJLE (2011), Interview Louise Muxoll Grønhaug, Vejle Hospital, Department 250, Denmark: Vejle. (24 January 2011).

Malling \& Schmidt (2008). Visit restaurant Malling \& Schmidt. Thorsten Schmidt, chef and restaurant owner, Denmark: Aarhus (April 2008) 


\title{
ILLUSTRATIONS
}

\author{
LIST OF FIGURES
}

Fig. 1.1 "My wonders and curiosity about Architecture" page 4, drawing by author

Fig. 2.1 "The Architect's Brain" page 18, drawing by author inspired by Frascari (2011:65)

Fig. 2.2 "The bourgeois interior" page 21, drawing by author inspired by Gannon \& Miller (2010:91)

Fig. 2.3 "Shopping for an Interior" page 23 , drawing by author inspired by Sparke (2008:56)

Fig. 2.4 "The Neuroscientific Human" page 25 , drawing by author

Fig. 3.1 "Common area in ward" page 30 , photo by author

Fig. 3.2 "Shared common area between departments" page 31 , photo by author

Fig. 3.3 "Department of Infectious Diseases (7V)" page 32-33, drawings and photos by Author

Fig. 3.4 "Department of Orthopaedic Surgical Patients (A250)"

page 35, drawing by author inspired by photo provided by Grønhaug (2011)

Fig. 3.5 "Problem"

page 37 , drawing by author

Fig. 3.6 "Future Hospital Design"

page 37 , illustration by author

Fig. 3.7 "Hospital design practice - integrative model" page 39 , model inspired by Rubin \& Babbie (2010:21)

Fig. 3.8 "Research Problem: the synthesis of health, food and architecture" page 40 , model by author

Fig. 4.1 "Research-based knowledge"

page 42, drawing by author inspired from Frascari (2011:107)

Fig. 4.2 "Research-based knowledge" page 44 , model by author

Fig. 4.3 "Induction - Deduction"

page 46, model adopted from Brodersen (2007)

Fig. 4.4 "Abduction"

page 46 , model by author 
Fig. 4.5 “Theorizing”

page 51 , model by author

Fig. 4.6 "Different Types of Theory"

page 51 , model by author

Fig. 4.7 "System of Inquiry"

page 54, model by author inspired by and adopted from Groat \& Wang (2002:10)

Fig. 4.8 "Explorative System"

page 58 , model by author

Fig. 4.9 "Positive Theory"

page 60 , model by author

Fig. 4.10 "Deduction"

page 60 , model by author

Fig. 4.11 "Abduction"

page 62 , model by author

Fig. 4.12 "Multi-embedded Case Study"

page 62 , model by author

Fig. 4.13 "Explorative Study"

page 63 , model by author

Fig. 4.14 "Historical Review"

page 65 , drawing by author

Fig. 5.1 "Search Focus"

page 66, drawing by author

Fig. 5.2 "Food Choice and Expectations"

page 69, models by author adopted from Delizia \& MacFie (1996) and Furst et al. (1996)

Fig. 5.3 "Kitchenscape, Tablescape, Platescape and Foodscape"

page 71, illustration by author inspired by Sobal \& Wansink (2007:128)

Fig. 5.4 "The Meal Experience"

page 71, model by author adopted from Gustafsson (2004)

Fig. 5.5 "The Meal Experience - extended"

page 74-75, illustrations by author

Fig. 6.1 "Normative Theory"

page 84, drawing by author inspired from Frascari (2011:37).

Fig. 6.2 "The Ancient"

page 90 , drawing by author

Fig. 6.3 "The Temple"

page 91 , drawing by author

Fig. 6.4 "The Triclinium"

page $92-93$, drawing by author

Fig. 6.5 "The Church and Monastery"

page 96 , drawing by author

Fig. 6.6 "The Monastery"

page 98 , drawing by author

Fig. 6.7 "The Sugar Banquet"

page 101 , drawing by author 
Fig. 6.8 "17th century"

page 102, drawing by author adopted from Sabban \& Serventi (1998:117)

Fig. 6.9 "Body and Mind"

page 103 , drawing by author

Fig. 6.10 "The Primitive Hut"

page 108, drawing by author adopted from Hvattum (2004:32)

Fig. 6.11 "The bourgeois Restaurant"

page 110, drawing by author adopted from Spang (2000:120)

Fig. 6.12 "Carême's pieces montées"

page 112, drawing by author adopted from Kelly (2003:23)

Fig. 6.13 "Polychromy"

page 113, drawing by author adopted from Mallgrave (1996:37)

Fig. 6.14 "The Universal Symposium"

page 115, drawing by author adopted from Clement-lorford (2012:111)

Fig. 6.15 "A Holistic View"

page 1116-117, drawing by author adopted from Heslet \& Dirckinck-Holmfeld (2007:33)

Fig. 6.16 "Willow Tea Rooms"

page 119, drawing by author adopted from Billcliffe (1979:153)

Fig. 6.17 "The Sanatorium"

page 120-121, drawings by author adopted from sarnitz $(2007: 46,49)$

Fig. 6.18 "The Nurse"

page 125, drawing by author inspired by picture in Bräüner (1952:21)

Fig. 6.19 "The Hotel”

page 128-129, drawings by author adopted from Christensen (2008:38) and

Sheridan (2003:156)

Fig. 6.20 "The Mega Hospital”

page 131, drawing by author adopted from Heslet \& Dirckinck-Holmfeld (2007:107)

Fig. 6.21 "A rationalized treatment"

page 132, drawing by author

Fig. 6.22 "The Food Theatre"

page 136, drawing by author adopted from photo provided by Thorsten Schmidt

Fig. 6.23 "The Food"

page 137, drawing by author adopted from photo provided by Thorsten Schmidt

Fig. 6.24 "The Super Hospital"

page 138, drawing by author adopted froom NAUH (2012, juni:21)

Fig. 7.1 "Architectural Hats"

page 144, drawing by author inspired by Frascari (2011:79)

Fig. 7.2 "The Origin"

page 147, drawing by author

Fig. 7.3 "The 3"

page 155, drawing by author inspired by Frascari (2011b:27)

Fig. 7.4 "The Temple of Polychromy"

page 165, drawing by author adopted from Mallgrave (1996:37) 
Fig. 8.1 "The basic principles of design"

page 166, drawing by author adopted from Hvattum (2004:32)

Fig. 8.2 "The Caribbean Hut"

page 170, drawing by author adopted from Hvattum (2004:36)

Fig. 8.3 "The Roman Dining Interior"

page 172, drawing by author adopted from photo in Bek (1983:144)

Fig. 8.4 "The Hearth"

page 172, drawing by author adopted from photo in Bek (1983:144)

Fig. 8.5 "The Temple"

page 175 , drawing by author adopted from Semper (1863:119)

Fig. 8.6 "The Mask"

page 175, drawing by author adopted from Hvattum (2004:45)

Fig. 8.7 "The Origin"

page 178 , drawing by author

Fig. 8.8 "The Theatricality of the Dressing"

page 178 , drawing by author

Fig. 8.9 "The Design Process"

page 181, drawing by author inspired by Frascari (2011b:26)

Fig. 9.1 "Inspiration"

page 184, drawing by author

Fig. 9.2 "Patient Eating Environment"

page 188-189, photos by author

Fig. 9.3 "The Architects' Table"

page 197, drawing by author inspired by Frascari (2011:126)

Fig. 10.1 "Architectural Theatricality"

page 196, drawing by author

Fig. 10.2 "Architect and Architecture"

page 204, drawing by author inspired by Frascari (2011:66)

Fig. 10.3 "The Future"

page 207, drawing by author inspired by Frascari (2011:147) 